\section{SANDIA REPORT}

SAND86-0917 • UC-721

Unlimited Release

Printed September 1997
预ECEIVED

OCT 101997

OSTI

\title{
Analysis of Solutes in Groundwaters from the Rustler Formation At and Near the Waste Isolation Pilot Plant Site
}

Karen L. Robinson

\section{Prepared by}

Sandia National Laboratories

Albuquerque, New Mexico 87185 and Livermore, California 94550

Sandia is a multiprogram laboratory operated by Sandia

Corporation, a Lockheed Martin Compeny, for the United States

Department of Energy under Contract DE-AC04-94AL85000.

Approved for public release; distribution is unlimited.

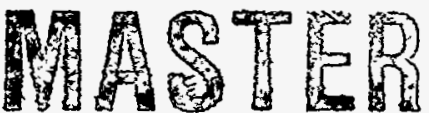

\section{团 \\ Sandia National Laboratories}


Issued by Sandia National Laboratories, operated for the United States Department of Energy by Sandia Corporation.

NOTICE: This report was prepared as an account of work sponsored by an agency of the United States Government. Neither the United States Government nor any agency thereof, nor any of their employees, nor any of their contractors, subcontractors, or their employees, makes any warranty, express or implied, or assumes any legal liability or responsibility for the accuracy, completeness, or usefulness of any information, apparatus, product, or process disclosed, or represents that its use would not infringe privately owned rights. Reference herein to any specific commercial product, process, or service by trade name, trademark, manufacturer, or otherwise, does not necessarily constitute or imply its endorsement, recommendation, or favoring by the United States Government, any agency thereof, or any of their contractors or subcontractors. The views and opinions expressed herein do not necessarily state or reflect those of the United States Government, any agency thereof, or any of their contractors.

Printed in the United States of America. This report has been reproduced directly from the best available copy.

Available to DOE and DOE contractors from

Office of Scientific and Technical Information

P.O. Box 62

Oak Ridge, TN 37831

Prices available from (615) 576-8401, FTS 626-8401

Available to the public from

National Technical Information Service

U.S. Department of Commerce

5285 Port Royal Rd

Springfield, VA 22161

NTIS price codes

Printed copy: A13

Microfiche copy: A01 
SAND86-0917

Distribution

Unlimited Release

Printed September 1997

Category UC-721

\title{
Analysis of Solutes in Groundwaters from the Rustler Formation At and Near the Waste Isolation Pilot Plant Site
}

\author{
Karen L. Robinson \\ WIPP Disposal Room Systems Department \\ Nuclear Waste Management Center \\ Sandia National Laboratories \\ P.O. Box 5800 \\ Albuquerque, NM 87185-1147
}

\begin{abstract}
Between 1976 and 1986, groundwater samples from more than 60 locations in the vicinity of the Waste Isolation Pilot Plant site were collected and analyzed for a variety of major, minor, and trace solutes. Most of the samples were from the Rustler Formation (the Culebra Dolomite, the Magenta Dolomite, or the zone at the contact between the Rustler and underlying Salado Formations) or the Dewey Lake Red Beds.
\end{abstract}

Between 1984 and 1986, the analytical laboratory at United Nuclear Corp. (UNC) Technical Services (formerly Bendix Field Engineering Corp.), Grand Junction, CO, determined the following parameters in 44 samples for Sandia National Laboratories (SNL): $\mathrm{Cl}^{-}, \mathrm{SO}_{4}^{\overline{ }}$, alkalinity, $\mathrm{Ca}, \mathrm{Mg}, \mathrm{K}, \mathrm{Na}, \mathrm{Br}^{-}, \mathrm{I}^{-}, \mathrm{F}, \mathrm{B}, \mathrm{Cs}, \mathrm{Li}, \mathrm{Sr}, \mathrm{SiO}, \mathrm{Fe}, \mathrm{Mn}$, and sometimes $\mathrm{NO}_{3}^{-}$. Before 1984, SNL's Analytical Chemistry Division, UNC/Bendix, KC Services, the University of Arizona, and the Kansas Geological Survey determined a variety of solutes in many groundwater samples for SNL or one of SNL's subcontractors. The analytical data from the laboratories are presented here with accompanying discussions of sample collection methods, supporting field measurements, and laboratory analytical methods.

In addition to SNL's analytical work, groundwater samples have been analyzed by the United States Geological Survey (USGS), IT Analytical Services (ITAS), and the New Mexico Bureau of Mines and Mineral Resources for the New Mexico Environmental Evaluation Group (EEG); data from these sources are summarized in this report.

A comparison of the SNL, USGS, ITAS, and EEG data sets and a preliminary evaluation of the data for the major solutes $\left(\mathrm{Cl}^{-}, \mathrm{SO}_{4}^{\overline{ }}, \mathrm{Na}, \mathrm{K}, \mathrm{Ca}\right.$, and $\mathrm{Mg}$ ) shows that the data for samples analyzed by UNC/Bendix for SNL seem to be the most reliable, but that at some locations, samples representative of the native, unperturbed groundwater have not been collected. At other locations, the water chemistry has apparently changed between sampling episodes. 


\section{ACKNOWLEDGMENTS}

Many reviewers read various draft versions of the report and provided helpful comments on portions or all of the manuscript: The author thanks George Saulnier, Malcolm Siegel, Carol Stein, Doug Uhland, Lynn Brandvold, Al Lappin.

Steve Lambert and Jerry Mercer provided enlightening information about groundwater sampling, analyses, and the history of WIPP investigations in general.

Dan Colton, Doug Uhland, Bill Randall, and Mark Lyon of IT Corp. were extremely helpful in providing copies of the Water Quality Sampling Program (WQSP) data and in discussing the status and progress of the WQSP.

Jenny Chapman kindly provided copies of the EEG data to include in the preliminary evaluation in this report.

Mary Gonzales assisted in the initial preparation of the database files from which some of the tables in this report were created.

Dan Garber facilitated the preparation of this report.

Ed Lorusso, Debbie Rivard, and Frances Forrest (Tech Reps, Inc.) helped prepare the manuscript for publication. 


\section{DISCLAMIER}

Portions of this document may be illegible in electronic image products. Images are produced from the best available original document. 


\section{CONTENTS}

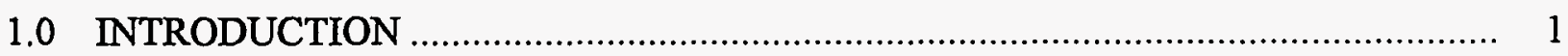

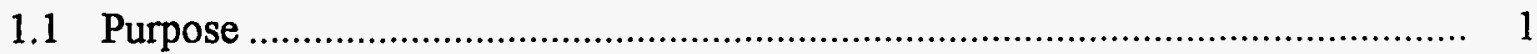

1.2 Scope and Organization of Report ................................................................... 1

1.3 Terminology, Abbreviations, and Conversion Factors............................................ 2

1.3.1 Well Nomenclature …........................................................................ 3

1.3.2 Statistical Terms ............................................................................... 5

1.3.3 Terms Used to Describe Groundwater Samples and Sampling Programs ... 8

1.3.4 Terms Used to Describe the Analyses and the Evaluation of the Data ....... 10

1.3.5 Abbreviations Used in This Report....................................................... 15

1.3.6 Conversion Factors ...................................................................... 16

1.4 Agencies Responsible for Collecting and/or Analyzing Samples.......................... 16

1.5 Study Area........................................................................................... 17

1.5.1 Location and Stratigraphy ............................................................... 17

1.5.2 Groundwater Samples..................................................................... 21

2.0 METHODS OF EVALUATING SOLUTE DATA ……......................................... 23

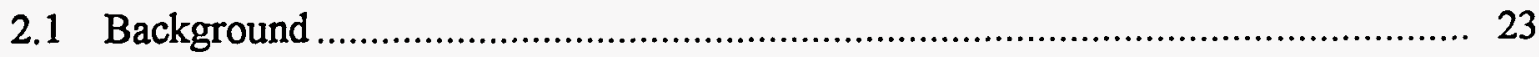

2.2 Evaluating the Representativeness of Samples .................................................. 24

2.2.1 Background ............................................................................. 24

2.2.2 Discussion of Representativeness ........................................................ 24

2.2.3 Methods of Evaluating the Representativeness of Samples ...................... 25

2.3 Evaluating the Stability (Shelf Life) of Samples ................................................ 27

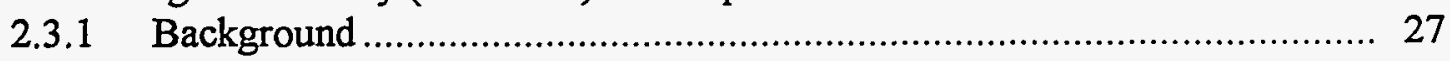

2.3.2 Shelf-Life Studies............................................................................ 29

2.3.3 Methods of Evaluating the Stability (Shelf life) of Samples ....................... 30

2.4 Evaluating the Quality of the Analyses ............................................................... 31

2.4.1 Background ................................................................................... 31

2.4.2 Methods of Evaluating the Quality of the Analytical Data........................ 31

2.5 Summary of Methods of Evaluating Solute Data ................................................ 33

3.0 DATA FROM SANDIA AND SANDIA'S SUBCONTRACTORS …………............... 35

3.1 Introduction........................................................................................... 35

3.2 Samples Collected Before 1980 .................................................................. 36

3.2.1 Program Description and Wells Sampled ................................................ 36

3.2.2 Field Data and Sample Collection...................................................... 36

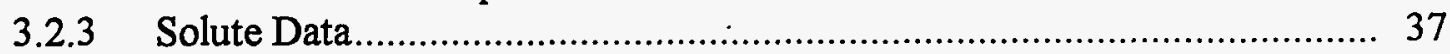

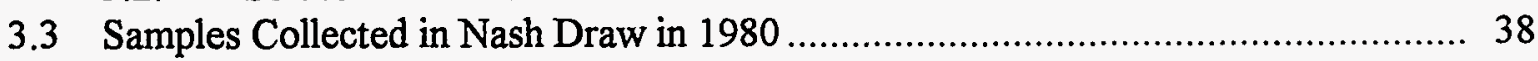

3.3.1 Program Description and Wells Sampled............................................ 38

3.3.2 Field Data and Sample Collection.......................................................... 38

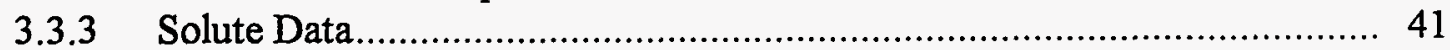

3.4 Samples Collected in 1980-1981 During Hydrologic Tests .................................. 41

3.4.1 Program Descriptions and Wells Sampled .............................................. 41

3.4.2 Field Data and Sample Collection......................................................... 41

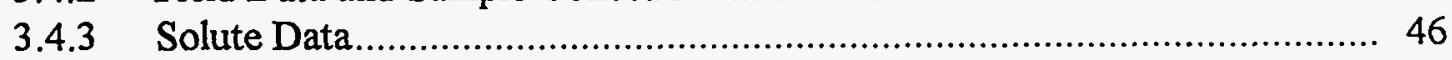

3.5 Samples Collected in 1983-1984 During Hydrologic Tests ................................. 46 
3.5.1 Program Description and Wells Sampled ................................................ 46

3.5.2 Field Data and Sample Collection...................................................... 46

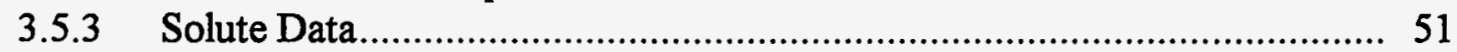

3.6 Samples Collected in June and August 1984 During Convergent-Flow Tracer

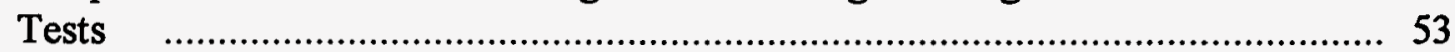

3.6.1 Program Descriptions and Wells Sampled ............................................ 53

3.6.2 Field Data and Sample Collection.................................................... 53

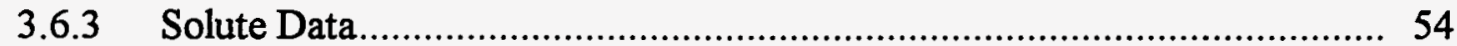

3.7 Samples Collected During Round One of the WQSP ....................................... 55

3.7.1 Program Description and Wells Sampled .................................................. 55

3.7.2 Field Data and Sample Collection.............................................................. 55

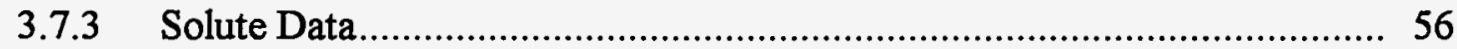

3.8 Analytical Methods Used by UNC/Bendix..................................................... 56

3.8.1 Samples and Analytes..................................................................... 56

3.8.2 Analytical Methods and Method Validation......................................... 57

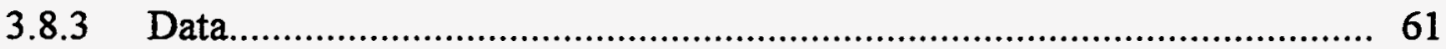

3.8.4 Analytical Uncertainties and Accuracy..................................................... 61

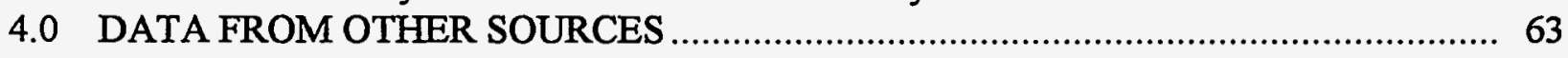

4.1 Data Reported by the United States Geological Survey ......................................... 63

4.1.1 Program Description and Wells Sampled ............................................... 63

4.1.2 Field Data and Sample Collection............................................................ 64

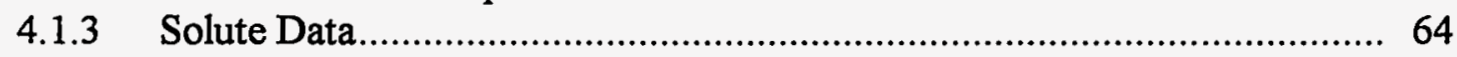

4.2 Data Reported by the Management and Operating Contractor ............................... 66

4.2.1 Program Description and Wells Sampled ............................................... 66

4.2.2 Field Data and Sample Collection........................................................ 67

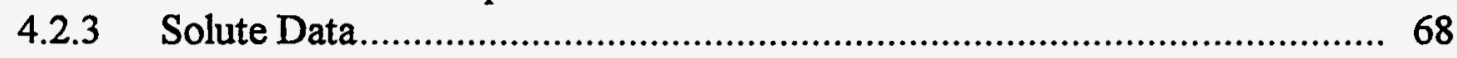

4.3 Data Reported by the NM Environmental Evaluation Group ................................ 68

4.3.1 Program Description and Wells Sampled............................................. 68

4.3.2 Field Data and Sample Collection.......................................................... 68

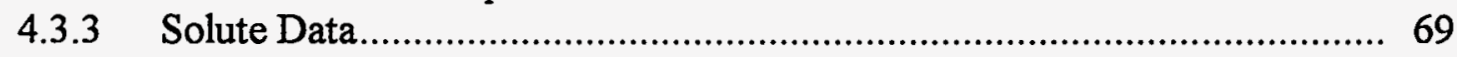

5.0 COMPARISON AND PRELIMINARY EVALUATION OF THE DATA .................... 71

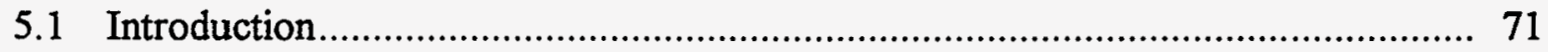

5.1.1 Summary of Methods of Evaluating Data .............................................. 71

5.1.2 Comments About Some Parameters ………......................................... 73

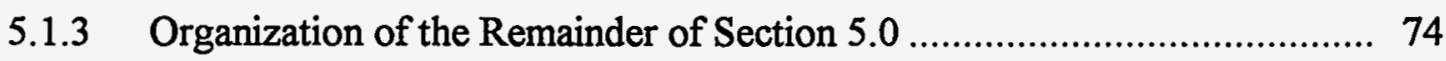

5.2 Peliminary Evaluation of Data from the Culebra Dolomites ................................ 75

5.2.1 DOE-1 Culebra (Table 71) ............................................................. 75

5.2.2 DOE-2 Culebra (Table 72) .................................................................. 76

5.2.3 FR-10 Culebra (Table 73) …………........................................... 76

5.2.4 H-1 Culebra (Table 74) ............................................................... 76

5.2.5 H-2 Culebra (Table 75) .................................................................... 77

5.2.6 H-3 Culebra (Table 76) ................................................................... 78

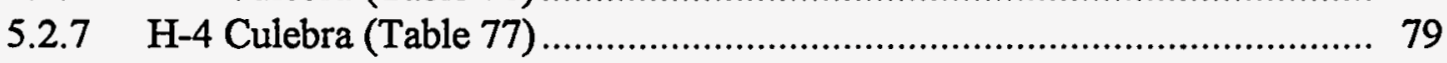

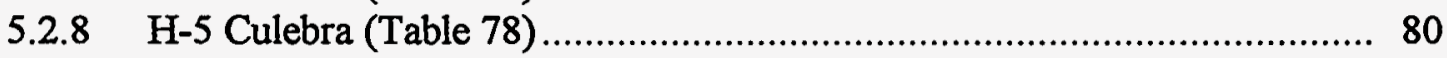

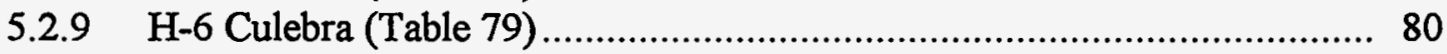




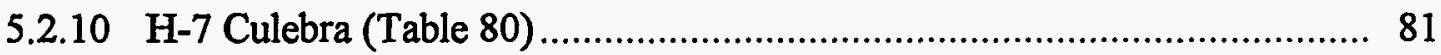

5.2.11 H-8 Culebra (Table 81) .............................................................. 82

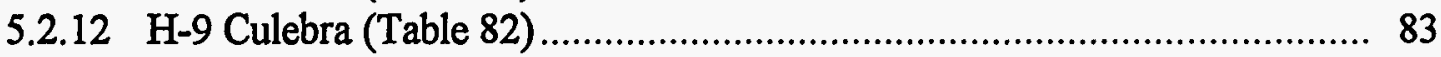

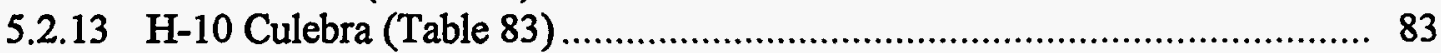

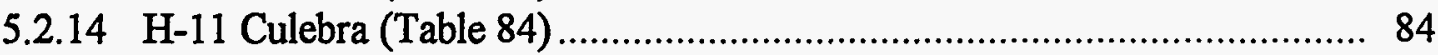

5.2.15 H-12 Culebra (Table 85) ................................................................... 84

5.2.16 P-14 Culebra (Table 86)................................................................. 85

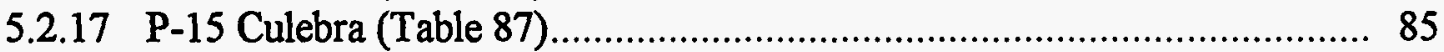

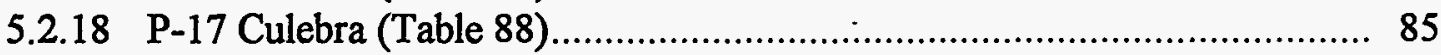

5.2.19 P-18 Culebra (Table 89)................................................................... 86

5.2.20 WIPP-25 Culebra (Table 90) ........................................................... 86

5.2.21 WIPP-26 Culebra (Table 91) ............................................................. 87

5.2.22 WIPP-27 Culebra (Table 92) ………………................................... 89

5.2.23 WIPP-28 Culebra (Table 93) ........................................................... 89

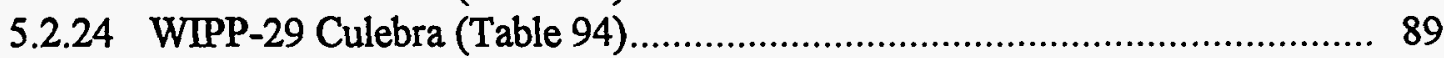

5.2.25 WIPP-30 Culebra (Table 95)............................................................... 90

5.2.26 Engle Well - Culebra (Table 96).......................................................... 90

5.3 Preliminary Evaluation of Data from the Magenta Dolomite.................................... 91

5.3.1 H-1 Magenta (Table 97) .................................................................. 91

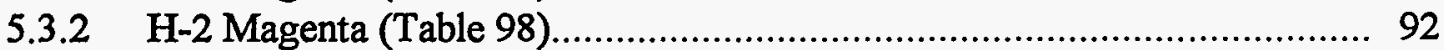

5.3.3 H-3 Magenta (Table 99)................................................................... 92

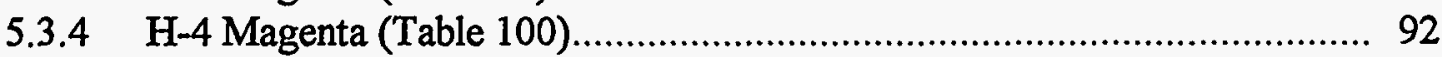

5.3.5 H-5 Magenta (Table 101) .................................................................. 94

5.3.6 H-6 Magenta (Table 102)............................................................... 95

5.3.7 H-8 Magenta (Table 103).................................................................... 95

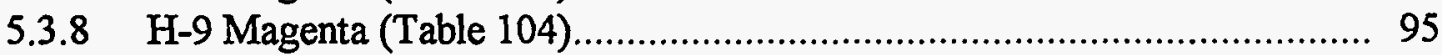

5.3.9 H-10 Magenta (Table 105) ................................................................ 96

5.3.10 WIPP-25 Magenta (Table 106) ...................................................... 96

5.3.11 WIPP-27 Magenta (Table 107) ......................................................... 96

5.3.12 WIPP-30 Magenta (Table 108) ........................................................... 96

5.4 Preliminary Evaluation of Data from the Rustler/Salado Contact Zone .................. 97

5.4.1 H-1 Rustler/Salado (Table 110)............................................................ 97

5.4.2 H-2 Rustler/Salado (Table 111).......................................................... 97

5.4.3 H-3 Rustler/Salado (Table 112)........................................................ 97

5.4.4 H-4 Rustler/Salado (Table 113) ......................................................... 98

5.4.5 H-5 Rustler/Salado (Table 114)............................................................. 98

5.4.6 H-6 Rustler/Salado (Table 115),.......................................................... 98

5.4.7 H-7 Rustler/Salado (Table 116).......................................................... 99

5.4.8 H-8 Rustler/Salado (Table 117)............................................................ 99

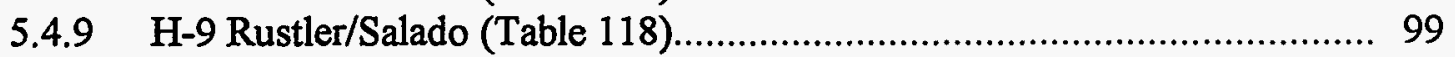

5.4.10 H-10 Rustler/Salado (Table 119) ...................................................... 99

5.4.11 P-14 Rustler/Salado (Table 120) …….............................................. 99

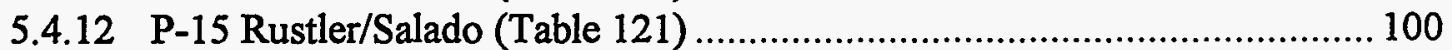

5.4.13 P-17 Rustler/Salado (Table 122) .......................................................... 100

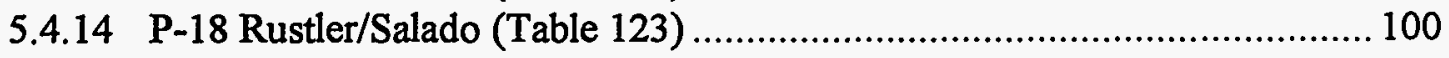




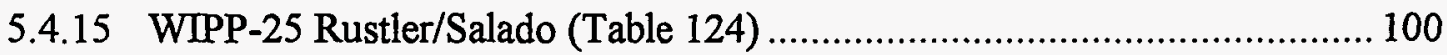

5.4.16 WIPP-26 Rustler/Salado (Table 125) ………........................................ 100

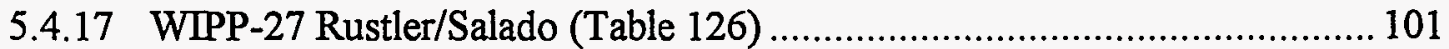

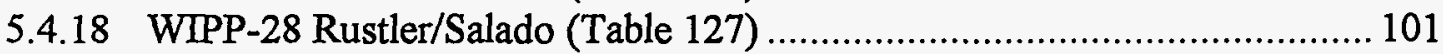

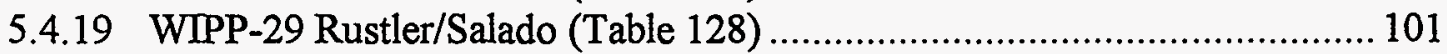

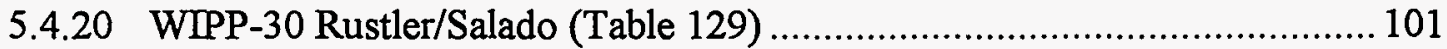

5.5 Preliminary Evaluation of Data from the Dewey Lake Red Beds............................ 102

5.5.1 Pocket Well Dewey Lake (Table 130) …................................................ 102

5.5.2 Ranch Well Dewey Lake (Table 131) ...................................................... 102

5.5.3 Twin Wells/Pasture Well Dewey Lake (Table 132).................................. 102

5.5.4 Unger Well Dewey Lake (Table 133) ………........................................... 103

5.6 Preliminary Evaluation of Data from Other Formations ........................................... 103

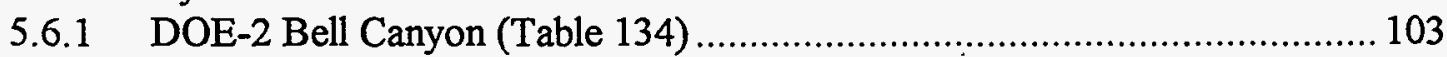

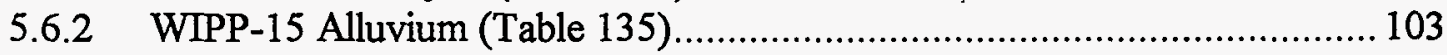

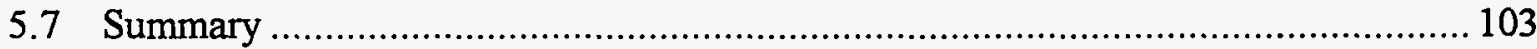

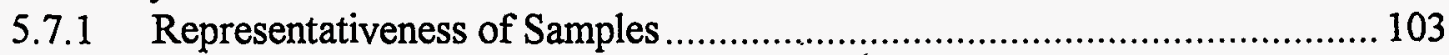

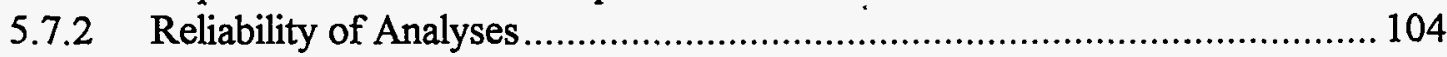

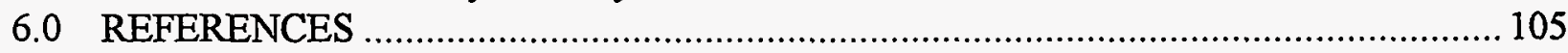

Figures

1 Map of southeastern New Mexico showing location of WIPP site and of Well WIPP-15. 18

$2 \quad$ Map of WIPP and vicinity showing well locations................................................. 19

3 Generalized stratigraphic column of rocks at and near the WIPP site............................ 20

\section{Tables}

1 List of Wells and Zones Sampled by the WQSP, HGC, SNL and/or the USGS

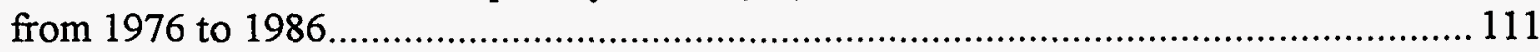

2 List of Tests in Which Samples Were Collected and Analyzed for Solutes........................ 114

3 List of Samples for Which Data are Included in This Report ........................................ 118

4 Data from Serial Samples Collected from the Culebra at H-4B in May 1981 .................. 125

5 Data from Serial Samples Collected from the Culebra at H-5B in May/June 1981 ........... 125

6 Data from Serial Samples Collected from the Culebra at H-5C in Oct 1981.................... 126

7 Data for Serial Samples Collected from the Culebra at H-6B in May 1981 ..................... 126

8 Data for Serial Samples Collected from the Culebra at H-6C in May 1981 .................... 126

9 Data for Serial Samples Collected from the Culebra at H-3B3 in June 1984 ................... 127

10 Data for Serial Samples Cóllected from the Culebra at H-4C in Aug 1984...................... 127

11 Steady-State Field Results for Serial-Sampling Parameters Determined in Nash Draw in $1980 \quad 128$

12 Steady-State Field Results for Serial-Sampling Parameters Determined During Hydrologic Tests in 1980 and 1981 129

13 Steady-State or Best Available Field Results for Serial-Sampling Parameters Determined During Hydrologic Tests in 1983 and 1984 129 
14 Steady-State Field Results for Serial-Sampling Parameters Determined During Tracer Tests in June and August 1984.

15 Steady-State Field Results for Serial-Sampling Parameters Determined During Round 1 of the WQSP in 1985 and 1986.

16 Results of Analyses of Solutes in Samples Collected by the USGS and Analyzed by the

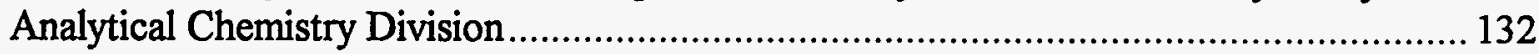

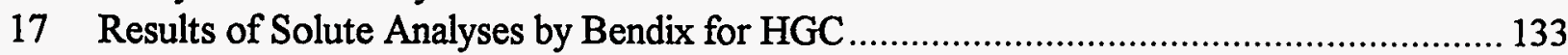

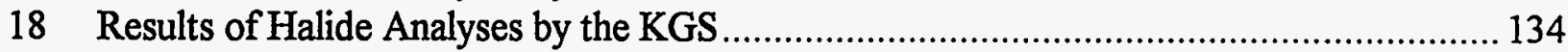

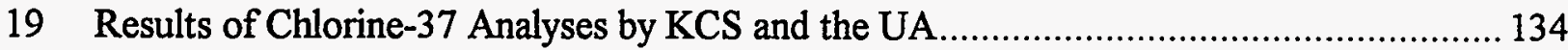

20 Results of Solute Analyses by UNC/Bendix: WIPP-25 Culebra ...................................... 135

21 Results of Solute Analyses by UNC/Bendix: WIPP-26 Culebra ....................................... 136

22 Results of Solute Analyses by UNC/Bendix: WIPP-27 Culebra ........................................ 137

23 Results of Solute Analyses by UNC/Bendix: WIPP-28 Culebra ....................................... 138

24 Results of Solute Analyses by UNC/Bendix: WIPP-29 Culebra ......................................... 139

25 Results of Solute Analyses by UNC/Bendix: WIPP-30 Culebra ..................................... 140

26 Results of Solute Analyses by UNC/Bendix: WIPP-25 Magenta..................................... 141

27 Results of Solute Analyses by UNC/Bendix: WIPP-27 Magenta..................................... 142

28 Results of Solute Analyses by UNC/Bendix: WIPP-25 Rustler/Salado ............................. 143

29 Results of Solute Analyses by UNC/Bendix: WIPP-26 Rustler/Salado ............................ 144

30 Results of Solute Analyses by UNC/Bendix: WIPP-28 Rustler/Salado ........................... 145

31 Results of Solute Analyses by UNC/Bendix: WIPP-29 Rustler/Salado .......................... 146

32 Results of Solute Analyses by UNC/Bendix: WIPP-30 Rustler/Salado ......................... 147

33 Results of Solute Analyses by UNC/Bendix: H-4B Culebra.......................................... 148

34 Results of Solute Analyses by UNC/Bendix: H-5B Culebra.......................................... 149

35 Results of Solute Analyses by UNC/Bendix: H-5C Culebra.......................................... 150

36 Results of Solute Analyses by UNC/Bendix: H-6B Culebra.............................................. 151

37 Results of Solute Analyses by UNC/Bendix: H-3B3 Culebra........................................ 152

38 Results of Solute Analyses by UNC/Bendix: H-4C Culebra ............................................ 153

39 Results of Solute Analyses by UNC/Bendix: DOE-1 Culebra ........................................ 154

40 Results of Solute Analyses by UNC/Bendix: DOE-2 Culebra ......................................... 155

41 Results of Solute Analyses by UNC/Bendix: H-2A Culebra.............................................156

42 Results of Solute Analyses by UNC/Bendix: H-3B3 Culebra......................................... 157

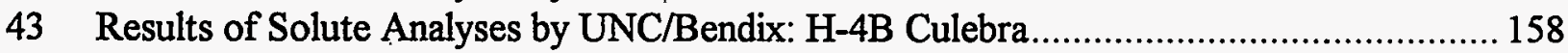

44 Results of Solute Analyses by UNC/Bendix: H-5B Culebra............................................ 159

45 Results of Solute Analyses by UNC/Bendix: H-6B Culebra........................................... 160

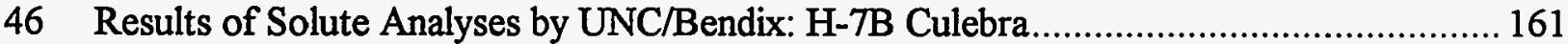

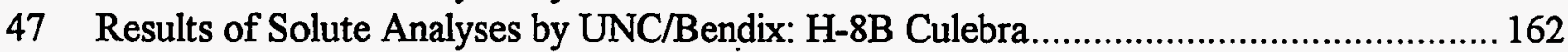

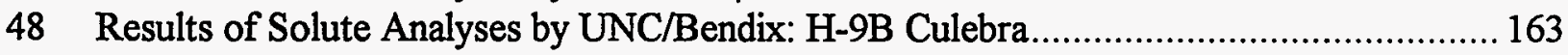

49 Results of Solute Analyses by UNC/Bendix: H-11B3 Culebra ............................................ 164

50 Results of Solute Analyses by UNC/Bendix: H-12 Culebra ............................................. 165

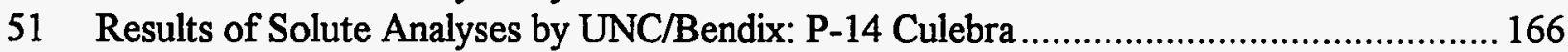

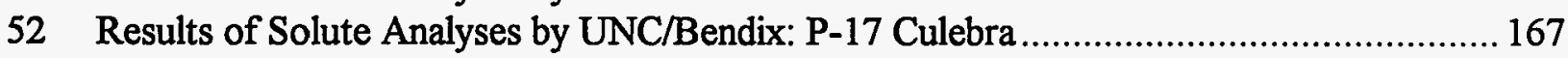

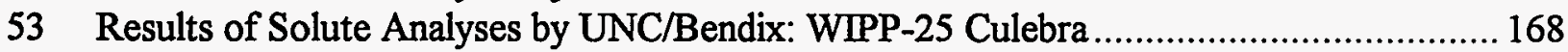

54 Results of Solute Analyses by UNC/Bendix: WIPP-26 Culebra .........................................169

55 Results of Solute Analyses by UNC/Bendix: WIPP-29 Culebra ..................................... 170 
56 Results of Solute Analyses by UNC/Bendix: Engle Well - Culebra ................................ 171

57 Results of Solute Analyses by UNC/Bendix: H-3B1 Magenta ……............................... 172

58 Results of Solute Analyses by UNC/Bendix: H-4C Magenta ....................................... 173

59 Results of Solute Analyses by UNC/Bendix: H-5C Magenta ......................................... 174

60 Results of Solute Analyses by UNC/Bendix: H-6C Magenta ..........................................175

61 Results of Solute Analyses by UNC/Bendix: Ranch Well - Dewey Lake .......................... 176

62 Results of Solute Analyses by UNC/Bendix: Twin Wells/Pasture Well - Dewey Lake...... 177

63 Results of Solute Analyses by UNC/Bendix: DOE-2 Bell Canyon .................................. 178

64 Summary of Results of Laboratory Analyses by UNC/Bendixfor Sandia National

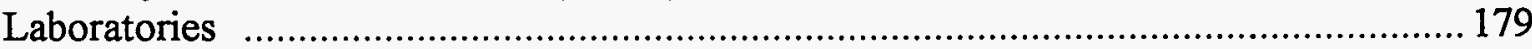

65 Analytical Methods Used by UNC/Bendix (1984-1986) .............................................. 183

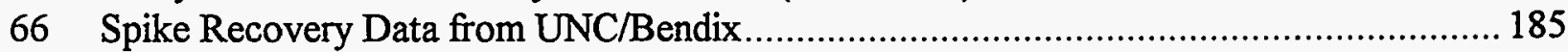

67 Results from Analyses of Acid Blanks by UNC/Bendix .................................................. 187

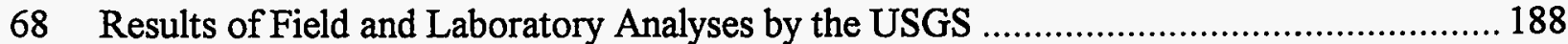

69 Results of Laboratory Analyses by ITAS (WQSP Round 1) ......................................... 193

70 Results of Laboratory Analyses by the NMBM\&MR for the EEG.................................... 197

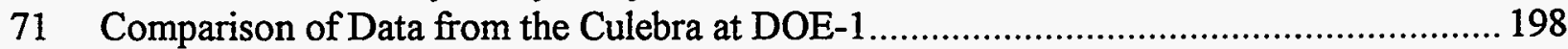

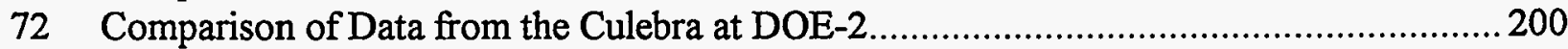

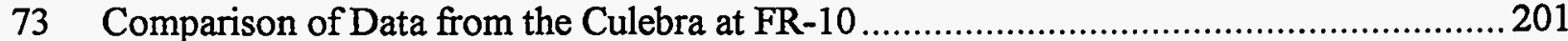

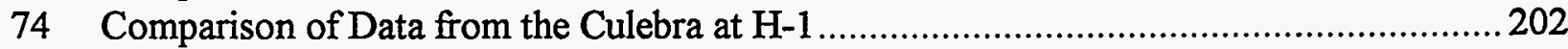

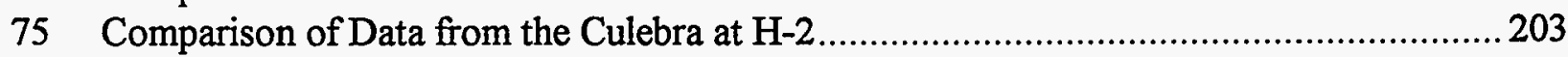

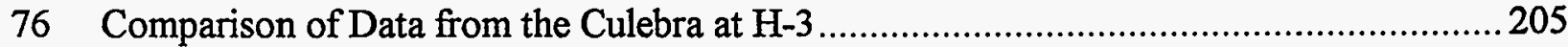

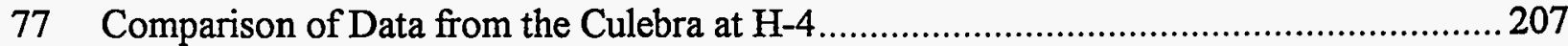

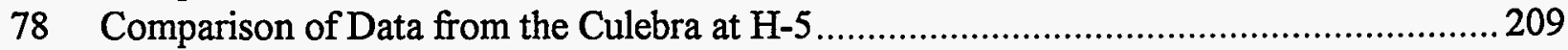

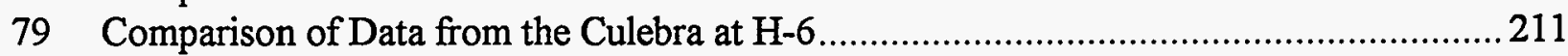

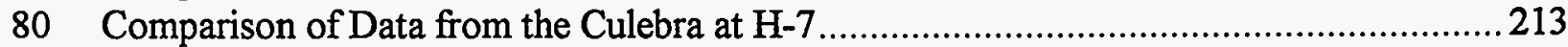

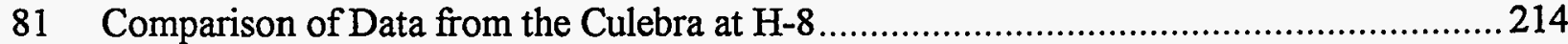

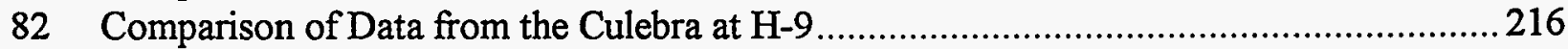

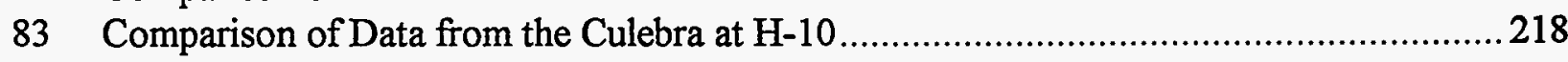

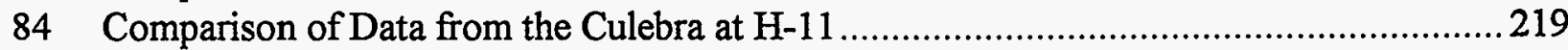

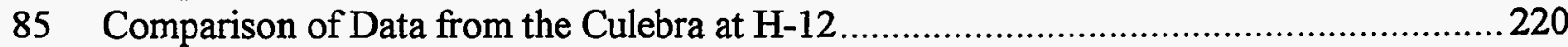

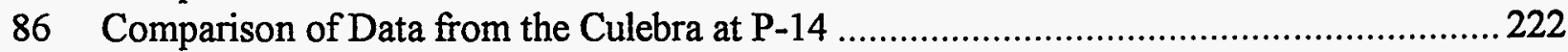

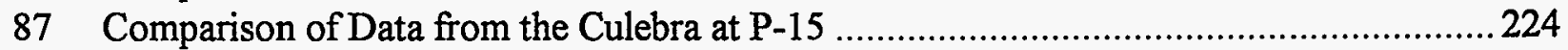

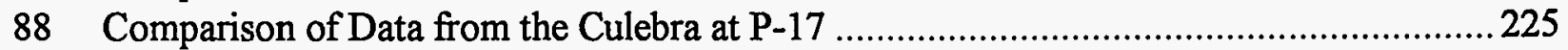

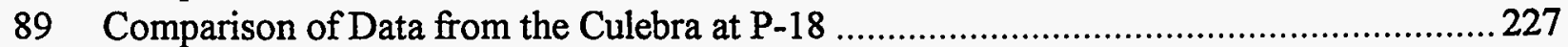

90 Comparison of Data from the Culebra at WIPP-25 …..............................................228

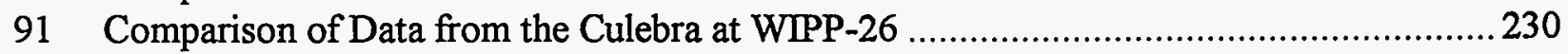

92 Comparison of Data from the Culebra at WIPP-27 .....................................................232

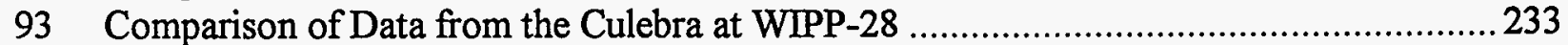

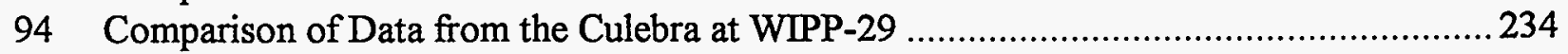

95 Comparison of Data from the Culebra at WIPP-30 ...................................................2236

96 Comparison of Data from the Culebra at Engle Well ...................................................237

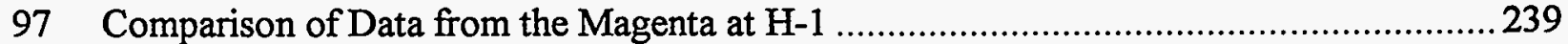

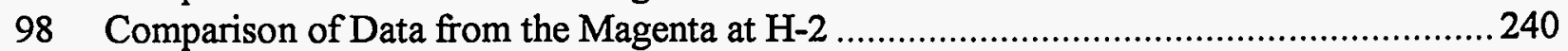

99 Comparison of Data from fhe Magenta at H-3 ........................................................... 241 


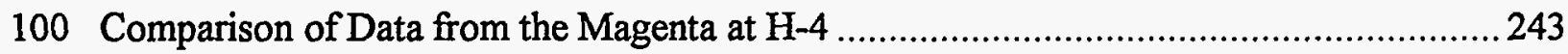

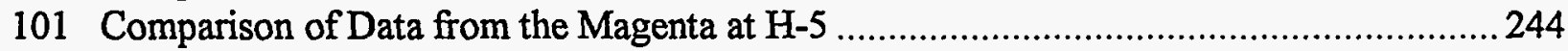

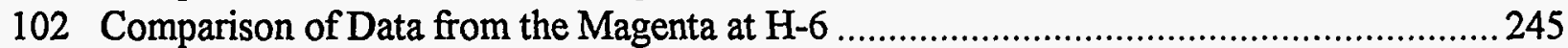

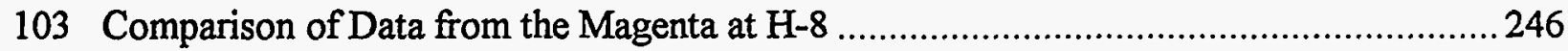

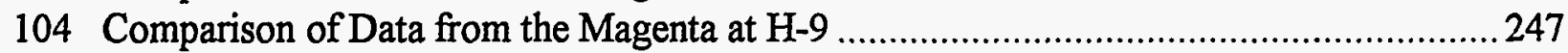

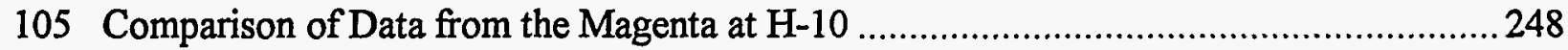

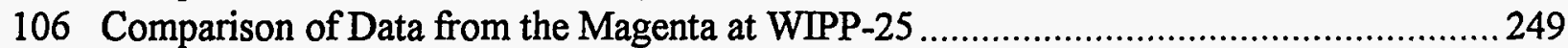

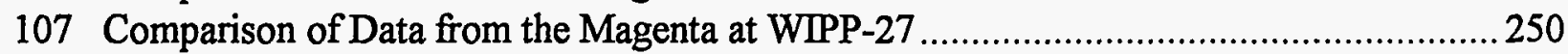

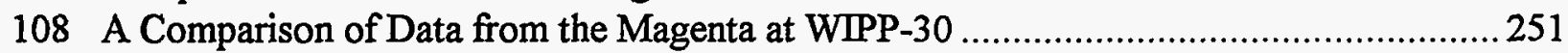

109 Serial-Sampling Field Data from the Magenta at WIPP-30 Compared with USGS

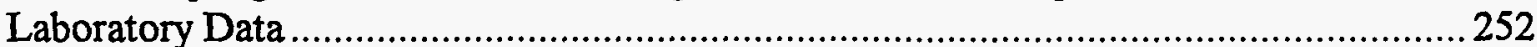

110 Comparison of Data from the Rustler/Salado Contact Zone at H-1 ...............................253

111 Comparison of Data from the Rustler/Salado Contact Zone at H-2 …..........................254

112 Comparison of Data from the Rustler/Salado Contact Zone at H-3 ….........................25

113 Comparison of Data from the Rustler/Salado Contact Zone at H-4 …..........................256

114 Comparison of Data from the Rustler/Salado Contact Zone at H-5 ..............................257

115 Comparison of Data from the Rustler/Salado Contact Zone at H-6 …...........................258

116 Comparison of Data from the Rustler/Salado Contact Zone at H-7 ................................259

117 Comparison of Data from the Rustler/Salado Contact Zone at H-8 …...........................2.260

118 Comparison of Data from the Rustler/Salado Contact Zone at H-9 ..............................2261

119 Comparison of Data from the Rustler/Salado Contact Zone at H-10 …..........................262

120 Comparison of Data from the Rustler/Salado Contact Zone at P-14 …..........................263

121 Comparison of Data from the Rustler/Salado Contact Zone at P-15 .............................264

122 Comparison of Data from the Rustler/Salado Contact Zone at P-17 ..............................265

123 Comparison of Data from the Rustler/Salado Contact Zone at P-18 …...........................266

124 Comparison of Data from the Rustler/Salado Contact Zone at WIPP-25 ….....................267

125 Comparison of Data from the Rustler/Salado Contact Zone at WIPP-26 ........................2.268

126 Comparison of Data from the Rustler/Salado Contact Zone at WIPP-27 .......................269

127 Comparison of Data from the Rustler/Salado Contact Zone at WIPP-28 ........................2270

128 Comparison of Data from the Rustler/Salado Contact Zone at WIPP-29 .......................2271

129 Comparison of Data from the Rustler/Salado Contact Zone at WIPP-30 .......................2.272

130 Comparison of Data from the Dewey Lake at Pocket Well..............................................2273

131 Comparison of Data from the Dewey Lake at Ranch Well...........................................22

132 Comparison of Data from the Dewey Lake Red Beds at Twin Wells/Pasture Well...........275

133 Comparison of Data from the Dewey Lake at Unger Well.........................................2.276

134 Comparison of Data from the Bell Canyon at DOE-2 …….........................................227

135 Comparison of Data from the Alluvium at WIPP-15 ................................................... 278 


\subsection{INTRODUCTION}

\subsection{Purpose}

The Waste Isolation Pilot Plant (WIPP) is a facility operated by the United States Department of Energy (DOE) to demonstrate the safe disposal of transuranic (TRU) nuclear waste generated by defense programs.

Solute data from regional groundwater studies are important to the WIPP site characterization program, the long-term monitoring programs (radionuclide and environmental), and the performance assessment program, because groundwater movement is considered to be a potentially important method of nuclide transport between the WIPP facility and the accessible environment.

The purposes of this report are the following:

- to publish Sandia National Laboratories' (SNL's) available groundwater solute data and associated (but previously unpublished) field data

- to identify, begin to understand, and, where possible, begin to reconcile the discrepancies between various sets of analyses and various samples of groundwater from the same location (that is, the same stratigraphic zone at the same hydropad)

- for the major solutes $\left(\mathrm{Cl}^{-}, \mathrm{SO}_{4}^{=}, \mathrm{Na}, \mathrm{K}, \mathrm{Ca}\right.$, and $\left.\mathrm{Mg}\right)$ in groundwaters from the sampled localities, to begin to develop a set of recommended, defensible analytical data for use by other WIPP project personnel

\subsection{Scope and Organization of Report}

This report includes solute data for groundwater samples from the Rustler Formation and related rocks in the vicinity of the WIPP site that were analyzed for SNL (or SNL's subcontractors) between 1979 and 1986. It also includes selected solute data for WIPP groundwaters reported by the United States Geological Survey (USGS), the WIPP Management \& Operating Contractor (MOC), and the New Mexico Environmental Evaluation Group (EEG).

The quality of the major-solute data from SNL, the USGS, the MOC, and the New Mexico Environmental Evaluation Group (EEG) are compared and evaluated. Some trace- and minorsolute data from SNL, the USGS, the MOC, and the New Mexico Environmental Evaluation Group (EEG) are included, but are discussed only briefly and are not evaluated.

Section 1.0 contains introductory material, including the following:

- a discussion of some of the terminology, abbreviations, and conversion factors used in this report (Section 1.3)

- a list of the agencies that collected and/or analyzed the groundwater samples discussed here (Section 1.4) 
- a brief description of the study area (Section 1.5)

Section 2.0 discusses ways of evaluating the data, including the following:

- methods of evaluating the representativeness of the samples

- methods of evaluating the stability (shelf life) of the samples

- methods of evaluating the quality of the analyses

Section 3.0 presents the analytical data that were generated by or specifically for SNL, including discussions of the sample collection methods, the analytical methods used in the field, the results of field measurements, the analytical methods used in the laboratory, and the results of laboratory measurements.

In Section 3.0, samples are divided into six groups, according to when and by whom they were collected.

- samples collected before 1980 by the USGS

- samples collected in 1980 in Nash Draw by SNL

- samples collected in 1980/1981 by SNL during hydrologic tests

- samples collected in 1983/1984 by Hydro Geo Chem (HGC) during hydrologic tests

- samples collected in June and August 1984 by Hydro Geo Chem (HGC) during convergent-flow tracer tests

- samples collected in 1985/1986 during round one of the Water Quality Sampling Program (WQSP)

Section 4.0 presents the analytical data that have been published or made available by:

- the USGS

- the New Mexico Environmental Evaluation Group (EEG)

- the DOE MOC

Section 5.0 presents a comparison of the data from all the agencies and a preliminary evaluation of the data for the major solutes $\left(\mathrm{Cl}^{-}, \mathrm{SO}_{4}^{\overline{\bar{N}}}, \mathrm{Na}, \mathrm{Ca}, \mathrm{Mg}\right.$, and $\left.\mathrm{K}\right)$.

\subsection{Terminology, Abbreviations, and Conversion Factors}

This section has descriptions and definitions of many of the terms and phrases used in this report. Because many readers will be familiar with at least some (if not all) of this material, the following subsections are organized so they may be easily skimmed.

Section Contents

1.3.1 Well nomenclature

1.3.2 Statistical terms

1.3.3 Terms used to describe groundwater samples and sampling programs 
1.3.4 Terms used to describe the analyses and the evaluation of data

1.3.5 Abbreviations used in this report

1.3.6 Conversion factors

\subsubsection{Well Nomenclature}

Most of the wells mentioned in this report were drilled specifically for the WIPP project. A few stock wells (ranch wells that produce water suitable for watering stock but not for human consumption) are also included. Because knowing exactly which well was sampled can be important in evaluating the solute data, and because a well is sometimes known by more than one name, well nomenclature is discussed in some detail here.

\subsubsection{STOCK WELLS}

Stock wells are identified in this report by their locally used names. Some of the wells have, or have had, more than one locally used name. Table 1 includes the stock wells, the names used in this report, and some of their synonyms (names by which these wells have been identified in other reports).

\subsubsection{WIPP WELLS}

Each well drilled for the WIPP project is given a name at the time of drilling. This name often appears in various documents (field notes, memoranda, laboratory documentation and reports, published reports, etc.) in a variety of forms (abbreviations or synonyms). Some well names are changed (that is, given suffixes) when an additional wells are subsequently drilled at the same hydropad.

At multi-well hydropads, knowing exactly which well was sampled may be important for evaluating the representativeness of samples for various solutes because different wells, even on the same hydropad, may have different configurations and histories.

Because the same well may appear under different names in various reports (a source of confusion for those not intimately familiar with the project), the conventions used in naming wells drilled for the WIPP are explained here.

Wells drilled for the WIPP project are designated by a prefix followed by a one- or two-digit number and sometimes a suffix. Examples include WIPP-25 and H-3B3.

\section{Prefixes}

Each multiple-purpose well is given a prefix such as AEC, ERDA, WIPP, or DOE, depending on when it was drilled. Wells originally intended for potash resource assessment or hydrologic testing and monitoring are given the prefixes "P" and "H," respectively. (Note that because some 
wells are later recompleted or configured, the prefix does not necessarily indicate the current status of the well.)

\section{Suffixes}

When more than one well is located on a hydropad, the well names include suffixes. Some hydropads originally contained three wells. These were given the suffixes $A, B$, and $C$ (or $a, b$, and c), indicating completion in the Magenta, Culebra, and Rustler/Salado contact zone, respectively, or the suffixes $\mathrm{B} 1, \mathrm{~B} 2$, and $\mathrm{B} 3$, indicating that all three were completed in the Culebra. Some examples are the $\mathrm{H}-2$ hydropad $(\mathrm{H}-2 \mathrm{~A}, \mathrm{H}-2 \mathrm{~B}$, and $\mathrm{H}-2 \mathrm{C})$ and the $\mathrm{H}-11$ hydropad (H-11B1, H-11B2, and H-11B3).

Because additional wells have been drilled at some hydropads, including $\mathrm{H}-2, \mathrm{H}-3$, and $\mathrm{H}-7$, the suffixes of some older wells have been modified. For example, H-2B is now H-2B1. Table 1 indicates which wells have "new" names and why.

\section{Variations of Names of WIPP Wells}

A given well name may be "spelled" in a variety of ways.

- The prefix may be spelled out or abbreviated, for example, WIPP or W.

- The prefix and number may be separated by a hyphen or not, for example, WIPP-25 or WIPP 25 or WIPP25.

- The number, if a single digit, may be preceded by a zero or not, for example, H-08 or H-8. The former designation allows convenient sorting (alphabetizing) by computer programs.

- The suffix letters may be upper or lower case, for example, H-10A or H-10a.

Thus, a single well may be identified by several names. For example, H3b3, H-3b3, H03b3, $\mathrm{H} 3 \mathrm{~B} 3, \mathrm{H}-3 \mathrm{~B} 3$, and H-03B3 all refer to the same well; similarly WIPP-25, WIPP 25, W25, W 25 , and $\mathrm{W}-25$ are different designations for one well.

\section{Conventions Used in this Report}

In this report, the following conventions have been used in referring to WIPP wells:

- Prefixes are spelled out.

- A hyphen separates the prefix and the number.

- One-digit numbers are not given a leading zero.

- Suffix letters are upper case.

Some examples are $\mathrm{H}-3, \mathrm{H}-10 \mathrm{~A}$, and WIPP-25.

In some data tables, however, the well names are abbreviated to save space. Table 1 lists both the well names used in the text and the abbreviations used in some of the data tables. 
To facilitate comparison of the various data sets included in this report (from the USGS, the MOC, the New Mexico Environmental Evaluation Group (EEG), and SNL), wells that have been renamed are referred to by their current names. For example, when the USGS collected samples at the H-3 hydropad in 1977 and 1978, there was a single well there, designated H-3. When additional wells were drilled at that hydropad, the original well was designated $\mathrm{H}-3 \mathrm{~B} 1$. Table 68, which summarizes the USGS data from Mercer (1983), thus refers to H-3B1 (the designation used in this report), rather than H-3 (the designation used by Mercer, 1983).

\subsubsection{Statistical Terms}

The following concepts are briefly discussed here:

- accuracy

- precision

- confidence limits

For a detailed discussion of the statistical treatment of analytical data, the reader may refer to statistics texts such as Caulcutt and Boddy (1983) or Natrella (1966).

\subsubsection{ACCURACY}

Accuracy refers to the closeness of a measured value (or the average of a set of measured values) to the actual or "true" value of a parameter. Sources of inaccuracy in a measurement include the following (Caulcutt and Boddy, 1983; Keith et al., 1983):

- random errors (imprecision)

- gross errors

- systematic errors (bias)

Random errors are discussed under "precision" in the next subsection.

Gross errors have been defined as errors "which differ from random or systematic errors in that they are rare occurences which do not fit into the usual pattern of errors associated with a particular situation" (Caulcutt and Boddy, 1983). Examples of gross errors that could affect some of the WIPP solute data include the following:

- using the wrong equipment - for example, using a $5-\mathrm{mL}$ instead of a $10-\mathrm{mL}$ pipette

- incorrectly identifying the analyte - for example, using the wrong peak in a spectrum

- incorrectly calculating or reporting the results - for example, using the wrong equation or data, miscopying a number from a notebook, or making an arithmetic error

If there is sufficient evidence that a value is incorrect because of a gross error (one that cannot be corrected), then that value should be discarded. If, however, the error can be corrected (for example, if an arithmetic error can be identified and corrected) then the incorrect value can, of course, be replaced. 
Systematic errors, or bias, affect a group of determinations equally, although these errors may be different from one group of determinations to the next. Causes of systematic errors that could affect some of the WIPP solute data include the following:

- the analytical method used - for example, one that fails to correct for a positive or negative interference

- the analyst - for example, an individual who consistently misidentifies the endpoint of a titration

- the equipment or reagents used - for example, a miscalibrated balance

The systematic error associated with a measurement can only be quantified if the true value of the measured parameter is known. Thus, for a given water sample, the systematic error cannot be quantified.

However, the functioning of the method, equipment, reagents, and analyst can be verified by the analysis of standard and control samples. The analysis of spiked samples allows for possible recognition of bias introduced by the sample itself (such as an interferent in the sample matrix). In addition, bias can sometimes be recognized by comparing results from different laboratories for samples of the same composition or by comparing results for the same sample obtained by different methods in the same laboratory.

The required accuracy of a measurement depends on the intended use of the data. For example, for many analytes determined for the monitoring programs, it may be important only to know if a species is present in amounts greater than some specified quantity defined by a regulatory agency; that agency may specify the required accuracy (and/or precision) for the

analyses. For other programs it may be important to recognize and measure changes in concentrations from year to year, in which case the accuracy must be sufficient to allow such changes to be recognized.

\subsubsection{PRECISION}

Precision refers to the reproducibility of a measurement, or how closely together replicate measurements cluster. Imprecision in a group of replicate measurements is caused by random errors. The precision of a measurement of an analyte will vary with the method used, the sample bulk composition or matrix, and often with the analyst and equipment used.

A measure of precision, the standard deviation, $\sigma$, of a set of measurements is estimated by the parameter "s," calculated as follows:

$$
s=\left[\frac{1}{n-1} \sum_{i=1}^{i=n}\left(x_{i}-\bar{x}\right)^{2}\right]^{1 / 2}
$$

where $x_{i}=$ value of the $i^{\text {th }}$ result

$$
\overline{\mathrm{x}}=\text { average result }\left(\sum \mathrm{x}_{\mathfrak{i}} / \mathrm{n}\right)
$$




$$
\mathrm{n}=\text { number of replicates }
$$

The number of degrees of freedom (DF) associated with a calculated standard deviation, $\mathrm{s}$, is n-1.

If more than one set of measurements, each with a calculated $s$, has been made and if all of these sets can be assumed to have the same population standard deviation, $\sigma$, then the calculated standard deviations (the s's) may be averaged as follows:

$$
\mathrm{s}_{\text {avg }}=\left[\frac{\sum_{\mathrm{i}=1}^{\mathrm{i}=\mathrm{k}} \mathrm{DF} \mathrm{F}_{\mathrm{i}}\left(\mathrm{s}_{\mathrm{i}}^{2}\right)}{\sum_{\mathrm{i}=\mathrm{l}}^{\mathrm{i}=\mathrm{k}} \mathrm{DF}}\right]^{1 / 2}
$$

where $\mathrm{k} \quad$ = the number of sets of measurements

$\mathrm{s}_{\mathrm{i}}=$ the calculated standard deviation for the $\mathrm{i}^{\text {th }}$ set

$\mathrm{DF}_{\mathrm{i}}=$ the number of degrees of freedom associated with the $i^{\text {th }}$ set

The number of degrees of freedom associated with $s_{a v g}$ is $\sum_{i=1}^{i=k} D F_{i}$.

In this report, estimates of precision are given in two ways:

- as a relative standard deviation

- as a relative percent difference

The relative standard deviation (RSD), in percent, is calculated by the following equation, with $\mathrm{s}$ calculated in equation 1 :

$$
\operatorname{RSD}(\%)=\frac{s}{\bar{x}} \cdot 100
$$

The relative percent deviation (RPD), in percent, can be used when two measurements were made; it is calculated as follows:

$$
\operatorname{RPD}(\%)=\frac{\left[\mathrm{x}_{1}-\mathrm{x}_{2}\right]}{\overline{\mathrm{x}}} \cdot 100
$$

As with accuracy, the required precision of a measurement depends on the intended use of the data. For example, in analyzing parameters in serial samples, the precision must be good enough to allow the field chemist to recognize fairly small changes from sample to sample. 


\subsubsection{CONFIDENCE LIMITS}

Confidence limits for a given confidence level are calculated as follows:

$$
\mathrm{CL}=\frac{\mathrm{t} \cdot \mathrm{s}}{(\mathrm{n})^{1 / 2}}
$$

where $s$ = estimated standard deviation (may be an "average" s, calculated as in equation 2 , if appropriate)

$\mathrm{n}=$ number of replicate measurements

$t=$ Students $t$ factor; the value decreases with an increasing number of degrees of freedom associated with $\mathrm{s}$ and increases with an increasing desired confidence level

For example, a value reported as "1200 $\pm 100 \mathrm{mg} / \mathrm{L}$ (95\% C.L., 1 rep)" means that we are $95 \%$ confident that the "true" value represented by a single measurement of $1200 \mathrm{mg} / \mathrm{L}$ will lie between 1100 and $1300 \mathrm{mg} / \mathrm{L}$.

Similarly, a value reported as "950 $\pm 50 \mathrm{mg} / \mathrm{L}$ (90\% C.L., 2 reps)" means that if we have two measurements whose average is $950 \mathrm{mg} / \mathrm{L}$, we are $90 \%$ confident that the "true" value will lie between 900 and $1000 \mathrm{mg} / \mathrm{L}$.

\subsubsection{Terms Used to Describe Groundwater Samples and Sampling Programs}

The following terms are defined in this section:

- representative sample

- serial sample

- steady state

- final sample

- Water Quality Sampling Program (WQSP)

\subsubsection{REPRESENTATIVE SAMPLE}

A representative sample is a sample that represents the native unperturbed groundwater. Colton and Morse (1985) defined a representative sample as one that is "chemically identical to the aquifer groundwater in its pristine and unaltered physico-chemical state, i.e., completely unaltered by the effects of drilling and any post drilling processes and reactions and sampling procedures, organic and inorganic."

Colton and Morse recognized that their definition described an unobtainable theoretical ideal. A sample may be, and often will be, representative with respect to some parameters but not to others (this is discussed in more detail in Section 2.0). 
In this report, "representative" usually refers to a sample that is considered representative with respect to the major solutes $\left(\mathrm{Cl}^{-}, \mathrm{SO}_{4}^{-}, \mathrm{Na}, \mathrm{K}, \mathrm{Mg}\right.$, and $\mathrm{Ca}$ ) but not necessarily with respect to other parameters.

Although a thorough discussion of the possible sources of contamination in nonrepresentative samples is beyond the scope of this report, among the sources will be the following:

- contamination introduced during drilling and (re)completion of the well, such as, drilling brines, materials used to control lost circulation, lubricants, and so forth

- products from the reaction of groundwater with materials left in the well, such as cement, casing, screen, pumps, and so forth

- products from the reaction of introduced materials with the surrounding rock

- contamination introduced during hydrologic testing, such as tracers and so forth

- contamination introduced by the sampling and preserving procedures

Representativeness must be evaluated separately for each parameter in each sample. Users should be cautious about using and interpreting data for unevaluated parameters. Methods of evaluating representativeness are discussed in Section 2.0 of this report.

\subsubsection{SERIAL SAMPLE}

Serial samples are groundwater samples collected and analyzed for selected parameters in the field, usually during a lengthy pump test; they are used to help evaluate sample representativeness. Serial samples are usually collected at regular intervals (for example, every four hours or every day) until the measured parameters reach "steady state" (see below).

\subsubsection{STEADY STATE}

When a parameter is monitored in the field by means of the collection and analysis of serial samples, the measured values typically start at some value and increase or decrease with time until a constant value, or a value about which the measured values oscillate, is reached; this value is called the steady-state value.

\subsubsection{FINAL SAMPLE}

Final samples are samples that are collected and sent to various laboratories for analysis. Ideally, final samples should be representative with respect to the parameters that will be determined in the laboratory. For many parameters, however, such as the minor and trace solutes, sample representativeness may not have been evaluated. Some parameters (for example, $\mathrm{pH}$, alkalinity, and Eh, all of which may be unstable with time) are usually measured in the field at the time final samples are collected. 


\subsubsection{WATER QUALITY SAMPLING PROGRAM (WQSP)}

The Water Quality Sampling Program (WQSP) is a long-term, regional, groundwatersampling program conducted by the DOE. For the WQSP, selected wells will be sampled many times (typically annually or biennially) in the next few years. Serial samples are collected, several parameters are measured in the field, and final samples are collected after the values of certain parameters reach steady state. The WQSP is fully described in Colton and Morse (1985) and in the Water Quality Sampling Manual (WP 7-2); in this report, Section 4.2 gives more information about the WQSP.

\subsubsection{Terms Used to Describe the Analyses and the Evaluation of the Data}

The following terms are defined in this section:

- acid blank

- alkalinity

- charge-balance error (CBE)

- control sample

- density/specific gravity

- divalent cations

- equivalence and equivalent weight

- spiked sample

- total dissolved solids (TDS)

\subsubsection{ACID BLANK}

An acid blank is a sample of deionized water to which acid has been added. It is prepared in the field using the same acid (that is, from the same stock bottle) that was used to acidify the groundwater samples to $\mathrm{pH}<2$. The acid is added to the deionized water in the same proportion in which it was added to the samples.

For example, if $1 \mathrm{~mL}$ of nitric acid was added to each liter of sample, then the blank is prepared by adding $1 \mathrm{~mL}$ of nitric acid to $1 \mathrm{~L}$ of deionized water (or $0.5 \mathrm{~mL}$ of nitric acid to $0.5 \mathrm{~L}$ of deionized water).

\subsubsection{ALKALINITY}

Alkalinity refers to the ability of a solution to neutralize acids. Total alkalinity is the equivalent sum of the bases that are titratable with a strong acid (Drever, 1982; Stumm and Morgan, 1981). These bases may include species such as $\mathrm{HCO}_{3}^{-}, \mathrm{CO}_{3}^{-}, \mathrm{B}(\mathrm{OH})_{4}^{-}, \mathrm{H}_{3} \mathrm{SiO}_{4}^{-}, \mathrm{HS}^{-}$, phosphates, organic bases, and $\mathrm{OH}^{-}$. In many groundwaters, the alkalinity is dominated by bicarbonate $\left(\mathrm{HCO}_{3}^{-}\right)$and/or carbonate $\left(\mathrm{CO}_{3}^{\overline{-}}\right)$. 
Because most of the noncarbonate species listed above occur in the Rustler groundwaters in negligible quantities, the total alkalinity in these waters is assumed to be equal to $\mathrm{HCO}_{3}^{-}$plus $\mathrm{CO}_{3}^{\overline{3}}$, with the ratio of the two species varying with $\mathrm{pH}$. Although many of the Rustler groundwaters contain appreciable silica and boron, these are assumed to be present mostly as $\mathrm{B}(\mathrm{OH})_{3}$ and $\mathrm{H}_{4} \mathrm{SiO} 4$, typical of most groundwaters (Stumm and Morgan, 1981), and thus are assumed to not contribute to the total alkalinity. ${ }^{1}$

Alkalinity is measured by titration with a standard acid (Lambert and Robinson, 1984; Colton and Morse, 1985; ASTM D1067-82 and ASTM D3875-80) and may be reported as meq/L or as some convenient compound. For example, alkalinity is often reported as $\mathrm{CaCO}_{3}$, although such a value does not necessarily say anything about the concentrations of $\mathrm{Ca}$ or $\mathrm{CO}_{3}^{-}$actually present in the solution.

Because, for the groundwaters discussed in this report, the total alkalinity can be assumed to be $\mathrm{HCO}_{3}^{-}$plus $\mathrm{CO}_{3}^{-}$, presentation of the alkalinity results as concentrations of $\mathrm{HCO}_{3}^{-}$and $\mathrm{CO}_{3}^{-}$ is reasonable. However, many of the laboratory results included in this report were reported by the laboratories as $\mathrm{mg} / \mathrm{L} \mathrm{CaCO}$.

Conversion of results to other units: For most of the groundwaters discussed in this report, alkalinity values reported as $\mathrm{mg} / \mathrm{L} \mathrm{CaCO}_{3}$ may be converted to $\mathrm{mg} / \mathrm{L} \mathrm{HCO}_{3}^{-}$. At a $\mathrm{pH}$ of less than $\sim 8.1$ (true for most of these groundwaters) the $\mathrm{CO}_{3}^{=}$concentration will be negligible, with $\mathrm{HCO}_{3}^{-}$dominating. For these samples, results reported as $\mathrm{CaCO}_{3}$ can be converted to $\mathrm{HCO}_{3}^{-}$by the following equation:

$$
\text { alkalinity }\left(\mathrm{mg} / \mathrm{L} \mathrm{HCO}_{3}^{-}\right)=\text {alkalinity }\left(\mathrm{mg} / \mathrm{L} \mathrm{CaCO}_{3}\right) \times \frac{61}{50}
$$

For samples with a $\mathrm{pH}$ greater than 8.1 or for samples with unknown $\mathrm{pH}$, the conversion should not be made.

To convert results from $\mathrm{mg} / \mathrm{L} \mathrm{HCO}_{3}^{-}$and/or $\mathrm{mg} / \mathrm{L} \mathrm{CO}_{3}^{-}$to meq/L, the following equation is used:

$$
\text { alkalinity }(\text { meq } / \mathrm{L})=\frac{1}{61}\left[\text { alkalinity }\left(\mathrm{mg} / \mathrm{L} \mathrm{HCO}_{3}^{-}\right)\right]+\frac{1}{30}[(\text { alkalinity }(\mathrm{mg} / \mathrm{L} \mathrm{CO} \overline{3})]
$$

To convert to $\mathrm{mg} / \mathrm{L} \mathrm{CaCO}$, the result in meq/ $\mathrm{L}$ is multiplied by 50 .

\footnotetext{
${ }^{1}$ This assumption will not be appropriate for certain other water samples of interest to the WIPP, for example, some brines from the repository level in the Salado Formation.
} 


\subsubsection{CHARGE-BALANCE ERROR (CBE)}

In a solution, the sum of the positive ionic charges must equal the sum of the negative ionic charges. The charge-balance error (CBE) is a measure of the apparent deviation from neutrality. A large CBE may be caused by errors in the reported concentrations of the major species or by important ionic species not being included in the calculation, presumably because they were not measured.

The CBEs given in this report were calculated by summing the quantities of the major anions in meq/ $\mathrm{L}\left(\mathrm{Cl}^{-}\right.$plus $\mathrm{SO}_{4}^{-}$plus laboratory or field $\mathrm{HCO}_{3}^{-}$and $\mathrm{CO}_{3}^{-}$, if available, plus $\mathrm{NO}_{3}^{-}$in selected Dewey Lake samples) and the major cations in meq/L (Na plus $\mathrm{K}$ plus $\mathrm{Mg}$ plus $\mathrm{Ca}$ ) and calculating the $\mathrm{CBE}$ in percent using the following equation:

$$
\mathrm{CBE}(\%)=\frac{\sum \text { cations }(\mathrm{meq} / \mathrm{L})-\sum \text { anions }(\mathrm{meq} / \mathrm{L})}{\sum \text { cations }\left(\mathrm{meq} / \mathrm{L}+\sum \text { anions }(\mathrm{meq} / \mathrm{L})\right.} \cdot 100
$$

For most of the samples discussed in this report, bicarbonate/carbonate can be safely ignored in the CBE calculation. In most of these waters, the $\mathrm{Cl}^{-}$and $\mathrm{SO}_{4}^{-}$concentrations are much

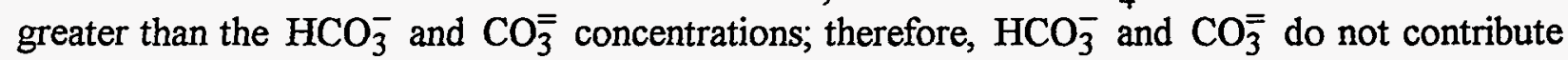
significantly to the charge-balance error (CBE).

In some of the fresher waters (such as the Culebra and Magenta samples from $\mathrm{H}-7, \mathrm{H}-8, \mathrm{H}-9$, and Engle Well), the bicarbonate/carbonate contribution becomes noticeable. For example, using. the EEG data from the H-9B Culebra sample, the CBE is $+2.1 \%$ when bicarbonate/carbonate is excluded and $+0.1 \%$ when a field bicarbonate/carbonate value is included. Both charge-balance errors (CBEs) are, however, acceptably low.

In very fresh waters (such as the Dewey Lake sample from Twin Wells/Pasture Well), bicarbonate is a major contributor to the charge-balance error (CBE) and must be included to calculate a meaningful CBE.

\subsubsection{CONTROL SAMPLE}

A control sample is a sample with "known" concentrations of certain analytes of interest. A control may be a well-characterized sample (as those available from the National Bureau of Standards, the Environmental Protection Agency, the USGS, and so forth) or a synthetic standard. A control is analyzed as an unknown in the laboratory.

\subsubsection{DENSITYISPECIFIC GRAVITY}

The terms density and specific gravity are often used interchangeably, although they are not exactly the same.

- Density is the mass per unit volume of a substance. 
- Specific gravity is the mass of a volume of a substance divided by the mass of an equal volume of a standard substance (which for liquids is pure water) with the temperature of the sample and the standard being specified.

The density of a given sample varies with temperature and pressure. The density of aqueous solutions is usually reported in $\mathrm{g} / \mathrm{mL}$; temperature should also be specified. In the 20 to $30^{\circ} \mathrm{C}$ temperature range, the change of density with temperature is typically $\sim 0.0002-0.0003 \mathrm{~g} / \mathrm{mL} /{ }^{\circ} \mathrm{C}$; it is somewhat less at lower temperatures (Kell, 1968). The density of a groundwater sample is usually measured in the laboratory by pipetting (with a volumetric pipette) and weighing an aliquot of the sample; the temperature of the sample should also be measured and recorded, although often it is not.

Specific gravity is a unitless quantity; however,the temperature of both the sample and the standard should be specified. Specific gravity is usually measured in the field with a specific gravity hydrometer certified for sample and pure water temperatures of $60^{\circ} \mathrm{F}\left(15.6^{\circ} \mathrm{C}\right)$. Temperature corrections, which are typically not made in this project, could be made as follows: correct to $60^{\circ} / 60^{\circ} \mathrm{F}$ by adding 0.0002 for each degree above $60^{\circ} \mathrm{F}$ (ASTM D1429-76).

Because the density of pure water is close to 1 in the temperature range $15^{\circ}-30^{\circ} \mathrm{C}^{2}$, the differences between densities and specific gravities of most groundwaters are small and are generally ignored. Similarly, the inaccuracies introduced by ignoring temperature differences in this range are ignored.

In this report, both field-measured specific gravities and laboratory-measured densities are given in the data tables. ${ }^{3}$. For samples that are thought to be representative of the same groundwater (that is, from the same stratigraphic zone at the same hydropad), differences in the reported numbers of up to $\sim 0.005$ may be attributed to temperature variations and/or some values being density and some being specific gravity. Larger differences may be caused by measurement inaccuracies (from inaccurate equipment such as hydrometers and volumetric ware or from analyst error), or the samples may really be different.

\subsubsection{DIVALENT CATIONS $\left(x^{++}\right)$}

The term divalent cations (or total divalent cations), sometimes abbreviated $\mathrm{X}^{++}$, is a synonym for hardness of water caused by alkaline earths. In Rustler and Dewey Lake groundwaters, the primary divalent cations are calcium and magnesium, with strontium usually and barium always being negligible.

\footnotetext{
${ }^{2} 0.99913 \mathrm{~g} / \mathrm{mL}$ at $15^{\circ} \mathrm{C}, 0.99823$ at $20^{\circ} \mathrm{C}, 0.99708$ at $25^{\circ} \mathrm{C}, 0.99568$ at $30^{\circ} \mathrm{C}(\mathrm{Kell}, 1968)$.

${ }^{3}$ In the data tables, densities have the units g/mL. Specific gravities are indicated by the initials "s.g."
} 
Divalent cations are measured in the field in serial samples by the EDTA-titration method (Lambert and Robinson, 1984; Colton and Morse, 1985). The results are reported here in meq/L. Laboratory "divalent cation" values are simply the sum of the reported calcium and magnesium values, again reported in meq/L.

\subsubsection{EQUIVALENCE AND EQUIVALENT WEIGHT}

The equivalent weight of an atomic or molecular species is the weight of the substance that would react with, or be produced by, the reaction of 1 mole of hydrogen atoms or $1 / 2$ mole of oxygen atoms.

For inorganic ionic species in groundwaters, the equivalent weight is therefore the atomic (or molecular) weight divided by the ionic charge. Some examples are shown in the following list.

\begin{tabular}{ccc} 
Species & Atomic Weight & Equivalent Weight \\
\cline { 1 - 1 } $\mathrm{Cl}^{-}$ & 35.5 & 35.5 \\
$\mathrm{Na}^{+}$ & 23.0 & 23.0 \\
$\mathrm{Ca}^{++}$ & 40.0 & 20.0 \\
$\mathrm{SO}_{4}^{-}$ & 96.0 & 48.0
\end{tabular}

To convert concentrations in $\mathrm{mg} / \mathrm{L}$ to meq/L, divide by the equivalent weight.

\subsubsection{SPIKED SAMPLE}

A spiked sample is an aliquot of sample to which a known amount of the analyte has been added. The spiked sample is analyzed as an unknown.

The spike recovery, in percent, is the amount of additional analyte measured divided by the amount added and multiplied by 100 .

\subsubsection{TOTAL DISSOLVED SOLIDS (TDS)}

Total dissolved solids (TDS) refers to the quantity of solids dissolved in a water sample. There are two common ways of determining TDS.

- Sum the analytical results for the individual solutes.

- Evaporate an aliquot of the sample to dryness, dry the residue to a constant weight at a specified temperature, and weigh the residue; the results from this method are sometimes known as residue on ignition (ROI). 
In general, results from the two methods, applied to the same sample, will not be the same. For Rustler groundwaters, the residue on ignition (ROI) value will typically be higher than the calculated TDS, because the residue will contain hydrated mineral species. (For other samples, the residue on ignition (ROI) might be lower than the calculated total dissolved solids (TDS), if volatile species were lost during ignition.)

In this report, the total dissolved solids contents (TDS-calc), were calculated by summing the concentrations, in $\mathrm{mg} / \mathrm{L}$, of $\mathrm{Cl}^{-}, \mathrm{SO}_{4}^{\overline{-}}, \mathrm{Na}, \mathrm{K}, \mathrm{Mg}$, and $\mathrm{Ca}$. Laboratory values of $\mathrm{HCO}_{3}^{-}$and

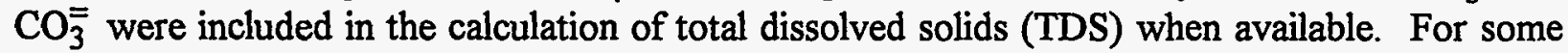
of the fresher waters from the Dewey Lake Red Beds, silica and nitrate were included in the calculation if they constituted a significant portion of the dissolved solids.

Laboratory measurements of TDS-ROI are also given when available, and the temperature at which the residue was dried is reported with the result.

\subsubsection{Abbreviations Used in This Report}

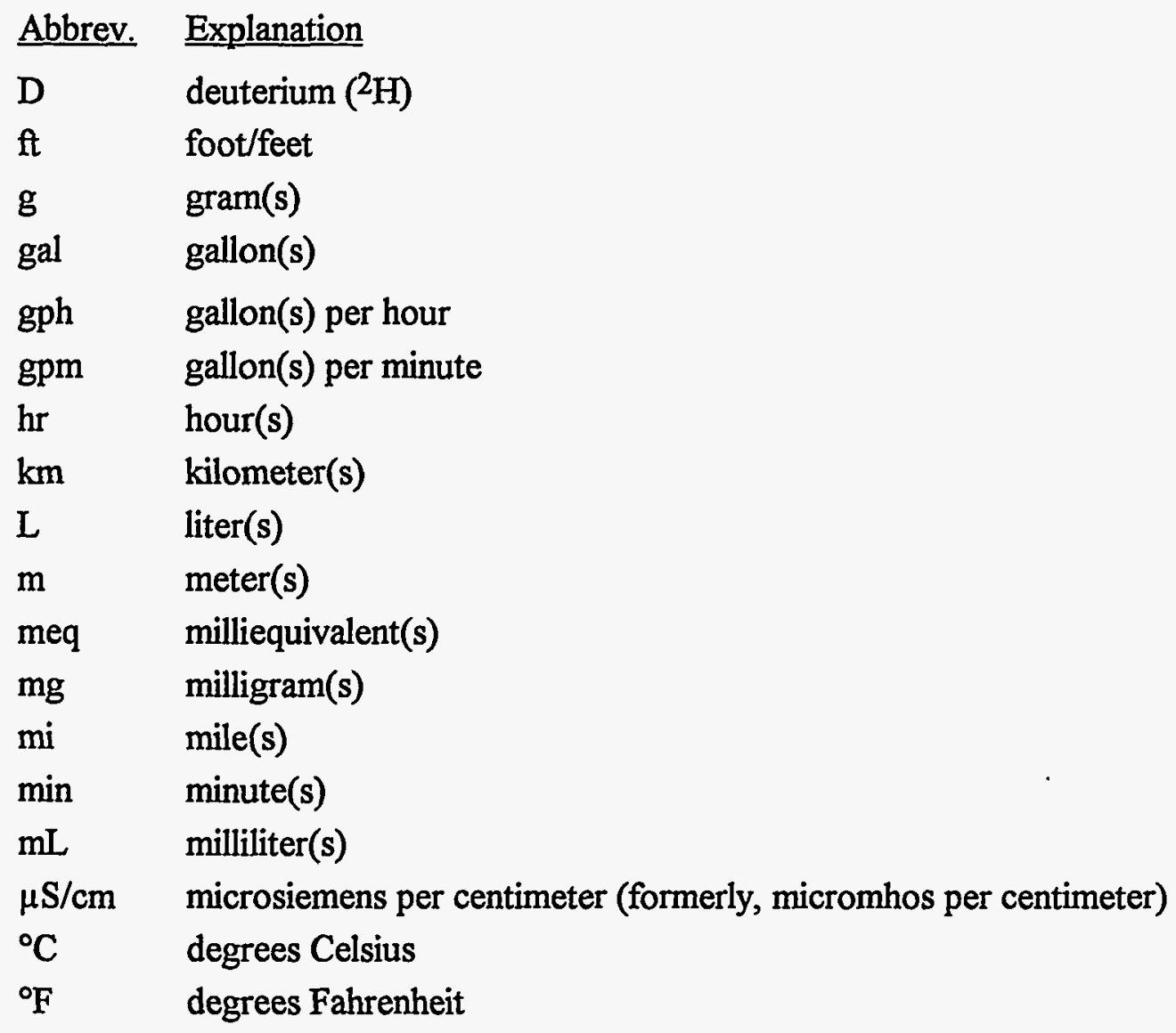




\subsubsection{Conversion Factors}

\begin{tabular}{clll} 
To convert from: & & to: & multiply by: \\
\cline { 1 - 2 } & & $\mathrm{m}$ & 0.3048 \\
$\mathrm{~L}$ & & $\mathrm{gal}$ & 0.2642 \\
$\mathrm{~L} / \mathrm{min}$ & & $\mathrm{gph}$ & 15.82 \\
$\mathrm{~L} / \mathrm{min}$ & & $\mathrm{gpm}$ & 0.2642 \\
$\mathrm{mi}$ & & $\mathrm{km}$ & 1.609
\end{tabular}

\subsection{Agencies Responsible for Collecting and/or Analyzing Samples}

A number of agencies were responsible for collecting samples, performing analyses, and reporting the data used in this report. Most of these agencies are more conveniently referred to by acronyms or abbreviations. Key personnel are also acknowledged here.

Bendix (BFEC): Bendix Field Engineering Corp, Grand Junction, CO, a facility run for the $\mathrm{DOE}$ and administered by Bendix. The analytical laboratory, managed by Ronald $\mathrm{B}$. Chessmore, performed many of the the analyses that are reported here. On 10/01/86, administration of the facility was assumed by United Nuclear Corp. (UNC), but the analytical-laboratory personnel and facilities remained the same. Most of the analyses for SNL that are in this report were done while the facility was managed by Bendix. In this report, the name "UNC/Bendix" is used; BFEC is used as an abbreviation in some data tables.

EEG: the New Mexico Environmental Evaluation Group (EEG), responsible for conducting an independent technical evaluation of the WIPP. The EEG is a part of the Environmental Improvement Division, which is a component of the New Mexico Health and Environmental Department.

HGC: Hydro Geo Chem, Inc., Tucson, AZ, a former Sandia subcontractor, responsible for hydrologic testing and groundwater sampling in many wells. Seth Gifford was responsible for many of the field measurements and collecting most of the samples in 1983 and 1984 . Wayne Stensrud, now with Intera Technologies, was responsible for coordinating many of the hydrologic field activities.

IT Corp.: International Technologies Corp., an MOC subcontractor. IT personnel were responsible for implementing and performing the WQSP. Dan Colton and John Morse were instrumental in setting up the program. Doug Uhland had the primary responsibility for implementing the program. During round 1 of the WQSP, field-laboratory support was supplied by personnel from IT Corp. and the MOC, including Gordie Tatro, Mike Debes, Bill Randall, Terry Szepesi, and others. Field hydrology support was provided by personnel from IT Corp. and the MOC, including Dan Winstanley, Ron Richardson, Rey Carrasco, Mel Balderrama, and others. 
ITAS: International Technologies Analytical Services Laboratory, Murraysville, PA, the analytical laboratory of IT Corp. ITAS has performed chemical analyses for MOC.

MOC: the DOE's Management and Operating Contractor for the WIPP project, formerly known as the Technical Support Contractor.

NMBM\&MR: New Mexico Bureau of Mines \& Mineral Resources, Socorro, NM. Dr. Lynn Brandvold analyzed solutes in many WQSP samples for the EEG.

SNL: Sandia National Laboratories, Albuquerque, NM. SNL serves as scientific advisor to the DOE and has been responsible for site-characterization efforts.

UNC or UNC Technical Services: United Nuclear Corp., on 10/01/86 replaced Bendix as manager of the DOE facility at Grand Junction, CO. See "Bendix."

USGS: the United States Geological Survey. The USGS, particularly through its personnel from the Water Resources Division, Albuquerque, NM, has been active in investigating the geohydrology of the WIPP area.

\subsection{Study Area}

\subsubsection{Location and Stratigraphy}

The WIPP site is located in southeastern New Mexico (see Figure 1). The wells discussed in this report are located in an $\sim 25$ mi by $30 \mathrm{mi}$ region; the well locations are shown in Figure 2 .

This report includes data from 48 wells, many of which have been sampled in more than one stratigraphic zone.

The stratigraphy of the WIPP site and vicinity has been presented elsewhere (Snyder, 1985; Mercer, 1983; Powers et al., 1978) and will not be discussed in this report. For the convenience of the reader, the stratigraphy is summarized in Figure 3.

Most of the samples discussed here come from the Culebra Dolomite or the Magenta Dolomite of the Rustler Formation or the "brine aquifer" of the Rustler/Salado contact zone. Samples were also collected from four stock wells completed in the Dewey Lake Red Beds. In addition, one sample came from the Bell Canyon Formation in well DOE-2, and one came from the alluvium in well WIPP-15. 


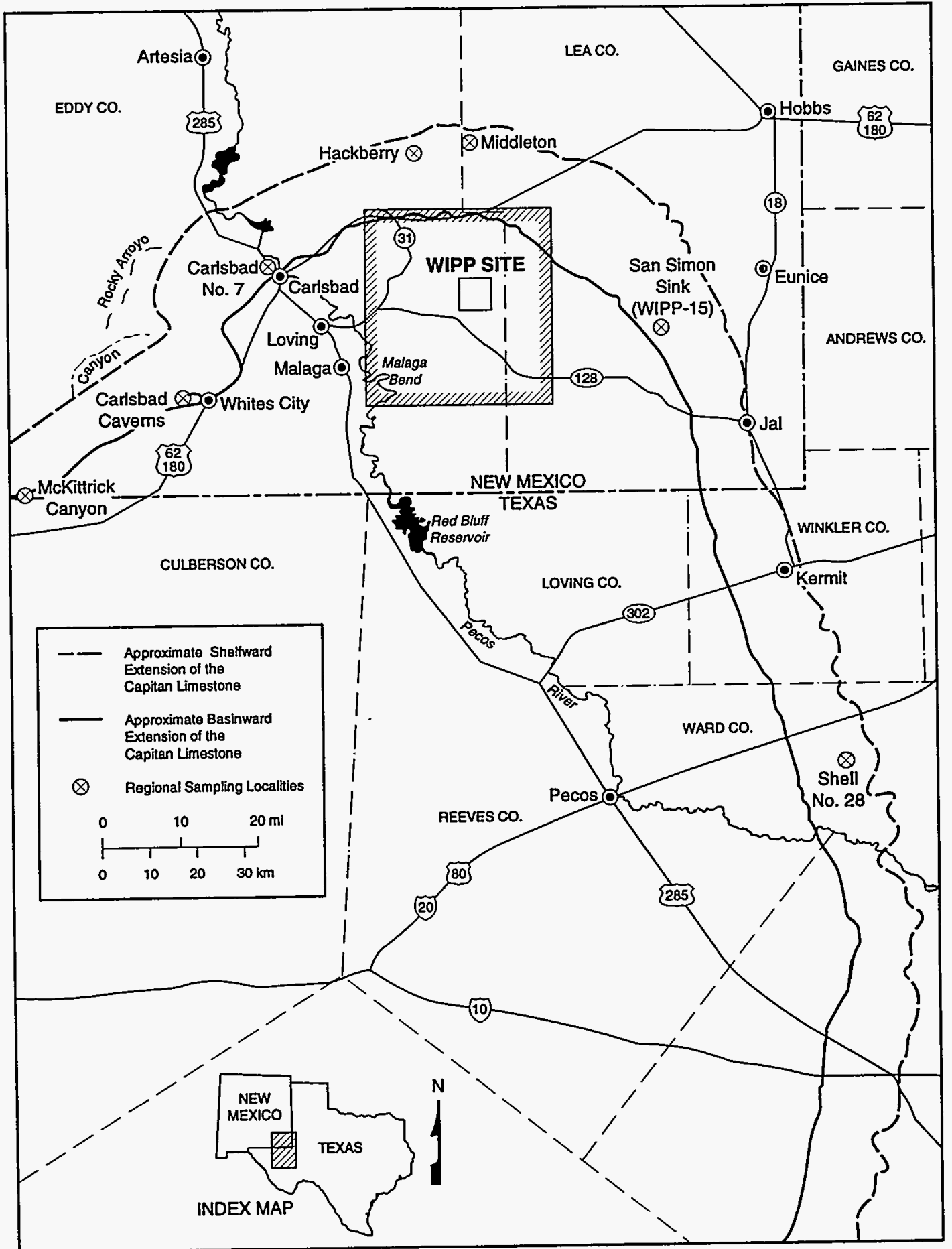

THI-6331-1.5

Figure 1. Map of southeastern New Mexico showing location of WIPP site and of Well WIPP-15 (figure 1 of Lambert and Harvey, 1987). 


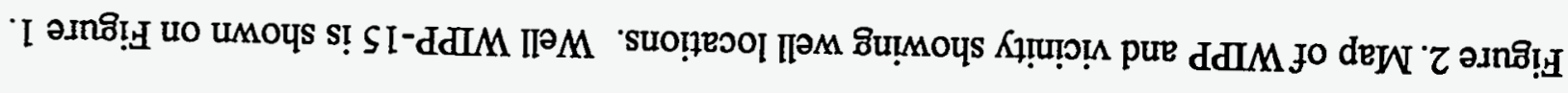
$\varepsilon-\ll-\circ \varepsilon \varepsilon-18 \perp$

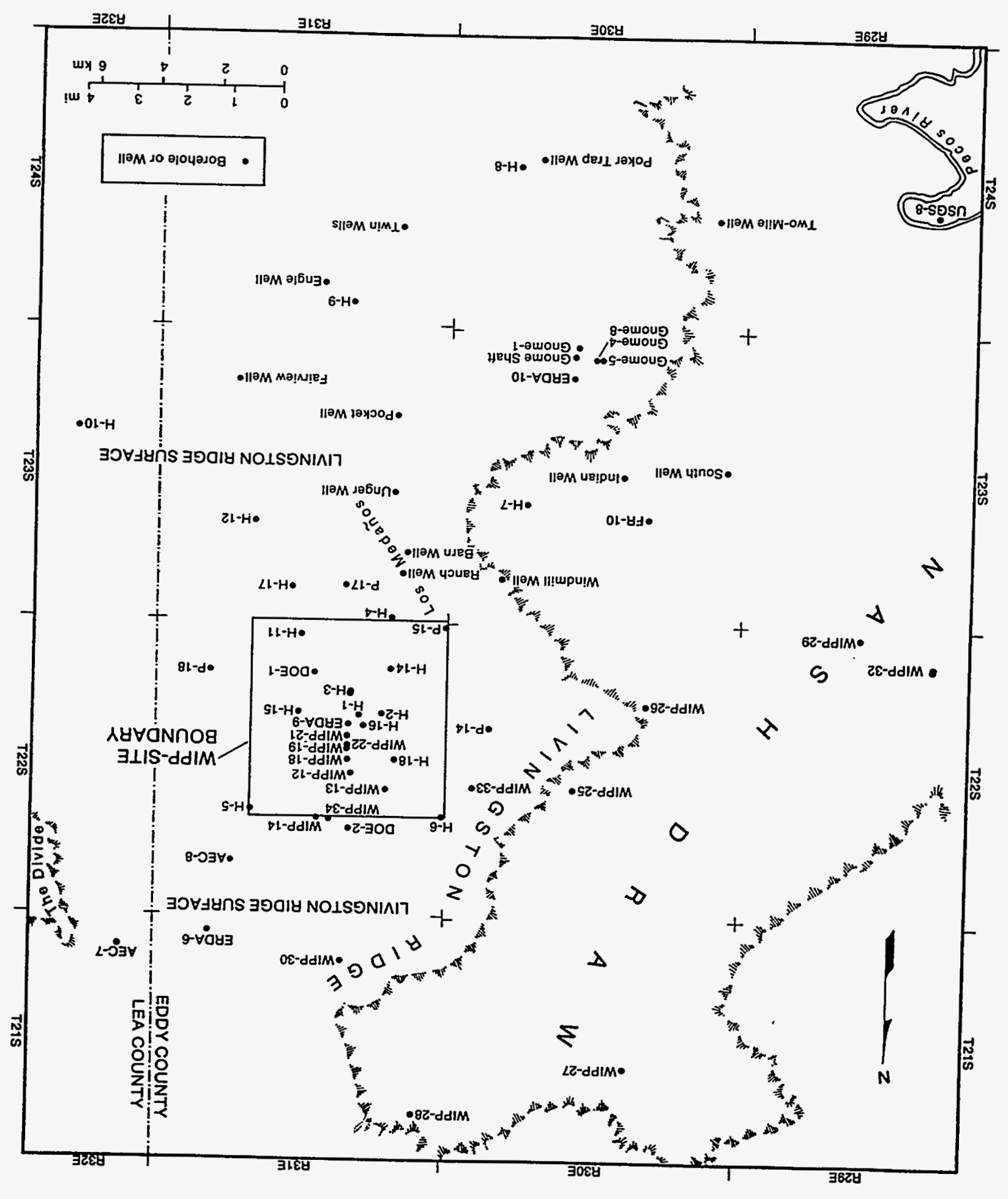




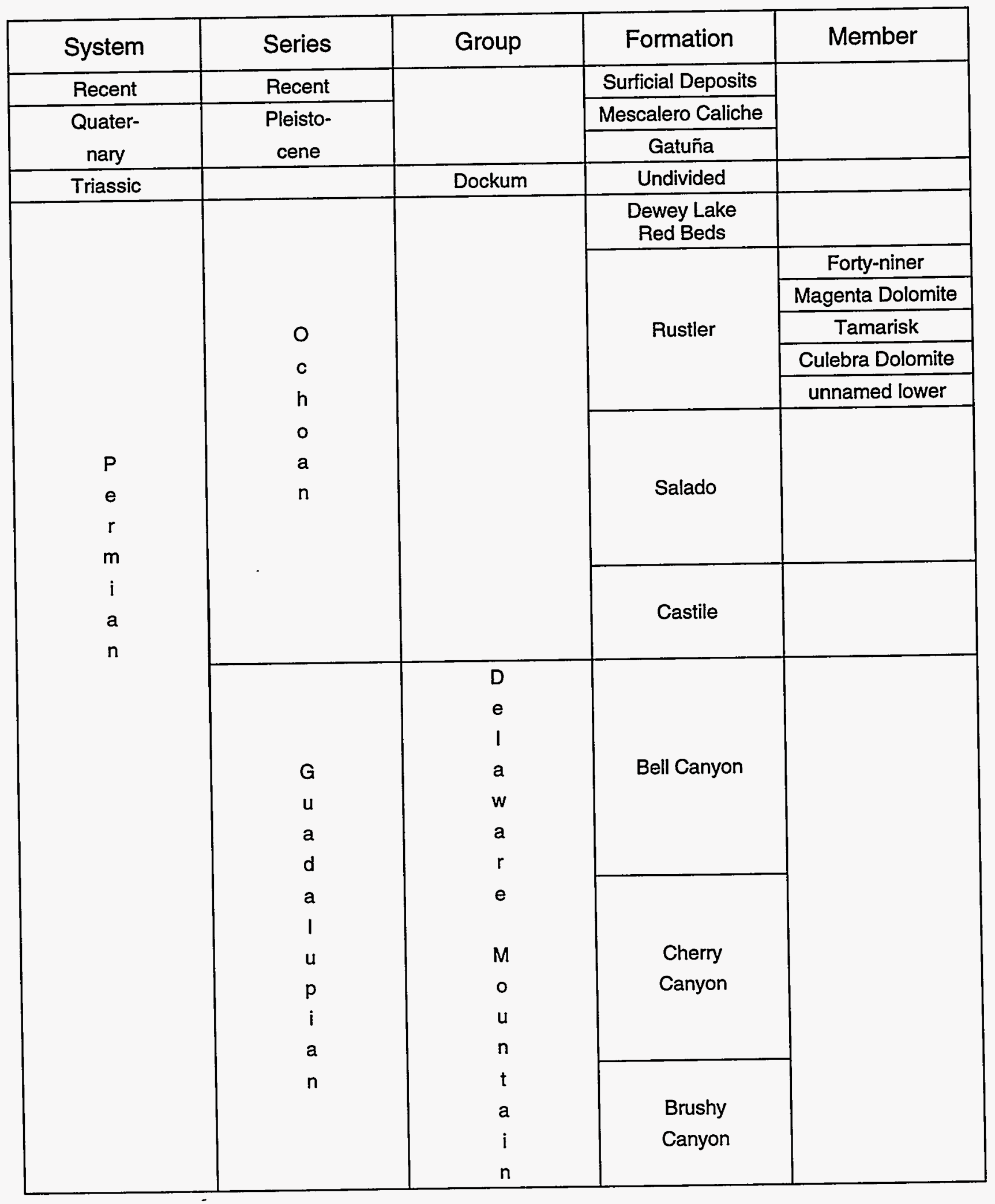

Figure 3. Generalized stratigraphic column of rocks at and near the WIPP site (figure 2-1 of Beauheim, 1987). 


\subsubsection{Groundwater Samples}

\subsubsection{WELLS AND STRATIGRAPHIC ZONES SAMPLED}

Table 1 lists all the wells included in this report and the zones sampled in each well. Details about these wells (drilling histories, stratigraphies, and so forth) are found in various basic data reports and summary reports. The relevant references for each well are included in Table 1.

\subsubsection{TESTS DURING WHICH GROUNDWATER SAMPLES WERE COLLECTED}

This report contains solute data for samples collected during 116 different tests, either hydrology tests or pumping tests conducted with the primary purpose of providing representative samples. Table 2 lists the tests and includes the date of the test, the agency that collected the final samples, the average pumping rate during the test, and the approximate quantity of water removed before final samples were collected.

\subsubsection{SAMPLES COLLECTED}

During many tests, suites of final samples were collected and sent to various laboratories for solute and other (for example, isotope) analyses. Table 3 lists all the samples for which solute data are included in this report. With the exception of the samples for stable isotopes of chlorine, samples for isotope analyses $\left(\mathrm{D},{ }^{18} \mathrm{O},{ }^{14} \mathrm{C}\right.$, and uranium) are not included in this table.

Also included in Table 3 are "field" samples, designated by "FLD" in the laboratory column. These are not actually single samples. Rather, data given in subsequent tables for these "samples" are the steady state (or best available) values of selected parameters that were measured in the field, usually during serial sampling.

For each sample, Table 3 gives the well name, stratigraphic zone, the date of sample collection (or range of dates during which field measurements were made), the agency that collected the sample, the laboratory that analyzed the sample, and a sample identification code for crossreferencing to other data tables. 


\subsection{METHODS OF EVALUATING SOLUTE DATA}

\subsection{Background}

In conducting a program to study the geochemistry of the groundwater in a region, one attempts to collect samples that are representative of the unperturbed groundwater for the parameters of interest, preserve the samples without changing the parameters of interest until they can be analyzed, and determine those parameters with the accuracy and precision required by the program or data user.

In practice, one often encounters some other situation. For example, in some cases, the samples and data were collected for some other program; the user must now evaluate the data for their suitability for the current project. In other cases, two or more sets of data for the "same" samples give conflicting results; the user must determine which results, if any, to believe.

In evaluating the data - that is, in determining how well the data represent the native unperturbed groundwater - one must consider two questions:

- Was the sample representative for the parameters of interest?

- Were the analyses of that sample reliable?.

Obviously, an excellent analysis of a nonrepresentative sample will be of little use. Although a poor analysis of a representative sample is also of little use, the analysis can sometimes be repeated (if sufficient sample was left over or archived) to give useful results.

The following sections discuss some ways of evaluating the samples and analyses. These sections summarize the processes the author used to develop the preliminary evaluation given in Section 5.0.

Section $\quad$ Contents

$2.2 \quad$ Evaluating the representativeness of samples

2.3 Evaluating the stability (shelf life) of samples

$2.4 \quad$ Evaluating the quality of the analyses

2.5 Summary

Although the considerations for evaluating the samples and analyses are presented as separate topics, in practice one considers them simultaneously, and the evaluation of the samples and analyses becomes an iterative process. 


\subsection{Evaluating the Representativeness of Samples}

This section discusses ways of determining if the samples collected represent the unperturbed native groundwater. The discussion comprises three parts.

- Background

- Discussion of representativeness

- Methods of evaluating the representativeness of samples

\subsubsection{Background}

Before 1980, groundwater samples that were collected and analyzed for the WIPP project were usually collected by bailing or swabbing during or after hydrologic testing at a well.

In 1980, Lambert and Robinson (1984) conducted a sampling program in which they demonstrated that:

"any arbitrarily chosen sample from a pumped or bailed well cannot be shown as representative of the nearly unperturbed subsurface reservoir... The well system, which includes local reservoir rock and the sampling system, must be purged of introduced material and stagnant products of the interaction of water with metal before a geologically significant water sample can be collected and analyzed."

Lambert and Robinson (1984) further showed that:

"criteria for determining a samples's significance are not absolute, but must instead be based on long-term observations of the well that include withdrawal of water and periodic measurements."

Useful criteria that can be measured precisely in the field include some major solutes (such as chloride and total divalent cations), alkalinity, and iron.

Since 1980, most samples have been collected after lengthy (days to weeks) pumping episodes, during which serial samples were collected and analyzed in the field for some or all of those parameters.

\subsubsection{Discussion of Representativeness}

A representative sample was defined in Section 1.3.3 as a sample that represents the native unperturbed groundwater. Because it is impossible to collect a sample without perturbing at least some parameters, in practice we accept as representative a sample in which the parameters of interest have not been perturbed. 
A sample that is representative for some parameters need not be and often will not be representative for other parameters.

This is sometimes seen during a serial-sampling program. Assuming for the moment that a steady-state value represents the unperturbed groundwater (not always a valid assumption, as will be discussed below), if several parameters are measured in serial samples, some parameters may reach steady state while others do not.

For example, in some tests, after the $\mathrm{Cl}^{-}$and $\mathrm{X}^{++}$field values reached steady state, the alkalinity was still changing (see, for example, Section 3.3.2.2). The samples were considered representative with respect to the major solutes but not with respect to alkalinity.

\subsubsection{Methods of Evaluating the Representativeness of Samples}

There are several questions that can be considered in evaluating the representativeness of a sample for a given parameter.

If parameters were measured in serial samples, were steady-state values reached?

- If steady state was not reached, the sample will not be representative for this parameter.

- Even if steady state was reached, the sample may not be representative. (See, then, the next question.)

If a steady-state value was reached, is there reason to believe that the steady-state value is representative or to believe that it is not representative of the unperturbed groundwater?

- If the steady-state value is a function of pumping rate, type of pump or other sampling apparatus (tubing, etc.), time of day, well-bore pressure, or some other nongeochemical or hydrochemical factor (as in the example that follows), then the probability of collecting a representative sample for that parameter is slight: the achievement of steady state will not mean that the samples are representative.

Example in which a steady-state value is not representative: Iron is often used as a field indicator of steady state for trace metals. However, the iron steady-state value is sometimes a function of the pumping rate. This was demonstrated during round two of the Water Quality Sampling Program (WQSP), when the Culebra at H-6B was being sampled. When the pumping rate was halved for a few days, the iron concentration increased dramatically; when the pumping rate was increased to its former value, iron dropped to its former "steady-state" concentration (Uhland et al., 1987). In such a case, even the lowest observed iron concentrations are unlikely to represent the native groundwater. In contrast, the major solutes, $\mathrm{Cl}^{-}$and $\mathrm{X}^{++}$, had reached steady state before the pumping rate was decreased and remained constant throughout the remainder of the test, independent of the pumping rate.

- If the steady-state value is not a function of any circumstantial factors, then we are more confident that the value is representative. Note, however, that an apparent steady-state 
value may not really be "steady state" but may be slowly changing or varying in some way not obvious to the field chemist. For example, the apparent steady-state value may be changing too slowly to be observed during a test lasting a few days to weeks. Or, the test may be sampling a large contamination plume (Colton and Morse, 1985).

Example in which a steady-state value is usually representative: Chloride and divalent cations $\left(\mathrm{X}^{++}\right)$are considered useful indicators of representativeness of a sample for the major solutes $\mathrm{Cl}^{-}, \mathrm{SO}_{4}^{\overline{ }} \mathrm{Na}, \mathrm{Ca}, \mathrm{Mg}$, and $\mathrm{K}$ for the following reasons. First, at several locations, values of $\mathrm{Cl}^{-}$and $\mathrm{X}^{++}$have repeatedly reached the same steady-state values in different tests and, as mentioned above, in a test during which the pumping rate varied by a factor of two, $\mathrm{Cl}^{-}$and $\mathrm{X}^{++}$remained constant once steady state was reached. Second, in final samples from those tests (different times at the same location), laboratory values for all the major solutes are the same, within expected analytical variation; that is the $\mathrm{Na}$ results agree with each other, the $\mathrm{K}$ results agree with each other, and so forth. (Note, however, that at a few locations, different "steady-state" values of $\mathrm{Cl}^{-}$and $\mathrm{X}^{++}$were reached during different tests. These cases are discussed in Section 5.0.)

During many tests we do not know if steady-state values are factors of nongeochemical or hydrochemical conditions for two reasons.

First, pumping and sampling tests are performed with a set of sampling apparatus (pump, tubing, discharge pipe, and so forth) and generally are conducted at a constant pumping rate. Although possible, it is time consuming and expensive to conduct multiple tests at various pumping rates to check for correlation of steady-state values with pumping rate. In practice, this exercise has not been performed intentionally, but has sometimes been mandated by the test conditions, as at $\mathrm{H}-6 \mathrm{~B}$ described above.

Second, varying the sampling apparatus and well conditions ranges from difficult to impossible. For example, once the well casing is in place, it usually stays there. Nonetheless, such variation has occurred occasionally because different agencies have conducted tests in the same wells during the history of the WIPP project and some wells have been reconfigured to meet the needs of a specific test.

Because of this, knowing the borehole histories and well configurations at the time of sampling is important in evaluating the data for some solutes.

How well do the results compare with results for other samples from the same location in the same stratigraphic zone and at the same hydropad?

- If, in samples collected at different times (perhaps by different methods), the concentrations of the parameter(s) of interest are the same, we have greater confidence that the samples were representative.

- If the concentrations are different, other questions must be asked to determine why they are different. For example:

- Did the samples degrade between the times of collection and analysis? 
- Were the analyses of poor quality?

- Did the composition of the produced water change with time? ${ }^{4}$

If the answer to each of these questions is no, then at least one of the samples must have been nonrepresentative.

\section{Other considerations}

Some workers (Meijer et al., 1987; Bodine and Jones, 1986; Bodine et al., 1988) have evaluated the representativeness of some WIPP groundwater samples for certain parameters by running geochemical codes such as PHREEQE and SNORM. The modeling results are compared with the observed mineralogies and are checked for consistency. The presence of extraneous components such as certain major solutes (from, for example, drilling fluids, casing cements, acid from acidization, and so forth) can sometimes be demonstrated this way. This report, which gives a preliminary evaluation of the data quality, does not use these modeling techniques.

\subsection{Evaluating the Stability (Shelf Life) of Samples}

This section discusses ways of determining if the composition of a sample changed between the time of collection and the time of analysis. The discussion comprises three parts.

- Background

- Shelf-life studies

- Methods of evaluating stability (shelf life) of samples

\subsubsection{Background}

The composition of a groundwater can change as it is being collected, as it is being preserved, or between the times of preservation and analysis.

\subsubsection{CHANGES DURING COLLECTION OF SAMPLES}

The composition of a sample can and probably does change somewhat as it is being collected, that is, as it is coming up the sampling tube or pipe from aquifer depth to the surface.

\footnotetext{
${ }^{4}$ The chance of the water quality varying with time depends on both the geographic location of the well and the stratigraphic zone being sampled. For example, the water quality of the Magenta and Culebra in WIPP-27 and the Culebra in WIPP-29 appear to be influenced by surface activities such as potash mining activities in nearby parts of Nash Draw. Thus, variations in water samples collected at different times in parts of Nash Draw are thought to be real but caused by surface activities.
} 
For example, when a sample is brought from depth to the surface, it may lose some gases such as dissolved $\mathrm{CO}_{2}$. Similarly, when the sample comes in contact with air, the ratios of different oxidation states of some multivalent elements may change.

Because these processes aren't believed to affect the concentrations of the major solutes, these problems are not considered further in this report. But anyone who uses other data from these samples should be aware of the potential for a problem; for example, all $\mathrm{pH}$ and alkalinity data should be used with caution.

\subsubsection{CHANGES RESULTING FROM PRESERVATION PROCEDURES}

A sample could be contaminated in various ways during the preservation process. In particular, a sample could be contaminated by the following:

- the filter membrane or filtering apparatus

- dirt or residue in the container in which it will be stored

- the acid used as a preservative

Although the possibility of contamination during the preservation process is considered negligible for the major solutes, it will have to be considered in evaluating the minor and trace element data.

The sample collection procedure includes several steps to minimize the chances of contamination during the collection and preservation operations and to help recognize contamination if it occurs.

- To minimize the chance of contamination from the filter apparatus or membrane, when a new membrane is put in the membrane holder, the first aliquot of filtered water (typically $\sim 50 \mathrm{~mL}$ ) is discarded.

- To remove any trace metals left on the surface from the manufacturing process, the plastic sample bottles are washed with nitric acid before they are used. The washing step also removes any dirt or other residue that might be in the bottles.

- To aid in identifying contamination introduced by the acid used as a preservative, acidblank samples are prepared and analyzed.

\subsubsection{CHANGES DURING STORAGE}

The sample may gain solutes from or lose solutes to its container, between the time it is bottled up and the time it is analyzed.

During storage, solutes can increase, or apparently increase, in concentration by several mechanisms. 
- absorbtion from the container walls (a concern in trace-constituent analyses)

- evaporative loss of water from the container

- dissolution of the suspended solids in nonfiltered samples, leading to an increase in certain solutes

The first two mechanisms are not of concern for the samples and parameters considered in this report. The third mechanism does not seem to be a problem in the samples reviewed. However, because of this possibility, samples that have been filtered in the field immediately after collection are preferred.

Similarly, solutes can be lost by more than one mechanism.

- adsorption onto the container walls

- precipitation

Adsorption may be a problem for certain trace constituents of interest here, and precipitation may be a problem for some of the samples of interest here.

Acidifying a sample inhibits the loss of many solutes, especially the cations. However, some parameters, notably the anions, are better determined in an unacidified sample. In fact, the unacidified samples usually do contain some solid material by the time they reach the laboratory, even if received just a few days after collection. This solid material is usually removed by filtration before analysis. The small quantities observed have been considered negligible with respect to the major solutes but may be significant for some minor or trace constituents.

\subsubsection{Shelf-Life Studies}

Although the shelf lives of the WIPP groundwater samples have not been specifically tested, this could be done by collecting a large quantity of selected samples and analyzing each sample immediately after collection as well as at specified intervals (for example, one wk, one mo, six wk, three mo, six mo, one yr, two yr, and so forth) after collection. This test could be done for groundwater samples of varying ionic strengths.

However, because some WIPP groundwater samples had to sit for months to years before being analyzed (because of manpower and budget constraints), there is some indirect evidence that sample stability is not necessarily a problem with these samples.

Samples collected in 1980 and 1981 remained at SNL until 1985, when they were shipped to UNC/Bendix for analysis. The samples did not appear to degrade, at least with respect to the parameters of interest, between the time of collection and time of analysis.

- The resulting data sets had small CBEs, even though the cations were determined in fieldacidified samples, which are expected to be very stable, and the anions were determined in 
field-filtered unacidified samples, which might be expected to degrade over a several-year period.

- For the 1980 samples, the agreement between the field and laboratory chloride and divalent cation values is excellent, indicating that there was no loss of chloride from the unacidified samples or of calcium or magnesium from the acidified samples. (Because these solutes were not determined in the field in 1981, the comparison cannot be made for the 1981 samples.)

- Several sites sampled in 1980 and 1981 (the Culebra in H-4B, H-5B, H-6B, WIPP-25, WIPP-26, and WIPP-29) were resampled during round one of the WQSP in 1985 and 1986. The samples were analyzed by UNC/Bendix within a few weeks or months of collection. The agreement between the "old" and "new" samples is good, and the observed differences cannot be explained by degradation or instability of the older (1980/1981) samples. (See also Section 5.0 for discussions of specific sites.)

The shelf life of the unfiltered/unacidified samples has not been systematically considered, but it is expected to be similar to the shelf life of the field-filtered/unacidified samples.

The preceding discussion refers to the author's samples, which were stored at ambient laboratory temperatures $\left(60\right.$ to $\left.75^{\circ} \mathrm{F}\right)$ until they could be analyzed. Samples stored at extreme temperatures are more likely to degrade. For example, if an unacidified sample gets very cold, species that are close to saturation at warmer temperatures may precipitate. These reactions are typically not reversible (on a laboratory time scale); that is, the solids do not redissolve when the sample is warmed up again. Thus, knowledge of the history of a sample, that is, its storage and shipping conditions, may sometimes be useful in evaluating sample stability.

\subsubsection{Methods of Evaluating the Stability (Shelf Life) of Samples}

Even though there is no evidence of degradation of any of the samples analyzed by UNC/Bendix for SNL, the possibility of sample degradation cannot be ignored when discrepancies between data sets exist.

In evaluating the stability of samples, several questions may be considered.

- Are the solute concentrations in the unacidified samples (field-filtered or not) significantly lower than values observed during field analyses?

- Are the total meq/L of anions in an unacidified sample significantly lower than the total $\mathrm{meq} / \mathrm{L}$ cations in the acidified fraction?

- For two samples collected at the same place and time, are the solutes in an unacidified sampled analyzed in one laboratory significantly lower than the solutes in a demonstrably stable sample analyzed in another laboratory?

.If the answer to any of these questions is yes, the sample may have degraded. In all cases, however, one must rule out the possibility that analytical error is the cause of the differences. 


\subsection{Evaluating the Quality of the Analyses}

This section discusses ways of evaluating the quality of the analyses. The discussion comprises two sections:

- Background

- Methods of evaluating the quality of the analyses

\subsubsection{Background}

In principle, one should be able to evaluate the quality of the laboratory data without considering the quality of the sample. In practice, one often doesn't have all the information needed to do so, but can qualitatively evaluate the data by indirect means.

To evaluate the reliability of the data, without regards to the source or quality of the sample, one needs to know that the analytical method is appropriate for this type of sample and have access to all of the laboratory data, including results from analyses of replicates, control samples, spiked samples, and standards.

Without that information (for example, when using published data from another source), then one can only evaluate the data by comparing them to other data.

\subsubsection{Methods of Evaluating the Quality of the Analytical Data}

In evaluating the quality of analyses, several questions can be considered.

Are the data internally consistent; that is, is the charge-balance error reasonable?

- Charge-balance errors (CBEs) can be calculated when all of the major solutes are determined. For most of the Rustler waters, which contain just a few major solutes, CBEs of less than $\pm 3 \%$ have been routinely obtained by $\mathrm{UNC} / \mathrm{Bendix}$.

- If the CBE is large, one or more of the major solute values may be incorrect; however, it is necessary to first consider the possibility that one or more major solutes was not determined. For example, a large positive CBE for the Ranch Well Dewey Lake sample, a relatively fresh water, led UNC/Bendix to determine nitrate in the sample; nitrate proved to be an important constituent in the Ranch Well water.

- If the CBE is small, this is only an indication of apparent internal consistency and, by itself, does not guarantee the quality of the data. For example, errors in two or more solutes could cancel each other out and would not show up in the CBE calculation.

- In addition, because just two or three solutes dominate the composition of many WIPP waters (for example, $\mathrm{Na}$ and $\mathrm{Cl}^{-}$, or $\mathrm{Mg}, \mathrm{Ca}$, and $\mathrm{SO}_{4}^{-}$), large inaccuracies in the other solutes (including some considered "major") will not be reflected in the CBE. For 
example, many of the USGS potassium values appear to be in error by as much as two orders of magnitude (see Section 4.1.3), yet the CBEs are reasonable.

Do the calculated total dissolved solids and the measured residue-on-ignition agree?

- If the full suite of major solutes is determined, the total dissolved solids (TDS) content of the sample can be calculated. If the residue-on-ignition (ROI) is also measured in the laboratory (as described in Section 1.3.4), the calculated TDS is expected to be slightly less than the observed ROI, as the residue will probably contain excess water (in hydrated mineral precipitates). If the calculated TDS is much larger than the observed ROI, the analytical results should be viewed with suspicion.

Do the results meet the precision and accuracy requirements of the user?

- If replicates were analyzed, does the calculated precision meet the needs of the data user or program?

- If a laboratory has determined the same analyte by two methods, do the results agree within the limits of the methods? For example, UNC/Bendix determined bromide in a sample of water from the Culebra at H-3B3, collected in June 1984, by X-ray fluorescence (XRF) and differential pulse polarography (DPP). The results differed by less than 10 percent.

- If spiked samples were analyzed, do the recoveries meet the accuracy requirements of the data user or program?

- If control samples were analyzed, do the results agree with the "true" values within the limits of the analytical method?

If parameters were determined in the field, do the laboratory and field results agree within the limits of the analytical methods?

- If the laboratory results are lower, the problem could be caused by sample instability, or either of the analyses could be incorrect.

- If the laboratory results are higher, either of the analyses could be in error.

- If the laboratory and field results agree, but were determined by the same method, then sample stability is indicated, but nothing is learned about the accuracy of the method because both results could be inaccurate by the same amount.

- If they agree and were determined by different methods (for example, $\mathrm{Cl}^{-}$by titration in the field and ion-specific electrode in the laboratory; $\mathrm{X}^{++}$by titration in the field and atomic-absorption or inductively coupled plasma spectrophotometry in the laboratory), then both the sample stability and the quality of the analyses appear satisfactory.

If different laboratories analyzed samples collected at the same time from the same place (such as Water Quality Sampling Program samples), are the results the same, within the limits of the analytical methods? 
- If the results are different, and if sample instability can be ruled out as the cause of the difference, then at least one of the results is in error.

- If the results are the same, but were determined by the same methods, then again sample stability is indicated, but nothing is learned about the accuracy of the method.

- If the results are the same and were determined by different methods, then both the sample stability and the quality of the analyses appear satisfactory.

\subsection{Summary of Methods of Evaluating Solute Data}

In summary, the evaluation of quality of the analyses and the representativeness of the samples cannot usually be separated.

If appropriate laboratory data (especially analyses of replicates, spiked, and control samples) and field data are available, one may be able to distinguish differences in supposedly similar samples caused by the following:

- normal analytical variation

- analytical error

- nonrepresentative samples

- real changes in water quality at a location with time

If the problem is nonrepresentativeness, and if appropriate field data are available, one may be able to determine why the sample was not representative.

- a nonrepresentative sample was collected

- the sample was contaminated during preservation or it degraded in the bottle

Unfortunately, for some of the data considered in this report, we do not have enough information to evaluate the quality of the samples or the analytical results. These data must be used with caution.

Although the considerations for evaluating the samples and data were presented here as separate topics, in practice one considers them simultaneously, and the evaluation of the samples and data becomes an iterative process. 


\subsection{DATA FROM SNL AND SNL'S SUBCONTRACTORS}

\subsection{Introduction}

Since the late 1970s, SNL has been involved in the sampling and analysis of groundwaters from many wells in the vicinity of the WIPP. For convenience in this report, the samples in which various solutes were analyzed either by SNL or by a subcontractor are divided into six groups. For these groups, field data summaries, sample collection methods, and solute data are discussed in the sections indicated in the following list. Section 3.8 gives the analytical methods used by UNC/Bendix, who did most of SNL's laboratory analyses. Other methods are discussed in Sections 3.2 through 3.7 where appropriate.

Section Samples collected

3.2 before 1980 by the USGS and analyzed by SNL's Analytical Chemistry Division

3.3 in 1980 by SNL and analyzed by UNC/Bendix

3.4 in 1981 by SNL and analyzed by UNC/Bendix

3.5 in $1983 / 1984$ by $\mathrm{HGC}$ and analyzed by various $\mathrm{HGC}$ subcontractors

3.6 in the summer of 1984 by HGC and analyzed by UNC/Bendix and others

3.7 in 1985/1986 during round one of the WQSP and analyzed by UNC/Bendix.

Field data are included for serial samples collected in 1981, 1983, and 1984 because these data have not been published elsewhere.

Steady-state values or, in the absence of serial-sampling data, the best available field values for selected parameters are given for all samples. Steady-state values for various solutes (such as $\mathrm{Cl}^{-}, \mathrm{X}^{+}, \mathrm{Fe}$ ) are included to allow comparison with laboratory results for the final samples.

The steady-state values were selected by the author after examination of all the serial-sampling data. Note that a steady-state value reported here is not necessarily the same as the value measured in the last serial sample. Once a parameter reaches steady state, the measured value will vary within the limits of analytical precision. Thus, a steady-state value given here is the average of the serial-sampling values measured after that parameter had, in the author's opinion, reached steady state. Apparent outliers were rejected.

The steady-state values were rounded as follows:

- $\mathrm{pH}$ to 0.1 unit

- specific gravity to 0.01 or 0.001

- $\mathrm{HCO}_{3}^{-}, \mathrm{CO}_{3}^{\overline{2}}, \mathrm{Cl}^{-}, \mathrm{X}^{+}$, and $\mathrm{Ca}$ to 2 significant figures

- $\mathrm{SO}_{4}^{\bar{z}}$ and $\mathrm{Fe}$ to 1 significant figure 
The concept of steady state is not meaningful for temperature, which often varies diurnally, especially at low pumping rates; temperatures are therefore given as ranges of the minimum to maximum values observed during serial sampling.

Steady-state values are not included for specific conductance, which is at best a crude indicator of total dissolved solids (TDS), or Eh, which is not well understood. Although Eh can be a useful indicator of steady state (Lambert and Robinson, 1984), the observed value varies with the method of measurement, and the interpretation of the results is debated.

Serial-sampling data were not available for some samples and parameters. In those cases, the best available (often the only available) field values are given.

\subsection{Samples Collected Before 1980}

\subsubsection{Program Description and Wells Sampled}

In the late 1970s, the USGS performed hydrologic tests at many WIPP wells and collected water samples in conjunction with many of these tests. The USGS work is discussed further in Section 4.1. Bottles of some of the samples were sent to Sandia for solute and/or stable isotope $\left(\mathrm{D}\right.$ and ${ }^{18} \mathrm{O}$ ) analyses. The stable isotope results are reported by Lambert and Harvey (1987).

Solute analyses are given in this section for samples from the following nine locations:

Stratigraphic Zone

Alluvium

Culebra

Magenta

Rustler/Salado
Well(s)

WIPP-15

$\mathrm{P}-15$

$\mathrm{H}-3 \mathrm{~B} 1$

\subsubsection{Field Data and Sample Collection}

As is discussed in Section 4.1, samples were collected by bailing or swabbing according to standard USGS protocols. Samples sent to SNL for solute analyses were collected in one-liter plastic bottles and were not field filtered or acidified. These samples were stored at ambient temperature at SNL until analysis.

Serial samples were generally not collected or analyzed during these tests, but some parameters such as $\mathrm{pH}$ and alkalinity were sometimes measured in the field at the time samples were collected. Mercer (1983) published the field data along with the USGS laboratory results (see Section 4.1); these data are included in Table 68 of this report. 


\subsubsection{Solute Data}

Solutes were analyzed by SNL's Analytical Chemistry Division in late 1979 and early 1980. Suspended solids were removed by filtration through Whatman 42 paper, which the manufacturer states has a $2.5-\mu \mathrm{m}$-particle-size retention, or by high speed centrifugation when filtration failed. A density for each sample was determined by weighing a $10-\mathrm{mL}$ aliquot at room temperature.

Solutes were determined as follows:

Solute(s)

$\mathrm{CO}_{3}^{-}$and $\mathrm{HCO}_{3}^{-}$

$\mathrm{SO}_{4}^{\bar{z}}$

$\mathrm{Cl}^{-}$

$\mathrm{Na}$ and $\mathrm{K}$

$\mathrm{Ca}$ and $\mathrm{Mg}$
Method

titration with standard hydrochloric acid solution to the phenolphthalein and methyl-red endpoints, respectively

gravimetry: precipitation as barium sulfate

titration with silver nitrate

atomic absorbtion

atomic absorption and/or EDTA titration

The data are presented in Table 16. Total dissolved solids contents and charge-balance errors were calculated as discussed in Section 1.3.4.

Precisions can be estimated for some, but not all, of the measured parameters. Density was determined just once for each sample so the analytical precision for density cannot be estimated. Bicarbonate, carbonate, chloride, and sulfate were determined in duplicate and the precisions ( $95 \%$ confidence limits, two replicates) have been estimated as follows:

\begin{tabular}{|c|c|c|}
\hline Solute & $\begin{array}{c}\text { Applicable } \\
\text { Concentration Range }\end{array}$ & $\begin{array}{c}\text { Estimated } \\
\text { Confidence Limits }\end{array}$ \\
\hline $\mathrm{Cl}^{-}$ & $\begin{array}{l}<20000 \mathrm{mg} / \mathrm{L} \mathrm{Cl}^{-} \\
20000-100000 \mathrm{mg} / \mathrm{L} \\
>100000 \mathrm{mg} / \mathrm{L}\end{array}$ & $\begin{array}{l} \pm 100 \mathrm{mg} / \mathrm{L} \\
\pm 300 \mathrm{mg} / \mathrm{L} \\
\pm 1000 \mathrm{mg} / \mathrm{L}\end{array}$ \\
\hline $\mathrm{SO}_{4}^{=}$ & $\begin{array}{l}<1000 \mathrm{mg} / \mathrm{L} \mathrm{SO}=\overline{4} \\
1000-8000 \mathrm{mg} / \mathrm{L}\end{array}$ & $\begin{array}{l} \pm 10 \mathrm{mg} / \mathrm{L} \\
\pm 100 \mathrm{mg} / \mathrm{L}\end{array}$ \\
\hline $\mathrm{HCO}_{3}^{-}, \mathrm{CO}_{\overline{3}}^{\overline{3}}$ & & $\pm 10 \mathrm{mg} / \mathrm{L}$ \\
\hline
\end{tabular}

The author has been unable to determine if the major cations were analyzed in replicate and is therefore unable to estimate the precisions of those analyses. 


\subsection{Samples Collected in Nash Draw in $\mathbf{1 9 8 0}$}

\subsubsection{Program Description and Wells Sampled}

In 1980, SNL and the USGS undertook a program of hydrological and geochemical studies in Nash Draw, west of the WIPP site. The following 15 locations were tested:

\begin{tabular}{ll} 
Stratigraphic Zone & Wells \\
\cline { 1 - 2 } Culebra & WIPP-25, WIPP-26, WIPP-27, WIPP-28, WIPP-29, WIPP-30 \\
Magenta & WIPP-25, WIPP-27, WIPP-30 \\
Rustler/Salado & WIPP-25, WIPP-26, WIPP-27, WIPP-28, WIPP-29, WIPP-30
\end{tabular}

The Magenta was not tested in wells WIPP-26, WIPP-28, or WIPP-29 because there was too little water to pump at WIPP-26 and WIPP-28, and the Magenta is nonexistent (eroded away) at WIPP-29.

The USGS field activities are described in Richey (1987), and SNL's field activities are summarized in Lambert and Robinson (1984). In brief, in each of the six wells, the process was the following:

- The USGS perforated the well casing, tested and collected samples from the Rustler/Salado contact zone in the spring of 1980, and performed additional hydrologic tests in the Rustler/Salado contact zone in July 1980.

- When the USGS was finished at a well, SNL did hydrologic tests and collected samples.

- After SNL was finished with the Rustler/Salado contact zone, a bridge-plug packer was set below the Culebra, the Culebra was perforated, and the USGS did a series of hydrologic tests and collected samples.

- Again, when the USGS was finished, SNL did hydrologic tests and collected samples.

- When SNL finished testing the Culebra, the procedure was repeated for the Magenta: a bridge-plug packer was set below the Magenta, the zone was perforated, the USGS tested and collected samples, and finally Sandia tested and collected samples.

The USGS testing and sampling chronologies are given in Richey (1987), and their laboratory solute data are given in Mercer (1983). The USGS solute data are summarized in this report in Section 4.1.

\subsubsection{Field Data and Sample Collection}

SNL's sample-collection program is described in detail in Lambert and Robinson (1984) and is summarized here. During extended ( $>24 \mathrm{hr}$.) pumping tests that were performed with jack pumps or submersible pumps, serial samples were periodically collected and analyzed in the field for parameters including temperature, $\mathrm{pH}, \mathrm{Eh}$, specific gravity, specific conductance, alkalinity, and concentrations of $\mathrm{Cl}^{-}, \mathrm{X}^{++}$, and total $\mathrm{Fe}$. Final samples were collected only after certain parameters (usually $\mathrm{Cl}^{-}, \mathrm{X}^{++}$, alkalinity, and $\mathrm{Fe}$ ) reached steady state. 
During three sampling episodes, one or more parameters failed to reach steady state; as a result, the usual suites of final samples were not collected. Specifically, from the Culebra at WIPP-28, a limited suite of final samples was collected, and from the Rustler/Salado contact at WIPP-27 and the Magenta at WIPP-30, no final samples were collected. These three cases are discussed in more detail in Sections 3.3.2.1 through 3.3.2.3.

The methods of measuring parameters in the field, criteria for collecting samples, methods of collecting samples, and descriptions of the collected samples, as well as all of the serial-sampling data, are given in Lambert and Robinson (1984). Steady-state field values for $\mathrm{pH}$, specific gravity, alkalinity, $\mathrm{Cl}^{-}, \mathrm{X}+, \mathrm{Ca}, \mathrm{SO}_{4}^{\bar{\nu}}$, and $\mathrm{Fe}$ and the range of temperatures observed during serial sampling are given here in Table 11.

Note that because of uncertainties regarding the accuracy of the analyses, Lambert and Robinson (1984) presented their field solute data $\left(\mathrm{Cl}^{-}, \mathrm{X}^{++}, \mathrm{Ca}^{++}\right.$, and $\left.\mathrm{SO}_{4}^{=}\right)$as ratios to the initial values in their Tables 4-1 through 4-15 and as approximate values rounded to one significant digit in their Table 6-1. Because it was not possible, at that time, to analyze control samples and spiked samples in the field, there was not sufficient information to evaluate the accuracy of the methods. However, subsequent comparisons of the field data with laboratory data have shown that the field titrimetric measurements of $\mathrm{Cl}^{-}, \mathrm{Ca}^{++}$, and $\mathrm{X}^{++}$agree with the laboratory values quite well (generally to better than $\pm 10 \%$ ), so field measurements for those three parameters are given here as actual concentrations rounded to two significant figures.

In contrast, the field $\mathrm{SO}_{4}^{\overline{ }}$ and $\mathrm{Fe}$ measurements were made by less accurate methods than are used in the laboratory. For example, samples were diluted using plastic measuring pipettes and graduated cylinders rather than glass volumetric pipettes and flasks (Lambert and Robinson, 1984). Therefore, field $\mathrm{SO}_{4} \overline{-}$ and $\mathrm{Fe}$ measurements are given as approximate values rounded to one significant figure.

Although limited time and manpower precluded the routine analysis of replicates in the field, enough replicates were analyzed to allow crude estimations of analytical precision either as confidence limits (95\% C.L., 1 replicate) or relative standard deviations (RSDs). As reported by Lambert and Robinson (1984) the estimates were the following:

$\begin{array}{lll}\text { Parameter } & \text { Estimated Precision } \\ \text { temperature } & & \pm 1^{\circ} \mathrm{C} \text { (conf. limits) } \\ \text { pH } & \pm 0.1 \text { (conf. limits) } \\ \text { specific gravity } & \pm 0.02 \text { (conf. limits) } \\ \mathrm{HCO}_{3}^{-}, \mathrm{CO}_{3}^{\bar{y}} & \pm 6 \mathrm{mg} / \mathrm{L} \text { (conf. limits) } \\ \mathrm{Cl}^{-}, \mathrm{Ca}, \mathrm{X}^{++} & \pm 2 \% \text { (RSD) } \\ \mathrm{Fe} & \pm 10 \% \text { (RSD) } \\ \mathrm{SO}_{4}^{\bar{y}} & \pm 10 \% \text { (RSD) for }<5000 \mathrm{mg} / \mathrm{L} \mathrm{SO}= \\ & \pm 20 \% \text { (RSD) for } 10000-20000 \mathrm{mg} / \mathrm{L} \mathrm{SO}=\end{array}$


The samples for solute analysis were stored at ambient temperature in the author's laboratory in Albuquerque until June 1985, when they were sent to Grand Junction, CO, for analysis by $\mathrm{UNC} /$ Bendix. Samples collected for analyses of stable isotopes $\left(\mathrm{D}\right.$ and ${ }^{18} \mathrm{O}$ ), radioisotopes $\left({ }^{3} \mathrm{H}\right.$ and ${ }^{14} \mathrm{C}$ ), and uranium isotopes have also been analyzed; the results are presented in Lambert and Harvey (1987), Lambert (1987), and Lambert and Carter (1987), respectively. In addition, Hydro Geo Chem sent aliquots of Culebra samples from WIPP-26, WIPP-28, WIPP-29, and WIPP-30 to the Kansas Geological Survey (KGS) for halide analyses (see Section 3.5.3 and Table 18).

The following three subsections contain details about the three tests during which full suites of final samples were not collected: WIPP-27 Rustler/Salado; WIPP-28 Culebra; and WIPP-30 Magenta.

\subsubsection{WIPP-27 RUSTLER/SALADO (JULY 1980)}

As the Rustler/Salado contact zone at WIPP-27 was being tested, field measurements indicated apparent steady state after $24 \mathrm{hr}$ of pumping. However, by this time the pumping rate had dropped to less than two gph (from an initial rate of eight gph), the water level in the borehole had continually dropped, indicating that the well was nearly "dry," and the iron concentration was high $(\sim 20 \mathrm{mg} / \mathrm{L})$, indicating prolonged contact with the well casing and/or discharge pipe. Because there was sufficient reason to doubt that the water being produced at such a low pumping rate was representative of the reservoir, final samples were not collected from the Rustler/Salado contact zone at WIPP-27 (Lambert and Robinson, 1984).

\subsubsection{WIPP-28 CULEBRA (SEPTEMBER 1980)}

After the Culebra at WIPP-28 had been pumped for one day, all parameters except alkalinity had stabilized. After two days of pumping, the alkalinity values were still slowly but steadily decreasing. Samples were taken for solute analyses and isotope (D, ${ }^{18} \mathrm{O}$, and uranium) analyses, but not for radiocarbon analyses. A representative alkalinity value for the Culebra at WIPP-28 is not available (Lambert and Robinson, 1984).

\subsubsection{WIPP-30 MAGENTA (DECEMBER 1980)}

As the Magenta at WIPP-30 was being tested, the pumping rate was very low $(<100 \mathrm{~mL} / \mathrm{min})$. During the first $48 \mathrm{hr}$ of pumping, the major solutes appeared to be close to steady state, with chloride, divalent cations, and calcium varying $\pm 5 \%$ and sulfate $\pm 10 \%$ in the three serial samples analyzed. However, a day later the sulfate value had tripled and the chloride, calcium, and divalent-cation values had approximately doubled (see Section 5.3.12 for a discussion of the possible cause). During the next few days, the major solutes decreased steadily. After five additional days of pumping, the chloride value had dropped to $80 \%$ of its original value, while the divalent-cation and calcium values were still $\sim 50 \%$ and $\sim 70 \%$ above their original values, respectively. Because the spectrometer malfunctioned, sulfate analyses had been discontinued two days after the abrupt rise. At that time sulfate was $\sim 2.5$ times its original value. As there was 
no indication that steady state was being approached, the test was terminated without final water samples being collected (Lambert and Robinson, 1984).

\subsubsection{Solute Data}

Samples were analyzed by UNC/Bendix during the fall of 1985 . Analytical methods are described in Section 3.8 and are summarized in Table 65.

UNC/Bendix results for the 13 samples from Nash Draw are given in Tables 20 to 32 and are summarized in Table 64. Total dissolved solids contents and charge-balance errors were calculated as discussed in Section 1.3.4. The calculation of analytical uncertainties is discussed in Section 3.8.

\subsection{Samples Collected in 1980-1981 During Hydrologic Tests}

\subsubsection{Program Descriptions and Wells Sampled}

In 1980 and 1981 SNL and Hydro Geo Chem (HGC) performed a two-well recirculation tracer test at the H-2 hydropad. In December of 1980 the author, at the request of SNL's staff hydrologist, made some field measurements at $\mathrm{H}-2$. These measurements are discussed below (Section 3.4.2.1).

In 1981, SNL and HGC performed a series of interference pumping tests in the Culebra at hydropads H-4, H-5, and H-6. These tests are described in detail in HGC (1985) and are summarized here. Three wells are located on each hydropad, denoted with the suffixes A, B, and C. The wells were originally drilled in 1978 and were completed in the Magenta, Culebra, and Rustler/Salado, respectively. The "A" and " $\mathrm{C}$ " wells were later re-configured to allow access to the Culebra (HGC, 1985). In each "C" well, a packer was set above the Rustler/Salado, and the Culebra was perforated. Each "A" well was deepened to just below the Culebra, and a packer was set to isolate the Culebra from the Magenta.

For the interference tests at each hydropad, first the " $\mathrm{B}$ " well was pumped while the " $\mathrm{A}$ " and " $C$ " wells were observed. Then the " $C$ " well was pumped while " $A$ " and " $B$ " served as observation wells. Because at that time SNL's staff hydrologist was interested in continuing the radiocarbon sampling program started in Nash Draw the previous year, serial samples were collected, selected parameters were measured in the field, and final samples for solute and/or isotope analyses were collected from five wells, $\mathrm{H}-4 \mathrm{~B}, \mathrm{H}-5 \mathrm{~B}, \mathrm{H}-5 \mathrm{C}, \mathrm{H}-6 \mathrm{~B}$, and $\mathrm{H}-6 \mathrm{C}$.

\subsubsection{Field Data and Sample Collection}

Field procedures and data for the test at $\mathrm{H}-2$ are discussed in Section 3.4.2.1. 
At the H-4, H-5, and H-6 hydropads, the author used a modified version of the Nash Draw procedures of Lambert and Robinson (1984). The primary purpose of this sampling program was to obtain representative samples for attempted radiocarbon dating. Because of a lack of available manpower, only the following parameters could be measured in the field: $\mathrm{pH}$, Eh, specific gravity, specific conductance, temperature, alkalinity, and occasionally sulfate. The groundwater was considered representative when four parameters (alkalinity, specific conductance, specific gravity, and $\mathrm{pH}$ ) reached steady state after a lengthy pumping period. Samples were collected in a polyethylene bucket from the discharge line and were transferred to the appropriate containers.

Parameters were measured in the field using the methods described in Lambert and Robinson (1984); they are summarized below. Temperature, specific gravity, specific conductance, $\mathrm{pH}$, and Eh were measured immediately after each serial sample was collected. In addition, immediately after collection, one liter of sample was transferred to a polyethylene bottle for alkalinity and sulfate determinations to be done as soon as possible.

Parameters were measured as follows:

- Temperature was measured with an American Society for Testing Materials (ASTM) \#1C thermometer. (The thermometer was not calibrated.)

- Specific gravity was measured with a hydrometer with a range of 1.000 to 1.2200 . (The hydrometer was not calibrated.)

- Specific conductance was measured with a Lab-Line Mark V conductance meter, Model MC-1, and a beaker-type cell with a cell constant of 1.0.

- The $\mathrm{pH}$ was measured with an Orion model $399 \mathrm{~A} / \mathrm{F}$ meter and model 91-04 combination $\mathrm{pH}$ electrode. Before each measurement, the $\mathrm{pH}$ measuring system was standardized with two buffer solutions, either $\mathrm{pH} 4$ and 7 or $\mathrm{pH} 7$ and 10 , chosen to bracket the sample $\mathrm{pH}$ value.

- Eh was measured with an Orion model $399 \mathrm{~A} / \mathrm{F}$ meter and model 96-78 redox electrode. The system was checked with ZoBell solutions each day.

- Alkalinity was determined by titrating with a standard sulfuric acid solution to a $\mathrm{pH}$ of 4.5 and is reported as bicarbonate. In all these samples, carbonate alkalinity was negligible.

- Sulfate was determined by the turbidimetric method using a Hach portable field spectrometer.

Analytical precisions, either confidence limits (95\% C.L., 1 replicate) or relative standard deviations (RSDs), are assumed to be the same as in Nash Draw (Lambert and Robinson, 1984):

Parameter
Temperature
Specific gravity
pH
Specific conductance
Bicarbonate
Sulfate

Estimated Precision

$\pm 1^{\circ} \mathrm{C}$ (conf. limits)

\pm 0.02 (conf. limits)

\pm 0.1 (conf. limits)

$\pm 2 \times 10^{4} \mu \mathrm{S} / \mathrm{cm}$ (conf. limits)

$\pm 6 \mathrm{mg} / \mathrm{L}$ (conf. limits)

$\pm 10 \%$ (RSD) 
Precision for Eh was not determined; the manufacturer reports the accuracy of the measuring system is better than $\pm 10 \mathrm{mV}$.

The methods of collecting and treating final samples (filtering, acidifying, radiocarbon chemistry) were the same as those used by Lambert and Robinson (1984). Depending on the intended use, samples were either untreated (unfiltered and unacidified), filtered through a $0.45 \mu \mathrm{m}$ membrane, or filtered and acidified to $\mathrm{pH}<2$ with high-purity nitric acid. The treatment of samples for radiocarbon analysis is given in Lambert and Robinson (1984).

The samples for solute analyses were stored at ambient temperature in the author's laboratory in Albuquerque until June 1985, when they were shipped to Grand Junction, CO, for analysis by $\mathrm{UNC/Bendix.} \mathrm{Samples} \mathrm{collected} \mathrm{for} \mathrm{various} \mathrm{isotopic} \mathrm{analyses} \mathrm{have} \mathrm{been} \mathrm{analyzed,} \mathrm{and} \mathrm{the} \mathrm{results}$ are presented in Lambert and Harvey (1987), Lambert (1987), and Lambert and Carter (1987).

The next six subsections give some observations made during the tests at six wells, $\mathrm{H}-2 \mathrm{C}$, $\mathrm{H}-4 \mathrm{~B}, \mathrm{H}-5 \mathrm{~B}, \mathrm{H}-5 \mathrm{C}, \mathrm{H}-6 \mathrm{~B}$, and H-6C.

\subsubsection{H-2C CULEBRA (DECEMBER 1980)}

H-2 is a multi-well pad with the Culebra accessible in all the wells. In early 1980, a tracer test was begun in which Culebra water was pumped from $\mathrm{H}-2 \mathrm{~B} 1$ and reinjected, along with added tracers (sodium benzoate, sodium pentafluorobenzoate, and a suite of halocarbons $-\mathrm{CCl}_{4}, \mathrm{CFCl}_{3}$, $\mathrm{CF}_{2} \mathrm{Cl}_{2}$ ), into well $\mathrm{H}-2 \mathrm{C}$. The test was terminated prematurely because of equipment failure. In July 1980 , the system was reconfigured and a second test was started with $\mathrm{H}-2 \mathrm{C}$ as the pumping well, $\mathrm{H}-2 \mathrm{~B} 1$ as the injection well, and sodium thiocyanate and difluorochlorobromomethane as the added tracers (HGC, 1985 and 1986).

On 12/10/80 at the request of SNL's staff hydrologist, the author collected a groundwater sample from a spigot that had been placed in the circulating system near the pump to allow withdrawal of samples for tracer analysis. Temperature, $\mathrm{pH}$, Eh, specific gravity, and specific conductance were measured in the field using the same equipment and methods that were being used in Nash Draw at the time (Lambert and Robinson, 1984; see also Section 3.3). The field results are included in Table 12.

Samples were also collected for laboratory analysis, but they had not yet been analyzed when the data for this report were compiled because of serious doubts about their representativeness (see Section 5.2.5).

\subsubsection{H-4B CULEBRA (MAY 1981)}

During two pumping tests at the $\mathrm{H}-4$ hydropad, $\mathrm{H}-4 \mathrm{~B}$ was pumped with a jack pump with a single-action pump cylinder. The first test started at 09:00 on 05/14/81. After two days of pumping at an average rate of $20 \mathrm{gph}$, water stopped flowing at $\sim 11: 00$ on $05 / 16 / 81$. The test was terminated later that day. During the two days of pumping, the water produced was clear 
and odorless, and the slight effervescence observed at the start of the test disappeared after one day of pumping. Four serial samples were collected during the test; Eh increased, $\mathrm{pH}$ decreased, and the sulfate concentration fluctuated.

The second test started at $12: 30$ on $05 / 21 / 81$ and continued until $05 / 30 / 81$ with an average pumping rate of $15 \mathrm{gph}$ (HGC, 1985). Serial sampling began on 05/27/81 and continued though $05 / 29 / 81$. The water was clear, odorless, and very slightly effervescent. Field parameters had reached steady-state by $05 / 27 / 81$, when serial sampling resumed; that is, the measured values were the same, within the limits of precision of the measurements, as they had been when the pump failed on $05 / 16 / 81$, and they did not change over the next two days.

Serial-sampling data from both pumping tests are shown in Table 4 and steady-state field values are in Table 12.

On $05 / 29 / 81$, final samples for the analysis of solutes, stable isotopes (D and ${ }^{18} \mathrm{O}$ ), and uranium isotopes were collected. In addition, $\sim 38$ gallons of unfiltered/unacidified groundwater were collected in red plastic jerrycans for radiocarbon analysis.

\subsubsection{H-5B CULEBRA (MAY THROUGH JUNE 1981)}

H-5B was pumped with a jack pump with a single-action pump cylinder. The pumping test started at $12: 30$ on $05 / 27 / 81$. Pumping was interrupted the evening of $05 / 29 / 81$ because of a pump failure and resumed at $11: 10$ on $05 / 30 / 81$. The pump failed again at $15: 20$ on $06 / 02 / 81$ and was not restarted. The average pumping rate had been $\sim 12 \mathrm{gph}$ (HGC, 1985).

Four serial samples were collected between $05 / 29$ and $06 / 02 / 81$. At the start of pumping on $05 / 27 / 81$, the produced water was "milky" in color, but by the time serial sampling began, it was clear and odorless and remained so throughout the test. On 06/02/81, all parameters except alkalinity appeared to have reached steady state. Alkalinity appeared to be decreasing slowly at a rate of $\sim 1 \mathrm{mg} / \mathrm{L}$ per day.

Serial-sampling data are shown in Table 5 and the steady-state field values are in Table 12.

Because of concerns about the stability of the pump, final samples for solute, stable isotope (D and ${ }^{18} \mathrm{O}$ ), and uranium isotope analyses were collected on $06 / 02 / 81$. When the pump failed later that day, the decision was made to terminate the test and collect radiocarbon samples during a later test at the $\mathrm{H}-5$ hydropad.

\subsubsection{H-5C CULEBRA (OCTOBER 1981)}

$\mathrm{H}-5 \mathrm{C}$ was pumped with a jack pump with a single-action pump cylinder. The pumping test began at $09: 35$ on 10/07/81 and continued until 10/16/81. The average pumping rate was $\sim 7.5$ gph (HGC, 1985). 
Serial sampling began on 10/12/81 and continued through $10 / 15 / 81$. The produced water was clear and odorless. The specific gravity, specific conductance, $\mathrm{pH}$, and $\mathrm{Eh}$ values were the same as they had been at H-5B in May and June, while the alkalinity was slightly higher. At $\mathrm{H}-5 \mathrm{~B}$, the alkalinity was $84 \mathrm{mg} / \mathrm{L} \mathrm{HCO}_{3}$ on $05 / 29 / 81$ and decreased to $80 \mathrm{mg} / \mathrm{L}$ on $06 / 02 / 81$. At $\mathrm{H}-5 \mathrm{C}$, it was $90 \mathrm{mg} / \mathrm{L} \mathrm{HCO}_{3}$ on $10 / 12 / 81$ and decreased to $86 \mathrm{mg} / \mathrm{L}$ on $10 / 15 / 81$. The rate of decrease was very small, but steady, and at the time, the author was not sure if it was a real trend or an analytical artifact.

Serial-sampling data are shown in Table 6 and the steady-state field values are in Table 12.

On 10/15/81 final samples for solute, stable isotope (D and ${ }^{18} \mathrm{O}$ ), and uranium isotope analyses were collected. Because there was a reasonable chance that the apparent decreasing trend in the alkalinity values was an analytical artifact (and thus that the samples might be representative with respect to inorganic carbon), $25 \mathrm{gal}$ of unfiltered/unacidified groundwater were collected in red plastic jerrycans for radiocarbon analysis. However, Lambert (1987) has since shown that the Culebra waters at H-5 in 1981 were contaminated with modern carbon. Thus, the decreasing trend for alkalinity was apparently real and the samples were not representative with respect to inorganic carbon.

\subsubsection{H-6B CULEBRA (MAY 1981)}

$\mathrm{H}-6 \mathrm{~B}$ was pumped with a submersible pump. The pumping test began at 10:20 on 05/01/81 and continued through 10:20 on $05 / 03 / 81$. The average pumping rate was $\sim 23 \mathrm{gpm}$ (HGC, 1985).

Serial samples were taken on 05/01 and 05/02/81. The water was clear and odorless, and an initial effervescence disappeared after the first day of pumping. Field parameters appeared to be at steady state after a few hours of pumping, exhibiting no change after $\sim 24 \mathrm{hr}$ of pumping at 23 gpm.

Serial-sampling data are shown in Table 7 and the steady-state field values are in Table 12.

On 05/02/81 final samples were collected for solute, stable isotope ( $\mathrm{D}$ and ${ }^{18} \mathrm{O}$ ), and uranium isotope analyses. A sample for radiocarbon analysis was not collected because two data points were not considered adequate to indicate steady-state conditions for alkalinity, which had been seen to exhibit very small but steady rates of change in some tests (for example, at WIPP-28 Culebra in 1980). The decision was made to collect a radiocarbon sample during a test at $\mathrm{H}-6 \mathrm{C}$, scheduled for later that month.

\subsubsection{H-6C CULEBRA (MAY 1981)}

H-6C was pumped with a submersible pump; two pumping tests were performed. The first test began at $16: 05$ on $05 / 12 / 81$ and continued until $01: 10$ on $05 / 14 / 81$, when the generator failed. The average pumping rate was $\sim 19$ gpm (HGC, 1985). A serial sample collected on $05 / 13 / 81$ 
showed that field parameters, including alkalinity, were the same as they had been at $\mathrm{H}-6 \mathrm{~B}$ in early May. The water was clear, odorless, and frothy.

A second test began at $10: 45$ on $05 / 21 / 81$ and continued until $15: 12$ on $05 / 27 / 81$ with an average pumping rate of $\sim 17 \mathrm{gpm}$ (HGC, 1985). Again, the water was clear, odorless, and frothy or foamy. A serial sample taken on $05 / 27 / 81$ showed no change from that taken on $05 / 13 / 81$.

Serial-sampling data from both pumping tests are shown in Table 8 and the steady-state field values are in Table 12 .

On 05/27/81 a final sample was collected for stable isotope ( $\mathrm{D}$ and $18 \mathrm{O}$ ) analysis and 1 liter of unfiltered/unacidified sample was collected and archived. In addition, 150 liters of water were collected and chemically treated to precipitate the inorganic carbon as $\mathrm{BaCO}_{3}$ for subsequent radiocarbon determination (see Lambert and Robinson, 1984, for a detailed description of the chemical procedure).

\subsubsection{Solute Data}

Samples from H-4B, H-5B, H-5C, and H-6B were analyzed by UNC/Bendix during the fall of 1985. Analytical methods are described in Section 3.8 and are summarized in Table 65.

The analytical results from UNC/Bendix are given in Tables 33 to 36 and are summarized in Table 64. Total dissolved solids contents and charge-balance errors were calculated as discussed in Section 1.3.4. The calculation of analytical uncertainties is discussed in Section 3.8.

\subsection{Samples Collected in 1983-1984 During Hydrologic Tests}

\subsubsection{Program Description and Wells Sampled}

In 1983 and 1984 a variety of hydrological tests were performed at several wells by Hydro Geo Chem (HGC) for SNL. During many of these tests, water-quality parameters such as temperature, specific conductance, and specific gravity were monitored during testing, and samples were collected for subsequent laboratory analysis of solutes and/or isotopes. Samples were collected and later analyzed from the Culebra at DOE-1, FR-10, H-9, Engle Well, and H-12 and from the Dewey Lake Red Beds in Pocket Well and Unger Well.

\subsubsection{Field Data and Sample Collection}

Because the testing and field-measurement procedures varied from test to test, each test is discussed separately below. In general, the methods and equipment used are not well documented but are believed in many cases to be the same as or similar to those given in Hydro Geo Chem (1984). For example, we think that in most cases temperature was measured with a mercuryfilled thermometer or a YSI thermistor probe, specific gravity with a hydrometer, $\mathrm{pH}$ with an 
Orion 399A/F meter and combination pH electrode, Eh with the Orion 399A/F meter and a combination redox electrode, and specific conductance with a Lab-line conductance meter and beaker-type cell.

Alkalinity was determined by titrating with standard acid to a $\mathrm{pH}$ of 4.5 or to the methyl-red endpoint. However, because of several factors, the uncertainty associated with these alkalinity values must be considered quite large.

- the uncertain quality of the standard acid, which that was probably commercially prepared, possibly several years old, and probably not re-standardized before use in the field

- the small $(<5 \mathrm{~mL})$ quantities of acid used in each titration

- the unspecified method of determining the endpoint (dye indicator or $\mathrm{pH}$ )

- the lack of documentation regarding the method and equipment

The data are therefore presented as approximate values and should be used with extreme caution (for example, to corroborate other data).

Most final samples were collected in polyethylene bottles, were filtered when appropriate through a $0.45 \mu \mathrm{m}$ membrane, and were acidified when appropriate with nitric acid. Samples for tritium, $\mathrm{D}$, and ${ }^{18} \mathrm{O}$ analyses were collected in glass bottles with screw caps that were sealed with a paraffin/beeswax mixture. Samples for radiocarbon analysis were collected in 500-mL stainlesssteel sample cylinders (see HGC, 1984).

\subsubsection{DOE-1 CULEBRA (APRIL 1983)}

In the spring of 1983 the Culebra at DOE-1 was tested using a jack pump. A 15-day pumping test began on $04 / 13 / 83$. The average pumping rate was $\sim 0.5 \mathrm{gpm}$.

Temperature and specific conductance were monitored during the test, and specific gravity was measured occasionally. After one day of pumping, the specific conductance values stabilized at $125000 \pm 5000 \mu \mathrm{S} / \mathrm{cm}$. Temperature ranged from 20 to $22^{\circ} \mathrm{C}$. The specific gravity was a steady $1.090 \pm 0.002$ from the fifth day of pumping through the end of the test. On 04/21/83, the $\mathrm{pH}$ was 7.6 and alkalinity was $65-70 \mathrm{mg} / \mathrm{L} \mathrm{HCO}_{3}^{-}$. Field data are summarized in Table 13 .

Final samples were collected for stable isotope (D and ${ }^{18} \mathrm{O}$ ) and ${ }^{37} \mathrm{Cl}$ analyses. Because conflicting dates appear in the field notes and laboratory reports, the date on which final samples were collected is uncertain, but is either $04 / 19,04 / 20$, or $04 / 21 / 83$. In this report the $04 / 19 / 83$ date is used arbitrarily. The stable isotope data are reported by Lambert and Harvey (1987). The ${ }^{37} \mathrm{Cl}$ results are given in Table 19 and are discussed in Section 3.5.3. 


\subsubsection{FR-10 CULEBRA (OCTOBER 1983)}

On 10/06/83 the Culebra at FR-10 was tested. Because of the condition of the well, the pump intake was set just five feet below the water level. The pump was turned on for $10 \mathrm{sec}$, or until the pump broke suction, at 7 to 10 min intervals for an 8.5 -hr period, during which time $\sim 220 \mathrm{gal}$ of water were removed from the well.

During the test, temperature and specific conductance were monitored. The temperature ranged from 21 to $23^{\circ} \mathrm{C}$ and specific conductance was $3200 \pm 100 \mu \mathrm{S} / \mathrm{cm}$. Late in the test, the $\mathrm{pH}$ was 7.4 and the specific gravity was 1.000 . The alkalinity was $\sim 260 \mathrm{mg} / \mathrm{L} \mathrm{HCO}_{3}^{-}$. Field data are summarized in Table 13.

After the test, a suite of final samples was collected over a four-hr period. Final samples were collected for solute, halide, stable isotope ( $\mathrm{D}$ and ${ }^{18} \mathrm{O}$ ), ${ }^{37} \mathrm{Cl}$, and radiocarbon analyses. The stable isotope and radiocarbon results are discussed in Lambert and Harvey (1987) and Lambert (1987), respectively. The solute, halide, and ${ }^{37} \mathrm{Cl}$ data are given in Tables 17, 18, and 19, respectively, and are discussed in Section 3.5.3.

\subsubsection{H-9B CULEBRA (SEPTEMBER THROUGH OCTOBER 1983)}

In September 1983 the Culebra at the H-9 hydropad was tested using a submersible pump. $\mathrm{H}-9 \mathrm{~B}$ was pumped for nine days while $\mathrm{H}-9 \mathrm{~A}$ and $\mathrm{H}-9 \mathrm{C}$ served as observation wells (Intera Technologies and HGC, 1985); the average pumping rate was $10 \mathrm{gpm}$. After eight days of recovery, a second, brief ( two-hour-long) pumping test was performed, during which final samples were collected.

During the first test, specific conductance and temperature were periodically measured. The specific conductance held constant at $3900 \mu \mathrm{S} / \mathrm{cm}$ and the temperature ranged from 24 to $25^{\circ} \mathrm{C}$ (Intera Technologies and HGC, 1985, Table 4-8).

For the second test, the pump was started on 10/07/83 at 13:54; the average pumping rate was $10 \mathrm{gpm}$. Final samples were collected at 14:40 that day and the test was terminated approximately one hour later. At the time samples were collected, several parameters were measured: temperature, $24^{\circ} \mathrm{C}$; specific conductance, $3600 \mu \mathrm{S} / \mathrm{cm}$; specific gravity, $1.000 ; \mathrm{pH}$, 7.9; alkalinity, $\sim 240 \mathrm{mg} / \mathrm{L} \mathrm{HCO}_{3}^{-}$. The field data for both tests are summarized in Table 13.

Final samples were collected for solute, halide, stable isotope (D and ${ }^{18} \mathrm{O}$ ), ${ }^{37} \mathrm{Cl}$, and radiocarbon analyses. The stable isotope and radiocarbon results are discussed in Lambert and Harvey (1987) and Lambert (1987), respectively. The solute, halide, and ${ }^{37} \mathrm{Cl}$ data are given in Tables 17, 18, and 19, respectively, and are discussed in Section 3.5.3. 


\subsubsection{H-12 CULEBRA (JANUARY 1984)}

In January 1984, the Culebra at the $\mathrm{H}-12$ hydropad was tested twice using a jack pump. The first test ran from $01 / 07 / 84$ to $01 / 12 / 84$. The average pumping rate was $8.4 \mathrm{gph}$. Recovery was monitored until 10:18 on 01/23/84 (Intera Technologies and HGC, 1985). On 01/23/84 at 10:30 the second test, lasting two and one half days, was started; the pumping rate was $13.5 \mathrm{gph}$.

During the first test, specific conductance and specific gravity were monitored periodically. The data were reported in Table 3-1 of Intera Technologies and HGC (1985). The specific conductance data are considered unreliable because the measuring equipment malfunctioned. The specific gravity was initially $\sim 1.07$ and increased to 1.115 during the first day of pumping; the value then decreased slowly to 1.090 on the last day. Final samples were collected from a 7-ft extension off the pump jack at $\sim 07: 30$ on $01 / 11 / 84$, after four days of pumping. The $\mathrm{pH}$ was 7.9 at 14:00 that day. Field data are summarized in Table 13.

No field measurements were made during the second test. Between 15:00 and 16:00 on $01 / 25 / 84$, after more than two days of pumping, final samples were collected. After sampling, the $0.45 \mu \mathrm{m}$ filter membrane was observed to have accumulated a "thick coat of grey-green mud".

On $01 / 11 / 84$, during the first test, final samples were collected for solute, halide, and ${ }^{37} \mathrm{Cl}$ analyses. On $01 / 25 / 84$, during the second test, final samples were collected for solute, halide, and tritium analyses. The tritium results are discussed in Lambert and Harvey (1987). The solute, halide, and ${ }^{37} \mathrm{Cl}$ data are given in Tables 17,18 , and 19, respectively, and are discussed in Section 3.5.3.

\subsubsection{ENGLE WELL - CULEBRA (NOVEMBER 1983)}

Engle Well was tested in November 1983 using a submersible pump. A step-drawdown pumping test was performed on $11 / 03 / 83$, and $\sim 1240$ gal were pumped from the borehole. On $11 / 04 / 83$ a week-long pumping test began; the average pumping rate was $9.8 \mathrm{gpm}$.

During the step-drawdown test and subsequent week-long pumping test, temperature and specific conductance were periodically monitored. During the step-drawdown test, the specific conductance decreased from 5000 to $4600 \mu \mathrm{S} / \mathrm{cm}$. The water temperature was $23^{\circ} \mathrm{C}$, and the water was black to blackish-brown. During the week-long pumping test, the specific conductance decreased from $4800 \mu \mathrm{S} / \mathrm{cm}$ at the beginning of the test to $3600 \mu \mathrm{S} / \mathrm{cm}$ approximately one day later and thereafter was constant at $3600 \pm 200 \mu \mathrm{S} / \mathrm{cm}$. The water temperature averaged $23 \pm 1^{\circ} \mathrm{C}$ throughout the test. At the time final samples were collected, the temperature was $22^{\circ} \mathrm{C}$, the specific conductance was $3600 \mu \mathrm{S} / \mathrm{cm}$, and the $\mathrm{pH}$ was 7.3. Alkalinity was $\sim 230 \mathrm{mg} / \mathrm{L} \mathrm{HCO}_{3}^{-}$. The field data are summarized in Table 13.

After five or six days of pumping, samples for laboratory analysis were collected from the end of the discharge line $\sim 40 \mathrm{ft}$ from the well head. The date on which the samples were collected is uncertain. Documents associated with the samples, such as HGC's water-sample forms and various laboratory reports, indicate that samples were collected on 11/10/83 at 16:00 hr. 
However, the field hydrology notebook indicates that samples were collected on $11 / 09 / 83$ at 16:00 hr. The 11/10/83 date is used here because it appears on more records and reports.

Final samples were collected for solute, halide, stable isotope (D and ${ }^{18} \mathrm{O}$ ), ${ }^{37} \mathrm{Cl}$, and radioisotope $\left({ }^{14} \mathrm{C}\right.$ and $\left.{ }^{3} \mathrm{H}\right)$ analyses. The stable isotope and radioisotope results are discussed in Lambert and Harvey (1987) and Lambert (1987), respectively. The solute, halide, and ${ }^{37} \mathrm{Cl}$ data are given in Tables 17, 18, and 19, respectively, and are discussed in Section 3.5.3.

\subsubsection{POCKET WELL - DEWEY LAKE (OCTOBER - NOVEMBER 1983)}

Pocket Well was tested in October and November 1983 using a submersible pump. A stepdrawdown pumping test was performed on 10/26/83; 610 gal were pumped from the well. A five-day pumping test was conducted from 10/27/83 through 11/01/83 at an average pumping rate of $4.9 \mathrm{gpm}$. After approximately one hr of recovery, a one-and-one-half-hour test was conducted at a pumping rate of $8.7 \mathrm{gpm}$. After an $\sim$ two-hr recovery period, the pump was again turned on at a pumping rate of $\sim 8.6 \mathrm{gpm}$, and the pump was run for another day (through 11/02/83) in order to fill the stock tanks at the well.

During the five-day pumping test, specific conductance and temperature were periodically monitored. The temperature remained fairly constant at $20 \pm 1^{\circ} \mathrm{C}$ throughout the test. Specific conductance was $3400 \mu \mathrm{S} / \mathrm{cm}$ after one hr of pumping, increased to $3800 \mu \mathrm{S} / \mathrm{cm}$ an hour later, and stabilized at $3800 \pm 200 \mu \mathrm{S} / \mathrm{cm}$ for the rest of the test. When final samples were collected, the temperature was $21^{\circ} \mathrm{C}$, the specific conductance was $3800 \mu \mathrm{S} / \mathrm{cm}$, the $\mathrm{pH}$ was 7.7 , and the specific gravity was 1.000 . The alkalinity was $\sim 140 \mathrm{mg} / \mathrm{L} \mathrm{HCO}_{3}^{-}$. Field data are summarized in Table 13.

Final samples were collected during this final pumping episode on 11/02/83 between 09:30 12:30. Final samples were collected for solute, halide, stable isotope $\left(\mathrm{D}\right.$ and $\left.{ }^{18} \mathrm{O}\right),{ }^{37} \mathrm{Cl}$, and radiocarbon analyses. The stable isotope and radiocarbon results are discussed in Lambert and Harvey (1987) and Lambert (1987), respectively. The solute, halide, and ${ }^{37} \mathrm{Cl}$ data are given in Tables 17, 18, and 19, respectively, and are discussed in Section 3.5.3.

\subsubsection{UNGER WELL - DEWEY LAKE (JANUARY 1984)}

Unger Well, which is thought to be completed in the Dewey Lake Red Beds, was tested in January 1984 using a submersible pump. A step-drawdown pumping test was performed on 01/24/84, during which $\sim 2700$ gallons of turbid water were pumped from the well. A 31-hr pumping test was then conducted on $01 / 25 / 84$ and $01 / 26 / 84$ at an average pumping rate of $9.6 \mathrm{gpm}$. The author was unable to find any records of field measurements in the field hydrology notebooks.

A sampling " $\mathrm{T}$ " was placed in the discharge line and final samples were collected at $\sim 16: 00 \mathrm{hr}$ on $01 / 26 / 84$. Final samples were collected for solute, halide, ${ }^{37} \mathrm{Cl}$, and tritium analyses. The 
tritium results are discussed in Lambert and Harvey (1987). The solute, halide, and ${ }^{37} \mathrm{Cl}$ data are given in Tables 17, 18, and 19, respectively, and are discussed in Section 3.5.3.

\subsubsection{Solute Data}

The solute data are presented as follows:

- Major, minor, and trace solutes

- Halides

- Chlorine-37

\subsubsection{MAJOR, MINOR, AND TRACE SOLUTES}

Selected solutes were analyzed by UNC/Bendix for HGC. The data are given in Table 17.

Samples were analyzed in 1983 and early 1984 using UNC/Bendix's standard methods for water analysis, which were not necessarily the same as those described in Section 3.8 of this report. Some of the methods described in Section 3.8 were developed specifically for the WIPP groundwater samples after June 1984.

Because a single value was reported for each parameter, analytical precisions cannot be estimated from the data available to the author. Solutes were analyzed in unfiltered/unacidified ("raw") samples or in field-filtered/acidified samples as follows:

\begin{tabular}{|c|c|c|}
\hline Wells & Sample type & Parameters \\
\hline $\begin{array}{l}\text { H-9B, Engle, } \\
\text { Pocket }\end{array}$ & $\begin{array}{l}\text { unfiltered/ } \\
\text { unacidified (frozen) }\end{array}$ & $\mathrm{SO}_{4}^{\overline{-}}, \mathrm{Cl}^{-}, \mathrm{NO}_{3}^{-}, \mathrm{Si}$ \\
\hline $\begin{array}{l}\text { H-9B, FR-10, } \\
\text { Pocket }\end{array}$ & $\begin{array}{l}\text { filtered/ } \\
\text { acidified }\end{array}$ & $\mathrm{Ca}, \mathrm{Mg}, \mathrm{Na}, \mathrm{K}, \mathrm{Li}, \mathrm{Mn}, \mathrm{Fe}$ \\
\hline $\begin{array}{l}\text { H-12 (2 samples), } \\
\text { Unger }\end{array}$ & $\begin{array}{l}\text { unfiltered/ } \\
\text { unacidified }\end{array}$ & $\mathrm{Ca}, \mathrm{Mg}, \mathrm{Na}, \mathrm{K}, \mathrm{SO}_{4}^{\overline{-}}, \mathrm{Cl}^{-}, \mathrm{NO}_{3}^{-}, \mathrm{Br}^{-}, \mathrm{I}^{-}, \mathrm{Si}$ \\
\hline H-12, Unger & $\begin{array}{l}\text { filtered/ } \\
\text { acidified }\end{array}$ & $\mathrm{Li}, \mathrm{Mn}, \mathrm{Fe}$ \\
\hline
\end{tabular}

\subsubsection{HALIDES}

Halides were determined by Donald Whittemore of the Kansas Geological Survey (KGS). The data are presented in Table 18.

Unfiltered/unacidified samples were refrigerated at the KGS lab until the time of analysis. Bromide, chloride, and iodide were determined by automated methods using a Technicon autoanalyzer. Bromide was measured by the phenol-red method of Basel et al. (1982). Chloride was determined by the ferric thiocyanate method and iodide by the ceric-arsenious acid oxidation 
method. USGS standard reference waters were analyzed periodically by the KGS laboratory as controls. Estimated precisions reported by Whittemore, who did not give the method of calculation, are:

\begin{tabular}{|c|c|c|}
\hline Solute & Estimated Uncertainty & Applicable Concentration Range \\
\hline $\mathrm{Cl}^{-}$ & $\pm 2 \%$ & \\
\hline \multirow[t]{3}{*}{$\mathrm{Br}^{-}$} & $\pm 0.05 \mathrm{mg} / \mathrm{L}$ & $\mathrm{Br}^{-}<0.5 \mathrm{mg} / \mathrm{L}$ \\
\hline & $\pm 10 \%$ & $\mathrm{Br}^{-} 0.5-1.0 \mathrm{mg} / \mathrm{L}$ \\
\hline & $\pm 5 \%$ & $\mathrm{Br}^{-} 70-80 \mathrm{mg} / \mathrm{L}$ \\
\hline \multirow[t]{2}{*}{$\mathrm{I}^{-}$} & $\pm 10 \%$ & low $\mathrm{I}^{-}$concentrations (or low $\mathrm{I}^{-} / \mathrm{Cl}^{-}$ratios) \\
\hline & $\pm 5 \%$ & high $\mathrm{I}^{-}$concentrations (or high $\mathrm{I}^{-} / \mathrm{Cl}^{-}$ratios) \\
\hline
\end{tabular}

Two bottles of water from Pocket Well were sent to the KGS and were analyzed separately; hence there are two sets of analyses for Pocket Well in Table 18.

Bicarbonate was determined in some of the low-bromide waters. The method of bicarbonate analysis and estimated precision were not reported.

\subsubsection{CHLORINE-37}

Chlorine-37 was determined in unfiltered/unacidified samples by K.C. Services (KCS) and the University of Arizona Laboratory of Isotope Geochemistry (UA). The data are given in Table 19.

KCS analyzed seven WIPP groundwater samples, four of which were aliquots of samples collected by SNL in Nash Draw in 1980 (from the Culebra at WIPP-26, WIPP-28, WIPP-29, and WIPP-30). The ${ }^{37} \mathrm{Cl} /{ }^{35} \mathrm{Cl}$ ratio is reported in parts per thousand (per mil or \%) as a delta value, $\delta$, relative to standard mean ocean chloride (SMOC). The delta value is calculated as follows:

$$
\delta(\%)=\frac{\mathbf{R}_{\text {sample }}-\mathbf{R}_{\text {standard }}}{\mathbf{R}_{\text {standard }}} \times 1000
$$

where $\mathrm{R}=\frac{{ }^{37} \mathrm{Cl}}{{ }^{35} \mathrm{Cl}}$ in the sample or standard

The analytical precision was estimated by the KCS laboratory to be better than \pm 0.24 per mil. KCS also determined total chloride by a gravimetric method; the analytical precision estimated by the lab was $\pm 10 \%$.

The UA lab analyzed four WIPP groundwater samples, two of which were splits of samples collected from the Culebra at H-3B3 in June 1984 (by HGC) and February 1985 (by the WQSP) (see Sections 3.6 and 3.7). The UA lab determined the chlorine-isotope ratio by a mass spectrometric measurement on methylchloride gas that had been generated from the sample 
(Kaufmann, 1984). The results are reported in per mil (\%) relative to SMOC. The analytical precision estimated by the laboratory is $\pm 0.1 \%$.

\subsection{Samples Collected in June and August 1984 During Convergent-Flow Tracer Tests}

\subsubsection{Program Descriptions and Wells Sampled}

In the spring of 1984, Hydro Geo Chem (HGC) developed a water sampling protocol for use in collecting groundwater samples during hydrologic pumping tests (HGC, 1984). The Culebra was sampled at $\mathrm{H}-3 \mathrm{~B} 3$ in June 1984 using the protocol while it was in review. The Culebra at $\mathrm{H}-4 \mathrm{C}$ was sampled in August 1984.

\subsubsection{Field Data and Sample Collection}

Field procedures are described in HGC (1984) and are summarized here.

Temperature, $\mathrm{pH}$, and Eh were measured in a flow cell similar to that described by Collins (1975).

- Temperature was measured with a thermistor thermometer (YSI model 43) that was periodically checked against a calibrated mercury thermometer.

- The $\mathrm{pH}$ was measured with a $\mathrm{pH} / \mathrm{mV}$ meter (Orion model 399A/F) and combination $\mathrm{pH}$ electrode. Before each $\mathrm{pH}$ measurement, the system was calibrated with two buffer solutions, one with a pH of 7 and the other with a pH of either 9.2 or 10 .

- The Eh was measured with the Orion 399A/F meter and a combination redox electrode.

Specific gravity and specific conductance were measured at atmospheric pressure in open containers.

- Specific conductance was measured with a Lab-line Mark V meter and a beaker-type cell with a cell constant of 1.0 .

- Specific gravity was measured with a hydrometer.

The tracer tests during which the samples were collected are briefly summarized in the following two subsections.

\subsubsection{H-3B3 CULEBRA (APRIL THROUGH JUNE 1984)}

From April through June 1984, a convergent-flow tracer test was done at the H-3 hydropad. Starting on 04/22/84, H-3B3 was pumped at $3 \mathrm{gpm}$ for 17 days. On $05 / 09 / 84$, a sodium metatrifluoromethylbenzoate tracer was injected in $\mathrm{H}-3 \mathrm{~B} 1$ and a sodium pentafluorobenzoate tracer was injected in H-3B2. Pumping continued at H-3B3 until 06/11/84 (HGC, 1985). 
On $06 / 10$ and $06 / 11 / 84$, five parameters (temperature, specific gravity, specific conductance, $\mathrm{pH}$, and $\mathrm{Eh}$ ) were measured in three serial samples. The Eh values, which are not reported here, are considered unreliable because they were measured in a flow cell, and subsequent work showed that the redox electrode was rapidly poisoned (that is, the electrode filling solution was contaminated with sample water) in this environment. Other serial-sample data are given in Table 9. Steady-state values are given in Table 14.

Final samples were collected on $06 / 11 / 84$ for solute, stable isotope (D and ${ }^{18} \mathrm{O}$ ), ${ }^{37} \mathrm{Cl}$, and tritium analyses. The stable isotope and tritium results are discussed by Lambert and Harvey (1987) and Lambert (1987), respectively. The ${ }^{37} \mathrm{Cl}$ results are discussed in Section 3.5.3, and the solute results are discussed below.

\subsubsection{H-4C CULEBRA (OCTOBER 1982 THROUGH OCTOBER 1984)}

From October 1982 to October 1984, a convergent-flow tracer test was done at the H-4 hydropad. $\mathrm{H}-4 \mathrm{C}$ was pumped at $\sim 15$ gph for 3 days starting on $10 / 24 / 82$. On $10 / 27 / 82$, sodium thiocyanate and sodium meta-trifluoromethylbenzoate tracers were injected into $\mathrm{H}-4 \mathrm{~B}$, and on $11 / 05 / 84$, sodium para-fluorobenzoate and sodium pentafluorobenzoate tracers were injected into $\mathrm{H}-4 \mathrm{~A}$. Pumping continued at $\mathrm{H}-4 \mathrm{C}$ for $\sim$ two $\mathrm{yr}$, until $10 / 15 / 84$. On $06 / 11 / 83$, the pumping rate was increased from $15 \mathrm{gph}$ to $\sim 30 \mathrm{gph}$ (HGC, 1985).

On $08 / 09$ and $08 / 10 / 84$, five parameters (temperature, specific gravity, specific conductance, $\mathrm{pH}$, and $\mathrm{Eh}$ ) were measured in four serial samples. The Eh values, which are not reported here, are considered unreliable because they were measured in a flow cell, and subsequent work showed that the redox electrode was rapidly poisoned (that is, the filling solution was contaminated with sample water) in this environment. Other serial-sample data are given in Table 10. Steady-state values are given in Table 14 .

Final samples for solute analysis were collected on $08 / 10 / 84$. The data are presented below.

\subsubsection{Solute Data}

The H-3B3 sample was analyzed by UNC/Bendix during the summer of 1984 and was used to validate their analytical methods (see Section 3.8). The H-4C sample was analyzed during the summer of 1985. Analytical methods are described in Section 3.8 and are summarized in Table 65 .

The UNC/Bendix analytical results are given in Tables 37 and 38 and are summarized in Table 64. Total dissolved solids contents and charge-balance errors were calculated as discussed in Section 1.3.4. The calculation of analytical uncertainties is discussed in Section 3.8. 


\subsection{Samples Collected During Round One of the WQSP}

\subsubsection{Program Description and Wells Sampled}

The Water Quality Sampling Program (WQSP) is a long-term regional groundwater sampling effort, conducted by the Management and Operating Contractor (MOC) for the Department of Energy (DOE), in which wells will be sampled many times in the next few years. The WQSP provides field data and samples to several monitoring programs and to SNL's site characterization program (Colton and Morse, 1985). The WQSP is discussed in more detail in Section 4.2 of this report. SNL received samples from the following 25 locations sampled in 1985-1986 during the first round of the WQSP.

\section{Zone Well(s) \\ Bell Canyon DOE-2}

Culebra DOE-1, DOE-2, H-2A, H-3B3, H-4B, H-5B, H-6B, H-7B1, H-8B, H-9B, H-11B3, H-12, P-14, P-17, WIPP-25, WIPP-26, WIPP-29, Engle Well

Dewey Lake Ranch Well, Twin Wells/Pasture Well

Magenta $\quad H-3 B 1, H-4 C, H-5 C, H-6 C$

\subsubsection{Field Data and Sample Collection}

Field procedures and sample collection methods for the WQSP are discussed in Section 4.2. Steady-state field values of selected parameters are summarized in Table 15.

Two suites of samples were collected for SNL. One suite consisted of filtered/unacidified and filtered/acidified water samples for solute analysis and an acid blank (nitric acid in deionized water), all in plastic bottles; these samples were shipped directly to UNC/Bendix from the field and were stored there at ambient temperature.

The other suite included, in most cases, unfiltered/unacidified, filtered/unacidified, and filtered/acidified samples in plastic bottles for solute and possible uranium-isotope analyses, unfiltered/unacidified samples in glass bottles for possible stable-isotope analyses, an unfiltered/unacidified sample in a 500-mL stainless-steel sample cylinder for possible radiocarbon analysis, and an acid blank in a plastic bottle. These samples were sent to the author's laboratory in Albuquerque, NM, and were stored at ambient temperature.

Selected isotope analyses were done on some of these samples but will not be discussed in this report. UNC/Bendix has analyzed selected solutes in the samples sent directly to them; the results are discussed in the next section. The solute samples at SNL have been archived and may be analyzed as needed to help resolve discrepancies among the data sets from various laboratories analyzing WIPP groundwaters. 


\subsubsection{Solute Data}

Samples were analyzed by UNC/Bendix in 1985 and 1986. Analytical methods are described in Section 3.8 and are summarized in Table 65.

The results for the WQSP samples are presented in Tables 39 to 63 and are summarized in Table 64. Total dissolved solids contents and charge-balance errors were calculated as discussed in Section 1.3.4. The calculation of analytical uncertainties is discussed in Section 3.8.

\subsection{Analytical Methods Used by UNC/Bendix}

\subsubsection{Samples and Analytes}

This report contains data from 44 samples analyzed by UNC/Bendix for SNL including:

- 13 collected by SNL in Nash Draw in 1980

- 4 collected by SNL during hydrologic testing in 1981

- 2 collected by HGC during tracer tests in 1984

- 25 collected during the first round of the WQSP

As is summarized in the following table, the major solutes, as well as some minor and trace solutes, were determined in all samples, alkalinity and other minor and trace solutes were determined in selected samples, and nitrate was determined in one sample.

\section{Parameter(s)}

$\mathrm{Ca}, \mathrm{Mg}, \mathrm{Na}, \mathrm{K}, \mathrm{Cl}^{-}, \mathrm{SO}_{4}^{\overline{-}}$

Alkalinity, $\mathrm{Br}^{-}, \mathrm{B}, \mathrm{Li}, \mathrm{Si}, \mathrm{Sr}$

$\mathrm{F}^{-}, \mathrm{I}^{-}, \mathrm{Cs}, \mathrm{Fe}, \mathrm{Mn}$

$\mathrm{NO}_{3}^{-}$
Samples

all samples

samples for which there was sufficient quantity

selected samples

the Ranch Well (Dewey Lake) sample

UNC/Bendix was sent samples of field-filtered/unacidified and field-filtered/acidified water for all wells, with one exception. (The H-11B3 Culebra "unacidified" sample had been inadvertently acidified in the field.) Most of the unacidified samples had to be filtered again in the UNC/Bendix laboratory before analysis because small amounts of precipitated matter were seen in many bottles.

In general, cations and trace metals were determined in the acidified fractions and anions and silica in the unacidified fractions. The exceptions were the following:

- $\mathrm{Cl}^{-}, \mathrm{SO}_{4}^{\bar{y}}$, and $\mathrm{Br}^{-}$were determined in the acidified fraction of the $\mathrm{H}-11 \mathrm{~B} 3$ Culebra sample (other anions were not determined in this sample).

- Silica was determined in the acidified fraction of the H-11B3 Culebra sample, but the results are considered unreliable and are not reported here. 
- $\mathrm{SO}_{4}^{\bar{z}}$ and $\mathrm{F}^{-}$were determined in the acidified fraction of the H-3B3 Culebra sample of $06 / 11 / 84$, although other anions and silica were determined in the unacidified fraction.

In addition, UNC/Bendix received acid blanks from many of the WQSP wells. Selected cations were determined in some of the acid blanks.

\subsubsection{Analytical Methods and Method Validation}

The analytical methods used by UNC/Bendix included:

- differential pulse polarography (DPP)

- flame atomic absorption spectrophotometry (flame AAS)

- graphite furnace atomic absorption spectrophotometry (GFAAS)

- inductively-coupled plasma atomic emission spectrophotometry (ICP)

- ion chromatography (IC) .

- ion-selective electrodes (ISE)

- titrimetric methods

- ultraviolet/visible spectrophotometry (UV/VIS)

- $\mathrm{x}$-ray fluorescence (XRF)

The following list summarizes the analytes and methods used to determined them.

Analyte

Alkalinity

B

$\mathrm{Br}^{-}$

$\mathrm{Ca}$

$\mathrm{Cl}^{-}$

Cs

$\mathrm{F}^{-}$

$\mathrm{Fe}$

$\mathrm{I}^{-}\left(\mathrm{IO}_{3}^{-}\right)$

K

$\mathrm{Li}$

$\mathrm{Mg}$

$\mathrm{Mn}$

$\mathrm{Na}$

$\mathrm{NO}_{3}^{-}$

$\mathrm{SiO}_{2}$
Method(s)

Electrometric titration

ICP

XRF; DPP; UV/VIS

Flame AAS; ICP

ISE; Mohr titration

GFAAS

ISE

Flame AAS; GFAAS

DPP

Flame AAS; ICP

Flame AAS; ICP

Flame AAS; ICP

Flame AAS; GFAAS

Flame AAS; ICP

IC

UV/VIS; ICP 
$\mathrm{SO}_{4}^{\overline{2}} \quad \mathrm{IC}$

$\mathrm{Sr} \quad$ Flame AAS; ICP

Table 65 shows specifically which methods were used for each sample. All methods used by UNC/Bendix are documented in their in-house procedures manual (Bendix Field Engineering Corp., 1984). The methods, in alphabetical order, are briefly summarized here.

\section{Differential Pulse Polarography $\left(\mathrm{Br}^{-}, \mathrm{I}^{-}, \mathrm{IO}_{3}^{-}\right)$}

Bromide $\left(\mathrm{Br}^{-}\right)$was oxidized to bromate $\left(\mathrm{BrO}_{3}^{-}\right)$with sodium hypochlorite and the bromate was determined by DPP. Sample blanks were analyzed to correct for bromate in the samples. Standardization was done by the method of additions. At least one control sample was analyzed with some sets of groundwater samples.

Iodide $\left(\mathrm{I}^{-}\right)$was oxidized to iodate $\left(\mathrm{IO}_{3}^{-}\right)$with bromine water at a $\mathrm{pH}$ of less than 2 and the iodate was determined by DPP. Blanks were analyzed to correct for iodate in the samples (measureable iodate was found in two WIPP samples). Standardization was done by the method of additions.

Flame Atomic Absorbtion Spectrophotometry ( $\mathrm{Ca}, \mathrm{Fe}, \mathrm{K}, \mathrm{Li}, \mathrm{Mg}, \mathrm{Mn}, \mathrm{Na}, \mathrm{Sr}$ )

Samples were diluted as necessary to bring the element of interest into the appropriate concentration range. Standard techniques were used (as given by the instrument manufacturer, Perkin-Elmer Corporation); ionization suppressants and interference inhibitors were added as necessary. Standardization was usually done by the standard curve method; the method of additions was used for some of the iron and manganese determinations. At least one spiked sample was analyzed with each set of groundwater samples. At least one control sample was analyzed with each set of groundwater samples.

\section{Graphite-Furnace Atomic Absorbtion Spectrophotometry (Cs, Fe, Mn)}

Iron and manganese were determined by standard methods (as given by the instrument manufacturer, Perkin-Elmer Corporation). Standardization was done by the standard curve method. Cesium was determined by the method of Grobenski et al. (1983): samples were diluted with $1 \% \mathrm{HNO}_{3}$ and $1 \% \mathrm{H}_{2} \mathrm{SO}_{4}$ and analyzed using recommended instrumental conditions with standardization by the method of additions (Grobenski et al., 1983). At least one spiked sample was analyzed with each set of groundwater samples. For $\mathrm{Fe}$ and $\mathrm{Mn}$, at least one control sample was analyzed with each set of groundwater samples.

\section{Inductively Coupled Plasma Atomic Emission Spectrophotometry (B, Ca, K, Li, $\mathrm{Mg}, \mathrm{Na}, \mathrm{Si}, \mathrm{Sr}$ )}

Samples were diluted as necessary to bring the analyte into the appropriate concentration range. Standard methods were used (as given by the instrument manufacturer, Perkin-Elmer Corporation). Standardization was done by the standard curve method. At least one spiked sample was analyzed with each set of groundwater samples. At least one control sample was analyzed with each set of groundwater samples. 


\section{Ion Chromatography $\left(\mathrm{NO}_{3}^{-}, \mathrm{SO}_{4}^{\overline{-}}\right)$}

Sulfate $\left(\mathrm{SO}_{4}^{\overline{-}}\right)$ and nitrate $\left(\mathrm{NO}_{3}^{-}\right)$were determined by standard ion chromatographic methods (as given by the instrument manufacturer, Dionex Corporation). Standardization was done sometimes with a standard curve and sometimes with internal standards. At least one spiked sample was analyzed with most sets of groundwater samples. At least one control sample was analyzed with most sets of groundwater samples.

\section{Ion-Specific Electrode $\left(\mathrm{Cl}^{-}, \mathrm{F}^{-}\right)$}

Chloride $\left(\mathrm{Cl}^{-}\right)$was determined in some samples with an Orion chloride electrode using the standard procedure for chloride determinations in brines (Orion Research, 1981). Standardization was by the standard curve method. At least one spiked sample was analyzed with most sets of groundwater samples. At least one control sample was analyzed with some sets of groundwater samples.

Fluoride $\left(\mathrm{F}^{-}\right)$was determined with an Orion fluoride electrode using the method of Warner (1971). Standardization was by the method of additions. At least one control sample was analyzed with each set of groundwater samples.

Titrimetric methods (alkalinity, $\mathrm{Cl}^{-}$)

Alkalinity was determined by titrating with standard sulfuric acid to an endpoint of 4.5 (APHA, 1975a). A control sample was analyzed with some sets of groundwater samples.

Total alkalinity was reported as $\mathrm{CaCO}_{3}$. To allow easier comparison with other sets of data from the field and other laboratories, in the summary data tables (Tables 71 to 135) in this report, the results as calcium carbonate $\left(\mathrm{CaCO}_{3}\right)$ have been converted to bicarbonate $\left(\mathrm{HCO}_{3}^{-}\right)$as described in Section 1.3.4.

Chloride was determined in some samples by titrating with silver nitrate (Mohr titration) (Blaedel and Meloche, 1963). At least one spiked sample was analyzed with each set of groundwater samples.

\section{Ultraviolet/Visible Spectrophotometry $\left(\mathrm{Br}^{-}, \mathrm{SiO}_{2}\right)$}

Bromide $\left(\mathrm{Br}^{-}\right)$was determined in some samples by oxidizing the bromide to bromate $\left(\mathrm{BrO}_{3}^{-}\right)$, reacting the bromate with iodide $\left(\mathrm{I}^{-}\right)$to produce iodine $\left(\mathrm{I}_{2}\right)$, and measuring the iodine spectrophotometrically. Iodide was determined independently and subtracted, if significant, from the apparent concentration to get the actual bromide concentration. (ASTM D1246-95; Bendix Field Engineering Corp., 1984) Standardization was done with a standard curve. At least one spiked sample and at least one control sample were run with each set of groundwater samples.

Silica was determined by the molybdosilicate method (ASTM D859-68; APHA, 1975b). Both molybdate-reactive silica and total (reactive plus unreactive) silica were determined, but only the 
total silica values are reported here. Standardization was done with a standard curve. At least one spiked sample was analyzed with each set of groundwater samples.

\section{$\underline{\mathrm{X}-\mathrm{Ray} \text { Fluorescence }}\left(\mathrm{Br}^{-}\right)$}

Bromide $\left(\mathrm{Br}^{-}\right)$was determined in one sample by XRF using the method of Smith (1981). Standardization was by the method of additions.

\section{Method validation}

In June 1984, a 10-L filtered/unacidified sample and a 10-L filtered/acidified sample of Culebra water from H-3B3, collected on 06/11/84, were sent to UNC/Bendix for method validation. All analytes were determined in triplicate, controls were analyzed when available, and spikes were analyzed in triplicate for all analytes except alkalinity and those determined by the method of standard additions. The results indicated that the laboratory's methods, with appropriate dilutions and instrumental operating conditions, met the SNL geochemists' requirements of analytical precision and accuracy with the exception of cesium. The cesium method of Grobenski et al. (1983) was later adopted for use in the laboratory, although in all samples analyzed to date, the cesium values have been below the laboratory's reporting limit ( $<0.001$ to $<0.01 \mathrm{mg} / \mathrm{L}$ depending on the bulk sample composition).

Bromide was first determined in the 06/11/84 H-3B3 Culebra sample by the XRF method. However, before the beginning of routine analyses of WIPP samples in the spring of 1985, UNC/Bendix's XRF spectrometer malfunctioned. The DPP method was developed and tested on some of the remaining 06/11/84 H-3B3 Culebra samples. Agreement between the two methods was very good. The XRF result was $28.3 \mathrm{mg} / \mathrm{L}(0.3 \% \mathrm{RSD}$ for $3 \mathrm{reps})$, and the DPP result was $26.2 \mathrm{mg} / \mathrm{L}$ ( $2.2 \% \mathrm{RSD}$ for $3 \mathrm{reps})$.

Strictly speaking, because method accuracy and precision are often a function of the sample bulk composition, the validation of the methods applied only to samples with compositions similar to H-3B3 Culebra water. Therefore, in the first sets of WQSP samples analyzed, all analytes were analyzed in triplicate and spiked samples were analyzed whenever possible.

After many samples had been analyzed, it became apparent that the methods were appropriate over the composition ranges of the WIPP samples. Thereafter, each analyte was routinely determined in duplicate. Spiked samples were analyzed periodically. If the duplicate results did not agree within specified limits (that is, if the RPD exceeded the value specified by SNL), a third or even a fourth replicate was analyzed to allow a "wild" value to be recognized and discarded or to bring the RSD of all the values to less than SNL's specified value. Sulfate was routinely run in triplicate, because the precision of the sulfate analytical technique is not quite as good as the precisions of the analytical techniques used to determine the other major solutes. 


\subsubsection{Data}

The UNC/Bendix analytical data are given in Tables 20 through 63 and are summarized in Table 64.

Results of individual analyses are given to two or three "significant" figures although for the most solutes, the final digit will not truly be significant (because the precisions of most methods are better than the accuracies). The extra significant digits are reported here to allow the reader to perform additional statistical calculations if desired.

In the summary tables in Section 5.0, all results except those for the major solutes are rounded arbitrarily to two significant figures. The major solutes are all rounded to three significant figures. Again, the extra digits are given to allow the reader to perform additional calculations if desired. Until confidence limits can be calculated, it remains unknown how many figures are truly significant for a value of a given parameter in a given sample.

Results from the analyses of the acid blanks are given in Table 67. Analytes in the blanks were below reporting limits in all the blanks, indicating that the nitric acid used for sample preservation was not a source of contamination for those analytes.

Charge-balance errors and total dissolved solids contents were calculated as discussed in Section 1.3.4.

\subsubsection{Analytical Uncertainties and Accuracy}

Each analyte was measured two, three, or even four times in each sample (with the exception of iodide in the H-4C Culebra sample, which was determined only once because of a limited quantity of sample). Precisions have been estimated and are shown as RPDs for two replicates, or RSDs, for three or four replicates, in Tables 20 to 63 . Precisions are routinely better than $\pm 3 \%$ for the major solutes and better than $10 \%$ for other analytes.

Confidence limits have not been calculated at this time because the large Student's $t$ factors associated with one or two degrees of freedom (associated with the individual standard deviations) may lead to misleadingly large confidence limits, which in turn could obscure some real differences between analytical results. However, all the replicate data are presented so that the interested reader can perform these calculations if desired.

For the appropriate analytes in selected samples, spiked samples were analyzed. The spike recoveries are summarized in Table 66 . Some of the recovery values are averages of two or three replicates. Spike recoveries were generally in the range of 95 to $105 \%$ for the major solutes and 85 to $115 \%$ for other analytes.

As discussed in Section 1.3.2, the required accuracy of a measurement depends on the intended use of the data. For their site characterization studies, the SNL geochemists requested accuracies of \pm 3 to $5 \%$ for the major solutes and $\pm 10 \%$ for the minor and trace solutes. They also 
specified a CBE of less than 3\%. As accuracy itself cannot be measured, they used spike recoveries as checks on the analytical error.

Similarly, the required precision of a measurement depends on the intended use of the data. For their site characterization work, the SNL geochemists requested \pm 3 to $5 \%$ (RSD for more than two replicates, or RPD for two replicates) for the major solutes and $\pm 10 \%$ (RSD or RPD) for the minor and trace solutes. 


\subsection{DATA FROM OTHER SOURCES}

This section presents data from three other sources:

Section

Data reported by

4.1

4.2

the United States Geological Survey (USGS)

4.3

the Management and Operating Contractor (MOC)

the New Mexico Environmental Evaluation Group (EEG).

Only selected parameters of those reported by the USGS, MOC, and EEG are given here. Specifically, only those solutes that were also analyzed by UNC/Bendix for SNL are included: $\mathrm{Cl}^{-}, \mathrm{SO}_{4}^{\overline{-}}, \mathrm{Ca}, \mathrm{K}, \mathrm{Mg}, \mathrm{Na}, \mathrm{Br}^{-}, \mathrm{I}^{-}, \mathrm{F}^{-}, \mathrm{NO}_{3}^{-}, \mathrm{B}, \mathrm{Cs}, \mathrm{Fe}, \mathrm{Li}, \mathrm{Mn}, \mathrm{Si}$, Sr, and alkalinity.

In addition, laboratory determinations of total dissolved solids (residue-on-ignition) and laboratory measurements of $\mathrm{pH}$ and density are included when available.

Charge-balance errors and total dissolved solids concentrations were calculated as described in Section 1.3.4.

\subsection{Data Reported by the United States Geological Survey}

\subsubsection{Program Description and Wells Sampled}

Between 1976 and 1980, during hydrologic testing at many WIPP wells, the USGS collected samples for subsequent laboratory analysis of various solutes and/or isotopes. The USGS has reported laboratory data from the following wells (Mercer and Orr, 1979; Mercer, 1983):

\begin{tabular}{|c|c|}
\hline Zone & Well(s) \\
\hline Culebra & $\begin{array}{l}\text { H-1, H-2B1, H-2C, H-3B1, H-4B, Н-5B, H-6B, Н-7B1, Н-8B, Н-9B, } \\
\text { H-10B, P-14, P-15, P-17, P-18, WIPP-25, WIPP-26, WIPP-27, WIPP-28, } \\
\text { WIPP-29, WIPP-30 }\end{array}$ \\
\hline Magenta & $\begin{array}{l}\text { H-1,H-2A,H-3B1, H-4A, H-5A, H-6A, H-8A, H-9A, H-10A, WIPP-25, } \\
\text { WIPP-27, WIPP-30 }\end{array}$ \\
\hline Rustler/Salado & $\begin{array}{l}\text { H-1, H-2C, H-3B1, H-4C, H-5C, H-6C, H-7C, H-8C, H-9C, H-10C, P-14, } \\
\text { P-15, P-17, P-18, WIPP-25, WIPP-26, WIPP-27, WIPP-28, WIPP-29, } \\
\text { WIPP-30 }\end{array}$ \\
\hline
\end{tabular}




\subsubsection{Field Data and Sample Collection}

Field activities, hydrologic testing, and sample collection methods are described in several USGS documents. Mercer (1983) summarizes all the procedures and most of the laboratory data. In addition, the reports listed below describe specific tests and provide detailed information about the well configuration and condition during testing, the test methods and equipment used, basic hydrologic data from the tests, and the times and methods of sampling.

Document

Mercer and Orr (1979)

Mercer et al. (1981)

Dennehy and Mercer (1982)

Dennehy (1982)

Richey (1986)

Richey (1987)
Wells

H-1, H-2A, H-2B1, H-2C, H-3B1, P-14, P-15, P-17, P-18

$\mathrm{H}-4 \mathrm{~A}, \mathrm{H}-4 \mathrm{~B}, \mathrm{H}-4 \mathrm{C}$

$\mathrm{H}-5 \mathrm{~A}, \mathrm{H}-5 \mathrm{~B}, \mathrm{H}-5 \mathrm{C}$

$\mathrm{H}-6 \mathrm{~A}, \mathrm{H}-6 \mathrm{~B}, \mathrm{H}-6 \mathrm{C}$

H-7A, H-7B1, H-7C, H-8A, H-8B, H-8C, H-9A, H-9B, $\mathrm{H}-9 \mathrm{C}, \mathrm{H}-10 \mathrm{~A}, \mathrm{H}-10 \mathrm{~B}, \mathrm{H}-10 \mathrm{C}$

WIPP-25, WIPP-26, WIPP-27, WIPP-28, WIPP-29, WIPP-30

In some cases, such as the sampling episodes in 1977, the test zone was bailed or swabbed until field measurements of water temperature, specific conductance, and density had stabilized (Mercer and Orr, 1979). At other sites, the test zone was bailed or swabbed to remove the water standing in the casing before samples were collected (Mercer et al., 1981; Dennehy, 1982). Often samples were collected after other hydrologic tests (bailing, slug, and so forth) had been performed. Samples were collected according to the standard USGS methods of Brown et al. (1970). Alkalinity and $\mathrm{pH}$ were usually measured in the field at the time of sample collection.

\subsubsection{Solute Data}

Solute data from Mercer and Orr (1979) and Mercer (1983) are summarized in Table 68. Alkalinity and $\mathrm{pH}$ were often determined in the field. Other parameters were determined in the USGS Central Laboratory according to the USGS standard procedures of Brown et al. (1970). Data were routinely reported with two significant figures.

Analytical uncertainties (standard deviations) are given by Brown et al. (1970) for most parameters, but were usually determined by analyzing a single sample many (often 20-30) times. Because the precision and accuracy of a method often varies with the sample composition, the reported precisions may not apply to the WIPP samples, particularly those with higher total dissolved solids (TDS) contents. 


\subsubsection{POTASSIUM DATA}

A comparison of all of the USGS data with data from other laboratories showed that some of the USGS potassium values appear to be incorrect by as much as two orders of magnitude. In particular, several samples were collected in Nash Draw in August and September 1980, including five samples from the Culebra (at WIPP-25, WIPP-26, WIPP-27, WIPP-28, and WIPP-29) and one sample from the Magenta at (WIPP-25). The USGS potassium result for the WIPP-27 Culebra sample was a factor of 10 lower than the UNC/Bendix result for the SNL sample collected a few days later. The USGS potassium results for the other five samples were a factor of 100 lower than the UNC/Bendix results for the SNL samples collected a few days later. Because the USGS and SNL samples were otherwise similar (see Section 5.0), there is reason to doubt that the potassium concentrations were really different, at least not by one or two orders of magnitude.

One explanation for the apparently low potassium results is that the six samples may have been analyzed at the same time; all would have required dilution by a factor of 10,100 , or even 1000 before analysis. During data reduction, the results might not have been corrected for the dilutions (or the wrong dilution factors might have been used, such as 10 instead of 100 or 1000). In this report, although only circumstantial evidence supports this hypothesis, the apparently low USGS potassium values for the six samples listed above are attributed to "laboratory error," perhaps a missing or incorrect dilution factor correction.

Some other USGS potassium results differ from the results reported by other laboratories by factors of five low to as much as 200 high. However, these are all for samples collected at much different times, often years apart, whereas the USGS and SNL samples discussed above were collected a few days or, at most, weeks apart. Many of these other differences are therefore suspected to be real. The very high results, for example, could be caused by contamination of the USGS samples with a potassium-rich drilling brine. Thus the samples might not be representative, but the analyses would be reasonably accurate.

\subsubsection{OTHER DATA}

After the first draft of this report was written and reviewed, the author learned of another set of USGS analytical data for many of these samples. When USGS personnel collected and sent samples to the USGS Central Laboratories, they also sent replicates to Blair Jones of the USGS, Reston, VA. These samples were analyzed by Shirley Rettig, and the results are available in Bodine et al. (1988).

Because of time constraints, these data could not be considered in this report. However, in many cases we believe that Rettig's data are more reliable than those from the USGS Central Laboratories. 


\subsection{Data Reported by the Management and Operating Contractor}

\subsubsection{Program Description and Wells Sampled}

The Water Quality Sampling Program (WQSP) is a long-term regional groundwater sampling program that provides samples to several programs including the MOC's Radiological Baseline and Ecological Monitoring Programs (RBP and EMPs) and SNL's site characterization program (Colton and Morse, 1985). More than 20 wells have been and will continue to be sampled approximately annually or biennially for the next several years.

The first round of sampling ran from January 1985 to November 1986. Round two began in April 1986 and was still in progress as work on this report began. Rounds one and two overlapped because the last few wells to be sampled in round one needed extensive recompletion work before they could be sampled. While this work was being planned and done, round-two sampling was started elsewhere.

Because very little round-two data were available to the author at the time this report was started, this report includes only the data from round-one samples collected in 1985 and 1986 . At a few locations, where the solute data are particularly confusing, the available round-two data have been briefly considered, but they are not included in the data tables.

The following sites were sampled in 1985 and 1986 (WQSP round one):

Zone

Culebra

Magenta

Dewey Lake

Bell Canyon
Well(s)

DOE-1, DOE-2, H-2A, H-3B3, H-4B, H-5B, H-6B, H-7B1, H-8B, H-9B, H-11B3, H-12, P-14, P-17, WIPP-25, WIPP-26, WIPP-29, Engle Well

$\mathrm{H}-3 \mathrm{~B} 1, \mathrm{H}-4 \mathrm{C}, \mathrm{H}-5 \mathrm{C}, \mathrm{H}-6 \mathrm{C}, \mathrm{H}-8 \mathrm{~A}$

Twin Wells/Pasture Well, Ranch Well

DOE-2

In addition, a sample was collected from the Culebra at $\mathrm{H}-3 \mathrm{~B} 2$ at the end of a long-term multi-pad pumping test.

Note: Other wells were added to the program in 1987; results were not available in time to be included in this report. These wells are not discussed further in this report; more information is in Randall et al. (1988). SNL's data for samples from these wells will be published in a future document. 


\subsubsection{Field Data and Sample Collection}

The field-analysis and sampling procedures are described in Colton and Morse (1985) and the Water Quality Sampling Manual (WP 7-2). Serial samples were collected and several parameters were measured in the field, including the following:

$\begin{array}{ll}\text { Parameter } & \text { Method } \\ \text { alkalinity } & \text { titration with sulfuric acid to specified pH } \\ \mathrm{Cl}^{-} & \text {titration with silver nitrate } \\ \mathrm{Eh} & \text { platinum electrode } \\ \mathrm{Fe} & \text { spectrophotometry } \\ \mathrm{pH} & \text { glass electrode } \\ \text { specific conductance } & \text { specific conductance probe and meter } \\ \text { specific gravity } & \text { hydrometer } \\ \text { temperature } & \text { temperature probe or mercury thermometer } \\ \text { divalent cations }\left(\mathrm{X}^{++}\right) & \text {titration with EDTA }\end{array}$

The serial-sampling field data from the WQSP are given in a series of annual reports: Uhland and Randall (1986), Uhland et al. (1987), Randall et al. (1988), Lyon (1989). This report includes some data from the first two annual reports. Steady-state values for selected parameters are summarized here in Table 15.

Final samples were collected when the solutes, alkalinity, and $\mathrm{pH}$ reached steady-state values. Several suites of final samples were collected and sent to various laboratories for analyses. Some samples were sent to SNL, to UNC/Bendix (for SNL), and to the New Mexico EEG; these samples are discussed elsewhere in this report.

The ITAS laboratory in Murraysville, PA, analyzed solutes for the MOC's Environmental Monitoring Program. The ITAS laboratory was sent bottles of field-filtered/acidified samples for metals and cation analyses, bottles of field-filtered/unacidified samples for anion analyses, bottles of unfiltered/unacidified samples for general chemistry (parameters such as $\mathrm{pH}$, TDS, and sometimes anions), and an acid blank.

As was mentioned above, a sample was collected from the Culebra at $\mathrm{H}-3 \mathrm{~B} 2$ at the end of a long-term multi-pad pumping test. The collection procedures and analyses are discussed in Uhland et al. (1987). The pumping test is described in Intera Technologies (1986). 


\subsubsection{Solute Data}

The solute data from ITAS that are used in this report are taken from Uhland and Randall (1986) and Uhland et al. (1987). Selected parameters are summarized in Table 69. Note that the major solutes $\left(\mathrm{Ca}, \mathrm{Mg}, \mathrm{Na}, \mathrm{K}, \mathrm{Cl}^{-}\right.$, and $\mathrm{SO}_{4}^{\overline{-}}$ ) were not analyzed by ITAS in the first nine samples collected during the WQSP.

Methods of analysis and estimates of precision were not reported for the round-one data. However, some parameters were run in duplicate; the duplicate results were reported by Uhland and Randall (1986) and Uhland et al. (1987). Although only the averages are given here, the interested reader could estimate precisions for several parameters from the duplicate data in the source documents.

Uhland and Randail (1986) and Uhland et al. (1987) usually reported the ITAS laboratory results with one or two significant figures. Note that when an average value is given in this report, the average is presented here with one additional significant figure. As with the UNC/Bendix data (Section 3.8), the additional figures are probably not truly significant, but are presented here for the convenience of the reader who wants to do further statistical calculations.

\subsection{Data Reported by the NM Environmental Evaluation Group}

\subsubsection{Program Description and Wells Sampled}

The New Mexico Environmental Evaluation Group (EEG) was sent samples of water from wells sampled during the WQSP. Data from the following 18 wells were available for inclusion in this report and were provided to the author by J.B. Chapman:

$\begin{array}{ll}\text { Zone } & \text { Well(s) } \\ \text { Culebra } & \text { DOE-1, DOE-2, H-3B3, H-4B, H-5B, H-6B, H-8B, H-9B, H-11B3, H-12, } \\ & \text { P-14, P-17, WIPP-26, WIPP-29, Engle } \\ \text { Magenta } & \text { H-3B1 } \\ \text { Dewey Lake } & \text { Twin Wells/Pasture Well } \\ \text { Bell Canyon } & \text { DOE-2 }\end{array}$

The data for these and other samples have since been published in Chapman (1988).

\subsubsection{Field Data and Sample Collection}

Field data and sample collection methods are summarized in Section 4.2. The EEG supplied its own sample bottles. The bottles were not pre-treated (such as by acid-washing) but were rinsed with sample water several times before filling, in accordance with the standard WQSP procedures of Colton and Morse (1985). Samples were treated (for example, filtered and 
acidified) according to standard WQSP procedures. Samples supplied to the EEG included bottles of unfiltered/unacidified groundwater, field-filtered/unacidified groundwater, and fieldfiltered/acidified groundwater.

\subsubsection{Solute Data}

Solutes were analyzed by Lynn Brandvold, a Senior Chemist with the New Mexico Bureau of Mines and Mineral Resources, Socorro, NM.

Dr. Brandvold received either unfiltered/unacidified or field-filtered/unacidified groundwater samples. Some of the filtered samples arrived with a precipitate and continued to precipitate on standing; the precipitate did not dissolve when the sample was heated. Therefore, laboratory personnel routinely made $1: 10,1: 100$, and 1:1000 dilutions of the samples when the samples arrived. The diluted samples appeared stable with no further precipitation occurring. Major solutes were determined in the diluted samples.

Density was determined by shaking an undiluted sample, allowing it to settle, and pipetting and weighing an aliquot.

The solute and density data are presented in Table 70. Solutes were determined by the following methods:

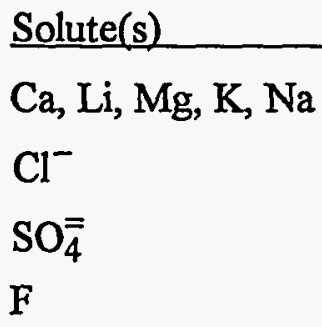
Method
atomic absorption spectrophotometry
titration by the mercuric nitrate method
gravimetry as barium sulfate
ion-specific electrode

The author does not have sufficient information to estimate the analytical uncertainties or accuracies of these analytical results. However, Brandvold reported that standards were analyzed to verify the accuracy of their methods. Because they did not have reference standards with which to check the accuracy of their methods, laboratory personnel prepared synthetic water samples of varying TDS and analyzed one synthetic sample with each set of groundwater samples. If they found a greater variation than $3 \%$, they rechecked those analyses.

In addition, laboratory personnel calculated a charge-balance error for each sample. They included laboratory determinations of alkalinity ${ }^{5}$ in their CBE calculations. If the CBE exceeded $3 \%$, the analyses of that sample were rechecked.

\footnotetext{
${ }^{5}$ Because the EEG did not request the determination of alkalinity and did not request that the results be included in the reports to them, these data are not available to the author.
} 
For the data tables in this report, charge-balance errors and total dissolved solids concentrations were calculated as described in Section 1.3.4. Alkalinity values were not included in the calculation of CBE, with the exception of the sample from the Twin Wells/Pasture Well, for which the field value was used. As explained in Section 1.3.4, for most of the samples discussed in this report, alkalinities can be safely ignored in the CBE calculation because in most of these waters the $\mathrm{Cl}^{-}$and $\mathrm{SO}_{4}^{-}$concentrations are the predominant anions; $\mathrm{HCO}_{3}^{-}$and $\mathrm{CO}_{3}^{\bar{y}}$ do not contribute significantly to the $\mathrm{CBE}$.

In the fresher Culebra and Magenta waters (from H-7, H-8, H-9, and Engle Well), the alkalinity contribution becomes noticeable. For example, using the EEG data from the H-9B Culebra sample, the $\mathrm{CBE}$ is $+2.1 \%$ when alkalinity is excluded and $+0.1 \%$ when a field alkalinity value is included. Both CBE's are, however, acceptably low. In very fresh waters (such as the Dewey Lake sample from Twin Wells/Pasture Well), alkalinity is a major contributor to the CBE and must be included to get meaningful results. 


\subsection{COMPARISON AND PRELIMINARY EVALUATION OF THE DATA}

\subsection{Introduction}

This Section (5.0) gives comparisons of various data sets and preliminary evaluations of the quality of the available major solute data. Because the evaluations are preliminary, when a more complete evaluation is done (including the data from subsequent rounds of the WQSP), some of the conclusions and recommendations given here may be contradicted. The information given here should, however, help users of this data to understand that not all of the available data are equally reliable and, in addition, may provide a reasonable data set for some calculations and modeling efforts.

Topics covered in the rest of this introductory Section (5.1) include:

- Summary of methods of evaluating data

- Comments about some parameters

- Organization of the remainder of this section

\subsubsection{Summary of Methods of Evaluating Data}

Methods of data evaluation were discussed in some detail in Section 2.0 and are summarized here. In evaluating the data included in this report, both the representativeness of the samples and the quality of the analyses were considered.

\subsubsection{QUALITY OF THE ANALYSES}

The qualities of various sets of analytical data were evaluated by examining their internal consistencies and considering supporting data (replicates, spiked samples, control samples) when available; by comparing the laboratory results for chloride and divalent cations with the field results, if available; and by comparing results from various laboratories for samples collected at the same time from the same well and zone.

The WQSP field results for the solutes (especially chloride, divalent cations, and iron) are considered highly reliable for several reasons:

- Duplicates were routinely analyzed; results agreed well

- At each well, one spiked sample for each solute was analyzed; spike recoveries were acceptable

- Standard solutions were restandardized at each well

The UNC/Bendix laboratory data are considered highly reliable for similar reasons:

- Replicates were routinely analyzed; results agreed well

- Spiked samples were analyzed when appropriate; spike recoveries were acceptable 
- Control samples were analyzed when possible; results were acceptable

- Calculated CBEs were acceptably low

In addition, the general good agreement between the field and UNC/Bendix results for $\mathrm{Cl}^{-}$ and $\mathrm{X}^{++}$indicated that both the laboratory and field results for those parameters were reliable.

Similarly, the good agreement between the UNC/Bendix laboratory data and the field results from the Nash Draw studies in 1980 (Lambert and Robinson, 1984) indicated that those field results were reliable.

The data from other sources (such as the New Mexico Environmental Evaluation Group (EEG) and the ITAS laboratory) are also supported, in many cases, by the analysis of replicates, spiked samples, and/or control samples. However, most of these supporting data were not available to the author and could not be used to evaluate the quality of those data sets. Those data were therefore evaluated by comparing them, if possible, with the field and UNC/Bendix data.

\subsubsection{REPRESENTATIVENESS OF SAMPLES}

Sample representativeness was evaluated by considering the method of collection; by considering the field (serial-sampling) data, if available; and by comparing analyses of samples collected during different hydrologic tests (sampling episodes) at the same location (hydropad and zone), if possible.

Samples collected after serial-sampling results for $\mathrm{Cl}^{-}$and $\mathrm{X}^{++}$reached steady state were initially assumed to be representative with respect to the major solutes. This includes all final samples collected in 1980 and during round one of the WQSP, with the exceptions of H-2A Culebra, which did not reach steady state, and H-8A Magenta, for which serial samples could not be collected. Laboratory results for these samples (that is, those assumed to be representative) provide most of the basis for evaluating the representativeness of other samples for which serialsampling data are not available.

In a few cases, the initial assumption (that is, that steady-state conditions imply that the sample is representative with respect to the major solutes) has been shown to be of questionable validity, but for most of the samples the assumption appears reasonable.

\subsubsection{FACTORS NOT CONSIDERED IN THIS WORK}

Because this is a preliminary evaluation, some potentially important factors could not, at this time, be systematically considered in this evaluation process. In particular the following factors have, for the most part, been ignored for the time being:

- the well configuration at the time of testing (such as open hole versus cased/perforated, type and location of packers, and so forth) 
- the test conditions (such as, for pumping tests, the type of pump, the pumping rate, and the total volume pumped before sampling)

- the well history, including possible additions to the groundwater (brine added during drilling and/or coring operations, other material added to control lost circulation or help dislodge a piece of equipment that was stuck in the borehole, fluids injected for tracer tests, and so forth) or possible removal of large quantities of water (because of many tests being conducted in the same wells over the years)

In a few cases, the author knew from personal experience that these factors might be important; in other cases, reviewers pointed out possible difficulties caused by one or more of the factors. For these few cases, some of the factors have been considered and are mentioned in the sections discussing the cases.

\subsubsection{Comments About Some Parameters}

\subsubsection{MAJOR SOLUTES}

This report primarily addresses the evaluation of the analytical data for the major solutes $\mathrm{Na}$, $\mathrm{K}, \mathrm{Ca}, \mathrm{Mg}, \mathrm{Cl}^{-}$, and $\mathrm{SO}_{4}^{\overline{ }}$. Note that when samples are described as "representative" in Sections 5.2 to 5.6, this means representative with respect to those major solutes, but not necessarily representative with respect to any other solute or parameter.

\subsubsection{MINOR AND TRACE SOLUTES}

Minor and trace solute data are presented, but are only briefly discussed and are not evaluated here. The minor and trace solute data are presented for the convenience of those readers who may want to evaluate or use them.

For solutes such as silica and fluoride, the interlaboratory and intertest results tend to agree rather well, that is, they are the same order of magnitude. However, the data should be used with caution until the representativeness of the samples for these parameters can be evaluated.

For some other solutes, such as bromide and cesium, the interlaboratory results sometimes vary by as much as one or more orders of magnitude, although results from the same laboratory for samples from different tests at the same site are comparable. The interlaboratory analytical variations must be understood before the sample representativeness can be evaluated for these parameters, so again, the data must be used with extreme caution.

Because some, and perhaps all, final samples are not representative with respect to iron (see Section 2.0), all trace metal data must be viewed with suspicion until the sample representativeness for each specific metal of interest in each sample can be evaluated. Also, the large interlaboratory variations for some trace metal analyses must be understood before the sample representativeness for these parameters can be completely evaluated. 


\subsubsection{ALKALINITY AND pH}

Field values for $\mathrm{pH}$ and alkalinity are recommended over the laboratory values. The laboratory values are primarily used to show how much (or little) a nonacidified sample may have changed between the time of collection and time of analysis and for calculations of charge-balance error for some samples.

However, even the field $\mathrm{pH}$ and alkalinity data must be used with caution for two reasons.

- First, the groundwaters in many wells have been contaminated with bicarbonate/carbonate, perhaps from bacterial degradation of organic materials introduced during drilling or coring operations (Lambert, 1987). Because of this modern contamination, the observed alkalinity and $\mathrm{pH}$ values in samples from these locations are probably not representative of the native, unperturbed groundwater.

- Second, even in uncontaminated wells, loss of carbon dioxide gas at the wellhead during the sampling operation will result in an increased $\mathrm{pH}$ (Stumm and Morgan, 1981). Although loss of $\mathrm{CO}_{2}$ gas will not affect the total alkalinity, the increased $\mathrm{pH}$ will affect the bicarbonate/carbonate ratio (Stumm and Morgan, 1981). A loss of some $\mathrm{CO}_{2}$ gas probably occurs during most of our sampling efforts, but the amount of the loss cannot be quantified. Therefore, even for samples with demonstrated minimal contamination of modern inorganic carbon, the field $\mathrm{pH}$ and alkalinity values must be used with caution.

\subsubsection{Organization of the Remainder of Section 5.0}

The remainder of Section 5.0 is organized as follows:

Subsection

5.2

5.3

5.4

5.5

5.6
Topic

Preliminary evaluation of data from the Culebra Dolomite

Preliminary evaluation of data from the Magenta Dolomite

Preliminary evaluation of data from the Rustler/Salado contact zone

Preliminary evaluation of data from the Dewey Lake Red Beds

Preliminary evaluation of data from other stratigraphic zones

Within each subsection, the WIPP wells are listed first, in alphabetical order, followed by the stock wells in alphabetical order. Wells located at the same hydropad are grouped together; for example, the Culebra samples from $\mathrm{H}-5 \mathrm{~B}$ and $\mathrm{H}-5 \mathrm{C}$ are discussed and compared in the same subsubsection.

For each location (hydropad and stratigraphic zone), a summary table shows the data from various laboratories and the field (these data are from Tables 11 to 15). Charge-balance errors and total dissolved solids contents were calculated as discussed in Section 1.3.4. To allow comparison of field divalent-cation values with laboratory data, the laboratory calcium and magnesium values (converted to meq/L) have been summed to give a laboratory divalent-cation 
value. Alkalinity values are given both as $\mathrm{mg} / \mathrm{L} \mathrm{CaCO}$ and as $\mathrm{mg} / \mathrm{L} \mathrm{HCO}_{3}^{-}$plus $\mathrm{mg} / \mathrm{L} \mathrm{CO}=$ Conversions were made as described in Section 1.3.4.

Remember: when samples are described as "representative" in Sections 5.2 to 5.6, this means "representative with respect to the major solutes $\mathrm{Na}, \mathrm{K}, \mathrm{Ca}, \mathrm{Mg}, \mathrm{Cl}^{-}$, and $\mathrm{SO}_{4}^{\overline{\bar{N}}}$," but not necessarily representative with respect to any other solute or parameter.

\subsection{Preliminary Evaluation of Data from the Culebra Dolomite}

\subsubsection{DOE-1 Culebra (Table 71)}

The Culebra at DOE-1 was sampled by HGC in 1983 and during round one of the WQSP in 1985. It was sampled again during rounds two and three of the WQSP; the field and ITAS laboratory data are given in Uhland et al. (1987) and Randall et al. (1988).

\section{Sample}

During a 1983 pumping test, $\mathrm{HGC}$ made some field measurements and collected final samples for stable isotope (D and ${ }^{18} \mathrm{O}$ ) and for ${ }^{37} \mathrm{Cl}$ analyses (see Section 3.5.2.1).

The KCS laboratory, which did the ${ }^{37} \mathrm{Cl}$ measurements, reported a total chloride concentration of $94000 \pm 10000 \mathrm{mg} / \mathrm{L}$, determined gravimetrically. Although the concentration is $\sim 25 \%$ higher than the chloride concentration measured in the field and by UNC/Bendix for the WQSP sample, the results may be reasonable within the limits of the analytical methods. Therefore, we cannot evaluate the representativeness of the 1983 sample with the available information.

\section{Samples (WQSP round one)}

UNC/Bendix and the EEG analyzed WQSP samples; ITAS did not determine major solutes in their samples. However, ITAS analyzed two different "metal" samples, collected on two days of final sampling, for selected minor and trace cations (Uhland et al., 1987).

Both the UNC/Bendix and EEG data sets seem to be internally consistent. However, for reasons that are not yet understood, the EEG's major solute determinations are systematically lower than those of UNC/Bendix. The UNC/Bendix results are considered more reliable because their $\mathrm{Cl}^{-}$and $\mathrm{X}^{++}$value values agree closely with the values measured in the field.

\section{Preliminary recommendations}

The representativeness of the 1983 sample cannot be evaluated.

The 1985 samples are considered representative with respect to the major solutes; the UNC/Bendix major-solute data are recommended. 


\subsubsection{DOE-2 Culebra (Table 72)}

The Culebra at DOE-2 was sampled during round one of the WQSP in 1985. It was sampled again during rounds two and three of the WQSP; the field and ITAS laboratory data are given in Uhland et al. (1987) and Lyon (1989).

\section{5 samples (WQSP round one)}

UNC/Bendix and the EEG analyzed WQSP samples; ITAS did not determine major solutes in their sample. The UNC/Bendix and EEG data sets seem to be internally consistent. Differences between the two data sets are not systematic, and in most cases can be attributed to analytical variation. However, the EEG $\mathrm{Ca}$ value is significantly higher than the $\mathrm{UNC} / \mathrm{Bendix}$ value. Correspondingly, the EEG $\mathrm{X}^{++}$value is higher than both the UNC/Bendix value and the field value, which are in good agreement with each other. The EEG Ca value may be in error; for other major solutes, both the UNC/Bendix and EEG results are thought to be reliable.

\section{Preliminary recommendations}

The WQSP samples are considered representative with respect to the major solutes. The UNC/Bendix and the EEG major-solute results, with the exception of the EEG Ca value, are recommended.

Caution: Because large amounts of brine and diesel oil were used in drilling this well, and because some field personnel with sensitive noses could still detect a faint odor of diesel oil at the time final samples were collected, data for other constituents, such as trace metals and organics, must be used with extreme caution.

\subsubsection{FR-10 Culebra (Table 73)}

The Culebra at FR-10 was sampled by HGC in 1983 (see Section 3.5.2.2). This well is no longer available for testing or sampling. Selected cations were analyzed for HGC by UNC/Bendix, halides by the KGS, and ${ }^{37} \mathrm{Cl}$ by KCS. Neither the sample collection procedures nor the laboratory analyses are well documented; as a result, it is difficult to evaluate either the sample representativeness or the quality of the analyses. Because sulfate was not determined, a $\mathrm{CBE}$ cannot be calculated. However, the low chloride and low major-cation concentrations are consistent with the other relatively fresh Culebra waters found to the south of the WIPP site.

\subsubsection{H-1 Cullebra (Table 74)}

The Culebra at H-1 was sampled by the USGS in 1976 and 1977. Both sets of USGS laboratory analyses seem to be internally consistent. The 1977 sample contained significantly more $\mathrm{Cl}^{-}, \mathrm{SO}_{4}^{\overline{\bar{y}}}, \mathrm{Na}, \mathrm{K}$, and $\mathrm{Mg}$ than the 1976 sample. Lambert and Harvey (1987) showed that the 1977 sample was probably contaminated with water from the Rustler/Salado contact zone in the same well. The 1977 sample is not considered representative. Because at this time we cannot 
evaluate the representativeness of the 1976 sample, the USGS analyses of the 1976 sample should be used with caution.

\subsubsection{H-2 Culebra (Table 75)}

The Culebra at H-2 was sampled by the USGS in 1977 (H-2B1 and $\mathrm{H}-2 \mathrm{C})$ and during round one of the WQSP in $1986(\mathrm{H}-2 \mathrm{~A})$. In addition, in December 1980, the author made some field measurements at $\mathrm{H}-2 \mathrm{C}$ during a recirculating tracer test. The Culebra at $\mathrm{H}-2$ was sampled again during rounds two and three of the WQSP; the field and ITAS laboratory data are reported in Randall et al. (1988) and Lyon (1989).

\section{7 samples}

The USGS collected samples from H-2B1 in February 1977 and from H-2C in March 1977. Both sets of USGS laboratory results seem to be internally consistent. Most of the major solutes were comparable in the two samples, with the notable exception of $\mathrm{Na}$ and $\mathrm{Cl}^{-}$. Both $\mathrm{Na}$ and $\mathrm{Cl}^{-}$were $\sim 70 \%$ higher at $\mathrm{H}-2 \mathrm{C}$ than they had been at H-2B1. Mercer (1983) used a density of $1.012 \mathrm{~g} / \mathrm{mL}$ (in his Table 9) to correct the water level to a freshwater equivalent head, but he does not reference the source of this density value.

\section{0 sample}

In December 1980, the author made some field measurements at $\mathrm{H}-2 \mathrm{C}$ during a recirculating tracer test (see Section 3.4.2.1). The specific gravity was 1.002. Of course, water sampled during a recirculating test cannot be expected to be representative of the native groundwater, because the added tracer-bearing fluid is a source of contamination and recirculating the pumped water does not allow for the flushing or purging of contaminants. However, in order for the recirculating water to have a density much lower than the native groundwater, the groundwater would have to have been diluted with very large quantities of a low density fluid. The amount of tracer-bearing fluid injected at this hydropad probably was not enough to affect the density of the groundwater at this site.

\section{6 samples (WQSP round one)}

UNC/Bendix and ITAS analyzed WQSP samples. Both sets of laboratory data seem to be internally consistent. The major solute results from the two laboratories are comparable; sulfate differs by $\sim 10 \%$ and the others agree more closely.

However, steady state had apparently not been reached at the time the WQSP samples were collected. Close examination of the field data in Uhland and Randall (1986) shows that the chloride values were still slowly decreasing, even after more than two weeks of pumping. The specific gravity measured in the field at the time of final sample collection was 1.009 . 


\section{Preliminary recommendations}

The specific gravity of 1.002 observed in 1980 may have been slightly low because of some dilution by tracer-bearing fluids. However, the accuracy of the 1977 density, 1.012, is also doubted because of the large dilution that would be needed to go from 1.012, in 1977, to the observed specific gravity of 1.002 in 1980 .

The UNC/Bendix and ITAS results for the 1986 samples are comparable to the USGS results for the March 1977 H-2C sample. But (as discussed above) the 1986 samples are not considered representative because the field chloride concentration did not reach steady state.

At this time, none of the previously collected samples can be considered representative. Samples collected during later rounds of the WQSP may give more information about the chemistry of the Culebra water at $\mathrm{H}-2$.

\subsubsection{H-3 Culebra (Table 76)}

The Culebra at H-3 was sampled by the USGS in 1977 (H-3B1), by HGC in 1984 (H-3B3), during round one of the WQSP in 1985 (H-3B3), and by WQSP personnel in December 1985 $(\mathrm{H}-3 \mathrm{~B} 2)$. The Culebra at $\mathrm{H}-3$ was sampled again during rounds two and three of the WQSP; the field and ITAS laboratory data are given in Uhland et al. (1987) and Randall et al. (1988).

\section{7 and 1984 samples}

The USGS laboratory results for the 1977 sample seem to be internally consistent, as do the $\mathrm{UNC/Bendix}$ results for the 1984 sample.

\section{5 samples (WQSP round one and H-3B2)}

WQSP samples from H-3B3 were analyzed by UNC/Bendix and the EEG; ITAS did not determine major solutes in their sample. The UNC/Bendix and EEG results seem to be internally consistent. The two data sets are in good agreement and both sets are considered reliable.

The sample collected at H-3B2 in December 1985 was analyzed by ITAS; the results seem to be internally consistent.

\section{Preliminary recommendations}

Results from all of the sets of samples and analyses are comparable. The few significant differences (noted here) can be attributed to analytical variations and/or errors.

- the USGS $\mathrm{SO}_{4}^{\bar{z}}$ value is high

- the ITAS Ca value is high 
- the February 1985 field value for $\mathrm{X}^{++}$appears high ${ }^{6}$

All of the other field and laboratory major-solute data are considered reliable.

All samples are considered representative with respect to the major solutes. With the exceptions noted in the preceding paragraph, all of the major-solute data are considered reliable. However, because supporting field data and documentation are available for the WQSP samples, the UNC/Bendix and EEG major-solute data for the WQSP round-one samples are recommended.

\subsubsection{H-4 Culebra (Table 77)}

The Culebra at H-4 was sampled by the USGS in 1978 (H-4B), by SNL in 1981 (H-4B), by HGC in 1984 (H-4C), and during round one of the WQSP in 1985 (H-4B). The Culebra at H-4 was sampled again during rounds two and three of the WQSP; the field and ITAS laboratory data are given in Uhland et al. (1987) and Randall et al. (1988).

\section{8,1981 , and 1984 samples}

The USGS laboratory results for the 1978 sample seem to be internally consistent, as do the UNC/Bendix results for the 1981 and 1984 samples.

\section{5 samples (WOSP round one)}

UNC/Bendix and the EEG analyzed WQSP samples; ITAS did not determine major solutes in their sample. The UNC/Bendix and EEG data sets both seem to be internally consistent. The EEG $\mathrm{SO}_{4}^{\bar{y}}, \mathrm{Ca}, \mathrm{Mg}$, and $\mathrm{K}$ results are comparable to the $\mathrm{UNC} / \mathrm{Bendix}$ results, but, for reasons that are not yet understood, their $\mathrm{Na}$ and $\mathrm{Cl}^{-}$results are significantly lower. The UNC/Bendix chloride value agrees closely with the field value, and therefore the $\mathrm{UNC} / \mathrm{Bendix} \mathrm{Na}$ and $\mathrm{Cl}^{-}$data are recommended; the $\mathrm{SO}_{4}^{\bar{y}}, \mathrm{Ca}, \mathrm{Mg}$, and $\mathrm{K}$ results from both laboratories are considered reliable.

\section{Preliminary recommendations}

The USGS 1978 sample contained significantly less $\mathrm{Ca}$ and $\mathrm{SO}_{4}^{\overline{ }}$ than the later samples; its representativeness is doubted. The 1981, 1984, and 1985 samples, which are all thought to be representative with respect to the major solutes, contained comparable quantities of major solutes, although the $\mathrm{Na}$ and $\mathrm{Cl}^{-}$concentrations seem to be slightly lower in the 1985 samples. As the difference is slight, $\sim 6 \%$, we cannot say whether it is caused by analytical imprecision, with both

\footnotetext{
${ }^{6}$ The high field $\mathrm{X}^{++}$value apparently resulted from improper standardization of the EDTA solution used in the titrimetric analysis. This was the first well sampled during the WQSP, and procedures were being developed and tested. Uhland et al. (1987) report a round-two field $X^{++}$value of $\sim 140 \mathrm{meq} / \mathrm{L}$, which agrees with the Bendix and EEG lab values for the round one samples. The inaccurate standardization during round one does not affect the conclusion that stability for this parameter was reached.
} 
$\mathrm{Na}$ and $\mathrm{Cl}^{-}$coincidentally varying by the same amount, or whether there was a real difference in the water samples.

For the 1981 and 1984 samples, the UNC/Bendix major-solute data are considered reliable. For the WQSP samples, both the UNC/Bendix and the EEG major-solute data, with the exception of the EEG Na and $\mathrm{Cl}^{-}$values, are considered reliable.

\subsubsection{H-5 Culebra (Table 78)}

The Culebra at H-5 was sampled by the USGS in 1978 (H-5B), by SNL in 1981 (H-5B and $\mathrm{H}-5 \mathrm{C}$ ), and during round one of the WQSP in 1985 (H-5B). The Culebra at H-5 was sampled again during rounds two and three of the WQSP; the field and ITAS laboratory data are given in Uhland et al. (1987) and Lyon (1989).

\section{8 and 1981 samples}

The USGS laboratory results for the 1978 sample seem to be internally consistent, as do the UNC/Bendix analyses of the 1981 samples.

\section{5 samples (WQSP round one)}

UNC/Bendix, ITAS, and the EEG analyzed WQSP samples. All three data sets seem to be internally consistent. However, for reasons that are not yet understood, the EEG results are consistently lower than the UNC/Bendix results. The ITAS results are, with the exception of $\mathrm{Cl}^{-}$and $\mathrm{K}$, also lower than the UNC/Bendix results. The differences between the three data sets may be caused by analytical variation and error and/or to sample degradation. Because the UNC/Bendix $\mathrm{Cl}^{-}$and $\mathrm{X}^{++}$results agree with those obtained in the field, the UNC/Bendix majorsolute data tentatively are considered more reliable.

\section{Preliminary recommendations}

The USGS 1978 sample contained significantly less $\mathrm{SO}_{4}^{\bar{z}}$ and $\mathrm{Ca}$ than the later samples and its representativeness is questioned.

The 1981 and 1985 samples, which are all thought to be representative with respect to the major solutes, contained comparable amounts of the major solutes; observed differences between 1981 and 1985 may be attributed to analytical variation. The UNC/Bendix major-solute data for the 1981 and 1985 samples are recommended.

\subsubsection{H-6 Culebra (Table 79)}

The Culebra at H-6 was sampled by the USGS in 1978 (H-6B), by SNL in 1981 (H-6B), and during round one of the WQSP in 1985. Also, SNL made some selected field and isotope measurements at $\mathrm{H}-6 \mathrm{C}$ in 1981 . The Culebra at H-6 was sampled again during rounds two and 
three of the WQSP; the field and ITAS laboratory data are given in Uhland et al. (1987) and Randall et al. (1988).

\section{8 and 1981 samples}

The USGS laboratory data for the 1978 sample seem to be internally consistent, as do the UNC/Bendix data for the 1981 sample.

\section{5 samples (WQSP round one)}

UNC/Bendix, ITAS, and the EEG analyzed samples from the WQSP. The UNC/Bendix and EEG data seem to be internally consistent and are in good agreement with each other and the field measurements of $\mathrm{Cl}^{-}$and $\mathrm{X}^{++}$. The ITAS results have a large CBE (-11\%) and, except for $\mathrm{Cl}^{-}$ and $\mathrm{Ca}$, show poor agreement with the other data sets. The UNC/Bendix and EEG major-solute data are considered more reliable.

\section{Preliminary recommendations}

The USGS sample contained somewhat less $\mathrm{Cl}^{-}$and $\mathrm{Ca}$ than the later samples; its representativeness is doubted.

The 1981 and 1985 samples, which are all thought to be representative with respect to the major solutes, contain comparable amounts of the major solutes. The slightly higher $\mathrm{SO}_{4}^{\bar{N}}, \mathrm{Na}$, and $\mathrm{Ca}$ values in the 1981 samples are attributed to analytical variations, although the possibility that the differences are real cannot be ruled out at this time. The UNC/Bendix major-solute data for the 1981 samples and the UNC/Bendix and EEG major-solute data for the 1985 samples are recommended.

\subsubsection{H-7 Culebra (Table 80)}

The Culebra at $\mathrm{H}-7$ was sampled by the USGS in 1980 (H-7B1) and during round one of the WQSP in 1986 (H-7B1). It was sampled again during rounds two and three of the WQSP; the field and ITAS laboratory data are given in Randall et al. (1988) and Lyon (1989).

\section{0 sample}

The USGS laboratory data seem to be internally consistent.

\section{6 samples (WQSP round one)}

UNC/Bendix and ITAS analyzed samples from the WQSP. The UNC/Bendix data seem to be internally consistent and their values for $\mathrm{Cl}^{-}$and $\mathrm{X}^{++}$are in good agreement with the field data for those parameters. The ITAS data show poor internal agreement with a CBE of $-20 \%$ and a higher calculated TDS than observed ROI. The ITAS chloride value is nearly twice those reported by UNC/Bendix and observed in the field, and the ITAS sulfate value is $\sim 25 \%$ higher than the UNC/Bendix value, indicating a possible problem with the ITAS anion sample. The ITAS major-cation data agree well with the UNC/Bendix data. The UNC/Bendix major-anion 
data are considered more reliable; the major-cation data from both UNC/Bendix and ITAS are considered reliable.

\section{Preliminary recommendation}

With the exception of $\mathrm{K}$, which is five times lower in the USGS 1980 sample than in the 1985 WQSP samples, the 1980 and 1985 samples contain comparable quantities of the major solutes. Because the apparently low USGS $\mathrm{K}$ value could be a laboratory error and because the other major solutes are the same in the USGS and WQSP samples, the USGS sample was probably representative with respect to the major solutes. The 1985 samples are considered representative with respect to the major solutes. For the 1985 samples, the UNC/Bendix data for the major anions and cations and the ITAS data for the major cations are recommended.

\subsubsection{H-8 Culebra (Table 81)}

The Culebra at H-8 was sampled by the USGS in 1980 (H-8B) and during round one of the WQSP in 1986 (H-8B). It was sampled again during rounds two and three; the field and ITAS laboratory data are given in Randall et al. (1988) and Lyon (1989).

\section{0 sample}

The USGS laboratory results for the 1980 sample seem to be internally consistent.

\section{6 samples (WQSP round one)}

UNC/Bendix, ITAS, and the EEG analyzed WQSP samples. The UNC/Bendix and EEG data seem to be internally consistent and are generally in good agreement; the EEG $\mathrm{K}$ value of 4.6 $\mathrm{mg} / \mathrm{L}$ is $\sim 20 \%$ higher than the UNC/Bendix value. The ITAS results seem to be less internally consistent, with a $\mathrm{CBE}$ of $+8 \%$. The ITAS $\mathrm{SO}_{4}=$ value is significantly lower than the UNC/Bendix and EEG results, which could explain the CBE. The ITAS $\mathrm{Cl}^{-}$and major cation values agree with the results from the other laboratories within acceptable analytical limits. Major-solute data from all three laboratories are therefore considered reliable with the exception of the ITAS $\mathrm{SO}_{4}^{\overline{-}}$ value.

\section{Preliminary recommendation}

The USGS 1980 sample contained significantly more $\mathrm{Na}$ and $\mathrm{Cl}^{-}$than the WQSP 1986 samples, although the other major solutes were the same in 1980 and 1986 . The representativeness of the USGS sample is questioned.

The WQSP samples are considered representative with respect to the major solutes, and the major-solute results from all three laboratories, with the exception of the ITAS $\mathrm{SO}_{4}^{\overline{-}}$ value, are recommended. 


\subsubsection{H-9 Culebra (Table 82)}

The Culebra at H-9 was sampled by the USGS in 1980 (H-9B), by HGC in 1983 (H-9B), and during round one of the WQSP in 1985 (H-9B). It was sampled again during rounds two and three of the WQSP; the field and ITAS laboratory data are given in Randall et al: (1988) and Lyon (1989).

\section{0 sample}

The USGS laboratory data for their 1980 sample are apparently not internally consistent. However, the CBE of $+26 \%$ could be caused by an incorrect $\mathrm{K}$ value. The $\mathrm{K}$ value is a factor of 200 higher than the values reported by the other laboratories for samples collected in later years.

\section{3 sample}

The UNC/Bendix data for the 1983 sample seem to be internally consistent.

\section{5 samples (WQSP round one)}

UNC/Bendix, ITAS, and the EEG analyzed WQSP samples. The UNC/Bendix and EEG results seem to be internally consistent and are in good agreement with each other. The ITAS results show poorer internal consistency. The $\mathrm{CBE}$ of $+10 \%$ is attributed to a low $\mathrm{SO}_{4}^{\bar{z}}$ value; the ITAS $\mathrm{SO}_{4}^{-}$value is $\sim 25 \%$ lower than the UNC/Bendix and EEG values. The ITAS $\mathrm{Cl}^{-}$and major cations values agree with those reported by $\mathrm{UNC/Bendix}$ and the EEG within acceptable limits. Major-solute data from all three laboratories are therefore considered reliable, with the exception of the ITAS $\mathrm{SO}_{4}^{\bar{z}}$ value.

\section{Preliminary recommendations}

The USGS 1980 sample contained significantly higher quantities of $\mathrm{Na}$ and $\mathrm{Cl}^{-}$than the later samples. The representativeness of the USGS sample is questioned.

The 1983 and 1985 samples contained comparable quantities of major solutes, with differences observed being attributable to analytical variation. Both groups of samples are considered representative with respect to the major solutes, but the major-solute data from the 1985 samples, with the exception of the ITAS $\mathrm{SO}_{4}^{\overline{\bar{N}}}$ value as explained above, are recommended because the documentation of sample collection and analysis is better.

\subsubsection{H-10 Culebra (Table 83)}

The Culebra at $\mathrm{H}-10$ (well $\mathrm{H}-10 \mathrm{~B}$ ) was sampled by the USGS in 1980. The USGS laboratory data seem to be internally consistent. However, because we cannot evaluate the representativeness of this sample, the data should be used with caution. 


\subsubsection{H-11 Culebra (Table 84)}

The Culebra at $\mathrm{H}-11$ was sampled during round one of the WQSP in $1985(\mathrm{H}-11 \mathrm{~B} 3)$. It was sampled again during rounds two and three of the WQSP; the field and ITAS laboratory data are given in Uhland et al. (1987) and Randall et al. (1988).

\section{5 samples (WQSP round one)}

UNC/Bendix and the EEG analyzed WQSP samples; ITAS did not determine major solutes in their sample. The UNC/Bendix and EEG results both seem to be internally consistent. However, for reasons that are not understood, the EEG $\mathrm{Cl}^{-}$value is slightly lower than the UNC/Bendix value and the $\mathrm{SO}_{4}^{=}$and $\mathrm{K}$ values are significantly lower. $\mathrm{Na}, \mathrm{Ca}$, and $\mathrm{Mg}$ agree within the limits of analytical precision. The UNC/Bendix major-solute results are considered more reliable because the $\mathrm{UNC} / \mathrm{Bendix} \mathrm{Cl}^{-}$value agrees with the field value.

\section{Preliminary recommendation}

The samples are considered representative with respect to the major solutes and the UNC/Bendix major-solute results are recommended as explained above.

\subsubsection{H-12 Culebra (Table 85)}

The Culebra at H-12 was sampled twice by HGC in 1984 and during round one of the WQSP in 1985. It was sampled again during rounds two and three of the WQSP; the field and ITAS data are given in Randall et al. (1988) and Lyon (1989).

\section{4 samples}

UNC/Bendix analyzed the 1984 samples for HGC, and the analytical results for the two samples seem to be internally consistent. The two sets of results show good agreement except for $\mathrm{SO}_{4}^{=}$, which varies by a factor of two, 8400 versus $4000 \mathrm{mg} / \mathrm{L}$. This difference is not understood.

\section{5 samples (WQSP round one)}

UNC/Bendix, ITAS, and the EEG analyzed samples from the WQSP. All the data sets seem to show internal consistency. However, for reasons that are not yet known, the EEG results are consistently lower than those from UNC/Bendix. The ITAS $\mathrm{SO}_{4}^{\overline{ }}, \mathrm{Na}$, and $\mathrm{Mg}$ results are lower than those from UNC/Bendix, while the ITAS $\mathrm{K}$ result is slightly higher. Because the $\mathrm{UNC} / \mathrm{Bendix} \mathrm{Cl}^{-}$and $\mathrm{X}^{++}$results agree with the field data, the UNC/Bendix major-solute results are considered more reliable.

\section{Preliminary recommendations}

The major-solute contents of the 1984 and 1985 samples are comparable. The observed differences could be caused by analytical variation, or the 1984 samples might have been slightly contaminated. The WQSP samples are considered representative with respect to the major solutes, and the UNC/Bendix major-solute data are recommended. 


\subsubsection{P-14 Culebra (Table 86)}

The Culebra at P-14 was sampled by the USGS in 1977 and during round one of the WQSP in 1986. It was sampled again during rounds two and three of the WQSP; the field and ITAS laboratory data are given in Randall et al. (1988) and Lyon (1989).

\section{7 sample}

The USGS laboratory results for the 1977 sample seem to be internally consistent.

\section{6 samples (WQSP round one)}

UNC/Bendix, ITAS, and the EEG analyzed WQSP samples. The data sets seem to be internally consistent. The EEG K results are higher than those from the other labs. Major-solute results from all three laboratories, with the exception of the EEG $\mathrm{K}$ value, are considered reliable.

\section{Preliminary recommendations}

The USGS sample contained significantly more $\mathrm{Na}$ and $\mathrm{Cl}^{-}$than the WQSP samples, and its representativeness is questioned.

The WQSP samples are considered representative with respect to the major solutes, and the major-solute results from all three laboratories, with the exception of the EEG $\mathrm{K}$ value, are recommended.

\subsubsection{P-15 Culebra (Table 87)}

The Culebra at P-15 was sampled by the USGS in 1977 and 1979. The USGS laboratory data for the 1977 sample seem to be internally consistent, as do the SNL laboratory data for the 1979 sample. The 1979 sample contained significantly higher amounts of the major solutes than the 1977 samples. Lambert and Harvey (1987) suspected that the 1979 samples were contaminated; they are not considered representative. Because the representativeness of the 1977 sample cannot be evaluated, the USGS data should be used with caution.

\subsubsection{P-17 Culebra (Table 88)}

The Culebra at P-17 was sampled by the USGS in 1977 and during round one of the WQSP in 1986. It was sampled again during rounds two and three of the WQSP; the field and ITAS laboratory data are given in Uhland et al. (1987) and Randall et al. (1988).

\section{7 sample}

The USGS laboratory results for the 1977 sample seem to be internally consistent. 
1986 samples (WQSP round one)

UNC/Bendix, ITAS, and the EEG analyzed samples from the WQSP. All the data sets seem to be internally consistent and are in agreement, with a few exceptions. For reasons that are not understood, the EEG Na and $\mathrm{Cl}^{-}$results are slightly lower than those from the other two laboratories, and the ITAS $\mathrm{SO}_{4}^{\overline{ }}$ result is higher than the values reported by the other two other laboratories. Major-solute results from all three laboratories are considered reliable, except for the EEG Na and $\mathrm{Cl}^{-}$and the ITAS $\mathrm{SO}_{4}^{\overline{-}}$ results.

\section{Preliminary recommendations}

The USGS 1977 sample contained slightly less $\mathrm{SO}_{4} \overline{ }$ and $\mathrm{K}$ and slightly more $\mathrm{Cl}^{-}$than the WQSP samples. Lambert and Harvey (1987) suspected a packer leak and resulting contamination with water from the Rustler/Salado zone in this well. The 1977 sample is not considered representative.

The WQSP samples are considered representative with respect to the major solutes, and the major-solute results from all three laboratories, with the exceptions of the EEG Na and $\mathrm{Cl}^{-}$and the ITAS $\mathrm{SO}_{4}^{\bar{n}}$ results, are recommended.

\subsubsection{P-18 Culebra (Table 89)}

The Culebra at P-18 was sampled by the USGS in 1977. The USGS analyses seem to be internally consistent. However, Lambert and Harvey (1987) doubted the representativeness of the sample because of the extremely low productivity of the well. The sample is not considered representative.

\subsubsection{WIPP-25 Culebra (Table 90)}

The Culebra at WIPP-25 was sampled by the USGS and SNL in 1980 and during round one of the WQSP in 1986. It was sampled again during rounds two and three of the WQSP; the field and ITAS laboratory data are given in Randall et al. (1988) and Lyon (1989).

\section{0 samples}

The USGS laboratory data for their 1980 sample seem to be internally consistent, as do the UNC/Bendix data for SNL's 1980 sample. However, the USGS K value is apparently low by a factor of 100; this is attributed to a laboratory error (see Section 4.1.3).

\section{6 samples (WQSP round one)}

UNC/Bendix and ITAS analyzed samples from the WQSP. Both sets of results seem to be internally consistent and are in agreement with each other. Both sets of major-solute data are considered reliable. 


\section{Preliminary recommendations}

The USGS 1980 sample contained significantly more $\mathrm{Na}$ and $\mathrm{Cl}$ than the other samples, and its representativeness is doubted.

The 1980 SNL and 1986 WQSP samples were all thought to be representative of the groundwater at the time the samples were collected because the serial-sampling parameters had reached steady state in both cases. However, the 1986 samples contained $\sim 20 \%$ more $\mathrm{Cl}, \mathrm{Ca}$, and $\mathrm{Mg}$ and $\sim 40 \%$ more K than the 1980 samples. Some observations about the 1980 and 1986 tests follow.

- The 1980 samples were collected after $28 \mathrm{hr}$ of pumping at $33 \mathrm{gpm}$ (Lambert and Robinson, 1984), at which time $\sim 55,000$ gal of groundwater had been pumped from the well.

- The 1986 samples were collected after two weeks of pumping at seven gpm; more than 164,000 gal of water had been pumped before final sampling began (Uhland and Randall, 1986).

- Serial-sampling data from round two of the WQSP indicate that there is little or no difference between the round-one and round-two samples.

Any of the samples, from 1980 or from the WQSP, could be contaminated. Even though steady state was reached during the serial-sampling episodes, an apparent steady state could have been observed during the sampling of a large contamination plume.

At this time, the differences between SNL's 1980 samples and the WQSP samples cannot be explained. However, a future evaluation of all the existing data (including the minor and trace element data) plus additional data from the WQSP, coupled with a more detailed knowledge of the well's history, may lead to an understanding of these differences.

For SNL's 1980 sample, the UNC/Bendix data are recommended; for the WQSP round-one samples, the major solute data from UNC/Bendix and ITAS, as explained above, are considered reliable. However, all the data must be used with caution until the differences between SNL's 1980 samples and the WQSP samples are understood.

\subsubsection{WIPP-26 Culebra (Table 91)}

The Culebra at WIPP-26 was sampled by the USGS and SNL in 1980 and during round one of the WQSP in 1985. It was sampled again during rounds two and three of the WQSP; the field and ITAS laboratory data are given in Randall et al. (1988) and Lyon (1989).

\section{0 samples}

The USGS laboratory data for their 1980 sample seem to be internally consistent although the CBE is rather large (-6.7\%). The UNC/Bendix data for the 1980 SNL sample seem to be internally consistent. 


\section{5 samples (WQSP round one)}

UNC/Bendix, ITAS, and the EEG analyzed samples from the WQSP. All the data sets seem to be internally consistent. The UNC/Bendix and EEG data are in good agreement. The ITAS $\mathrm{Cl}^{-}$and $\mathrm{Ca}$ values are higher and the $\mathrm{SO}_{4}^{\overline{4}}$ value is lower than those from the other laboratories. Because the UNC/Bendix and EEG $\mathrm{Cl}^{-}$and $\mathrm{X}^{++}$results agree with the field values, the UNC/Bendix and EEG major-solute results are considered more reliable.

\section{Preliminary recommendations}

The 1980 USGS sample apparently contained significantly more $\mathrm{Cl}^{-}$than the $1980 \mathrm{SNL}$ sample. However, this value may be in error, which would explain the slightly large negative CBE (-6.7\%). The USGS K value is apparently low by a factor of 100 ; this is attributed to a laboratory error (see Section 4.1.3). The USGS sample was probably representative, but the use of the USGS data is not recommended because of the apparent errors in the $\mathrm{Cl}^{-}$and $\mathrm{K}$ data.

The 1980 SNL and 1985 WQSP samples were thought to be representative of the groundwater at the time the samples were collected because the serial-sampling parameters had reached steady state in both cases. However, the 1985 samples contained more $\mathrm{Cl}^{-}, \mathrm{Na}, \mathrm{K}$, and $\mathrm{X}^{++}$than the 1980 samples.

- The 1980 samples were collected after 26 hours of pumping at $\sim 34$ gpm (Lambert and Robinson, 1984), at which time $\sim 53000$ gal of groundwater had been pumped from the well.

- The 1985 samples were collected after the well had been initially purged for $61 \mathrm{hr}$ at 14.4 gpm and then pumped for eight days at $\sim 53 \mathrm{gph}$; more than 60,000 gal of water had been pumped from the well before final sampling began (Uhland and Randall, 1986).

- During round two of the WQSP in March and April 1987, pumping continued for nine days at $\sim 47 \mathrm{gph} \sim 9000 \mathrm{gal}$ of water were removed from the well. Data from the last serial sample indicated that chloride was $\sim 5800 \mathrm{mg} / \mathrm{L}(\sim 1400 \mathrm{mg} / \mathrm{L}$ lower than in 1980 and $\sim 3000 \mathrm{mg} / \mathrm{L}$ lower than in 1985$)$, divalent cations were $\sim 85 \mathrm{meq} / \mathrm{L}$ ( $\sim 6 \mathrm{meq} / \mathrm{L}$ lower than in 1980 and $~ 15 \mathrm{meq} / \mathrm{L}$ lower than in 1985), and sulfate and alkalinity were about the same as they had been in earlier years.

Any of the samples could be contaminated. Even though steady state was apparently reached during all the serial-sampling episodes, steady state could have been observed during the sampling of a large contamination plume. At this time, the differences between SNL's 1980 sample and the WQSP samples cannot be explained.

However, a further evaluation of all the data (including the minor and trace element data) plus additional data from the WQSP, coupled with a more detailed knowledge of the well's history, may lead to an understanding of these differences.

For the 1980 SNL sample, the UNC/Bendix major-solute data are recommended. For the WQSP samples, the UNC/Bendix and the EEG major-solute results are both considered reliable. 
However, because at this time the differences between the various sets of samples cannot be explained, all the data must be used with caution.

\subsubsection{WIPP-27 Culebra (Table 92)}

The Culebra at WIPP-27 was sampled by the USGS and SNL in 1980. The USGS laboratory data seem to be internally consistent. However, the $\mathrm{K}$ result appears to be low by a factor of $\sim 10$. This is attributed to a laboratory error (see Section 4.1.3). The UNC/Bendix results for the SNL sample also seem to be internally consistent. The two data sets are comparable, except for $\mathrm{K}$, as explained above. Both samples are considered representative with respect to the major solutes, and both sets of major-solute data are considered reliable, except for the USGS K value.

\subsubsection{WIPP-28 Culebra (Table 93)}

The Culebra at WIPP-28 was sampled by the USGS and SNL in 1980. The USGS results seem to be internally consistent. The $\mathrm{K}$ value, however, is thought to be low by a factor of $\sim 100$. This is attributed to a laboratory error (see Section 4.1.3). The UNC/Bendix results for the SNL sample also seem to be internally consistent. The USGS sample contained significantly more $\mathrm{Na}$ and $\mathrm{Cl}^{-}$and somewhat less $\mathrm{Mg}$ and $\mathrm{SO}_{4}^{-}$than the SNL sample. The representativeness of the USGS sample is doubted. The SNL sample is considered representative with respect to the major solutes, and the UNC/Bendix major-solute data are recommended. As was discussed in Section 3.3.2.2, the alkalinity was still dropping at the time of final sample collection, so a representative alkalinity value has not been obtained for the Culebra at WIPP-28.

\subsubsection{WIPP-29 Culebra (Table 94)}

The Culebra at WIPP-29 was sampled by the USGS and SNL in 1980 and during round one of the WQSP in 1985. It was sampled again during round two of the WQSP; the field and ITAS laboratory data are given in Randall et al. (1988).

\section{0 samples}

The USGS laboratory data seem to be internally consistent as do the UNC/Bendix data for the 1980 SNL sample. The data agree well, except for K. The USGS K value is thought to be low by a factor of $\sim 100$; this is attributed to a laboratory error (see Section 4.1.3). Both the UNC/Bendix and the USGS major-solute data are considered reliable except for the USGS K value.

\section{5 samples (WOSP round one)}

UNC/Bendix, ITAS, and the EEG analyzed samples from the WQSP. All the data sets seem to be internally consistent. For reasons that are not yet understood, the EEG $\mathrm{Cl}^{-}, \mathrm{Na}$, and $\mathrm{Mg}$ results are significantly lower than those of UNC/Bendix and ITAS; as a result, they are not recommended. The UNC/Bendix and ITAS results agree well for all the major solutes except $\mathrm{Ca}$, 
for which the ITAS value is $\sim 60 \%$ higher. The UNC/Bendix $\mathrm{Ca}$ value is recommended because the $\mathrm{Ca}$ spike recovery for this sample was $105 \%$; both the UNC/Bendix and ITAS data for the other major solutes are considered reliable.

\section{Preliminary recommendations}

The 1980 samples contained significantly less $\mathrm{Cl}^{-}, \mathrm{SO}_{4}^{\overline{ }}, \mathrm{Na}$, and $\mathrm{K}$, and significantly more $\mathrm{Ca}$ than the 1985 samples. However, all the samples are considered representative of the water at the time of collection and the differences are attributed to real changes in the water quality at this location. The top of the Culebra at WIPP-29 lies only 12 feet below ground level and the water quality is almost certainly affected by the inflow of surface water runoff and/or potash mining activities elsewhere in Nash Draw. For the 1980 samples, the UNC/Bendix and USGS majorsolute data are recommended (except for the USGS K value). For the 1985 samples, the UNC/Bendix and ITAS major-solute data are recommended (except for the ITAS Ca value).

\subsubsection{WIPP-30 Culebra (Table 95)}

The Culebra at WIPP-30 was sampled by the USGS and SNL in 1980. The USGS laboratory results seem to be internally consistent, as do the UNC/Bendix results for the SNL sample. However, the USGS sample contained significantly higher amounts of several solutes than the SNL sample. It is possible to account for this difference. The first SNL attempt at testing and sampling the Culebra at this site was abandoned because of unusual field geochemical results and hydrologic (drawdown) observations. The packer isolating the Culebra from the Rustler/Salado contact zone was removed from the well, found to be defective, and replaced (Lambert and Robinson, 1984). The test was repeated successfully. The USGS sample was collected when the defective packer was in use and was probably contaminated with Rustler/Salado water. The SNL sample is considered representative with respect to the major solutes, and the UNC/Bendix majorsolute results are recommended.

\subsubsection{Engle Well - Culebra (Table 96)}

The Culebra at Engle Well was sampled by HGC in 1983 and during round one of the WQSP in 1985. It was sampled again during the private well sampling portion of the WQSP; the field and ITAS laboratory data are given in Randall et al. (1988).

\section{3 sample}

Very few solute analyses were done on the 1983 sample; as a result, it is difficult to evaluate sample representativeness or the quality of the analytical data. However, the general agreement of the $\mathrm{Cl}^{-}$data from UNC/Bendix and the KGS with the $\mathrm{Cl}^{-}$data for the 1985 samples and the general agreement of data for several trace solutes with the data for the 1985 samples indicate there is no reason to doubt the representativeness of the 1983 samples. 


\section{5 samples (WQSP round one)}

UNC/Bendix and the EEG analyzed samples from the WQSP; ITAS did not determine major solutes in their sample. The UNC/Bendix and EEG data sets seem to be internally consistent. The two sets of data agree well, except that the EEG $\mathrm{Cl}^{-}$value is significantly lower than the $\mathrm{UNC} / \mathrm{Bendix}$ value, which agrees well with the field value. The $\mathrm{UNC} / \mathrm{Bendix} \mathrm{Cl}^{-}$value is considered more reliable; for other major solutes, data from both laboratories are considered reliable.

\section{Preliminary recommendations}

As explained above, there is not enough information to evaluate the analyses of the 1983 samples. However, there is no reason to doubt the representativeness of the 1983 samples.

The WQSP samples are considered representative with respect to the major solutes. The UNC/Bendix and EEG major-solute data, with the exception of the EEG $\mathrm{Cl}^{-}$value, are recommended.

\subsection{Preliminary Evaluation of Data from the Magenta Dolomite}

\subsubsection{H-1 Magenta (Table 97)}

The Magenta at H-1 was sampled by the USGS in 1976 and 1977. The USGS laboratory results for both samples seem to be internally consistent. Major solute contents for the two samples were comparable (but different); the $\mathrm{Mg}$ values differed by $\sim 50 \%$ and the $\mathrm{Cl}^{-}, \mathrm{SO}_{4}^{\overline{ }}, \mathrm{Na}$, and $\mathrm{Ca}$ values differed by less than $20 \%$. The $\mathrm{K}$ values differed by an order of magnitude. The observed differences between the major solutes could be caused by analytical variations; however, the samples might really have been different.

Because the well conditions and water production rates were different for the two sampling episodes, we cannot rule out the possibility that the samples were really different. In both cases, packers were used to isolate the Magenta from the lower stratigraphic zones. In June 1976, the well was open (not cased or screened) and after the zone was developed by swabbing, only $\sim 13$ gal of liquid were produced in $13.5 \mathrm{hr}$ of monitoring (Mercer and Orr, 1979). In May 1977, the well had been cased and the casing was perforated in the water-producing zones. The Magenta was described as "fairly productive" (Mercer and Orr, 1979).

Because we cannot evaluate the representativeness of either sample, the data should be used with caution. 


\subsubsection{H-2 Magenta (Table 98)}

The Magenta at H-2 (well H-2A) was sampled by the USGS in 1977. The USGS laboratory results seem to be internally consistent. Because we cannot evaluate the representativeness of this sample, which was collected by bailing or swabbing, the data should be used with caution.

\subsubsection{H-3 Magenta (Table 99)}

The Magenta at H-3 (well H-3B1) was sampled by the USGS in 1977 and 1979 and during round one of the WQSP in 1985. It was sampled again during rounds two and three of the WQSP; the field and ITAS laboratory data are given in Uhland et al. (1987) and Randall et al. (1988).

\section{7 and 1979 samples}

The USGS laboratory results for the 1977 sample seem to be internally consistent, as do SNL's laboratory results for the 1979 sample.

\section{5 samples (WQSP round one)}

UNC/Bendix and the EEG analyzed WQSP samples; ITAS did not determine major solutes in their sample. The UNC/Bendix and EEG results seem to be internally consistent. But for reasons that are not understood, the EEG results for the major solutes are slightly but consistently lower than the UNC/Bendix results. For several of the major solutes, the differences are no more than can be attributed to analytical variation. However, because the EEG results are all $\sim 10 \%$ lower than the UNC/Bendix results, rather than some being lower and some higher, and because the $\mathrm{UNC/Bendix} \mathrm{Cl}^{-}$and $\mathrm{X}^{++}$results agree more closely with the field results, the UNC/Bendix major-solute results are tentatively considered more reliable.

\section{Preliminary recommendations}

The 1977 and 1979 samples contained comparable quantities of the major solutes. They also contained significantly higher amounts of $\mathrm{Cl}^{-}, \mathrm{Na}, \mathrm{Mg}$, and $\mathrm{SO}_{4}^{-}$than the WQSP samples. The representativeness of the 1977 and 1979 samples is questioned.

The 1985 samples are considered representative with respect to the major solutes, and the UNC/Bendix major-solute data, as explained above, are recommended.

\subsubsection{H-4 Magenta (Table 100)}

The Magenta at H-4 was sampled by the USGS in $1978(\mathrm{H}-4 \mathrm{~A})$ and during round one of the WQSP in 1986 (H-4C). It was sampled again during rounds two and three of the WQSP; the field and ITAS laboratory data are given in Randall et al. (1988) and Lyon (1989). 
1978 samples

The USGS laboratory results for their 1978 sample seem to be internally consistent.

1986 samples (WOSP round one)

UNC/Bendix and ITAS analyzed WQSP samples. Both sets of data seem to be internally consistent. However, the ITAS results are consistently higher than the UNC/Bendix results; in addition, the calculated TDS concentration is slightly higher than their observed ROI. Because the $\mathrm{UNC} / B$ endix results for $\mathrm{Cl}^{-}$and $\mathrm{X}^{++}$values agree more closely with the field results, the $\mathrm{UNC} /$ Bendix major-solute data are tentatively considered more reliable.

\section{Preliminary recommendations}

The 1978 sample contained significantly less $\mathrm{Ca}$ and $\mathrm{Cl}^{-}$than the 1986 samples. Some differences in the two tests are noted here:

- The 1978 sample was collected from well H-4A, which was cased to the top of the Magenta but open in the Magenta.

- The 1986 samples were collected from well H-4C, which was cased and perforated in the Magenta; a packer was used to isolate the tested interval from the Culebra.

- The 1978 sample was collected after the well, H-4A, had been bailed to remove standing water (Mercer et al., 1981).

- The 1986 samples were collected after $\sim 700$ gal of water had been pumped from the well, H-4C, over a 7-day period (Uhland et al., 1987).

Although we usually use the achievement of steady state for the field parameters as an indicator of representativeness, several factors make that criterion perhaps inappropriate for the samples from H-4C. For the following reasons, the possibility that the 1986 sample from H-4C was contaminated by reaction with the cement cannot be ruled out at this time:

- $\mathrm{H}-4 \mathrm{C}$ was sampled at a very low pumping rate of $4 \mathrm{gph}$, which resulted in a fairly small volume of water being purged before sampling.

- The $\mathrm{H}-4 \mathrm{C}$ sample contained higher amounts of $\mathrm{Ca}$ and $\mathrm{Cl}^{-}$than the $\mathrm{H}-4 \mathrm{~A}$ sample collected from an open interval. Note that calcium chloride is a common component of cement mixtures and that the sample was collected from a cased and cemented interval.

Even though steady state was apparently achieved during serial sampling, steady state could have been observed during the sampling of a contamination plume. The USGS major-solute data for their 1978 sample and the UNC/Bendix major-solute data for their 1986 sample are considered analytically satisfactory. However, because the representativeness of the 1986 sample is questioned and because the representativeness of the USGS sample cannot be evaluated, all the data must be used with caution. Data from later rounds of the WQSP may help resolve these problems. 


\subsubsection{H-5 Magenta (Table 101)}

The Magenta at H-5 was sampled by the USGS in $1978(\mathrm{H}-5 \mathrm{~A})$ and during round one of the WQSP in 1986 (H-5C). It was sampled again during rounds two and three of the WQSP; the field and ITAS laboratory data are given in Lyon (1989).

\section{8 samples}

The USGS laboratory results seem to be internally consistent.

\section{6 samples (WQSP round one)}

UNC/Bendix and ITAS analyzed WQSP samples. Both sets of data seem to be internally consistent. However, the ITAS results are consistently higher than the UNC/Bendix results. In addition, ITAS's calculated TDS concentration is $\sim 25 \%$ higher than their ROI. Because the $\mathrm{UNC} / B$ Bendix $\mathrm{Cl}^{-}$and $\mathrm{X}^{++}$values agree more closely with the field results, the UNC/Bendix major-solute data are considered more reliable.

\section{Preliminary recommendations}

The 1978 sample contained significantly less $\mathrm{Ca}$ and somewhat less $\mathrm{Cl}^{-}$and $\mathrm{SO}_{4}^{\overline{-}}$ than the 1986 samples. Some differences in the two tests are noted here:

- The 1978 sample was collected from well H-5A, which was cased to the top of the Magenta but open in the Magenta (Dennehy and Mercer, 1982).

- The 1986 samples were collected from well H5C, which was cased and perforated in the Magenta; a packer was used to isolate the tested interval from the Culebra (Uhland et al., 1987).

- The 1978 sample was collected after the well, H-5A, had been bailed to remove standing water (Dennehy and Mercer, 1982).

- The 1986 samples were collected after $\sim 6200$ gal of water had been pumped from the well, H-5C, over a three-week period (Uhland et al., 1987).

Although we usually use the achievement of steady state for the field parameters as an indicator of representativeness, several factors make that criterion perhaps inappropriate for the samples from H-5C. For the following reason, the possibility that the 1986 samples from H-5C were contaminated by reaction with the cement cannot be ruled out at this time:

- The $\mathrm{H}-5 \mathrm{C}$ sample contained higher amounts of $\mathrm{Ca}$ and $\mathrm{Cl}^{-}$than the $\mathrm{H}-5 \mathrm{~A}$ sample from an open interval. Note that calcium chloride is a common component of cement mixtures and that the sample was collected from a cased and cemented interval.

Even though steady state was apparently achieved during serial sampling, steady state could have been observed during the sampling of a contamination plume.

The USGS major-solute data for their 1978 sample and the UNC/Bendix major-solute data for their 1986 sample are considered analytically satisfactory. However, because the 
representativeness of the 1986 sample is questioned and because the representativeness of the USGS sample cannot be evaluated, all the data must be used with caution. Data from later rounds of the WQSP may help resolve these problems.

\subsubsection{H-6 Magenta (Table102)}

The Magenta at H-6 was sampled by the USGS in $1978(\mathrm{H}-6 \mathrm{~A})$ and during round one of the WQSP in 1986 (H-6C). It was sampled again during rounds two and three of the WQSP; the field and ITAS laboratory data are given in Randall et al. (1988) and Lyon (1989).

\section{8 samples}

The USGS laboratory results seem to be internally consistent.

\section{6 samples (WQSP round one)}

UNC/Bendix and ITAS analyzed WQSP samples. The UNC/Bendix results seem to be internally consistent but the ITAS results have an unacceptably high CBE of $+19 \%$. The ITAS $\mathrm{Na}$ and $\mathrm{K}$ results are $\sim 60 \%$ higher than the UNC/Bendix results. The high $\mathrm{Na}$ is probably the cause of the large positive $\mathrm{CBE}$ and the reason for the calculated TDS being larger than the observed ROI. The UNC/Bendix major-solute results are considered more reliable.

\section{Preliminary recommendations}

The 1978 sample contained significantly more $\mathrm{Cl}^{-}, \mathrm{Na}$, and $\mathrm{K}$ than the 1986 samples, as a result; its representativeness is doubted. The 1986 samples are considered more likely to be representative and, as explained above, the UNC/Bendix major-solute results are recommended.

\subsubsection{H-8 Magenta (Table 103)}

The Magenta at H-8 (well H-8A) was sampled by the USGS in 1980 and during round one of the WQSP in 1985. The USGS laboratory results appear to be internally consistent. ITAS analyzed the WQSP sample, and their results also seem to be internally consistent.

The 1980 sample had $\sim 25 \%$ more calculated TDS than the WQSP sample; the individual major solutes ranged from $15 \%$ to $50 \%$ higher. During the 1985 sampling period, only 25 gal of water could be pumped from the well at $\sim 40 \mathrm{gph}$. Because of the low productivity of the well, the representativeness of both samples is questioned. Therefore the data should be used with extreme caution.

\subsubsection{H-9 Magenta (Table 104)}

The Magenta at H-9 (well H-9A) was sampled by the USGS in 1980. The USGS laboratory results seem to be internally consistent. However, because the representativeness of this sample, 
which was collected by bailing or swabbing, cannot be evaluated, the data should be used with caution.

\subsubsection{H-10 Magenta (Table 105)}

The Magenta at $\mathrm{H}-10$ (well $\mathrm{H}-10 \mathrm{~A}$ ) was sampled by the USGS in 1980 . The USGS laboratory results seem to be internally consistent. However, because the representativeness of this sample, which was collected by bailing or swabbing, cannot be evaluated, the data should be used with caution.

\subsubsection{WIPP-25 Magenta (Table 106)}

The Magenta at WIPP-25 was sampled by the USGS and SNL in 1980. The USGS laboratory data seem to be internally consistent, as do the UNC/Bendix data for the SNL sample. The USGS K value seems to be low by a factor of $\sim 100$, possibly because of a laboratory error (see Section 4.1.3).

Except for $\mathrm{K}$, both sets of results are comparable. The USGS Na and $\mathrm{Cl}^{-}$results are both slightly higher than the UNC/Bendix results. Although the difference could be attributed to normal analytical variation, because both $\mathrm{Na}$ and $\mathrm{Cl}^{-}$are high by the same amount, $\sim 10$ meq/L, the possibility of slight contamination of the USGS sample cannot be ruled out. The SNL sample is considered representative with respect to the major solutes, and the UNC/Bendix major-solute results are recommended.

\subsubsection{WIPP-27 Magenta (Table 107)}

The Magenta at WIPP-27 was sampled by the USGS and SNL in 1980. The USGS laboratory data seem to be internally consistent, as do the UNC/Bendix analyses of the SNL sample. The two sets of analyses are comparable; $\mathrm{SO}_{4}^{\overline{\bar{y}}}$ differs by $\sim 15 \%$ and $\mathrm{K}$ differs by $\sim 25 \%$. These differences can be attributed to analytical variations and/or error, rather than to real differences between the samples.

The USGS sample was probably representative, and the SNL sample is considered representative with respect to the major solutes. The UNC/Bendix major-solute results may be preferred by some users, because the SNL sample collection procedures and UNC/Bendix analytical procedures are better documented than the USGS procedures.

\subsubsection{WIPP-30 Magenta (Table 108)}

The Magenta at WIPP-30 was sampled by the USGS and SNL in 1980. The USGS laboratory results seem to be internally consistent. However, as was explained in Section 3.3.2.3, SNL was unable to obtain a representative sample at this location. 
Table 108 shows the USGS data and the field data from SNL's final serial sample. SNL's serial-sampling results for solutes that did not reach steady state are presented as upper limits.

To help evaluate the representativeness of the USGS sample, SNL's serial-sampling data for several parameters are shown in Table 109, along with the USGS laboratory data. Alkalinity is shown both as $\mathrm{HCO}_{3}^{-} / \mathrm{CO}_{3}^{-}$and as total meq/L. Because the $\mathrm{HCO}_{3}^{-} / \mathrm{CO}_{3}^{-}$ratio in a sample is a function of $\mathrm{pH}$ and because the determination of these two species involved titration to a fixed $\mathrm{pH}$ that was not necessarily the true equivalence point for each sample, the presentation of the data as total alkalinity in meq/L allows easier visualization of the variations in total alkalinity with time or other parameters, such as temperature.

The variations in the SNL field results occurred because of sample-collection circumstances. The depth to water in the well was measured with a steel tape sometime during the afternoon or evening of 4 December 1980 after serial sample three had been collected at 12:55 hr. Apparently this measurement dislodged some salts from the borehole casing and/or discharge pipe. These salts were then dissolved and flushed out of the well, the chlorides relatively rapidly and the sulfates more slowly. With a pumping rate of only $50 \mathrm{~mL} / \mathrm{min}$, the slow approach to steady state is not surprising.

SNL did not collect final samples and the SNL field data indicate that the USGS sample was probably not representative of the unperturbed groundwater either.

\subsection{Preliminary Evaluation of Data from the Rustler/Salado Contact Zone}

\subsubsection{H-1 Rustler/Salado (Table 110)}

The Rustler/Salado contact zone at H-1 was sampled by the USGS in 1977 . The USGS laboratory results seem to be internally consistent. However, because the representativeness of the sample, which was collected by bailing or swabbing, cannot be evaluated, the data should be used with caution.

\subsubsection{H-2 Rustler/Salado (Table 111)}

The Rustler/Salado contact zone at $\mathrm{H}-2$ (well H-2C) was sampled by the USGS in 1977. The USGS laboratory results seem to be internally consistent. However, because the representativeness of the sample, which was collected by bailing or swabbing, cannot be evaluated, the data should be used with caution.

\subsubsection{H-3 Rustler/Salado (Table 112)}

The Rustler/Salado contact zone at H-3 (well H-3B1) was sampled by the USGS in 1977. The USGS laboratory results seem to be internally consistent. However, because the 
representativeness of the sample, which was collected by bailing or swabbing, cannot be evaluated, the data should be used with caution.

\subsubsection{H-4 Rustler/Salado (Table 113)}

The Rustler/Salado contact zone at H-4 (well H-4C) was sampled by the USGS in 1979. Samples were analyzed by the USGS and SNL. Both sets of laboratory data seem to be internally consistent and the analytical results are comparable, except for $\mathrm{SO}_{4}^{=}$and $\mathrm{K}$. The $\mathrm{SNL}^{\mathrm{SO}}=$ result was a factor of two lower than the USGS result and the SNL K result was a factor of two higher than the USGS result. These differences are probably partly caused by analytical variation and/or error but could also partly be caused by sample instability or some other cause (for example, the samples could have been collected from different swabbing or bailing runs).

Because the reliability of the analyses cannot be evaluated, the results from both laboratories are tentatively considered equally reliable. However, because the representativeness of the samples cannot be evaluated, these data should be used with caution.

\subsubsection{H-5 Rustler/Salado (Table 114)}

The Rustler/Salado contact zone at H-5 (well H-5C) was sampled by the USGS in 1979. Samples were analyzed by the USGS and SNL. Both sets of laboratory data seem to be internally consistent but the SNL results are generally lower than the USGS results except for Na. This systematic difference may be caused mainly by sample instability, although analytical variation and/or error may also explain some of the differences. For example, the SNL sample could have lost some solutes as a result of precipitation, in which case the USGS results would be more accurate.

However, Dennehy and Mercer (1982) reported that these samples were collected before hydrologic testing because of the low productivity of the zone. The well was bailed dry, water from the Rustler/Salado contact zone was allowed to run into the well, and samples were collected with a stainless-steel sampling tool (Dennehy and Mercer, 1982). Under such conditions, if the samples sent to the two laboratories were from different sampling runs, then possibly the samples sent to the two laboratories were not identical. Dennehy and Mercer (1982) expressed concern about the quality of the samples and suggested that the data. be used with discretion.

Because Dennehy and Mercer (1982) had reservations about the quality of the samples, the data must be used with extreme caution.

\subsubsection{H-6 Rustler/Salado (Table 115)}

The Rustler/Salado contact zone at H-6 (well H-6C) was sampled by the USGS in 1979. Samples were analyzed by the USGS and SNL. Both sets of laboratory results seem to be internally consistent; the analytical results are comparable, except that $\mathrm{SNL}^{\mathrm{s}} \mathrm{SO}_{4}^{\overline{\bar{y}}}$ and $\mathrm{K}$ results 
are lower than the USGS results. These differences are probably partly caused by analytical variation and perhaps partly caused by sample instability or some other cause.

As the reliability of the analyses cannot be evaluated, both sets of data are tentatively considered equally reliable. However, because the representativeness of the samples cannot be evaluated, these data should be used with caution.

\subsubsection{H-7 Rustler/Salado (Table 116)}

The Rustler/Salado contact zone at H-7 (well H-7C) was sampled by the USGS in 1980. The USGS laboratory results seem to be internally consistent. However, because the representativeness of the sample, which was collected by bailing or swabbing, cannot be evaluated, the data should be used with caution.

\subsubsection{H-8 Rustler/Salado (Table 117)}

The Rustler/Salado contact zone at H-8 (well H-8C) was sampled by the USGS in 1980 . The USGS laboratory results seem to be internally consistent. However, because the representativeness of the sample, which was collected by bailing or swabbing, cannot be evaluated, the data should be used with caution.

\subsubsection{H-9 Rustler/Salado (Table 118 )}

The Rustler/Salado contact zone at H-9 (well H-9C) was sampled by the USGS in 1980 . The USGS laboratory results seem to be internally consistent. However, because the representativeness of the sample, which was collected by bailing or swabbing, cannot be evaluated, the data should be used with caution.

\subsubsection{H-10 Rustler/Salado (Table 119)}

The Rustler/Salado contact zone at H-10 (well H-10C) was sampled by the USGS in 1980. The USGS laboratory results seem to be internally consistent. However, because the representativeness of the sample, which was collected by bailing or swabbing, cannot be evaluated, the data should be used with caution.

\subsubsection{P-14 Rustler/Salado (Table 120)}

The Rustler/Salado contact zone at P-14 was sampled by the USGS in 1977. The USGS laboratory results seem to be internally consistent. However, because the representativeness of the sample, which was collected by bailing or swabbing, cannot be evaluated, the data should be used with caution. 


\subsubsection{P-15 Rustler/Salado (Table 121)}

The Rustler/Salado contact zone at P-15 was sampled by the USGS in 1979. Samples were analyzed by the USGS and SNL. Both sets of data seem to be internally consistent and the results are comparable; the differences may be attributed to analytical variations. If the samples were representative, use of both sets of data would be recommended. However, Lambert and Harvey (1987) indicated that the samples were probably contaminated with Culebra water from the same well. Therefore, the samples are not considered representative.

\subsubsection{P-17 Rustler/Salado (Table 122)}

The Rustler/Salado contact zone at P-17 was sampled by the USGS in 1979. Samples were analyzed by the USGS and SNL. Unfortunately, SNL's cation data have been lost. The USGS results seem to be internally consistent. The USGS and SNL $\mathrm{Cl}^{-}$results were the same; the SNL $\mathrm{SO}_{4}^{\overline{ }}$ result was a factor of two lower than the USGS result. The $\mathrm{SO}_{4}^{\overline{ }}$ difference may be caused by analytical error, sample instability, or some other cause. The USGS data are considered more reliable. However, because the representativeness of the samples cannot be evaluated, the USGS data should be used with caution.

\subsubsection{P-18 Rustler/Salado (Table 123)}

The Rustler/Salado contact zone at P-18 was sampled by the USGS in 1979. Samples were analyzed by the USGS and SNL. The analytical results were comparable; the difference may be attributed to analytical variations. If these samples were representative, the use of both sets of data would be recommended. However, Lambert and Harvey (1987) doubted the representativeness of the samples because of the low productivity of the well. The samples are not considered representative.

\subsubsection{WIPP-25 Rustler/Salado (Table 124)}

The Rustler/Salado contact zone at WIPP-25 was sampled by the USGS and SNL in 1980. The USGS laboratory results for their sample seem to be internally consistent, as do the UNC/Bendix results for the SNL sample. However, the USGS sample contained significantly less $\mathrm{Cl}^{-}, \mathrm{Na}$, and $\mathrm{K}$ than the SNL sample. The representativeness of the USGS sample is questioned. The SNL sample is tentatively considered representative with respect to the major solutes, and the UNC/Bendix major-solute data are recommended.

\subsubsection{WIPP-26 Rustler/Salado (Table 125)}

The Rustler/Salado contact zone at WIPP-26 was sampled by the USGS and SNL in 1980. The USGS laboratory results for their sample seem to be internally consistent, as do the UNC/Bendix results for the SNL sample. However, the USGS sample contained significantly less $\mathrm{Cl}^{-}$and $\mathrm{Na}$ and more Ca than the SNL sample. The representativeness of the USGS sample is 
questioned. The SNL sample is tentatively considered representative with respect to the major solutes, and the UNC/Bendix major-solute data are recommended.

\subsubsection{WIPP-27 Rustler/Salado (Table 126)}

The Rustler/Salado contact zone in WIPP-27 was sampled by the USGS and SNL in 1980. The USGS laboratory results seem to be internally consistent. However, SNL was unable to collect a representative sample at this site (see Section 3.3.2.1). As SNL's final serial-sampling results showed significantly less $\mathrm{Cl}^{-}$and more $\mathrm{X}^{++}$than the USGS final sample, the representativeness of the USGS sample is doubted. A representative sample of water from the Rustler/Salado contact zone in WIPP-27 has probably not been collected.

\subsubsection{WIPP-28 Rustler/Salado (Table 127)}

The Rustler/Salado contact zone at WIPP-28 was sampled by the USGS and SNL in 1980. The USGS laboratory results for their sample seem to be internally consistent, as do the UNC/Bendix results for the SNL sample. However, the USGS sample contained significantly lower amounts of the major solutes, except $\mathrm{Ca}$, than the SNL sample. The representativeness of the USGS sample is questioned. The SNL sample is tentatively considered representative with respect to the major solutes, and the UNC/Bendix major-solute data are recommended.

\subsubsection{WIPP-29 Rustler/Salado (Table 128)}

The Rustler/Salado contact zone at WIPP-29 was sampled by the USGS and SNL in 1980. The USGS laboratory results for their sample seem to be internally consistent, as do the UNC/Bendix results for the SNL sample. However, the USGS sample contained significantly lower amounts of the major solutes, except $\mathrm{SO}_{4}^{\bar{y}}$, than the $\mathrm{SNL}$ sample. The representativeness of the USGS sample is questioned. The SNL sample is tentatively considered representative with respect to the major solutes, and the UNC/Bendix major-solute data are recommended.

\subsubsection{WIPP-30 Rustler/Salado (Table 129)}

The Rustler/Salado contact zone at WIPP-30 was sampled by the USGS and SNL in 1980. The USGS laboratory results for their sample seem to be internally consistent, as do the UNC/Bendix results for the SNL sample. However, the USGS sample contained smaller amounts of the major solutes, except $\mathrm{Na}$, than the SNL sample. Although most of the observed differences could be caused by analytical variation, the possibility that the USGS sample was not representative cannot be ruled out. The SNL sample is tentatively considered representative with respect to the major solutes, and the UNC/Bendix major-solute data are recommended. 


\subsection{Preliminary Evaluation of Data from the Dewey Lake Red Beds}

\subsubsection{Pocket Well Dewey Lake (Table 130)}

Pocket Well was sampled by HGC in 1983 (see Section 3.5.2.6). The UNC/Bendix analytical results seem to be internally consistent. Two samples were sent to the KGS for halide analysis. The $\mathrm{Cl}^{-}, \mathrm{Br}^{-}$, and $\mathrm{I}^{-}$contents of one sample were 1.6 times higher than in the other sample; this difference is not understood. The lower $\mathrm{Cl}^{-}$value agrees with that obtained by UNC/Bendix. Except for the one apparently anomalously salty halide sample sent to the KGS, there is no reason to doubt the representativeness of the samples, which were collected after a five-day pumping test. However, because the sample-collection and analytical procedures are not very well documented, the data should be used with caution.

\subsubsection{Ranch Well Dewey Lake (Table 131)}

Ranch Well was sampled during round one of the WQSP in 1986. It was sampled again during the private well sampling portion of the WQSP; field and ITAS laboratory data are given in Randall et al. (1988) and Lyon (1989).

Round-one samples were analyzed by UNC/Bendix and ITAS. Both sets of data seem to be internally consistent and are in reasonable agreement. The results from both laboratories are considered reliable. The samples are thought to be representative with respect to the major solutes, and the major-solute results from UNC/Bendix and ITAS are recommended.

\subsubsection{Twin Wells/Pasture Well Dewey Lake (Table 132)}

The Twin Wells/Pasture Well was sampled during round one of the WQSP in 1986. It was sampled again during the private well sampling portion of the WQSP; field and ITAS laboratory data are given in Lyon (1989).

Round-one samples were analyzed by UNC/Bendix, ITAS, and the EEG. The UNC/Bendix results seem internally consistent if the field alkalinity, rather than the laboratory value, is used to calculate the CBE. The EEG results also seem internally consistent; the field alkalinity must be used to calculate the CBE because the laboratory alkalinity was not reported. The ITAS results are not internally consistent; the CBE is $-21 \%$ (even when alkalinity is included).

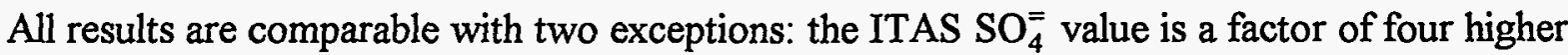
than the values reported by the other laboratories (and is probably the cause of the large negative $\mathrm{CBE}$ ) and the EEG Ca value seems to be $\sim 25 \%$ low. The results from all three laboratories are considered reliable with the exception of the ITAS $\mathrm{SO}_{4}^{-}$and $\mathrm{EEG} \mathrm{Ca}$ values.

The samples are considered representative with respect to the major solutes. The majorsolute results from all three laboratories are recommended, with the exceptions of the ITAS $\mathrm{SO}_{4}=$ and EEG $\mathrm{Ca}$ values. 


\subsubsection{Unger Well Dewey Lake (Table 133)}

Unger Well was sampled by HGC in 1984 (see Section 3.5.2.7). It was sampled again during the private well sampling portion of the WQSP; field and ITAS laboratory data are given in Randall et al. (1988) and Lyon (1989).

The UNC/Bendix solute data for the 1984 sample seem to be internally consistent. The UNC/Bendix $\mathrm{Cl}^{-}$result agrees with that obtained by the KGS in the sample sent for halide analysis. There is no reason to doubt the representativeness of the 1984 samples, which were collected after a lengthy pumping test. However, the data should be used with caution until they can be compared with the WQSP data.

\subsection{Preliminary Evaluation of Data from Other Formations}

\subsubsection{DOE-2 Bell Canyon (Table 134)}

The Hayes Sandstone member of the Bell Canyon Formation in DOE-2 was sampled by WQSP personnel in 1985. This location is not scheduled to be sampled again. Samples were analyzed by UNC/Bendix and the EEG; ITAS did not determine major solutes in their sample. The UNC/Bendix and EEG data sets seem to be internally consistent, but for reasons that are not understood, the EEG results are systematically lower that those of UNC/Bendix. Because the $\mathrm{UNC} / B$ endix $\mathrm{Cl}^{-}$and $\mathrm{X}^{++}$results agree more closely with the field data, the UNC/Bendix results are tentatively considered more reliable. The samples are thought to be representative with respect to the major solutes, and the UNC/Bendix major-solute results are recommended.

\subsubsection{WIPP-15 Alluvium (Table 135)}

WIPP-15 was sampled by the USGS in 1979. Water from this well is thought to come from the alluvium (Lambert and Harvey, 1987). SNL analyzed the sample; the laboratory results appear to be internally consistent. However, because the representativeness of the sample cannot be evaluated, the data should be used with caution.

\subsection{Summary}

\subsubsection{Representativeness of Samples}

In general, samples are considered representative with respect to the major solutes if serialsampling values for $\mathrm{Cl}^{-}$and $\mathrm{X}^{++}$reached steady state before the final samples were collected.

Representative samples have not been collected from certain locations, including the Culebra at $\mathrm{H}-2$, the Magenta at WIPP-30, the Rustler/Salado at WIPP-27, and possibly several other locations where the only samples were collected by bailing or swabbing. 
The representativeness of samples collected by bailing or swabbing must be considered doubtful, unless analyses of later samples are in close agreement with the analyses of the bailed or swabbed sample or until another method of verifying sample representativeness is developed.

At this time we do not understand the variations observed in samples collected at different times from the Culebra at WIPP-25 and WIPP-26 and from the Magenta at H-4 and H-5.

\subsubsection{Reliability of Analyses}

Given only a single set of laboratory analyses for a location, the analytical results are considered adequate if they seem to be internally consistent, but this does not mean that the sample was necessarily representative. Also, despite apparent internal consistency, some values may be in error. For example, many USGS potassium values are apparently in error by factors of $\sim 100$, although the small CBEs indicate apparent internal consistency. Thus, the tentative designation of "adequate" for a single set of results is subject to change if other data become available.

The UNC/Bendix analytical results are generally considered the most reliable. They show good precision, good spike recovery, small CBEs, and good agreement with the field results.

The EEG analyses are thought to be of high quality, as they show small CBE and usually good agreement with the field results. However, results for some samples vary systematically from both the field and the UNC/Bendix results. The cause of the variations has not yet been thoroughly investigated.

Similarly, much of the ITAS analytical work is thought to be of good quality. However, the results for some samples showed large CBEs and/or rather large differences for some solutes between the ITAS results and the results from the field and the UNC/Bendix and EEG laboratories. The differences noted between the ITAS results and the results from the other laboratories and the field are not all understood. But since the time this report was started, some of the differences have been investigated by personnel from the MOC and ITAS. Some analytical procedures used by ITAS were changed during round two of the WQSP, and the ITAS majorsolute results from rounds two and three (Uhland et al., 1987; Randall et al., 1988; Lyon, 1989) are tentatively thought to be reliable.

All minor and trace solute data must be used with extreme caution until the sample representativeness and quality of analyses for these analytes can be evaluated. 


\subsection{REFERENCES}

APHA (American Public Health Association). 1976a. "403 Alkalinity," Standard Methods For the Examination of Water and Wastewater. 14th ed. Washington, DC: American Public Health Association. 278-282. (Copy on file in the Sandia WIPP Central Files, Sandia National Laboratories, Albuquerque, NM as WPO\#44230.)

APHA (American Public Health Association). 1976b. "426 B. Molybdosilicate Method," Standard Methods For the Examination of Water and Wastewater. 14th ed. Washington, DC: American Public Health Association. 487-490. (Copy on file in the Sandia WIPP Central Files, Sandia National Laboratories, Albuquerque, NM as WPO\#44231.)

ASTM D859-68. "Standard Methods of Test for Silica in Industrial Water and Industrial Waste Water," Annual Book of ASTM Standards, Part 31 - Water. Standard D859-68. Philadelphia, PA: American Society for Testing and Materials. (Copy on file in the Sandia WIPP Central Files, Sandia National Laboratories, Albuquerque, NM as WPO\#44607.)

ASTM D1067-82. "Standard Test Methods for Acidity or Alkalinity of Water," Annual Book of ASTM Standards, Section 11 - Water and Environmental Technology, Volume 11.01 - Water(I). Standard D1067-82. Philadelphia, PA: American Society for Testing and Materials. (Copy on file in the Sandia WIPP Central Files, Sandia National Laboratories, Albuquerque, NM as WPO\#45666.)

ASTM D1246-82a. "Standard Test Methods for Iodide and Bromide in Water," Annual Book of ASTM Standards, Section 11 - Water and Environmental Technology, Volume 11.01 - Water(I). Standard D1246-82a. Philadelphia, PA: American Society for Testing and Materials. (Copy on file in the Sandia WIPP Central Files, Sandia National Laboratories, Albuquerque, NM as WPO\#44609.)

ASTM D1429-76. "Standard Test Methods for Specific Gravity of Water and Brine," Annual Book of ASTM Standards, Section 11 - Water and Environmental Technology, Volume 11.01 - Water(I). Standard D142976. Philadelphia, PA: American Society for Testing and Materials. (Superseded standard available from Southwest Center for Codes and Standards, New Mexico State University Library, Box 30006, Dept. 3475, Las Cruces, NM 88003-8006, 505/646-6834 as ASTM D1429-76.)

ASTM D3875-80. "Standard Test Method for Alkalinity in Brackish Water, Seawater, and Brines," Annual Book of ASTM Standards, Section 11 - Water and Environmental Technology, Volume 11.02 - Water(II). Standard D3875-80. Philadelphia, PA: American Society for Testing and Materials. (Copy on file in the Sandia WIPP Central Files, Sandia National Laboratories, Albuquerque, NM as WPO\#45670.)

Basel, C.L., J.D. Defreese, and D.O. Whittemore. 1982. "Interferences in Automated Phenol Red Method for Determination of Bromide in Water," Analytical Chemistry. Vol. 54, no. 12, 2090-2094.

Beauheim, R.L. 1987. Interpretation of the WIPP-13 Multipad Pumping Test of the Culebra Dolomite at the Waste Isolation Pilot Plant (WIPP) Site. SAND87-2456. Albuquerque, NM: Sandia National Laboratories.

Bendix Field Engineering Corporation. 1984. "Handbook of Analytical and Sample-Preparation Procedures." Revision 00 (March 1984). Grand Junction, CO: Bendix Field Engineering Corporation, Grand Junction Operations. (Copy on file in the Sandia WIPP Central Files, Sandia National Laboratories, Albuquerque, NM as WPO\#45672.)

Blaedel, W.J., and V.W. Meloche. 1963. Elementary Quantitative Analysis: Theory and Practice. 2nd ed. New York, NY: Harper \& Row. 303-308. (Pages on file in the Sandia WIPP Central Files, Sandia National Laboratories, Albuquerque, NM as WPO\#42885.) 
Bodine, M.W., Jr., and B.F. Jones. 1986. The Salt Norm: A Quantitative Chemical-Mineralogical Characterization of Natural Waters. Water-Resources Investigations Report 86-4086. Denver, CO: U.S. Geological Survey. (Copy on file in the Sandia WIPP Central Files, Sandia National Laboratories, Albuquerque, NM as WPO\#44175.)

Bodine, M.W., Jr., B.F. Jones, and S.J. Lambert. 1988. "Chapter 4: Normative Analysis of Groundwaters from the Rustler Formation Associated with the Waste Isolation Pilot Plant, Southeastern New Mexico," Hydrogeochemical Studies of the Rustler Formation and Related Rocks in the Waste Isolation Pilot Plant Area, Southeastern New Mexico. Eds. M.D. Siegel, S.J. Lambert, and K.L. Robinson. SAND88-0196. Albuquerque, NM: Sandia National Laboratories. 4-1 through 4-140.

Brown, E., M.W. Skougstad, and M.J. Fishman. 1970. Methods for Collection and Analysis of Water Samples for Dissolved Minerals and Gases. Techniques of Water-Resources Investigations of the United States Geological Survey, Book 5, Chapter A1. Washington, DC: U.S. Government Printing Office. 160 pp. (Copy on file in the Sandia WIPP Central Files, Sandia National Laboratories, Albuquerque, NM as WPO\#44408.)

Caulcutt, R., and R. Boddy. 1983. Statistics for Analytical Chemists. London; New York: Chapman and Hall.

Chapman, J.B. 1988. Chemical and Radiochemical Characteristics of Groundwater in the Culebra Dolomite, Southeastern New Mexico. EEG-39. Santa Fe, NM: Environmental Evaluation Group, Environmental Improvement Division, Health and Environment Department. (Copy on file in the Sandia WIPP Central Files, Sandia National Laboratories, Albuquerque, NM as WPO\#41223.)

Collins, A.G. 1975. Geochemistry of Oilfield Waters. New York, NY: Elsevier Scientific Publishing Company. Chapter 2.

Colton, I.D., and J. Morse. 1985. Water Quality Sampling Plan. WIPP-DOE-215. Carlsbad, NM: Westinghouse Electric Corporation. (Copy on file in the Sandia WIPP Central Files, Sandia National Laboratories, Albuquerque, NM as WPO\#44044.)

Cooley, M.E. 1973. "Ground-Water Hydrology," Salt Deposits of the Los Medaños Area, Eddy and Lea Counties, New Mexico, With Sections on Ground Water Hydrology and Surficial Geology. Open-File Report USGS4339-7. [Denver, CO]: United States Department of the Interior, Geological Survey. 41-56. (USGS-4339-7 is on file in the Sandia WIPP Central Files, Sandia National Laboratories, Albuquerque, NM as WPO\#43835.)

Cooper, J.B., and V.M. Glanzman. 1971. Geohydrology of Project Gnome Site, Eddy County, New Mexico. U.S. Geological Survey Professional Paper 712-A. Washington, DC: United States Government Printing Office. (Copy on file in the Sandia WIPP Central Files, Sandia National Laboratories, Albuquerque, NM as WPO\#41278.)

Dennehy, K.F. 1982. Results of Hydrologic Tests and Water-Chemistry Analyses, Wells H-6A, H-6B, and H-6C, at the Proposed Waste Isolation Pilot Plant Site, Southeastern New Mexico. Water-Resources Investigations Report 82-8. Albuquerque, NM: U.S. Geological Survey. (Copy on file in the Sandia WIPP Central Files, Sandia National Laboratories, Albuquerque, NM as WPO\#42623.)

Dennehy, K.F., and J.W. Mercer. 1982. Results of Hydrologic Tests and Water-Chemistry Analyses, Wells H-5A, H-5B, and H-5C, at the Proposed Waste Isolation Pilot Plant Site, Southeastern New Mexico. WaterResources Investigations Report 82-19. Albuquerque, NM: U.S. Geological Survey. (Copy on file in the Sandia WIPP Central Files, Sandia National Laboratories, Albuquerque, NM as WPO\#42332.)

Drellack, S.L., Jr., and J.G. Wells. 1982a. Geologic and Well-Construction Data for the H-7 Borehole Complex Near the Proposed Waste Isolation Pilot Plant Site, Southeastern New Mexico. Water-Resources 
Investigations Report 82-38. Albuquerque, NM: U.S. Geological Survey. (Copy on file in the Sandia WIPP Central Files, Sandia National Laboratories, Albuquerque, NM as WPO\#42437.)

Drellack, S.L., Jr., and J.G. Wells. 1982b. Geologic and Well-Construction Data for the H-9 Borehole Complex Near the Proposed Waste Isolation Pilot Plant Site, Southeastern New Mexico. Water-Resources Investigations Report 82-4111. Albuquerque, NM: U.S. Geological Survey. (Copy on file in the Sandia WIPP Central Files, Sandia National Laboratories, Albuquerque, NM as WPO\#42314.)

Drever, J.I. 1982. The Geochemistry of Natural Waters. Englewood Cliffs, NJ: Prentice-Hall, Inc.

Freeland, M.H. 1982. Basic Data Report for Borehole DOE-1 Waste Isolation Pilot Plant (WIPP) Project Southeastern New Mexico. Report TME-3159. Albuquerque, NM: U.S. Department of Energy, Waste Isolation Pilot Plant. (Copy on file in the Sandia WIPP Central Files, Sandia National Laboratories, Albuquerque, NM as WPO\#42668.)

Grobenski, Z., D. Weber, B. Welz, and J. Wolff. 1983. "Determination of Cs and Rb by Flame and Furnace Atomic-Adsorption Spectrometry," The Analyst, The Analytical Journal of the Royal Society of Chemistry. Vol. 108, no. 1289, 925-932. (Copy on file in the Sandia WIPP Central Files, Sandia National Laboratories, Albuquerque, NM as WPO\#44236.)

HGC (Hydro Geo Chem, Inc.). 1984. “Appendix E Water Quality Sampling Criteria for Pumped Wells," WIPP Hydrology Program, Waste Isolation Pilot Plant, SENM Hydrologic Data Report \#1. SAND85-7206. Albuquerque, NM: Sandia National Laboratories. 529-571. (Revision of July 23, 1984 contractor report to Sandia National Laboratories.)

HGC (Hydro Geo Chem, Inc.). 1985. WIPP Hydrology Program, Waste Isolation Pilot Plant, SENM Hydrologic Data Report \#1. SAND85-7206. Albuquerque, NM: Sandia National Laboratories.

HGC (Hydro Geo Chem, Inc.). 1986. Two-Well Recirculation Tracer Tests at the H-2 Hydropad, Waste Isolation Pilot Plant (WIPP), Southeastern New Mexico. SAND86-7092. Albuquerque, NM: Sandia National Laboratories.

Intera Technologies, Inc. 1986. WIPP Hydrology Program, Waste Isolation Pilot Plant, Southeastern New Mexico, Hydrologic Data Report \#3. SAND86-7109. Albuquerque, NM: Sandia National Laboratories.

Intera Technologies, Inc. and Hydro Geo Chem, Inc. 1985. WIPP Hydrology Program, Waste Isolation Pilot Plant, Southeastern New Mexico, Hydrologic Data Report \#2. SAND85-7263. Albuquerque, NM: Sandia National Laboratories.

Jones, C.L. 1978. Test Drilling for Potash Resources: Waste Isolation Pilot Plant Site, Eddy County, New Mexico. Open-File Report 78-592. Denver, CO: U.S. Geological Survey. Vols. 1-2. (Copy on file in the Sandia WIPP Central Files, Sandia National Laboratories, Albuquerque, NM as WPO\#43108.)

Kaufmann, R.S. 1984. "Chloride in Groundwater: Stable Isotope Distribution." Ph.D. dissertation. Tucson, AZ: University of Arizona. (Copy on file in the Sandia WIPP Central Files, Sandia National Laboratories, Albuquerque, NM as WPO\#46565.)

Keith, L.H., W. Crummett, J. Deegan, Jr., R.A. Libby, J.K. Taylor, and G. Wentler. 1983. "Principles of Environmental Analysis," Analytical Chemistry. Vol. 55, no. 14, 2210-2218.

Kell, G.S. 1968. "Volume Properties of Ordinary Water," CRC Handbook of Chemistry and Physics. 49th ed. Ed. R.C. Weast. Boca Raton, FL: CRC Press. p. F-5. (Copy of page on file in the Sandia WIPP Central Files, Sandia National Laboratories, Albuquerque, NM as WPO\#45665.) 
Lambert, S.J. 1987. Feasibility Study: Applicability of Geochronologic Methods Involving Radiocarbon and Other Nuclides to the Groundwater Hydrology of the Rustler Formation, Southeastern New Mexico. SAND861054. Albuquerque, NM: Sandia National Laboratories.

Lambert, S.J., and J.A. Carter. 1987. Uranium-Isotope Systematics in Groundwaters of the Rustler Formation, Northern Delaware Basin, Southeastern New Mexico. I: Principles and Preliminary Results. SAND870388. Albuquerque, NM: Sandia National Laboratories.

Lambert, S.J., and D.M. Harvey. 1987. Stable-Isotope Geochemistry of Groundwaters in the Delaware Basin of Southeastern New Mexico. SAND87-0138. Albuquerque, NM: Sandia National Laboratories.

Lambert, S.J., and K.L. Robinson. 1984. Field Geochemical Studies of Groundwaters in Nash Draw, Southeastern New Mexico. SAND83-1122. Albuquerque, NM: Sandia National Laboratories.

Lyon, M.L. 1989. Annual Water Quality Data Report for the Waste Isolation Pilot Plant. DOE/WIPP 89-001. Carlsbad, NM: Westinghouse Electric Corporation. (Copy on file in the Sandia WIPP Central Files, Sandia National Laboratories, Albuquerque, NM as WPO\#42889.)

Meijer, A.J., J.L. Lolcama, and F.J. Pearson. 1987. "Appendix E: Consistency of Densities and Chemical Compositions of Water Samples from the Culebra Dolomite," Modeling of Ground-Water Flow in the Culebra Dolomite at the Waste Isolation Pilot Plant (WIPP) Site: Interim Report. A. Haug, V.A. Kelley, A.M. LaVenue, and J.F. Pickens. SAND86-7167. Albuquerque, NM: Sandia National Laboratories. E-1 through E-30.

Mercer, J.W. 1983. Geohydrology of the Proposed Waste Isolation Pilot Plant Site, Los Medaños Area, Southeastern New Mexico. Water-Resources Investigations Report 83-4016. Albuquerque, NM: U.S. Geological Survey. (Copy on file in the Sandia WIPP Central Files, Sandia National Laboratories, Albuquerque, NM as WPO\#42430.)

Mercer, J.W., and B.R. Orr. 1979. Interim Data Report on the Geohydrology of the Proposed Waste Isolation Pilot Plant Site, Southeast New Mexico. Water-Resources Investigations Report 79-98. Albuquerque, NM: U.S. Geological Survey. (Copy on file in the Sandia WIPP Central Files, Sandia National Laboratories, Albuquerque, NM as WPO\#42431.)

Mercer, J.W., P. Davis, K.F. Dennehy, and C.L. Goetz. 1981. Results of Hydrologic Tests and Water-Chemistry Analyses, Wells $H-4 A, H-4 B$, and $H-4 C$ at the Proposed Waste Isolation Pilot Plant Site, Southeastern New Mexico. Water-Resources Investigations Report 81-36. Albuquerque, NM: U.S. Geological Survey. (Copy on file in the Sandia WIPP Central Files, Sandia National Laboratories, Albuquerque, NM as WPO\#42987.)

Mercer, J.W., R.L. Beauheim, R.P. Snyder, and G.M. Fairer. 1987. Basic Data Report for Drilling and Hydrologic Testing of Drillhole DOE-2 at the Waste Isolation Pilot Plant (WIPP) Site. SAND86-0611. Albuquerque, NM: Sandia National Laboratories.

Natrella, M.G. 1966. Experimental Statistics. National Bureau of Standards Handbook 91. Reprinted October 1966 with corrections. Washington, DC: U.S. Department of Commerce, National Bureau of Standards; For sale by the Superintendent of Documents, U.S. Government Printing Office. (Copy of cited pages on file in the Sandia WIPP Central Files, Sandia National Laboratories, Albuquerque, NM as WPO\#44652.)

Orion Research. 1981. "Chloride in Drinking Water, Wastewaters, and Brines." Application Information Procedure No. 507. Cambridge, MA: Orion Research. (Copy on file in the Sandia WIPP Central Files, Sandia National Laboratories, Albuquerque, NM as WPO\#45671.)

Powers, D.W., S.J. Lambert, S-E. Shaffer, L.R. Hill, and W.D. Weart, eds. 1978. Geological Characterization Report, Waste Isolation Pilot Plant (WIPP) Site, Southeastern New Mexico. SAND78-1596. Albuquerque, NM: Sandia National Laboratories. 
Randall, W.S., M.E. Crawley, and M.L. Lyon. 1988. 1988 Annual Water Quality Data Report for the Waste Isolation Pilot Plant. DOE-WIPP-88-006. Carlsbad, NM: Westinghouse Electric Corporation for the U.S. Department of Energy. (Copy on file in the Sandia WIPP Central Files, Sandia National Laboratories, Albuquerque, NM as WPO\#43850.)

Richey, S.F. 1986. Hydrologic-Test Data from Wells at Hydrologic-Test Pads $\mathrm{H}-7, \mathrm{H}-8, \mathrm{H}-9$, and $\mathrm{H}-10 \mathrm{Near}$ the Proposed Waste Isolation Pilot Plant Site, Southeastern New Mexico. Open File Report 86-413. Albuquerque, NM: U.S. Geological Survey. (Copy on file in the Sandia WIPP Central Files, Sandia National Laboratories, Albuquerque, NM as WPO\#44409.)

Richey, S.F. 1987. Preliminary Hydrologic Data for Wells Tested in Nash Draw, Near the Proposed Waste Isolation Pilot Plant Site, Southeastern New Mexico. Open File Report 87-37. Albuquerque, NM: U.S. Geological Survey. (Copy on file in the Sandia WIPP Central Files, Sandia National Laboratories, Albuquerque, NM as WPO\#44411.)

Sandia National Laboratories and United States Geological Survey. 1979a. Basic Data Report for Drillhole WIPP 25 (Waste Isolation Pilot Plant - WIPP). SAND79-0279. Albuquerque, NM: Sandia National Laboratories.

Sandia National Laboratories and United States Geological Survey. 1979b. Basic Data Report for Drillhole WIPP 26 (Waste Isolation Pilot Plant - WIPP). SAND79-0280. Albuquerque, NM: Sandia National Laboratories.

Sandia National Laboratories and United States Geological Survey. 1979c. Basic Data Report for Drillhole WIPP 27 (Waste Isolation Pilot Plant - WIPP). SAND79-0281. Albuquerque, NM: Sandia National Laboratories.

Sandia National Laboratories and United States Geological Survey. 1979d. Basic Data Report for Drillhole WIPP 28 (Waste Isolation Pilot Plant - WIPP). SAND79-0282. Albuquerque, NM: Sandia National Laboratories.

Sandia National Laboratories and United States Geological Survey. 1979e. Basic Data Report for Drillhole WIPP 29 (Waste Isolation Pilot Plant - WIPP). SAND79-0283. Albuquerque, NM: Sandia National Laboratories.

Sandia National Laboratories and United States Geological Survey. 1980. Basic Data Report for Drillhole WIPP 30 (Waste Isolation Pilot Plant - WIPP). SAND79-0284. Albuquerque, NM: Sandia National Laboratories.

Sandia National Laboratories and University of New Mexico. 1981. Basic Data Report for Drillhole WIPP 15 (Waste Isolation Pilot Plant - WIPP). SAND79-0274. Albuquerque, NM: Sandia National Laboratories.

Seward, P.D., comp. 1982. Abridged Borehole Histories for the Waste Isolation Pilot Plant (WIPP) Studies. SAND82-0080. Albuquerque, NM: Sandia National Laboratories.

Smith, C.L. 1981. Analysis of Bromine in Brines Using Energy Dispersive X-Ray Fluorescence. Open-File Report 81-750. U.S. Geological Survey Saudi Arabian Mission Miscellaneous Document 28 (Interagency Report 364). Jiddah, Saudi Arabia: U.S. Geological Survey. (Copy on file in the Sandia WIPP Central Files, Sandia National Laboratories, Albuquerque, NM as WPO\#44174.)

Snyder, R.P. 1985. Dissolution of Halite and Gypsum, and Hydration of Anhydrite to Gypsum, Rustler Formation, in the Vicinity of the Waste Isolation Pilot Plant, Southeastern New Mexico. Open File Report 85-229. Denver, CO: U.S. 'Geological Survey. (Copy on file in the Sandia WIPP Central Files, Sandia National Laboratories, Albuquerque, NM as WPO\#42985.)

Stumm, W., and J.J. Morgan. 1981. Aquatic Chemistry. 2nd ed. New York, NY: John Wiley \& Sons, Inc.

Uhland, D.W., and W.S. Randall. 1986. 1986 Annual Water Quality Data Report for the Waste Isolation Pilot Plant. DOE-WIPP-86-006. Carlsbad, NM: Westinghouse Electric Corporation. (Copy on file in the Sandia WIPP Central Files, Sandia National Laboratories, Albuquerque, NM as WPO\#44177.) 
Uhland, D.W., W.S. Randall, and R.C. Carrasco. 1987. 1987 Annual Water Quality Data Report for the Waste Isolation Pilot Plant. DOE-WIPP-87-006. Carlsbad, NM: Westinghouse Electric Corporation. (Copy on file in the Sandia WIPP Central Files, Sandia National Laboratories, Albuquerque, NM as WPO\#44161.)

Warner, T.B. 1971. "Normal Fluoride Content of Seawater," Deep-Sea Research. Vol. 18, no. 12, 1255-1263. (Copy on file in the Sandia WIPP Central Files, Sandia National Laboratories, Albuquerque, NM as WPO\#44070.)

WP 7-2. 1987. "Waste Isolation Pilot Plant Water Quality Sampling Manual." WP 7-2 Revision 1. [Carlsbad, NM]: Waste Isolation Pilot Plant. (Copy on file in the Sandia WIPP Central Files, Sandia National Laboratories, Albuquerque, NM as WPO\#45673.)

Wells, J.G., and S.L. Drellack, Jr. 1982. Geologic and Well-Construction Data for the H-8 Borehole Complex Near the Proposed Waste Isolation Pilot Plant Site, Southeastern New Mexico. USGS Water-Resources Investigations Report 82-4118. Albuquerque, NM: U.S. Geological Survey. (Copy on file in the Sandia WIPP Central Files, Sandia National Laboratories, Albuquerque, NM as WPO\#42891.)

Wells, J.G., and S.L. Drellack, Jr. 1983. Geologic and Well-Construction Data for the H-10 Borehole Complex Near the Proposed Waste Isolation Pilot Plant Site, Southeastern New Mexico. USGS Water-Resources Investigations Report 83-4124. Albuquerque, NM: U.S. Geological Survey. (Copy on file in the Sandia WIPP Central Files, Sandia National Laboratories, Albuquerque, NM as WPO\#43199.)

Winstanley, D.J., and R.C. Carrasco. 1986. Annual Hydrogeologic Data Report: 1985/1986 for the Waste Isolation Pilot Plant. DOE-WIPP-86-004. Carlsbad, NM: Westinghouse Electric Corporation. (Copy on file in the Sandia WIPP Central Files, Sandia National Laboratories, Albuquerque, NM as WPO\#44176.) 
Table 1. List of Wells and Zones Sampled by the WQSP, HGC, SNL, and/or the USGS from 1976 to 1986 (WIPP wells are listed first, alphabetically, followed by the stock wells.)

\begin{tabular}{|c|c|c|c|c|}
\hline Well Name ${ }^{1}$ & Abbrev ${ }^{2}$ & Synonyms ${ }^{3}$ & Zones $^{4}$ & $\operatorname{Refs}^{5}$ \\
\hline DOE-1 & DOE-1 & & $\mathrm{Cul}$ & $\mathrm{b}, \mathrm{w}$ \\
\hline DOE-2 & DOE-2 & DOE-II & $\mathrm{Cul}, \mathrm{BC}$ & $\mathrm{j}, \mathrm{w}$ \\
\hline FR-10 & FR-10 & $\mathrm{H}-13, \mathrm{RF}-10^{6}$ & Cul & -- \\
\hline $\mathrm{H}-1$ & $\mathrm{H}-1$ & & Mag,Cul,RS & $\mathrm{i}, 1, \mathrm{t}, \mathrm{w}$ \\
\hline $\begin{array}{l}H-2 A \\
H-2 B 1 \\
H-2 C\end{array}$ & $\begin{array}{l}\mathrm{H}-2 \mathrm{~A} \\
\mathrm{H}-2 \mathrm{~B} 1 \\
\mathrm{H}-2 \mathrm{C}\end{array}$ & $\mathrm{H}-2 \mathrm{~B}^{7}$ & $\begin{array}{l}\text { Mag,Cul } \\
\text { Cul } \\
\text { Cul,RS }\end{array}$ & $\begin{array}{l}g, i, 1, t, w \\
i, 1, t, w \\
i, 1, t, w\end{array}$ \\
\hline $\begin{array}{l}\text { H-3B1 } \\
\text { H-3B2 } \\
\text { H-3B3 }\end{array}$ & $\begin{array}{l}\text { H-3B1 } \\
\text { H-3B2 } \\
\text { H-3B3 }\end{array}$ & $\mathrm{H}-3, \mathrm{H}-3 \mathrm{~A}, \mathrm{H}-3 \mathrm{~B}^{8}$ & $\begin{array}{l}\text { Mag,Cul,RS } \\
\text { Cul } \\
\text { Cul }\end{array}$ & $\begin{array}{l}\mathrm{i}, 1, \mathrm{t}, \mathrm{w} \\
\mathrm{g}, \mathrm{w} \\
\mathrm{g}, \mathrm{w}\end{array}$ \\
\hline $\begin{array}{l}\mathrm{H}-4 \mathrm{~A} \\
\mathrm{H}-4 \mathrm{~B} \\
\mathrm{H}-4 \mathrm{C}\end{array}$ & $\begin{array}{l}\mathrm{H}-4 \mathrm{~A} \\
\mathrm{H}-4 \mathrm{~B} \\
\mathrm{H}-4 \mathrm{C}\end{array}$ & & $\begin{array}{l}\text { Mag } \\
\text { Cul } \\
\text { Mag,Cul,RS }\end{array}$ & $\begin{array}{l}i, k, t, w \\
i, k, t, w \\
i, k, t, w\end{array}$ \\
\hline $\begin{array}{l}H-5 A \\
H-5 B \\
H-5 C\end{array}$ & $\begin{array}{l}\mathrm{H}-5 \mathrm{~A} \\
\mathrm{H}-5 \mathrm{~B} \\
\mathrm{H}-5 \mathrm{C}\end{array}$ & & $\begin{array}{l}\text { Mag } \\
\text { Cul } \\
\text { Mag,Cul,RS }\end{array}$ & $\begin{array}{l}d, i, t, w \\
d, i, t, w \\
d, i, t, w\end{array}$ \\
\hline $\begin{array}{l}H-6 A \\
H-6 B \\
H-6 C\end{array}$ & $\begin{array}{l}H-6 A \\
H-6 B \\
H-6 C\end{array}$ & & $\begin{array}{l}\text { Mag } \\
\text { Cul } \\
\text { Mag,Cul,RS }\end{array}$ & $\begin{array}{l}c, i, t, w \\
c, i, t, w \\
c, i, t, w\end{array}$ \\
\hline $\begin{array}{l}\mathrm{H}-7 \mathrm{~B} 1 \\
\mathrm{H}-7 \mathrm{C}\end{array}$ & $\begin{array}{l}\text { H-7B1 } \\
\text { H-7C }\end{array}$ & $\mathrm{H}-7 \mathrm{~B}^{9}$ & $\begin{array}{l}\text { Cul } \\
\text { RS }\end{array}$ & $\begin{array}{l}e, i, t, w \\
e, i, t, w\end{array}$ \\
\hline $\begin{array}{l}H-8 A \\
H-8 B \\
H-8 C\end{array}$ & $\begin{array}{l}\mathrm{H}-8 \mathrm{~A} \\
\mathrm{H}-8 \mathrm{~B} \\
\mathrm{H}-8 \mathrm{C}\end{array}$ & & $\begin{array}{l}\text { Mag } \\
\text { Cul } \\
\text { RS }\end{array}$ & $\begin{array}{l}\mathrm{i}, \mathrm{t}, \mathrm{u}, \mathrm{w} \\
\mathrm{i}, \mathrm{t}, \mathrm{u}, \mathrm{w} \\
\mathrm{i}, \mathrm{t}, \mathrm{u}, \mathrm{w}\end{array}$ \\
\hline $\begin{array}{l}H-9 A \\
H-9 B \\
H-9 C\end{array}$ & $\begin{array}{l}\mathrm{H}-9 \mathrm{~A} \\
\mathrm{H}-9 \mathrm{~B} \\
\mathrm{H}-9 \mathrm{C}\end{array}$ & & $\begin{array}{l}\text { Mag } \\
\text { Cul } \\
\text { RS }\end{array}$ & $\begin{array}{l}f, g, i, t, w \\
f, i, t, w \\
f, i, t, w\end{array}$ \\
\hline $\begin{array}{l}H-10 A \\
H-10 B \\
H-10 C\end{array}$ & $\begin{array}{l}\text { H-10A } \\
\text { H-10B } \\
\text { H-10C }\end{array}$ & & $\begin{array}{l}\text { Mag } \\
\text { Cul } \\
\text { RS }\end{array}$ & $\begin{array}{l}i, t, v, w \\
i, t, v, w \\
i, t, v, w\end{array}$ \\
\hline $\mathrm{H}-11 \mathrm{~B} 3$ & H-11B3 & & $\mathrm{Cul}$ & $g, w$ \\
\hline $\mathrm{H}-12$ & $\mathrm{H}-12$ & & Cul & $\mathrm{g}, \mathrm{w}$ \\
\hline P-14 & P-14 & & Cul,RS & $h, i, 1, t, w$ \\
\hline P-15 & P-15 & & Cul,RS & $h, i, l, t, w$ \\
\hline P-17 & P-17 & & Cul,RS & $h, i, 1, t, w$ \\
\hline P-18 & P-18 & & Cul, RS & $\mathrm{h}, \mathrm{i}, 1, \mathrm{t}, \mathrm{w}$ \\
\hline WIPP-15 & W-15 & & Alluvium & $\mathrm{i}, \mathrm{s}, \mathrm{t}$ \\
\hline WIPP-25 & $\mathrm{W}-25$ & & Mag,Cul,RS & $\mathrm{i}, \mathrm{m}, \mathrm{t}, \mathrm{w}$ \\
\hline WIPP-26 & W-26 & & Cul,RS & $\mathrm{i}, \mathbf{n}, \mathrm{t}, \mathrm{w}$ \\
\hline WIPP-27 & W-27 & & Mag,Cul,RS & $i, o, t, w$ \\
\hline
\end{tabular}


Table 1. List of Wells and Zones Sampled by the WQSP, HGC, SNL, and/or the USGS from 1976 to 1986 (continued)

\begin{tabular}{|c|c|c|c|c|}
\hline Well Name ${ }^{1}$ & Abbrev $^{2}$ & Synonyms ${ }^{3}$ & Zones $^{4}$ & $\operatorname{Refs}^{5}$ \\
\hline WIPP-28 & W-28 & & Cul,RS & $\mathrm{i}, \mathrm{p}, \mathrm{t}, \mathrm{w}$ \\
\hline WIPP-29 & W-29 & & Cul,RS & $\mathrm{i}, \mathrm{q}, \mathrm{t}, \mathrm{w}$ \\
\hline WIPP-30 & $\mathrm{W}-30$ & & Mag,Cul,RS & $\mathrm{i}, \mathrm{r}, \mathrm{t}, \mathrm{w}$ \\
\hline Engle Well & ENGLE & Ingle 10 & Cul & $a, w$ \\
\hline Pocket Well & POCKET & Walker ${ }^{11}$ & DL & $a, w, x$ \\
\hline Ranch Well & RANCH & Ranch Headqtrs 12 & DL & $a, w, x$ \\
\hline Twin Wells - Pasture & TWIN-P & see footnote ${ }^{13}$ & DL & $w$ \\
\hline Unger Well & UNGER & Inger ${ }^{14}$ & DL & $a, w$ \\
\hline
\end{tabular}

1. Well names used in this report (see Section 1.3.1).

2. Abbreviations used in some data tables in this report.

3. Synonyms or other names that have been used in published reports or in unpublished field notes and/or memoranda.

4. Stratigraphic zones sampled:
BC - Bell Canyon Formation
Cul - Culebra Dolomite
DL - Dewey Lake Red Beds
Mag - Magenta Dolomite
RS - Rustler/Salado contact zone

5. References containing details about well locations and histories. Complete citations are in Section 6.
a. Cooper and Glanzman, 1971
m. SNL and USGS, 1979a
b. D'Appolonia, 1982 = Freeland, 1982
n. SNL and USGS, $1979 \mathrm{~b}$
c. Dennehy, 1982
o. SNL and USGS, 1979c
d. Dennehy and Mercer, 1982
p. SNL and USGS, 1979d
e. Drellack and Wells, 1982a
f. Drellack and Wells, 1982b
q. SNL and USGS, 1979e
g. Hydro Geo Chem, 1985
h. Jones, 1978
i. Mercer, 1983
j. Mercer et al., 1987
k. Mercer et al., 1981
1. Mercer and Orr, 1979
r. SNL and USGS, 1980
s. SNL and UNM, 1981
t. Seward, 1982
u. Wells and Drellack, 1982
v. Wells and Drellack, 1983
w. Winstanley and Carrasco, 1986
x. Cooley, 1973

6. Well was originally designated $\mathrm{H}-13$ and is referred to by this name in field notes and in several laboratory reports. "RF-10" appears to be a typographical error that was propagated through several requests for analysis and laboratory reports.

7. H-2 was originally a three-well hydropad, with the wells designated H-2A, H-2B, and H-2C. An additional well was drilled and completed in the Culebra in 1983 and was designated $\mathrm{H}-2 \mathrm{~B} 2$. The original " $\mathrm{B}$ " well is now usually designated $\mathrm{H}-2 \mathrm{~B} 1$.

8. H-3 was originally a single-well hydropad, with the well designated H-3. Two additional wells were drilled in 1983 and 1984 and were designated $\mathrm{H}-3 \mathrm{~B} 2$ and $\mathrm{H}-3 \mathrm{~B} 3$. The original well is now usually designated $\mathrm{H}-$ 3B1 but has appeared in some documents as $\mathrm{H}-3 \mathrm{~A}$ or $\mathrm{H}-3 \mathrm{~B}$. 
Table 1. List of Wells and Zones Sampled by the WQSP, HGC, SNL and/or the USGS from 1976 to 1986 (continued)

9. H-7 was originally a three-well hydropad, with the wells designated H-7A, H-7B, and H-7C. An additional well was drilled in 1983 and designated H-7B2. The original H-7B well is now usually designated H-7B1.

10. Engle Well was called "Ingle" well by Cooper and Glanzman (1971; location 24.31.4.430) and is called Engles Windmill on the Big Sinks Quadrangle map (USGS 71/2-minute topographic series).

11. Pocket Well was called "Walker" well by Cooper and Glanzman (1971; location 23.31.29.113) and is shown as an unnamed windmill on the Los Medaños Quadrangle map (USGS 71/2-min. topographic series).

12. Ranch Well was called "Ranch Headquarters" well by Cooper and Glanzman (1971; location 23.31.6.444).

13. Two wells are located on Twin Wells Ranch (NW1/4 of T24S, R31E, S17; Big Sinks Quadrangle, USGS 71/2min. topographic series). The Twin Wells - House well corresponds to the "Ranch Headquarters" well of Cooper and Glanzman (1971; location 24.31.17.111); the Twin Wells - Pasture well is not mentioned in Cooper and Glanzman (1971). Both wells are included in the database of Winstanley and Carrasco (1986).

14. Unger Well was misspelled as "Inger" well in a series of field notes, requests for analysis, and laboratory reports. It was called "Unger" well by Cooper and Glanzman (1971; location 23.31.17.310) and is shown as an unnamed windmill on the Los Medaños Quadrangle map (USGS 71/2-min. topographic series). 
Table 2. List of Tests in Which Samples Were Collected and Analyzed for Solutes (Wells are grouped first by stratigraphic zone --in the order Culebra, Magenta, Rustler/Salado contact zone, Dewey Lake, Bell Canyon, and alluvium -- and then by hydropad, with the WIPP wells first, alphabetically, followed by the stock wells.)

\begin{tabular}{|c|c|c|c|c|c|c|}
\hline $\begin{array}{c}\text { Well } \\
\text { Abbrev } 1 \\
\end{array}$ & $\begin{array}{l}\text { Strat. } \\
\text { Zone }^{2} \\
\end{array}$ & Date & Agency $^{3}$ & $\begin{array}{c}\text { Average } \\
\text { Pumping Rate } \\
\end{array}$ & $\begin{array}{l}\text { Approx. Vol. } \\
\text { Pumped }^{4}\end{array}$ & $\operatorname{Refs}^{5}$ \\
\hline DOE-1 & Cul & Apr 83 & HGC & $30 \mathrm{gph}(0.5 \mathrm{gpm})$ & $>4000 \mathrm{gal}$ & $c, q$ \\
\hline DOE-1 & $\mathrm{Cul}$ & Apr 85 & WQSP-R1 & $500 \mathrm{gph}(8.3 \mathrm{gpm})$ & $135000 \mathrm{gal}$ & $0, q$ \\
\hline DOE-2 & $\mathrm{Cul}$ & Mar 85 & WQSP-R1 & $380 \mathrm{gph}(6.3 \mathrm{gpm})$ & $178000 \mathrm{gal}$ & $i, o, q$ \\
\hline FR-10 & $\mathrm{Cul}$ & Oct 83 & HGC & pump pulse test & -200 gal & \\
\hline $\mathrm{H}-1$ & $\mathrm{Cul}$ & Jun 76 & USGS & bail or swab & -- & h,k,q \\
\hline H-1 & $\mathrm{Cul}$ & Mar 77 & USGS & bail or swab & -- & $k, q$ \\
\hline $\mathrm{H}-2 \mathrm{~B} 1$ & Cul & Feb 77 & USGS & bail or swab & -- & $h, k, q$ \\
\hline $\mathrm{H}-2 \mathrm{C}$ & $\mathrm{Cul}$ & Mar 77 & USGS & bail or swab & -- & $k, q$ \\
\hline $\mathrm{H}-2 \mathrm{C}$ & Cul & Dec 80 & SNL & recirc. tracer test & -- & $\mathrm{c}, \mathrm{d}, \mathrm{q}$ \\
\hline $\mathrm{H}-2 \mathrm{~A}$ & Cul & Apr 86 & WQSP-R1 & $23 \mathrm{gph}$ & 9700 gal & $0, q$ \\
\hline $\mathrm{H}-3 \mathrm{~B} 1$ & $\mathrm{Cul}$ & Mar 77 & USGS & bail or swab & -- & $\mathrm{h}, \mathrm{k}, \mathrm{q}$ \\
\hline $\mathrm{H}-3 \mathrm{~B} 3$ & Cul & Jun 84 & HGC & $180 \mathrm{gph}$ (3 gpm) & -- & q \\
\hline $\mathrm{H}-3 \mathrm{~B} 3$ & Cul & Feb 85 & WQSP-R1 & $180 \mathrm{gph}(3 \mathrm{gpm})$ & 16000 gal & $0, q$ \\
\hline $\mathrm{H}-3 \mathrm{~B} 2$ & Cul & Dec 85 & WQSP-R1 & $290 \mathrm{gph}(4.8 \mathrm{gpm})$ & --- & $\mathrm{p}, \mathrm{q}, \mathrm{r}$ \\
\hline$H-4 B$ & Cul & Dec 78 & USGS & bail or swab & - & $h, j, q$ \\
\hline $\mathrm{H}-4 \mathrm{~B}$ & Cul & May 81 & SNL & $15 \mathrm{gph}$ & $\sim 3000 \mathrm{gal}$ & $c, q$ \\
\hline $\mathrm{H}-4 \mathrm{C}$ & Cul & Aug 84 & HGC & $30 \mathrm{gph}$ & -- & $e, q$ \\
\hline $\mathrm{H}-4 \mathrm{~B}$ & Cul & Jul 85 & WQSP-R1 & $20 \mathrm{gph}$ & $3600 \mathrm{gal}$ & $0, q$ \\
\hline $\mathrm{H}-5 \mathrm{~B}$ & Cul & Dec 78 & USGS & bail or swab & -- & $\mathrm{b}, \mathrm{h}, \mathrm{q}$ \\
\hline $\mathrm{H}-5 \mathrm{~B}$ & Cul & Jun 81 & SNL & $12 \mathrm{gph}$ & $-1000 \mathrm{gal}$ & $c, q$ \\
\hline $\mathrm{H}-5 \mathrm{C}$ & Cul & Oct 81 & SNL & $7.5 \mathrm{gph}$ & $-1400 \mathrm{gal}$ & $c, q$ \\
\hline $\mathrm{H}-5 \mathrm{~B}$ & Cul & Aug 85 & WQSP-R1 & $8 \mathrm{gph}$ & $1100 \mathrm{gal}$ & $0, q$ \\
\hline $\mathrm{H}-6 \mathrm{~B}$ & Cul & Dec 78 & USGS & bail or swab & -- & a,h,q \\
\hline $\mathrm{H}-6 \mathrm{~B}$ & Cul & May 81 & SNL & $1400 \mathrm{gph}(23 \mathrm{gpm})$ & $-33000 \mathrm{gal}$ & $c, q$ \\
\hline $\mathrm{H}-6 \mathrm{C}$ & $\mathrm{Cul}$ & May 81 & SNL & $1100 \mathrm{gph}(19 \mathrm{gpm})$ & $-150000 \mathrm{gal}$ & $c, q$ \\
\hline $\mathrm{H}-6 \mathrm{~B}$ & $\mathrm{Cul}$ & Sep 85 & WQSP-R1 & $330 \mathrm{gph}(5.5 \mathrm{gpm})$ & $80000 \mathrm{gal}$ & $0, q$ \\
\hline H-7B1 & Cul & Mar 80 & USGS & bail or swab & -- & $\mathrm{h}, 1, \mathrm{q}$ \\
\hline H-7B1 & $\mathrm{Cul}$ & Mar 86 & WQSP-R1 & $270 \mathrm{gph}(4.5 \mathrm{gpm})$ & $39000 \mathrm{gal}$ & $0, q$ \\
\hline $\mathrm{H}-8 \mathrm{~B}$ & Cul & Feb 80 & USGS & bail or swab & -- & $\mathrm{h}, \mathrm{l}, \mathrm{q}$ \\
\hline $\mathrm{H}-8 \mathrm{~B}$ & Cul & Jan 86 & WQSP-R1 & $40 \mathrm{gph}$ & $11000 \mathrm{gal}$ & $0, q$ \\
\hline $\mathrm{H}-9 \mathrm{~B}$ & Cul & Feb 80 & USGS & bail or swab & - & $h, 1, q$ \\
\hline $\mathrm{H}-9 \mathrm{~B}$ & Cul & Oct 83 & HGC & $600 \mathrm{gph}(10 \mathrm{gpm})$ & $>500 \mathrm{gal}$ & $\mathrm{f}, \mathrm{q}$ \\
\hline H-9B & $\mathrm{Cul}$ & Nov 85 & WQSP-R1 & $38 \mathrm{gph}$ & $8400 \mathrm{gal}$ & $0, q$ \\
\hline $\mathrm{H}-10 \mathrm{~B}$ & $\mathrm{Cul}$ & Mar 80 & USGS & bail or swab & -- & $\mathrm{h}, \mathrm{l}, \mathrm{q}$ \\
\hline H-11B3 & Cul & Jun 85 & WQSP-R1 & $330 \mathrm{gph}(5.5 \mathrm{gpm})$ & $109000 \mathrm{gal}$ & $0, q$ \\
\hline
\end{tabular}


Table 2. List of Tests in Which Samples Were Collected and Analyzed for Solutes (continued)

\begin{tabular}{|c|c|c|c|c|c|c|}
\hline $\begin{array}{c}\text { Well } \\
\text { Abbrev1 }\end{array}$ & $\begin{array}{l}\text { Strat. } \\
\text { Zone }^{2}\end{array}$ & Date & Agency $^{3}$ & $\begin{array}{c}\text { Average } \\
\text { Pumping Rate } \\
\end{array}$ & $\begin{array}{c}\text { Approx. Vol. } \\
\text { Pumped }^{4}\end{array}$ & Refs $^{5}$ \\
\hline $\mathrm{H}-12$ & $\mathrm{Cul}$ & Jan 84 & $\mathrm{HGC}$ & $8.4 \mathrm{gph}$ & $-800 \mathrm{gal}$ & $f, q$ \\
\hline H-12 & $\mathrm{Cul}$ & $\operatorname{Jan} 84$ & $\mathrm{HGC}$ & $13.5 \mathrm{gph}$ & -700 gal & $\mathrm{q}$ \\
\hline $\mathrm{H}-12$ & Cul & Aug 85 & WQSP-R1 & $17 \mathrm{gph}$ & $2400 \mathrm{gal}$ & $0, q$ \\
\hline P-14 & $\mathrm{Cul}$ & Mar 77 & USGS & bail or swab & - & $h, k, q$ \\
\hline P-14 & $\mathrm{Cul}$ & Feb 86 & WQSP-R1 & $33 \mathrm{gph}$ & $6500 \mathrm{gal}$ & $0, q$ \\
\hline P-15 & $\mathrm{Cul}$ & May 77 & USGS & bail or swab & -- & $h, k, q$ \\
\hline P-15 & Cul & Apr 79 & USGS & bail or swab & - & $\mathrm{h}, \mathrm{q}$ \\
\hline P-17 & Cul & May 77 & USGS & bail or swab & -- & $\mathrm{h}, \mathrm{k}, \mathrm{q}$ \\
\hline P-17 & Cul & Mar 86 & WQSP-R1 & $30 \mathrm{gph}(0.5 \mathrm{gpm})$ & $8700 \mathrm{gal}$ & $0, q$ \\
\hline P-18 & $\mathrm{Cul}$ & May 77 & USGS & bail or swab & - & $\mathrm{h}, \mathrm{k}, \mathrm{q}$ \\
\hline $\mathrm{W}-25$ & $\mathrm{Cul}$ & Aug 80 & USGS & bail or swab & - & $h, m, q$ \\
\hline $\mathrm{W}-25$ & Cul & Aug 80 & SNL & $2000 \mathrm{gph}(33 \mathrm{gpm})$ & $55000 \mathrm{gal}$ & $g, q$ \\
\hline $\mathrm{W}-25$ & $\mathrm{Cul}$ & Feb 86 & WQSP-R1 & $430 \mathrm{gph}$ (7.1 gpm) & $164000 \mathrm{gal}$ & $0, \bar{q}$ \\
\hline$W-26$ & Cul & Aug 80 & USGS & bail or swab & - & $h, m, q$ \\
\hline W-26 & $\mathrm{Cul}$ & Aug 80 & SNL & $2000 \mathrm{gph}(34 \mathrm{gpm})$ & $53000 \mathrm{gal}$ & $g, q$ \\
\hline W-26 & Cul & Nov 85 & WQSP-R1 & $52 \mathrm{gph}^{6}$ & $61000 \mathrm{gal}$ & $0, q$ \\
\hline W-27 & $\mathrm{Cul}$ & Aug 80 & USGS & bail or swab & -- & $\mathrm{h}, \mathrm{m}, \mathrm{q}$ \\
\hline W-27 & Cul & Sep 80 & SNL & $1500 \mathrm{gph}(25 \mathrm{gpm})$ & $30000 \mathrm{gal}$ & $g, q$ \\
\hline W-28 & Cul & Aug 80 & USGS & bail or swab & - & $h, m, q$ \\
\hline W-28 & $\mathrm{Cul}$ & Sep 80 & SNL & $1000 \mathrm{gph}(17 \mathrm{gpm})$ & $46000 \mathrm{gal}$ & $g, q$ \\
\hline W-29 & Cul & Aug 80 & USGS & bail or swab & -- & $\mathrm{h}, \mathrm{m}, \mathrm{q}$ \\
\hline W-29 & Cul & Aug 80 & SNL & $2200 \mathrm{gph}(37 \mathrm{gpm})$ & $98000 \mathrm{gal}$ & $\mathrm{g}, \mathrm{q}$ \\
\hline W-29 & $\mathrm{Cul}$ & Dec 85 & WQSP-R1 & $60 \mathrm{gph}^{7}$ & $138000 \mathrm{gal}$ & $0, q$ \\
\hline $\mathrm{W}-30$ & Cul & Aug 80 & USGS & bail or swab & -- & $h, m, q$ \\
\hline W-30 & Cul & Sep 80 & SNL & $12 \mathrm{gph}^{8}$ & $1000 \mathrm{gal}$ & $\mathrm{g}, \mathrm{q}$ \\
\hline ENGLE & $\mathrm{Cul}$ & Nov 83 & HGC & $590 \mathrm{gph}(9.8 \mathrm{gpm})$ & $-70000 \mathrm{gal}$ & $q$ \\
\hline ENGLE & Cul & Mar 85 & WQSP-R1 & $50 \mathrm{gph}(0.8 \mathrm{gpm})$ & 7500 gal & $0, q$ \\
\hline H-1 & Mag & Jun 76 & USGS & bail or swab & -- & $\mathrm{h}, \mathrm{k}, \mathrm{q}$ \\
\hline H-1 & Mag & May 77 & USGS & bail or swab & -- & $h, k, q$ \\
\hline $\mathrm{H}-2 \mathrm{~A}$ & Mag & Feb 77 & USGS & bail or swab & - & $\mathrm{h}, \mathrm{k}, \mathrm{q}$ \\
\hline H-3B1 & Mag & May 77 & USGS & bail or swab & - & $\mathrm{h}, \mathrm{k}, \mathrm{q}$ \\
\hline H-3B1 & Mag & May 79 & USGS & bail or swab & -- & $\mathrm{h}, \mathrm{q}$ \\
\hline H-3B1 & Mag & Jul 85 & WQSP-R1 & $14 \mathrm{gph}$ & $3800 \mathrm{gal}$ & $0, q$ \\
\hline $\mathrm{H}-4 \mathrm{~A}$ & Mag & Dec 78 & USGS & bail or swab & - & $h, j, q$ \\
\hline $\mathrm{H}-4 \mathrm{C}$ & Mag & Nov 86 & WQSP-R1 & $4 \mathrm{gph}$ & $700 \mathrm{gal}$ & $p, q$ \\
\hline H-5A & Mag & Dec 78 & USGS & bail or swab & -- & $\mathrm{b}, \mathrm{h}, \mathrm{q}$ \\
\hline $\mathrm{H}-5 \mathrm{C}$ & Mag & Oct 86 & WQSP-R1 & $13 \mathrm{gph}$ & $5800 \mathrm{gal}$ & $\mathrm{p}, \mathrm{q}$ \\
\hline H-6A & Mag & Dec 78 & USGS & bail or swab & -- & $a, h, q$ \\
\hline $\mathrm{H}-6 \mathrm{C}$ & Mag & Oct 86 & WQSP-R1 & $24 \mathrm{gph}$ & $7000 \mathrm{gal}$ & $\mathrm{p}, \mathrm{q}$ \\
\hline
\end{tabular}


Table 2. List of Tests in Which Samples Were Collected and Analyzed for Solutes (continued)

\begin{tabular}{|c|c|c|c|c|c|c|}
\hline $\begin{array}{c}\text { Well } \\
\text { Abbrev } 1\end{array}$ & $\begin{array}{l}\text { Strat. } \\
\text { Zone }^{2}\end{array}$ & Date & Agency $^{3}$ & $\begin{array}{c}\text { Average } \\
\text { Pumping Rate } \\
\end{array}$ & $\begin{array}{c}\text { Approx. Vol. } \\
\text { Pumped }\end{array}$ & $\operatorname{Refs}^{5}$ \\
\hline $\mathrm{H}-8 \mathrm{~A}$ & Mag & Feb 80 & USGS & bail or swab & -- & $\mathrm{h}, \mathrm{l}, \mathrm{q}$ \\
\hline $\mathrm{H}-8 \mathrm{~A}$ & Mag & Oct 85 & WQSP-R1 & $40 \mathrm{gph}$ & $25 \mathrm{gal}$ & $o, q$ \\
\hline $\mathrm{H}-9 \mathrm{~A}$ & Mag & Feb 80 & USGS & bail or swab & -- & h,l,q \\
\hline $\mathrm{H}-10 \mathrm{~A}$ & Mag & Mar 80 & USGS & bail or swab & -- & $\mathrm{h}, 1, \mathrm{q}$ \\
\hline $\mathrm{W}-25$ & Mag & Sep 80 & USGS & bail or swab & -- & $\mathrm{h}, \mathrm{m}, \mathrm{q}$ \\
\hline W-25 & Mag & Sep 80 & SNL & $2000 \mathrm{gph}(34 \mathrm{gpm})$ & $51000 \mathrm{gal}$ & $\mathrm{g}, \mathrm{q}$ \\
\hline W-27 & Mag & Sep 80 & USGS & bail or swab & -- & $\mathrm{h}, \mathrm{m}, \mathrm{q}$ \\
\hline W-27 & Mag & Sep 80 & SNL & $560 \mathrm{gph}(9.4 \mathrm{gpm})$ & $15000 \mathrm{gal}$ & $g, q$ \\
\hline W-30 & Mag & Sep 80 & USGS & bail or swab & -- & $\mathrm{h}, \mathrm{m}, \mathrm{q}$ \\
\hline W-30 & Mag & Dec 80 & SNL & $<100 \mathrm{~mL} / \mathrm{min}^{9}$ & & $g, q$ \\
\hline $\mathrm{H}-1$ & $\mathrm{RS}$ & Feb 77 & USGS & bail or swab & -- & $h, k, q$ \\
\hline $\mathrm{H}-2 \mathrm{C}$ & RS & Feb 77 & USGS & bail or swab & -- & $h, k, q$ \\
\hline H-3B1 & RS & Feb 77 & USGS & bail or swab & -- & $h, k, q$ \\
\hline $\mathrm{H}-4 \mathrm{C}$ & RS & Mar 79 & USGS & bail or swab & - & $\mathrm{h}, \mathrm{j}, \mathrm{q}$ \\
\hline $\mathrm{H}-5 \mathrm{C}$ & $\mathrm{RS}$ & May 79 & USGS & bail or swab & - & $\mathrm{b}, \mathrm{h}, \mathrm{q}$ \\
\hline $\mathrm{H}-6 \mathrm{C}$ & $\mathrm{RS}$ & Apr 79 & USGS & bail or swab & -- & $a, h, q$ \\
\hline $\mathrm{H}-7 \mathrm{C}$ & $\mathrm{RS}$ & Mar 80 & USGS & bail or swab & -- & $a, 1, q$ \\
\hline $\mathrm{H}-8 \mathrm{C}$ & $\mathrm{RS}$ & Sep 80 & USGS & bail or swab & - & $\mathrm{h}, 1, \mathrm{q}$ \\
\hline $\mathrm{H}-9 \mathrm{C}$ & RS & May 80 & USGS & bail or swab & -- & $\mathrm{h}, 1, \mathrm{q}$ \\
\hline $\mathrm{H}-10 \mathrm{C}$ & $\mathrm{RS}$ & May 80 & USGS & bail or swab & -- & $\mathrm{h}, 1, \mathrm{q}$ \\
\hline P-14 & RS & Feb 77 & USGS & bail or swab & - & $h, k, q$ \\
\hline P-15 & RS & Apr 79 & USGS & bail or swab & -- & $\mathrm{h}, \mathrm{q}$ \\
\hline P-17 & $\mathrm{RS}$ & May 79 & USGS & bail or swab & -- & $\mathrm{h}, \mathrm{q}$ \\
\hline P-18 & RS & May 79 & USGS & bail or swab & -- & $h, q$ \\
\hline W-25 & RS & Mar 80 & USGS & bail or swab & 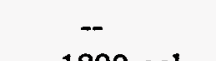 & $\mathrm{h}, \mathrm{m}, \mathrm{q}$ \\
\hline W-25 & RS & Jul 80 & SNL & $70 \mathrm{gph}(1.1 \mathrm{gpm})$ & $1800 \mathrm{gal}$ & $g, q$ \\
\hline W-26 & $\mathrm{RS}$ & Mar 80 & USGS & bail or swab & $-\bar{s}$ & $\mathrm{~h}, \mathrm{~m}, \mathrm{q}$ \\
\hline W-26 & RS & Jul 80 & SNL & $25 \mathrm{gph}(0.42 \mathrm{gpm})$ & $900 \mathrm{gal}$ & $\mathrm{g}, \mathrm{q}$ \\
\hline$W-27$ & RS & May 80 & USGS & bail or swab & - & $h, m, q$ \\
\hline W-27 & RS & Aug 80 & SNL & $4.2 \mathrm{gph}^{10}$ & $100 \mathrm{gal}$ & $g, q$ \\
\hline W-28 & RS & Mar 80 & USGS & bail or swab & - & $\mathrm{h}, \mathrm{m}, \mathrm{q}$ \\
\hline W-28 & RS & Jul 80 & SNL & $190 \mathrm{gph}(3.1 \mathrm{gpm})$ & $7600 \mathrm{gal}$ & $\mathrm{g}, \mathrm{q}$ \\
\hline W-29 & RS & Mar 80 & USGS & bail or swab & - & $h, m, q$ \\
\hline W-29 & RS & Jul 80 & SNL & $90 \mathrm{gph}(1.5 \mathrm{gpm})$ & $4100 \mathrm{gal}$ & $\mathrm{g}, \mathrm{q}$ \\
\hline $\begin{array}{l}\text { W-30 } \\
\text { W-30 }\end{array}$ & $\begin{array}{l}\text { RS } \\
\text { RS }\end{array}$ & $\begin{array}{l}\text { Mar } 80 \\
\text { Jul } 80\end{array}$ & $\begin{array}{l}\text { USGS } \\
\text { SNL }\end{array}$ & $\begin{array}{l}\text { bail or swab } \\
13 \mathrm{gph}(0.22 \mathrm{gpm})\end{array}$ & $\overline{500} a 91$ & $\mathrm{~h}, \mathrm{~m}, \mathrm{q}$ \\
\hline & & Jul 80 & & $13 \mathrm{gph}(0.22 \mathrm{gpm})$ & $590 \mathrm{gal}$ & $\mathrm{g}, \mathrm{q}$ \\
\hline
\end{tabular}


Table 2. List of Tests in Which Samples Were Collected and Analyzed for Solutes (continued)

\begin{tabular}{|c|c|c|c|c|c|c|}
\hline $\begin{array}{c}\text { Well } \\
\text { Abbrev } 1 \\
\end{array}$ & $\begin{array}{l}\text { Strat. } \\
\text { Zone }^{2} \\
\end{array}$ & Date & Agency ${ }^{3}$ & $\begin{array}{c}\text { Average } \\
\text { Pumping Rate } \\
\end{array}$ & $\begin{array}{c}\text { Approx. Vol. } \\
\text { Pumped }^{4}\end{array}$ & Refs $^{5}$ \\
\hline POCKET & DL & Nov 83 & $\mathrm{HGC}$ & $510 \mathrm{gph}(8.6 \mathrm{gpm})$ & $>40000 \mathrm{gal}$ & $q$ \\
\hline RANCH & DL & Jun 86 & WQSP-R1 & $160 \mathrm{gph}(2.7 \mathrm{gpm})$ & $20000 \mathrm{gal}$ & $\mathrm{p}, \mathrm{q}$ \\
\hline TWIN-P & DL & Jan 86 & WQSP-R1 & $33 \mathrm{gph}$ & $5000 \mathrm{gal}$ & $0, q$ \\
\hline UNGER & DL & $\operatorname{Jan} 84$ & HGC & $570 \mathrm{gph}(9.6 \mathrm{gpm})$ & $\sim 17000 \mathrm{gal}$ & $q$ \\
\hline DOE-2 & $\mathrm{BC}$ & Jul 85 & WQSP-R1 & 250 gal per swab & $>10000 \mathrm{gal}$ & $\mathrm{i}, \mathrm{o}, \mathrm{q}$ \\
\hline W-15 & Alluvium & Mar 79 & USGS & bail or swab & - & $\mathbf{n}$ \\
\hline
\end{tabular}

1. Abbreviations of well names are are explained in Table 1.

2. Stratigraphic zone sampled:

BC - Bell Canyon Formation

Cul - Culebra Dolomite

DL - Dewey Lake Red Beds

Mag - Magenta Dolomite

RS - Rustler/Salado contact zone

3. Agency or program responsible for sample collection:

HGC - Hydro Geo Chem, Inc., Tucson, AZ

SNL - Sandia National Laboratories, Albuquerque, NM

USGS - United States Geological Survey

WQSP-R1 - Round One of the Water Quality Sampling Program

4. Approximate volume of water removed from the well before final samples were collected.

5. References containing information about hydrologic testing, equipment, well configuration during testing, and so forth. Complete citations are given in Section 6.
a. Dennehy, 1982
k. Mercer and Orr, 1979
b. Dennehy and Mercer, 1982
1. Richey, 1986
c. Hydro Geo Chem, 1985
m. Richey, 1987
d. Hydro Geo Chem, 1986
n. SNL and UNM, 1981
f. Intera and HGC, 1985
o. Uhland and Randall, 1986
g. Lambert and Robinson, 1984
p. Uhland et al., 1987
h. Mercer, 1983
q. Winstanley and Carrasco, 1986

i. Mercer et al., 1987

j. Mercer et al., 1981

6. Before serial sampling began, the well was purged at a pumping rate of $870 \mathrm{gph} ; 54500 \mathrm{gal}$ were pumped from the well. For sampling, the pumping rate was reduced to $52 \mathrm{gph}$.

7. Before serial sampling, this well was purged for $63 \mathrm{hr}$ at $33 \mathrm{gpm}$. For sampling, the pumping rate was reduced to $60 \mathrm{gph}$.

8. At the beginning of the test, the pumping rate was $\sim 0.3 \mathrm{gpm}$; by the end of the test it was $\sim 0.1 \mathrm{gpm}$. The average pumping rate was $\sim 0.2 \mathrm{gpm}$ (12 gph).

9. At the beginning of the test, the pumping rate was $\sim 100 \mathrm{~mL} / \mathrm{min}$; the rate decreased to $\sim 50 \mathrm{~mL} / \mathrm{min}$ by the end of the test.

10. The pumping rate was initially $\sim 0.13 \mathrm{gpm}$ and decreased to $\sim 0.02 \mathrm{gpm}$ during the test. The average pumping rate was $\sim 0.07 \mathrm{gpm}$ (4.2 gph). 
Table 3. List of Samples for Which Data Are Included in This Report

(Samples are ordered by stratigraphic zone (Cul, Mag, RS, DL, BC, alluvium), then by hydropad (WIPP wells precede stock wells), and then by test.)

\begin{tabular}{|c|c|c|c|c|c|}
\hline Well Abbrev1 & $\begin{array}{l}\text { Strat. } \\
\text { Zone }\end{array}$ & Collection Date $(s)^{3}$ & Agency ${ }^{4}$ & $\mathrm{Lab}^{5}$ & Sample ID 6 \\
\hline DOE-1 & Cul & $04 / 13 / 83-04 / 21 / 83$ & $\mathrm{HGC}$ & FLD & D1.C483F \\
\hline DOE-1 & Cul & $04 / 19 / 83$ & HGC & $\mathrm{KCS}$ & D1.C483KC \\
\hline DOE-1 & Cul & $04 / 12 / 85-04 / 25 / 85$ & WQSP-R1 & FLD & D1.C485F \\
\hline DOE-1 & $\mathrm{Cul}$ & $04 / 24,25 / 85$ & WQSP-R1 & BFEC & D1.C485B \\
\hline DOE-1 & $\mathrm{Cul}$ & $04 / 24,25 / 85$ & WQSP-R1 & EEG & D1.C485E \\
\hline DOE-1 & Cul & $04 / 24 / 85$ & WQSP-R1 & ITAS & D1.C485Ia \\
\hline DOE-1 & Cul & $04 / 25 / 85$ & WQSP-R1 & ITAS & D1.C485Ib \\
\hline DOE-2 & Cul & $02 / 20 / 85-03 / 12 / 85$ & WQSP-R1 & FLD & D2.C385F \\
\hline DOE-2 & Cul & $03 / 11,12 / 85$ & WQSP-R1 & BFEC & D2.C385B \\
\hline DOE-2 & Cul & $03 / 11,12 / 85$ & WQSP-R1 & EEG & D2.C385E \\
\hline DOE-2 & Cul & $03 / 11,12 / 85$ & WQSP-R1 & ITAS & D2.C385I \\
\hline FR-10 & Cul & $10 / 06 / 83$ & HGC & FLD & FR10.C1083F \\
\hline FR-10 & Cul & $10 / 06 / 83$ & HGC & H-B & FR10.C1083HB \\
\hline FR-10 & Cul & $10 / 06 / 83$ & HGC & KCS & FR10.C1083KC \\
\hline FR-10 & Cul & $10 / 06 / 83$ & HGC & KGS & FR10.C1083K \\
\hline $\mathrm{H}-1$ & Cul & $06 / 02 / 76$ & USGS & USGS & H01.C676G \\
\hline H-1 & $\mathrm{Cul}$ & $03 / 17 / 77$ & USGS & USGS & H01.C377G \\
\hline $\mathrm{H}-2 \mathrm{~B} 1$ & Cul & $02 / 22 / 77$ & USGS & USGS & H02B1.C277G \\
\hline $\mathrm{H}-2 \mathrm{C}$ & $\mathrm{Cul}$ & $03 / 16 / 77$ & USGS & USGS & H02C.C377G \\
\hline $\mathrm{H}-2 \mathrm{C}$ & Cul & $12 / 10 / 80$ & SNL & FLD & H02C.C1280F \\
\hline $\mathrm{H}-2 \mathrm{~A}$ & Cul & $04 / 04 / 86-04 / 21 / 86$ & WQSP-R1 & FLD & H02A.C486F \\
\hline $\mathrm{H}-2 \mathrm{~A}$ & Cul & $04 / 21 / 86$ & WQSP-R1 & BFEC & H02A.C486B \\
\hline $\mathrm{H}-2 \mathrm{~A}$ & Cul & $04 / 21 / 86$ & WQSP-R1 & ITAS & H02A.C486I \\
\hline $\mathrm{H}-3 \mathrm{~B} 1$ & $\mathrm{Cul}$ & $03 / 17 / 77$ & USGS & USGS & H03B1.C377G \\
\hline H-3B3 & Cul & $06 / 10 / 84-06 / 11 / 84$ & HGC & FLD & H03B3.C684F \\
\hline H-3B3 & Cul & $06 / 11 / 84$ & HGC & BFEC & H03B3.C684B \\
\hline $\mathrm{H}-3 \mathrm{~B} 3$ & Cul & $06 / 11 / 84$ & HGC & UA & H03B3.C684UA \\
\hline $\mathrm{H}-3 \mathrm{~B} 3$ & Cul & $01 / 29 / 85-02 / 04 / 85$ & WQSP-R1 & FLD & H03B3.C285F \\
\hline H-3B3 & Cul & $02 / 04 / 85$ & WQSP-R1 & BFEC & H03B3.C285B \\
\hline H-3B3 & Cul & $02 / 04 / 85$ & WQSP-R1 & EEG & H03B3.C285E \\
\hline H-3B3 & Cul & $02 / 04 / 85$ & WQSP-R1 & ITAS & H03B3.C285I \\
\hline $\mathrm{H}-3 \mathrm{~B} 3$ & $\mathrm{Cul}$ & $02 / 04 / 85$ & WQSP-R1 & UA & H03B3.C285UA \\
\hline $\mathrm{H}-3 \mathrm{~B} 2$ & $\mathrm{Cul}$ & $12 / 16 / 85$ & WQSP & ITAS & H03B2.C1285I \\
\hline $\mathrm{H}-4 \mathrm{~B}$ & $\mathrm{Cul}$ & $12 / 14 / 78$ & USGS & USGS & H04B.C1278G \\
\hline$H-4 B$ & $\mathrm{Cul}$ & $05 / 14 / 81-05 / 29 / 81$ & SNL & FLD & H04B.C581F \\
\hline $\mathrm{H}-4 \mathrm{~B}$ & $\mathrm{Cul}$ & $05 / 29 / 81$ & SNL & BFEC & H04B.C581B \\
\hline $\mathrm{H}-4 \mathrm{C}$ & $\mathrm{Cul}$ & $08 / 09 / 84-08 / 10 / 84$ & HGC & FLD & H04C.C884F \\
\hline $\mathrm{H}-4 \mathrm{C}$ & $\mathrm{Cul}$ & $08 / 10 / 84$ & $\mathrm{HGC}$ & BFEC & H04C.C884B \\
\hline
\end{tabular}


Table 3. List of Samples for Which Data Are Included in This Report (continued)

\begin{tabular}{|c|c|c|c|c|c|}
\hline Well Abbrev 1 & $\begin{array}{l}\text { Strat. } \\
\text { Zone }\end{array}$ & Collection Date $(s)^{3}$ & Agency ${ }^{4}$ & $\mathrm{Lab}^{5}$ & Sample ID 6 \\
\hline $\mathrm{H}-4 \mathrm{~B}$ & Cul & $07 / 08 / 85-07 / 25 / 85$ & WQSP-R1 & FLD & H04B.C785F \\
\hline H-4B & $\mathrm{Cul}$ & $07 / 20 / 85$ & WQSP-R1 & BFEC & H04B.C785B \\
\hline $\mathrm{H}-4 \mathrm{~B}$ & Cul & $07 / 25 / 85$ & WQSP-R1 & EEG & H04B.C785E \\
\hline $\mathrm{H}-4 \mathrm{~B}$ & Cul & $07 / 20 / 85$ & WQSP-R1 & ITAS & H04B.C785I \\
\hline $\mathrm{H}-5 \mathrm{~B}$ & Cul & $12 / 19 / 78$ & USGS & USGS & H05B.C1278G \\
\hline H-5B & Cul & $05 / 27 / 81-06 / 02 / 81$ & SNL & FLD & H05B.C681F \\
\hline H-5B & Cul & $06 / 01 / 81$ & SNL & BFEC & H05B.C681B \\
\hline $\mathrm{H}-5 \mathrm{C}$ & Cul & $10 / 07 / 81-10 / 15 / 81$ & SNL & FLD & H05C.C1081F \\
\hline $\mathrm{H}-5 \mathrm{C}$ & Cul & $10 / 15 / 81$ & SNL & BFEC & H05C.C1081B \\
\hline H-5B & Cul & $08 / 22 / 85-08 / 30 / 85$ & WQSP-R1 & FLD & H05B.C885F \\
\hline H-5B & Cul & $08 / 26,27 / 85$ & WQSP-R1 & BFEC & H05B.C885B \\
\hline H-5B & $\mathrm{Cul}$ & $08 / 26 / 85$ & WQSP-R1 & EEG & H05B.C885E \\
\hline H-5B & $\mathrm{Cul}$ & $08 / 26 / 85$ & WQSP-R1 & ITAS & H05B.C885I \\
\hline H-6B & Cul & $12 / 20 / 78$ & USGS & USGS & H06B.C1278G \\
\hline $\mathrm{H}-6 \mathrm{~B}$ & Cul & $05 / 01 / 81-05 / 02 / 81$ & SNL & FLD & H06B.C581F \\
\hline H-6B & Cul & $05 / 02 / 81$ & SNL & BFEC & H06B.C581B \\
\hline $\mathrm{H}-6 \mathrm{C}$ & Cul & $05 / 12 / 81-05 / 27 / 81$ & SNL & FLD & H06C.C581F \\
\hline $\mathrm{H}-6 \mathrm{~B}$ & Cul & $09 / 04 / 85-09 / 16 / 85$ & WQSP-R1 & FLD & H06B.C985F \\
\hline H-6B & Cul & $09 / 15 / 85$ & WQSP-RI & BFEC & H06B.C985B \\
\hline H-6B & Cul & $09 / 15 / 85$ & WQSP-R1 & EEG & H06B.C985E \\
\hline$H-6 B$ & Cul & $09 / 15 / 85$ & WQSP-R1 & ITAS & H06B.C985I \\
\hline $\mathrm{H}-7 \mathrm{~B} 1$ & Cul & $03 / 20 / 80$ & USGS & USGS & H07B1.C380G \\
\hline H-7B1 & Cul & $03 / 20 / 86-03 / 27 / 86$ & WQSP-R1 & FLD & H07B1.C386F \\
\hline $\mathrm{H}-7 \mathrm{~B} 1$ & $\mathrm{Cul}$ & $03 / 26 / 86$ & WQSP-R1 & $\mathrm{BFEC}$ & H07B1.C386B \\
\hline H-7B1 & Cul & $03 / 27 / 86$ & WQSP-R1 & ITAS & H07B1.C386I \\
\hline H-8B & $\mathrm{Cul}$ & $02 / 11 / 80$ & USGS & USGS & H08B.C280G \\
\hline $\mathrm{H}-8 \mathrm{~B}$ & Cul & $01 / 09 / 86-01 / 23 / 86$ & WQSP-R1 & FLD & H08B.C186F \\
\hline H-8B & Cul & $01 / 22 / 86$ & WQSP-R1 & BFEC & H08B.C186B \\
\hline H-8B & Cul & $01 / 22 / 86$ & WQSP-R1 & EEG & H08B.C186E \\
\hline H-8B & $\mathrm{Cul}$ & $01 / 21-23 / 86$ & WQSP-R1 & ITAS & H08B.C186I \\
\hline $\mathrm{H}-9 \mathrm{~B}$ & $\mathrm{Cul}$ & $02 / 05 / 80$ & USGS & USGS & H09B.C280G \\
\hline $\mathrm{H}-9 \mathrm{~B}$ & Cul & $10 / 07 / 83$ & HGC & FLD & H09B.C1083F \\
\hline H-9B & Cul & $10 / 07 / 83$ & HGC & H-B & Н09B.С1083HВ \\
\hline H-9B & Cul & $10 / 07 / 83$ & HGC & $\mathrm{KCS}$ & H09B.C1083KC \\
\hline H-9B & Cul & $10 / 07 / 83$ & $\mathrm{HGC}$ & KGS & H09B.C1083K \\
\hline H-9B & $\mathrm{Cul}$ & $10 / 30 / 85-11 / 14 / 85$ & WQSP-R1 & FLD & H09B.C1185F \\
\hline H-9B & $\mathrm{Cul}$ & $11 / 14 / 85$ & WQSP-R1 & BFEC & H09B.C1185B \\
\hline H-9B & Cul & $11 / 14 / 85$ & WQSP-R1 & EEG & H09B.C1185E \\
\hline H-9B & Cul & $11 / 14 / 85$ & WQSP-R1 & ITAS & H09B.C1185I \\
\hline $\mathrm{H}-10 \mathrm{~B}$ & $\mathrm{Cul}$ & $03 / 21 / 80$ & USGS & USGS & H10B.C380G \\
\hline
\end{tabular}


Table 3. List of Samples for Which Data Are Included in This Report (continued)

\begin{tabular}{|c|c|c|c|c|c|}
\hline Well Abbrev 1 & $\begin{array}{l}\text { Strat. } \\
\text { Zone }^{2}\end{array}$ & Collection Date $(\mathrm{s})^{3}$ & Agency 4 & $\mathrm{Lab}^{5}$ & Sample ID 6 \\
\hline H-11B3 & Cul & $05 / 13 / 85-06 / 04 / 85$ & WQSP-R1 & FLD & H11B3.C685F \\
\hline H-11B3 & Cul & $06 / 03,04 / 85$ & WQSP-R1 & BFEC & H11B3.C685B \\
\hline H-11B3 & Cul & $06 / 03,04 / 85$ & WQSP-R1 & EEG & H11B3.C685E \\
\hline H-11B3 & Cul & $06 / 03 / 85$ & WQSP-R1 & ITAS & H11B3.C685I \\
\hline $\mathrm{H}-12$ & Cul & $01 / 07 / 84-01 / 12 / 84$ & HGC & FLD & H12.C184F \\
\hline $\mathrm{H}-12$ & Cul & $01 / 11 / 84$ & HGC & H-B & $\mathrm{H} 12 . \mathrm{C} 184 \mathrm{HBa}$ \\
\hline $\mathrm{H}-12$ & Cul & $01 / 11 / 84$ & HGC & KGS & $\mathrm{H} 12 . \mathrm{C} 184 \mathrm{Ka}$ \\
\hline $\mathrm{H}-12$ & Cul & $01 / 11 / 84$ & HGC & UA & H12.C184UAa \\
\hline $\mathrm{H}-12$ & Cul & $01 / 25 / 84$ & HGC & H-B & $\mathrm{H} 12 . \mathrm{C} 184 \mathrm{HBb}$ \\
\hline $\mathrm{H}-12$ & $\mathrm{Cul}$ & $01 / 25 / 84$ & HGC & KGS & $\mathrm{H} 12 . \mathrm{C} 184 \mathrm{~Kb}$ \\
\hline $\mathrm{H}-12$ & $\mathrm{Cul}$ & $08 / 01 / 85-08 / 09 / 85$ & WQSP-R1 & FLD & H12.C885F \\
\hline $\mathrm{H}-12$ & Cul & $08 / 08 / 85$ & WQSP-R1 & BFEC & H12.C885B \\
\hline $\mathrm{H}-12$ & Cul & $08 / 09 / 85$ & WQSP-R1 & EEG & H12.C885E \\
\hline $\mathrm{H}-12$ & Cul & $08 / 09 / 85$ & WQSP-R1 & ITAS & H12.C885I \\
\hline P-14 & Cul & $03 / 14 / 77$ & USGS & USGS - & P14.C377G \\
\hline P-14 & $\mathrm{Cul}$ & $02 / 18 / 86-02 / 27 / 86$ & WQSP-R1 & FLD & P14.C286F \\
\hline P-14 & Cul & $02 / 26 / 86$ & WQSP-R1 & BFEC & P14.C286B \\
\hline P-14 & Cul & $02 / 26 / 86$ & WQSP-R1 & EEG & P14.C286E \\
\hline P-14 & Cul & $02 / 26,27 / 86$ & WQSP-R1 & ITAS & P14.C286I \\
\hline P-15 & Cul & $05 / 10 / 77$ & USGS & USGS & P15.C577G \\
\hline P-15 & $\mathrm{Cul}$ & $04 / 11 / 79$ & USGS & SNL & P15.C479S \\
\hline P-17 & Cul & $05 / 10 / 77$ & USGS & USGS & P17.C577G \\
\hline P-17 & $\mathrm{Cul}$ & $03 / 04 / 86-03 / 17 / 86$ & WQSP-R1 & FLD & P17.C386F \\
\hline P-17 & $\mathrm{Cul}$ & $03 / 17 / 86$ & WQSP-R1 & BFEC & P17.C386B \\
\hline$P-17$ & $\mathrm{Cul}$ & $03 / 17 / 86$ & WQSP-R1 & EEG & P17.C386E \\
\hline P-17 & Cul & $03 / 17 / 86$ & WQSP-R1 & ITAS & P17.C386I \\
\hline P-18 & $\mathrm{Cul}$ & $05 / 10 / 77$ & USGS & USGS & P18.C577G \\
\hline $\mathrm{W}-25$ & $\mathrm{Cul}$ & $08 / 14 / 80$ & USGS & USGS & W25.C880G \\
\hline $\mathrm{W}-25$ & $\mathrm{Cul}$ & $08 / 19 / 80-08 / 20 / 80$ & SNL & FLD & W25.C880F \\
\hline W-25 & $\mathrm{Cul}$ & $08 / 20 / 80$ & SNL & BFEC & W25.C880B \\
\hline W-25 & $\mathrm{Cul}$ & $01 / 31 / 86-02 / 13 / 86$ & WQSP-R1 & FLD & $\mathrm{W} 25 . \mathrm{C} 286 \mathrm{~F}$ \\
\hline W-25 & Cul & $02 / 12 / 86$ & WQSP-R1 & BFEC & W25.C286B \\
\hline W-25 & $\mathrm{Cul}$ & $02 / 12 / 86$ & WQSP-R1 & ITAS & W25.C286I \\
\hline W-26 & $\mathrm{Cul}$ & $08 / 18 / 80$ & USGS & USGS & W26.C880G \\
\hline W-26 & Cul & $08 / 23 / 80-08 / 24 / 80$ & SNL & FLD & W26.C880F \\
\hline W-26 & Cul & $08 / 24 / 80$ & SNL & BFEC & W26.C880B \\
\hline W-26 & Cul & $08 / 24 / 80$ & SNL & $\mathrm{KCS}$ & W26.C880KC \\
\hline W-26 & Cul & $11 / 19 / 85-11 / 26 / 85$ & WQSP-R1 & FLD & W26.C1185F \\
\hline W-26 & $\mathrm{Cul}$ & $11 / 25 / 85$ & WQSP-R1 & $\mathrm{BFEC}$ & W26.C1185B \\
\hline W-26 & $\mathrm{Cul}$ & $11 / 25 / 85$ & WQSP-R1 & EEG & W26.C1185E \\
\hline W-26 & Cul & $11 / 25 / 85$ & WQSP-R1 & ITAS & W26.C1185I \\
\hline
\end{tabular}


Table 3. List of Samples for Which Data Are Included in This Report (continued)

\begin{tabular}{|c|c|c|c|c|c|}
\hline Well Abbrev 1 & $\begin{array}{l}\text { Strat. } \\
\text { Zone }^{2} \\
\end{array}$ & Collection Date(s) ${ }^{3}$ & Agency $^{4}$ & $\mathrm{Lab}^{5}$ & Sample ID 6 \\
\hline W-27 & $\mathrm{Cul}$ & $08 / 22 / 80$ & USGS & USGS & W27.C880G \\
\hline $\begin{array}{l}W-27 \\
W-27\end{array}$ & $\begin{array}{l}\text { Cul } \\
\text { Cul }\end{array}$ & $\begin{array}{l}09 / 02 / 80-09 / 05 / 80 \\
09 / 03 / 80\end{array}$ & $\begin{array}{l}\text { SNL } \\
\text { SNL }\end{array}$ & $\begin{array}{l}\text { FLD } \\
\text { BFEC }\end{array}$ & $\begin{array}{l}\text { W27.C980F } \\
\text { W27.C980B }\end{array}$ \\
\hline W-28 & Cul & $08 / 21 / 80$ & USGS & USGS & W28.C880G \\
\hline $\begin{array}{l}W-28 \\
W-28 \\
W-28\end{array}$ & $\begin{array}{l}\mathrm{Cul} \\
\mathrm{Cul} \\
\mathrm{Cul}\end{array}$ & $\begin{array}{l}09 / 09 / 80-09 / 12 / 80 \\
09 / 11 / 80 \\
09 / 11 / 80\end{array}$ & $\begin{array}{l}\text { SNL } \\
\text { SNL } \\
\text { SNL }\end{array}$ & $\begin{array}{l}\text { FLD } \\
\text { BFEC } \\
\text { KCS }\end{array}$ & $\begin{array}{l}\text { W28.C } 980 F \\
\text { W28.C980B } \\
\text { W28.C980KC }\end{array}$ \\
\hline W-29 & $\mathrm{Cul}$ & $08 / 20 / 80$ & USGS & USGS & W29.C880G \\
\hline $\begin{array}{l}\text { W-29 } \\
W-29 \\
W-29\end{array}$ & $\begin{array}{l}\mathrm{Cul} \\
\mathrm{Cul} \\
\mathrm{Cul}\end{array}$ & $\begin{array}{l}08 / 26 / 80-08 / 28 / 80 \\
08 / 28 / 80 \\
08 / 28 / 80\end{array}$ & $\begin{array}{l}\text { SNL } \\
\text { SNL } \\
\text { SNL }\end{array}$ & $\begin{array}{l}\text { FLD } \\
\text { BFEC } \\
\text { KCS }\end{array}$ & $\begin{array}{l}\text { W29.C } 880 F \\
W 29 . C 880 B \\
W 29 . C 880 K C\end{array}$ \\
\hline $\begin{array}{l}\text { W-29 } \\
\text { W-29 } \\
\text { W-29 } \\
\text { W-29 }\end{array}$ & $\begin{array}{l}\text { Cul } \\
\text { Cul } \\
\text { Cul } \\
\text { Cul }\end{array}$ & $\begin{array}{l}12 / 05 / 85-12 / 15 / 85 \\
12 / 14 / 85 \\
12 / 14 / 85 \\
12 / 14 / 85\end{array}$ & $\begin{array}{l}\text { WQSP-R1 } \\
\text { WQSP-R1 } \\
\text { WQSP-R1 } \\
\text { WQSP-R1 }\end{array}$ & $\begin{array}{l}\text { FLD } \\
\text { BFEC } \\
\text { EEG } \\
\text { ITAS }\end{array}$ & $\begin{array}{l}\text { W29.C1285F } \\
\text { W29.C1285B } \\
\text { W29.C1285E } \\
\text { W29.C1285I }\end{array}$ \\
\hline W-30 & $\mathrm{Cul}$ & $08 / 13 / 80$ & USGS & USGS & W30.C880G \\
\hline $\begin{array}{l}\text { W-30 } \\
W-30 \\
W-30\end{array}$ & $\begin{array}{l}\text { Cul } \\
\text { Cul } \\
\text { Cul }\end{array}$ & $\begin{array}{l}09 / 02 / 80-09 / 06 / 80 \\
09 / 06 / 80 \\
09 / 06 / 80\end{array}$ & $\begin{array}{l}\text { SNL } \\
\text { SNL } \\
\text { SNL }\end{array}$ & $\begin{array}{l}\text { FLD } \\
\text { BFEC } \\
\text { KCS }\end{array}$ & $\begin{array}{l}\text { W30.C980F } \\
\text { W30.C980B } \\
\text { W30.C980KC }\end{array}$ \\
\hline $\begin{array}{l}\text { ENGLE } \\
\text { ENGLE } \\
\text { ENGLE } \\
\text { ENGLE }\end{array}$ & $\begin{array}{l}\text { Cul } \\
\text { Cul } \\
\text { Cul } \\
\text { Cul }\end{array}$ & $\begin{array}{l}11 / 04 / 83-11 / 10 / 83 \\
11 / 10 / 83 \\
11 / 10 / 83 \\
11 / 10 / 83\end{array}$ & $\begin{array}{l}\text { HGC } \\
\text { HGC } \\
\text { HGC } \\
\text { HGC }\end{array}$ & $\begin{array}{l}\text { FLD } \\
\text { H-B } \\
\text { KGS } \\
\text { UA }\end{array}$ & $\begin{array}{l}\text { XENG.C1183F } \\
\text { XENG.C1183HB } \\
\text { XENG.C1183K } \\
\text { XENG.C1183UA }\end{array}$ \\
\hline $\begin{array}{l}\text { ENGLE } \\
\text { ENGLE } \\
\text { ENGLE } \\
\text { ENGLE }\end{array}$ & $\begin{array}{l}\text { Cul } \\
\text { Cul } \\
\text { Cul } \\
\text { Cul }\end{array}$ & $\begin{array}{l}02 / 26 / 85-03 / 05 / 85 \\
03 / 05 / 85 \\
03 / 04,05 / 85 \\
03 / 04,05 / 85\end{array}$ & $\begin{array}{l}\text { WQSP-R1 } \\
\text { WQSP-R1 } \\
\text { WQSP-R1 } \\
\text { WQSP-R1 }\end{array}$ & $\begin{array}{l}\text { FLD } \\
\text { BFEC } \\
\text { EEG } \\
\text { ITAS }\end{array}$ & $\begin{array}{l}\text { XENG.C385F } \\
\text { XENG.C385B } \\
\text { XENG.C385E } \\
\text { XENG.C385I }\end{array}$ \\
\hline $\mathrm{H}-1$ & Mag & $06 / 04 / 76$ & USGS & USGS & H01.M676G \\
\hline $\mathrm{H}-1$ & Mag & $05 / 10 / 77$ & USGS & USGS & H01.M577G \\
\hline $\mathrm{H}-2 \mathrm{~A}$ & Mag & $02 / 22 / 77$ & USGS & USGS & H02A.M277G \\
\hline $\mathrm{H}-3 \mathrm{~B} 1$ & Mag & $05 / 10 / 77$ & USGS & USGS & H03B1.M577G \\
\hline H-3B1 & Mag & $05 / 10 / 79$ & USGS & SNL & H03B1.M579S \\
\hline $\begin{array}{l}\text { H-3B1 } \\
\text { H-3B1 } \\
\text { H-3B1 } \\
\text { H-3B1 }\end{array}$ & $\begin{array}{l}\text { Mag } \\
\text { Mag } \\
\text { Mag } \\
\text { Mag }\end{array}$ & $\begin{array}{l}06 / 17 / 85-07 / 02 / 85 \\
07 / 01 / 85 \\
07 / 01 / 85 \\
07 / 01 / 85\end{array}$ & $\begin{array}{l}\text { WQSP-R1 } \\
\text { WQSP-R1 } \\
\text { WQSP-R1 } \\
\text { WQSP-R1 }\end{array}$ & $\begin{array}{l}\text { FLD } \\
\text { BFEC } \\
\text { EEG } \\
\text { ITAS }\end{array}$ & $\begin{array}{l}\text { H03B1.M785F } \\
\text { H03B1.M785B } \\
\text { H03B1.M785E } \\
\text { H03B1.M785I }\end{array}$ \\
\hline $\mathrm{H}-4 \mathrm{~A}$ & Mag & $12 / 14 / 78$ & USGS & USGS & H04A.M1278G \\
\hline $\begin{array}{l}\mathrm{H}-4 \mathrm{C} \\
\mathrm{H}-4 \mathrm{C} \\
\mathrm{H}-4 \mathrm{C}\end{array}$ & $\begin{array}{l}\text { Mag } \\
\text { Mag } \\
\text { Mag }\end{array}$ & $\begin{array}{l}10 / 30 / 86-11 / 04 / 86 \\
11 / 04 / 86 \\
11 / 04 / 86\end{array}$ & $\begin{array}{l}\text { WQSP-R1 } \\
\text { WQSP-R1 } \\
\text { WQSP-R1 }\end{array}$ & $\begin{array}{l}\text { FLD } \\
\text { BFEC } \\
\text { ITAS }\end{array}$ & $\begin{array}{l}\text { H04C.M1186F } \\
\text { H04C.M1186B } \\
\text { H04C.M1186I }\end{array}$ \\
\hline
\end{tabular}


Table 3. List of Samples for Which Data Are Included in This Report (continued)

\begin{tabular}{|c|c|c|c|c|c|}
\hline Well Abbrev 1 & $\begin{array}{l}\text { Strat, } \\
\text { Zone }^{2}\end{array}$ & Collection Date $(s)^{3}$ & Agency $^{4}$ & $\mathrm{Lab}^{5}$ & Sample ID 6 \\
\hline $\mathrm{H}-5 \mathrm{~A}$ & Mag & $12 / 14 / 78$ & USGS & USGS & H05A.M1278G \\
\hline $\begin{array}{l}\mathrm{H}-5 \mathrm{C} \\
\mathrm{H}-5 \mathrm{C} \\
\mathrm{H}-5 \mathrm{C}\end{array}$ & $\begin{array}{l}\text { Mag } \\
\text { Mag } \\
\text { Mag }\end{array}$ & $\begin{array}{l}10 / 07 / 86-10 / 24 / 86 \\
10 / 24 / 86 \\
10 / 24 / 86\end{array}$ & $\begin{array}{l}\text { WQSP-R1 } \\
\text { WQSP-R1 } \\
\text { WQSP-R1 }\end{array}$ & $\begin{array}{l}\text { FLD } \\
\text { BFEC } \\
\text { ITAS }\end{array}$ & $\begin{array}{l}\text { H05C.M1086F } \\
\text { H05C.M1086B } \\
\text { H05C.M1086I }\end{array}$ \\
\hline $\mathrm{H}-6 \mathrm{~A}$ & Mag & $12 / 20 / 78$ & USGS & USGS & H06A.M1278G \\
\hline $\begin{array}{l}H-6 C \\
H-6 C \\
H-6 C\end{array}$ & $\begin{array}{l}\text { Mag } \\
\text { Mag } \\
\text { Mag }\end{array}$ & $\begin{array}{l}09 / 22 / 86-10 / 01 / 86 \\
10 / 01 / 86 \\
10 / 01 / 86\end{array}$ & $\begin{array}{l}\text { WQSP-R1 } \\
\text { WQSP-R1 } \\
\text { WQSP-R1 }\end{array}$ & $\begin{array}{l}\text { FLD } \\
\text { BFEC } \\
\text { ITAS }\end{array}$ & $\begin{array}{l}\text { H06C.M1086F } \\
\text { H06C.M1086B } \\
\text { H06C.M1086I }\end{array}$ \\
\hline $\mathrm{H}-8 \mathrm{~A}$ & Mag & $02 / 12 / 80$ & USGS & USGS & H08A.M280G \\
\hline $\mathrm{H}-8 \mathrm{~A}$ & Mag & $10 / 21 / 85$ & WQSP-R1 & ITAS & H08A.M1085I \\
\hline $\mathrm{H}-9 \mathrm{~A}$ & Mag & $02 / 05 / 80$ & USGS & USGS & H09A.M280G \\
\hline $\mathrm{H}-10 \mathrm{~A}$ & Mag & $03 / 21 / 80$ & USGS & USGS & H10A.M380G \\
\hline $\mathrm{W}-25$ & Mag & $09 / 04 / 80$ & USGS & USGS & W25.M980G \\
\hline $\begin{array}{l}\text { W-25 } \\
\text { W-25 }\end{array}$ & $\begin{array}{l}\text { Mag } \\
\text { Mag }\end{array}$ & $\begin{array}{l}09 / 16 / 80-09 / 18 / 80 \\
09 / 17 / 80\end{array}$ & $\begin{array}{l}\text { SNL } \\
\text { SNL }\end{array}$ & $\begin{array}{l}\text { FLD } \\
\text { BFEC }\end{array}$ & $\begin{array}{l}\text { W25.M980F } \\
\text { W25.M980B }\end{array}$ \\
\hline W-27 & Mag & $09 / 04 / 80$ & USGS & USGS & W27.M980G \\
\hline $\begin{array}{l}\text { W-27 } \\
\text { W-27 }\end{array}$ & $\begin{array}{l}\text { Mag } \\
\text { Mag }\end{array}$ & $\begin{array}{l}09 / 24 / 80-09 / 25 / 80 \\
09 / 25 / 80\end{array}$ & $\begin{array}{l}\text { SNL } \\
\text { SNL }\end{array}$ & $\begin{array}{l}\text { FLD } \\
\text { BFEC }\end{array}$ & $\begin{array}{l}\text { W27.M980F } \\
\text { W27.M980B }\end{array}$ \\
\hline W-30 & Mag & $09 / 20 / 80$ & USGS & USGS & W30.M980G \\
\hline W-30 & Mag & $12 / 02 / 80-12 / 10 / 80$ & SNL & FLD & W30.M1280F \\
\hline $\mathrm{H}-1$ & RS & $02 / 23 / 77$ & USGS & USGS & H01.R277G \\
\hline $\mathrm{H}-2 \mathrm{C}$ & RS & $02 / 23 / 77$ & USGS & USGS & H02C.R277G \\
\hline $\mathrm{H}-3 \mathrm{~B} 1$ & $\mathrm{RS}$ & $02 / 23 / 77$ & USGS & USGS & H03B1.R277G \\
\hline $\begin{array}{l}\mathrm{H}-4 \mathrm{C} \\
\mathrm{H}-4 \mathrm{C}\end{array}$ & $\begin{array}{l}\mathrm{RS} \\
\mathrm{RS}\end{array}$ & $\begin{array}{l}03 / 16 / 79 \\
03 / 16 / 79\end{array}$ & $\begin{array}{l}\text { USGS } \\
\text { USGS }\end{array}$ & $\begin{array}{l}\text { SNL } \\
\text { USGS }\end{array}$ & $\begin{array}{l}\text { H04C.R379S } \\
\text { H04C.R379G }\end{array}$ \\
\hline $\begin{array}{l}\mathrm{H}-5 \mathrm{C} \\
\mathrm{H}-5 \mathrm{C}\end{array}$ & $\begin{array}{l}\text { RS } \\
\text { RS }\end{array}$ & $\begin{array}{l}05 / 16 / 79 \\
05 / 16 / 79\end{array}$ & $\begin{array}{l}\text { USGS } \\
\text { USGS }\end{array}$ & $\begin{array}{l}\text { SNL } \\
\text { USGS }\end{array}$ & $\begin{array}{l}\text { H05C.R579S } \\
\text { H05C.R579G }\end{array}$ \\
\hline $\begin{array}{l}H-6 C \\
H-6 C\end{array}$ & $\begin{array}{l}\text { RS } \\
\text { RS }\end{array}$ & $\begin{array}{l}04 / 09 / 79 \\
04 / 09 / 79\end{array}$ & $\begin{array}{l}\text { USGS } \\
\text { USGS }\end{array}$ & $\begin{array}{l}\text { SNL } \\
\text { USGS }\end{array}$ & $\begin{array}{l}\text { H06C.R479S } \\
\text { H06C.R479G }\end{array}$ \\
\hline $\mathrm{H}-7 \mathrm{C}$ & RS & $03 / 20 / 80$ & USGS & USGS & H07C.R380G \\
\hline $\mathrm{H}-8 \mathrm{C}$ & RS & $09 / 06 / 80$ & USGS & USGS & H08C.R980G \\
\hline $\mathrm{H}-9 \mathrm{C}$ & RS & $05 / 20 / 80$ & USGS & USGS & H09C.R580G \\
\hline $\mathrm{H}-10 \mathrm{C}$ & RS & $05 / 19 / 80$ & USGS & USGS & H10C.R580G \\
\hline P-14 & RS & $02 / 24 / 77$ & USGS & USGS & P14.R277G \\
\hline
\end{tabular}


Table 3. List of Samples for Which Data Are Included in This Report (continued)

\begin{tabular}{|c|c|c|c|c|c|}
\hline Well Abbrev 1 & $\begin{array}{l}\text { Strat. } \\
\text { Zone }^{2} \\
\end{array}$ & Collection Date(s) & Agency 4 & $\mathrm{Lab}^{5}$ & Sample ID 6 \\
\hline P-15 & RS & $04 / 03 / 79$ & USGS & SNL & P15.R479S \\
\hline P-15 & RS & $04 / 03 / 79$ & USGS & USGS & P15.R479G \\
\hline P-17 & RS & $05 / 11 / 79$ & USGS & SNL & P17.R579S \\
\hline P-17 & RS & $05 / 11 / 79$ & USGS & USGS & P17.R579G \\
\hline P-18 & RS & $05 / 11 / 79$ & USGS & SNL & P18.R579S \\
\hline P-18 & RS & $05 / 11 / 79$ & USGS & USGS & P18.R579G \\
\hline W-25 & RS & $03 / 19 / 80$ & USGS & USGS & W25.R380G \\
\hline$W-25$ & RS & $07 / 16 / 80-07 / 17 / 80$ & SNL & FLD & W25.R780F \\
\hline W-25 & RS & $07 / 17 / 80$ & SNL & BFEC & W25.R780B \\
\hline W-26 & RS & $03 / 18 / 80$ & USGS & USGS & W26.R380G \\
\hline W-26 & RS & $07 / 22 / 80-07 / 23 / 80$ & SNL & FLD & W26.R780F \\
\hline W-26 & $\mathbf{R S}$ & $07 / 23 / 80$ & SNL & BFEC & W26.R780B \\
\hline W-27 & RS & $05 / 21 / 80$ & USGS & USGS & W27.R580G \\
\hline W-27 & RS & 08/05/80 - 08/07/80 & SNL & FLD & W27.R780F \\
\hline W-28 & RS & $03 / 20 / 80$ & USGS & USGS & W28.R380G \\
\hline W-28 & RS & $07 / 30 / 80-07 / 31 / 80$ & SNL & FLD & W28.R780F \\
\hline W-28 & RS & $07 / 31 / 80$ & SNL & $\mathrm{BFEC}$ & W28.R780B \\
\hline W-29 & RS & $03 / 18 / 80$ & USGS & USGS & W29.R380G \\
\hline W-29 & RS & $07 / 22 / 80-07 / 24 / 80$ & SNL & FLD & W29.R780F \\
\hline W-29 & RS & $07 / 24 / 80$ & SNL & BFEC & W29.R780B \\
\hline W-30 & RS & $03 / 19 / 80$ & USGS & USGS & W30.R380G \\
\hline $\begin{array}{l}\text { W-30 } \\
\text { W-30 }\end{array}$ & $\begin{array}{l}\text { RS } \\
\text { RS }\end{array}$ & $\begin{array}{l}07 / 16 / 80-07 / 17 / 80 \\
07 / 17 / 80\end{array}$ & $\begin{array}{l}\text { SNL } \\
\text { SNL }\end{array}$ & $\begin{array}{l}\text { FLD } \\
\text { BFEC }\end{array}$ & $\begin{array}{l}\text { W30.R780F } \\
\text { W30.R780B }\end{array}$ \\
\hline POCKET & $\mathrm{DL}$ & $10 / 27 / 83-11 / 02 / 83$ & HGC & FLD & XPOC.D1183F \\
\hline POCKET & DL & $11 / 02 / 83$ & HGC & H-B & XPOC.D1183HB \\
\hline POCKET & DL & $11 / 02 / 83$ & HGC & KGS & XPOC.D1183Ka \\
\hline POCKET & DL & $11 / 02 / 83$ & HGC & KGS & XPOC.D1183Kb \\
\hline POCKET & DL & $11 / 02 / 83$ & $\mathrm{HGC}$ & UA & XPOC.D1183UA \\
\hline RANCH & DL & $06 / 13 / 86-06 / 18 / 86$ & WQSP-R1 & FLD & XRAN.D686F \\
\hline RANCH & DL & $06 / 18 / 86$ & WQSP-R1 & BFEC & XRAN.D686B \\
\hline RANCH & $\overline{D L}$ & $06 / 18 / 86$ & WQSP-R1 & ITAS & XRAN.D686I \\
\hline TWIN-P & $\mathrm{DL}$ & $01 / 24 / 86-02 / 02 / 86$ & WQSP-R1 & FLD & XTWP.D186F \\
\hline TWIN-P & DL & $01 / 30 / 86$ & WQSP-RI & BFEC & XTWP.D186B \\
\hline TWIN-P & DL & $01 / 31 / 86$ & WQSP-R1 & EEG & XTWP.D186E \\
\hline TWIN-P & DL & $01 / 30,31 / 86$ & WQSP-R1 & ITAS & XTWP.D186I \\
\hline UNGER & DL & $01 / 26 / 84$ & HGC & H-B & XUNG.D184HB \\
\hline UNGER & DL & $01 / 26 / 84$ & HGC & KGS & XUNG.D184K \\
\hline UNGER & DL & $01 / 26 / 84$ & HGC & UA & XUNG.D184UA \\
\hline
\end{tabular}


Table 3. List of Samples for Which Data Are Included in This Report (continued)

\begin{tabular}{|c|c|c|c|c|c|}
\hline Well Abbrev 1 & $\begin{array}{l}\text { Strat, } \\
\text { Zone }^{2}\end{array}$ & Collection Date(s) ${ }^{3}$ & Agency 4 & $\mathrm{Lab}^{5}$ & Sample ID 6 \\
\hline DOE-2 & $\mathrm{BC}$ & $07 / 20 / 85-07 / 23 / 85$ & WQSP-R1 & FLD & D2.B785F \\
\hline DOE-2 & $\mathrm{BC}$ & $07 / 23 / 85$ & WQSP-R1 & BFEC & D2.B785B \\
\hline DOE-2 & $\mathrm{BC}$ & $07 / 23 / 85$ & WQSP-R1 & EEG & D2.B785E \\
\hline DOE-2 & $\mathrm{BC}$ & $07 / 23 / 85$ & WQSP-R1 & ITAS & D2.B785I \\
\hline $\mathrm{W}-15$ & Alluvium & $03 / 12 / 79$ & USGS & SNL & W15.Q379S \\
\hline
\end{tabular}

1. Abbreviations of well names are explained in Table 1.

2. Stratigraphic zones sampled:

BC - Bell Canyon Formation

Cul - Culebra Dolomite

DL - Dewey Lake Red Beds

Mag - Magenta Dolomite

RS - Rustler/Salado contact zone

3. Date(s) on which final samples were collected or range of dates during which serial samples were collected.

4. Agency responsible for sample collection:

HGC - Hydro Geo Chem, Inc., Tucson, AZ

SNL - Sandia National Laboratories, Albuquerque, NM

USGS - United States Geological Survey

WQSP-R1 - Round One of the Water Quality Sampling Program

5. Laboratory that did analyses:

BFEC - Bendix Field Engineering Corp., Grand Junction, CO (now UNC Technical Services; called UNC/Bendix in the text)

EEG - New Mexico Bureau of Mines \& Mineral Resources, Socorro, NM

FLD - Field measurements, either steady-state values or the best available values

H-B - Bendix Field Engineering Corp., Grand Junction, CO

ITAS - IT Analytical Services, Murraysville, PA

KCS - KC Services

KGS - Kansas Geological Survey

SNL - Sandia National Laboratories, Albuquerque, NM

UA - University of Arizona, Laboratory of Isotope Geochemistry

USGS - United States Geological Survey, Central Laboratories

6. Sample identification code used for cross-referencing to other data tables. The codes contain the following: a well abbreviation; a period; a zone abbreviation $(C=$ Culebra, and so forth.); the month and year of collection; a letter code indicating the laboratory; optionally, a lower-case suffix to distinguish either more than one sample sent to the same lab or more than one sample collected in the same month. 
Table 4. Data from Serial Samples Collected from the Culebra at H-4B in May 1981

\begin{tabular}{|c|c|c|c|c|c|c|c|c|}
\hline Date & $\begin{array}{l}\text { Collection } \\
\text { Time: } \\
\text { Start - End }\end{array}$ & $\begin{array}{l}\text { Temp } \\
\left({ }^{\circ} \mathrm{C}\right)\end{array}$ & $\begin{array}{l}\text { Specific } \\
\text { Gravity }\end{array}$ & $\mathrm{pH}$ & $\begin{array}{c}\text { Eh } \\
\text { (volts) }\end{array}$ & $\begin{array}{c}\text { Specific } \\
\text { Conductance } \\
(\mu \mathrm{S} / \mathrm{cm})\end{array}$ & $\begin{array}{c}\text { Alkalinity } \\
\mathrm{HCO}_{\overline{3}} \\
(\mathrm{mg} / \mathrm{L})\end{array}$ & $\begin{array}{c}\mathrm{SO}_{4} \\
(\mathrm{mg} / \mathrm{L})\end{array}$ \\
\hline $05 / 14 / 81$ & $17: 50-17: 55$ & 21.0 & 1.015 & 8.30 & -0.057 & 32000 & 69.7 & $\sim 5500$ \\
\hline $05 / 15 / 81$ & $08: 25-08: 30$ & 20.0 & 1.010 & 8.14 & 0.024 & 25000 & 71.0 & -6400 \\
\hline $05 / 15 / 81$ & $15: 50-15: 55$ & 23.0 & 1.010 & 8.09 & 0.080 & 29500 & 71.0 & -3900 \\
\hline $05 / 16 / 81$ & $06: 00-06: 05$ & 19.5 & 1.010 & 8.08 & 0.114 & 23700 & 71.3 & -4800 \\
\hline $05 / 27 / 81$ & $13: 50-13: 55$ & 25.0 & 1.010 & 8.03 & 0.173 & 30000 & 71.3 & $\sim 5500$ \\
\hline $05 / 28 / 81$ & $10: 20-10: 25$ & 22.0 & 1.010 & 8.00 & 0.123 & 26500 & 71.9 & -5900 \\
\hline $05 / 29 / 81$ & $10: 10-10: 15$ & 22.0 & 1.010 & 8.00 & 0.158 & 25500 & 71.0 & -6300 \\
\hline
\end{tabular}

First test: pumping started on 05/14/81 at 09:00. Average pumping rate was $20 \mathrm{gph}$.

Second test: pumping started on 05/21/81 at 12:30. Average pumping rate was $15 \mathrm{gph}$.

Table 5. Data from Serial Samples Collected from the Culebra at H-5B in May/June 1981

\begin{tabular}{|c|c|c|c|c|c|c|c|c|}
\hline Date & $\begin{array}{l}\text { Collection } \\
\text { Time: } \\
\text { Start - End }\end{array}$ & $\begin{array}{l}\text { Temp } \\
\left({ }^{\circ} \mathrm{C}\right)\end{array}$ & $\begin{array}{l}\text { Specific } \\
\text { Gravity }\end{array}$ & $\mathrm{pH}$ & $\begin{array}{c}\text { Eh } \\
\text { (volts) }\end{array}$ & $\begin{array}{c}\text { Specific } \\
\text { Conductance } \\
(\mu \mathrm{S} / \mathrm{cm})\end{array}$ & $\begin{array}{c}\text { Alkalinity } \\
\mathrm{HCO}_{\overline{3}} \\
(\mathrm{mg} / \mathrm{L})\end{array}$ & $\begin{array}{c}\mathrm{SO}_{4}= \\
(\mathrm{mg} / \mathrm{L})\end{array}$ \\
\hline 05/29/81 & $12: 00-12: 05$ & 23.5 & 1.100 & 7.90 & 0.052 & 170000 & 84.4 & -8700 \\
\hline $05 / 31 / 81$ & $09: 40-09: 45$ & 22.0 & 1.100 & 7.90 & 0.052 & 140000 & 83.1 & -8000 \\
\hline $06 / 01 / 81$ & $10: 00-10: 05$ & 22.5 & 1.100 & 7.90 & 0.044 & 130000 & 81.2 & -8500 \\
\hline $06 / 02 / 81$ & $08: 30-08: 35$ & 21.5 & 1.100 & 7.90 & 0.045 & 150000 & 79.9 & -8500 \\
\hline
\end{tabular}

Pumping started on $05 / 27 / 81$ at $12: 30$ and stopped during the evening of $05 / 29 / 81$. Pumping was restarted on $05 / 30 / 81$ at 11:30. Average pumping rate was $12 \mathrm{gph}$. 
Table 6. Data from Serial Samples Collected from the Culebra at H-5C in Oct. 1981

Collection Times:

\begin{tabular}{|c|c|c|c|c|c|c|c|c|}
\hline Date & $\begin{array}{l}\mathrm{HCO}_{\overline{3}} \\
\text { Sample } \\
\end{array}$ & $\begin{array}{l}\text { Other Samples } \\
\text { Start - End }\end{array}$ & $\begin{array}{l}\text { Temp } \\
\left({ }^{\circ} \mathrm{C}\right)\end{array}$ & $\begin{array}{l}\text { Specific } \\
\text { Gravity }\end{array}$ & $\mathrm{pH}$ & $\begin{array}{c}\text { Eh } \\
\text { (volts) }\end{array}$ & $\begin{array}{c}\text { Specific } \\
\text { Conductance } \\
(\mu \mathrm{S} / \mathrm{cm})\end{array}$ & $\begin{array}{c}\text { Alkalinity } \\
\mathrm{HCO}_{\overline{3}} \\
(\mathrm{mg} / \mathrm{L})\end{array}$ \\
\hline $10 / 12 / 81$ & $14: 50$ & $14: 55-15: 00$ & 24.0 & & 7.90 & 0.052 & 140000 & 90.3 \\
\hline $10 / 13 / 81$ & $11: 55$ & $12: 00-12: 05$ & 25.0 & 1.110 & 7.92 & 0.051 & 150000 & 87.1 \\
\hline $10 / 14 / 81$ & $10: 05$ & $10: 10-10: 15$ & 24.0 & 1.102 & 7.91 & 0.062 & 160000 & 86.4 \\
\hline $10 / 15 / 81$ & $10: 35$ & $10: 40-10: 45$ & 23.5 & & 7.89 & 0.032 & 140000 & 85.5 \\
\hline
\end{tabular}

Pumping started on 10/07/81 at 09:35. Average pumping rate was $7.5 \mathrm{gph}$.

Table 7. Data from Serial Samples Collected from the Culebra at H-6B in May 1981

\begin{tabular}{|c|c|c|c|c|c|c|c|c|}
\hline Date & $\begin{array}{l}\text { Collection } \\
\text { Time: }\end{array}$ & $\begin{array}{l}\text { Temp } \\
\left({ }^{\circ} \mathrm{C}\right)\end{array}$ & $\begin{array}{l}\text { Specific } \\
\text { Gravity }\end{array}$ & $\mathrm{pH}$ & $\begin{array}{c}\text { Eh } \\
\text { (volts) }\end{array}$ & $\begin{array}{c}\text { Specific } \\
\text { Conductance } \\
(\mu \mathrm{S} / \mathrm{cm})\end{array}$ & $\begin{array}{l}\text { Alkalinity } \\
\mathrm{HCO}_{\overline{3}} \\
(\mathrm{mg} / \mathrm{L})\end{array}$ & $\begin{array}{c}\mathrm{SO}_{4}^{=} \\
(\mathrm{mg} / \mathrm{L})\end{array}$ \\
\hline $05 / 01 / 81$ & $16: 30$ & 23.0 & 1.040 & 7.00 & 0.242 & 73000 & 97.5 & -3500 \\
\hline $05 / 02 / 81$ & $05: 20$ & 22.0 & 1.040 & 7.00 & 0.243 & 70000 & 96.3 & -3900 \\
\hline
\end{tabular}

Pumping started on 05/01/81 at 10:20. Average pumping rate was $23 \mathrm{gpm}$.

Table 8. Data from Serial Samples Collected from the Culebra at H-6C in May 1981

Collection times:

\begin{tabular}{|c|c|c|c|c|c|c|c|c|c|}
\hline Date & $\begin{array}{l}\mathrm{HCO}_{3} \\
\text { Sample }\end{array}$ & $\begin{array}{l}\text { Other } \\
\text { Samples }\end{array}$ & $\begin{array}{l}\text { Temp } \\
\left({ }^{\circ} \mathrm{C}\right)\end{array}$ & $\begin{array}{l}\text { Specific } \\
\text { Gravity }\end{array}$ & $\mathrm{pH}$ & $\begin{array}{c}\text { Eh } \\
\text { (volts) }\end{array}$ & $\begin{array}{c}\text { Specific } \\
\text { Conductance } \\
(\mu \mathrm{S} / \mathrm{cm})\end{array}$ & $\begin{array}{c}\text { Alkalinity } \\
\mathrm{HCO}_{\overline{3}} \\
(\mathrm{mg} / \mathrm{L})\end{array}$ & $\begin{array}{c}\mathrm{SO}_{4}^{=} \\
(\mathrm{mg} / \mathrm{L})\end{array}$ \\
\hline $05 / 13 / 81$ & $10: 25$ & $10: 25$ & 23.0 & 1.040 & 7.10 & 0.280 & 80000 & 95.3 & -4000 \\
\hline $05 / 27 / 81$ & $13: 00$ & $11: 20$ & 23.5 & 1.040 & 7.20 & 0.277 & 80000 & 94.3 & -3800 \\
\hline
\end{tabular}

Pumping started on 05/12/81 at 16:05. Generator failed on 05/14/81 at 01:10. Average pumping rate was $19 \mathrm{gpm}$. Pumping was restarted on 05/21/81 at 10:45. Average pumping rate was $17 \mathrm{gpm}$. 
Table 9. Data from Serial Samples Collected from the Culebra at H-3B3 in June 1984

\begin{tabular}{|c|c|c|c|c|c|}
\hline $\begin{array}{c}\text { Collection } \\
\text { Date }\end{array}$ & $\begin{array}{c}\text { Collection } \\
\text { Time } \\
\end{array}$ & $\begin{array}{l}\text { Temp } \\
\left({ }^{\circ} \mathrm{C}\right) \\
\end{array}$ & $\begin{array}{l}\text { Specific } \\
\text { Gravity }\end{array}$ & $\mathrm{pH}$ & $\begin{array}{c}\text { Specific } \\
\text { Conductance } \\
(\mu \mathrm{S} / \mathrm{cm})\end{array}$ \\
\hline $06 / 10 / 84$ & $16: 59$ & 25.8 & 1.034 & 7.40 & 73700 \\
\hline $06 / 11 / 84$ & $09: 30$ & 25.6 & 1.034 & 7.41 & 68900 \\
\hline $06 / 11 / 84$ & $15: 00$ & 25.6 & 1.035 & 7.46 & 74800 \\
\hline
\end{tabular}

Table 10. Data from Serial Samples Collected from the Culebra at $\mathrm{H}-4 \mathrm{C}$ in August 1984

\begin{tabular}{|c|c|c|c|c|c|c|}
\hline $\begin{array}{c}\text { Collection } \\
\text { Date }\end{array}$ & $\begin{array}{c}\text { Collection } \\
\text { Time }\end{array}$ & $\begin{array}{c}\text { Temp } \\
\left({ }^{\circ} \mathrm{C}\right)\end{array}$ & $\begin{array}{l}\text { Specific } \\
\text { Gravity }\end{array}$ & $\mathrm{pH}$ & $\begin{array}{c}\text { Specific } \\
\text { Conductance } \\
(\mu S / \mathrm{cm})\end{array}$ & $\begin{array}{l}\text { Alkalinity } \\
\mathrm{HCO}_{\overline{3}} \\
(\mathrm{mg} / \mathrm{L})\end{array}$ \\
\hline $08 / 09 / 84$ & $11: 53$ & 23 & 1.012 & 7.70 & 25800 & \\
\hline $08 / 09 / 84$ & $22: 00$ & 21 & 1.012 & 7.90 & 24300 & \\
\hline $08 / 10 / 84$ & $12: 12$ & 21.5 & 1.010 & 8.55 & 24500 & \\
\hline $08 / 10 / 84$ & $15: 45$ & 21.5 & 1.01 & 7.80 & 24500 & 75 \\
\hline
\end{tabular}


Table 11. Steady-State Field Results for Serial-Sampling Parameters Determined in Nash Draw in $1980^{1}$

\begin{tabular}{|c|c|c|c|c|c|c|c|c|c|c|c|c|}
\hline Well & Zone & $\begin{array}{l}\text { Serial-Sampling } \\
\text { Dates } \\
\text { (start - stop) }\end{array}$ & $\begin{array}{l}\text { Temp } \\
\text { Range } \\
\left({ }^{\circ} \mathrm{C}\right)\end{array}$ & $\mathrm{pH}$ & $\begin{array}{l}\text { Spec. } \\
\text { Grav. }\end{array}$ & $\begin{array}{c}\text { Alk. } \\
\mathrm{CO} \overline{\overline{3}} \\
\text { (mg/L) }\end{array}$ & $\begin{array}{c}\text { Alk. } \\
\mathrm{HCO} \overline{3} \\
(\mathrm{mg} / \mathrm{L})\end{array}$ & $\begin{array}{c}\mathrm{Cl}^{-} \\
(\mathrm{mg} / \mathrm{L})\end{array}$ & $\underset{(\mathrm{meq} / \mathrm{L})}{\mathrm{X}^{++}}$ & $\begin{array}{c}\mathrm{Ca} \\
(\mathrm{mg} / \mathrm{L})\end{array}$ & $\begin{array}{c}\mathrm{SO}_{\overline{4}} \\
(\mathrm{mg} / \mathrm{L})\end{array}$ & $\begin{array}{c}\text { Total } \\
\mathrm{Fe} \\
(\mathrm{mg} / \mathrm{L})\end{array}$ \\
\hline W-25 & RS & $07 / 16 / 80-07 / 17 / 80$ & $22-23$ & 7.4 & na & 0 & 130 & 190000 & 290 & na & na & na \\
\hline $\mathrm{W}-25$ & $\mathrm{Cul}$ & $08 / 19 / 80-08 / 20 / 80$ & $22-23$ & 6.9 & 1.01 & 0 & 210 & 5200 & 66 & 910 & -3000 & -0.6 \\
\hline W-25 & Mag & $09 / 16 / 80-09 / 18 / 80$ & $21-23$ & 6.9 & 1.004 & 0 & 180 & 4900 & 66 & 920 & -3000 & -0.6 \\
\hline W-26 & RS & $07 / 22 / 80-07 / 23 / 80$ & $23-25$ & 7.7 & na & 0 & 270 & 110000 & 190 & na & na & na \\
\hline W-26 & $\mathrm{Cul}$ & $08 / 23 / 80-08 / 24 / 80$ & $21-23$ & 6.9 & 1.005 & 0 & 140 & 6900 & 91 & 1300 & -3000 & -0.3 \\
\hline $\mathrm{W}-27$ & $\mathrm{RS}^{2}$ & $08 / 05 / 80-08 / 07 / 80$ & $22-31$ & $(-7.1)$ & $(\sim 1.07)$ & $(\sim 0)$ & $(\sim 70)$ & $(\sim 58000)$ & $(-220)$ & na & $(-10000)$ & na \\
\hline W-27 & $\mathrm{Cul}$ & $09 / 02 / 80-09 / 05 / 80$ & $21-25$ & 6.4 & 1.09 & 0 & 120 & 77000 & 320 & 3300 & -4000 & -0.4 \\
\hline W-27 & Mag & $09 / 24 / 80-09 / 25 / 80$ & $21-22$ & 6.4 & 1.09 & 0 & 210 & 84000 & 330 & 3600 & -3000 & -2 \\
\hline W-28 & RS & $07 / 30 / 80-07 / 31 / 80$ & $23-25$ & 7.0 & 1.18 & 0 & 170 & 150000 & 300 & na & -20000 & $\sim 0.1$ \\
\hline $\mathrm{W}-28$ & Cul & $09 / 09 / 80-09 / 12 / 80$ & $22-23$ & 6.5 & 1.03 & 0 & $<350^{3}$ & 24000 & 100 & 1200 & $\sim 4000$ & -0.8 \\
\hline W-29 & RS & $07 / 22 / 80-07 / 24 / 80$ & $20-22$ & 7.2 & na & 0 & 200 & 57000 & 230 & na & $\sim 10000$ & na \\
\hline W-29 & $\mathrm{Cul}$ & $08 / 26 / 80-08 / 28 / 80$ & $20-21$ & 6.1 & 1.16 & 0 & 210 & 130000 & 480 & 1100 & -10000 & -0.8 \\
\hline $\mathrm{W}-30$ & RS & $07 / 16 / 80-07 / 17 / 80$ & $22-27$ & 7.5 & na & 0 & 620 & 180000 & 260 & $(-900)$ & na & na \\
\hline$W-30$ & Cul & $09 / 02 / 80-09 / 06 / 80$ & $21-25$ & 8.8 & 1.02 & 17 & 40 & 15000 & 97 & 1200 & -4000 & $\sim 0.05$ \\
\hline $\mathrm{W}-30$ & $\mathrm{Mag}^{4}$ & $12 / 02 / 80-12 / 10 / 80$ & $4-20$ & $(\sim 8.6)$ & $(<1.01)$ & $(-10)$ & $(\sim 50)$ & $(<4000)$ & $(<44)$ & $(<620)$ & $(<4000)$ & -0.1 \\
\hline
\end{tabular}

1. Key: $\mathrm{na}=\mathrm{not}$ analyzed; $\mathrm{RS}=\mathrm{Rustler} /$ Salado contact zone; $\mathrm{Cul}=$ Culebra Dolomite; $\mathrm{Mag}=$ Magenta Dolomite; abbreviations of well names are explained in Table 1.

2. Representative sample not collected from WIPP-27 Rustler/Salado. Field values are presented as approximations ( $\left(^{-}\right)$.

3. Alkalinity at WIPP-28 Culebra was still decreasing when test terminated. Value is presented as an upper limit.

4. Representative sample not collected from WIPP-30 Magenta. Solute concentrations were decreasing when test terminated, so values are given as upper limits. 
Table 12. Steady-State Field Results for Serial-Sampling Parameters Determined During Hydrologic Tests in 1980 and $1981^{1}$

\begin{tabular}{|c|c|c|c|c|c|c|c|}
\hline Well & Zone & $\begin{array}{l}\text { Serial-Sampling } \\
\text { Dates } \\
\text { (start - stop) }\end{array}$ & $\begin{array}{l}\text { Temp. } \\
\text { Range } \\
\left({ }^{\circ} \mathrm{C}\right)\end{array}$ & $\mathrm{pH}$ & $\begin{array}{l}\text { Specific } \\
\text { Gravity }\end{array}$ & $\begin{array}{c}\text { Alk. } \\
\mathrm{HCO}_{\overline{3}} \\
(\mathrm{mg} / \mathrm{L})\end{array}$ & $\begin{array}{c}\mathrm{SO}_{4} \\
(\mathrm{mg} / \mathrm{L})\end{array}$ \\
\hline $\mathrm{H}-2 \mathrm{C}$ & Cul & $12 / 10 / 80$ & $\sim 19$ & 7.9 & 1.002 & na & na \\
\hline $\mathrm{H}-4 \mathrm{~B}$ & Cul & $05 / 14 / 81-05 / 29 / 81$ & $19-25$ & 8.0 & 1.01 & 71 & -6000 \\
\hline H-5B & $\mathrm{Cul}$ & $05 / 27 / 81-06 / 02 / 81$ & $21-24$ & 7.9 & 1.10 & 80 & $\sim 8000$ \\
\hline $\mathrm{H}-5 \mathrm{C}$ & Cul & $10 / 07 / 81-10 / 15 / 81$ & $23-25$ & 7.9 & 1.10 & 86 & na \\
\hline$H-6 B$ & $\mathrm{Cul}$ & $05 / 01 / 81-05 / 02 / 81$ & $22-23$ & 7.0 & 1.04 & 96 & $\sim 4000$ \\
\hline $\mathrm{H}-6 \mathrm{C}$ & $\mathrm{Cul}$ & $05 / 12 / 81-05 / 27 / 81$ & $23-24$ & 7.2 & 1.04 & 94 & -4000 \\
\hline
\end{tabular}

1. Key: na $=$ not analyzed; $\mathrm{Cul}=$ Culebra Dolomite.

Table 13. Steady-State or Best Available Field Results for Serial-Sampling Parameters Determined During Hydrologic Tests in 1983 and $1984^{1}$

\begin{tabular}{|c|c|c|c|c|c|c|c|}
\hline Well & Zone & $\begin{array}{l}\text { Serial-Sampling } \\
\text { Dates } \\
\text { (start - stop) }\end{array}$ & $\begin{array}{l}\text { Temp. } \\
\text { Range } \\
\left({ }^{\circ} \mathrm{C}\right)\end{array}$ & $\begin{array}{l}\text { Specific } \\
\text { Gravity }\end{array}$ & $\mathrm{pH}$ & $\begin{array}{c}\text { Specific } \\
\text { Conductance } \\
(\mu \mathrm{S} / \mathrm{cm})\end{array}$ & $\begin{array}{c}\text { Alk. }^{2} \\
\mathrm{HCO}_{\overline{3}} \\
\text { (mg/L) }\end{array}$ \\
\hline DOE-1 & Cul & $04 / 13 / 83-04 / 21 / 83$ & $20-22$ & 1.090 & 7.6 & 125000 & $-65-70$ \\
\hline ENGLE & $\mathrm{Cul}$ & $11 / 04 / 83-11 / 10 / 83$ & $22-24$ & & 7.3 & 3600 & -230 \\
\hline FR-10 & Cul & $10 / 06 / 83$ & $21-23$ & 1.000 & 7.4 & 3200 & -260 \\
\hline H-9B & Cul & $10 / 07 / 83$ & 24 & 1.000 & 7.9 & 3600 & -240 \\
\hline $\mathrm{H}-12$ & $\mathrm{Cul}$ & $01 / 07 / 84-01 / 12 / 84$ & & 1.090 & 7.9 & & \\
\hline POCKET & DL & $10 / 27 / 83-11 / 02 / 83$ & $19-21$ & 1.000 & 7.7 & 3800 & -140 \\
\hline
\end{tabular}

1. Key: $\mathrm{Cul}=$ Culebra Dolomite; $\mathrm{DL}=$ Dewey Lake Red Beds; abbreviations of well names are explained in Table 1.

2. Values highly uncertain. See discussion in Section 3.5.2. 
Table 14. Steady-State Field Results for Serial-Sampling Parameters Determined During Tracer Tests in June and August 1984 1

\begin{tabular}{|c|c|c|c|c|c|}
\hline Well & Zone & $\begin{array}{c}\text { Serial-Sampling } \\
\text { Dates } \\
\text { (start - stop) }\end{array}$ & $\begin{array}{l}\text { Temp. } \\
\text { Range } \\
\left({ }^{\circ} \mathrm{C}\right)\end{array}$ & $\begin{array}{l}\text { Specific } \\
\text { Gravity }\end{array}$ & $\mathrm{pH}$ \\
\hline H-3B3 & $\mathrm{Cul}$ & $06 / 10 / 84-06 / 11 / 84$ & $25-26$ & 1.03 & 7.4 \\
\hline $\mathrm{H}-4 \mathrm{C}$ & Cul & $08 / 09 / 84-08 / 10 / 84$ & $21-23$ & 1.01 & 7.8 \\
\hline
\end{tabular}

1. Key: $\mathrm{Cul}=$ Culebra Dolomite 
Table 15. Steady-State Field Results for Serial-Sampling Parameters Determined During Round One of the WQSP in 1985 and $1986^{1}$

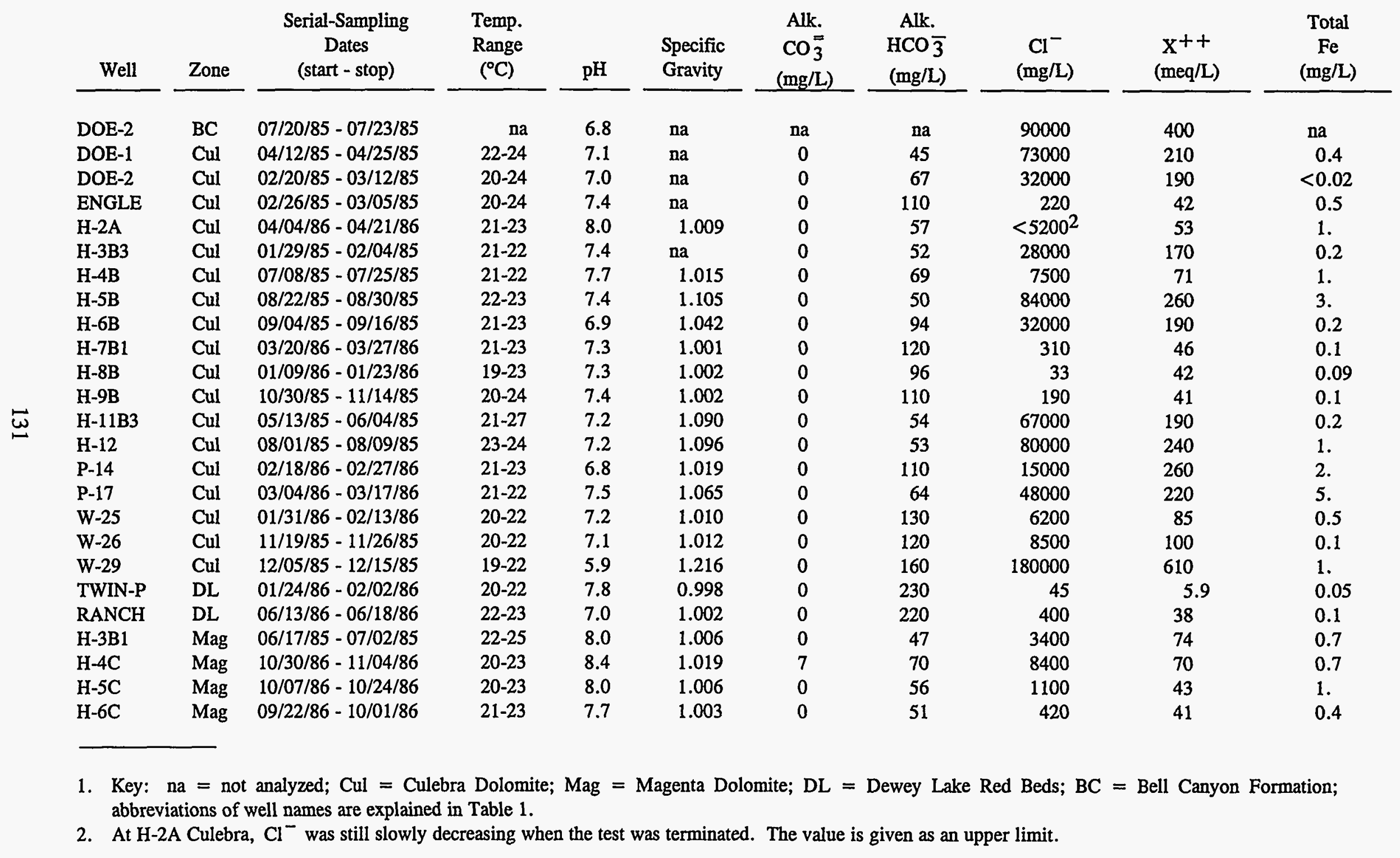


Table 16. Results of Analyses of Solutes in Samples Collected by the USGS and Analyzed by the Analytical Chemistry Division, SNL 1

\begin{tabular}{|c|c|c|c|c|c|c|c|c|c|c|c|c|c|}
\hline Well & Zone & $\begin{array}{c}\text { Date } \\
\text { Collected }\end{array}$ & $\begin{array}{l}\text { Density } \\
(\mathrm{g} / \mathrm{mL}) \\
\end{array}$ & $\begin{array}{c}\text { Calc'd } \\
\text { TDS } \\
\text { (mg/L) }\end{array}$ & $\begin{array}{c}\mathrm{CBE}^{2} \\
(\%) \\
\end{array}$ & $\begin{array}{c}\text { Alk. } \\
\mathrm{CO} \overline{\overline{3}} \\
(\mathrm{mg} / \mathrm{L}) \\
\end{array}$ & $\begin{array}{c}\text { Alk. } \\
\mathrm{HCO}_{\overline{3}} \\
(\mathrm{mg} / \mathrm{L}) \\
\end{array}$ & $\begin{array}{c}\mathrm{Cl}^{-} \\
(\mathrm{mg} / \mathrm{L})\end{array}$ & $\begin{array}{c}\mathrm{SO}_{\overline{4}} \\
(\mathrm{mg} / \mathrm{L})\end{array}$ & $\begin{array}{c}\mathrm{Na} \\
(\mathrm{mg} / \mathrm{L}) \\
\end{array}$ & $\begin{array}{c}\mathrm{K} \\
(\mathrm{mg} / \mathrm{L}) \\
\end{array}$ & $\begin{array}{c}\mathrm{Ca} \\
(\mathrm{mg} / \mathrm{L}) \\
\end{array}$ & $\begin{array}{c}\mathrm{Mg} \\
(\mathrm{mg} / \mathrm{L}) \\
\end{array}$ \\
\hline W-15 & Alv & $03 / 12 / 79$ & 0.999 & 1920 & 1.0 & 92 & 1130 & 109 & 32 & 480 & 20 & 20 & 42 \\
\hline $\mathrm{H}-3 \mathrm{~B} 1$ & Mag & $05 / 10 / 79$ & 1.019 & 29000 & 1.1 & 0 & 52 & 14300 & 3580 & 7810 & 1360 & 1120 & 730 \\
\hline $\mathrm{H}-4 \mathrm{C}$ & RS & $03 / 16 / 79$ & 1.208 & 315200 & -0.2 & 0 & $<10$ & 202000 & 730 & 64400 & 14500 & 8560 & 25400 \\
\hline $\mathrm{H}-5 \mathrm{C}$ & RS & $05 / 16 / 79$ & 1.258 & 372300 & -0.4 & 0 & 200 & 262000 & 1430 & 14200 & 16100 & 1780 & 76400 \\
\hline $\mathrm{H}-6 \mathrm{C}$ & RS & $04 / 09 / 79$ & 1.207 & 312600 & -1.9 & 0 & $<10$ & 201000 & 1450 & 79400 & 6670 & 4170 & 20200 \\
\hline P-15 & RS & $04 / 03 / 79$ & 1.045 & 67600 & -0.6 & 0 & 95 & 38000 & 3350 & 23700 & 1350 & 800 & 320 \\
\hline P-15 & $\mathrm{Cul}$ & $04 / 11 / 79$ & 1.060 & 89600 & -0.8 & 23 & 150 & 47100 & 7430 & 26000 & 6610 & 780 & 1510 \\
\hline P-17 & RS & $05 / 11 / 79$ & 1.194 & -- & -- & 0 & 740 & 186000 & 540 & lost & lost & lost & lost \\
\hline P-18 & RS & $05 / 11 / 79$ & 1.221 & 325200 & -0.7 & 0 & 400 & 217000 & 610 & 45600 & 11700 & 10200 & 39800 \\
\hline
\end{tabular}

1. Key: $\mathrm{Alv}=$ alluvium; $\mathrm{Cul}=$ Culebra Dolomite; $\mathrm{Mag}=$ Magenta Dolomite; $\mathrm{RS}=$ Rustler/Salado contact zone; SNL $=$ Sandia National Laboratories; abbreviations of well names are explained in Table 1.

心 $\quad$ 2. $\mathrm{CBE}=$ charge-balance error 
Table 17. Results of Solute Analyses by Bendix for $\mathrm{HGC}^{1}$

\begin{tabular}{|c|c|c|c|c|c|c|c|c|c|c|}
\hline Well & Zone & $\begin{array}{c}\text { Collection } \\
\text { Date }\end{array}$ & $\begin{array}{c}\mathrm{CBE}^{2} \\
(\%) \\
\end{array}$ & $\begin{array}{c}\text { Calc'd } \\
\text { TDS } \\
\text { (mg/L) }\end{array}$ & $\begin{array}{c}\mathrm{Cl}^{-} \\
(\mathrm{mg} / \mathrm{L}) \\
\end{array}$ & $\begin{array}{c}\mathrm{SO}_{\overline{4}} \\
(\mathrm{mg} / \mathrm{L})\end{array}$ & $\begin{array}{c}\mathrm{Ca} \\
(\mathrm{mg} / \mathrm{L}) \\
\end{array}$ & $\begin{array}{c}\mathrm{Mg} \\
(\mathrm{mg} / \mathrm{L}) \\
\end{array}$ & $\begin{array}{c}\mathrm{Na} \\
(\mathrm{mg} / \mathrm{L}) \\
\end{array}$ & $\begin{array}{c}\mathrm{K} \\
(\mathrm{mg} / \mathrm{L}) \\
\end{array}$ \\
\hline ENGLE & Cul & $11 / 10 / 83$ & -- & - & 230 & 1100 & na & na & na & na \\
\hline FR-10 & Cul & $10 / 06 / 83$ & -- & - & na & na & 520 & 150 & 77 & 8.5 \\
\hline $\mathrm{H}-9 \mathrm{~B}$ & Cul & $10 / 07 / 83$ & -5.4 & 2290 & 180 & 1500 & 400 & 94 & 110 & 5.0 \\
\hline H-12 & Cul (a) & $01 / 11 / 84$ & -1.3 & 143700 & 85000 & 4000 & 1400 & 1300 & 51000 & 970 \\
\hline H-12 & Cul (b) & $01 / 25 / 84$ & -0.8 & 149100 & 84000 & 8400 & 1300 & 1300 & 53000 & 1000 \\
\hline POCKET & DL & $11 / 02 / 83$ & 3.8 & 1880 & 210 & 1100 & 380 & 96 & 95 & 2.4 \\
\hline UNGER & $\mathrm{DL}$ & $01 / 26 / 84$ & -2.9 & 2840 & 260 & 1800 & 530 & 130 & 120 & 3.2 \\
\hline
\end{tabular}

\begin{tabular}{|c|c|c|c|c|c|c|c|c|c|}
\hline Well & Zone & $\begin{array}{c}\text { Collection } \\
\text { Date }\end{array}$ & $\begin{array}{c}\mathrm{Si} \\
(\mathrm{mg} / \mathrm{L}) \\
\end{array}$ & $\begin{array}{c}\mathrm{Li} \\
(\mathrm{mg} / \mathrm{L}) \\
\end{array}$ & $\begin{array}{c}\mathrm{Fe} \\
(\mathrm{mg} / \mathrm{L}) \\
\end{array}$ & $\begin{array}{c}\mathrm{Mn} \\
(\mathrm{mg} / \mathrm{L}) \\
\end{array}$ & $\begin{array}{c}\mathrm{Br}^{-} \\
(\mathrm{mg} / \mathrm{L}) \\
\end{array}$ & $\begin{array}{c}\mathrm{I}^{-} \\
(\mathrm{mg} / \mathrm{L}) \\
\end{array}$ & $\begin{array}{c}\mathrm{NO} \overline{3} \\
(\mathrm{mg} / \mathrm{L})\end{array}$ \\
\hline ENGLE & Cul & $11 / 10 / 83$ & 9 & na & na & na & na & na & 2 \\
\hline FR-10 & Cul & $10 / 06 / 83$ & na & 0.51 & 0.06 & 0.04 & na & na & na \\
\hline H-9B & Cul & $10 / 07 / 83$ & 13 & 0.13 & 0.08 & 0.02 & na & na & $<1$ \\
\hline H-12 & Cul (a) & $01 / 11 / 84$ & 5.0 & 0.25 & 0.55 & 0.10 & 70 & 0.33 & $<1$ \\
\hline $\mathrm{H}-12$ & Cul (b) & $01 / 25 / 84$ & 5.0 & 0.29 & 1.1 & 0.14 & 76 & 0.34 & $<1$ \\
\hline POCKET & $\mathrm{DL}$ & $11 / 02 / 83$ & 12 & 0.06 & 0.14 & 0.02 & na & na & 8 \\
\hline UNGER & DL & $01 / 26 / 84$ & 1 & 0.05 & $<0.05$ & 0.03 & 15 & 0.06 & 11 \\
\hline
\end{tabular}

1. Key: $\mathrm{Cul}=$ Culebra Dolomite; $\mathrm{DL}=$ Dewey Lake Red Beds; HGC = Hydro Geo Chem; abbreviations of well names are explained in Table 1 , na $=$ not analyzed.

2. $\mathrm{CBE}=$ charge-balance error 
Table 18. Results of Halide Analyses by the KGS ${ }^{1}$

\begin{tabular}{|c|c|c|c|c|c|c|}
\hline Well & Zone & $\begin{array}{c}\text { Collection } \\
\text { Date }\end{array}$ & $\begin{array}{c}\mathrm{Cl}^{-} \\
(\mathrm{mg} / \mathrm{L})\end{array}$ & $\begin{array}{c}\mathrm{Br}^{-} \\
(\mathrm{mg} / \mathrm{L})\end{array}$ & $\begin{array}{c}\mathrm{I}^{-} \\
(\mathrm{mg} / \mathrm{L})\end{array}$ & $\begin{array}{r}\text { Alk. } \\
\mathrm{HCO} \\
(\mathrm{mg} / \mathrm{L})\end{array}$ \\
\hline ENGLE & Cul & $11 / 10 / 83$ & 163 & 0.47 & 0.008 & 98 \\
\hline FR-10 & Cul & $10 / 06 / 83$ & 49.5 & 0.21 & 0.009 & na \\
\hline H-9B & Cul & $10 / 07 / 83$ & 206 & 0.43 & 0.109 & na \\
\hline $\mathrm{H}-12$ & Cul & $01 / 25 / 84$ & 80100 & 77 & 0.290 & na \\
\hline H-12 & Cul & $01 / 11 / 84$ & 86500 & 72 & 0.250 & na \\
\hline POCKET & $\mathrm{DL}$ & $11 / 02 / 83$ & 340 & 0.71 & 0.019 & 120 \\
\hline POCKET & DL & $11 / 02 / 83$ & 214 & 0.46 & 0.012 & 95 \\
\hline UNGER & $\mathrm{DL}$ & $01 / 26 / 84$ & 268 & 0.56 & 0.010 & 130 \\
\hline
\end{tabular}

1. Key: $\mathrm{na}=$ not analyzed; $\mathrm{Cul}=$ Culebra Dolomite; $\mathrm{DL}=$ Dewey Lake Red Beds; $\mathrm{KGS}=$ Kansas Geological Survey; abbreviations of well names are explained in Table 1.

Table 19. Results of Chlorine-37 Analyses by KCS and the UA ${ }^{1}$

\begin{tabular}{|c|c|c|c|c|c|}
\hline Well & Zone & Collection Date & $\mathrm{Cl}^{-}(\mathrm{mg} / \mathrm{L})$ & $\begin{array}{l}\delta^{37} \mathrm{Cl} \text { (per } \\
\text { mil relative } \\
\text { to } \mathrm{SMOC}^{2} \text { ) } \\
\end{array}$ & $\mathrm{Lab}$ \\
\hline DOE-1 & Cul & $04 / 19 / 83$ & 94100 & -0.38 & KCS \\
\hline ENGLE & Cul & $10 / 11 / 83$ & & -0.73 & UA \\
\hline FR-10 & Cul & $10 / 06 / 83$ & 100 & 1.32 & $\mathrm{KCS}$ \\
\hline H-3B3 & $\mathrm{Cul}$ & $06 / 11 / 84$ & & 0.06 & UA \\
\hline $\mathrm{H}-3 \mathrm{~B} 3$ & Cul & $02 / 04 / 85$ & & -0.55 & UA \\
\hline $\mathrm{H}-9 \mathrm{~B}$ & Cul & $10 / 07 / 83$ & 255 & 1.35 & $\mathrm{KCS}$ \\
\hline $\mathrm{H}-12$ & $\mathrm{Cul}$ & $01 / 11 / 84$ & & 0.30 & UA \\
\hline W-26 & Cul & $08 / 24 / 80$ & 8240 & -0.50 & $\mathrm{KCS}$ \\
\hline W-28 & Cul & $09 / 11 / 80$ & 21600 & -0.50 & KCS \\
\hline W-29 & Cul & $08 / 28 / 80$ & 201000 & -0.45 & $\mathrm{KCS}$ \\
\hline W-30 & Cul & $09 / 06 / 80$ & 18700 & -1.03 & $\mathrm{KCS}$ \\
\hline POCKET & DL & $11 / 11 / 83$ & & 0.25 & UA \\
\hline UNGER & DL & $01 / 26 / 84$ & & -0.47 & UA \\
\hline
\end{tabular}

1. Key: Cul = Culebra Dolomite; DL $=$ Dewey Lake Red Beds; KCS $=$ KC Services; UA = University of Arizona, Laboratory of Isotope Geochemistry; abbreviations of well names are explained in Table 1.

2. $S M O C=$ standard mean ocean chloride 
Table 20. Results of Solute Analyses by UNC/Bendix: WIPP-25 Culebra 1

Sample ID: W25.C880B

Collection date: $8 / 20 / 80$

\begin{tabular}{|c|c|c|c|c|}
\hline Analyte & $\begin{array}{c}\text { rep } 1 \\
(\mathrm{mg} / \mathrm{L}) \\
\end{array}$ & $\begin{array}{c}\text { rep } 2 \\
\text { (mg/L) }\end{array}$ & $\begin{array}{l}\text { average } \\
(\mathrm{mg} / \mathrm{L})\end{array}$ & $\begin{array}{l}\text { RPD } \\
(\%) \\
\end{array}$ \\
\hline $\mathrm{Ca}$ & 910 & 900 & 905 & 1.1 \\
\hline $\mathrm{Mg}$ & 260 & 260 & 260 & 0 \\
\hline $\mathrm{K}$ & 74.0 & 73.0 & 73.5 & 1.4 \\
\hline $\mathrm{Na}$ & 3120 & 3190 & 3160 & 2.2 \\
\hline $\mathrm{Cl}^{-}$ & 5200 & 5300 & 5250 & 1.9 \\
\hline $\mathrm{SO}_{\overline{4}}=$ & 2460 & 2530 & 2500 & 2.8 \\
\hline Alk-CaCO 3 & & & na & \\
\hline B & 1.52 & 1.52 & 1.52 & 0 \\
\hline Cs & & & na & \\
\hline $\mathrm{Fe}$ & & & na & \\
\hline $\mathrm{Li}$ & 0.20 & 0.20 & 0.20 & 0 \\
\hline $\mathrm{Mn}$ & & & na & \\
\hline $\mathrm{Si}\left(\mathrm{SiO}_{2}\right)$ & 33.6 & 35.0 & 34.3 & 4.1 \\
\hline $\mathrm{Sr}$ & 12.0 & 12.1 & 12.0 & 0.8 \\
\hline $\mathrm{Br}^{-}$ & 2.6 & 2.5 & 2.6 & 3.9 \\
\hline $\mathrm{F}^{-}$ & & & na & \\
\hline $\mathrm{I}^{-}$ & & & na & \\
\hline $\mathrm{NO}_{\overline{3}}$ & & & na & \\
\hline
\end{tabular}

1. Key: $\mathrm{na}=$ not analyzed; $\mathrm{RPD}=$ relative percent difference. 
Table 21. Results of Solute Analyses by UNC/Bendix: WIPP-26 Culebra 1

Sample ID: W26.C880B

Collection date: $08 / 24 / 80$

\begin{tabular}{|c|c|c|c|c|}
\hline Analyte & $\begin{array}{c}\text { rep 1 } \\
(\mathrm{mg} / \mathrm{L})\end{array}$ & $\begin{array}{c}\text { rep } 2 \\
(\mathrm{mg} / \mathrm{L})\end{array}$ & $\begin{array}{l}\text { average } \\
(\mathrm{mg} / \mathrm{L})\end{array}$ & $\begin{array}{l}\text { RPD } \\
(\%)\end{array}$ \\
\hline $\mathrm{Ca}$ & 1240 & 1230 & 1240 & 0.8 \\
\hline $\mathrm{Mg}$ & 360 & 350 & 355 & 2.8 \\
\hline $\mathrm{K}$ & 170 & 170 & 170 & 0 \\
\hline $\mathrm{Na}$ & 3590 & 3660 & 3620 & 1.9 \\
\hline $\mathrm{Cl}^{-}$ & 7300 & 7100 & 7200 & 2.8 \\
\hline $\mathrm{SO}_{\overline{4}}$ & 2470 & 2490 & 2480 & 0.8 \\
\hline Alk- $\mathrm{CaCO}_{3}$ & & & na & \\
\hline $\begin{array}{l}\mathrm{B} \\
\mathrm{Cs}\end{array}$ & 1.42 & 1.48 & 1.45 & 4.1 \\
\hline $\mathrm{Fe}$ & & & na & \\
\hline $\mathrm{Li}$ & 0.23 & 0.25 & 0.24 & 8.3 \\
\hline $\mathrm{Mn}$ & & & na & \\
\hline $\mathrm{Si}\left(\mathrm{SiO}_{2}\right)$ & 33.3 & 33.5 & 33.4 & 0.6 \\
\hline $\mathrm{Sr}$ & 16.5 & 17.2 & 16.8 & 4.1 \\
\hline $\mathrm{Br}^{-}$ & 3.2 & 3.2 & 3.20 & 0 \\
\hline $\mathrm{F}^{-}$ & & & na & \\
\hline $\mathrm{I}^{-}$ & & & na & \\
\hline $\mathrm{NO}_{\overline{3}}$ & & . & na & \\
\hline
\end{tabular}

1. Key: na $=$ not analyzed; $R P D=$ relative percent difference. 
Table 22. Results of Solute Analyses by UNC/Bendix: WIPP-27 Culebra 1

Sample ID: W27.C980B

Collection date: $09 / 03 / 80$

\begin{tabular}{|c|c|c|c|c|c|c|}
\hline Analyte & $\begin{array}{c}\text { rep } 1 \\
(\mathrm{mg} / \mathrm{L})\end{array}$ & $\begin{array}{c}\text { rep 2 } \\
(\mathrm{mg} / \mathrm{L})\end{array}$ & $\begin{array}{c}\mathrm{rep} 3 \\
(\mathrm{mg} / \mathrm{L})\end{array}$ & $\begin{array}{c}\text { average } \\
(\mathrm{mg} / \mathrm{L})\end{array}$ & $\begin{array}{l}\text { RSD } \\
(\%)\end{array}$ & $\begin{array}{l}\text { RPD } \\
(\%)\end{array}$ \\
\hline $\mathrm{Ca}$ & 3210 & 3210 & & 3210 & & 0 \\
\hline $\mathrm{Mg}$ & 1920 & 1890 & & 1900 & & 1.6 \\
\hline $\mathrm{K}$ & 8010 & 8120 & & 8060 & & 1.4 \\
\hline $\mathrm{Na}$ & 39400 & 38900 & & 39200 & & 1.3 \\
\hline $\mathrm{Cl}^{-}$ & 79000 & 78000 & & 78500 & & 1.3 \\
\hline $\mathrm{SO}_{\overline{4}}$ & 3800 & 3860 & & 3830 & & 1.6 \\
\hline Alk-CaCO 3 & & & & na & & \\
\hline B & 2.20 & 2.40 & & 2.30 & & 8.7 \\
\hline Cs & & & & na & & \\
\hline $\mathrm{Fe}$ & & & & na & & \\
\hline $\mathrm{Li}$ & 0.340 & 0.320 & & 0.33 & & 6.1 \\
\hline $\mathrm{Mn}$ & & & & na & & \\
\hline $\mathrm{Si}\left(\mathrm{SiO}_{2}\right)$ & 23.1 & 22.0 & & 22.6 & & 4.9 \\
\hline $\mathrm{Sr}$ & 50.9 & 50.9 & & 50.9 & & 0 \\
\hline $\mathrm{Br}^{-}$ & 30.0 & 26.0 & 29.0 & 28.3 & 7.3 & \\
\hline $\mathrm{F}^{-}$ & & & & na & & \\
\hline$I^{-}$ & & & & na & & \\
\hline $\mathrm{NO}_{\overline{3}}$ & & & & na & & \\
\hline
\end{tabular}

1. Key: $\mathrm{na}=$ not analyzed; $\mathrm{RSD}=$ relative standard deviation; $\mathrm{RPD}=$ relative percent difference. 
Table 23. Results of Solute Analyses by UNC/Bendix: WIPP-28 Culebra 1

Sample ID: W28.C980B

Collection date: $09 / 11 / 80$

\begin{tabular}{|c|c|c|c|c|c|c|c|}
\hline Analyte & $\begin{array}{c}\text { rep 1 } \\
(\mathrm{mg} / \mathrm{L})\end{array}$ & $\begin{array}{c}\text { rep 2 } \\
\text { (mg/L) }\end{array}$ & $\begin{array}{c}\text { rep 3 } \\
(\mathrm{mg} / \mathrm{L}) \\
\end{array}$ & $\begin{array}{c}\text { rep } 4 \\
(\mathrm{mg} / \mathrm{L})\end{array}$ & $\begin{array}{l}\text { average } \\
\text { (mg/L) }\end{array}$ & $\begin{array}{r}\text { RSD } \\
(\%)\end{array}$ & $\begin{array}{l}\text { RPD } \\
(\%)\end{array}$ \\
\hline $\mathrm{Ca}$ & 1150 & 1210 & 1170 & 1200 & 1180 & 2.3 & \\
\hline $\mathrm{Mg}$ & 550 & 560 & & & 555 & & 1.8 \\
\hline K & 490 & 480 & & & 485 & & 2.1 \\
\hline $\mathrm{Na}$ & 15200 & 15300 & & & 15200 & & 0.7 \\
\hline $\mathrm{Cl}^{-}$ & 24800 & 24700 & & & 24800 & & 0.4 \\
\hline $\mathrm{SO}_{\overline{4}}$ & 4460 & 4300 & & & 4380 & & 3.7 \\
\hline Alk-CaCO 3 & & & & & na & & \\
\hline B & 5.76 & 5.90 & & & 5.83 & & 2.4 \\
\hline Cs & & & & & na & & \\
\hline $\mathrm{Fe}$ & & & & & na & & \\
\hline $\mathrm{Li}$ & 0.300 & 0.310 & & & 0.300 & & 3.3 \\
\hline Mn & & & & & na & & \\
\hline $\mathrm{Si}\left(\mathrm{SiO}_{2}\right)$ & 36.3 & 36.2 & & & 36.2 & & 0.3 \\
\hline $\mathrm{Sr}$ & 15.4 & 15.6 & & & 15.5 & & 1.3 \\
\hline $\mathrm{Br}^{-}$ & 7.00 & 7.50 & & & 7.20 & & 6.7 \\
\hline $\mathrm{F}^{-}$ & & & & & na & & \\
\hline $\mathrm{I}^{-}$ & & & & & na & & \\
\hline NO $\overline{3}$ & & & & & na & & \\
\hline
\end{tabular}

1. Key: $\mathrm{na}=$ not analyzed; $\mathrm{RSD}=$ relative standard deviation; $\mathrm{RPD}=$ relative percent difference. 
Table 24. Results of Solute Analyses by UNC/Bendix: WIPP-29 Culebra 1

Sample ID: W29.C880B

Collection date: $08 / 28 / 80$

\begin{tabular}{|c|c|c|c|c|c|c|}
\hline Analyte & $\begin{array}{c}\text { rep } 1 \\
(\mathrm{mg} / \mathrm{L})\end{array}$ & $\begin{array}{c}\text { rep } 2 \\
(\mathrm{mg} / \mathrm{L})\end{array}$ & $\begin{array}{c}\text { rep } 3 \\
(\mathrm{mg} / \mathrm{L})\end{array}$ & $\begin{array}{l}\text { average } \\
(\mathrm{mg} / \mathrm{L})\end{array}$ & $\begin{array}{l}\text { RSD } \\
(\%)\end{array}$ & $\begin{array}{l}\text { RPD } \\
(\%)\end{array}$ \\
\hline $\mathrm{Ca}$ & 950 & 950 & & 950 & & 0 \\
\hline $\mathrm{Mg}$ & 5450 & 5500 & & 5480 & & 0.9 \\
\hline $\mathrm{K}$ & 15600 & 15500 & & 15600 & & 0.6 \\
\hline $\mathrm{Na}$ & 71100 & 71700 & & 71400 & & 0.8 \\
\hline $\mathrm{Cl}^{-}$ & 140000 & 137000 & & 138000 & & 2.2 \\
\hline $\mathrm{SO}_{\overline{4}}^{\overline{4}}$ & 14200 & 13900 & & 14000 & & 2.1 \\
\hline $\mathrm{Alk}-\mathrm{CaCO}_{3}$ & & & & na & & \\
\hline B & 4.20 & 4.60 & & 4.40 & & 9.1 \\
\hline Cs & & & & na & & \\
\hline $\mathrm{Fe}$ & & & & na & & \\
\hline $\mathbf{L i}$ & 0.800 & 0.750 & & 0.780 & & 6.5 \\
\hline $\mathrm{Mn}$ & & & & na & & \\
\hline $\mathrm{Si}\left(\mathrm{SiO}_{2}\right)$ & 21.6 & 22.4 & & 22.0 & & 3.6 \\
\hline $\mathrm{Sr}$ & 29.0 & 28.6 & & 28.8 & & 1.4 \\
\hline $\mathrm{Br}^{-}$ & 47.0 & 41.0 & 47.0 & 45.0 & 7.7 & \\
\hline $\mathrm{F}^{-}$ & & & & na & & \\
\hline $\mathrm{I}^{-}$ & & & & na & & \\
\hline $\mathrm{NO}_{\overline{3}}$ & & & & na & & \\
\hline
\end{tabular}

1. Key: $\mathrm{na}=$ not analyzed; $\mathrm{RSD}=$ relative standard deviation; $\mathrm{RPD}=$ relative percent difference. 
Table 25. Results of Solute Analyses by UNC/Bendix: WIPP-30 Culebra ${ }^{1}$

Sample ID: W30.C980B

Collection date: 09/06/80

\begin{tabular}{|c|c|c|c|c|c|c|}
\hline Analyte & $\begin{array}{c}\text { rep } 1 \\
(\mathrm{mg} / \mathrm{L})\end{array}$ & $\begin{array}{c}\text { rep } 2 \\
(\mathrm{mg} / \mathrm{L}) \\
\end{array}$ & $\begin{array}{c}\text { rep } 3 \\
(\mathrm{mg} / \mathrm{L}) \\
\end{array}$ & $\begin{array}{c}\text { average } \\
(\mathrm{mg} / \mathrm{L})\end{array}$ & $\begin{array}{c}\text { RSD } \\
(\%)\end{array}$ & $\begin{array}{l}\text { RPD } \\
(\%)\end{array}$ \\
\hline $\mathrm{Ca}$ & 1140 & 1150 & & 1140 & & 0.9 \\
\hline $\mathrm{Mg}$ & 460 & 460 & & 460 & & 0 \\
\hline $\mathrm{K}$ & 250 & 260 & & 255 & & 3.9 \\
\hline $\mathrm{Na}$ & 8520 & 8620 & & 8570 & & 1.2 \\
\hline $\mathrm{Cl}^{-}$ & 14800 & 14500 & & 14600 & & 2.0 \\
\hline $\mathrm{SO}_{4}^{\bar{y}}$ & 4050 & 4190 & & 4120 & & 3.4 \\
\hline Alk-CaCO 3 & & & & na & & \\
\hline B & 6.18 & 6.00 & & 6.09 & & 3.0 \\
\hline Cs & & & & na & & \\
\hline $\mathrm{Fe}$ & & & & na & & \\
\hline $\mathrm{Li}$ & 0.27 & 0.27 & & 0.270 & & 0 \\
\hline $\mathrm{Mn}$ & & & & na & & \\
\hline $\mathrm{Si}\left(\mathrm{SiO}_{2}\right)$ & 6.90 & 6.30 & 6.30 & 6.50 & 5.3 & \\
\hline $\mathrm{Sr}$ & 17.8 & 18.0 & & 17.9 & & 1.1 \\
\hline $\mathrm{Br}^{-}$ & 11.0 & 10.0 & & 10.5 & & 9.5 \\
\hline $\mathrm{F}^{-}$ & & & & na & & \\
\hline $\mathrm{I}^{-}$ & & & & na & & \\
\hline $\mathrm{NO}_{\overline{3}}$ & & & & na & & \\
\hline
\end{tabular}

1. Key: na = not analyzed; $R S D=$ relative standard deviation; $R P D=$ relative percent difference. 
Table 26. Results of Solute Analyses by UNC/Bendix: WIPP-25 Magenta 1

Sample ID: W25.M980B

Collection date: $09 / 17 / 80$

\begin{tabular}{|c|c|c|c|c|}
\hline Analyte & $\begin{array}{c}\text { rep } 1 \\
(\mathrm{mg} / \mathrm{L})\end{array}$ & $\begin{array}{c}\mathrm{rep} 2 \\
(\mathrm{mg} / \mathrm{L})\end{array}$ & $\begin{array}{l}\text { average } \\
(\mathrm{mg} / \mathrm{L})\end{array}$ & $\begin{array}{l}\text { RPD } \\
(\%)\end{array}$ \\
\hline $\mathrm{Ca}$ & 900 & 910 & 905 & 1.1 \\
\hline $\mathrm{Mg}$ & 260 & 260 & 260 & 0 \\
\hline $\mathrm{K}$ & 72.0 & 71.0 & 71.5 & 1.4 \\
\hline $\mathrm{Na}$ & 2920 & 2900 & 2910 & 0.7 \\
\hline $\mathrm{Cl}^{-}$ & 5300 & 5200 & 5250 & 1.9 \\
\hline $\mathrm{SO}_{\overline{4}}$ & 2470 & 2510 & 2490 & 1.6 \\
\hline Alk-CaCO 3 & & & na & \\
\hline B & 1.58 & 1.50 & 1.54 & 5.2 \\
\hline Cs & & & na & \\
\hline $\mathrm{Fe}$ & & & na & \\
\hline $\mathbf{L i}$ & 0.20 & 0.20 & 0.200 & 0 \\
\hline $\mathrm{Mn}$ & & & na & \\
\hline $\mathrm{Si}\left(\mathrm{SiO}_{2}\right)$ & 33.3 & 33.5 & 33.4 & 0.6 \\
\hline $\mathrm{Sr}$ & 11.9 & 12.1 & 12.0 & 1.7 \\
\hline $\mathrm{Br}^{-}$ & 2.40 & 2.60 & 2.50 & 8.0 \\
\hline $\mathrm{F}^{-}$ & & & na & \\
\hline$I^{-}$ & & & na & \\
\hline $\mathrm{NO}_{\overline{3}}$ & & & na & \\
\hline
\end{tabular}

1. Key: $\mathrm{na}=$ not analyzed; $\mathrm{RPD}=$ relative percent difference. 
Table 27. Results of Solute Analyses by UNC/Bendix: WIPP-27 Magenta 1

Sample ID: W27.M980B

Collection date: $09 / 25 / 80$

\begin{tabular}{|c|c|c|c|c|c|c|c|}
\hline Analyte & $\begin{array}{c}\text { rep 1 } \\
(\mathrm{mg} / \mathrm{L})\end{array}$ & $\begin{array}{c}\text { rep 2 } \\
(\mathrm{mg} / \mathrm{L})\end{array}$ & $\begin{array}{c}\text { rep } 3 \\
(\mathrm{mg} / \mathrm{L}) \\
\end{array}$ & $\begin{array}{c}\text { rep } 4 \\
(\mathrm{mg} / \mathrm{L}) \\
\end{array}$ & $\begin{array}{c}\text { average } \\
(\mathrm{mg} / \mathrm{L})\end{array}$ & $\begin{array}{l}\text { RSD } \\
(\%) \\
\end{array}$ & $\begin{array}{l}\text { RPD } \\
(\%)\end{array}$ \\
\hline $\mathrm{Ca}$ & 3680 & 3640 & & & 3660 & & 1.1 \\
\hline $\mathrm{Mg}$ & 2110 & 2090 & & & 2100 & & 0.9 \\
\hline $\mathrm{K}$ & 8060 & 8120 & & & 8090 & & 0.7 \\
\hline $\mathrm{Na}$ & 44400 & 42600 & 42500 & 43400 & 43200 & 2.0 & \\
\hline $\mathrm{Cl}^{-}$ & 86500 & 84000 & & & 85200 & & 2.9 \\
\hline $\mathrm{SO}_{4}=$ & 3330 & 3490 & & & 3410 & & 4.7 \\
\hline Alk- $\mathrm{CaCO}_{3}$ & & & & & na & & \\
\hline B & 2.15 & 2.45 & 2.30 & 2.38 & 2.32 & 5.5 & \\
\hline Cs & & & & & na & & \\
\hline $\mathrm{Fe}$ & & & & & na & & \\
\hline $\mathrm{Li}$ & 0.34 & 0.34 & & & 0.340 & & 0 \\
\hline $\mathrm{Mn}$ & & & & & na & & \\
\hline $\mathrm{Si}\left(\mathrm{SiO}_{2}\right)$ & 30.3 & 29.7 & & & 30.0 & & 2.0 \\
\hline $\mathrm{Sr}$ & 58.9 & 58.2 & & & 58.6 & & 1.2 \\
\hline $\mathrm{Br}^{-}$ & 30.0 & 26.0 & 29.0 & & 28.3 & 7.3 & \\
\hline $\mathrm{F}^{-}$ & & & & & na & & \\
\hline $\mathrm{I}^{-}$ & & & & & na & & \\
\hline NO $\overline{3}$ & & & & & na & & \\
\hline
\end{tabular}

1. Key: $\mathrm{na}=$ not analyzed; $\mathrm{RSD}=$ relative standard deviation; $\mathrm{RPD}=$ relative percent difference. 
Table 28. Results of Solute Analyses by UNC/Bendix: WIPP-25 Rustler/Salado ${ }^{1}$

Sample ID: W25.R780B

Collection date: $07 / 17 / 80$

\begin{tabular}{|c|c|c|c|c|}
\hline Analyte & $\begin{array}{c}\text { rep 1 } \\
(\mathrm{mg} / \mathrm{L}) \\
\end{array}$ & $\begin{array}{c}\text { rep 2 } \\
(\mathrm{mg} / \mathrm{L})\end{array}$ & $\begin{array}{l}\text { average } \\
(\mathrm{mg} / \mathrm{L})\end{array}$ & $\begin{array}{l}\text { RPD } \\
(\%) \\
\end{array}$ \\
\hline $\mathrm{Ca}$ & 560 & 560 & 560 & 0 \\
\hline $\mathrm{Mg}$ & 3230 & 3300 & 3260 & 2.1 \\
\hline $\mathbf{K}$ & 3310 & 3350 & 3330 & 1.2 \\
\hline $\mathrm{Na}$ & 123400 & 122200 & 122800 & 1.0 \\
\hline $\mathrm{Cl}^{-}$ & 194000 & 190000 & 192000 & 2.1 \\
\hline $\mathrm{SO}_{4}^{\overline{4}}$ & 12600 & 12100 & 12400 & 4.0 \\
\hline Alk-CaCO 3 & & & na & \\
\hline
\end{tabular}

$\begin{array}{lcccc}\mathrm{B} & 41.4 & 40.4 & 40.9 & 2.4 \\ \mathrm{Cs} & & & \mathrm{na} & \\ \mathrm{Fe} & 1.55 & 1.60 & \mathrm{na} & \\ \mathrm{Li} & & & \mathrm{na} & 3.5 \\ \mathrm{Mn} & 4.0 & 3.9 & 4.00 & 2.6 \\ \mathrm{Si}\left(\mathrm{SiO}_{2}\right) & 11.2 & 11.4 & 11.3 & 1.2 \\ \mathrm{Sr} & & & & \\ & 49.0 & 53.0 & \mathrm{51.0} & 7.8 \\ \mathrm{Br}^{-} & & & \mathrm{na} & \\ \mathrm{F}^{-} & & & \mathrm{na} & \\ \mathrm{I}^{-} & & & \mathrm{na} & \\ \mathrm{NO}^{-} & & & & \end{array}$

1. Key: na = not analyzed; $\mathrm{RPD}=$ relative percent difference. 
Table 29. Results of Solute Analyses by UNC/Bendix: WIPP-26 Rustler/Salado 1

Sample ID: W26.R780B

Collection date: $07 / 23 / 80$

\begin{tabular}{|c|c|c|c|c|c|c|}
\hline Analyte & $\begin{array}{c}\text { rep 1 } \\
(\mathrm{mg} / \mathrm{L})\end{array}$ & $\begin{array}{c}\text { rep } 2 \\
(\mathrm{mg} / \mathrm{L})\end{array}$ & $\begin{array}{c}\text { rep } 3 \\
(\mathrm{mg} / \mathrm{L})\end{array}$ & $\begin{array}{l}\text { average } \\
(\mathrm{mg} / \mathrm{L})\end{array}$ & $\begin{array}{l}\text { RSD } \\
(\%)\end{array}$ & $\begin{array}{l}\text { RPD } \\
(\%)\end{array}$ \\
\hline $\mathrm{Ca}$ & 1410 & 1420 & & 1420 & & 0.7 \\
\hline $\mathrm{Mg}$ & 1670 & 1650 & & 1660 & & 1.2 \\
\hline $\mathrm{K}$ & 1200 & 1190 & & 1200 & & 0.8 \\
\hline $\mathrm{Na}$ & 68200 & 69100 & & 68600 & & 1.3 \\
\hline $\mathrm{Cl}^{-}$ & 110000 & 107000 & & 108000 & & 2.7 \\
\hline $\mathrm{SO}_{\overline{4}}^{\overline{4}}$ & 7390 & 7560 & & 7480 & & 2.3 \\
\hline Alk-CaCO 3 & & & & na & & \\
\hline B & 31.6 & 32.1 & & 31.8 & & 1.6 \\
\hline Cs & & & & na & & \\
\hline $\mathrm{Fe}$ & & & & na & & \\
\hline $\mathrm{Li}$ & 1.15 & 1.15 & & 1.15 & & 0 \\
\hline $\mathrm{Mn}$ & & & & na & & \\
\hline $\mathrm{Si}\left(\mathrm{SiO}_{2}\right)$ & 6.2 & 6.3 & & 6.20 & & 1.7 \\
\hline Sr & 27.0 & 27.0 & & 27.0 & & 0 \\
\hline $\mathrm{Br}^{-}$ & 20.0 & 18.0 & 20.0 & 19.3 & 6.0 & \\
\hline $\mathrm{F}^{-}$ & & & & na & & \\
\hline $\mathrm{I}^{-}$ & & & & na & & \\
\hline $\mathrm{NO}_{\overline{3}}$ & & & & na & & \\
\hline
\end{tabular}

1. Key: na = not analyzed; $R S D=$ relative standard deviation; $R P D=$ relative percent difference. 
Table 30. Results of Solute Analyses by UNC/Bendix: WIPP-28 Rustler/Salado 1

Sample ID: W28.R780B

Collection date: $07 / 31 / 80$

\begin{tabular}{|c|c|c|c|c|}
\hline Analyte & $\begin{array}{c}\text { rep 1 } \\
(\mathrm{mg} / \mathrm{L})\end{array}$ & $\begin{array}{c}\text { rep } 2 \\
(\mathrm{mg} / \mathrm{L})\end{array}$ & $\begin{array}{c}\text { average } \\
(\mathrm{mg} / \mathrm{L})\end{array}$ & $\begin{array}{c}\text { RPD } \\
(\%)\end{array}$ \\
\hline $\mathrm{Ca}$ & 610 & 600 & 605 & 1.7 \\
\hline $\mathrm{Mg}$ & 3400 & 3400 & 3400 & 0 \\
\hline $\mathrm{K}$ & 4290 & 4310 & 4300 & 0.5 \\
\hline $\mathrm{Na}$ & 98000 & 96200 & 97100 & 1.8 \\
\hline $\mathrm{Cl}^{-}$ & 157000 & 153000 & 155000 & 2.6 \\
\hline $\mathrm{SO}_{\overline{4}}^{\overline{4}}$ & 16700 & 16700 & 16700 & 0 \\
\hline Alk-CaCO 3 & & & na & \\
\hline
\end{tabular}

$\begin{array}{lcccc}\mathrm{B} & 45.6 & 46.9 & 46.2 & 2.8 \\ \mathrm{Cs} & & & \mathrm{na} & \\ \mathrm{Fe} & 1.85 & 1.80 & \mathrm{na} & \\ \mathrm{Li} & & & \mathrm{na} & 2.8 \\ \mathrm{Mn} & 7.70 & 7.80 & 7.80 & 1.3 \\ \mathrm{Si}\left(\mathrm{SiO}_{2}\right) & 11.6 & 11.5 & 11.6 & 0.8 \\ \mathrm{Sr} & & & & \\ & & & & \\ \mathrm{Br}^{-} & 30.0 & 28.0 & 29.0 & 3.4 \\ \mathrm{~F}^{-} & & & \text {na } & \\ \mathrm{I}^{-} & & & \text {na } & \\ \mathrm{NO}_{\overline{3}}^{-} & & & \text {na } & \end{array}$

1. Key: na = not analyzed; $R P D=$ relative percent difference. 
Table 31. Results of Solute Analyses by UNC/Bendix: WIPP-29 Rustler/Salado1

Sample ID: W29.R780B

Collection date: $07 / 24 / 80$

\begin{tabular}{|c|c|c|c|c|c|c|c|}
\hline Analyte & $\begin{array}{c}\text { rep } 1 \\
(\mathrm{mg} / \mathrm{L})\end{array}$ & $\begin{array}{c}\text { rep } 2 \\
(\mathrm{mg} / \mathrm{L})\end{array}$ & $\begin{array}{c}\text { rep } 3 \\
(\mathrm{mg} / \mathrm{L})\end{array}$ & $\begin{array}{c}\text { rep } 4 \\
(\mathrm{mg} / \mathrm{L})\end{array}$ & $\begin{array}{c}\text { average } \\
(\mathrm{mg} / \mathrm{L})\end{array}$ & $\begin{array}{l}\text { RSD } \\
(\%)\end{array}$ & $\begin{array}{l}\text { RPD } \\
(\%) \\
\end{array}$ \\
\hline $\mathrm{Ca}$ & 1030 & 1100 & 1060 & 1120 & 1080 & 3.7 & \\
\hline $\mathrm{Mg}$ & 2310 & 2330 & & & 2320 & & 0.9 \\
\hline $\mathrm{K}$ & 1490 & 1460 & & & 1480 & & 2.0 \\
\hline $\mathrm{Na}$ & 36200 & 36000 & & & 36100 & & 0.6 \\
\hline $\mathrm{Cl}^{-}$ & 57500 & 58500 & & & 58000 & & 1.7 \\
\hline $\mathrm{SO}_{4}=$ & 12100 & 12000 & & & 12000 & & 0.8 \\
\hline Alk-CaCO 3 & & & & & na & & \\
\hline B & 19.6 & 20.2 & & & 19.9 & & 3.0 \\
\hline Cs & & & & & na & & \\
\hline $\mathrm{Fe}$ & & & & & na & & \\
\hline $\mathrm{Li}$ & 1.36 & 1.32 & & & 1.34 & & 1.5 \\
\hline $\mathrm{Mn}$ & & & & & na & & \\
\hline $\mathrm{Si}\left(\mathrm{SiO}_{2}\right)$ & 14.9 & 15.1 & & & 15.0 & & 1.3 \\
\hline $\mathrm{Sr}$ & 21.0 & 20.9 & & & 21.0 & & 0.5 \\
\hline $\mathrm{Br}^{-}$ & 12.0 & 13.0 & & & 12.5 & & 8.0 \\
\hline $\mathrm{F}^{-}$ & & & & & na & & \\
\hline $\mathrm{I}^{-}$ & & & & & na & & \\
\hline NO $\overline{3}$ & & & & & na & & \\
\hline
\end{tabular}

1. Key: na = not analyzed; $R S D=$ relative standard deviation; $R P D=$ relative percent difference. 
Table 32. Results of Solute Analyses by UNC/Bendix: WIPP-30 Rustler/Salado 1

Sample ID: W30.R780B

Collection date: $07 / 17 / 80$

\begin{tabular}{|c|c|c|c|c|}
\hline Analyte & $\begin{array}{c}\text { rep } 1 \\
(\mathrm{mg} / \mathrm{L})\end{array}$ & $\begin{array}{c}\text { rep } 2 \\
(\mathrm{mg} / \mathrm{L})\end{array}$ & $\begin{array}{l}\text { average } \\
(\mathrm{mg} / \mathrm{L})\end{array}$ & $\begin{array}{l}\text { RPD } \\
(\%)\end{array}$ \\
\hline $\mathrm{Ca}$ & 960 & 950 & 955 & 1.1 \\
\hline $\mathrm{Mg}$ & 2760 & 2780 & 2770 & 0.7 \\
\hline $\mathrm{K}$ & 2170 & 2190 & 2180 & 0.9 \\
\hline $\mathrm{Na}$ & 121400 & 119900 & 120600 & 1.2 \\
\hline $\mathrm{Cl}^{-}$ & 195000 & 190000 & 192000 & 2.6 \\
\hline $\mathrm{SO}_{\overline{4}}$ & 7440 & 7340 & 7390 & 1.4 \\
\hline Alk-CaCO 3 & & & na & \\
\hline
\end{tabular}

$\begin{array}{lcccc}\mathrm{B} & 82.5 & 80.7 & 81.6 & 2.2 \\ \mathrm{Cs} & & & \mathrm{na} & \\ \mathrm{Fe} & & & \mathrm{na} & \\ \mathrm{Li} & 0.70 & 0.75 & 0.720 & 6.8 \\ \mathrm{Mn} & & & \mathrm{na} & \\ \mathrm{Si}\left(\mathrm{SiO}_{2}\right) & 5.5 & 5.5 & 5.50 & 0 \\ \mathrm{Sr} & 18.2 & 18.6 & 18.4 & 2.2 \\ & & & & \\ \mathrm{Br}^{-} & 79.0 & 77.0 & 78.0 & 2.6 \\ \mathrm{~F}^{-} & & & \text {na } & \\ \mathrm{I}^{-} & & & \text {na } & \\ \mathrm{NO}_{\overline{3}}^{-} & & & \text {na } & \end{array}$

1. Key: na = not analyzed; $\mathrm{RPD}=$ relative percent difference. 
Table 33. Results of Solute Analyses by UNC/Bendix: H-4B Culebra 1

Sample ID: H04B.C581B Collection date: 05/29/81

\begin{tabular}{|c|c|c|c|c|}
\hline Analyte & $\begin{array}{c}\text { rep } 1 \\
\text { (mg/L) }\end{array}$ & $\begin{array}{c}\text { rep } 2 \\
(\mathrm{mg} / \mathrm{L}) \\
\end{array}$ & $\begin{array}{l}\text { average } \\
(\mathrm{mg} / \mathrm{L})\end{array}$ & $\begin{array}{l}\text { RPD } \\
(\%)\end{array}$ \\
\hline $\mathrm{Ca}$ & 710 & 690 & 700 & 2.8 \\
\hline $\mathrm{Mg}$ & 450 & 460 & 455 & 2.2 \\
\hline $\mathrm{K}^{\circ}$ & 210 & 220 & 215 & 4.6 \\
\hline $\mathrm{Na}$ & 6150 & 6020 & 6080 & 2.1 \\
\hline $\mathrm{Cl}^{-}$ & 8050 & 7900 & 7980 & 1.9 \\
\hline $\mathrm{SO}_{4}^{\overline{4}}$ & 6290 & 6170 & 6230 & 1.9 \\
\hline Alk-CaCO 3 & & & na & \\
\hline B & 18.2 & 17.6 & 17.9 & 3.3 \\
\hline Cs & & & na & \\
\hline $\mathrm{Fe}$ & & & na & \\
\hline $\mathrm{Li}$ & 0.39 & 0.39 & 0.390 & 0 \\
\hline $\mathrm{Mn}$ & & & ǹa & \\
\hline $\mathrm{Si}\left(\mathrm{SiO}_{2}\right)$ & 11.1 & 10.9 & 11.0 & 1.8 \\
\hline $\mathrm{Sr}$ & 13.9 & 14.2 & 14.0 & 2.1 \\
\hline $\mathrm{Br}^{-}$ & 43.0 & 40.0 & 41.5 & 7.2 \\
\hline $\mathrm{F}^{-}$ & & & na & \\
\hline $\mathrm{I}^{-}$ & & & na & \\
\hline $\mathrm{NO}_{\overline{3}}$ & & & na & \\
\hline
\end{tabular}

1. Key: $\mathrm{na}=$ not analyzed; $\mathrm{RPD}=$ relative percent difference. 
Table 34. Results of Solute Analyses by UNC/Bendix: H-5B Culebra 1

Sample ID: H05B.C681B

Collection date: $06 / 01 / 81$

\begin{tabular}{|c|c|c|c|c|c|c|}
\hline Analyte & $\begin{array}{c}\text { rep } 1 \\
(\mathrm{mg} / \mathrm{L}) \\
\end{array}$ & $\begin{array}{c}\text { rep } 2 \\
(\mathrm{mg} / \mathrm{L})\end{array}$ & $\begin{array}{c}\operatorname{rep~} 3 \\
(\mathrm{mg} / \mathrm{L}) \\
\end{array}$ & $\begin{array}{l}\text { average } \\
(\mathrm{mg} / \mathrm{L})\end{array}$ & $\begin{array}{l}\text { RSD } \\
(\%)\end{array}$ & $\begin{array}{c}\text { RPD } \\
(\%) \\
\end{array}$ \\
\hline $\mathrm{Ca}$ & 1680 & 1740 & & 1710 & & 3.5 \\
\hline $\mathrm{Mg}$ & 2140 & 2130 & & 2140 & & 0.5 \\
\hline $\mathbf{K}$ & 1300 & 1280 & & 1290 & & 1.6 \\
\hline $\mathrm{Na}$ & 52900 & 51800 & & 52400 & & 2.1 \\
\hline $\mathrm{Cl}^{-}$ & 90000 & 89000 & & 89500 & & 1.1 \\
\hline $\mathrm{SO}_{4}=$ & 7310 & 7420 & & 7360 & & 1.5 \\
\hline Alk-CaCO 3 & & & & na & & \\
\hline B & 33.4 & 33.0 & & 33.2 & & 1.2 \\
\hline Cs & & & & na & & 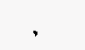 \\
\hline $\mathrm{Fe}$ & & & & na & & \\
\hline $\mathrm{Li}$ & 0.78 & 0.76 & & 0.770 & & 2.6 \\
\hline $\mathrm{Mn}$ & & & & na & & \\
\hline $\mathrm{Si}\left(\mathrm{SiO}_{2}\right)$ & 5.9 & 6.3 & 6.5 & 6.20 & 4.9 & \\
\hline $\mathrm{Sr}$ & 31.6 & 31.6 & & 31.6 & & 0 \\
\hline $\mathrm{Br}^{-}$ & 65.0 & 60.0 & & 62.5 & & 8.0 \\
\hline $\mathrm{F}^{-}$ & & & & na & & \\
\hline $\mathrm{I}^{-}$ & & & & na & & \\
\hline $\mathrm{NO}_{\overline{3}}$ & & & & na & & \\
\hline
\end{tabular}

1. Key: $\mathrm{na}=$ not analyzed; $\mathrm{RSD}=$ relative standard deviation; $\mathrm{RPD}=$ relative percent difference. 
Table 35. Results of Solute Analyses by UNC/Bendix: H-5C Culebra 1

Sample ID: H05C.C1081B

Collection date: $10 / 15 / 81$

\begin{tabular}{|c|c|c|c|c|c|c|}
\hline Analyte & $\begin{array}{c}\text { rep } 1 \\
(\mathrm{mg} / \mathrm{L})\end{array}$ & $\begin{array}{c}\text { rep 2 } \\
(\mathrm{mg} / \mathrm{L})\end{array}$ & $\begin{array}{c}\text { rep } 3 \\
(\mathrm{mg} / \mathrm{L}) \\
\end{array}$ & $\begin{array}{l}\text { average } \\
\text { (mg/L) }\end{array}$ & $\begin{array}{l}\text { RSD } \\
(\%)\end{array}$ & $\begin{array}{l}\text { RPD } \\
(\%)\end{array}$ \\
\hline $\mathrm{Ca}$ & 1710 & 1730 & & 1720 & & 1.2 \\
\hline $\mathrm{Mg}$ & 2160 & 2140 & & 2150 & & 0.9 \\
\hline $\mathrm{K}$ & 1290 & 1300 & & 1300 & & 0.8 \\
\hline $\mathrm{Na}$ & 52400 & 52200 & & 52300 & & 0.4 \\
\hline $\mathrm{Cl}^{-}$ & 90000 & 89000 & & 89500 & & 1.1 \\
\hline $\mathrm{SO}_{\overline{4}}^{\bar{y}}$ & 7670 & 7470 & & 7570 & & 2.6 \\
\hline Alk-CaCO 3 & & & & na & & \\
\hline B & 35.7 & 34.8 & & 35.2 & & 2.6 \\
\hline Cs & & & & na & & \\
\hline $\mathrm{Fe}$ & & & & na & & \\
\hline $\mathrm{Li}$ & 0.78 & 0.76 & & 0.770 & & 2.6 \\
\hline Mn & & & & na & & \\
\hline $\mathrm{Si}\left(\mathrm{SiO}_{2}\right)$ & 5.50 & 5.90 & 6.10 & 5.80 & 5.3 & \\
\hline $\mathrm{Sr}$ & 31.4 & 31.2 & & 31.3 & & 0.6 \\
\hline $\mathrm{Br}^{-}$ & 65.0 & 63.0 & & 64.0 & & 3.1 \\
\hline $\mathrm{F}^{-}$ & & & & na & & \\
\hline $\mathrm{I}^{-}$ & & & & na & & \\
\hline $\mathrm{NO}_{\overline{3}}$ & & & & na & & \\
\hline
\end{tabular}

1. Key: na = not analyzed; $R S D=$ relative standard deviation; $R P D=$ relative percent difference. 
Table 36. Results of Solute Analyses by UNC/Bendix: H-6B Culebra 1

Sample ID: H06B.C581B

Collection date: $05 / 02 / 81$

\begin{tabular}{|c|c|c|c|c|c|c|}
\hline Analyte & $\begin{array}{c}\text { rep } 1 \\
\text { (mg/L) }\end{array}$ & $\begin{array}{c}\mathrm{rep} 2 \\
(\mathrm{mg} / \mathrm{L})\end{array}$ & $\begin{array}{c}\text { rep } 3 \\
(\mathrm{mg} / \mathrm{L}) \\
\end{array}$ & $\begin{array}{l}\text { average } \\
(\mathrm{mg} / \mathrm{L})\end{array}$ & $\begin{array}{l}\text { RSD } \\
(\%)\end{array}$ & $\begin{array}{l}\text { RPD } \\
(\%)\end{array}$ \\
\hline $\mathrm{Ca}$ & 2180 & 2120 & & 2150 & & 2.8 \\
\hline Mg & 1070 & 1080 & & 1080 & & 0.9 \\
\hline $\mathrm{K}$ & 450 & 450 & & 450 & & 0 \\
\hline $\mathrm{Na}$ & 18600 & 18600 & & 18600 & & 0 \\
\hline $\mathrm{Cl}^{-}$ & 33000 & 33000 & & 33000 & & 0 \\
\hline So $\overline{4}$ & 4020 & 3940 & & 3980 & & 2.0 \\
\hline Alk- $\mathrm{CaCO}_{3}$ & & & & na & & \\
\hline B & 10.9 & 10.9 & & 10.9 & & 0 \\
\hline Cs & & & & na & & \\
\hline $\mathrm{Fe}$ & & & & na & & \\
\hline $\mathrm{Li}$ & 0.44 & 0.44 & & 0.440 & & 0 \\
\hline $\mathrm{Mn}$ & & & & na & & \\
\hline $\mathrm{Si}\left(\mathrm{SiO}_{2}\right)$ & 20.1 & 20.5 & 21.0 & 20.5 & 2.2 & \\
\hline $\mathrm{Sr}$ & 32.1 & 31.8 & & 32.0 & & 0.9 \\
\hline $\mathrm{Br}^{-}$ & 35.0 & 33.0 & 35.0 & 34.3 & & 3.4 \\
\hline $\mathrm{F}^{-}$ & & & & na & & \\
\hline $\mathrm{I}^{-}$ & & & & na & & \\
\hline NO $\overline{3}$ & & & & na & & \\
\hline
\end{tabular}

1. Key: na = not analyzed; RSD = relative standard deviation; RPD = relative percent difference. 
Table 37. Results of Solute Analyses by UNC/Bendix: H-3B3 Culebra 1

Sample ID: H03B3.C684B

Collection date: $06 / 11 / 84$

\begin{tabular}{|c|c|c|c|c|c|}
\hline Analyte & $\begin{array}{c}\text { rep 1 } \\
(\mathrm{mg} / \mathrm{L})\end{array}$ & $\begin{array}{c}\text { rep } 2 \\
(\mathrm{mg} / \mathrm{L}) \\
\end{array}$ & $\begin{array}{c}\text { rep } 3 \\
(\mathrm{mg} / \mathrm{L}) \\
\end{array}$ & $\begin{array}{l}\text { average } \\
(\mathrm{mg} / \mathrm{L})\end{array}$ & $\begin{array}{l}\text { RSD } \\
(\%)\end{array}$ \\
\hline $\mathrm{Ca}$ & 1560 & 1530 & 1560 & 1550 & 1.1 \\
\hline $\mathrm{Mg}$ & 827 & 816 & 845 & 829 & 1.8 \\
\hline $\mathrm{K}$ & 509 & 488 & 487 & 495 & 2.6 \\
\hline $\mathrm{Na}$ & 17800 & 17300 & 17200 & 17400 & 1.8 \\
\hline $\mathrm{Cl}^{-}$ & 29900 & 28800 & 29900 & 29500 & 2.2 \\
\hline $\mathrm{SO}_{4}=$ & 5160 & 5170 & 5060 & 5130 & 1.2 \\
\hline Alk-CaCO 3 & 43.3 & 43.2 & 43.6 & 43.4 & 0.5 \\
\hline B & 29.8 & 29.7 & 30.5 & 30.0 & 1.5 \\
\hline Cs & $<0.007$ & $<0.007$ & $<0.007$ & $<0.007$ & \\
\hline $\mathrm{Fe}$ & 0.55 & 0.57 & 0.60 & 0.573 & 4.4 \\
\hline $\mathrm{Li}$ & 0.51 & 0.53 & 0.55 & 0.530 & 3.8 \\
\hline $\mathrm{Mn}$ & 0.13 & 0.14 & 0.13 & 0.133 & 4.5 \\
\hline $\mathrm{Si}\left(\mathrm{SiO}_{2}\right)$ & 9.88 & 10.02 & 9.44 & 9.78 & 3.1 \\
\hline $\mathrm{Sr}$ & 23.4 & 22.2 & 22.3 & 22.6 & 2.9 \\
\hline $\mathrm{Br}^{-}$ & 28.7 & 28.8 & 28.8 & 28.8 & 0.3 \\
\hline $\mathrm{F}^{-}$ & 2.10 & 2.07 & 2.10 & 2.09 & 1.0 \\
\hline $\mathrm{I}^{-}$ & 0.125 & 0.132 & 0.141 & 0.133 & 6.0 \\
\hline $\mathrm{NO}_{\overline{3}}$ & & & & na & \\
\hline
\end{tabular}

1. Key: na $=$ not analyzed; $R P D=$ relative percent difference. 
Table 38. Results of Solute Analyses by UNC/Bendix: H-4C Culebra 1

Sample ID: H04C.C884B

Collection date: $08 / 10 / 84$

\begin{tabular}{|c|c|c|c|c|c|c|}
\hline Analyte & $\begin{array}{c}\text { rep } 1 \\
\text { (mg/L) }\end{array}$ & $\begin{array}{c}\text { rep } 2 \\
(\mathrm{mg} / \mathrm{L})\end{array}$ & $\begin{array}{c}\text { rep } 3 \\
\text { (mg/L) }\end{array}$ & $\begin{array}{c}\text { rep } 4 \\
(\mathrm{mg} / \mathrm{L}) \\
\end{array}$ & $\begin{array}{c}\text { average } \\
(\mathrm{mg} / \mathrm{L})\end{array}$ & $\begin{array}{l}\text { RSD } \\
(\%) \\
\end{array}$ \\
\hline $\mathrm{Ca}$ & 705 & 690 & 700 & & 698 & 1.1 \\
\hline $\mathrm{Mg}$ & 505 & 500 & 510 & & 505 & 1.0 \\
\hline $\mathbf{K}$ & 222 & 221 & 224 & & 222 & 0.7 \\
\hline $\mathrm{Na}$ & 6140 & 6180 & 6120 & & 6150 & 0.5 \\
\hline $\mathrm{Cl}^{-}$ & 7900 & 7950 & 8000 & & 7950 & 0.6 \\
\hline SO $\overline{\overline{4}}$ & 5780 & 5490 & 5840 & & 5700 & 3.3 \\
\hline Alk-CaCO 3 & & & & & na & \\
\hline B & 19.8 & 20.0 & 19.6 & & 19.8 & 1.0 \\
\hline Cs & $<0.003$ & $<0.003$ & $<0.002$ & & $<0.002$ & \\
\hline $\mathrm{Fe}$ & 2.24 & 2.16 & 2.10 & & 2.17 & 3.2 \\
\hline $\mathrm{Li}$ & 0.51 & 0.49 & 0.48 & & 0.490 & 3.1 \\
\hline $\mathbf{M n}$ & 0.192 & 0.204 & 0.199 & & 0.198 & 3.0 \\
\hline $\mathrm{Si}\left(\mathrm{SiO}_{2}\right)$ & 12.5 & 13.5 & & & 13.0 & 7.0 \\
\hline $\mathrm{Sr}$ & 18.0 & 17.7 & $17: 7$ & & 17.8 & 1.0 \\
\hline $\mathrm{Br}^{-}$ & 52.5 & 47.7 & 46.0 & 44.6 & 47.7 & 7.2 \\
\hline $\mathrm{F}^{-}$ & 2.21 & 2.05 & 2.12 & & 2.13 & 3.8 \\
\hline $\mathrm{I}^{-}$ & 0.226 & & & & 0.226 & \\
\hline $\mathrm{NO}_{3}$ & & & & & na & \\
\hline
\end{tabular}

1. Key: na = not analyzed; RSD = relative standard deviation. 
Table 39. Results of Solute Analyses by UNC/Bendix: DOE-1 Culebra ${ }^{1}$

Sample ID: D1.C485B

Collection date: $04 / 24,25 / 85$

\begin{tabular}{|c|c|c|c|c|c|c|}
\hline Analyte & $\begin{array}{c}\text { rep } 1 \\
(\mathrm{mg} / \mathrm{L})\end{array}$ & $\begin{array}{c}\text { rep } 2 \\
\text { (mg/L) }\end{array}$ & $\begin{array}{c}\mathrm{rep} 3 \\
(\mathrm{mg} / \mathrm{L})\end{array}$ & $\begin{array}{l}\text { average } \\
(\mathrm{mg} / \mathrm{L})\end{array}$ & $\begin{array}{l}\text { RSD } \\
(\%)\end{array}$ & $\begin{array}{l}\text { RPD } \\
(\%) \\
\end{array}$ \\
\hline $\mathrm{Ca}$ & 1740 & 1720 & & 1730 & & 1.2 \\
\hline $\mathrm{Mg}$ & 1580 & 1640 & & 1610 & & 3.7 \\
\hline $\mathbf{K}$ & 1120 & 1080 & & 1100 & & 3.6 \\
\hline $\mathrm{Na}$ & 46000 & 45600 & & 45800 & & 0.9 \\
\hline $\mathrm{Cl}^{-}$ & 73600 & 73600 & & 73600 & & 0 \\
\hline $\mathrm{SO}_{\overline{4}}$ & 7470 & 7230 & & 7350 & & 3.3 \\
\hline Alk-CaCO 3 & 35 & 35 & & 35.0 & & 0 \\
\hline B & 35.2 & 38.1 & & 36.6 & & 7.9 \\
\hline Cs & & & & na & & \\
\hline $\mathrm{Fe}$ & 0.272 & 0.294 & 0.276 & 0.281 & 4.2 & \\
\hline $\mathrm{Li}$ & 0.65 & 0.62 & & 0.635 & & 4.7 \\
\hline $\mathrm{Mn}$ & & & & na & & \\
\hline $\mathrm{Si}\left(\mathrm{SiO}_{2}\right)$ & 8.3 & 8.6 & & 8.45 & & 3.6 \\
\hline $\mathrm{Sr}$ & 26.0 & 26.4 & & 26.2 & & 1.5 \\
\hline $\mathrm{Br}^{-}$ & 56.1 & 56.0 & & 56.0 & & 0.2 \\
\hline $\mathrm{F}^{-}$ & & & & na & & \\
\hline $\mathrm{I}^{-}$ & & & & na & & \\
\hline $\mathrm{NO}_{\overline{3}}$ & & & & na & & \\
\hline
\end{tabular}

1. Key: $\mathrm{na}=$ not analyzed; $\mathrm{RSD}=$ relative standard deviation; $\mathrm{RPD}=$ relative percent difference. 
Table 40. Results of Solute Analyses by UNC/Bendix: DOE-2 Culebra ${ }^{1}$

Sample ID: D2.C385B

Collection date: $03 / 11,12 / 85$

\begin{tabular}{|c|c|c|c|c|c|c|}
\hline Analyte & $\begin{array}{c}\text { rep } 1 \\
(\mathrm{mg} / \mathrm{L})\end{array}$ & $\begin{array}{c}\text { rep } 2 \\
(\mathrm{mg} / \mathrm{L})\end{array}$ & $\begin{array}{c}\text { rep } 3 \\
(\mathrm{mg} / \mathrm{L})\end{array}$ & $\begin{array}{c}\text { rep 4 } \\
(\mathrm{mg} / \mathrm{L})\end{array}$ & $\begin{array}{l}\text { average } \\
(\mathrm{mg} / \mathrm{L})\end{array}$ & $\begin{array}{l}\text { RSD } \\
(\%)\end{array}$ \\
\hline $\mathrm{Ca}$ & 1970 & 1960 & 1940 & & 1960 & 0.8 \\
\hline $\mathrm{Mg}$ & 1060 & 1050 & 1060 & & 1060 & 0.5 \\
\hline $\mathbf{K}$ & 406 & 409 & 414 & & 410 & 1.0 \\
\hline $\mathrm{Na}$ & 18400 & 18300 & 18500 & & 18400 & 0.5 \\
\hline $\mathrm{Cl}^{-}$ & 34700 & 34700 & 34500 & & 34600 & 0.3 \\
\hline $\mathrm{SO}_{4}^{\overline{4}}$ & 4000 & 4010 & 3840 & & 3950 & 2.4 \\
\hline Alk-CaCO 3 & 53.6 & 53.6 & 53.6 & & 53.6 & 0 \\
\hline B & 15.6 & 16.0 & 15.2 & & 15.6 & 2.6 \\
\hline Cs & $<0.007$ & $<0.007$ & $<0.007$ & & $<0.007$ & \\
\hline $\mathrm{Fe}$ & 0.0384 & 0.0360 & 0.0344 & & 0.0363 & 5.5 \\
\hline $\mathrm{Li}$ & 0.46 & 0.48 & 0.48 & & 0.470 & 2.5 \\
\hline $\mathbf{M n}$ & 0.298 & 0.294 & 0.295 & & 0.296 & 0.7 \\
\hline $\mathrm{Si}\left(\mathrm{SiO}_{2}\right)$ & 17.0 & 16.7 & 18.5 & & 17.4 & 5.5 \\
\hline $\mathrm{Sr}$ & 37.8 & 37.2 & 38.0 & & 37.7 & 1.1 \\
\hline $\mathrm{Br}^{-}$ & 34.6 & 35.2 & 31.6 & 32.5 & 33.5 & 5.1 \\
\hline $\mathrm{F}^{-}$ & 1.69 & 1.69 & 1.70 & & 1.69 & 0.3 \\
\hline $\mathrm{I}^{-}$ & 0.243 & 0.206 & 0.226 & & 0.225 & 8.2 \\
\hline NO $\overline{3}$ & & & & & na & \\
\hline
\end{tabular}

1. Key: na = not analyzed; $R S D=$ relative standard deviation. 
Table 41. Results of Solute Analyses by UNC/Bendix: H-2A Culebra 1

Sample ID: H02A.C486B

Collection date: $04 / 21 / 86$

\begin{tabular}{|c|c|c|c|c|c|c|}
\hline Analyte & $\begin{array}{c}\text { rep } 1 \\
(\mathrm{mg} / \mathrm{L})\end{array}$ & $\begin{array}{c}\text { rep } 2 \\
(\mathrm{mg} / \mathrm{L})\end{array}$ & $\begin{array}{c}\text { rep } 3 \\
(\mathrm{mg} / \mathrm{L}) \\
\end{array}$ & $\begin{array}{c}\text { average } \\
(\mathrm{mg} / \mathrm{L})\end{array}$ & $\begin{array}{l}\text { RSD } \\
(\%)\end{array}$ & $\begin{array}{l}\text { RPD } \\
(\%)\end{array}$ \\
\hline $\mathrm{Ca}$ & 750 & 736 & & 743 & & 1.9 \\
\hline $\mathrm{Mg}$ & 170 & 160 & 170 & 167 & 3.4 & \\
\hline $\mathrm{K}$ & 93.0 & 94 & & 93.5 & & 1.1 \\
\hline $\mathrm{Na}$ & 3500 & 3620 & 3600 & 3570 & 1.8 & \\
\hline $\mathrm{Cl}^{-}$ & 5350 & 5270 & & 5310 & & 1.5 \\
\hline $\mathrm{SO}_{\overline{4}}$ & 2970 & 3010 & 2950 & 2980 & 1.0 & \\
\hline Alk-CaCO 3 & 46.0 & 43.5 & 42.5 & 44.0 & 4.1 & \\
\hline B & 10.4 & 10.5 & & 10.4 & & 1.0 \\
\hline Cs & $<0.01$ & & & $<0.01$ & & \\
\hline $\mathrm{Fe}$ & 1.04 & 1.11 & & 1.08 & & 6.5 \\
\hline $\mathrm{Li}$ & 0.22 & 0.23 & & 0.225 & & 4.5 \\
\hline $\mathrm{Mn}$ & 0.054 & 0.056 & & 0.0550 & & 3.6 \\
\hline $\mathrm{Si}\left(\mathrm{SiO}_{2}\right)$ & 12.4 & 12.8 & & 12.6 & & 3.2 \\
\hline $\mathrm{Sr}$ & 9.52 & 9.56 & & 9.54 & & 0.4 \\
\hline $\mathrm{Br}^{-}$ & 5.7 & 5.5 & & 5.60 & & 3.6 \\
\hline $\mathrm{F}^{-}$ & 2.20 & 2.28 & & 2.24 & & 3.6 \\
\hline $\mathrm{I}^{-}$ & 0.077 & 0.086 & 0.081 & 0.0813 & 5.6 & \\
\hline $\mathrm{NO}_{\overline{3}}$ & & & & na & & \\
\hline
\end{tabular}

1. Key: na $=$ not analyzed; $R S D=$ relative standard deviation; $R P D=$ relative percent difference. 
Table 42. Results of Solute Analyses by UNC/Bendix: H-3B3 Culebra ${ }^{1}$

Sample ID: H03B3.C285B

Collection date: $02 / 04 / 85$

\begin{tabular}{|c|c|c|c|c|c|c|}
\hline Analyte & $\begin{array}{c}\text { rep } 1 \\
(\mathrm{mg} / \mathrm{L})\end{array}$ & $\begin{array}{c}\text { rep } 2 \\
(\mathrm{mg} / \mathrm{L}) \\
\end{array}$ & $\begin{array}{c}\text { rep } 3 \\
\text { (mg/L) }\end{array}$ & $\begin{array}{c}\text { rep } 4 \\
\text { (mg/L) }\end{array}$ & $\begin{array}{l}\text { average } \\
(\mathrm{mg} / \mathrm{L})\end{array}$ & $\begin{array}{l}\text { RSD } \\
(\%)\end{array}$ \\
\hline $\mathrm{Ca}$ & 1470 & 1460 & 1470 & & 1470 & 0.4 \\
\hline $\mathrm{Mg}$ & 790 & 760 & 800 & & 783 & 2.7 \\
\hline $\mathbf{K}$ & 420 & 428 & 426 & & 425 & 1.0 \\
\hline $\mathrm{Na}$ & 18000 & 17900 & 18100 & & 18000 & 0.6 \\
\hline $\mathrm{Cl}^{-}$ & 30000 & 30300 & 30500 & & 30300 & 0.8 \\
\hline $\mathrm{SO}_{\overline{4}}$ & 4990 & 4670 & 4810 & & 4820 & 3.3 \\
\hline $\mathrm{Alk}-\mathrm{CaCO}_{3}$ & 40.4 & 40.0 & 40.4 & & 40.3 & 0.6 \\
\hline B & 26.4 & 26.6 & 26.0 & & 26.3 & 1.2 \\
\hline Cs & $<0.007$ & $<0.007$ & $<0.007$ & & $<0.007$ & \\
\hline $\mathrm{Fe}$ & 0.207 & 0.197 & 0.197 & & 0.200 & 2.9 \\
\hline $\mathrm{Li}$ & 0.40 & 0.39 & 0.41 & & 0.400 & 2.5 \\
\hline $\mathrm{Mn}$ & 0.114 & 0.117 & 0.119 & & 0.117 & 2.2 \\
\hline $\mathrm{Si}\left(\mathrm{SiO}_{2}\right)$ & 11.7 & 11.2 & 11.0 & & 11.3 & 3.2 \\
\hline $\mathrm{Sr}$ & 30.6 & 29.9 & 31.0 & & 30.5 & 1.8 \\
\hline $\mathrm{Br}^{-}$ & 24.3 & 27.5 & 24.4 & 26.9 & 25.8 & 6.4 \\
\hline$F^{-}$ & 1.97 & 1.90 & 1.96 & & 1.94 & 1.9 \\
\hline$I^{-}$ & 0.129 & 0.138 & 0.146 & & 0.138 & 6.2 \\
\hline $\mathrm{NO} \overline{3}$ & & & & & na & \\
\hline
\end{tabular}

1. Key: na = not analyzed; $\mathrm{RSD}=$ relative standard deviation. 
Table 43. Results of Solute Analyses by UNC/Bendix: H-4B Culebra 1

Sample ID: H04B.C785B

Collection date: $07 / 20 / 85$

\begin{tabular}{|c|c|c|c|c|c|c|}
\hline Analyte & $\begin{array}{c}\text { rep 1 } \\
(\mathrm{mg} / \mathrm{L})\end{array}$ & $\begin{array}{c}\text { rep } 2 \\
\text { (mg/L) }\end{array}$ & $\begin{array}{c}\text { rep 3 } \\
\text { (mg/L) }\end{array}$ & $\begin{array}{l}\text { average } \\
(\mathrm{mg} / \mathrm{L})\end{array}$ & $\begin{array}{l}\text { RSD } \\
(\%)\end{array}$ & $\begin{array}{l}\text { RPD } \\
(\%) \\
\end{array}$ \\
\hline $\mathrm{Ca}$ & 698 & 684 & & 691 & & 2.0 \\
\hline $\mathrm{Mg}$ & 422 & 432 & 428 & 427 & 1.2 & \\
\hline $\mathrm{K}$ & 210 & 210 & & 210 & & 0 \\
\hline $\mathrm{Na}$ & 5830 & 5870 & & 5850 & & 0.7 . \\
\hline $\mathrm{Cl}^{-}$ & 7480 & 7490 & & 7480 & & 0.1 \\
\hline $\mathrm{SO}_{\overline{4}}$ & 5650 & 5400 & & 5520 & & 4.5 \\
\hline Alk-CaCO 3 & 55 & 54 & & 54 & & 1.9 \\
\hline B & 13.0 & 15.2 & & 14.1 & & 15.6 \\
\hline Cs & & & & na & & \\
\hline $\mathrm{Fe}$ & 0.32 & 0.324 & 0.322 & 0.322 & 0.6 & \\
\hline $\mathrm{Li}$ & 0.39 & 0.40 & & 0.395 & & 2.6 \\
\hline Mn & 0.104 & 0.109 & & 0.106 & & 4.7 \\
\hline $\mathrm{Si}\left(\mathrm{SiO}_{2}\right)$ & 14.4 & 14.2 & & 14.3 & & 1.4 \\
\hline $\mathrm{Sr}$ & 14.4 & 14.2 & & 14.3 & & 1.4 \\
\hline $\mathrm{Br}^{-}$ & 42.5 & 42.7 & & 42.6 & & 0.5 \\
\hline $\mathrm{F}^{-}$ & & & & na & & \\
\hline $\mathrm{I}^{-}$ & & & & na & & \\
\hline $\mathrm{NO}_{\overline{3}}$ & & & & na & & \\
\hline
\end{tabular}

1. Key: na = not analyzed; $\mathrm{RSD}=$ relative standard deviation; $\mathrm{RPD}=$ relative percent difference. 
Table 44. Results of Solute Analyses by UNC/Bendix: H-5B Culebra 1

Sample ID: H0SB.C885B

Collection date: $08 / 26,27 / 85$

\begin{tabular}{|c|c|c|c|c|c|c|}
\hline Analyte & $\begin{array}{c}\text { rep 1 } \\
(\mathrm{mg} / \mathrm{L})\end{array}$ & $\begin{array}{c}\text { rep } 2 \\
(\mathrm{mg} / \mathrm{L})\end{array}$ & $\begin{array}{c}\text { rep } 3 \\
(\mathrm{mg} / \mathrm{L}) \\
\end{array}$ & $\begin{array}{c}\text { average } \\
(\mathrm{mg} / \mathrm{L})\end{array}$ & $\begin{array}{l}\text { RSD } \\
(\%)\end{array}$ & $\begin{array}{l}\text { RPD } \\
(\%) \\
\end{array}$ \\
\hline $\mathrm{Ca}$ & 1680 & 1720 & & 1700 & & 2.4 \\
\hline $\mathrm{Mg}$ & 2160 & 2280 & 2070 & 2170 & 5.1 & \\
\hline $\mathrm{K}$ & 1360 & 1340 & & 1350 & & 1.5 \\
\hline $\mathrm{Na}$ & 53800 & 54500 & & 54100 & & 1.3 \\
\hline $\mathrm{Cl}^{-}$ & 85600 & 85100 & & 85400 & & 0.6 \\
\hline $\mathrm{SO}_{\overline{4}}^{\bar{z}}$ & 7880 & 7800 & & 7840 & & 1.0 \\
\hline Alk-CaCO 3 & 35 & 34 & & 34.0 & & 2.9 \\
\hline B & 33.0 & 34.4 & & 33.7 & & 3.3 \\
\hline Cs & $<0.01$ & $<0.01$ & & $<0.01$ & & \\
\hline $\mathrm{Fe}$ & 2.80 & 2.93 & & 2.86 & & 4.5 \\
\hline $\mathrm{Li}$ & 0.80 & 0.82 & & 0.810 & & 2.5 \\
\hline $\mathrm{Mn}$ & 0.282 & 0.306 & & 0.294 & & 8.2 \\
\hline $\mathrm{Si}\left(\mathrm{SiO}_{2}\right)$ & 7.1 & 7.1 & & 7.10 & & 0 \\
\hline $\mathrm{Sr}$ & 30.0 & 28.6 & & 29.3 & & 4.8 \\
\hline $\mathrm{Br}^{-}$ & 48.9 & 48.4 & & 48.6 & & 1.0 \\
\hline $\mathrm{F}^{-}$ & 2.0 & 1.9 & & 1.95 & & 5.1 \\
\hline $\mathrm{I}^{-}$ & 0.197 & 0.185 & & 0.191 & & 3.1 \\
\hline $\mathrm{NO}_{\overline{3}}$ & & & & na & & \\
\hline
\end{tabular}

1. Key: na = not analyzed; $R S D=$ relative standard deviation; $R P D=$ relative percent difference. 
Table 45. Results of Solute Analyses by UNC/Bendix: H-6B Culebra 1

Sample ID: H06B.C985B

Collection date: $09 / 15 / 85$

\begin{tabular}{|c|c|c|c|c|c|c|}
\hline Analyte & $\begin{array}{c}\text { rep 1 } \\
(\mathrm{mg} / \mathrm{L})\end{array}$ & $\begin{array}{c}\text { rep } 2 \\
(\mathrm{mg} / \mathrm{L})\end{array}$ & $\begin{array}{c}\text { rep } 3 \\
(\mathrm{mg} / \mathrm{L})\end{array}$ & $\begin{array}{l}\text { average } \\
(\mathrm{mg} / \mathrm{L})\end{array}$ & $\begin{array}{l}\text { RSD } \\
(\%)\end{array}$ & $\begin{array}{c}\text { RPD } \\
(\%)\end{array}$ \\
\hline $\mathrm{Ca}$ & 2050 & 2040 & & 2040 & & 0.5 \\
\hline $\mathbf{M g}$ & 1040 & 1040 & & 1040 & & 0 \\
\hline $\mathbf{K}$ & 376 & 374 & & 375 & & 0.5 \\
\hline $\mathrm{Na}$ & 17900 & 18000 & & 18000 & & 0.6 \\
\hline $\mathrm{Cl}^{-}$ & 32110 & 32560 & & 32330 & & 1.4 \\
\hline $\mathrm{SO}_{\overline{4}}$ & 3550 & 3630 & 3530 & 3570 & 1.5 & \\
\hline Alk-CaCO 3 & 67.5 & 70.0 & & 68.8 & & 3.6 \\
\hline B & 10.4 & 10.5 & & 10.4 & & 1.0 \\
\hline Cs & $<0.01$ & & & $<0.01$ & & \\
\hline $\mathrm{Fe}$ & 0.093 & 0.096 & & 0.0945 & & 3.2 \\
\hline $\mathrm{Li}$ & 0.46 & 0.44 & & 0.450 & & 4.4 \\
\hline $\mathrm{Mn}$ & 0.133 & 0.124 & & 0.128 & & 7.0 \\
\hline $\mathrm{Si}\left(\mathrm{SiO}_{2}\right)$ & 17.6 & 18.0 & & 17.8 & & 2.2 \\
\hline Sr & 29.9 & 31.0 & & 30.4 & & 3.6 \\
\hline $\mathrm{Br}^{-}$ & 33.0 & 35.0 & & 34.0 & & 2.9 \\
\hline$F^{-}$ & 1.90 & 1.91 & 1.90 & 1.90 & 0.3 & \\
\hline $\mathrm{I}^{-}$ & 0.100 & 0.090 & 0.097 & 0.0957 & 5.3 & \\
\hline $10 \overline{3}$ & 0.10 & & & 0.10 & & \\
\hline $\mathrm{NO}_{\overline{3}}$ & & & & na & & \\
\hline
\end{tabular}

1. Key: na = not analyzed; RSD = relative standard deviation; RPD = relative percent difference. 
Table 46. Results of Solute Analyses by UNC/Bendix: H-7B Culebra 1

Sample ID: H07B.C386B

\begin{tabular}{|c|c|c|c|c|c|c|}
\hline Analyte & $\begin{array}{c}\text { rep } 1 \\
(\mathrm{mg} / \mathrm{L})\end{array}$ & $\begin{array}{c}\text { rep 2 } \\
(\mathrm{mg} / \mathrm{L})\end{array}$ & $\begin{array}{c}\mathrm{rep} 3 \\
(\mathrm{mg} / \mathrm{L})\end{array}$ & $\begin{array}{l}\text { average } \\
(\mathrm{mg} / \mathrm{L})\end{array}$ & $\begin{array}{l}\text { RSD } \\
(\%)\end{array}$ & $\begin{array}{l}\text { RPD } \\
(\%)\end{array}$ \\
\hline $\mathrm{Ca}$ & 586 & 588 & & 587 & & 0.3 \\
\hline $\mathrm{Mg}$ & 130 & 130 & & 130 & & 0 \\
\hline $\mathrm{K}$ & 7.00 & 7.00 & & 7.00 & & 0 \\
\hline $\mathrm{Na}$ & 208 & 206 & & 207 & & 1.0 \\
\hline $\mathrm{Cl}^{-}$ & 325 & 317 & 317 & 320 & 1.4 & \\
\hline $\mathrm{SO}_{\overline{4}}^{\overline{7}}$ & 1840 & 1910 & 1810 & 1850 & 2.8 & \\
\hline Alk-CaCO 3 & 97.5 & 99.0 & & 98.2 & & 1.5 \\
\hline B & 0.75 & 0.76 & & 0.755 & & 1.3 \\
\hline Cs & $<0.01$ & & & $<0.01$ & & \\
\hline $\mathrm{Fe}$ & 0.055 & 0.057 & & 0.0560 & & 3.6 \\
\hline $\mathbf{L i}$ & 0.10 & 0.10 & & 0.100 & & 0 \\
\hline $\mathrm{Mn}$ & 0.051 & 0.050 & & 0.0505 & & 2.0 \\
\hline $\mathrm{Si}\left(\mathrm{SiO}_{2}\right)$ & 47.5 & 47.1 & & 47.3 & & 0.8 \\
\hline $\mathrm{Sr}$ & 8.84 & 8.18 & & 8.51 & & 7.7 \\
\hline $\mathrm{Br}^{-}$ & 0.58 & 0.56 & & 0.570 & & 3.5 \\
\hline $\mathrm{F}^{-}$ & 1.51 & 1.51 & & 1.51 & & 0 \\
\hline$I^{-}$ & 0.053 & 0.052 & & 0.0525 & & 1.9 \\
\hline $\mathrm{NO}_{\overline{3}}$ & & & & na & & \\
\hline
\end{tabular}

1. Key: na = not analyzed; $R S D=$ relative standard deviation; $R P D=$ relative percent difference. 
Table 47. Results of Solute Analyses by UNC/Bendix: H-8B Culebra ${ }^{1}$

Sample ID: H08B.C186B

Collection date: 01/22/86

\begin{tabular}{|c|c|c|c|c|c|c|}
\hline Analyte & $\begin{array}{c}\text { rep } 1 \\
(\mathrm{mg} / \mathrm{L})\end{array}$ & $\begin{array}{c}\text { rep } 2 \\
(\mathrm{mg} / \mathrm{L}) \\
\end{array}$ & $\begin{array}{c}\text { rep } 3 \\
(\mathrm{mg} / \mathrm{L}) \\
\end{array}$ & $\begin{array}{l}\text { average } \\
(\mathrm{mg} / \mathrm{L})\end{array}$ & $\begin{array}{l}\text { RSD } \\
(\%)\end{array}$ & $\begin{array}{l}\text { RPD } \\
(\%)\end{array}$ \\
\hline $\mathrm{Ca}$ & 556 & 540 & & 548 & & 2.9 \\
\hline $\mathrm{Mg}$ & 160 & 150 & 160 & 157 & 3.7 & \\
\hline $\mathrm{K}$ & 3.84 & 3.82 & & 3.83 & & 0.5 \\
\hline $\mathrm{Na}$ & 54.4 & 55.8 & & 55.1 & & 2.5 \\
\hline $\mathrm{Cl}^{-}$ & 30.4 & 30.4 & 30.6 & 30.5 & 0.4 & \\
\hline $\mathrm{SO}_{4}=$ & 1870 & 2050 & 1920 & 1950 & 4.8 & \\
\hline Alk- $\mathrm{CaCO}_{3}$ & 75.0 & 72.5 & & 73.7 & & 3.4 \\
\hline B & 0.48 & 0.49 & & 0.485 & & 2.1 \\
\hline Cs & $<0.01$ & & & $<0.01$ & & \\
\hline $\mathrm{Fe}$ & 0.033 & 0.037 & 0.039 & 0.0363 & 8.5 & \\
\hline $\mathrm{Li}$ & 0.12 & 0.11 & & 0.115 & & 9.1 \\
\hline Mn & 0.022 & 0.020 & & 0.0210 & & 9.5 \\
\hline $\mathrm{Si}\left(\mathrm{SiO}_{2}\right)$ & 28.6 & 29.8 & & 29.2 & & 4.1 \\
\hline $\mathrm{Sr}$ & 7.04 & 6.80 & & 6.92 & & 3.5 \\
\hline $\mathrm{Br}^{-}$ & 0.075 & 0.100 & 0.080 & 0.0850 & 15.6 & \\
\hline $\mathrm{F}^{-}$ & 2.53 & 2.38 & & 2.46 & & 6.1 \\
\hline$I^{-}$ & 0.150 & 0.140 & & 0.145 & & 6.9 \\
\hline NO $\overline{3}$ & & & & na & & \\
\hline
\end{tabular}

1. Key: na = not analyzed; $R S D=$ relative standard deviation; $R P D=$ relative percent difference. 
Table 48. Results of Solute Analyses by UNC/Bendix: H-9B Culebra 1

Sample ID: H09B.C1185B

Collection date: $11 / 14 / 85$

\begin{tabular}{|c|c|c|c|c|c|c|}
\hline Analyte & $\begin{array}{c}\text { rep } 1 \\
(\mathrm{mg} / \mathrm{L}) \\
\end{array}$ & $\begin{array}{c}\text { rep } 2 \\
(\mathrm{mg} / \mathrm{L})\end{array}$ & $\begin{array}{c}\text { rep 3 } \\
(\mathrm{mg} / \mathrm{L}) \\
\end{array}$ & $\begin{array}{c}\text { average } \\
(\mathrm{mg} / \mathrm{L})\end{array}$ & $\begin{array}{l}\text { RSD } \\
(\%)\end{array}$ & $\begin{array}{l}\text { RPD } \\
(\%) \\
\end{array}$ \\
\hline $\mathrm{Ca}$ & 596 & 584 & & 590 & & 2.0 \\
\hline $\mathbf{M g}$ & 140 & 130 & 140 & 137 & 4.2 & \\
\hline $\mathrm{K}$ & 6.90 & 6.80 & & 6.85 & & 0.7 \\
\hline $\mathrm{Na}$ & 145 & 147 & & 146 & & 0.7 \\
\hline $\mathrm{Cl}^{-}$ & 194 & 193 & & 194 & & 0.5 \\
\hline $\mathrm{SO}_{\overline{4}}^{\overline{4}}$ & 1900 & 1970 & 1840 & 1900 & 3.4 & \\
\hline Alk-CaCO 3 & 87.0 & 87.5 & & 87.2 & & 0.6 \\
\hline B & 0.64 & 0.62 & & 0.630 & & 3.2 \\
\hline Cs & $<0.01$ & & & $<0.01$ & & \\
\hline $\mathrm{Fe}$ & 0.030 & 0.033 & & 0.0315 & & 9.7 \\
\hline $\mathrm{Li}$ & 0.18 & 0.17 & & 0.175 & & 5.9 \\
\hline Mn & 0.016 & 0.014 & 0.016 & 0.0153 & 7.7 & \\
\hline $\mathrm{Si}\left(\mathrm{SiO}_{2}\right)$ & 27.1 & 26.8 & & 27.0 & & 1.1 \\
\hline $\mathrm{Sr}$ & 7.53 & 7.47 & & 7.50 & & 0.8 \\
\hline $\mathrm{Br}^{-}$ & 0.23 & 0.25 & & 0.240 & & 4.2 \\
\hline $\mathrm{F}^{-}$ & 3.38 & 3.29 & 3.25 & 3.31 & 2.0 & \\
\hline $1^{-}$ & 0.11 & 0.11 & & 0.110 & & 0 \\
\hline $\mathrm{NO}_{\overline{3}}$ & & & & na & & \\
\hline
\end{tabular}

1. Key: na = not analyzed; $\mathrm{RSD}=$ relative standard deviation; $\mathrm{RPD}=$ relative percent difference. 
Table 49. Results of Solute Analyses by UNC/Bendix: H-11B3 Culebra 1

Sample ID: H11B3.C685B

Collection date: $06 / 03,04 / 85$

\begin{tabular}{|c|c|c|c|c|c|c|}
\hline Analyte & $\begin{array}{c}\text { rep 1 } \\
(\mathrm{mg} / \mathrm{L})\end{array}$ & $\begin{array}{c}\text { rep } 2 \\
(\mathrm{mg} / \mathrm{L}) \\
\end{array}$ & $\begin{array}{c}\text { rep } 3 \\
(\mathrm{mg} / \mathrm{L})\end{array}$ & $\begin{array}{l}\text { average } \\
(\mathrm{mg} / \mathrm{L})\end{array}$ & $\begin{array}{l}\text { RSD } \\
(\%)\end{array}$ & $\begin{array}{l}\text { RPD } \\
(\%)\end{array}$ \\
\hline $\mathrm{Ca}$ & 1700 & 1700 & & 1700 & & 0 \\
\hline $\mathrm{Mg}$ & 1300 & 1350 & & 1320 & & 3.5 \\
\hline$K^{\circ}$ & 970 & 920 & 940 & 943 & 2.7 & \\
\hline $\mathrm{Na}$ & 40300 & 40600 & & 40400 & & 0.7 \\
\hline $\mathrm{Cl}^{-}$ & 65800 & 66100 & & 65900 & & 0.4 \\
\hline $\mathrm{SO}_{4}=$ & 7360 & 7000 & & 7180 & & 5.0 \\
\hline Alk- $\mathrm{CaCO}_{3}$ & & & & na & & \\
\hline B & 29.8 & 33.6 & & 31.7 & & 12 \\
\hline Cs & & & & na & & \\
\hline $\mathrm{Fe}$ & 0.134 & 0.143 & 0.133 & 0.137 & 4.0 & \\
\hline $\mathrm{Li}$ & 0.62 & 0.61 & & 0.615 & & 3.3 \\
\hline $\mathrm{Mn}$ & 0.215 & 0.231 & & 0.223 & & 7.2 \\
\hline $\mathrm{Si}\left(\mathrm{SiO}_{2}\right)$ & & & & na & & \\
\hline $\mathrm{Sr}$ & 25.2 & 24.2 & & 24.7 & & 4.0 \\
\hline $\mathrm{Br}^{-}$ & 46.0 & 48.9 & & 47.4 & & 6.1 \\
\hline $\mathrm{F}^{-}$ & & & & na & & \\
\hline $\mathbf{I}^{-}$ & & & & na & & \\
\hline $\mathrm{NO}_{\overline{3}}$ & & & & na & & \\
\hline
\end{tabular}

1. Key: na = not analyzed; $R S D=$ relative standard deviation; $R P D=$ relative percent difference. 
Table 50. Results of Solute Analyses by UNC/Bendix: H-12 Culebra 1

Sample ID: H12.C885B

\begin{tabular}{|c|c|c|c|c|c|c|}
\hline Analyte & $\begin{array}{c}\text { rep } 1 \\
(\mathrm{mg} / \mathrm{L})\end{array}$ & $\begin{array}{c}\text { rep 2 } \\
(\mathrm{mg} / \mathrm{L})\end{array}$ & $\begin{array}{c}\text { rep } 3 \\
(\mathrm{mg} / \mathrm{L}) \\
\end{array}$ & $\begin{array}{l}\text { average } \\
(\mathrm{mg} / \mathrm{L})\end{array}$ & $\begin{array}{l}\text { RSD } \\
(\%) \\
\end{array}$ & $\begin{array}{l}\text { RPD } \\
(\%)\end{array}$ \\
\hline $\mathrm{Ca}$ & 1770 & 1790 & 1730 & 1760 & 1.7 & \\
\hline $\mathrm{Mg}$ & 1960 & 1990 & & 1980 & & 1.5 \\
\hline $\mathrm{K}$ & 1310 & 1240 & 1260 & 1270 & 2.8 & \\
\hline $\mathrm{Na}$ & 49600 & 48900 & & 49200 & & 1.4 \\
\hline $\mathrm{Cl}^{-}$ & 78900 & 79200 & & 79000 & & 0.2 \\
\hline $\mathrm{SO}_{4}$ & 7400 & 7030 & & 7210 & & 5.1 \\
\hline Alk-CaCO 3 & 40 & 41 & & 40.0 & & 2.5 \\
\hline B & 37.6 & 41.1 & & 39.3 & & 8.9 \\
\hline Cs & & & & na & & \\
\hline $\mathrm{Fe}$ & 0.220 & 0.240 & 0.214 & 0.225 & 6.1 & \\
\hline $\mathrm{Li}$ & 1.1 & 1.2 & & 1.15 & & 8.7 \\
\hline $\mathrm{Mn}$ & 0.085 & 0.090 & 0.087 & 0.0873 & 2.9 & \\
\hline $\mathrm{Si}\left(\mathrm{SiO}_{2}\right)$ & 7.3 & 7.2 & & 7.25 & & 1.4 \\
\hline $\mathrm{Sr}$ & 30.6 & 30.2 & $31: 0$ & 30.6 & 1.3 & \\
\hline $\mathrm{Br}^{-}$ & 73.5 & 78.5 & & 76.0 & & 6.6 \\
\hline $\mathrm{F}^{-}$ & & & & na & & \\
\hline $\mathrm{I}^{-}$ & & & & na & & \\
\hline $\mathrm{NO}_{\overline{3}}$ & & & & na & & \\
\hline
\end{tabular}

1. Key: na = not analyzed; $\mathrm{RSD}=$ relative standard deviation; $\mathrm{RPD}=$ relative percent difference. 
Table 51. Results of Solute Analyses by UNC/Bendix: P-14 Culebra 1

Sample ID: P14.C286B

Collection date: $02 / 26 / 86$

\begin{tabular}{|c|c|c|c|c|c|c|}
\hline Analyte & $\begin{array}{c}\text { rep 1 } \\
(\mathrm{mg} / \mathrm{L}) \\
\end{array}$ & $\begin{array}{c}\text { rep 2 } \\
\text { (mg/L) }\end{array}$ & $\begin{array}{c}\text { rep 3 } \\
(\mathrm{mg} / \mathrm{L})\end{array}$ & $\begin{array}{c}\text { average } \\
(\mathrm{mg} / \mathrm{L})\end{array}$ & $\begin{array}{l}\text { RSD } \\
(\%) \\
\end{array}$ & $\begin{array}{l}\text { RPD } \\
(\%) \\
\end{array}$ \\
\hline $\mathrm{Ca}$ & 3550 & 3480 & & 3520 & & 2.0 \\
\hline $\mathrm{Mg}$ & 840 & 840 & & 840 & & 0 \\
\hline $\mathrm{K}$ & 38.0 & 37.8 & & 37.9 & & 0.5 \\
\hline $\mathrm{Na}$ & 4240 & 4440 & 4400 & 4360 & 2.4 & \\
\hline $\mathrm{Cl}^{-}$ & 14570 & 14370 & & 14470 & & 1.4 \\
\hline $\mathrm{SO}_{4}=$ & 1550 & 1670 & 1540 & 1590 & 4.5 & \\
\hline Alk-CaCO 3 & 80 & 80 & & 80.0 & & 0 \\
\hline B & 0.72 & 0.72 & & 0.720 & & 0 \\
\hline Cs & $<0.01$ & & & $<0.01$ & & \\
\hline $\mathrm{Fe}$ & 1.91 & 2.09 & & 2.00 & & 9.0 \\
\hline $\mathrm{Li}$ & 0.27 & 0.28 & & 0.275 & & 3.7 \\
\hline $\mathrm{Mn}$ & 0.183 & 0.184 & & 0.184 & & 0.5 \\
\hline $\mathrm{Si}\left(\mathrm{SiO}_{2}\right)$ & 29.2 & 30.4 & & 29.8 & & 4.0 \\
\hline $\mathrm{Sr}$ & 52.1 & 49.6 & & 50.8 & & 4.9 \\
\hline $\mathrm{Br}^{-}$ & 70.0 & 74.0 & & 72.0 & & 5.5 \\
\hline $\mathrm{F}^{-}$ & 1.66 & 1.72 & & 1.69 & & 3.6 \\
\hline$I^{-}$ & 0.42 & 0.41 & & 0.415 & & 2.4 \\
\hline $\mathrm{NO}_{\overline{3}}$ & & & & na & & \\
\hline
\end{tabular}

1. Key: na = not analyzed; $R S D=$ relative standard deviation; $R P D=$ relative percent difference. 
Table 52. Results of Solute Analyses by UNC/Bendix: P-17 Culebra ${ }^{1}$

Sample ID: P17.C386B

Collection date: $03 / 17 / 86$

\begin{tabular}{|c|c|c|c|c|c|c|}
\hline Analyte & $\begin{array}{c}\text { rep } 1 \\
(\mathrm{mg} / \mathrm{L})\end{array}$ & $\begin{array}{c}\text { rep } 2 \\
\text { (mg/L) }\end{array}$ & $\begin{array}{c}\text { rep } 3 \\
(\mathrm{mg} / \mathrm{L}) \\
\end{array}$ & $\begin{array}{c}\text { average } \\
(\mathrm{mg} / \mathrm{L})\end{array}$ & $\begin{array}{l}\text { RSD } \\
(\%)\end{array}$ & $\begin{array}{l}\text { RPD } \\
(\%) \\
\end{array}$ \\
\hline $\mathrm{Ca}$ & 1640 & 1600 & & 1620 & & 2.5 \\
\hline $\mathrm{Mg}$ & 1440 & 1480 & & 1460 & & 2.7 \\
\hline $\mathrm{K}$ & 780 & 784 & & 782 & & 0.5 \\
\hline $\mathrm{Na}$ & 28200 & 28400 & & 28300 & & 0.7 \\
\hline $\mathrm{Cl}^{-}$ & 48260 & 48190 & & 48220 & & 0.1 \\
\hline $\mathrm{SO}_{\overline{4}}^{\overline{4}}$ & 6020 & 5990 & 6040 & 6020 & 0.4 & \\
\hline Alk-CaCO 3 & 43.5 & 42.5 & & 43.0 & & 2.3 \\
\hline B & 37.4 & 37.6 & & 37.5 & & 0.5 \\
\hline Cs & $<0.01$ & & & $<0.01$ & & \\
\hline $\mathrm{Fe}$ & 4.04 & 4.00 & & 4.02 & & 1.0 \\
\hline $\mathrm{Li}$ & 0.87 & 0.87 & & 0.870 & & 0 \\
\hline $\mathrm{Mn}$ & 0.864 & 0.880 & & 0.872 & & 1.8 \\
\hline $\mathrm{Si}\left(\mathrm{SiO}_{2}\right)$ & 8.7 & 8.3 & & 8.50 & . & 4.7 \\
\hline $\mathrm{Sr}$ & 27.9 & 29.9 & 29.6 & 29.1 & 3.7 & \\
\hline $\mathrm{Br}^{-}$ & 71.0 & 72.0 & & 71.5 & & 1.4 \\
\hline $\mathrm{F}^{-}$ & 1.79 & 1.95 & & 1.87 & & 8.6 \\
\hline $\mathrm{I}^{-}$ & 0.18 & 0.17 & . & 0.175 & & 5.7 \\
\hline $\mathrm{NO}_{\overline{3}}$ & & & & na & & \\
\hline
\end{tabular}

1. Key: na = not analyzed; $\mathrm{RSD}=$ relative standard deviation; $\mathrm{RPD}=$ relative percent difference. 
Table 53. Results of Solute Analyses by UNC/Bendix: WIPP-25 Culebra 1

Sample ID: W25.C286B

Collection date: $02 / 12 / 86$

\begin{tabular}{|c|c|c|c|c|c|c|}
\hline Analyte & $\begin{array}{c}\text { rep 1 } \\
(\mathrm{mg} / \mathrm{L})\end{array}$ & $\begin{array}{c}\text { rep } 2 \\
(\mathrm{mg} / \mathrm{L})\end{array}$ & $\begin{array}{c}\mathrm{rep} 3 \\
(\mathrm{mg} / \mathrm{L})\end{array}$ & $\begin{array}{c}\text { average } \\
(\mathrm{mg} / \mathrm{L})\end{array}$ & $\begin{array}{r}\text { RSD } \\
(\%)\end{array}$ & $\begin{array}{l}\text { RPD } \\
(\%)\end{array}$ \\
\hline $\mathrm{Ca}$ & 1140 & 1130 & & 1140 & & 0.9 \\
\hline $\mathrm{Mg}$ & 320 & 310 & & 315 & & 3.2 \\
\hline $\mathrm{K}$ & 102 & 101 & & 102 & & 1.0 \\
\hline $\mathrm{Na}$ & 3140 & 3220 & & 3180 & & 2.5 \\
\hline $\mathrm{Cl}^{-}$ & 6380 & 6260 & & 6320 & & 1.9 \\
\hline $\mathrm{SO}_{\overline{4}}$ & 2440 & 2350 & 2350 & 2380 & 2.2 & \\
\hline Alk-CaCO 3 & 100 & 102 & & 101 & & 2.0 \\
\hline B & 1.63 & 1.71 & & 1.67 & & 2.4 \\
\hline Cs & $<0.01$ & & & $<0.01$ & & \\
\hline $\mathrm{Fe}$ & 0.47 & 0.54 & 0.50 & 0.503 & 7.0 & \\
\hline $\mathrm{Li}$ & 0.22 & 0.22 & & 0.220 & & 0 \\
\hline Mn & 0.108 & 0.108 & & 0.108 & & 0 \\
\hline $\mathrm{Si}\left(\mathrm{SiO}_{2}\right)$ & 32.0 & 33.2 & & 32.6 & & 3.7 \\
\hline $\mathrm{Sr}$ & 16.6 & 16.5 & & 16.6 & & 0.6 \\
\hline $\mathrm{Br}^{-}$ & 3.40 & 3.30 & & 3.35 & & 3.0 \\
\hline $\mathrm{F}^{-}$ & 1.67 & 1.70 & & 1.68 & & 1.2 \\
\hline $\mathrm{I}^{-}$ & 0.038 & 0.043 & 0.045 & 0.0420 & 8.6 & \\
\hline $\mathrm{NO}_{\overline{3}}$ & & & & na & & \\
\hline
\end{tabular}

1. Key: $\mathrm{na}=$ not analyzed; $\mathrm{RSD}=$ relative standard deviation; $\mathrm{RPD}=$ relative percent difference. 
Table 54. Results of Solute Analyses by UNC/Bendix: WIPP-26 Culebra ${ }^{1}$

Sample ID: W26.C1185B

Collection date: $11 / 25 / 85$

\begin{tabular}{|c|c|c|c|c|c|c|}
\hline Analyte & $\begin{array}{c}\text { rep } 1 \\
(\mathrm{mg} / \mathrm{L})\end{array}$ & $\begin{array}{c}\text { rep 2 } \\
(\mathrm{mg} / \mathrm{L})\end{array}$ & $\begin{array}{c}\text { rep } 3 \\
(\mathrm{mg} / \mathrm{L}) \\
\end{array}$ & $\begin{array}{c}\text { average } \\
(\mathrm{mg} / \mathrm{L})\end{array}$ & $\begin{array}{l}\text { RSD } \\
(\%)\end{array}$ & $\begin{array}{c}\text { RPD } \\
(\%)\end{array}$ \\
\hline $\mathrm{Ca}$ & 1360 & 1330 & & 1340 & & 2.2 \\
\hline $\mathrm{Mg}$ & 380 & 380 & & 380 & & 0 \\
\hline $\mathrm{K}$ & 344 & 342 & & 343 & & 0.3 \\
\hline $\mathrm{Na}$ & 4160 & 4280 & & 4220 & & 2.8 \\
\hline $\mathrm{Cl}^{-}$ & 8870 & 8670 & & 8770 & & 2.3 \\
\hline $\mathrm{SO}_{\overline{4}}$ & 2430 & 2470 & 2350 & 2420 & 2.5 & \\
\hline Alk- $\mathrm{CaCO}_{3}$ & 98 & 93 & 97 & 96.0 & 2.7 & \\
\hline B & 1.66 & 1.64 & & 1.65 & & 1.2 \\
\hline Cs & $<0.01$ & & & $<0.01$ & & \\
\hline $\mathrm{Fe}$ & 0.024 & 0.027 & 0.028 & 0.0263 & 8.0 & \\
\hline $\mathrm{Li}$ & 0.23 & 0.23 & & 0.230 & & 0 \\
\hline $\mathbf{M n}$ & $<0.01$ & & & $<0.01$ & & \\
\hline $\mathrm{Si}\left(\mathrm{SiO}_{2}\right)$ & 33.8 & 35.7 & & 34.8 & & 3.5 \\
\hline $\mathrm{Sr}$ & 19.5 & 19.5 & & 19.5 & & 0 \\
\hline $\mathrm{Br}^{-}$ & 3.8 & 4.0 & & 3.90 & & 2.6 \\
\hline$F^{-}$ & 1.86 & 1.68 & 1.64 & 1.73 & 6.8 & \\
\hline $\mathrm{I}^{-}$ & 0.069 & 0.070 & & 0.0695 & & 1.4 \\
\hline $\mathrm{NO}_{\overline{3}}$ & & & & na & & \\
\hline
\end{tabular}

1. Key: na = not analyzed; $\mathrm{RSD}=$ relative standard deviation; $\mathrm{RPD}=$ relative percent difference. 
Table 55. Results of Solute Analyses by UNC/Bendix: WIPP-29 Culebra 1

Sample ID: W29.C1285B

Collection date: $12 / 14 / 85$

\begin{tabular}{|c|c|c|c|c|c|c|}
\hline Analyte & $\begin{array}{c}\mathrm{rep} 1 \\
(\mathrm{mg} / \mathrm{L})\end{array}$ & $\begin{array}{c}\text { rep } 2 \\
(\mathrm{mg} / \mathrm{L}) \\
\end{array}$ & $\begin{array}{c}\mathrm{rep} 3 \\
(\mathrm{mg} / \mathrm{L}) \\
\end{array}$ & $\begin{array}{c}\text { average } \\
(\mathrm{mg} / \mathrm{L})\end{array}$ & $\begin{array}{l}\text { RSD } \\
(\%)\end{array}$ & $\begin{array}{l}\text { RPD } \\
(\%)\end{array}$ \\
\hline $\mathrm{Ca}$ & 420 & 406 & & 413 & & 3.4 \\
\hline $\mathrm{Mg}$ & 6600 & 6400 & & 6500 & & 3.1 \\
\hline $\mathrm{K}$ & 23800 & 22800 & 23400 & 23300 & 2.2 & \\
\hline $\mathrm{Na}$ & 92400 & 96400 & 96000 & 94900 & 2.3 & \\
\hline $\mathrm{Cl}^{-}$ & 179700 & 177900 & & 178800 & & 1.0 \\
\hline $\mathrm{SO}_{\overline{4}}$ & 19700 & 20300 & 20100 & 20000 & 1.5 & \\
\hline Alk-CaCO 3 & 123 & 127 & & 125 & & 3.2 \\
\hline B & 5.14 & 5.20 & & 5.17 & & 1.2 \\
\hline Cs & $<0.01$ & & & $<0.01$ & & \\
\hline $\mathrm{Fe}$ & 1.08 & 1.14 & & 1.11 & & 9.0 \\
\hline $\mathbf{L i}$ & 0.70 & 0.70 & & 0.700 & & 0 \\
\hline $\mathrm{Mn}$ & 1.74 & 1.72 & & 1.73 & & 1.2 \\
\hline $\mathrm{Si}\left(\mathrm{SiO}_{2}\right)$ & 14.9 & 14.3 & & 14.6 & & 4.1 \\
\hline $\mathrm{Sr}$ & 12.9 & 12.6 & & 12.8 & & 2.4 \\
\hline $\mathrm{Br}^{-}$ & 62.0 & 60.0 & & 61.0 & & 3.3 \\
\hline $\mathrm{F}^{-}$ & 4.79 & 4.40 & & 4.60 & & 8.5 \\
\hline $\mathrm{I}^{-}$ & 0.39 & 0.38 & & 0.385 & & 2.6 \\
\hline NO $\overline{3}$ & & & & na & & \\
\hline
\end{tabular}

1. Key: na = not analyzed; $\mathrm{RSD}=$ relative standard deviation; $\mathrm{RPD}=$ relative percent difference. 
Table 56. Results of Solute Analyses by UNC/Bendix: Engle Well - Culebra 1

Sample ID: XENG.C385B

Collection date: $03 / 05 / 85$

\begin{tabular}{|c|c|c|c|c|c|c|}
\hline Analyte & $\begin{array}{c}\text { rep } 1 \\
(\mathrm{mg} / \mathrm{L}) \\
\end{array}$ & $\begin{array}{c}\text { rep } 2 \\
(\mathrm{mg} / \mathrm{L}) \\
\end{array}$ & $\begin{array}{c}\text { rep 3 } \\
\text { (mg/L) }\end{array}$ & $\begin{array}{c}\text { rep } 4 \\
(\mathrm{mg} / \mathrm{L})\end{array}$ & $\begin{array}{c}\text { average } \\
(\mathrm{mg} / \mathrm{L})\end{array}$ & $\begin{array}{l}\text { RSD } \\
(\%)\end{array}$ \\
\hline $\mathrm{Ca}$ & 590 & 580 & 595 & & 588 & 1.3 \\
\hline $\mathrm{Mg}$ & 152 & 149 & 154 & & 152 & 1.7 \\
\hline K & 5.60 & 5.56 & 5.64 & & 5.60 & 0.7 \\
\hline $\mathrm{Na}$ & 198 & 199 & 202 & & 200 & 1.0 \\
\hline $\mathrm{Cl}^{-}$ & 228 & 230 & 235 & & 231 & 1.6 \\
\hline $\mathrm{SO}_{\overline{4}}$ & 1950 & 2040 & 1970 & & 1990 & 2.4 \\
\hline Alk-CaCO 3 & 86.5 & 87.0 & 87.0 & & 86.8 & 0.3 \\
\hline B & 0.98 & 0.96 & 0.96 & & 0.970 & 1.2 \\
\hline Cs & $<0.001$ & $<0.001$ & $<0.001$ & & $<0.001$ & \\
\hline $\mathrm{Fe}$ & 0.595 & 0.588 & 0.575 & & 0.586 & 1.7 \\
\hline $\mathbf{L i}$ & 0.18 & 0.16 & 0.17 & & 0.170 & 5.9 \\
\hline $\mathbf{M n}$ & 0.0590 & 0.0630 & 0.0575 & & 0.0598 & 4.7 \\
\hline $\mathrm{Si}\left(\mathrm{SiO}_{2}\right)$ & 30.5 & 28.2 & 28.5 & & 29.1 & 4.3 \\
\hline $\mathrm{Sr}$ & 8.40 & 8.20 & 8.48 & & 8.36 & 1.7 \\
\hline $\mathrm{Br}^{-}$ & 0.310 & 0.240 & 0.290 & 0.230 & 0.270 & 14.3 \\
\hline $\mathrm{F}^{-}$ & 2.81 & 2.80 & 2.79 & & 2.80 & 0.3 \\
\hline $\mathrm{I}^{-}$ & 0.110 & 0.121 & 0.117 & & 0.116 & 4.8 \\
\hline $\mathrm{NO}_{\overline{3}}$ & & & & & na & \\
\hline
\end{tabular}

1. Key: na = not analyzed; $\mathrm{RSD}=$ relative standard deviation. 
Table 57. Results of Solute Analyses by UNC/Bendix: H-3B1 Magenta 1

Sample ID: H03B1.M785B

Collection date: $07 / 01 / 85$

\begin{tabular}{|c|c|c|c|c|c|c|c|}
\hline Analyte & $\begin{array}{c}\text { rep } 1 \\
(\mathrm{mg} / \mathrm{L})\end{array}$ & $\begin{array}{c}\text { rep 2 } \\
(\mathrm{mg} / \mathrm{L})\end{array}$ & $\begin{array}{c}\mathrm{rep} 3 \\
(\mathrm{mg} / \mathrm{L})\end{array}$ & $\begin{array}{c}\text { rep } 4 \\
(\mathrm{mg} / \mathrm{L})\end{array}$ & $\begin{array}{l}\text { average } \\
(\mathrm{mg} / \mathrm{L})\end{array}$ & $\begin{array}{c}\text { RSD } \\
(\%)\end{array}$ & $\begin{array}{l}\text { RPD } \\
(\%)\end{array}$ \\
\hline $\mathrm{Ca}$ & 1010 & 1000 & & & 1000 & & 1.0 \\
\hline $\mathrm{Mg}$ & 290 & 294 & & & 292 & & 1.4 \\
\hline $\mathrm{K}$ & 35.0 & 34.0 & & & 34.5 & & 2.9 \\
\hline $\mathrm{Na}$ & 1570 & 1510 & 1490 & 1510 & 1520 & 2.3 & \\
\hline $\mathrm{Cl}^{-}$ & 3360 & 3360 & & & 3360 & & 0 \\
\hline $\mathrm{SO}_{4}^{\overline{4}}$ & 2340 & 2290 & & & 2310 & & 2.2 \\
\hline Alk-CaCO 3 & 35 & 35 & & & 35.0 & & 0 \\
\hline B & 2.0 & 2.1 & & & 2.05 & & 4.9 \\
\hline $\mathrm{Cs}$ & $<0.01$ & $<0.01$ & & & $<0.01$ & & \\
\hline $\mathrm{Fe}$ & 0.108 & 0.110 & 0.103 & & 0.107 & 3.4 & \\
\hline $\mathrm{Li}$ & 0.31 & 0.33 & & & 0.320 & & 6.2 \\
\hline $\mathrm{Mn}$ & 0.0264 & 0.0288 & & & 0.0276 & & 8.7 \\
\hline $\mathrm{Si}\left(\mathrm{SiO}_{2}\right)$ & 10.7 & 10.3 & & & 10.5 & & 3.8 \\
\hline $\mathrm{Sr}$ & 17.4 & 17.2 & & & 17.3 & & 1.2 \\
\hline $\mathrm{Br}^{-}$ & 5.9 & 5.8 & & & 5.85 & & 1.7 \\
\hline $\mathrm{F}^{-}$ & 2.50 & 2.36 & & & 2.43 & & 5.7 \\
\hline $\mathrm{I}^{-}$ & 1.21 & 1.20 & & & 1.20 & & 0.8 \\
\hline NO $\overline{3}$ & & & & & na & & \\
\hline
\end{tabular}

1. Key: $n a=$ not analyzed; $R S D=$ relative standard deviation; $R P D=$ relative percent difference. 
Table 58. Results of Solute Analyses by UNC/Bendix: H-4C Magenta 1

Sample ID: H04C.M1186

Collection date: 11/04/86

\begin{tabular}{|c|c|c|c|c|c|c|}
\hline Analyte & $\begin{array}{c}\text { rep } 1 \\
\text { (mg/L) }\end{array}$ & $\begin{array}{c}\text { rep } 2 \\
(\mathrm{mg} / \mathrm{L})\end{array}$ & $\begin{array}{c}\text { rep } 3 \\
(\mathrm{mg} / \mathrm{L})\end{array}$ & $\begin{array}{l}\text { average } \\
(\mathrm{mg} / \mathrm{L})\end{array}$ & $\begin{array}{c}\text { RSD } \\
(\%)\end{array}$ & $\begin{array}{l}\text { RPD } \\
(\%) \\
\end{array}$ \\
\hline $\mathrm{Ca}$ & 646 & 656 & & 651 & & 1.5 \\
\hline Mg & 410 & 412 & & 411 & & 0.5 \\
\hline $\mathrm{K}$ & 85.0 & 85.2 & & 85.1 & & 0.2 \\
\hline $\mathrm{Na}$ & 7075 & 7150 & & 7112 & & 1.0 \\
\hline $\mathrm{Cl}^{-}$ & 8463 & 8458 & & 8460 & & 0.1 \\
\hline $\mathrm{SO}_{\overline{4}}$ & 7190 & 7060 & 7050 & 7100 & 1.1 & \\
\hline Alk-CaCO 3 & 61.0 & 60.5 & & 60.8 & & 0.8 \\
\hline B & 11.3 & 11.7 & & 11.5 & & 3.5 \\
\hline Cs & $<0.01$ & & & $<0.01$ & & \\
\hline $\mathrm{Fe}$ & 0.72 & 0.70 & & 0.710 & & 2.8 \\
\hline $\mathrm{Li}$ & 0.46 & 0.45 & & 0.460 & & 2.2 \\
\hline $\mathrm{Mn}$ & 0.29 & 0.29 & & 0.290 & & 0 \\
\hline $\mathrm{Si}\left(\mathrm{SiO}_{2}\right)$ & 8.98 & 9.53 & 8.67 & 9.06 & 4.8 & \\
\hline $\mathrm{Sr}$ & 11.8 & 12.3 & & 12.0 & & 4.1 \\
\hline $\mathrm{Br}^{-}$ & 5.92 & 5.90 & & 5.91 & & 0.3 \\
\hline $\mathrm{F}^{-}$ & 2.34 & 2.52 & & 2.43 & & 7.4 \\
\hline$I^{-}$ & 0.303 & 0.325 & & 0.314 & & 7.0 \\
\hline $\mathrm{IO}_{\overline{3}}$ & $<0.01$ & & & $<0.01$ & & \\
\hline $\mathrm{NO}_{\overline{3}}$ & & & & na & & \\
\hline
\end{tabular}

1. Key: na = not analyzed; $R S D=$ relative standard deviation; $R P D=$ relative percent difference. 
Table 59. Results of Solute Analyses by UNC/Bendix: H-5C Magenta 1

Sample ID: H05C.M1086

Collection date: $10 / 24 / 86$

\begin{tabular}{|c|c|c|c|c|c|c|c|}
\hline Analyte & $\begin{array}{c}\text { rep } 1 \\
(\mathrm{mg} / \mathrm{L})\end{array}$ & $\begin{array}{c}\text { rep } 2 \\
(\mathrm{mg} / \mathrm{L}) \\
\end{array}$ & $\begin{array}{c}\text { rep } 3 \\
\text { (mg/L) }\end{array}$ & $\begin{array}{c}\text { rep } 4 \\
(\mathrm{mg} / \mathrm{L})\end{array}$ & $\begin{array}{l}\text { average } \\
(\mathrm{mg} / \mathrm{L})\end{array}$ & $\begin{array}{l}\text { RSD } \\
(\%)\end{array}$ & $\begin{array}{r}\text { RPD } \\
(\%) \\
\end{array}$ \\
\hline $\mathrm{Ca}$ & 548 & 552 & & & 550 & & 0.7 \\
\hline $\mathrm{Mg}$ & 174 & 172 & & & 173 & & 1.2 \\
\hline $\mathrm{K}$ & 33.4 & 33.7 & & & 33.6 & & 0.9 \\
\hline $\mathrm{Na}$ & 1500 & 1460 & & & 1480 & & 2.7. \\
\hline $\mathrm{Cl}^{-}$ & 1073 & 1071 & & & 1072 & & 0.2 \\
\hline $\mathrm{SO}_{4} \overline{\mathrm{H}}$ & 3610 & 3630 & 3620 & & 3620 & 0.3 & \\
\hline Alk-CaCO 3 & 41 & 41 & & & 41.0 & & 0 \\
\hline B & 10.6 & 10.6 & & & 10.6 & & 0.4 \\
\hline Cs & $<0.01$ & & & & $<0.01$ & & \\
\hline $\mathrm{Fe}$ & 1.52 & 1.55 & & & 1.54 & & 2.0 \\
\hline $\mathrm{Li}$ & 0.20 & 0.20 & & & 0.200 & & 0 \\
\hline $\mathbf{M n}$ & 0.020 & 0.020 & & & 0.0200 & & 0 \\
\hline $\mathrm{Si}\left(\mathrm{SiO}_{2}\right)$ & 10.4 & 10.8 & & & 10.6 & & 3.8 \\
\hline $\mathrm{Sr}$ & 10.3 & 10.6 & & & 10.4 & & 2.4 \\
\hline $\mathrm{Br}^{-}$ & 2.59 & 2.76 & 2.74 & 2.79 & 2.72 & 3.3 & \\
\hline $\mathrm{F}^{-}$ & 2.36 & 2.56 & & & 2.46 & & 8.1 \\
\hline $\mathrm{I}^{-}$ & 0.313 & 0.303 & & & 0.308 & & 3.2 \\
\hline $\mathrm{IO}_{\overline{3}}$ & $<0.01$ & & & & $<0.01$ & & \\
\hline $\mathrm{NO}_{\overline{3}}$ & & & & & na & & \\
\hline
\end{tabular}

1. Key: na $=$ not analyzed; $\mathrm{RSD}=$ relative standard deviation; $\mathrm{RPD}=$ relative percent difference. 
Table 60. Results of Solute Analyses by UNC/Bendix: H-6C Magenta 1

Sample ID: H06C.M1086

Collection date: $10 / 01 / 86$

\begin{tabular}{|c|c|c|c|c|c|c|c|}
\hline Analyte & $\begin{array}{c}\text { rep } 1 \\
(\mathrm{mg} / \mathrm{L})\end{array}$ & $\begin{array}{c}\text { rep } 2 \\
(\mathrm{mg} / \mathrm{L})\end{array}$ & $\begin{array}{c}\text { rep } 3 \\
(\mathrm{mg} / \mathrm{L}) \\
\end{array}$ & $\begin{array}{c}\text { rep } 4 \\
(\mathrm{mg} / \mathrm{L})\end{array}$ & $\begin{array}{l}\text { average } \\
(\mathrm{mg} / \mathrm{L})\end{array}$ & $\begin{array}{c}\text { RSD } \\
(\%)\end{array}$ & $\begin{array}{c}\text { RPD } \\
(\%) \\
\end{array}$ \\
\hline $\mathrm{Ca}$ & 542 & 550 & & & 546 & & 1.5 \\
\hline $\mathrm{Mg}$ & 160 & 160 & & & 160 & & 0 \\
\hline $\mathrm{K}$ & 16.7 & 16.7 & & & 16.6 & & 0.6 \\
\hline $\mathrm{Na}$ & 632 & 652 & & & 642 & & 3.1 \\
\hline $\mathrm{Cl}^{-}$ & 426 & 430 & & & 428 & & 0.9 \\
\hline $\mathrm{SO}_{\overline{4}}$ & 2720 & 2680 & 2700 & & 2700 & 0.7 & \\
\hline Alk-CaCO 3 & 38.5 & 39.0 & & & 38.8 & & 1.3 \\
\hline B & 2.12 & 2.20 & & & 2.16 & & 3.9 \\
\hline Cs & $<0.01$ & & & & $<0.01$ & & \\
\hline $\mathrm{Fe}$ & 0.26 & 0.26 & & & 0.260 & & 0 \\
\hline $\mathbf{L i}$ & 0.21 & 0.21 & & & 0.210 & & 0 \\
\hline $\mathbf{M n}$ & 0.010 & 0.010 & & & 0.0100 & & 0 \\
\hline $\mathrm{Si}\left(\mathrm{SiO}_{2}\right)$ & 11.7 & 11.0 & 10.4 & & 11.1 & 5.0 & \\
\hline $\mathrm{Sr}$ & 9.74 & 9.85 & & & 9.80 & & 1.1 \\
\hline $\mathrm{Br}^{-}$ & 1.08 & 1.09 & 1.08 & 1.11 & 1.09 & 1.3 & \\
\hline$F^{-}$ & 1.45 & 1.57 & & & 1.51 & & 7.9 \\
\hline $\mathrm{I}^{-}$ & 0.088 & 0.083 & & & 0.0860 & & 5.9 \\
\hline $\mathrm{IO}_{\overline{3}}$ & $<0.01$ & & & & $<0.01$ & & \\
\hline $\mathrm{NO}_{\overline{3}}$ & & & & & na & & \\
\hline
\end{tabular}

1. Key: $\mathrm{na}=$ not analyzed; $\mathrm{RSD}=$ relative standard deviation; $\mathrm{RPD}=$ relative percent difference. 
Table 61. Results of Solute Analyses by UNC/Bendix: Ranch Well - Dewey Lake ${ }^{1}$

Sample ID: XRAN.D686

Collection date: $06 / 18 / 86$

\begin{tabular}{|c|c|c|c|c|c|c|}
\hline Analyte & $\begin{array}{c}\text { rep } 1 \\
(\mathrm{mg} / \mathrm{L}) \\
\end{array}$ & $\begin{array}{c}\text { rep } 2 \\
(\mathrm{mg} / \mathrm{L}) \\
\end{array}$ & $\begin{array}{c}\text { rep } 3 \\
(\mathrm{mg} / \mathrm{L})\end{array}$ & $\begin{array}{l}\text { average } \\
(\mathrm{mg} / \mathrm{L})\end{array}$ & $\begin{array}{l}\text { RSD } \\
(\%)\end{array}$ & $\begin{array}{r}\text { RPD } \\
(\%) \\
\end{array}$ \\
\hline $\mathrm{Ca}$ & 418 & 422 & & 420 & & 1.0 \\
\hline $\mathrm{Mg}$ & 204 & 201 & & 202 & & 1.5 \\
\hline $\mathrm{K}$ & 3.94 & 4.06 & & 4.00 & & 3.0 \\
\hline $\mathrm{Na}$ & 200 & 199 & & 200 & & 0.5 \\
\hline $\mathrm{Cl}^{-}$ & 416 & 419 & & 418 & & .0 .7 \\
\hline $\mathrm{SO}_{\overline{4}}$ & 1100 & 1090 & 1110 & 1100 & 0.9 & \\
\hline Alk-CaCO 3 & 142 & 141 & & 142 & & 0.7 \\
\hline B & 0.10 & 0.10 & & 0.100 & & 0 \\
\hline Cs & $<0.010$ & & & $<0.01$ & & \\
\hline $\mathrm{Fe}$ & 0.024 & 0.024 & & 0.0240 & & 0 \\
\hline $\mathrm{Li}$ & 0.12 & 0.12 & & 0.120 & & 0 \\
\hline $\mathrm{Mn}$ & & & & $<0.01$ & & \\
\hline $\mathrm{Si}\left(\mathrm{SiO}_{2}\right)$ & 51.6 & 53.4 & 50.2 & 51.7 & 3.1 & \\
\hline $\mathrm{Sr}$ & 5.83 & 6.05 & & 5.94 & & 3.7 \\
\hline $\mathrm{Br}^{-}$ & 2.34 & 2.31 & & 2.32 & & 1.3 \\
\hline $\mathrm{F}^{-}$ & 0.79 & 0.85 & & 0.82 & & 7.3 \\
\hline $\mathrm{I}^{-}$ & 0.128 & 0.130 & & 0.129 & & 1.6 \\
\hline $10_{\overline{3}}$ & 0.150 & & & 0.150 & & \\
\hline NO $\overline{3}$ & 525 & 523 & & 524 & & 0.4 \\
\hline
\end{tabular}


Table 62. Results of Solute Analyses by UNC/Bendix: Twin Wells/Pasture Well - Dewey Lake ${ }^{1}$

Sample ID: XTWP.D186B

Collection date: $01 / 30 / 86$

\begin{tabular}{|c|c|c|c|c|c|c|}
\hline Analyte & $\begin{array}{c}\text { rep } 1 \\
\text { (mg/L) }\end{array}$ & $\begin{array}{c}\text { rep } 2 \\
(\mathrm{mg} / \mathrm{L})\end{array}$ & $\begin{array}{c}\mathrm{rep} 3 \\
(\mathrm{mg} / \mathrm{L})\end{array}$ & $\begin{array}{c}\text { average } \\
(\mathrm{mg} / \mathrm{L})\end{array}$ & $\begin{array}{c}\text { RSD } \\
(\%)\end{array}$ & $\begin{array}{l}\text { RPD } \\
(\%)\end{array}$ \\
\hline $\mathrm{Ca}$ & 81.0 & 79.8 & & 80.4 & & 1.5 \\
\hline $\mathrm{Mg}$ & 22.0 & 23.0 & & 22.5 & & 4.4 \\
\hline $\mathrm{K}$ & 3.84 & 3.86 & & 3.85 & & 0.5 \\
\hline $\mathrm{Na}$ & 25.0 & 25.8 & & 25.4 & & 3.1 \\
\hline $\mathrm{Cl}^{-}$ & 44.6 & 44.4 & 43.2 & 44.1 & 1.7 & \\
\hline $\mathrm{SO}_{4}=$ & 74.4 & 75.5 & 75.4 & 75.1 & 0.8 & \\
\hline Alk- $\mathrm{CaCO}_{3}$ & 120 & 128 & 122 & 123 & 3.4 & \\
\hline B & 0.13 & 0.13 & & 0.130 & & 0 \\
\hline Cs & $<0.01$ & & & $<0.01$ & & \\
\hline $\mathrm{Fe}$ & $<0.01$ & & & $<0.01$ & & \\
\hline $\mathrm{Li}$ & $<0.05$ & & & $<0.05$ & & \\
\hline $\mathrm{Mn}$ & $<0.01$ & & & $<0.01$ & & \\
\hline $\mathrm{Si}\left(\mathrm{SiO}_{2}\right)$ & 46.3 & 47.5 & & 46.9 & & 2.8 \\
\hline $\mathrm{Sr}$ & 1.07 & 1.06 & & 1.06 & & 1.0 \\
\hline $\mathrm{Br}^{-}$ & 0.17 & 0.17 & & 0.170 & & 0 \\
\hline $\mathrm{F}^{-}$ & 0.58 & 0.59 & & 0.58 & & 1.7 \\
\hline $\mathrm{I}^{-}$ & $<0.01$ & & & $<0.01$ & & \\
\hline NO $\overline{3}$ & & & & na & & \\
\hline
\end{tabular}

1. Key: na $=$ not analyzed; $R S D=$ relative standard deviation; $R P D=$ relative percent difference. 
Table 63. Results of Solute Analyses by UNC/Bendix: DOE-2 Bell Canyon 1

Sample ID: D2.B785B

Collection date: $07 / 23 / 85$

\begin{tabular}{|c|c|c|c|c|c|c|}
\hline Analyte & $\begin{array}{c}\text { rep } 1 \\
(\mathrm{mg} / \mathrm{L}) \\
\end{array}$ & $\begin{array}{c}\text { rep } 2 \\
\text { (mg/L) }\end{array}$ & $\begin{array}{c}\text { rep } 3 \\
(\mathrm{mg} / \mathrm{L})\end{array}$ & $\begin{array}{c}\text { average } \\
(\mathrm{mg} / \mathrm{L})\end{array}$ & $\begin{array}{r}\text { RSD } \\
(\%)\end{array}$ & $\begin{array}{r}\text { RPD } \\
(\%) \\
\end{array}$ \\
\hline $\mathrm{Ca}$ & 5860 & 5840 & 6040 & 5910 & 1.9 & \\
\hline $\mathrm{Mg}$ & 1320 & 1350 & 1310 & 1330 & 1.6 & \\
\hline $\mathrm{K}$ & 900 & 870 & & 885 & & 3.4 \\
\hline $\mathrm{Na}$ & 49900 & 49300 & & 49600 & & 1.2 \\
\hline $\mathrm{Cl}^{-}$ & 89900 & 89200 & 89900 & 89700 & 0.4 & \\
\hline $\mathrm{SO}_{4}=$ & 2130 & 1970 & 1950 & 2020 & 4.9 & \\
\hline Alk-CaCO 3 & 40 & 38 & & 39.0 & & 5.1 \\
\hline B & 52.0 & 55.7 & & 53.8 & & 6.9 \\
\hline Cs & $<0.01$ & $<0.01$ & & $<0.01$ & & \\
\hline $\mathrm{Fe}$ & 10.8 & 11.0 & 10.7 & 10.8 & 1.4 & \\
\hline $\mathrm{Li}$ & 5.7 & 6.0 & & 5.85 & & 5.2 \\
\hline $\mathrm{Mn}$ & 2.74 & 2.94 & & 2.84 & & 7.0 \\
\hline $\mathrm{Si}\left(\mathrm{SiO}_{2}\right)$ & 2.58 & 2.46 & & 2.52 & & 4.8 \\
\hline Sr & 145 & 146 & & 146 & & 0.7 \\
\hline $\mathrm{Br}^{-}$ & 239 & 270 & 244 & 251 & 6.6 & \\
\hline $\mathrm{F}^{-}$ & 1.14 & 1.10 & & 1.12 & & 3.6 \\
\hline$I^{-}$ & 6.33 & 6.46 & & 6.39 & & 2.0 \\
\hline $\mathrm{NO}_{\overline{3}}$ & & & & na & & \\
\hline
\end{tabular}

1. Key: $\mathrm{na}=$ not analyzed; $\mathrm{RSD}=$ relative standard deviation; $\mathrm{RPD}=$ relative percent difference. 
Table 64. Summary of Results of Laboratory Analyses by UNC/Bendix For SNL 1

\begin{tabular}{|c|c|c|c|c|c|c|}
\hline Well & Zone & $\begin{array}{l}\text { Collection } \\
\text { Date(s) }\end{array}$ & Sample ID & Table 2 & $\begin{array}{c}\text { Chg Bal } \\
\text { Error } \\
(\%)\end{array}$ & $\begin{array}{l}\text { TDS- } \\
\text { Calc'd } \\
\text { (mg/L) }\end{array}$ \\
\hline DOE-1 & $\mathrm{Cul}$ & $04 / 24,25 / 85$ & D1.C485B & 39 & 0.2 & 13120 \\
\hline DOE-2 & Cul & $03 / 11,12 / 85$ & D2.C385B & 40 & -3.2 & 6040 \\
\hline $\mathrm{H}-2 \mathrm{~A}$ & $\mathrm{Cul}$ & $04 / 21 / 86$ & H02A.C486B & 41 & -1.1 & 1290 \\
\hline H-3B3 & Cul & $06 / 11 / 84$ & H03B3.C684B & 37 & -1.4 & 5500 \\
\hline H-3B3 & Cul & $02 / 04 / 85$ & H03B3.C285B & 42 & -1.4 & 5580 \\
\hline $\mathrm{H}-4 \mathrm{~B}$ & Cul & $05 / 29 / 81$ & H04B.C581B & 33 & -1.9 & 2170 \\
\hline $\mathrm{H}-4 \mathrm{C}$ & Cul & $08 / 10 / 84$ & H04C.C884B & 38 & 1.0 & 2120 \\
\hline$H-4 B$ & Cul & $07 / 20 / 85$ & H04B.C785B & 43 & 0.4 & 2020 \\
\hline H-5B & Cul & $06 / 01 / 81$ & H05B.C681B & 34 & -2.1 & 15440 \\
\hline $\mathrm{H}-5 \mathrm{C}$ & Cul & $10 / 15 / 81$ & H05C.C1081B & 35 & -2.2 & 15450 \\
\hline H-5B & Cul & $08 / 26,27 / 85$ & H05B.C885B & 44 & 1.5 & 15260 \\
\hline H-6B & Cul & $05 / 02 / 81$ & H06B.C581B & 36 & 0.2 & 5930 \\
\hline $\mathrm{H}-6 \mathrm{~B}$ & $\mathrm{Cul}$ & $09 / 15 / 85$ & H06B.C985B & 45 & -0.5 & 5740 \\
\hline $\mathrm{H}-7 \mathrm{~B}$ & Cul & $03 / 26 / 86$ & H07B1.C386B & 46 & -0.4 & 322 \\
\hline H-8B & Cul & $01 / 22 / 86$ & H08B.C186B & 47 & -0.3 & 283 \\
\hline H-9B & $\mathrm{Cul}$ & $11 / 14 / 85$ & H09B.C1185B & 48 & 0.5 & 308 \\
\hline H-11B3 & Cul & $06 / 03,04 / 85$ & H11B3.C685B & 49 & -0.9 & 11740 \\
\hline $\mathrm{H}-12$ & Cul & 08/08/85 & H12.C885B & 50 & 0.9 & 14050 \\
\hline P-14 & Cul & $02 / 26 / 86$ & P14.C286B & 51 & -0.9 & 2490 \\
\hline P-17 & Cul & $03 / 17 / 86$ & P17.C386B & 52 & -1.2 & 8650 \\
\hline $\mathrm{W}-25$ & Cul & $08 / 20 / 80$ & W25.C880B & 20 & 1.4 & 1210 \\
\hline W-25 & Cul & $02 / 12 / 86$ & W25.C286B & 53 & -1.4 & 1360 \\
\hline W-26 & Cul & $08 / 24 / 80$ & W26.C880B & 21 & -0.4 & 1510 \\
\hline W-26 & Cul & $11 / 25 / 85$ & W26.C1185B & 54 & -1.6 & 1760 \\
\hline W-27 & Cul & 09/03/80 & W27.C980B & 22 & -1.5 & 13470 \\
\hline W-28 & Cul & $09 / 11 / 80$ & W28.C980B & 23 & -0.9 & 4660 \\
\hline W-29 & Cul & $08 / 28 / 80$ & W29.C880B & 24 & -2.3 & 24540 \\
\hline W-29 & Cul & $12 / 14 / 85$ & W29.C1285B & 55 & -1.8 & 32410 \\
\hline W-30 & Cul & $09 / 06 / 80$ & W30.C980B & 25 & -2.5 & 2910 \\
\hline ENGLE & $\mathrm{Cul}$ & $03 / 05 / 85$ & XENG.C385B & 56 & 1.0 & 327 \\
\hline $\mathrm{H}-3 \mathrm{~B} 1$ & Mag & $07 / 01 / 85$ & H03B1.M785B & 57 & -1.0 & 856 \\
\hline $\mathrm{H}-4 \mathrm{C}$ & Mag & $11 / 04 / 86$ & H04C.M1186B & 58 & -1.4 & 2390 \\
\hline $\mathrm{H}-5 \mathrm{C}$ & Mag & $10 / 24 / 86$ & H05C.M1086B & 59 & 0.2 & 698 \\
\hline $\mathrm{H}-6 \mathrm{C}$ & Mag & $10 / 01 / 86$ & H06C.M1086B & 60 & -0.3 & 454 \\
\hline W-25 & Mag & 09/17/80 & W25.M980B & 26 & -1.3 & 1190 \\
\hline W-27 & Mag & $09 / 25 / 80$ & W27.M980B & 27 & -0.7 & 14570 \\
\hline W-25 & RS & $07 / 17 / 80$ & W25.R780B & 28 & 0.4 & 33440 \\
\hline W-26 & RS & $07 / 23 / 80$ & W26.R780B & 29 & 0.3 & 18840 \\
\hline W-28 & RS & $07 / 31 / 80$ & W28.R780B & 30 & -0.9 & 27710 \\
\hline W-29 & RS & $07 / 24 / 80$ & W29.R780B & 31 & -1.0 & 11100 \\
\hline W-30 & RS & $07 / 17 / 80$ & W30.R780B & 32 & 0.1 & 32590 \\
\hline RANCH & $\mathrm{DL}$ & $06 / 18 / 86$ & XRAN.D686B & 61 & 0.3 & 252 \\
\hline TWIN-P & $\mathrm{DL}$ & $01 / 30 / 86$ & XTWP.D186B & 62 & $9.2^{3}$ & 40 \\
\hline DOE-2 & $\mathrm{BC}$ & $07 / 23 / 85$ & D2.B785B & 63 & 0.2 & 14950 \\
\hline
\end{tabular}


Table 64. Summary of Results of Laboratory Analyses by UNC/Bendix (continued)

\begin{tabular}{|c|c|c|c|c|c|c|c|c|c|c|}
\hline Well & Zone & Date & $\begin{array}{c}\text { Alk } \\
\mathrm{CO} \overline{\overline{3}} \\
(\mathrm{mg} / \mathrm{L})\end{array}$ & $\begin{array}{c}\mathrm{Alk} \\
\mathrm{HCO}_{\overline{3}} \\
(\mathrm{mg} / \mathrm{L})\end{array}$ & $\underset{(\mathrm{mg} / \mathrm{L})}{\mathrm{Ca}}$ & $\begin{array}{c}\mathrm{Mg} \\
(\mathrm{mg} / \mathrm{L})\end{array}$ & $\underset{(\mathrm{mg} / \mathrm{L})}{\mathrm{Na}}$ & $\underset{(\mathrm{mg} / \mathrm{L})}{\mathrm{K}}$ & $\begin{array}{c}\mathrm{Cl}^{-} \\
(\mathrm{mg} / \mathrm{L})\end{array}$ & $\begin{array}{c}\mathrm{SO}_{\overline{4}} \\
(\mathrm{mg} / \mathrm{L})\end{array}$ \\
\hline DOE-1 & Cul & $04 / 85$ & 0 & 43 & 1730 & 1610 & 45800 & 1100 & 73600 & 7350 \\
\hline DOE-2 & Cul & $03 / 85$ & 0 & 65 & 1960 & 1060 & 18400 & 410 & 34600 & 3950 \\
\hline $\mathrm{H}-2 \mathrm{~A}$ & Cul & $04 / 86$ & 0 & 54 & 743 & 167 & 3570 & 93.5 & 5310 & 2980 \\
\hline H-3B3 & $\mathrm{Cul}$ & $06 / 84$ & 0 & 53 & 1550 & 829 & 17400 & 495 & 29500 & 5130 \\
\hline H-3B3 & Cul & $02 / 85$ & 0 & 49 & 1470 & 783 & 18000 & 425 & 30300 & 4820 \\
\hline $\mathrm{H}-4 \mathrm{~B}$ & Cul & $05 / 81$ & na & na & 700 & 455 & 6080 & 215 & 7980 & 6230 \\
\hline $\mathrm{H}-4 \mathrm{C}$ & Cul & $08 / 84$ & na & na & 698 & 505 & 6150 & 222 & 7950 & 5700 \\
\hline $\mathrm{H}-4 \mathrm{~B}$ & $\mathrm{Cul}$ & $07 / 85$ & 0 & 66 & 691 & 427 & 5850 & 210 & 7480 & 5520 \\
\hline H-5B & Cul & $06 / 81$ & na & na & 1710 & 2140 & 52400 & 1290 & 89500 & 7360 \\
\hline $\mathrm{H}-5 \mathrm{C}$ & $\mathrm{Cul}$ & $10 / 81$ & na & na & 1720 & 2150 & 52300 & 1300 & 89500 & 7570 \\
\hline H-5B & Cul & $08 / 85$ & 0 & 41 & 1700 & 2170 & 54100 & 1350 & 85400 & 7840 \\
\hline$H-6 B$ & Cul & $05 / 81$ & na & na & 2150 & 1080 & 18600 & 450 & 33000 & 3980 \\
\hline H-6B & Cul & $09 / 85$ & 0 & 84 & 2040 & 1040 & 18000 & 375 & 32300 & 3570 \\
\hline H-7B1 & Cul & $03 / 86$ & 0 & 120 & 587 & 130 & 207 & 7.00 & 320 & 1850 \\
\hline $\mathrm{H}-8 \mathrm{~B}$ & Cul & $01 / 86$ & 0 & 90 & 548 & 157 & 55.1 & 3.83 & 30.5 & 1950 \\
\hline $\mathrm{H}-9 \mathrm{~B}$ & $\mathrm{Cul}$ & $11 / 85$ & 0 & 110 & 590 & 137 & 146 & 6.85 & 194 & 1900 \\
\hline H-11B3 & $\mathrm{Cul}$ & $06 / 85$ & na & na & 1700 & 1320 & 40400 & 943 & 65900 & 7180 \\
\hline $\mathrm{H}-12$ & Cul & $08 / 85$ & 0 & 49 & 1760 & 1980 & 49200 & 1270 & 79000 & 7210 \\
\hline P-14 & Cul & $02 / 86$ & 0 & 98 & 3520 & 840 & 4360 & 37.9 & 14500 & 1590 \\
\hline P-17 & Cul & $03 / 86$ & 0 & 52 & 1620 & 1460 & 28300 & 782 & 48200 & 6020 \\
\hline W-25 & Cul & $08 / 80$ & na & na & 905 & 260 & 3160 & 73.5 & 5250 & 2500 \\
\hline W-25 & Cul & $02 / 86$ & 0 & 120 & 1140 & 315 & 3180 & 102 & 6320 & 2380 \\
\hline W-26 & $\mathrm{Cul}$ & $08 / 80$ & na & na & 1240 & 355 & 3620 & 170 & 7200 & 2480 \\
\hline W-26 & Cul & $11 / 85$ & 0 & 120 & 1340 & 380 & 4220 & 343 & 8770 & 2420 \\
\hline W-27 & Cul & $09 / 80$ & na & na & 3210 & 1900 & 39200 & 8060 & 78500 & 3830 \\
\hline W-28 & $\mathrm{CuI}$ & $09 / 80$ & na & na & 1180 & 555 & 15200 & 485 & 24800 & 4380 \\
\hline W-29 & Cul & $08 / 80$ & na & na & 950 & 5480 & 71400 & 15600 & 138000 & 14000 \\
\hline W-29 & $\mathrm{Cul}$ & $12 / 85$ & 0 & 150 & 413 & 6500 & 94900 & 23300 & 179000 & 20000 \\
\hline W-30 & $\mathrm{Cul}$ & $09 / 80$ & na & na & 1140 & 460 & 8570 & 255 & 14600 & 4120 \\
\hline ENGLE & Cul & $03 / 85$ & 0 & 110 & 588 & 152 & 200 & 5.60 & 231 & 1990 \\
\hline H-3B1 & Mag & $07 / 85$ & 0 & 43 & 1000 & 292 & 1520 & 34.5 & 3360 & 2310 \\
\hline $\mathrm{H}-4 \mathrm{C}$ & Mag & $11 / 86$ & 0 & 74 & 651 & 411 & 7112 & 85.1 & 8460 & 7100 \\
\hline $\mathrm{H}-5 \mathrm{C}$ & Mag & $10 / 86$ & 0 & 50 & 550 & 173 & 1480 & 33.6 & 1070 & 3620 \\
\hline $\mathrm{H}-6 \mathrm{C}$ & Mag & $10 / 86$ & 0 & 47 & 546 & 160 & 642 & 16.6 & 428 & 2700 \\
\hline W-25 & Mag & $09 / 80$ & na & na & 905 & 260 & 2910 & 71.5 & 5250 & 2490 \\
\hline W-27 & Mag & $09 / 80$ & na & na & 3660 & 2100 & 43200 & 8090 & 85200 & 3410 \\
\hline W-25 & RS & $07 / 80$ & na & na & 560 & 3260 & 122800 & 3330 & 192000 & 12400 \\
\hline W-26 & RS & $07 / 80$ & na & na & 1420 & 1660 & 68600 & 1200 & 108000 & 7480 \\
\hline W-28 & RS & $07 / 80$ & na & na & 605 & 3400 & 97100 & 4300 & 155000 & 16700 \\
\hline W-29 & RS & $07 / 80$ & na & na & 1080 & 2320 & 36100 & 1480 & 58000 & 12000 \\
\hline W-30 & RS & $07 / 80$ & na & na & 955 & 2770 & 120600 & 2180 & 192000 & 7390 \\
\hline RANCH & DL & $06 / 86$ & 0 & 170 & 420 & 202 & 200 & 4.00 & 418 & 1100 \\
\hline TWIN-P & DL & $01 / 86$ & 0 & 150 & 80.4 & 22.5 & 25.4 & 3.85 & 44.1 & 75.1 \\
\hline DOE-2 & $\mathrm{BC}$ & $07 / 85$ & 0 & 48 & 5910 & 1330 & 49600 & 885 & 89700 & 2020 \\
\hline
\end{tabular}


Table 64. Summary of Results of Laboratory Analyses by UNC/Bendix (continued)

\begin{tabular}{|c|c|c|c|c|c|c|c|c|c|}
\hline Well & Zone & Date & $\begin{array}{c}\mathrm{B} \\
(\mathrm{mg} / \mathrm{L}) \\
\end{array}$ & $\begin{array}{c}\mathrm{Cs} \\
(\mathrm{mg} / \mathrm{L})\end{array}$ & $\begin{array}{c}\mathrm{Fe} \\
(\mathrm{mg} / \mathrm{L})\end{array}$ & $\begin{array}{c}\mathrm{Li} \\
(\mathrm{mg} / \mathrm{L}) \\
\end{array}$ & $\begin{array}{c}\mathrm{Mn} \\
(\mathrm{mg} / \mathrm{L})\end{array}$ & $\begin{array}{c}\mathrm{Si} \\
(\mathrm{mg} / \mathrm{L} \text { as } \\
\left.\mathrm{SiO}_{2}\right) \\
\end{array}$ & $\begin{array}{c}\mathrm{Sr} \\
(\mathrm{mg} / \mathrm{L})\end{array}$ \\
\hline DOE-1 & Cul & $04 / 85$ & 37. & $\mathrm{na}$ & 0.28 & 0.64 & na & 8.4 & 26. \\
\hline DOE-2 & Cul & $03 / 85$ & 16. & $<0.007$ & 0.036 & 0.47 & 0.30 & 17. & 38. \\
\hline $\mathrm{H}-2 \mathrm{~A}$ & Cul & $04 / 86$ & 10. & $<0.01$ & 1.1 & 0.22 & 0.055 & 13. & 9.5 \\
\hline H-3B3 & $\mathrm{Cul}$ & $06 / 84$ & 30. & $<0.007$ & 0.57 & 0.53 & 0.13 & 9.8 & 23. \\
\hline H-3B3 & Cul & $02 / 85$ & 26. & $<0.007$ & 0.20 & 0.40 & 0.12 & 11. & 30. \\
\hline $\mathrm{H}-4 \mathrm{~B}$ & Cul & $05 / 81$ & 18. & na & na & 0.39 & na & 11. & 14. \\
\hline $\mathrm{H}-4 \mathrm{C}$ & Cul & $08 / 84$ & 20. & $<0.002$ & 2.2 & 0.49 & 0.20 & 13. & 18. \\
\hline$H-4 B$ & Cul & $07 / 85$ & 14. & na & 0.32 & 0.40 & 0.11 & 14. & 14. \\
\hline 'H-5B & Cul & $06 / 81$ & 33. & na & na & 0.77 & na & 6.2 & 32. \\
\hline H-5C & $\mathrm{Cul}$ & $10 / 81$ & 35. & na & na & 0.77 & na & 5.8 & 31. \\
\hline H-5B & Cul & $08 / 85$ & 34. & $<0.01$ & 2.9 & 0.81 & 0.29 & 7.1 & 29. \\
\hline $\mathrm{H}-6 \mathrm{~B}$ & $\mathrm{Cul}$ & $05 / 81$ & 11. & na & na & 0.44 & na & 20. & 32. \\
\hline H-6B & $\mathrm{Cul}$ & $09 / 85$ & 10. & $<0.01$ & 0.094 & 0.45 & 0.13 & 18. & 30. \\
\hline H-7B1 & Cul & $03 / 86$ & 0.76 & $<0.01$ & 0.056 & 0.10 & 0.050 & 47. & 8.5 \\
\hline H-8B & $\mathrm{Cul}$ & $01 / 86$ & 0.48 & $<0.01$ & 0.036 & 0.12 & 0.021 & 29. & 6.9 \\
\hline $\mathrm{H}-9 \mathrm{~B}$ & Cul & $11 / 85$ & 0.63 & $<0.01$ & 0.032 & 0.18 & 0.015 & 27. & 7.5 \\
\hline H-11B3 & Cul & $06 / 85$ & 32. & na & 0.14 & 0.62 & 0.22 & na & 25. \\
\hline H-12 & $\mathrm{Cul}$ & $08 / 85$ & 39. & na & 0.22 & 1.2 & 0.087 & 7.2 & 31. \\
\hline P-14 & Cul & $02 / 86$ & 0.72 & $<0.01$ & 2.0 & 0.28 & 0.18 & 30. & 51. \\
\hline P-17 & Cul & $03 / 86$ & 38. & $<0.01$ & 4.0 & 0.87 & 0.87 & 8.5 & 29. \\
\hline W-25 & Cul & $08 / 80$ & 1.5 & na & na & 0.20 & na & 34. & 12. \\
\hline W-25 & $\mathrm{Cul}^{\circ}$ & $02 / 86$ & 1.7 & $<0.01$ & 0.50 & 0.22 & 0.11 & 33. & 17. \\
\hline W-26 & Cul & $08 / 80$ & 1.4 & na & na & 0.24 & na & 33. & 17. \\
\hline W-26 & Cul & $11 / 85$ & 1.6 & $<0.01$ & 0.026 & 0.23 & $<0.01$ & 35. & 20. \\
\hline W-27 & Cul & $09 / 80$ & 2.3 & na & na & 0.33 & na & 23. & 51. \\
\hline W-28 & $\mathrm{Cul}$ & $09 / 80$ & 5.8 & na & na & 0.30 & na & 36. & 16. \\
\hline W-29 & Cul & $08 / 80$ & 4.4 & na & na & 0.78 & na & 22. & 29. \\
\hline W-29 & Cul & $12 / 85$ & 5.2 & $<0.01$ & 1.1 & 0.70 & 1.7 & 15. & 13. \\
\hline W-30 & $\mathrm{Cul}$ & $09 / 80$ & 6.1 & na & na & 0.27 & na & 6.5 & 18. \\
\hline ENGLE & Cul & $03 / 85$ & 0.97 & $<0.001$ & 0.59 & 0.17 & 0.060 & 29. & 8.4 \\
\hline H-3B1 & Mag & $07 / 85$ & 2.0 & $<0.01$ & 0.11 & 0.32 & 0.028 & 10. & 17. \\
\hline $\mathrm{H}-4 \mathrm{C}$ & Mag & $11 / 86$ & 12. & $<0.01$ & 0.71 & 0.46 & 0.29 & 9.1 & 12. \\
\hline $\mathrm{H}-5 \mathrm{C}$ & Mag & $10 / 86$ & 11. & $<0.01$ & 1.5 & 0.20 & 0.020 & 11. & 10. \\
\hline $\mathrm{H}-6 \mathrm{C}$ & Mag & $10 / 86$ & 2.2 & $<0.01$ & 0.26 & 0.21 & 0.010 & 11. & 9.8 \\
\hline W-25 & Mag & $09 / 80$ & 1.5 & na & na & 0.20 & na & 33. & 12. \\
\hline W-27 & Mag & $09 / 80$ & 2.3 & na & na & 0.34 & na & 30. & 59. \\
\hline W-25 & RS & $07 / 80$ & 41. & na & na & 1.6 & na & 4.0 & 11. \\
\hline W-26 & RS & $07 / 80$ & 32. & na & na & 1.2 & na & 6.2 & 27. \\
\hline W-28 & RS & $07 / 80$ & 46. & na & na & 1.8 & na & $7: 8$ & 12. \\
\hline W-29 & RS & $07 / 80$ & 20. & na & na & 1.3 & na & 15. & 21. \\
\hline W-30 & RS & $07 / 80$ & 82. & na & na & 0.72 & na & 5.5 & 18. \\
\hline RANCH & DL & $06 / 86$ & 0.10 & $<0.01$ & 0.024 & 0.12 & $<0.01$ & 52. & 5.9 \\
\hline TWIN-P & $\mathrm{DL}$ & $01 / 86$ & 0.13 & $<0.01$ & $<0.01$ & $<0.05$ & $<0.01$ & 47. & 1.1 \\
\hline DOE-2 & $\mathrm{BC}$ & $07 / 85$ & 54. & $<0.01$ & 11. & 5.8 & 2.8 & 2.5 & 150. \\
\hline
\end{tabular}


Table 64. Summary of Results of Laboratory Analyses by UNC/Bendix (continued)

\begin{tabular}{|c|c|c|c|c|c|c|c|}
\hline Well & Zone & Date & $\begin{array}{c}\mathrm{Br}^{-} \\
(\mathrm{mg} / \mathrm{L})\end{array}$ & $\begin{array}{c}\mathrm{F}^{-} \\
(\mathrm{mg} / \mathrm{L})\end{array}$ & $\begin{array}{c}\mathrm{I}^{-} \\
(\mathrm{mg} / \mathrm{L}) \\
\end{array}$ & $\begin{array}{r}\mathrm{IO} \overline{3} \\
(\mathrm{mg} / \mathrm{L}) \\
\end{array}$ & $\begin{array}{c}\mathrm{NO}_{\overline{3}} \\
(\mathrm{mg} / \mathrm{L}) \\
\end{array}$ \\
\hline DOE-1 & Cul & $04 / 85$ & 56 & na & na & na & na \\
\hline DOE-2 & Cul & $03 / 85$ & 34 & 1.7 & 0.22 & na & na \\
\hline $\mathrm{H}-2 \mathrm{~A}$ & Cul & $04 / 86$ & 5.6 & 2.2 & 0.081 & na & na \\
\hline H-3B3 & Cul & $06 / 84$ & 29 & 2.1 & 0.13 & na & na \\
\hline H-3B3 & Cul & $02 / 85$ & 26 & 1.9 & 0.14 & na & na \\
\hline H-4B & Cul & $05 / 81$ & 42 & na & na & na & na \\
\hline $\mathrm{H}-4 \mathrm{C}$ & Cul & $08 / 84$ & 48 & 2.1 & 0.23 & na & na \\
\hline$H-4 B$ & Cul & $07 / 85$ & 43 & na & na & na & na \\
\hline H-5B & Cul & $06 / 81$ & 62 & na & na & na & na \\
\hline $\mathrm{H}-5 \mathrm{C}$ & Cul & $10 / 81$ & 64 & na & na & na & na \\
\hline H-5B & Cul & $08 / 85$ & 49 & 2.0 & 0.19 & na & na \\
\hline$H-6 B$ & Cul & $05 / 81$ & 34 & na & na & na & na \\
\hline H-6B & Cul & $09 / 85$ & 34 & 1.9 & 0.096 & 0.10 & na \\
\hline H-7B1 & Cul & $03 / 86$ & 0.57 & 1.5 & 0.052 & na & na \\
\hline $\mathrm{H}-8 \mathrm{~B}$ & Cul & $01 / 86$ & 0.085 & 2.5 & 0.14 & na & na \\
\hline H-9B & Cul & $11 / 85$ & 0.24 & 3.3 & 0.11 & na & na \\
\hline H-11B3 & Cul & $06 / 85$ & 47 & na & na & na & na \\
\hline $\mathrm{H}-12$ & Cul & $08 / 85$ & 76 & na & na & na & na \\
\hline P-14 & Cul & $02 / 86$ & 72 & 1.7 & 0.42 & na & na \\
\hline P-17 & Cul & $03 / 86$ & 72 & 1.9 & 0.18 & na & na \\
\hline W-25 & Cul & $08 / 80$ & 2.6 & na & na & na & na \\
\hline W-25 & Cul & $02 / 86$ & 3.4 & 1.7 & 0.042 & na & na \\
\hline W-26 & Cul & $08 / 80$ & 3.2 & na & na & na & na \\
\hline W-26 & Cul & $11 / 85$ & 3.9 & 1.7 & 0.070 & na & na \\
\hline W-27 & Cul & $09 / 80$ & 28 & na & na & na & na \\
\hline W-28 & Cul & $09 / 80$ & 7.2 & na & na & na & na \\
\hline W-29 & Cul & $08 / 80$ & 45 & na & na & na & na \\
\hline W-29 & Cul & $12 / 85$ & 61 & 4.6 & 0.38 & na & na \\
\hline W-30 & Cul & $09 / 80$ & 10 & na & na & na & na \\
\hline ENGLE & Cul & $03 / 85$ & 0.27 & 2.8 & 0.12 & na & na \\
\hline H-3B1 & Mag & $07 / 85$ & 5.8 & 2.4 & 1.2 & na & na \\
\hline $\mathrm{H}-4 \mathrm{C}$ & Mag & $11 / 86$ & 5.9 & 2.4 & 0.31 & $<0.01$ & na \\
\hline $\mathrm{H}-5 \mathrm{C}$ & Mag & $10 / 86$ & 2.7 & 2.5 & 0.31 & $<0.01$ & na \\
\hline H-6C & Mag & $10 / 86$ & 1.1 & 1.5 & 0.086 & $<0.01$ & na \\
\hline W-25 & Mag & $09 / 80$ & 2.5 & na & na & na & na \\
\hline W-27 & Mag & $09 / 80$ & 28 & na & na & na & na \\
\hline W-25 & RS & $07 / 80$ & 51 & na & na & na & na \\
\hline W-26 & RS & $07 / 80$ & 19 & na & na & na & na \\
\hline W-28 & RS & $07 / 80$ & 29 & na & na & na & na \\
\hline W-29 & RS & $07 / 80$ & 12 & na & na & na & na \\
\hline W-30 & RS & $07 / 80$ & 78 & na & na & na & na \\
\hline RANCH & DL & $06 / 86$ & 2.3 & 0.82 & 0.13 & 0.15 & 520 \\
\hline TWIN-P & DL & $01 / 86$ & 0.17 & 0.58 & $<0.01$ & na & na \\
\hline DOE-2 & $\mathrm{BC}$ & $07 / 85$ & 250 & 1.1 & 6.4 & na & na \\
\hline
\end{tabular}

1. Key: $\mathrm{na}=$ not analyzed; $\mathrm{Cul}=$ Culebra; $\mathrm{Mag}=$ Magenta; $\mathrm{RS}=$ Rustler/Salado; $\mathrm{DL}=$ Dewey Lake; $\mathrm{BC}=$ Bell Canyon; well abbreviations are explained in Table 1.

2. Table with replicate data and estimates of analytical precision.

3. $\mathrm{CBE}$ is $-1.0 \%$ if field alkalinity used rather than laboratory value. 
Table 65. Analytical Methods Used by UNC/Bendix (1984-1986) ${ }^{1}$

\begin{tabular}{|c|c|c|c|c|c|c|c|}
\hline SAMPLE ID ${ }^{2}$ & $\mathrm{Ca}$ & $\mathrm{Mg}$ & $\mathrm{Na}$ & $\mathrm{K}$ & Alk. & $\mathrm{Cl}^{-}$ & $\mathrm{SO}_{4}^{=}$ \\
\hline D1.C485B & ICP & ICP & AAS & AAS & Titm & Titrn & IC \\
\hline D2.C385B & AAS & AAS & AAS & AAS & Titrn & ISE & IC \\
\hline H02A.C486B & AAS & AAS & AAS & AAS & Titrn & Titm & IC \\
\hline H03B3.C684B & ICP & ICP & ICP & ICP & Titrn & ISE & IC \\
\hline H03B3.C285B & AAS & AAS & AAS & AAS & Titrn & ISE & IC \\
\hline H04B.C581B & AAS & AAS & AAS & AAS & -- & ISE & IC \\
\hline H04C.C884B & AAS & AAS & AAS & AAS & -- & ISE & IC \\
\hline H04B.C785B & ICP & ICP & AAS & AAS & Titrn & Titrn & IC \\
\hline H05B.C681B & AAS & AAS & AAS & AAS & - & ISE & IC \\
\hline H05C.C1081B & AAS & AAS & AAS & AAS & - & ISE & IC \\
\hline H05B.C885B & ICP & ICP & AAS & AAS & Titrn & Titrn & IC \\
\hline H06B.C581B & AAS & AAS & AAS & AAS & -- & ISE & IC \\
\hline H06B.C985B & AAS & AAS & AAS & AAS & Titrn & Titm & IC \\
\hline H07B1.C386B & AAS & AAS & AAS & AAS & Titrn & ISE & IC \\
\hline H08B.C186B & AAS & AAS & AAS & AAS & Titrn & ISE & IC \\
\hline H09B.C1185B & AAS & AAS & AAS & AAS & Titrn & ISE & IC \\
\hline H11B3.C685B & ICP & ICP & AAS & AAS & -- & Titrn & IC \\
\hline H12.C885B & ICP & ICP & AAS & AAS & Titm & Titrn & IC \\
\hline P14.C286B & AAS & AAS & AAS & AAS & Titrn & Titm & IC \\
\hline P17.C386B & AAS & AAS & AAS & AAS & Titrn & Titrn & IC \\
\hline W25.C880B & AAS & AAS & AAS & AAS & -- & ISE & IC \\
\hline W25.C286B & AAS & AAS & AAS & AAS & Titrn & Titrn & IC \\
\hline W26.C880B & AAS & AAS & AAS & AAS & - & ISE & IC \\
\hline W26.C1185B & AAS & AAS & AAS & AAS & Titrn & Titrn & IC \\
\hline W27.C980B & AAS & AAS & AAS & AAS & -- & ISE & IC \\
\hline W28.C980B & AAS & AAS & AAS & AAS & -- & ISE & IC \\
\hline W29.C880B & AAS & AAS & AAS & AAS & -- & ISE & IC \\
\hline W29.C1285B & AAS & AAS & AAS & AAS & Titrn & Titrn & IC \\
\hline W30.C980B & AAS & AAS & AAS & AAS & -- & ISE & IC \\
\hline XENG.C385B & AAS & AAS & AAS & AAS & Titm & ISE & IC \\
\hline H03B1.M785B & ICP & ICP & AAS & AAS & Titrn & Titm & IC \\
\hline H04C.M1186B & AAS & AAS & AAS & AAS & Titm & Titrn & IC \\
\hline H05C.M1086B & AAS & AAS & AAS & AAS & Titrn & Titm & IC \\
\hline H06C.M1086B & AAS & AAS & AAS & AAS & Titm & Titm & IC \\
\hline W25.M980B & AAS & AAS & AAS & AAS & -- & ISE & IC \\
\hline W27.M980B & AAS & AAS & AAS & AAS & -- & ISE & IC \\
\hline W25.R780B & AAS & AAS & AAS & AAS & -- & ISE & IC \\
\hline W26.R780B & AAS & AAS & AAS & AAS & -- & ISE & IC \\
\hline W28.R780B & AAS & AAS & AAS & AAS & - & ISE & IC \\
\hline W29.R780B & AAS & AAS & AAS & AAS & -- & ISE & IC \\
\hline W30.R780B & AAS & AAS & AAS & AAS & -- & ISE & IC \\
\hline XRAN.D686B & AAS & AAS & AAS & AAS & Titrn & Titrn & IC \\
\hline XTWP.D186B & AAS & AAS & AAS & AAS & Titrn & ISE & IC \\
\hline D2.B785B & ICP & ICP & AAS & AAS & Titm & Titm & IC \\
\hline
\end{tabular}


Table 65. Analytical Methods Used by UNC/Bendix (1984-1986) (continued)

\begin{tabular}{|c|c|c|c|c|c|c|c|c|c|c|c|}
\hline SAMPLE ID & $\mathrm{Br}^{-}$ & $\mathrm{F}^{-}$ & $\mathrm{I}^{-}$ & $\mathrm{NO}_{\overline{3}}$ & B & Cs & $\mathrm{Fe}$ & $\mathbf{L i}$ & Mn & $\mathrm{SiO}_{2}$ & $\mathrm{Sr}$ \\
\hline D1.C485B & DPP & -- & -- & -- & ICP & -- & GFAAS & AAS & - & UV/VI & ICP \\
\hline D2.C385B & DPP & ISE & DPP & - & ICP & GFAAS & GFAAS & AAS & GFAAS & UV/VI & AAS \\
\hline H02A.C $486 \mathrm{~B}$ & DPP & ISE & DPP & -- & ICP & GFAAS & AAS & AAS & (ac & UV/VI & ICP \\
\hline H03B3.C684B & XRF & ISE & DPP & -- & ICP & GFAAS & AAS & ICP & AAS & UV/VI & ICP \\
\hline H03B3.C285B & DPP & ISE & DPP & -- & ICP & GFAAS & GFAAS & AAS & GFAAS & UV/VI & AAS \\
\hline H04B.C581B & DPP & -- & -- & -- & ICP & - & - & AAS & -- & UV/VI & AAS \\
\hline H04C.C884B & DPP & ISE & DPP & - & ICP & GFAAS & GFAAS & AAS & GFAAS & UV/VI & AAS \\
\hline H04B.C785B & DPP & -- & -- & -- & ICP & - & GFAAS & AAS & GFAAS & UV/VI & ICP \\
\hline H05B.C681B & DPP & - & -- & - & ICP & -- & -- & AAS & - & UV/VI & AAS \\
\hline 1081B & DPP & -- & -- & -- & ICP & - & -- & AAS & -- & UV/VI & AAS \\
\hline $385 B$ & DPP & ISE & DPP & -- & ICP & GFAAS & GFAAS & AAS & GFAAS & JV/VI & ICP \\
\hline & DPP & -- & -- & -- & ICP & -- & -- & AAS & -- & JV/VI & AAS \\
\hline $35 \mathrm{~B}$ & DPP & ISE & DPP & -- & ICP & GFAAS & AAS & AAS & AAS & I/VI & ICP \\
\hline $86 \mathrm{~B}$ & DPP & ISE & DPP & -- & ICP & GFAAS & AAS & AAS & AAS & I/VI & ICP \\
\hline & DPP & ISE & DPP & -- & ICP & FAAS & AAS & AS & AAS & IVI & ICP \\
\hline & DPP & ISE & DPP & -- & ICP & GFAAS & AAS & AS & AAS & V/VI & ICP \\
\hline & DPP & -- & - & - & ICP & -- & GFAAS & AAS & GFAAS & - & ICP \\
\hline & DPP & -- & -- & -- & ICP & -- & GFAAS & AAS & GFAAS & V/VI & ICP \\
\hline & DPP & ISE & DPP & -- & ICP & GFAAS & AAS & AAS & AAS & $/ \mathrm{VI}$ & ICP \\
\hline & DPP & ISE & DPP & -- & ICP & GFAAS & AAS & AAS & AAS & IVI & ICP \\
\hline 30B & DPP & -- & -- & - & ICP & - & - & AAS & - & IVI & AAS \\
\hline & DPP & ISE & DPP & -- & ICP & GFAAS & AAS & AAS & AAS & /VI & ICP \\
\hline W2 & DPP & - & - & -- & ICP & - & - & AAS & - & I/VI & AAS \\
\hline & DPP & ISE & DPP & -- & ICP & GFAAS & AAS & AAS & AAS & V/VI & ICP \\
\hline W2 & DPP & -- & -- & -- & ICP & -- & -- & AAS & - & V/VI & AAS \\
\hline & DPP & -- & - & - & ICP & - & - & AAS & -- & V/VI & AAS \\
\hline & DPP & - & -- & -- & ICP & - & - & AAS & -- & V/VI & AAS \\
\hline $35 \mathrm{~B}$ & DPP & ISE & DPP & - & ICP & GFAAS & AAS & AAS & AAS & V/VI & ICP \\
\hline & DPP & -- & - & -- & ICP & - & -- & AAS & -- & V/VI & AAS \\
\hline 385B & DPP & ISE & DPP & -- & ICP & GFAAS & GFAAS & AAS & GFAAS & V/VI & AAS \\
\hline & DPP & ISE & DPP & -- & ICP & GFAAS & GFAAS & AAS & GFAAS & UV/VI & ICP \\
\hline H04C.M1186B & DPP & ISE & DPP & -- & ICP & GFAAS & AAS & AAS & AAS & ICP & ICP \\
\hline H05C.M1086B & UV/VIS & ISE & DPP & - & ICP & GFAAS & AAS & AAS & AAS & ICP & ICP \\
\hline H06C.M1086B & UV/VIS & ISE & DPP & -- & ICP & GFAAS & AAS & AAS & AAS & & ICP \\
\hline & DPP & - & -- & -- & ICP & -- & -- & AAS & -- & UV/VI & AAS \\
\hline W27.M980B & & -- & -- & -- & ICP & -- & -- & & -- & V/VI & AAS \\
\hline & DPP & -- & - & -- & ICP & -- & -- & AAS & -- & $\mathrm{V} / \mathrm{VI}$ & AAS \\
\hline & DPP & -- & - & -- & ICP & -- & -- & AAS & -. & V/VI & AAS \\
\hline & DPP & -- & - & -- & ICP & -- & -- & AAS & - & JV/VI & AAS \\
\hline & DPP & -- & - & -- & ICP & -- & -- & AAS & -- & UV/VI & AAS \\
\hline W30.R780B & DPP & -- & - & -- & ICP & -- & -- & AAS & - & UV/VI & AAS \\
\hline XRAN.D686B & DPP & ISE & DPP & IC & ICP & GFAAS & AAS & AAS & AAS & ICP & ICP \\
\hline XTWP.D186B & DPP & ISE & DPP & - & ICP & GFAAS & AAS & AAS & AAS & UV/VI & ICP \\
\hline D2.B785B & DPP & ISE & DPP & -- & ICP & GFAAS & GFAAS & AAS & GFAAS & $\mathrm{UV} / \mathrm{VI}$ & ICP \\
\hline
\end{tabular}

1. Abbreviations of analytical methods are explained in the text.

2. See Table 64 for well names, zones, and collection dates corresponding to Sample IDs. 
Table 66. Spike Recovery Data from UNC/Bendix ${ }^{1}$

\begin{tabular}{|c|c|c|c|c|c|c|c|}
\hline SAMPLE ID ${ }^{2}$ & $\mathrm{Ca}$ & $\mathrm{Mg}$ & $\mathrm{Na}$ & $\mathbf{K}$ & Alk & $\mathrm{Cl}^{-}$ & So $\overline{\overline{4}}$ \\
\hline D1.C485B & 96 & 98 & 99 & 104 & na & na & na \\
\hline D2.C385B & 104 & 103 & 102 & 100 & na & na & 106 \\
\hline H02A.C486B & na & na & na & na & na & na & na \\
\hline Н03В3.С684B & 101 & 102 & 102 & 96 & na & 99 & 98 \\
\hline H03В3.С285B & 100 & 102 & 101 & 99 & na & na & 100 \\
\hline H04B.C581B & na & 98 & na & na & - & na & na \\
\hline H04C.C884B & 102 & 99 & 101 & 98 & - & na & 109 \\
\hline H04B.C785B & 99 & 98 & na & na & na & 99 & na \\
\hline H05B.C681B & na & na & na & 96 & - & na & na \\
\hline H05C.C1081B & na & na & 99 & na & -- & 94 & na \\
\hline H05B.C885B & 98 & 96 & na & 101 & na & 101 & na \\
\hline H06B.C581B & na & na & na & na & -- & na & na \\
\hline H06B.C985B & 101 & 96 & 100 & 101 & na & 102 & 99 \\
\hline H07B1.C386B & na & na & na & na & na & na & na \\
\hline H08B.C186B & 107 & 102 & 100 & 102 & na & 98 & 95 \\
\hline H09B.C1185B & 101 & 100 & 100 & 101 & na & 97 & 96 \\
\hline H11B3.C685B & 93 & 93 & na & 97 & -- & na & na \\
\hline H12.C885B & 96 & 99 & na & na & na & na & na \\
\hline P14.C286B & na & na & na & na & na & na & na \\
\hline P17.C386B & na & na & na & na & na & na & na \\
\hline W25.C880B & na & na & na & na & -- & na & na \\
\hline W25.C286B & 104 & 102 & 98 & 101 & na & 102 & 92 \\
\hline W26.C880B & na & na & na & na & - & 96 & na \\
\hline W26.C1185B & na & na & na & na & na & na & na \\
\hline W27.C980B & na & na & na & na & -- & na & na \\
\hline W28.C980B & na & 104 & na & na & -- & na & na \\
\hline W29.C880B & 105 & na & na & na & -- & na & na \\
\hline W29.C1285B & 105 & 97 & 102 & 100 & na & 101 & 98 \\
\hline W30.C980B & na & na & na & na & - & 98 & na \\
\hline XENG.C385B & 100 & 99 & 102 & 99 & na & na & 103 \\
\hline H03B1.M785B & 99 & 102 & 102 & na & na & 99 & na \\
\hline H04C.M1186B & na & na & na & na & na & na & na \\
\hline H05C.M1086B & na & na & na & na & na & na & na \\
\hline H06C.M1086B & 99 & 102 & 101 & 95 & na & 100 & 103 \\
\hline W25.M980B & na & na & 96 & na & -- & na & na \\
\hline W27.M980B & na & na & 96 & na & -- & na & na \\
\hline W25.R780B & 105 & 103 & na & 105 & -- & na & na \\
\hline W26.R780B & na & na & na & na & -- & na & na \\
\hline W28.R780B & 99 & na & na & 104 & -- & na & na \\
\hline W29.R780B & na & na & na & na & -- & 98 & na \\
\hline W30.R780B & na & na & na & na & - & na & na \\
\hline XRAN.D686B & 98 & 100 & 99 & 98 & na & 100 & 101 \\
\hline XTWP.D186B & na & na & na & na & na & na & na \\
\hline D2.B785B & 93 & 100 & 97 & na & na & na & na \\
\hline
\end{tabular}


Table 66. Spike Recovery Data from UNC/Bendix (continued)

\begin{tabular}{|c|c|c|c|c|c|c|c|c|c|c|c|}
\hline SAMPLE ID & $\mathrm{Br}^{-}$ & $\mathrm{F}^{-}$ & $\mathrm{I}^{-}$ & $\mathrm{NO}_{\overline{3}}$ & B & Cs & $\mathrm{Fe}$ & $\mathrm{Li}$ & Mn & $\mathrm{SiO}_{2}$ & $\mathrm{Sr}$ \\
\hline D1.C485B & MA & -- & -- & - & 96 & -- & 93 & 96 & - & MA & 92 \\
\hline D2.C385B & MA & MA & MA & - & 103 & MA & 92 & 100 & 100 & MA & 104 \\
\hline H02A.C486B & MA & MA & MA & -- & na & na & na & na & na & na & na \\
\hline H03B3.C684B & MA & MA & 98 & - & 102 & MA & MA & 101 & MA & 99 & 95 \\
\hline H03B3.C285B & MA & MA & MA & - & 105 & MA & 95 & 99 & 94 & MA & 104 \\
\hline H04B.C581B & MA & -- & -- & -- & na & -- & - & na & - & na & na \\
\hline H04C.C884B & MA & MA & MA & -- & 102 & MA & 94 & 100 & 95 & MA & 101 \\
\hline H04B.C785B & MA & -- & -- & - & 99 & -- & na & 101 & na & MA & 97 \\
\hline H05B.С681B & MA & -- & -- & -- & na & - & - & 98 & -- & na & 96 \\
\hline H05C.C1081B & MA & -- & -- & - & na & -- & - & na & -- & na & na \\
\hline H05B.C885B & MA & MA & MA & - & 97 & MA & na & 100 & na & MA & 96 \\
\hline H06B.C581B & MA & -- & -- & -- & na & -- & - & na & -- & 92 & na \\
\hline H06B.C985B & MA & MA & MA & - & 104 & 98 & 90 & 100 & 91 & 103 & 98 \\
\hline H07B1.C386B & MA & MA & MA & -- & na & na & na & na & na & na & na \\
\hline H08B.C186B & MA & MA & MA & - & 101 & 101 & 98 & 100 & 92 & 102 & 100 \\
\hline H09B.C1185B & MA & MA & MA & - & 102 & 105 & 95 & 98 & 89 & 92 & 96 \\
\hline H11B3.C685B & MA & - & -- & - & 97 & - & na & 101 & 99 & -- & 93 \\
\hline H12.C885B & MA & -- & -- & -- & 96 & - & na & 95 & 94 & MA & 93 \\
\hline P14.C286B & MA & MA & MA & -- & na & na & na & na & na & na & na \\
\hline P17.C386B & MA & MA & MA & - & na & na & na & na & na & na & na \\
\hline W25.C880B & MA & -- & - & - & na & -- & - & na & - & na & 95 \\
\hline W25.C286B & MA & MA & MA & -- & 103 & 105 & 100 & 96 & 93 & 107 & 98 \\
\hline W26.C880B & MA & -- & -- & -- & na & -- & -- & na & -- & na & na \\
\hline W26.C1185B & MA & MA & MA & -- & na & na & na & na & na & na & na \\
\hline W27.C980B & MA & - & - & -- & 102 & -- & -- & 96 & -- & 96 & na \\
\hline W28.C980B & MA & -- & -- & -- & 96 & -- & - & na & - & na & 96 \\
\hline W29.C1285B & MA & MA & MA & -- & 99 & 100 & 100 & 100 & 110 & 92 & 95 \\
\hline W29.C880B & MA & -- & -- & -- & na & -- & - & na & -- & na & na \\
\hline W30.C980B & MA & -- & -- & -- & na & -- & - & na & -- & na & na \\
\hline XENG.C385B & MA & MA & MA & - & 104 & MA & 100 & 103 & 98 & MA & 101 \\
\hline H03B1.M785B & MA & MA & MA & - & 95 & MA & na & 103 & na & MA & 98 \\
\hline H04C.M1186B & MA & MA & MA & -- & na & 107 & na & na & na & na & na \\
\hline H05C.M1086B & 117 & MA & MA & -- & na & 106 & na & na & na & 102 & na \\
\hline H06C.M1086B & 112 & MA & MA & -- & 99 & 107 & 95 & 101 & 100 & na & 100 \\
\hline W25.M980B & MA & -- & -- & -- & na & - & -- & na & -- & na & na \\
\hline W27.M980B & MA & - & - & -- & na & - & - & na & -- & na & na \\
\hline W25.R780B & MA & -- & -- & -- & na & - & - & 97 & -- & na & na \\
\hline W26.R780B & MA & -- & -- & -- & 105 & - & - & na & -- & na & na \\
\hline W28.R780B & MA & - & -- & - & na & -- & -- & na & - & 96 & na \\
\hline W29.R780B & MA & -- & -- & -- & na & -- & -- & na & -- & na & na \\
\hline W30.R780B & MA & - & -- & - & 101 & -- & -- & na & - & 96 & na \\
\hline XRAN.D686B & MA & MA & MA & na & 96 & 98 & 102 & 102 & 96 & 100 & 99 \\
\hline XTWP.D186B & MA & MA & MA & -- & na & na & na & na & na & na & na \\
\hline D2.B785B & MA & MA & MA & -- & 98 & MA & na & 94 & na & MA & 107 \\
\hline
\end{tabular}

1. Spike recoveries are reported in percent (\%). Key: na = spiked sample not analyzed; $M A=$ method of additions used; -- = analyte not determined in this sample.

2. See Table 64 for well names, zones, and collection dates corresponding to Sample IDs. 
Table 67. Results from UNC/Bendix: Analyses of Acid Blanks

$\begin{array}{lllllllllll}\mathrm{Fe} & \mathrm{Mn} & \mathrm{Cs} & \mathrm{Ca} & \mathrm{Mg} & \mathrm{K} & \mathrm{Na} & \mathrm{B} & \mathrm{Li} & \mathrm{Sr}\end{array}$

Well Zone Date $\stackrel{(\mathrm{mg} / \mathrm{L})}{(\mathrm{mg} / \mathrm{L})} \underline{(\mathrm{mg} / \mathrm{L})} \underline{(\mathrm{mg} / \mathrm{L})} \underline{(\mathrm{mg} / \mathrm{L})} \underline{(\mathrm{mg} / \mathrm{L})} \underline{(\mathrm{mg} / \mathrm{L})} \underline{(\mathrm{mg} / \mathrm{L})} \underline{(\mathrm{mg} / \mathrm{L})} \underline{(\mathrm{mg} / \mathrm{L})}$

$\begin{array}{lllllllllllll}\text { DOE-1 } & \text { Cul } & 04 / 85 & <0.01 & & & & & & & & & \\ \text { H-5B } & \text { Cul } & 08 / 85 & <0.01 & <0.01 & & & & & & & & \\ \text { H-7B1 } & \text { Cul } & 03 / 86 & <0.01 & <0.01 & & <1 & <1 & <1 & <1 & <0.01 & <0.05 & <0.1 \\ \text { H-8B } & \text { Cul } & 01 / 86 & <0.01 & <0.01 & & <1 & <1 & <1 & <1 & <0.01 & <0.05 & <0.1 \\ \text { H-9B } & \text { Cul } & 11 / 85 & <0.01 & <0.01 & & <1 & <1 & <1 & <1 & <0.01 & <0.05 & <0.1 \\ \text { H-11B3 } & \text { Cul } & 06 / 85 & <0.01 & & & & & & & & & \\ \text { H-12 } & \text { Cul } & 08 / 85 & <0.01 & <0.01 & & & & & & & & \\ \text { H-3B1 } & \text { Mag } & 07 / 85 & <0.01 & & <0.01 & & & & & & & \\ \text { H-4C } & \text { Mag } & 11 / 86 & <0.01 & <0.01 & & <1 & <1 & <1 & <1 & <0.01 & <0.05 & <0.01 \\ \text { RANCH } & \text { DL } & 06 / 86 & <0.01 & <0.01 & & <1 & <1 & <1 & <1 & <0.01 & <0.05 & <0.01 \\ \text { TWIN-P } & \text { DL } & 01 / 86 & <0.01 & <0.05 & & <1 & <1 & <1 & <1 & <0.01 & <0.05 & <0.1 \\ \text { DOE-2 } & \text { BC } & 07 / 85 & <0.01 & <0.01 & & & & & & & & \end{array}$


Table 68. Results of Field and Laboratory Analyses by the USGS ${ }^{1}$ - Part A-Samples from the Culebra Dolomite (continued)

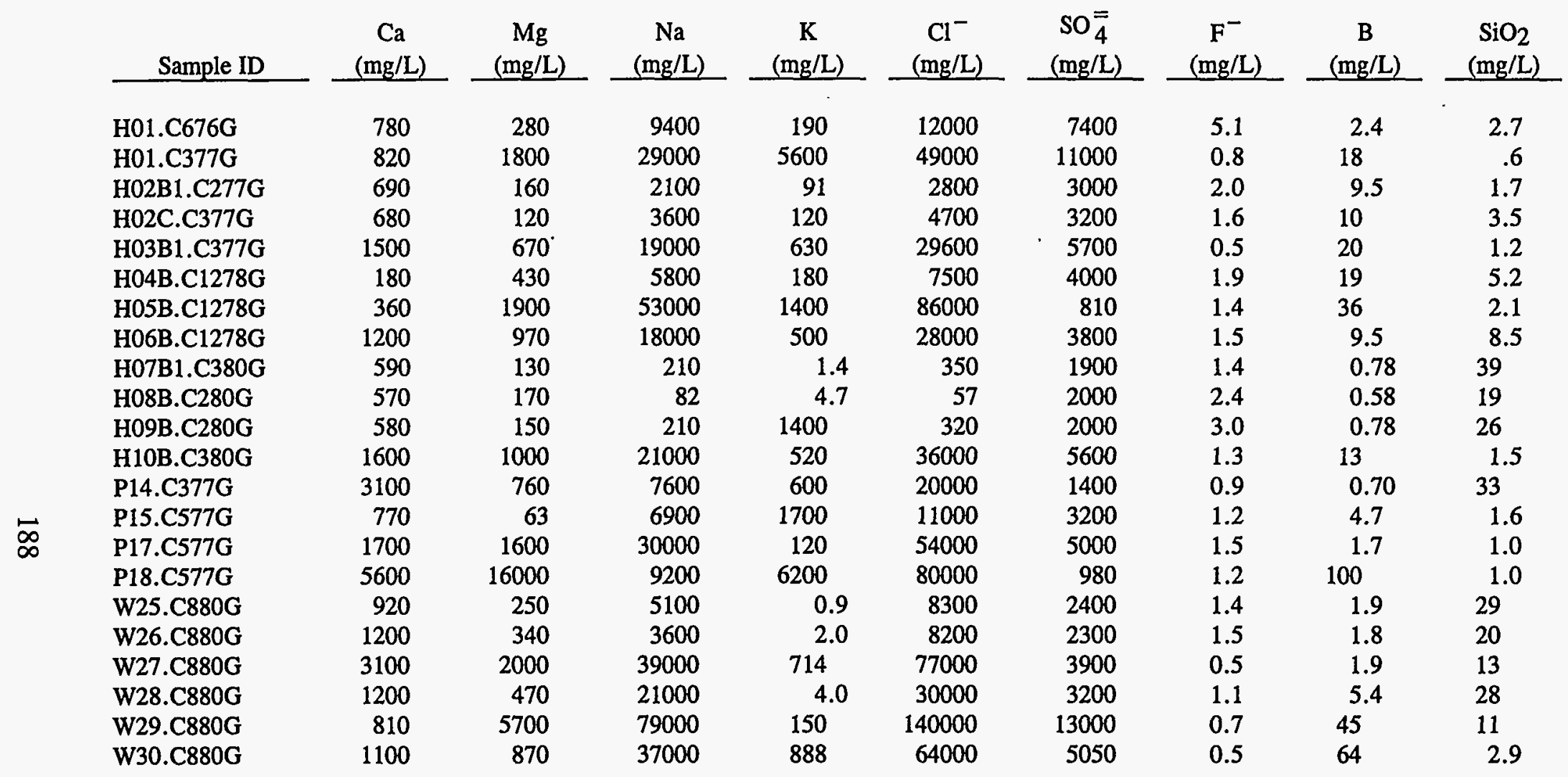


Table 68. Results of Field and Laboratory Analyses by the USGS ${ }^{1}$ - Part B - Samples from the Magenta Dolomite (continued)

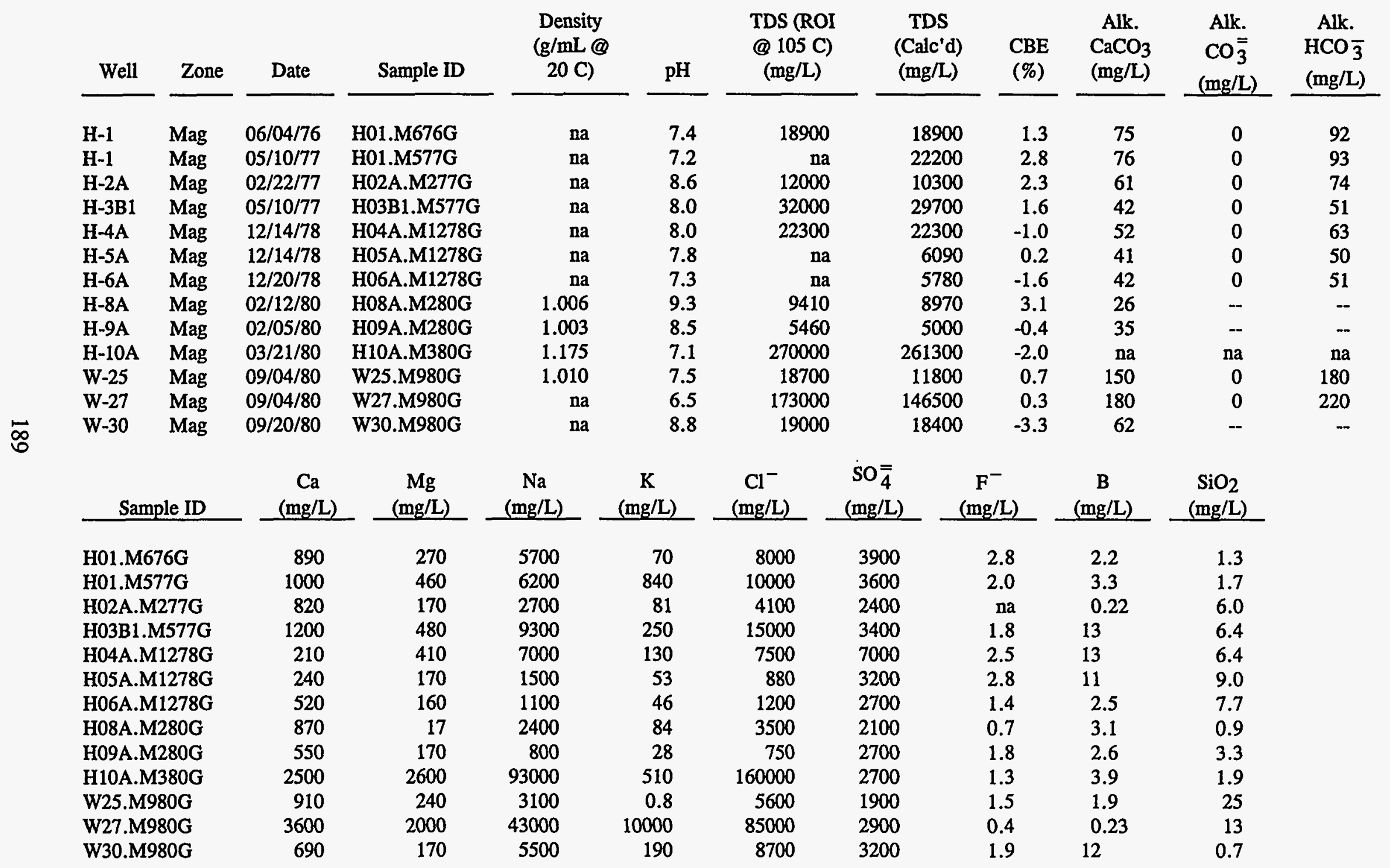


Table 68. Results of Field and Laboratory Analyses by the USGS ${ }^{1}$-Part C - Samples from the Rustler/Salado contact zone (continued)

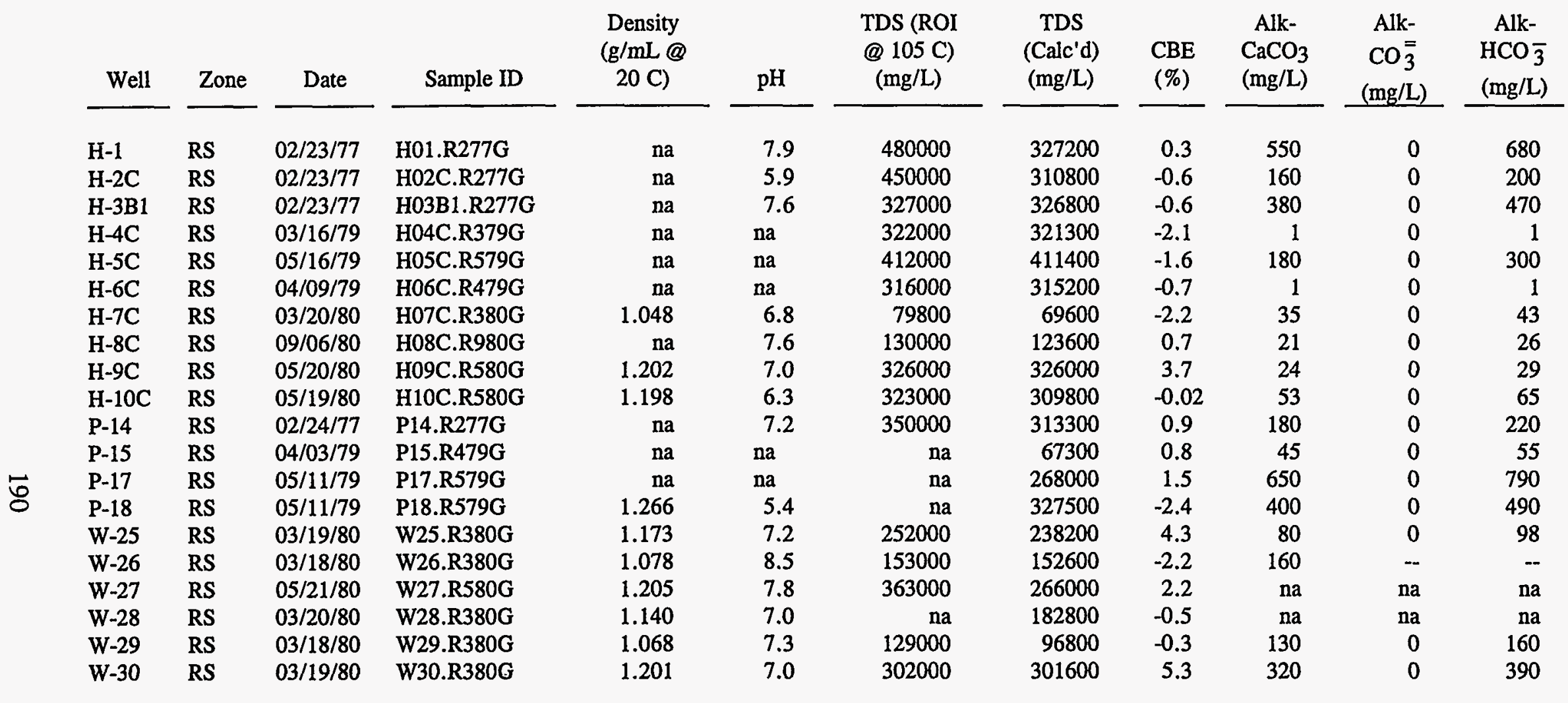


Table 68. Results of Field and Laboratory Analyses by the USGS ${ }^{1}$-Part C - Samples from the Rustler/Salado contact zone (continued)

\begin{tabular}{|c|c|c|c|c|c|c|c|c|c|}
\hline Sample ID & $\begin{array}{c}\mathrm{Ca} \\
(\mathrm{mg} / \mathrm{L})\end{array}$ & $\begin{array}{c}\mathrm{Mg} \\
(\mathrm{mg} / \mathrm{L})\end{array}$ & $\begin{array}{c}\mathrm{Na} \\
(\mathrm{mg} / \mathrm{L})\end{array}$ & $\begin{array}{c}\mathrm{K} \\
(\mathrm{mg} / \mathrm{L}) \\
\end{array}$ & $\begin{array}{c}\mathrm{Cl}^{-} \\
(\mathrm{mg} / \mathrm{L})\end{array}$ & $\begin{array}{c}\mathrm{SO}_{4} \\
(\mathrm{mg} / \mathrm{L})\end{array}$ & $\begin{array}{c}F^{-} \\
(\mathrm{mg} / \mathrm{L})\end{array}$ & $\begin{array}{c}\text { B } \\
(\mathrm{mg} / \mathrm{L})\end{array}$ & $\begin{array}{c}\mathrm{SiO}_{2} \\
(\mathrm{mg} / \mathrm{L})\end{array}$ \\
\hline H01.R277G & 13000 & 30000 & 56000 & 17000 & 210000 & 520 & na & 110 & $<0.1$ \\
\hline H02C.R277G & 9200 & 25000 & 66000 & 9100 & 200000 & 1300 & na & 150 & 2.0 \\
\hline H03B1.R277G & 18000 & 25000 & 59000 & 14000 & 210000 & 370 & na & 1.9 & 1.0 \\
\hline H04C.R379G & 8300 & 27000 & 66000 & 8600 & 210000 & 1400 & 1.7 & 360 & 1.3 \\
\hline H05C.R579G & 2100 & 82000 & 14000 & 21000 & 290000 & 2000 & $<0.1$ & 67 & 1.6 \\
\hline H06C.R479G & 4200 & 21000 & 80000 & 8000 & 200000 & 2000 & 1.0 & 200 & 1.4 \\
\hline H07C.R380G & 2600 & 910 & 22000 & 210 & 41000 & 2900 & 0.8 & 3.1 & 7.2 \\
\hline H08C.R980G & 1200 & 430 & 46000 & 660 & 70000 & 5300 & 0.4 & 1.3 & 0.8 \\
\hline H09C.R580G & 1300 & 870 & 130000 & 1200 & 190000 & 2600 & 0.1 & 19 & 3.8 \\
\hline H10C.R580G & 1500 & 11000 & 100000 & 4000 & 190000 & 3300 & 0.7 & 120 & 3.2 \\
\hline P14.R277G & 570 & 1200 & 120000 & 1300 & 180000 & 10000 & na & 1.7 & 2.0 \\
\hline P15.R479G & 770 & 350 & 24000 & 1400 & 38000 & 2800 & 1.3 & 3.7 & 1.3 \\
\hline P17.R579G & 15000 & 40000 & 23000 & 8800 & 180000 & 1200 & 3.8 & 0.88 & 15 \\
\hline P18.R579G & 10000 & 37000 & 48000 & 12000 & 220000 & 480 & 2.3 & 160 & 0.4 \\
\hline W25.R380G & 650 & 3200 & 90000 & 2400 & 130000 & 12000 & na & 35 & 2.6 \\
\hline W26.R380G & 2700 & 1300 & 52000 & 1000 & 88000 & 7600 & na & 30 & 2.5 \\
\hline W27.R580G & 1160 & 1040 & 102000 & 2570 & 154000 & 5190 & 0.2 & 1.3 & 0.1 \\
\hline W28.R380G & 615 & 2070 & 65000 & 2070 & 102000 & 11000 & 0.2 & 54 & 6.0 \\
\hline W29.R380G & 850 & 2000 & 32000 & 1000 & 49000 & 12000 & 0.9 & 21 & 3.5 \\
\hline W30.R380G & 850 & 2300 & 120000 & 1500 & 170000 & 7000 & na & 77 & 3.5 \\
\hline
\end{tabular}

1. Data from Mercer (1983) and Mercer and Orr (1979). Abbreviations of well names are explained in Table 1. Key: Cul = Culebra Dolomite; Mag = Magenta Dolomite; RS = Rustler/Salado Contact Zone; na = not analyzed. 
Table 68. Results of Field and Laboratory Analyses by the USGS ${ }^{1}$ - Part A-Samples from the Culebra Dolomite

\begin{tabular}{|c|c|c|c|c|c|c|c|c|c|c|c|}
\hline Well & Zone & Date & Sample ID & $\begin{array}{c}\text { Density } \\
(\mathrm{g} / \mathrm{mL} @ \\
20 \mathrm{C})\end{array}$ & $\mathrm{pH}$ & $\begin{array}{l}\text { TDS (ROI } \\
\text { @ 105 C) } \\
\text { (mg/L) }\end{array}$ & $\begin{array}{c}\text { TDS } \\
\text { (Calc'd) } \\
(\mathrm{mg} / \mathrm{L})\end{array}$ & $\begin{array}{l}\text { CBE } \\
(\%)\end{array}$ & $\begin{array}{c}\text { Alk. } \\
\mathrm{CaCO}_{3} \\
(\mathrm{mg} / \mathrm{L})\end{array}$ & $\begin{array}{c}\text { Alk. } \\
\mathrm{CO}_{3}= \\
(\mathrm{mg} / \mathrm{L})\end{array}$ & $\begin{array}{c}\text { Alk. } \\
\mathrm{HCO}_{\overline{3}} \\
(\mathrm{mg} / \mathrm{L})\end{array}$ \\
\hline H-1 & $\mathrm{CuI}$ & $06 / 02 / 76$ & H01.C676G & na & 7.6 & 30100 & 30200 & -2.0 & 86 & 0 & 100 \\
\hline H-1 & $\mathrm{Cul}$ & $03 / 17 / 77$ & H01.C377G & na & 7.3 & na & 97300 & -0.7 & 82 & 0 & 100 \\
\hline $\mathrm{H}-2 \mathrm{~B} 1$ & $\mathrm{Cul}$ & $02 / 22 / 77$ & H02B1.C277G & na & 8.4 & 9700 & 8900 & -0.5 & 57 & 5 & 59 \\
\hline $\mathrm{H}-2 \mathrm{C}$ & Cul & $03 / 16 / 77$ & H02C.C377G & na & 8.2 & na & 12500 & 0.8 & 51 & 0 & 62 \\
\hline H-3B1 & $\mathrm{Cul}$ & $03 / 17 / 77$ & H03B1.C377G & na & 7.4 & 62000 & 57200 & 0.9 & 94 & 0 & 120 \\
\hline H-4B & $\mathrm{Cul}$ & $12 / 14 / 78$ & H04B.C1278G & na & 7.6 & 18100 & 18100 & 0.9 & 48 & 0 & 59 \\
\hline $\mathrm{H}-5 \mathrm{~B}$ & Cul & $12 / 19 / 78$ & H05B.C1278G & na & 6.8 & 144000 & 143500 & 1.5 & 34 & 0 & 41 \\
\hline H-6B & $\mathrm{Cul}$ & $12 / 20 / 78$ & H06B.Cl278G & $\mathrm{na}$ & 7.3 & 52600 & 52500 & 3.7 & 85 & 0 & 100 \\
\hline H-7B1 & $\mathrm{Cul}$ & $03 / 20 / 80$ & H07B1.C380G & 1.001 & 7.0 & 3610 & 3180 & -0.2 & 100 & 0 & 120 \\
\hline H-8B & $\mathrm{Cul}$ & $02 / 11 / 80$ & H08B.C280G & 1.000 & 7.3 & 3200 & 2880 & 3.2 & 61 & 0 & 74 \\
\hline $\mathrm{H}-9 \mathrm{~B}$ & $\mathrm{Cul}$ & $02 / 05 / 80$ & H09B.C280G & na & 7.3 & 3590 & 4660 & 26. & 90 & 0 & 110 \\
\hline H-10B & $\mathrm{Cul}$ & $03 / 21 / 80$ & H10B.C380G & 1.045 & 8.3 & 69200 & 65700 & -2.0 & 37 & 0 & 45 \\
\hline P-14 & $\mathrm{Cul}$ & $03 / 14 / 77$ & P14.C377G & na & 6.0 & 38000 & 33800 & -3.2 & 290 & 0 & 360 \\
\hline P-15 & Cul & $05 / 10 / 77$ & P15.C577G & na & na & 24000 & 23700 & 1.2 & 92 & 24 & 63 \\
\hline P-17 & $\mathrm{Cul}$ & $05 / 10 / 77$ & P17.C577G & na & 7.4 & 97000 & 92500 & -3.4 & 63 & 0 & 77 \\
\hline P-18 & $\mathrm{Cul}$ & $05 / 10 / 77$ & P18.C577G & na & 7.2 & 420000 & 118300 & -3.0 & 250 & 0 & 310 \\
\hline W-25 & Cul & $08 / 14 / 80$ & W25.C880G & 1.014 & 7.3 & 22100 & 17000 & 0.8 & 370 & 0 & 450 \\
\hline W-26 & $\mathrm{Cul}$ & $08 / 18 / 80$ & W26.C880G & 1.013 & 6.9 & 23800 & 15600 & -6.7 & 130 & 0 & 160 \\
\hline W-27 & Cul & $08 / 22 / 80$ & W27.C880G & 1.094 & 6.4 & 186000 & 125700 & -5.2 & 150 & 0 & 180 \\
\hline W-28 & $\mathrm{Cul}$ & $08 / 21 / 80$ & W28.C880G & 1.044 & 6.4 & 74000 & 55900 & 5.2 & 670 & 0 & 820 \\
\hline W-29 & $\mathrm{Cul}$ & $08 / 20 / 80$ & W29.C880G & 1.178 & 6.1 & 239000 & 238700 & -3.4 & 210 & 0 & 260 \\
\hline W-30 & $\mathrm{Cul}$ & $08 / 13 / 80$ & W30.C880G & 1.072 & 6.8 & 110000 & 108900 & -4.2 & 74 & 0 & 90 \\
\hline
\end{tabular}


Table 69. Results of Laboratory Analysis by ITAS (WQSP Round 1) 1

\begin{tabular}{|c|c|c|c|c|c|c|c|}
\hline Well & Zone & Date & Sample ID & $\mathrm{pH}$ & $\begin{array}{c}\text { Chg Bal } \\
\text { Error } \\
(\%) \\
\end{array}$ & $\begin{array}{c}\text { TDS (ROI } \\
\text { at } 180 \mathrm{C}) \\
(\mathrm{mg} / \mathrm{L}) \\
\end{array}$ & $\begin{array}{c}\text { TDS } \\
\text { (Calc'd) } \\
(\mathrm{mg} / \mathrm{L})\end{array}$ \\
\hline DOE-1 & Cul(a) & $04 / 24 / 85$ & D1.C485Ia & 6.9 & -- & 130000 & -- \\
\hline DOE-1 & Cul(b) & $04 / 25 / 85$ & D1.C485Ib & na & -- & na & - \\
\hline DOE-2 & $\mathrm{Cul}$ & $3 / 11,12 / 85$ & D2.C385I & 7.1 & -- & 58000 & -- \\
\hline $\mathrm{H}-2 \mathrm{~A}$ & Cul & $04 / 21 / 86$ & H02A.C486I & 7.8 & -2.6 & 13500 & 13200 \\
\hline H-3B3 & $\mathrm{Cul}$ & $02 / 04 / 85$ & H03B3.C285I & 7.6 & - & 55000 & - \\
\hline $\mathrm{H}-3 \mathrm{~B} 2$ & $\mathrm{Cul}$ & $12 / 16 / 85$ & H03B2.C1285I & 7.1 & -1.7 & 54000 & 54900 \\
\hline$H-4 B$ & Cul & $07 / 20 / 85$ & H04B.C785I & 7.6 & - & 20000 & -- \\
\hline H-5B & $\mathrm{Cul}$ & $08 / 26 / 85$ & H05B.C885I & 7.0 & -6.3 & 142000 & 144600 \\
\hline $\mathrm{H}-6 \mathrm{~B}$ & Cul & $09 / 15 / 85$ & H06B.C985I & 7.2 & -11 & 58000 & 55200 \\
\hline $\mathrm{H}-7 \mathrm{~B} 1$ & Cul & 03/27/86 & H07B1.C386I & 7.5 & -20 & 3400 & 4020 \\
\hline H-8B & Cul & $01 / 21-23 / 86$ & H08B.C186I & 7.9 & 8.0 & 3150 & 2540 \\
\hline H-9B & $\mathrm{Cul}$ & $11 / 14 / 85$ & H09B.C1185I & 7.7 & 10 & 3300 & 2630 \\
\hline H-11B3 & Cul & $06 / 03 / 85$ & H11B3.C685I & 7.2 & -- & 122000 & -- \\
\hline $\mathrm{H}-12$ & Cul & 08/09/85 & H12.C885I & 7.3 & -4.4 & 142000 & 135200 \\
\hline P-14 & Cul & $02 / 26,27 / 86$ & P14.C286I & 7.0 & -0.99 & 26000 & 24200 \\
\hline P-17 & Cul & $03 / 17 / 86$ & P17.C386I & 7.0 & -2.7 & 88000 & 90400 \\
\hline W-25 & Cul & $02 / 12 / 86$ & W25.C286I & 7.7 & 1.5 & 14000 & 13700 \\
\hline W-26 & Cul & $11 / 25 / 85$ & W26.C1185I & 7.4 & 0.13 & 18000 & 18200 \\
\hline W-29 & Cul & $12 / 14 / 85$ & W29.C1285I & 6.6 & -3.7 & 330000 & 317200 \\
\hline ENGLE & Cul & $03 / 04,05 / 85$ & XENG.C385I & 6.5 & -- & 3460 & -- \\
\hline H-3B1 & Mag & $07 / 01 / 85$ & H03B1.M785I & 7.6 & - & 9000 & -- \\
\hline $\mathrm{H}-4 \mathrm{C}$ & Mag & $11 / 04 / 86$ & H04C.M1186I & 8.0 & -5.8 & 22500 & 28200 \\
\hline $\mathrm{H}-5 \mathrm{C}$ & Mag & $10 / 24 / 86$ & H05C.M1086I & 7.4 & -4.7 & 6800 & 8410 \\
\hline $\mathrm{H}-6 \mathrm{C}$ & Mag & $10 / 01 / 86$ & H06C.M10861 & 7.2 & 19 & 4600 & 4750 \\
\hline $\mathrm{H}-8 \mathrm{~A}$ & Mag & $10 / 21 / 85$ & H08A.M1085I & na & -5.3 & na & 7150 \\
\hline RANCH & $\mathrm{DL}$ & $06 / 18 / 86$ & XRAN.D686I & 7.7 & -1.0 & 3300 & 2270 \\
\hline TWIN-P & DL & $01 / 30,31 / 86$ & XTWP.D186I & 8.0 & -19 & 400 & 671 \\
\hline DOE-2 & $\mathrm{BC}$ & $07 / 23 / 85$ & D2.B785I & 6.7 & - & 160000 & -- \\
\hline
\end{tabular}


Table 69. Results of Laboratory Analysis by ITAS (WQSP Round 1) (continued)

\begin{tabular}{|c|c|c|c|c|c|c|}
\hline Sample ID & $\begin{array}{c}\mathrm{Ca} \\
(\mathrm{mg} / \mathrm{L})\end{array}$ & $\begin{array}{c}\mathrm{Mg} \\
(\mathrm{mg} / \mathrm{L})\end{array}$ & $\begin{array}{c}\mathrm{Na} \\
(\mathrm{mg} / \mathrm{L})\end{array}$ & $\begin{array}{c}\mathrm{K} \\
(\mathrm{mg} / \mathrm{L})\end{array}$ & $\begin{array}{c}\mathrm{Cl}^{-} \\
(\mathrm{mg} / \mathrm{L})\end{array}$ & $\begin{array}{c}\mathrm{SO}_{4} \\
(\mathrm{mg} / \mathrm{L})\end{array}$ \\
\hline D1.C485Ia & na & na & na & na & na & na \\
\hline D1.C485Ib & na & na & na & na & na & na \\
\hline D2.C385I & na & na & na & na & na & na \\
\hline H02A.C486I & 705. & 170. & 3600 & 97.5 & 5300 & 3300 \\
\hline H03B3.C285I & na & na & na & na & na & na \\
\hline H03B2.C1285I & 2100 & 690. & 17000 & 480. & 30000 & 4600 \\
\hline H04B.C785I & na & na & na & na & na & na \\
\hline H05B.C885I & 1300 & 1700 & 47000 & 1300 & 87000 & 6300 \\
\hline H06B.C985I & 1900 & 740. & 15000 & 485. & 34000 & 3000 \\
\hline H07B1.C386I & 540. & 130. & 210. & 7.00 & 700 . & 2300 \\
\hline H08B.C186I & 540. & 170. & 51.0 & 3.70 & 33.0 & 1650 \\
\hline H09B.C1185I & 560. & 140. & 150. & 7.55 & 200. & 1450 \\
\hline H11B3.C685I & na & na & na & na & na & na \\
\hline H12.C885I & 1850 & 1400 & 44500 & 1500 & 80000 & 5900 \\
\hline P14.C286I & 3900 & 760. & 3750 & 44.5 & 14000 & 1600 \\
\hline P17.C386I & 1650 & 1550 & 29000 & 795. & 51000 & 6400 \\
\hline W25.C286I & 1150 & 340. & 3350 & 105. & 6200 & 2400 \\
\hline W26.C1185I & 1800 & 375. & 4150 & 350. & 9450 & 1950 \\
\hline W29.C1285I & 630. & 6350 & 90000 & 23000 & 180000 & 17000 \\
\hline XENG.C385I & na & na & na & na & na & na \\
\hline H03B1.M785I & na & na & nà & na & na & na \\
\hline H04C.M1186I & 1100 & 470. & 7500 & 135. & 11000 & 7850 \\
\hline H05C.M1086I & 795. & 190. & 1500 & 51.5 & 1600 & 4200 \\
\hline H06C.M1086I & 620. & 170. & 1050 & 26.0 & 430. & 2400 \\
\hline H08A.M1085I & 555. & 10.5 & 1800 & 59.0 & 3000 & 1700 \\
\hline XRAN.D686I & 365. & 190. & 180. & 3.65 & 390. & 920 \\
\hline XTWP.D186I & 81.0 & 23.5 & 26.0 & 3.70 & 47.0 & 270 \\
\hline D2.B785I & na & na & na & na & na & na \\
\hline
\end{tabular}


Table 69. Results of Laboratory Analysis by ITAS (WQSP Round 1) (continued)

\begin{tabular}{|c|c|c|c|c|c|c|}
\hline Sample ID & $\begin{array}{c}\text { Alk. } \\
\mathrm{CO}_{\overline{3}} \\
(\mathrm{mg} / \mathrm{L})\end{array}$ & $\begin{array}{c}\text { Alk. } \\
\mathrm{HCO}_{\overline{3}} \\
(\mathrm{mg} / \mathrm{L})\end{array}$ & $\begin{array}{c}\mathrm{Br}^{-} \\
(\mathrm{mg} / \mathrm{L})\end{array}$ & $\begin{array}{c}F^{-} \\
(\mathrm{mg} / \mathrm{L})\end{array}$ & $\begin{array}{c}\mathrm{I}^{-} \\
(\mathrm{mg} / \mathrm{L})\end{array}$ & $\begin{array}{c}\mathrm{NO}_{\overline{3}} \\
\text { as } \mathrm{N} \\
(\mathrm{mg} / \mathrm{L})\end{array}$ \\
\hline D1.C485Ia & na & na & 64. & 1.0 & $<1$ & $<0.1$ \\
\hline D1.C485Ib & na & na & na & na & na & na \\
\hline D2.C385I & na & na & 50. & 1.2 & $<1$ & $<0.1$ \\
\hline H02A.C486I & 0 & 56 & $<1$ & 14. & 1.0 & 0.30 \\
\hline H03B3.C285I & na & na & 1.9 & 1.6 & 1.0 & $<0.1$ \\
\hline H03B2.C1285I & 0 & 52 & na & na & na & na \\
\hline H04B.C785I & na & na & 64. & 1.7 & 1.1 & $<0.1$ \\
\hline H05B.C885I & 0 & 47 & 94. & 1.3 & 1.1 & 0.40 \\
\hline H06B.C985I & 0 & 100 & 67. & 1.6 & $<1$ & 0.20 \\
\hline H07B1.C386I & 0 & 130 & 1.0 & 1.2 & $<1$ & 0.70 \\
\hline H08B.C186I & 0 & 94 & $<1$ & 2.4 & $<1$ & 1.4 \\
\hline H09B.C1185I & 0 & 120 & 1.0 & 2.6 & $<1$ & 0.20 \\
\hline H11B3.C685I & na & na & 100 & 1.0 & 1.1 & $<0.1$ \\
\hline H12.C885I & 0 & 56 & 140 & 1.2 & 1.6 & $<0.1$ \\
\hline P14.C286I & 0 & 100 & 24. & 1.2 & $<1$ & 0.20 \\
\hline P17.C386I & 0 & 54 & 98. & 1.2 & 7.3 & 0.30 \\
\hline W25.C286I & 0 & 120 & 4.2 & 1.6 & $<1$ & 3.6 \\
\hline W26.C1185I & 0 & 130 & 12. & 1.3 & $<1$ & 5.7 \\
\hline W29.C1285I & 0 & 170 & 100 & 0.9 & 2.1 & 0.10 \\
\hline XENG.C385I & na & na & 1.2 & 2.8 & $<1$ & 0.50 \\
\hline H03B1.M785I & na & na & 23. & 1.8 & 1.6 & $<0.1$ \\
\hline H04C.M1186I & 0 & 100 & $7.0^{\circ}$ & 2.2 & 1.0 & $<0.1$ \\
\hline H05C.M1086I & 0 & 69 & 4.0 & 2.5 & $<1$ & $<0.1$ \\
\hline H06C.M1086I & 0 & 52 & 1.0 & 1.7 & $<1$ & $<0.1$ \\
\hline H08A.M1085I & 0 & 30 & na & na & na & na \\
\hline XRAN.D686I & 0 & 220 & 2.3 & 1.0 & .96 & 120 \\
\hline XTWP.D186I & 0 & 220 & $<1$ & 0.7 & $<1$ & 7.8 \\
\hline D2.B785I & na & na & 94. & 0.4 & 7.9 & 0.75 \\
\hline
\end{tabular}


Table 69. Results of Laboratory Analysis by ITAS (WQSP Round 1) (continued)

\begin{tabular}{|c|c|c|c|c|c|c|c|}
\hline Sample ID & $\begin{array}{c}\text { B } \\
(\mathrm{mg} / \mathrm{L})\end{array}$ & $\begin{array}{c}\mathrm{Cs} \\
(\mathrm{mg} / \mathrm{L})\end{array}$ & $\begin{array}{c}\mathrm{Fe} \\
(\mathrm{mg} / \mathrm{L})\end{array}$ & $\begin{array}{c}\mathrm{Li} \\
(\mathrm{mg} / \mathrm{L})\end{array}$ & $\begin{array}{c}\mathrm{Mn} \\
(\mathrm{mg} / \mathrm{L})\end{array}$ & $\begin{array}{c}\mathrm{Si} \\
(\mathrm{mg} / \mathrm{L})\end{array}$ & $\begin{array}{c}\mathrm{Sr} \\
(\mathrm{mg} / \mathrm{L})\end{array}$ \\
\hline D1.C485Ia & 7.5 & 10. & 1.3 & na & 0.35 & 11. & 5.8 \\
\hline D1.C485Ib & 6.9 & 7.2 & 1.3 & na & 0.43 & 10. & 5.9 \\
\hline D2.C385I & 24. & 1.7 & 0.35 & na & 0.37 & 11. & 28. \\
\hline H02A.C486I & 10. & $<0.1$ & 0.76 & na & 0.080 & 13. & 6.8 \\
\hline H03B3.C285I & 34. & 1.6 & 0.38 & na & 0.18 & 8.8 & 25. \\
\hline H03B2.C1285I & na & na & na & na & na & na & na \\
\hline H04B.C785I & 23. & $<0.1$ & 0.43 & na & 0.12 & 14. & 15. \\
\hline H05B.C885I & 29. & $<1.0$ & 3.0 & na & 0.52 & 17. & 16. \\
\hline H06B.C985I & 7.1 & $<1.0$ & 0.55 & na & 0.20 & 20. & 24. \\
\hline H07B1.C386I & 0.74 & $<0.1$ & 0.08 & na & 0.050 & 43. & 5.8 \\
\hline H08B.C186I & 0.06 & $<1$ & 0.05 & na & $<0.1$ & 26. & 5.9 \\
\hline H09B.C1185I & $<0.1$ & 0.2 & $<0.1$ & na & 0.060 & 18. & 7.0 \\
\hline H11B3.C685I & 13. & .29 & 0.66 & na & 0.39 & 15. & 18. \\
\hline H12.C885I & 35. & $<10$ & 0.56 & na & 0.64 & 45. & 18. \\
\hline P14.C286I & 0.065 & $<0.01$ & 1.6 & na & 0.23 & 32. & 48. \\
\hline P17.C386I & 36. & $<0.1$ & 3.8 & na & 0.80 & $<0.2$ & 28. \\
\hline W25.C286I & 1.7 & $<0.1$ & 0.45 & na & 0.11 & 31. & 1.4 \\
\hline W26.C1185I & $<0.01$ & $<0.1$ & $<0.1$ & na & 0.090 & 30. & 17. \\
\hline W29.C1285I & 5.8 & $<1$ & 2.0 & na & 1.8 & 51. & 9.0 \\
\hline XENG.C385I & 0.77 & 0.07 & 0.32 & na & -0.01 & 25. & 7.0 \\
\hline H03B1.M785I & 4.5 & $<0.1$ & 0.14 & na & 0.045 & 11. & 17. \\
\hline H04C.M1186I & 11. & 0.1 & 0.90 & 0.43 & 0.46 & 10. & 13. \\
\hline H05C.M1086I & 10. & 0.2 & 1.3 & 0.20 & $<0.05$ & 12. & 8.4 \\
\hline H06C.M1086I & 2.4 & 0.3 & 0.30 & 0.19 & $<0.05$ & 13. & 7.1 \\
\hline H08A.M1085I & na & na & na & na & na & na & na \\
\hline XRAN.D686I & 0.19 & 0.1 & 0.020 & na & $<0.005$ & 40. & 3.2 \\
\hline XTWP.D186I & 0.16 & $<0.1$ & 0.34 & na & $<0.05$ & 42. & 0.6 \\
\hline D2.B785I & 61. & 3.3 & 9.1 & na & 2.5 & 14. & 300 \\
\hline
\end{tabular}

1. Data from Uhland and Randall (1986) and Uhland et al. (1987). Abbreviations of well names are explained in Table 1. Cul = Culebra Dolomite; Mag = Magenta Dolomite; $\mathrm{DL}=$ Dewey Lake Red Beds; $\mathrm{BC}=$ Bell Canyon Formation; na $=$ not analyzed. 
Table 70: Results of Laboratory Analyses by the NMBM\&MR for the EEG

\begin{tabular}{|c|c|c|c|c|c|c|c|c|c|}
\hline Well & Zone & Date & Sample ID & $\begin{array}{l}\text { Density } \\
\text { (mg/L) }\end{array}$ & $\mathrm{pH}$ & $\begin{array}{l}\text { TDS- } \\
\text { Calc'd } \\
(\mathrm{mg} / \mathrm{L})\end{array}$ & $\begin{array}{c}\text { Chg Bal } \\
\text { Error } \\
(\%)\end{array}$ & $\begin{array}{c}F^{-} \\
(\mathrm{mg} / \mathrm{L})\end{array}$ & $\underset{(m g / L)}{\mathrm{Li}}$ \\
\hline DOE-1 & Cul & $04 / 24,25 / 85$ & D1.C485 & 1.11 & 7.0 & 111200 & 3.0 & 1.7 & na \\
\hline DOE-2 & Cul & $03 / 11,12 / 85$ & D2.C385 & 1.06 & 7.2 & 57700 & -0.2 & 2.2 & na \\
\hline H-3B3 & Cul & $02 / 04 / 85$ & H03B3.C285 & 1.02 & 7.1 & 55300 & 0.2 & 0.23 & 0.30 \\
\hline H-4B & Cul & $07 / 25 / 85$ & H04B.C785 & 1.03 & 7.6 & 18700 & -0.9 & 2.7 & 0.40 \\
\hline H-5B & Cul & $08 / 26 / 85$ & H05B.C885 & 1.12 & 6.8 & 143500 & 1.3 & 1.2 & $<0.5$ \\
\hline H-6B & Cul & $09 / 15 / 85$ & H06B.C985 & 1.06 & 7.1 & 56900 & -0.6 & 1.5 & $<0.5$ \\
\hline H-8B & Cul & $01 / 22 / 86$ & H08B.C186 & 1.01 & 7.2 & 2670 & 1.5 & 2.1 & $<0.5$ \\
\hline H-9B & Cul & $11 / 14 / 85$ & H09B.C1185 & 1.01 & 6.9 & 2960 & 2.1 & 2.8 & $<0.5$ \\
\hline H-11B3 & Cul & $06 / 03,04 / 85$ & H11B3.C685 & 1.10 & 7.3 & 109500 & -0.7 & 1.6 & 0.38 \\
\hline $\mathrm{H}-12$ & Cul & 08/09/85 & H12.C885 & 1.12 & 7.0 & 122400 & -4.2 & 2.3 & 0.61 \\
\hline P-14 & Cul & $02 / 26 / 86$ & P14.C286 & 1.04 & 7.1 & 24800 & 0.1 & 1.5 & $<0.5$ \\
\hline P-17 & $\mathrm{Cul}$ & $03 / 17 / 86$ & P17.C386 & 1.08 & 6.9 & 81200 & -1.5 & 1.9 & $<0.5$ \\
\hline$W-26$ & Cul & $11 / 25 / 85$ & W26.C1185 & 1.03 & 7.5 & 16800 & -2.6 & 1.5 & $<0.5$ \\
\hline W-29 & Cul & $12 / 14 / 85$ & W29.C1285 & 1.22 & 6.9 & 265600 & -3.1 & 4.5 & $<0.5$ \\
\hline ENGLE & Cul & $03 / 04,05 / 85$ & XENG.C385 & 1.01 & 7.8 & 2940 & 4.0 & 2.9 & na \\
\hline H-3B1 & Mag & 07/01/85 & H03B1.M785 & 1.02 & 7.4 & 7820 & -2.0 & 2.6 & 0.32 \\
\hline TWIN-P & $\mathrm{DL}$ & $01 / 31 / 86$ & XTWP.D186 & 1.0 & 7.9 & 227 & $-6.3^{1}$ & 1.4 & $<0.5$ \\
\hline DOE-2 & BC & $07 / 23 / 85$ & D2.B785 & 1.12 & 6.8 & 130800 & -2.2 & 1.4 & 2.8 \\
\hline
\end{tabular}

\begin{tabular}{|c|c|c|c|c|c|c|}
\hline Sample ID & $\begin{array}{c}\mathrm{Ca} \\
(\mathrm{mg} / \mathrm{L})\end{array}$ & $\begin{array}{c}\mathrm{Mg} \\
(\mathrm{mg} / \mathrm{L})\end{array}$ & $\begin{array}{c}\mathrm{Na} \\
(\mathrm{mg} / \mathrm{L})\end{array}$ & $\begin{array}{c}\mathrm{K} \\
(\mathrm{mg} / \mathrm{L})\end{array}$ & $\begin{array}{c}\mathrm{Cl}^{-} \\
(\mathrm{mg} / \mathrm{L})\end{array}$ & $\begin{array}{c}\mathrm{SO}_{4} \\
(\mathrm{mg} / \mathrm{L})\end{array}$ \\
\hline D1.C485E & 1460 & 1370 & 40500 & 703 & 61400 & 5800 \\
\hline D2.C385E & 2740 & 962 & 17600 & 309 & 32600 & 3470 \\
\hline H03B3.C285E & 1410 & 719 & 18300 & 439 & 29500 & 4900 \\
\hline H04B.C785E & 690 & 409 & 5190 & 185 & 6670 & 5530 \\
\hline H05B.C885E & 1460 & 1910 & 51300 & 1110 & 81000 & 6730 \\
\hline Н06В.С985E & 1970 & 1130 & 17700 & 430 & 32300 & 3390 \\
\hline H08B.C186E & 520 & 160 & 55 & 4.6 & 30 & 1900 \\
\hline H09B.C1185E & 560 & 150 & 150 & 7.4 & 195 & 1900 \\
\hline H11B3.C685E & 1580 & 1360 & 37800 & 680 & 62000 & 6040 \\
\hline H12.C885E & 1510 & 1650 & 40400 & 670 & 71700 & 6520 \\
\hline P14.C286E & 3640 & 740 & 4200 & 60.0 & 13900 & 1650 \\
\hline P17.C386E & 1560 & 1440 & 26200 & 875 & 45200 & 5960 \\
\hline W26.C1185E & 1290 & 425 & 3820 & 360 & 8490 & 2370 \\
\hline W29.C1285E & 675 & 4750 & 75400 & 20800 & 147000 & 17000 \\
\hline XENG.C385E & 570 & 132 & 187 & 5.4 & 170 & 1880 \\
\hline H03B1.M785E & 892 & 273 & 1370 & 20.0 & 3030 & 2240 \\
\hline XTWP.D186E & 60 & 25 & 24 & 4.3 & 44 & 70 \\
\hline D2.B785E & 5320 & 1200 & 41800 & 600 & 80000 & 1880 \\
\hline
\end{tabular}

1. $\mathrm{CBE}$ for Twin Wells (Pasture) calculated using field alkalinity value. Alkalinity not included in CBE calculations for other samples. 
Table 71: Comparison of Data from the Culebra at DOE-1 (Footnotes follow Table 135)

\begin{tabular}{|c|c|c|c|c|c|}
\hline Well $^{1}$ & Agency $^{2}$ & Collection Date & Pumping Rate & $\mathrm{Lab}^{3}$ & Sample ID \\
\hline DOE-1 & HGC & $04 / 13 / 83-04 / 21 / 83$ & $0.5 \mathrm{gpm}$ & FLD & D1.C483F \\
\hline DOE-1 & HGC & $04 / 19 / 83$ & $0.5 \mathrm{gpm}$ & $\mathrm{KCS}$ & D1.C483KC \\
\hline DOE-1 & WQSP-R1 & $04 / 12 / 85-04 / 25 / 85$ & $8.3 \mathrm{gpm}$ & FLD & D1.C485F \\
\hline DOE-1 & WQSP-R1 & $04 / 24,25 / 85$ & $8.3 \mathrm{gpm}$ & BFEC & D1.C485B \\
\hline DOE-1 & WQSP-R1 & $04 / 24,25 / 85$ & $8.3 \mathrm{gpm}$ & EEG & D1.C485E \\
\hline DOE-1 & WQSP-R1 & $04 / 24 / 85$ & $8.3 \mathrm{gpm}$ & ITAS & D1.C485Ia \\
\hline DOE-1 & WQSP-R1 & $04 / 25 / 85$ & $8.3 \mathrm{gpm}$ & ITAS & D1.C485Ib \\
\hline
\end{tabular}

\begin{tabular}{|c|c|c|c|c|c|}
\hline Sample ID & $\begin{array}{c}\text { Density/ } \\
\text { Specific Gravity } \\
\end{array}$ & $\mathrm{pH}$ & $\begin{array}{c}\text { TDS (calc) } \\
(\mathrm{mg} / \mathrm{L})^{5}\end{array}$ & $\begin{array}{c}\text { TDS (ROI) } \\
(\mathrm{mg} / \mathrm{L})\end{array}$ & $\begin{array}{c}\text { Charge-Balance } \\
\text { Error } 5\end{array}$ \\
\hline D1.C483F & $1.090(\mathrm{sg})$ & 7.6 & & & \\
\hline \multicolumn{6}{|l|}{ D1.C483KC } \\
\hline D1.C485F & & 7.1 & & & \\
\hline D1.C485B & & & 131200 & & $0.2 \%$ \\
\hline D1.C485E & $1.11(\mathrm{~g} / \mathrm{mL})$ & 7.0 & 111200 & & $3.0 \%$ \\
\hline D1.C485Ia & & 6.9 & & $130000(180 \mathrm{C})$ & \\
\hline D1.C485Ib & & & & & \\
\hline
\end{tabular}

\begin{tabular}{|c|c|c|c|c|c|}
\hline Sample ID & $\begin{array}{c}\text { Alkalinity } \\
\left(\mathrm{mg} / \mathrm{L} \mathrm{CaCO}_{3}\right)^{6}\end{array}$ & $\begin{array}{c}\mathrm{HCO}_{3}^{-} \\
(\mathrm{mg} / \mathrm{L})^{6}\end{array}$ & $\begin{array}{c}\mathrm{CO}_{\overline{3}} \\
(\mathrm{mg} / \mathrm{L})^{6}\end{array}$ & $\begin{array}{c}\mathrm{Cl}^{-} \\
(\mathrm{mg} / \mathrm{L})\end{array}$ & $\begin{array}{c}\mathrm{SO} \overline{\overline{4}} \\
(\mathrm{mg} / \mathrm{L})\end{array}$ \\
\hline D1.C483F & & $-65-70$ & & & \\
\hline D1.C483KC & & & & 94000 & \\
\hline D1.C485F & 37 & 45 & 0 & 73000 & \\
\hline D1.C485B & 35 & 43 & 0 & 73600 & 7350 \\
\hline D1.C485E & & & & 61400 & 5800 \\
\hline
\end{tabular}

D1.C485Ia

D1.C485Ib

\begin{tabular}{|c|c|c|c|c|c|}
\hline Sample ID & $\begin{array}{c}\mathrm{Na} \\
(\mathrm{mg} / \mathrm{L})\end{array}$ & $\underset{(\mathrm{mg} / \mathrm{L})}{\mathbf{K}}$ & $\begin{array}{c}\mathrm{Ca} \\
(\mathrm{mg} / \mathrm{L})\end{array}$ & $\begin{array}{c}\mathrm{Mg} \\
(\mathrm{mg} / \mathrm{L})\end{array}$ & $\begin{array}{c}\mathrm{x}^{++} \\
(\mathrm{meq} / \mathrm{L})^{7}\end{array}$ \\
\hline \multicolumn{6}{|l|}{ D1.C483F } \\
\hline D1.C485F & & & & & 210 \\
\hline D1.C485B & 45800 & 1100 & 1730 & 1610 & 218 \\
\hline D1.C485E & 40500 & 703 & 1460 & 1370 & 185 \\
\hline \multicolumn{6}{|l|}{ D1.C485Ia } \\
\hline D1.C485Ib & & & & & \\
\hline
\end{tabular}


Table 71. Comparison of Data from the Culebra at DOE-1 (continued)

\begin{tabular}{|c|c|c|c|c|c|c|c|}
\hline Sample ID & $\begin{array}{c}\text { B } \\
(\mathrm{mg} / \mathrm{L})\end{array}$ & $\begin{array}{c}\mathrm{Cs} \\
(\mathrm{mg} / \mathrm{L})\end{array}$ & $\underset{(\mathrm{mg} / \mathrm{L})}{\mathrm{Li}}$ & $\begin{array}{c}\mathrm{SiO}_{2} \\
(\mathrm{mg} / \mathrm{L})\end{array}$ & $\begin{array}{c}\mathrm{Sr} \\
(\mathrm{mg} / \mathrm{L})\end{array}$ & $\begin{array}{c}\mathrm{Fe} \\
(\mathrm{mg} / \mathrm{L})\end{array}$ & $\underset{(\mathrm{mg} / \mathrm{L})}{\mathrm{Mn}}$ \\
\hline \multicolumn{8}{|l|}{$\begin{array}{l}\text { D1.C483F } \\
\text { D1.C483KC }\end{array}$} \\
\hline \multicolumn{8}{|l|}{ D1.C485F } \\
\hline D1.C485B & 37 & & 0.64 & 8.4 & 26 & 0.28 & \\
\hline \multicolumn{8}{|l|}{ D1.C485E } \\
\hline D1.C485Ia & 7.5 & 10 & & 11 as $\mathrm{Si}$ & 5.8 & 1.3 & 0.35 \\
\hline D1.C485Ib & 6.9 & 7.2 & & 10 as $\mathrm{Si}$ & 5.9 & 1.3 & 0.43 \\
\hline Sample ID & $\begin{array}{c}\mathrm{Br}^{-} \\
(\mathrm{mg} / \mathrm{L})\end{array}$ & $\begin{array}{c}\mathrm{F}^{-} \\
(\mathrm{mg} / \mathrm{L})\end{array}$ & $\underset{(\mathrm{mg} / \mathrm{L})}{\mathrm{I}^{-}}$ & $\begin{array}{r}\mathrm{NO}_{3}^{-} \\
(\mathrm{mg} / \mathrm{L}\end{array}$ & & & \\
\hline \multicolumn{8}{|l|}{ D1.C483F } \\
\hline \multicolumn{8}{|l|}{ D1.C483KC } \\
\hline \multicolumn{8}{|l|}{ D1.C485F } \\
\hline D1.C485B & 56 & & & & & & \\
\hline D1.C485E & & 1.7 & & & & & \\
\hline D1.C485Ia & 64 & 1.0 & $<1$ & $<0.1$ & & & \\
\hline D1.C485Ib & & & & & & & \\
\hline
\end{tabular}


Table 72. Comparison of Data from the Culebra at DOE-2

(Footnotes follow Table 135)

\begin{tabular}{|c|c|c|c|c|c|}
\hline Well ${ }^{1}$ & Agency $^{2}$ & Collection Date & Pumping Rate & $\mathrm{Lab}^{3}$ & Sample ID \\
\hline DOE-2 & WQSP-R1 & $02 / 20 / 85-03 / 12 / 85$ & $6 \mathrm{gpm}$ & FLD & D2.C385F \\
\hline DOE-2 & WQSP-R1 & $03 / 11,12 / 85$ & $6 \mathrm{gpm}$ & BFEC & D2.C385B \\
\hline DOE-2 & WQSP-R1 & $03 / 11,12 / 85$ & $6 \mathrm{gpm}$ & EEG & D2.C385E \\
\hline DOE-2 & WQSP-R1 & $03 / 11,12 / 85$ & $6 \mathrm{gpm}$ & ITAS & D2.C385I \\
\hline
\end{tabular}

\begin{tabular}{|c|c|c|c|c|c|}
\hline Sample ID & $\begin{array}{c}\text { Density/ } \\
\text { Specific Gravity } 4\end{array}$ & $\mathrm{pH}$ & $\begin{array}{l}\text { TDS (calc) } \\
(\mathrm{mg} / \mathrm{L})^{5}\end{array}$ & $\begin{array}{c}\text { TDS (ROI) } \\
(\mathrm{mg} / \mathrm{L})\end{array}$ & $\begin{array}{c}\text { Charge-Balance } \\
\text { Error } 5\end{array}$ \\
\hline $\mathrm{D} 2 . \mathrm{C} 385 \mathrm{~F}$ & & 7.0 & & & \\
\hline D2.C385B & & & 60400 & & $-3.2 \%$ \\
\hline D2.C385E & $1.06(\mathrm{~g} / \mathrm{mL})$ & 7.2 & 57700 & & $-0.2 \%$ \\
\hline D2.C385I & & 7.1 & & $58000(180 \mathrm{C}$ & \\
\hline
\end{tabular}

\begin{tabular}{|c|c|c|c|c|c|}
\hline Sample ID & $\begin{array}{c}\text { Alkalinity } \\
(\mathrm{mg} / \mathrm{L} \mathrm{CaCO})^{6} \\
\end{array}$ & $\begin{array}{l}\mathrm{HCO}_{3}^{-} \\
(\mathrm{mg} / \mathrm{L})^{6} \\
\end{array}$ & $\begin{array}{c}\mathrm{CO}_{\overline{3}} \\
(\mathrm{mg} / \mathrm{L})^{6} \\
\end{array}$ & $\begin{array}{c}\mathrm{Cl}^{-} \\
(\mathrm{mg} / \mathrm{L}) \\
\end{array}$ & $\begin{array}{c}\mathrm{SO} \overline{\overline{4}} \\
(\mathrm{mg} / \mathrm{L})\end{array}$ \\
\hline D2.C385F & 55 & 67 & 0 & 32000 & \\
\hline D2.C385B & 54 & 65 & 0 & 34600 & 3950 \\
\hline D2.C385E & & & & 32600 & 3470 \\
\hline D2.C385I & & & & & \\
\hline
\end{tabular}

\begin{tabular}{|c|c|c|c|c|c|}
\hline Sample ID & $\begin{array}{c}\mathrm{Na} \\
(\mathrm{mg} / \mathrm{L})\end{array}$ & $\underset{(\mathrm{mg} / \mathrm{L})}{\mathbf{K}}$ & $\begin{array}{c}\mathrm{Ca} \\
(\mathrm{mg} / \mathrm{L})\end{array}$ & $\begin{array}{c}\mathrm{Mg} \\
(\mathrm{mg} / \mathrm{L})\end{array}$ & $\underset{(\mathrm{meq} / \mathrm{L})^{7}}{\mathrm{x}^{++}}$ \\
\hline D2.C385F & & & & & 190 \\
\hline D2.C385B & 18400 & 410 & 1960 & 1060 & 185 \\
\hline D2.C385E & 17600 & 309 & 2740 & 962 & 216 \\
\hline D2.C385I & & & & & \\
\hline
\end{tabular}

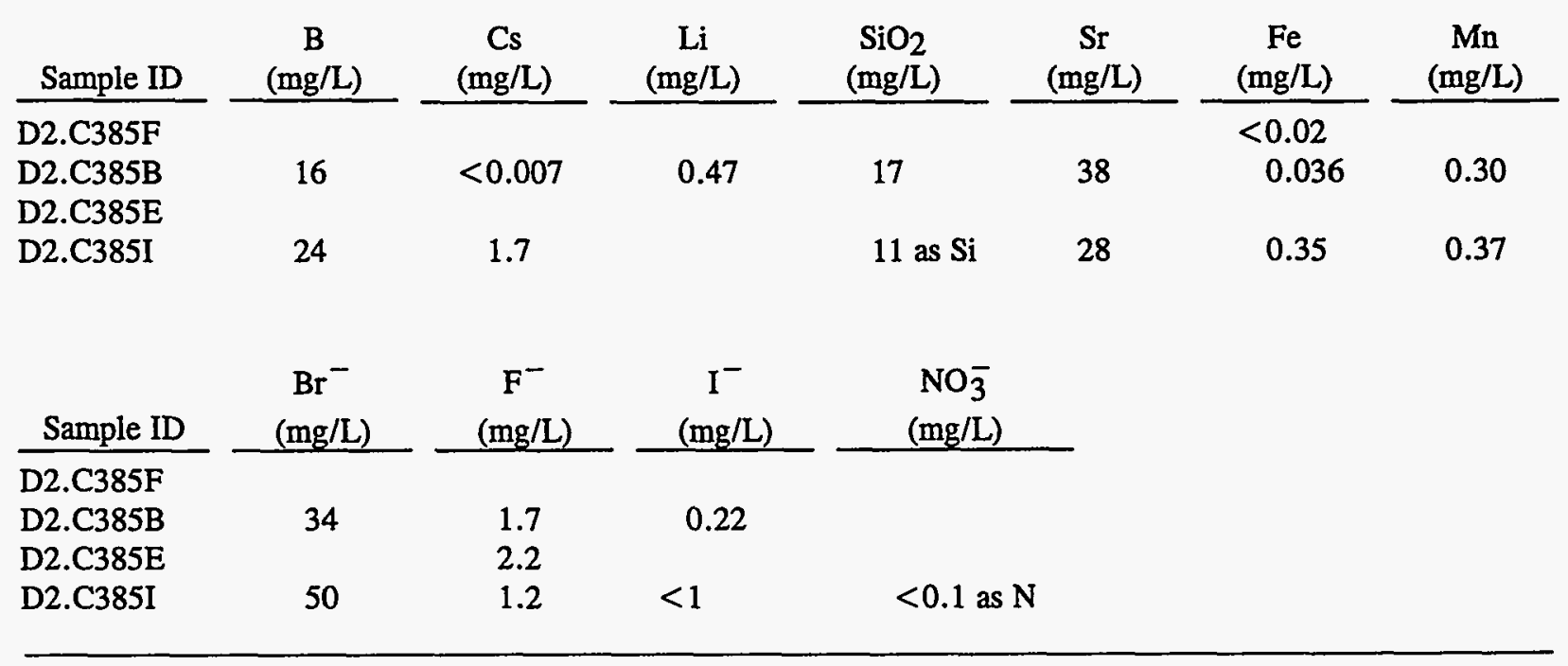


Table 73. Comparison of Data from the Culebra at FR-10

(Footnotes follow Table 135)

\begin{tabular}{|c|c|c|c|c|c|}
\hline Well 1 & Agency ${ }^{2}$ & Collection Date & Pumping Rate & $\mathrm{Lab}^{3}$ & Sample ID \\
\hline FR-10 & HGC & $10 / 06 / 83$ & pump pulse test & FLD & FR10.C1083F \\
\hline FR-10 & HGC & $10 / 06 / 83$ & pump pulse test & H-B & FR10.C1083HB \\
\hline FR-10 & HGC & $10 / 06 / 83$ & pump pulse test & KCS & FR10.C1083KC \\
\hline FR-10 & HGC & $10 / 06 / 83$ & pump pulse test & KGS & FR10.C1083K \\
\hline
\end{tabular}

\begin{tabular}{|c|c|c|c|c|c|}
\hline Sample ID & $\begin{array}{c}\text { Density/ } \\
\text { Specific Gravity } \\
\end{array}$ & $\mathrm{pH}$ & $\begin{array}{c}\text { TDS (calc) } \\
(\mathrm{mg} / \mathrm{L})^{5}\end{array}$ & $\begin{array}{c}\text { TDS (ROI) } \\
(\mathrm{mg} / \mathrm{L})\end{array}$ & $\begin{array}{c}\text { Charge-Balance } \\
\text { Error }^{5}\end{array}$ \\
\hline $\begin{array}{l}\text { FR10.C1083F } \\
\text { FR10.C1083HB } \\
\text { FR10.C1083KC } \\
\text { FR10.C1083K }\end{array}$ & $1.000(\mathrm{sg})$ & 7.4 & & & \\
\hline
\end{tabular}

\begin{tabular}{|c|c|c|c|c|c|}
\hline Sample ID & $\begin{array}{c}\text { Alkalinity } \\
\left(\mathrm{mg} / \mathrm{L} \mathrm{CaCO}_{3}\right)^{6}\end{array}$ & $\begin{array}{c}\mathrm{HCO}_{3}^{-} \\
(\mathrm{mg} / \mathrm{L})^{6}\end{array}$ & $\begin{array}{c}\mathrm{CO}_{3}^{\overline{3}} \\
(\mathrm{mg} / \mathrm{L})^{6} \\
\end{array}$ & $\begin{array}{c}\mathrm{Cl}^{-} \\
(\mathrm{mg} / \mathrm{L})\end{array}$ & $\begin{array}{c}\mathrm{SO} \overline{\overline{4}} \\
(\mathrm{mg} / \mathrm{L})\end{array}$ \\
\hline $\begin{array}{l}\text { FR10.C1083F } \\
\text { FR10.C1083HB }\end{array}$ & & $\sim 260$ & & & \\
\hline $\begin{array}{l}\text { FR10.C1083KC } \\
\text { FR10.C1083K }\end{array}$ & & & & 100 & \\
\hline
\end{tabular}

\begin{tabular}{|c|c|c|c|c|c|}
\hline Sample ID & $\begin{array}{c}\mathrm{Na} \\
(\mathrm{mg} / \mathrm{L})\end{array}$ & $\underset{(\mathrm{mg} / \mathrm{L})}{\mathrm{K}}$ & $\begin{array}{c}\mathrm{Ca} \\
(\mathrm{mg} / \mathrm{L})\end{array}$ & $\begin{array}{c}\mathrm{Mg} \\
(\mathrm{mg} / \mathrm{L})\end{array}$ & $\begin{array}{c}\mathrm{X}^{++} \\
(\mathrm{meq} / \mathrm{L})^{7}\end{array}$ \\
\hline FR10.C1083F & & & & & \\
\hline $\begin{array}{l}\text { FR10.C1083HB } \\
\text { FR10.C1083KC }\end{array}$ & 77 & 8.5 & 520 & 150 & 38.3 \\
\hline
\end{tabular}

\begin{tabular}{|c|c|c|c|c|c|c|c|}
\hline Sample ID & $\begin{array}{c}\mathrm{B} \\
(\mathrm{mg} / \mathrm{L}) \\
\end{array}$ & $\begin{array}{c}\mathrm{Cs} \\
(\mathrm{mg} / \mathrm{L})\end{array}$ & $\begin{array}{c}\mathrm{Li} \\
(\mathrm{mg} / \mathrm{L}) \\
\end{array}$ & $\begin{array}{c}\mathrm{SiO}_{2} \\
(\mathrm{mg} / \mathrm{L})\end{array}$ & $\begin{array}{c}\mathrm{Sr} \\
(\mathrm{mg} / \mathrm{L})\end{array}$ & $\begin{array}{c}\mathrm{Fe} \\
(\mathrm{mg} / \mathrm{L})\end{array}$ & $\begin{array}{c}\mathrm{Mn} \\
(\mathrm{mg} / \mathrm{L})\end{array}$ \\
\hline $\begin{array}{l}\text { FR10.C1083F } \\
\text { FR10.C1083HB }\end{array}$ & & & 0.51 & & & 0.06 & 0.04 \\
\hline $\begin{array}{l}\text { FR10.C1083KC } \\
\text { FR10.C1083K }\end{array}$ & & & & & & & \\
\hline
\end{tabular}

\begin{tabular}{|c|c|c|}
\hline Sample ID & $\begin{array}{c}\mathrm{Br}^{-} \\
(\mathrm{mg} / \mathrm{L})\end{array}$ & $\begin{array}{c}\mathrm{I}^{-} \\
(\mathrm{mg} / \mathrm{L})\end{array}$ \\
\hline $\begin{array}{l}\text { FR10.C1083F } \\
\text { FR10.C1083HB }\end{array}$ & & \\
\hline $\begin{array}{l}\text { FR10.C1083KC } \\
\text { FR10.C1083K }\end{array}$ & 0.21 & 0.009 \\
\hline
\end{tabular}


Table 74. Comparison of Data from the Culebra at $\mathrm{H}-1$ (Footnotes follow Table 135)

\begin{tabular}{|c|c|c|c|c|c|}
\hline Well $^{1}$ & Agency $^{2}$ & Collection Date & Pumping Rate & $\mathrm{Lab}^{3}$ & Sample ID \\
\hline $\mathrm{H}-1$ & USGS & $06 / 02 / 76$ & bail or swab & USGS & H01.C676G \\
\hline $\mathrm{H}-1$ & USGS & $03 / 17 / 77$ & bail or swab & USGS & H01.C377G \\
\hline
\end{tabular}

\begin{tabular}{|c|c|c|c|c|c|}
\hline Sample ID & $\begin{array}{c}\text { Density/ } \\
\text { Specific Gravity } 4\end{array}$ & $\mathrm{pH}$ & $\begin{array}{l}\text { TDS (calc) } \\
(\mathrm{mg} / \mathrm{L})^{5}\end{array}$ & $\begin{array}{l}\text { TDS (ROI) } \\
(\mathrm{mg} / \mathrm{L})\end{array}$ & $\begin{array}{l}\text { Charge-Balance } \\
\text { Error } 5\end{array}$ \\
\hline H01.Co & & 7.6 & 30200 & $30100(105 \mathrm{C})$ & $-2.0 \%$ \\
\hline H01.C377G & & 7.3 & 97300 & & $-0.7 \%$ \\
\hline
\end{tabular}

\begin{tabular}{|c|c|c|c|c|c|}
\hline Sample ID & $\begin{array}{c}\text { Alkalinity } \\
\left(\mathrm{mg} / \mathrm{L} \mathrm{CaCO}_{3}\right)^{6}\end{array}$ & $\begin{array}{c}\mathrm{HCO}_{3}^{-} \\
(\mathrm{mg} / \mathrm{L})^{6}\end{array}$ & $\begin{array}{c}\mathrm{CO}_{\overline{3}}^{\overline{3}} \\
(\mathrm{mg} / \mathrm{L})^{6}\end{array}$ & $\begin{array}{c}\mathrm{Cl}^{-} \\
(\mathrm{mg} / \mathrm{L})\end{array}$ & $\begin{array}{c}\mathrm{SO} \overline{\overline{4}} \\
(\mathrm{mg} / \mathrm{L})\end{array}$ \\
\hline 01 & 86 & 100 & 0 & 12000 & 7400 \\
\hline H01.C377G & 82 & 100 & 0 & 49000 & 11000 \\
\hline
\end{tabular}

\begin{tabular}{|c|c|c|c|c|c|}
\hline Sample ID & $\begin{array}{c}\mathrm{Na} \\
(\mathrm{mg} / \mathrm{L})\end{array}$ & $\underset{(\mathrm{mg} / \mathrm{L})}{\mathrm{K}}$ & $\begin{array}{c}\mathrm{Ca} \\
(\mathrm{mg} / \mathrm{L})\end{array}$ & $\underset{(\mathrm{mg} / \mathrm{L})}{\mathrm{Mg}}$ & $\underset{(\mathrm{meq} / \mathrm{L})^{7}}{\mathrm{x}^{++}}$ \\
\hline H01. & 9400 & 190 & 780 & 280 & 62 \\
\hline
\end{tabular}

\begin{tabular}{|c|c|c|c|c|c|c|c|}
\hline Sample ID & $\begin{array}{c}\text { B } \\
(\mathrm{mg} / \mathrm{L})\end{array}$ & $\begin{array}{c}\mathrm{Cs} \\
(\mathrm{mg} / \mathrm{L})\end{array}$ & $\begin{array}{c}\mathrm{Li} \\
(\mathrm{mg} / \mathrm{L})\end{array}$ & $\begin{array}{c}\mathrm{SiO}_{2} \\
(\mathrm{mg} / \mathrm{L})\end{array}$ & $\begin{array}{c}\mathrm{Sr} \\
(\mathrm{mg} / \mathrm{L})\end{array}$ & $\begin{array}{c}\mathrm{Fe} \\
(\mathrm{mg} / \mathrm{L})\end{array}$ & $\underset{(\mathrm{Mn} / \mathrm{L})}{\mathrm{Mn}}$ \\
\hline $\mathrm{H} 01 . \mathrm{C}$ & 2.4 & & & 2.7 & & & \\
\hline H01.C377G & 18 & & & .6 & & & \\
\hline
\end{tabular}

\begin{tabular}{|c|c|}
\hline Sample ID & $\underset{(\mathrm{mg} / \mathrm{L})}{\mathrm{F}^{-}}$ \\
\hline H01.C676G & 5.1 \\
\hline H01.C377G & 0.8 \\
\hline
\end{tabular}


Table 75. Comparison of Data from the Culebra at H-2

(Footnotes follow Table 135)

\begin{tabular}{|c|c|c|c|c|c|}
\hline Well $^{1}$ & Agency $^{2}$ & Collection Date & Pumping Rate & $\mathrm{Lab}^{3}$ & Sample ID \\
\hline $\mathrm{H}-2 \mathrm{~B} 1$ & USGS & $02 / 22 / 77$ & bail or swab & USGS & H02B1.C277G \\
\hline $\mathrm{H}-2 \mathrm{C}$ & USGS & $03 / 16 / 77$ & bail or swab & USGS & H02C.C377G \\
\hline $\mathrm{H}-2 \mathrm{C}$ & SNL & $12 / 10 / 80$ & recirc. & FLD & H02C.C1280F \\
\hline H-2A & WQSP-R1 & $04 / 04 / 86-04 / 21 / 86$ & $23 \mathrm{gph}$ & FLD & H02A.C486F \\
\hline H-2A & WQSP-R1 & $04 / 21 / 86$ & $23 \mathrm{gph}$ & BFEC & H02A.C486B \\
\hline $\mathrm{H}-2 \mathrm{~A}$ & WQSP-R1 & $04 / 21 / 86$ & $23 \mathrm{gph}$ & ITAS & H02A.C486I \\
\hline
\end{tabular}

\begin{tabular}{|c|c|c|c|c|c|}
\hline Sample ID & $\begin{array}{c}\text { Density/ } \\
\text { Specific Gravity } 4\end{array}$ & $\mathrm{pH}$ & $\begin{array}{l}\text { TDS (calc) } \\
(\mathrm{mg} / \mathrm{L})^{5}\end{array}$ & $\begin{array}{c}\text { TDS (ROI) } \\
(\mathrm{mg} / \mathrm{L})\end{array}$ & $\begin{array}{c}\text { Charge-Balance } \\
\text { Error } 5\end{array}$ \\
\hline H02B1.C277G & & 8.4 & 8900 & $9700(105 \mathrm{C})$ & $-0.5 \%$ \\
\hline H02C.C377G & & 8.2 & 12500 & & $0.8 \%$ \\
\hline H02C.C1280F & $1.002(\mathrm{sg})$ & 7.9 & & & \\
\hline H02A.C486F & $1.009(\mathrm{sg})$ & 8.0 & & & \\
\hline H02A.C486B & & & 12900 & & $-1.1 \%$ \\
\hline H02A.C486I & & 7.8 & 13200 & $13500(180 \mathrm{C})$ & $-2.6 \%$ \\
\hline
\end{tabular}

\begin{tabular}{|c|c|c|c|c|c|}
\hline Sample ID & $\begin{array}{c}\text { Alkalinity } \\
\left(\mathrm{mg} / \mathrm{L} \mathrm{CaCO}_{3}\right)^{6}\end{array}$ & $\begin{array}{l}\mathrm{HCO}_{3}^{-} \\
(\mathrm{mg} / \mathrm{L})^{6}\end{array}$ & $\begin{array}{c}\mathrm{CO} \overline{\overline{3}} \\
(\mathrm{mg} / \mathrm{L})^{6}\end{array}$ & $\underset{(\mathrm{mg} / \mathrm{L})}{\mathrm{Cl}^{-}}$ & $\begin{array}{c}\mathrm{SO}_{\overline{4}}^{\overline{4}} \\
(\mathrm{mg} / \mathrm{L})\end{array}$ \\
\hline H02B1.C277G & 57 & 59 & 5 & 2800 & 3000 \\
\hline H02C.C377G & 51 & 62 & 0 & 4700 & 3200 \\
\hline $\begin{array}{l}\text { H02C.C1280F } \\
\text { H02A.C486F }\end{array}$ & 47 & 57 & 0 & $(5200)$ & \\
\hline H02A.C486B & 44 & 54 & 0 & 5310 & 2980 \\
\hline H02A.C486I & 46 & 56 & 0 & 5300 & 3300 \\
\hline
\end{tabular}

\begin{tabular}{|c|c|c|c|c|c|}
\hline Sample ID & $\begin{array}{c}\mathrm{Na} \\
(\mathrm{mg} / \mathrm{L})\end{array}$ & $\begin{array}{c}\mathrm{K} \\
(\mathrm{mg} / \mathrm{L})\end{array}$ & $\begin{array}{c}\mathrm{Ca} \\
(\mathrm{mg} / \mathrm{L})\end{array}$ & $\underset{(\mathrm{mg} / \mathrm{L})}{\mathrm{Mg}}$ & $\begin{array}{c}\mathrm{X}^{++} \\
(\mathrm{meq} / \mathrm{L})^{7}\end{array}$ \\
\hline H02B1.C277G & 2100 & 91 & 690 & 160 & 48 \\
\hline $\begin{array}{l}\text { H02C.C } 377 \mathrm{G} \\
\text { H02C.C1280F }\end{array}$ & 3600 & 120 & 680 & 120 & 43.8 \\
\hline H02A.C486F & & & & & (53) \\
\hline H02A.C486B & 3570 & 93.5 & 743 & 167 & 50.8 \\
\hline H02A.C486I & 3600 & 97.5 & 705 & 170 & 49.2 \\
\hline
\end{tabular}


Table 75. Comparison of Data from the Culebra at H-2 (continued)

\begin{tabular}{|c|c|c|c|c|c|c|c|}
\hline Sample ID & $\begin{array}{c}\text { B } \\
(\mathrm{mg} / \mathrm{L})\end{array}$ & $\underset{(\mathrm{mg} / \mathrm{L})}{\mathrm{Cs}}$ & $\underset{(\mathrm{mg} / \mathrm{L})}{\mathrm{Li}}$ & $\begin{array}{c}\mathrm{SiO}_{2} \\
(\mathrm{mg} / \mathrm{L})\end{array}$ & $\begin{array}{c}\mathrm{Sr} \\
(\mathrm{mg} / \mathrm{L})\end{array}$ & $\begin{array}{c}\mathrm{Fe} \\
(\mathrm{mg} / \mathrm{L})\end{array}$ & $\begin{array}{c}\mathrm{Mn} \\
(\mathrm{mg} / \mathrm{L})\end{array}$ \\
\hline H02B1.C277G & 9.5 & & & 1.7 & & & \\
\hline H02C.C $377 \mathrm{G}$ & 10 & & & 3.5 & & & \\
\hline \multicolumn{8}{|l|}{ H02C.C1280F } \\
\hline H02A.C486F & & & & & & 1 & \\
\hline H02A.C486B & 10 & $<0.01$ & 0.22 & 13 & 9.5 & 1.1 & 0.055 \\
\hline H02A.C486I & 10 & $<0.1$ & & 13 as $\mathrm{Si}$ & 6.8 & 0.76 & 0.080 \\
\hline Sample ID & & $\begin{array}{c}\mathrm{Br}^{-} \\
(\mathrm{mg} / \mathrm{L})\end{array}$ & $\begin{array}{c}\mathrm{F}^{-} \\
(\mathrm{mg} / \mathrm{L})\end{array}$ & $\begin{array}{c}\mathrm{I}^{-} \\
(\mathrm{mg} / \mathrm{L})\end{array}$ & $\begin{array}{c}\mathrm{NO}_{3} \\
(\mathrm{mg} / \mathrm{L})\end{array}$ & & \\
\hline H02B1.C277G & & & 2.0 & & & & \\
\hline H02C.C377G & & & 1.6 & & & & \\
\hline \multicolumn{8}{|l|}{ H02C.C1280F } \\
\hline H02A.C486F & & & & & & & \\
\hline H02A.C486B & & 5.6 & 2.2 & 0.081 & & & \\
\hline H02A.C486I & & $<1$ & 14 & 1.0 & 0.30 as $\mathrm{N}$ & & \\
\hline
\end{tabular}


Table 76. Comparison of Data from the Culebra at H-3

(Footnotes follow Table 135)

\begin{tabular}{|c|c|c|c|c|c|}
\hline Well $^{1}$ & Agency $^{2}$ & Collection Date & Pumping Rate & $\mathrm{Lab}^{3}$ & Sample ID \\
\hline H-3B1 & USGS & $03 / 17 / 77$ & bail or swab & USGS & H03B1.C377G \\
\hline $\mathrm{H}-3 \mathrm{~B} 3$ & HGC & $06 / 10 / 84-06 / 11 / 84$ & $3 \mathrm{gpm}$ & FLD & H03B3.C684F \\
\hline H-3B3 & HGC & $06 / 11 / 84$ & $3 \mathrm{gpm}$ & BFEC & H03B3.C684B \\
\hline H-3B3 & HGC & $06 / 11 / 84$ & $3 \mathrm{gpm}$ & UA & H03B3.C684UA \\
\hline H-3B3 & WQSP-R1 & $01 / 29 / 85-02 / 04 / 85$ & $3 \mathrm{gpm}$ & FLD & H03B3.C285F \\
\hline H-3B3 & WQSP-R1 & $02 / 04 / 85$ & $3 \mathrm{gpm}$ & BFEC & H03B3.C285B \\
\hline $\mathrm{H}-3 \mathrm{~B} 3$ & WQSP-R1 & $02 / 04 / 85$ & $3 \mathrm{gpm}$ & EEG & H03B3.C285E \\
\hline $\mathrm{H}-3 \mathrm{~B} 3$ & WQSP-R1 & $02 / 04 / 85$ & $3 \mathrm{gpm}$ & ITAS & H03B3.C285I \\
\hline $\mathrm{H}-3 \mathrm{~B} 2$ & WQSP & $12 / 16 / 85$ & $4.8 \mathrm{gpm}$ & ITAS & H03B2.C1285I \\
\hline
\end{tabular}

\begin{tabular}{|c|c|c|c|c|c|}
\hline Sample ID & $\begin{array}{c}\text { Density/ } \\
\text { Specific Gravity } 4 \\
\end{array}$ & $\mathrm{pH}$ & $\begin{array}{c}\text { TDS (calc) } \\
(\mathrm{mg} / \mathrm{L})^{5}\end{array}$ & $\begin{array}{c}\text { TDS (ROI) } \\
(\mathrm{mg} / \mathrm{L})\end{array}$ & $\begin{array}{c}\text { Charge-Balance } \\
\text { Error } 5 \\
\end{array}$ \\
\hline H03B1.C377G & & 7.4 & 57200 & $62000(105 \mathrm{C})$ & $0.9 \%$ \\
\hline H03B3.C684F & $1.03(\mathrm{sg})$ & 7.4 & & & \\
\hline H03B3.C684B & & & 55000 & & $-1.4 \%$ \\
\hline H03B3.C684UA & & & & & \\
\hline H03B3.C285F & & 7.4 & & & \\
\hline H03B3.C285B & & & 55800 & & $-1.4 \%$ \\
\hline H03B3.C285E & $1.02(\mathrm{~g} / \mathrm{mL})$ & 7.1 & 55300 & & $0.2 \%$ \\
\hline H03B3.C285I & & 7.6 & - & $55000(180 \mathrm{C})$ & -- \\
\hline H03B2.C1285I & & 7.1 & 54900 & $54000(180 \mathrm{C})$ & $-1.7 \%$ \\
\hline
\end{tabular}

\begin{tabular}{|c|c|c|c|c|c|}
\hline Sample ID & $\begin{array}{c}\text { Alkalinity } \\
\left(\mathrm{mg} / \mathrm{L} \mathrm{CaCO}_{3}\right)^{6}\end{array}$ & $\begin{array}{l}\mathrm{HCO}_{3}^{-} \\
(\mathrm{mg} / \mathrm{L})^{6}\end{array}$ & $\begin{array}{c}\mathrm{CO}_{\overline{3}}^{\overline{3}} \\
(\mathrm{mg} / \mathrm{L})^{6} \\
\end{array}$ & $\begin{array}{c}\mathrm{Cl}^{-} \\
(\mathrm{mg} / \mathrm{L})\end{array}$ & $\begin{array}{c}\mathrm{SO} \overline{\overline{4}} \\
(\mathrm{mg} / \mathrm{L})\end{array}$ \\
\hline $\begin{array}{l}\text { H03B1.C377G } \\
\text { H03B3.C684F }\end{array}$ & 94 & 120 & 0 & 29600 & 5700 \\
\hline $\begin{array}{l}\text { H03B3.C684B } \\
\text { H03B3.C684UA }\end{array}$ & 43 & 53 & 0 & 29500 & 5130 \\
\hline H03B3.C285F & 43 & 52 & 0 & 28000 & \\
\hline $\begin{array}{l}\text { H03B3.C285B } \\
\text { H03B3.C285E }\end{array}$ & 40 & 49 & 0 & $\begin{array}{l}30300 \\
29500\end{array}$ & $\begin{array}{l}4820 \\
4900\end{array}$ \\
\hline H03B2.C1285I & 43 & 52 & 0 & 30000 & 4600 \\
\hline
\end{tabular}


Table 76. Comparison of Data from the Culebra at H-3 (continued)

\begin{tabular}{|c|c|c|c|c|c|}
\hline Sample ID & $\begin{array}{c}\mathrm{Na} \\
(\mathrm{mg} / \mathrm{L})\end{array}$ & $\begin{array}{c}\mathrm{K} \\
(\mathrm{mg} / \mathrm{L})\end{array}$ & $\underset{(\mathrm{mg} / \mathrm{L})}{\mathrm{Ca}}$ & $\underset{(\mathrm{mg} / \mathrm{L})}{\mathrm{Mg}}$ & $\underset{(\mathrm{meq} / \mathrm{L})^{7}}{\mathrm{X}^{++}}$ \\
\hline $\begin{array}{l}\text { H03B1.C377G } \\
\text { H03B3. C684F }\end{array}$ & 19000 & 630 & 1500 & 670 & 130 \\
\hline $\begin{array}{l}\text { H03B3.C684B } \\
\text { H03B3.C684UA }\end{array}$ & 17400 & 495 & 1550 & 829 & 145 \\
\hline H03B3.C285F & & & & & 170 \\
\hline H03B3.C285B & 18000 & 425 & 1470 & 783 & 138 \\
\hline $\begin{array}{l}\text { H03B3.C285E } \\
\text { H03B3.C285I }\end{array}$ & 18300 & 439 & 1410 & 719 & 129 \\
\hline H03B2.C1285I & 17000 & 480 & 2100 & 690 & 162 \\
\hline
\end{tabular}

\begin{tabular}{|c|c|c|c|c|c|c|c|}
\hline Sample ID & $\begin{array}{c}\mathrm{B} \\
(\mathrm{mg} / \mathrm{L})\end{array}$ & $\begin{array}{c}\mathrm{Cs} \\
(\mathrm{mg} / \mathrm{L})\end{array}$ & $\begin{array}{c}\mathrm{Li} \\
(\mathrm{mg} / \mathrm{L})\end{array}$ & $\begin{array}{c}\mathrm{SiO}_{2} \\
(\mathrm{mg} / \mathrm{L})\end{array}$ & $\begin{array}{c}\mathrm{Sr} \\
(\mathrm{mg} / \mathrm{L})\end{array}$ & $\begin{array}{c}\mathrm{Fe} \\
(\mathrm{mg} / \mathrm{L})\end{array}$ & $\begin{array}{c}\mathrm{Mn} \\
(\mathrm{mg} / \mathrm{L})\end{array}$ \\
\hline H03B1.C377G & 20 & & & 1.2 & & & \\
\hline $\begin{array}{l}\text { H03B3.C684F } \\
\text { H03B3.C684B } \\
\text { H03B3.C684UA }\end{array}$ & 30 & $<0.007$ & 0.53 & 9.8 & 23 & 0.57 & 0.13 \\
\hline H03B3.C285F & & & & & & 0.2 & \\
\hline $\begin{array}{l}\text { H03B3.C285B } \\
\text { H03B3. C285E }\end{array}$ & $\begin{array}{l}26 \\
0.30\end{array}$ & $<0.007$ & 0.40 & 11 & 30 & 0.20 & 0.12 \\
\hline $\begin{array}{l}\text { H03B3.C285I } \\
\text { H03B2.C1285I }\end{array}$ & 34 & 1.6 & & 8.8 as $\mathrm{Si}$ & 25 & 0.38 & 0.18 \\
\hline
\end{tabular}

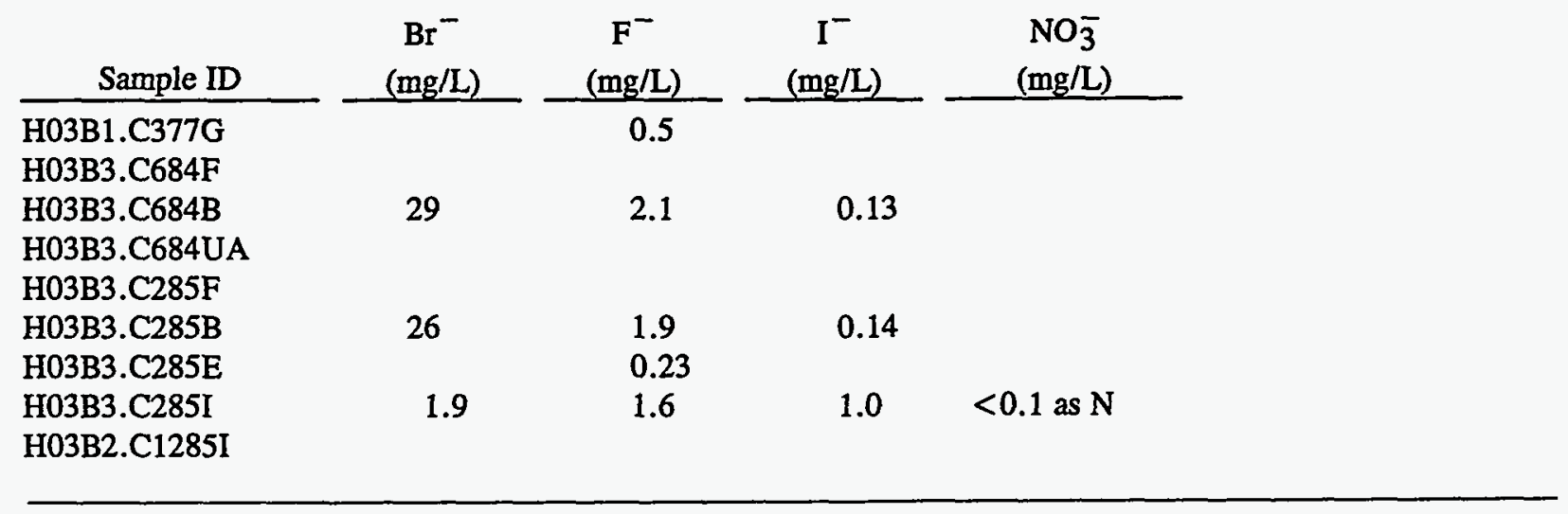


Table 77. Comparison of Data from the Culebra at $\mathrm{H}-4$

(Footnotes follow Table 135)

\begin{tabular}{|c|c|c|c|c|c|}
\hline Well ${ }^{1}$ & Agency $^{2}$ & Collection Date & Pumping Rate & $\mathrm{Lab}^{3}$ & Sample ID \\
\hline H-4B & USGS & $12 / 14 / 78$ & bail or swab & USGS & H04B.C1278G \\
\hline$H-4 B$ & SNL & $05 / 14 / 81-05 / 29 / 81$ & $.26 \mathrm{gpm}$ & FLD & H04B.C581F \\
\hline$H-4 B$ & SNL & $05 / 29 / 81$ & $.26 \mathrm{gpm}$ & BFEC & H04B.C581B \\
\hline $\mathrm{H}-4 \mathrm{C}$ & HGC & $08 / 09 / 84-08 / 10 / 84$ & $30 \mathrm{gph}$ & FLD & H04C.C884F \\
\hline $\mathrm{H}-4 \mathrm{C}$ & HGC & $08 / 10 / 84$ & $30 \mathrm{gph}$ & BFEC & H04C.C $884 B$ \\
\hline $\mathrm{H}-4 \mathrm{~B}$ & WQSP-R1 & $07 / 08 / 85-07 / 25 / 85$ & $20 \mathrm{gph}$ & FLD & H04B.C785F \\
\hline $\mathrm{H}-4 \mathrm{~B}$ & WQSP-R1 & $07 / 20 / 85$ & $20 \mathrm{gph}$ & BFEC & H04B.C785B \\
\hline $\mathrm{H}-4 \mathrm{~B}$ & WQSP-R1 & $07 / 25 / 85$ & $20 \mathrm{gph}$ & EEG & H04B.C785E \\
\hline $\mathrm{H}-4 \mathrm{~B}$ & WQSP-R1 & $07 / 20 / 85$ & $20 \mathrm{gph}$ & ITAS & H04B.C785I \\
\hline
\end{tabular}

\begin{tabular}{|c|c|c|c|c|c|}
\hline Sample ID & $\begin{array}{c}\text { Density/ } \\
\text { Specific Gravity } 4 \\
\end{array}$ & $\mathrm{pH}$ & $\begin{array}{l}\text { TDS (calc) } \\
(\mathrm{mg} / \mathrm{L})^{5}\end{array}$ & $\begin{array}{c}\text { TDS (ROI) } \\
(\mathrm{mg} / \mathrm{L})\end{array}$ & $\begin{array}{c}\text { Charge-Balance } \\
\text { Error }\end{array}$ \\
\hline H04B.C1278G & & 7.6 & 18100 & $18100(105 \mathrm{C})$ & $0.9 \%$ \\
\hline H04B.C581F & $1.01(\mathrm{sg})$ & 8.0 & & & \\
\hline H04B.C581B & & & 21700 & & $-1.9 \%$ \\
\hline H04C.C884F & $1.01(\mathrm{sg})$ & 7.8 & & & \\
\hline H04C.C884B & & & 21200 & & $1.0 \%$ \\
\hline H04B.C785F & 1.015 (sg) & 7.7 & & & \\
\hline H04B.C785B & & & 20200 & & $0.4 \%$ \\
\hline H04B.C785E & $1.034(\mathrm{~g} / \mathrm{mL})$ & 7.6 & 18700 & & $-0.9 \%$ \\
\hline H04B.C785I & & 7.6 & & $20000(180 \mathrm{C})$ & \\
\hline
\end{tabular}

\begin{tabular}{|c|c|c|c|c|c|}
\hline Sample ID & $\begin{array}{c}\text { Alkalinity } \\
\left(\mathrm{mg} / \mathrm{L} \mathrm{CaCO}_{3}\right)^{6}\end{array}$ & $\begin{array}{c}\mathrm{HCO}_{3}^{-} \\
(\mathrm{mg} / \mathrm{L})^{6} \\
\end{array}$ & $\begin{array}{c}\mathrm{CO}_{\overline{3}}^{\overline{3}} \\
(\mathrm{mg} / \mathrm{L})^{6}\end{array}$ & $\begin{array}{c}\mathrm{Cl}^{-} \\
(\mathrm{mg} / \mathrm{L})\end{array}$ & $\begin{array}{c}\mathrm{SO} \overline{\overline{4}} \\
(\mathrm{mg} / \mathrm{L})\end{array}$ \\
\hline H04B.C1278G & 48 & 59 & 0 & 7500 & 4000 \\
\hline H04B.C581F & 58 & 71 & & & -6000 \\
\hline H04B.C581B & & & & 7980 & 6230 \\
\hline H04C.C884F & 75 & & & & \\
\hline H04C.C884B & & & & 7950 & 5700 \\
\hline H04B.C785F & 57 & 69 & 0 & 7500 & \\
\hline H04B.C785B & 54 & 66 & 0 & 7480 & 5520 \\
\hline H04B.C785E & & & & 6670 & 5530 \\
\hline
\end{tabular}


Table 77. Comparison of Data from the Culebra at $\mathrm{H}-4$ (continued)

\begin{tabular}{|c|c|c|c|c|c|}
\hline Sample ID & $\begin{array}{c}\mathrm{Na} \\
(\mathrm{mg} / \mathrm{L})\end{array}$ & $\underset{(\mathrm{mg} / \mathrm{L})}{\mathrm{K}}$ & $\begin{array}{c}\mathrm{Ca} \\
(\mathrm{mg} / \mathrm{L})\end{array}$ & $\begin{array}{c}\mathrm{Mg} \\
(\mathrm{mg} / \mathrm{L})\end{array}$ & $\begin{array}{c}\mathrm{X}^{++} \\
(\mathrm{meq} / \mathrm{L})^{7}\end{array}$ \\
\hline $\begin{array}{l}\text { H04B.C1278G } \\
\text { H04B.C581F }\end{array}$ & 5800 & 180 & 180 & 430 & 44 \\
\hline $\begin{array}{l}\text { H04B.C581B } \\
\text { H04C.C884F }\end{array}$ & 6080 & 215 & 700 & 455 & 72.3 \\
\hline $\begin{array}{l}\text { H04C.C } 884 B \\
\text { H04B.C } 785 F\end{array}$ & 6150 & 222 & 698 & 505 & $\begin{array}{l}76.3 \\
71\end{array}$ \\
\hline H04B.C785B & 5850 & 210 & 691 & 427 & 69.6 \\
\hline $\begin{array}{l}\text { H04B.C785E } \\
\text { H04B.C785I }\end{array}$ & 5190 & 185 & 690 & 409 & 68.0 \\
\hline
\end{tabular}

\begin{tabular}{|c|c|c|c|c|c|c|c|}
\hline Sample ID & $\begin{array}{c}\mathrm{B} \\
(\mathrm{mg} / \mathrm{L})\end{array}$ & $\begin{array}{c}\mathrm{Cs} \\
(\mathrm{mg} / \mathrm{L})\end{array}$ & $\underset{(\mathrm{mg} / \mathrm{L})}{\mathrm{Li}}$ & $\begin{array}{c}\mathrm{SiO}_{2} \\
(\mathrm{mg} / \mathrm{L})\end{array}$ & $\begin{array}{c}\mathrm{Sr} \\
(\mathrm{mg} / \mathrm{L})\end{array}$ & $\begin{array}{c}\mathrm{Fe} \\
(\mathrm{mg} / \mathrm{L})\end{array}$ & $\underset{(\mathrm{mg} / \mathrm{L})}{\mathrm{Mn}}$ \\
\hline H04B.C1278G & 19 & & & 5.2 & & & \\
\hline $\begin{array}{l}\text { H04B.C581F } \\
\text { H04B.C581B } \\
\text { H04C C884F }\end{array}$ & 18 & & 0.39 & 11 & 14 & & \\
\hline $\begin{array}{l}\text { H04C.C884F } \\
\text { H04C.C884B } \\
\text { H04B.C785F }\end{array}$ & 20 & $<0.002$ & 0.49 & 13 & 18 & $\begin{array}{l}2.2 \\
1\end{array}$ & 0.20 \\
\hline $\begin{array}{l}\text { H04B.C785B } \\
\text { H04B.C785E }\end{array}$ & 14 & & $\begin{array}{l}0.40 \\
0.40\end{array}$ & 14 & 14 & 0.32 & 0.11 \\
\hline H04B.C785I & 23 & $<0.1$ & & 14 as $\mathrm{Si}$ & 15 & 0.43 & 0.12 \\
\hline
\end{tabular}

\begin{tabular}{|c|c|c|c|c|}
\hline Sample ID & $\begin{array}{c}\mathrm{Br}^{-} \\
(\mathrm{mg} / \mathrm{L}) \\
\end{array}$ & $\begin{array}{c}\mathrm{F}^{-} \\
(\mathrm{mg} / \mathrm{L})\end{array}$ & $\begin{array}{c}\mathrm{I}^{-} \\
(\mathrm{mg} / \mathrm{L})\end{array}$ & $\begin{array}{c}\mathrm{NO}_{3}^{\overline{3}} \\
(\mathrm{mg} / \mathrm{L}) \\
\end{array}$ \\
\hline H04B.C1278G & & 1.9 & & \\
\hline H04B.C581F & & & & \\
\hline H04B.C581B & 42 & & & \\
\hline H04C.C884F & & & & \\
\hline H04C.C884B & 48 & 2.1 & 0.23 & \\
\hline H04B.C785F & & & & \\
\hline H04B.C785B & 43 & & & \\
\hline H04B.C785E & & 2.7 & & \\
\hline H04B.C785I & 64 & 1.7 & 1.1 & $<0.1$ as $\mathrm{N}$ \\
\hline
\end{tabular}


Table 78. Comparison of Data from the Culebra at H-5

(Footnotes follow Table 135)

\begin{tabular}{|c|c|c|c|c|c|}
\hline Well ${ }^{1}$ & Agency $^{2}$ & Collection Date & Pumping Rate & $\mathrm{Lab}^{3}$ & Sample ID \\
\hline H-5B & USGS & $12 / 19 / 78$ & bail or swab & USGS & H05B.C1278G \\
\hline H-5B & SNL & $05 / 27 / 81-06 / 02 / 81$ & $12 \mathrm{gph}$ & FLD & H05B.C681F \\
\hline $\mathrm{H}-5 \mathrm{~B}$ & SNL & $06 / 01 / 81$ & $12 \mathrm{gph}$ & BFEC & H05B.C681B \\
\hline $\mathrm{H}-5 \mathrm{C}$ & SNL & $10 / 07 / 81-10 / 15 / 81$ & $7.5 \mathrm{gph}$ & FLD & H05C.C1081F \\
\hline $\mathrm{H}-5 \mathrm{C}$ & SNL & $10 / 15 / 81$ & $7.5 \mathrm{gph}$ & BFEC & H05C.C1081B \\
\hline H-5B & WQSP-R1 & $08 / 22 / 85-08 / 30 / 85$ & $8 \mathrm{gph}$ & FLD & H05B.C885F \\
\hline H-5B & WQSP-R1 & $08 / 26,27 / 85$ & $8 \mathrm{gph}$ & BFEC & H05B.C $885 B$ \\
\hline H-5B & WQSP-R1 & $08 / 26 / 85$ & $8 \mathrm{gph}$ & EEG & H05B.C885E \\
\hline H-5B & WQSP-R1 & $08 / 26 / 85$ & $8 \mathrm{gph}$ & ITAS & H05B.C885I \\
\hline
\end{tabular}

\begin{tabular}{|c|c|c|c|c|c|}
\hline Sample ID & $\begin{array}{c}\text { Density/ } \\
\text { Specific Gravity } 4\end{array}$ & $\mathrm{pH}$ & $\begin{array}{l}\text { TDS (calc) } \\
(\mathrm{mg} / \mathrm{L})^{5}\end{array}$ & $\begin{array}{c}\text { TDS (ROI) } \\
(\mathrm{mg} / \mathrm{L})\end{array}$ & $\begin{array}{c}\text { Charge-Balance } \\
\text { Error } 5\end{array}$ \\
\hline H05B.C1278G & & 6.8 & 143500 & $144000(105 \mathrm{C})$ & $1.5 \%$ \\
\hline H05B.C681F & $1.10(\mathrm{sg})$ & 7.9 & & & \\
\hline H05B.C681B & & & 154400 & & $-2.1 \%$ \\
\hline H05C.C1081F & $1.10(\mathrm{sg})$ & 7.9 & & & \\
\hline H05C.C1081B & & & 154500 & & $-2.2 \%$ \\
\hline H05B.C885F & $1.105(\mathrm{sg})$ & 7.4 & & & \\
\hline H05B.C885B & & & 152600 & & $1.5 \%$ \\
\hline H05B.C885E & $1.12(\mathrm{~g} / \mathrm{mL})$ & 6.8 & 143500 & & $1.3 \%$ \\
\hline H05B.C885I & & 7.0 & 144600 & $142000(180 \mathrm{C})$ & $-6.3 \%$ \\
\hline
\end{tabular}

\begin{tabular}{|c|c|c|c|c|c|}
\hline Sample ID & $\begin{array}{c}\text { Alkalinity } \\
\left(\mathrm{mg} / \mathrm{L} \mathrm{CaCO}_{3}\right)^{6} \\
\end{array}$ & $\begin{array}{c}\mathrm{HCO}_{3}^{-} \\
(\mathrm{mg} / \mathrm{L})^{6} \\
\end{array}$ & $\begin{array}{c}\mathrm{CO}_{\overline{3}}^{\overline{3}} \\
(\mathrm{mg} / \mathrm{L})^{6} \\
\end{array}$ & $\begin{array}{c}\mathrm{Cl}^{-} \\
(\mathrm{mg} / \mathrm{L})\end{array}$ & $\begin{array}{c}\mathrm{SO} \overline{4} \\
(\mathrm{mg} / \mathrm{L})\end{array}$ \\
\hline H05B.C1278G & 34 & 41 & 0 & 86000 & 810 \\
\hline H05B.C681F & 66 & 80 & & & -8000 \\
\hline H05B.C681B & & & & 89500 & 7360 \\
\hline H05C.C1081F & 70 & 86 & & & \\
\hline H05C.C1081B & & & & 89500 & 7570 \\
\hline H05B.C885F & 41 & 50 & 0 & 84000 & \\
\hline H05B.C885B & 34 & 41 & 0 & 85400 & 7840 \\
\hline H05B.C885E & & & & 81000 & 6730 \\
\hline H05B.C885I & 39 & 47 & 0 & 87000 & 6300 \\
\hline
\end{tabular}


Table 78. Comparison of Data from the Culebra at H-5 (continued)

\begin{tabular}{|c|c|c|c|c|c|}
\hline Sample ID & $\begin{array}{c}\mathrm{Na} \\
(\mathrm{mg} / \mathrm{L})\end{array}$ & $\underset{(\mathrm{mg} / \mathrm{L})}{\mathrm{K}}$ & $\begin{array}{c}\mathrm{Ca} \\
(\mathrm{mg} / \mathrm{L})\end{array}$ & $\underset{(\mathrm{mg} / \mathrm{L})}{\mathrm{Mg}}$ & $\begin{array}{c}\mathrm{x}^{++} \\
(\mathrm{meq} / \mathrm{L})^{7}\end{array}$ \\
\hline $\begin{array}{l}\text { H05B.C1278G } \\
\text { H05B.C } 681 F\end{array}$ & 53000 & 1400 & 360 & 1900 & 174 \\
\hline $\begin{array}{l}\text { H05B.C681B } \\
\text { H05C.C1081F }\end{array}$ & 52400 & 1290 & 1710 & 2140 & 261 \\
\hline $\begin{array}{l}\text { H05C.C1081B } \\
\text { H05B.C } 885 F\end{array}$ & 52300 & 1300 & 1720 & 2150 & $\begin{array}{l}262 \\
260\end{array}$ \\
\hline H05B.C885B & 54100 & 1350 & 1700 & 2170 & 263 \\
\hline H05B.C885E & 51300 & 1110 & 1460 & 1910 & 230 \\
\hline H05B.C885I & 47000 & 1300 & 1300 & 1700 & 204 \\
\hline
\end{tabular}

\begin{tabular}{|c|c|c|c|c|c|c|c|}
\hline Sample ID & $\begin{array}{c}\mathrm{B} \\
(\mathrm{mg} / \mathrm{L})\end{array}$ & $\begin{array}{c}\mathrm{Cs} \\
(\mathrm{mg} / \mathrm{L})\end{array}$ & $\begin{array}{c}\mathrm{Li} \\
(\mathrm{mg} / \mathrm{L})\end{array}$ & $\begin{array}{c}\mathrm{SiO}_{2} \\
(\mathrm{mg} / \mathrm{L})\end{array}$ & $\begin{array}{c}\mathrm{Sr} \\
(\mathrm{mg} / \mathrm{L})\end{array}$ & $\begin{array}{c}\mathrm{Fe} \\
(\mathrm{mg} / \mathrm{L})\end{array}$ & $\begin{array}{c}\mathrm{Mn} \\
(\mathrm{mg} / \mathrm{L}) \\
\end{array}$ \\
\hline $\begin{array}{l}\text { H05B.C1278G } \\
\text { H05B.C681F }\end{array}$ & 36 & & & 2.1 & & & \\
\hline $\begin{array}{l}\text { H05B.C681B } \\
\text { H05C.C1081F }\end{array}$ & 33 & & 0.77 & 6.2 & 32 & & \\
\hline H05C.C1081B & 35 & & 0.77 & 5.8 & 31 & & \\
\hline H05B.C885F F & & & & & & 3 & \\
\hline $\begin{array}{l}\text { H05B.C885B } \\
\text { H05B.C885E }\end{array}$ & 34 & $<0.01$ & $\begin{aligned} & 0.81 \\
< & 0.5\end{aligned}$ & 7.1 & 29 & 2.9 & 0.29 \\
\hline H05B.C885I & 29 & $<1.0$ & & 17 as $\mathrm{Si}$ & 16 & 3.0 & 0.52 \\
\hline
\end{tabular}

\begin{tabular}{|c|c|c|c|c|}
\hline Sample ID & $\begin{array}{c}\mathrm{Br}^{-} \\
(\mathrm{mg} / \mathrm{L})\end{array}$ & $\begin{array}{c}\mathrm{F}^{-} \\
(\mathrm{mg} / \mathrm{L})\end{array}$ & $\begin{array}{c}\mathrm{I}^{-} \\
(\mathrm{mg} / \mathrm{L})\end{array}$ & $\begin{array}{c}\mathrm{NO}_{3}^{-} \\
(\mathrm{mg} / \mathrm{L})\end{array}$ \\
\hline H05B.C1278G & & 1.4 & & \\
\hline H05B.C681F & & & & \\
\hline H05B.C681B & 62 & & & \\
\hline H05C.C1081F & & & & \\
\hline H05C.C1081B & 64 & & & \\
\hline H05B.C885F & & & & \\
\hline H05B.C885B & 49 & 2.0 & 0.19 & \\
\hline H05B.C885E & & 1.2 & & \\
\hline H05B.C885I & 94 & 1.3 & 1.1 & 0.40 as $\mathrm{N}$ \\
\hline
\end{tabular}


Table 79. Comparison of Data from the Culebra at H-6

(Footnotes follow Table 135)

\begin{tabular}{|c|c|c|c|c|c|}
\hline Well $^{1}$ & Agency 2 & Collection Date & Pumping Rate & $\mathrm{Lab}^{3}$ & Sample ID \\
\hline$H-6 B$ & USGS & $12 / 20 / 78$ & bail or swab & USGS & H06B.C1278G \\
\hline H-6B & SNL & $05 / 01 / 81-05 / 02 / 81$ & $23 \mathrm{gpm}$ & FLD & H06B.C581F \\
\hline $\mathrm{H}-6 \mathrm{C}$ & SNL & $05 / 12 / 81-05 / 27 / 81$ & $19 \mathrm{gpm}$ & FLD & H06C.C581F \\
\hline H-6B & SNL & $05 / 02 / 81$ & $23 \mathrm{gpm}$ & BFEC & H06B.C581B \\
\hline$H-6 B$ & WQSP-R1 & $09 / 04 / 85-09 / 16 / 85$ & $6 \mathrm{gpm}$ & FLD & H06B.C985F \\
\hline$H-6 B$ & WQSP-R1 & $09 / 15 / 85$ & $6 \mathrm{gpm}$ & BFEC & H06B.C985B \\
\hline$H-6 B$ & WQSP-R1 & $09 / 15 / 85$ & $6 \mathrm{gpm}$ & EEG & H06B.C985E \\
\hline H-6B & WQSP-R1 & $09 / 15 / 85$ & $6 \mathrm{gpm}$ & ITAS & H06B.C985I \\
\hline
\end{tabular}

\begin{tabular}{|c|c|c|c|c|c|}
\hline Sample ID & $\begin{array}{c}\text { Density/ } \\
\text { Specific Gravity } \\
\end{array}$ & $\mathrm{pH}$ & $\begin{array}{l}\text { TDS (calc) } \\
(\mathrm{mg} / \mathrm{L})^{5}\end{array}$ & $\begin{array}{c}\text { TDS (ROI) } \\
(\mathrm{mg} / \mathrm{L})\end{array}$ & $\begin{array}{c}\text { Charge-Balance } \\
\text { Error } 5\end{array}$ \\
\hline H06B.C1278G & & 7.3 & 52500 & $52600(105 \mathrm{C})$ & $3.7 \%$ \\
\hline H06B.C581F & $1.04(\mathrm{sg})$ & 7.0 & & & \\
\hline H06C.C581F & $1.04(\mathrm{sg})$ & 7.2 & & & \\
\hline H06B.C581B & & & 59300 & & $0.2 \%$ \\
\hline H06B.C985F & $1.042(\mathrm{sg})$ & 6.9 & & & \\
\hline H06B.C985B & & & 57400 & & $-0.5 \%$ \\
\hline H06B.C985E & $1.06(\mathrm{~g} / \mathrm{mL})$ & 7.1 & 56900 & & $-0.6 \%$ \\
\hline H06B.C985I & & 7.2 & 55200 & $58000(180 \mathrm{C})$ & $-11 \%$ \\
\hline
\end{tabular}

\begin{tabular}{|c|c|c|c|c|c|}
\hline Sample ID & $\begin{array}{c}\text { Alkalinity } \\
(\mathrm{mg} / \mathrm{L} \mathrm{CaCO})^{6}\end{array}$ & $\begin{array}{c}\mathrm{HCO}_{\overline{3}}^{-} \\
(\mathrm{mg} / \mathrm{L})^{6}\end{array}$ & $\begin{array}{c}\mathrm{CO}_{\overline{3}}^{\overline{3}} \\
(\mathrm{mg} / \mathrm{L})^{6}\end{array}$ & $\begin{array}{c}\mathrm{Cl}^{-} \\
(\mathrm{mg} / \mathrm{L})\end{array}$ & $\begin{array}{c}\mathrm{SO} \overline{\overline{4}} \\
(\mathrm{mg} / \mathrm{L})\end{array}$ \\
\hline H06B.C1278G & 85 & 100 & 0 & 28000 & 3800 \\
\hline H06B.C581F & 79 & 96 & & & -4000 \\
\hline H06C.C581F & 77 & 94 & & & -4000 \\
\hline H06B.C581B & & & & 33000 & 3980 \\
\hline H06B.C985F & 77 & 94 & 0 & 32000 & \\
\hline H06B.C985B & 69 & 84 & 0 & 32300 & 3570 \\
\hline H06B.C985E & & & & 32300 & 3390 \\
\hline H06B.C985I & 82 & 100 & 0 & 34000 & 3000 \\
\hline
\end{tabular}

\begin{tabular}{|c|c|c|c|c|c|}
\hline Sample ID & $\begin{array}{c}\mathrm{Na} \\
(\mathrm{mg} / \mathrm{L})\end{array}$ & $\begin{array}{c}\mathrm{K} \\
(\mathrm{mg} / \mathrm{L})\end{array}$ & $\begin{array}{c}\mathrm{Ca} \\
(\mathrm{mg} / \mathrm{L})\end{array}$ & $\begin{array}{c}\mathrm{Mg} \\
(\mathrm{mg} / \mathrm{L})\end{array}$ & $\begin{array}{c}\mathrm{X}^{++} \\
(\mathrm{meq} / \mathrm{L})^{7}\end{array}$ \\
\hline $\begin{array}{l}\text { H06B.C1278G } \\
\text { H06B.C581F }\end{array}$ & 18000 & 500 & 1200 & 970 & 140 \\
\hline $\begin{array}{l}\text { H06C.C581F } \\
\text { H06B.C581B } \\
\text { H06B.C985F }\end{array}$ & 18600 & 450 & 2150 & 1080 & $\begin{array}{l}196 \\
190\end{array}$ \\
\hline $\begin{array}{l}\text { H06B.C985F } \\
\text { H06B.C985B }\end{array}$ & 18000 & 375 & 2040 & 1040 & 187 \\
\hline H06B.C985E & 17700 & 430 & 1970 & 1130 & 191 \\
\hline H06B.C985I & 15000 & 485 & 1900 & 740 & 156 \\
\hline
\end{tabular}


Table 79: Comparison of Data from the Culebra at H-6 (continued)

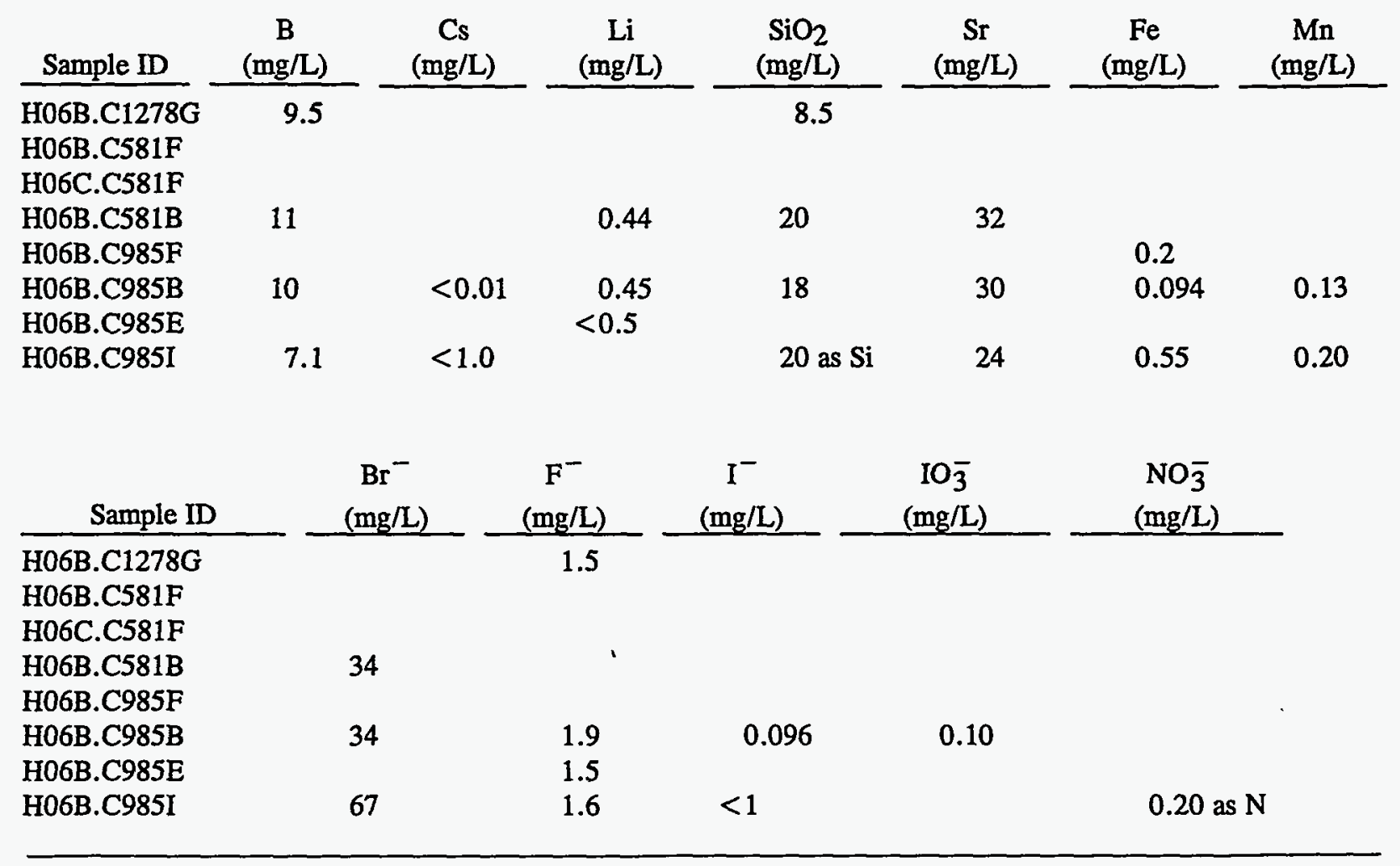


Table 80. Comparison of Data from the Culebra at H-7

(Footnotes follow Table 135)

\begin{tabular}{|c|c|c|c|c|c|}
\hline Well $^{1}$ & Agency 2 & Collection Date & Pumping Rate & $\mathrm{Lab}^{3}$ & Sample ID \\
\hline H-7B1 & USGS & $03 / 20 / 80$ & bail or swab & USGS & H07B1.C380G \\
\hline H-7B1 & WQSP-R1 & $03 / 20 / 86-03 / 27 / 86$ & 4 gpm & FLD & H07B1.C386F \\
\hline H-7B1 & WQSP-R1 & $03 / 26 / 86$ & $4 \mathrm{gpm}$ & BFEC & H07B1.C386B \\
\hline H-7B1 & WQSP-R1 & $03 / 27 / 86$ & $4 \mathrm{gpm}$ & ITAS & H07B1.C386I \\
\hline
\end{tabular}

\begin{tabular}{|c|c|c|c|c|c|}
\hline Sample ID & $\begin{array}{c}\text { Density/ } \\
\text { Specific Gravity } 4\end{array}$ & $\mathrm{pH}$ & $\begin{array}{c}\text { TDS (calc) } \\
(\mathrm{mg} / \mathrm{L})^{5}\end{array}$ & $\begin{array}{l}\text { TDS (ROI) } \\
(\mathrm{mg} / \mathrm{L})\end{array}$ & $\begin{array}{c}\text { Charge-Balance } \\
\text { Error }\end{array}$ \\
\hline H07B1.C380G & $1.001(\mathrm{~g} / \mathrm{mL})$ & 7.0 & 3180 & $3610(105 \mathrm{C})$ & $-0.2 \%$ \\
\hline H07B1.C386F & $1.001(\mathrm{sg})$ & 7.3 & & & \\
\hline H07B1.C386B & & & 3220 & & $-0.4 \%$ \\
\hline H07B1.C386I & & 7.5 & 4020 & $3400(180 \mathrm{C})$ & $-20 \%$ \\
\hline
\end{tabular}

\begin{tabular}{|c|c|c|c|c|c|}
\hline Sample ID & $\begin{array}{c}\text { Alkalinity } \\
(\mathrm{mg} / \mathrm{L} \mathrm{CaCO})^{6} \\
\end{array}$ & $\begin{array}{c}\mathrm{HCO}^{-} \\
(\mathrm{mg} / \mathrm{L})^{6} \\
\end{array}$ & $\begin{array}{c}\mathrm{CO}_{\overline{3}} \\
(\mathrm{mg} / \mathrm{L})^{6} \\
\end{array}$ & $\begin{array}{c}\mathrm{Cl}^{-} \\
(\mathrm{mg} / \mathrm{L}) \\
\end{array}$ & $\begin{array}{c}\mathrm{SO} \overline{\overline{4}} \\
(\mathrm{mg} / \mathrm{L})\end{array}$ \\
\hline H07B1.C380G & 100 & 120 & 0 & 350 & 1900 \\
\hline H07B1.C386F & 98 & 120 & 0 & 310 & \\
\hline H07B1.C386B & 98 & 120 & 0 & 320 & 1850 \\
\hline H07B1.C386I & 110 & 130 & 0 & 700 & 2300 \\
\hline
\end{tabular}

\begin{tabular}{|c|c|c|c|c|c|}
\hline Sample ID & $\begin{array}{c}\mathrm{Na} \\
(\mathrm{mg} / \mathrm{L})\end{array}$ & $\begin{array}{c}\mathrm{K} \\
(\mathrm{mg} / \mathrm{L})\end{array}$ & $\begin{array}{c}\mathrm{Ca} \\
(\mathrm{mg} / \mathrm{L})\end{array}$ & $\begin{array}{c}\mathrm{Mg} \\
(\mathrm{mg} / \mathrm{L})\end{array}$ & $\begin{array}{c}\mathrm{x}^{++} \\
(\mathrm{meq} / \mathrm{L})^{7}\end{array}$ \\
\hline H07B1.C380G & 210 & 1.4 & 590 & 130 & 40 \\
\hline H07B1.C386F & & & & & 46 \\
\hline H07B1.С386B & 207 & 7.00 & 587 & 130 & 40.0 \\
\hline H07B1.C386I & 210 & 7.00 & 540 & 130 & 37.7 \\
\hline
\end{tabular}

\begin{tabular}{|c|c|c|c|c|c|c|c|}
\hline Sample ID & $\begin{array}{c}\text { B } \\
(\mathrm{mg} / \mathrm{L})\end{array}$ & $\underset{(\mathrm{mg} / \mathrm{L})}{\mathrm{Cs}}$ & $\underset{(\mathrm{mg} / \mathrm{L})}{\mathrm{Li}}$ & $\begin{array}{c}\mathrm{SiO}_{2} \\
(\mathrm{mg} / \mathrm{L})\end{array}$ & $\underset{(\mathrm{mg} / \mathrm{L})}{\mathrm{Sr}}$ & $\begin{array}{c}\mathrm{Fe} \\
(\mathrm{mg} / \mathrm{L})\end{array}$ & $\underset{(\mathrm{mg} / \mathrm{L})}{\mathrm{Mn}}$ \\
\hline H07B1.C380G & 0.78 & & & 39 & & & \\
\hline H07B1.C386F & & & & & & 0.1 & \\
\hline H07B1.C386B & 0.76 & $<0.01$ & 0.10 & 47 & 8.5 & 0.056 & 0.050 \\
\hline H07B1.C3861 & 0.74 & $<0.1$ & & 43 as $\mathrm{Si}$ & 5.8 & 0.08 & 0.050 \\
\hline
\end{tabular}

\begin{tabular}{|c|c|c|c|c|}
\hline Sample ID & $\begin{array}{c}\mathrm{Br}^{-} \\
(\mathrm{mg} / \mathrm{L}) \\
\end{array}$ & $\begin{array}{c}F^{-} \\
(\mathrm{mg} / \mathrm{L})\end{array}$ & $\begin{array}{c}\mathrm{I}^{-} \\
(\mathrm{mg} / \mathrm{L})\end{array}$ & $\begin{array}{c}\mathrm{NO}_{3}^{-} \\
(\mathrm{mg} / \mathrm{L}) \\
\end{array}$ \\
\hline H07B1.C380G & & 1.4 & & \\
\hline H07B1.C386F & & & & \\
\hline H07B1.C386B & 0.57 & 1.5 & 0.052 & \\
\hline H07B1.C386I & 1.0 & 1.2 & $<1$ & 0.70 as $\mathrm{N}$ \\
\hline
\end{tabular}


Table 81. Comparison of Data from the Culebra at H-8

(Footnotes follow Table 135)

\begin{tabular}{|c|c|c|c|c|c|}
\hline Well 1 & Agency $^{2}$ & Collection Date & Pumping Rate & $\mathrm{Lab}^{3}$ & Sample ID \\
\hline H-8B & USGS & $02 / 11 / 80$ & bail or swab & USGS & H08B.C280G \\
\hline H-8B & WQSP-R1 & $01 / 09 / 86-01 / 23 / 86$ & $40 \mathrm{gph}$ & FLD & H08B.C186F \\
\hline $\mathrm{H}-8 \mathrm{~B}$ & WQSP-R1 & $01 / 22 / 86$ & $40 \mathrm{gph}$ & BFEC & H08B.C186B \\
\hline H-8B & WQSP-R1 & $01 / 22 / 86$ & $40 \mathrm{gph}$ & EEG & H08B.C186E \\
\hline $\mathrm{H}-8 \mathrm{~B}$ & WQSP-R1 & $01 / 21-23 / 86$ & $40 \mathrm{gph}$ & ITAS & H08B.C186I \\
\hline
\end{tabular}

\begin{tabular}{|c|c|c|c|c|c|}
\hline Sample ID & $\begin{array}{c}\text { Density/ } \\
\text { Specific Gravity } 4\end{array}$ & $\mathrm{pH}$ & $\begin{array}{c}\text { TDS (calc) } \\
(\mathrm{mg} / \mathrm{L})^{5}\end{array}$ & $\begin{array}{c}\text { TDS (ROI) } \\
(\mathrm{mg} / \mathrm{L})\end{array}$ & $\begin{array}{c}\text { Charge-Balance } \\
\text { Error }^{5} \\
\end{array}$ \\
\hline H08B.C280G & $1.000(\mathrm{~g} / \mathrm{mL})$ & 7.3 & 2880 & $3200(105 \mathrm{C})$ & $3.2 \%$ \\
\hline H08B.C186F & $1.002(\mathrm{sg})$ & 7.3 & & & \\
\hline H08B.C186B & & & 2830 & & $-0.3 \%$ \\
\hline H08B.C186E & $1.01(\mathrm{~g} / \mathrm{mL})$ & 7.2 & 2670 & & $1.5 \%$ \\
\hline H08B.C186I & & 7.9 & 2540 & $3150(180 \mathrm{C})$ & $8.0 \%$ \\
\hline
\end{tabular}

\begin{tabular}{|c|c|c|c|c|c|}
\hline Sample ID & $\begin{array}{c}\text { Alkalinity } \\
(\mathrm{mg} / \mathrm{L} \mathrm{CaCO})^{6} \\
\end{array}$ & $\begin{array}{c}\mathrm{HCO}_{3}^{-} \\
(\mathrm{mg} / \mathrm{L})^{6}\end{array}$ & $\begin{array}{c}\mathrm{CO}_{\overline{3}} \\
(\mathrm{mg} / \mathrm{L})^{6} \\
\end{array}$ & $\begin{array}{c}\mathrm{Cl}^{-} \\
(\mathrm{mg} / \mathrm{L})\end{array}$ & $\begin{array}{c}\mathrm{SO} 4 \\
(\mathrm{mg} / \mathrm{L})\end{array}$ \\
\hline H08B.C280G & 61 & 74 & 0 & 57 & 2000 \\
\hline H08B.C186F & 79 & 96 & 0 & 33 & \\
\hline H08B.C186B & 74 & 90 & 0 & 30.5 & 1950 \\
\hline H08B.C186E & & & & 30 & 1900 \\
\hline H08B.C186I & 77 & 94 & 0 & 33.0 & 1650 \\
\hline
\end{tabular}

\begin{tabular}{|c|c|c|c|c|c|}
\hline Sample ID & $\begin{array}{c}\mathrm{Na} \\
(\mathrm{mg} / \mathrm{L})\end{array}$ & $\begin{array}{c}\mathrm{K} \\
(\mathrm{mg} / \mathrm{L})\end{array}$ & $\begin{array}{c}\mathrm{Ca} \\
(\mathrm{mg} / \mathrm{L})\end{array}$ & $\begin{array}{c}\mathrm{Mg} \\
(\mathrm{mg} / \mathrm{L})\end{array}$ & $\begin{array}{c}\mathrm{X}^{++} \\
(\mathrm{meq} / \mathrm{L})^{7}\end{array}$ \\
\hline H08B.C280G & 82 & 4.7 & 570 & 170 & 42 \\
\hline H08B.C186F & & & & & 42 \\
\hline H08B.C186B & 55.1 & 3.83 & 548 & 157 & 40.3 \\
\hline H08B.C186E & 55 & 4.6 & 520 & 160 & 39.1 \\
\hline H08B.C186I & 51.0 & 3.70 & 540 & 170 & 40.9 \\
\hline
\end{tabular}

\begin{tabular}{|c|c|c|c|c|c|c|c|}
\hline Sample ID & $\begin{array}{c}\text { B } \\
(\mathrm{mg} / \mathrm{L}) \\
\end{array}$ & $\begin{array}{c}\mathrm{Cs} \\
(\mathrm{mg} / \mathrm{L})\end{array}$ & $\begin{array}{c}\mathrm{Li} \\
(\mathrm{mg} / \mathrm{L})\end{array}$ & $\begin{array}{c}\mathrm{SiO}_{2} \\
(\mathrm{mg} / \mathrm{L})\end{array}$ & $\begin{array}{c}\mathrm{Sr} \\
(\mathrm{mg} / \mathrm{L})\end{array}$ & $\begin{array}{c}\mathrm{Fe} \\
(\mathrm{mg} / \mathrm{L})\end{array}$ & $\begin{array}{c}\mathrm{Mn} \\
(\mathrm{mg} / \mathrm{L})\end{array}$ \\
\hline H08B.C280G & 0.58 & & & 19 & & & \\
\hline H08B.C186F & & & & & & 0.09 & \\
\hline H08B.C186B & 0.48 & $<0.01$ & 0.12 & 29 & 6.9 & 0.036 & 0.021 \\
\hline H08B.C186E & & & $<0.5$ & & & & \\
\hline H08B.C186I & 0.06 & $<1$ & & 26 as $\mathrm{Si}$ & 5.9 & 0.05 & $<0.1$ \\
\hline
\end{tabular}


Table 81. Comparison of Data from the Culebra at H-8 (continued)

\begin{tabular}{|c|c|c|c|c|}
\hline Sample ID & $\begin{array}{c}\mathrm{Br}^{-} \\
(\mathrm{mg} / \mathrm{L})\end{array}$ & $\begin{array}{c}F^{-} \\
(\mathrm{mg} / \mathrm{L})\end{array}$ & $\begin{array}{c}\mathrm{I}^{-} \\
(\mathrm{mg} / \mathrm{L})\end{array}$ & $\begin{array}{c}\mathrm{NO}_{3}^{\overline{3}} \\
(\mathrm{mg} / \mathrm{L}) \\
\end{array}$ \\
\hline $\begin{array}{l}\text { H08B.C280G } \\
\text { H08B.C186F }\end{array}$ & & 2.4 & & \\
\hline H08B.C186B & 0.085 & 2.5 & 0.14 & \\
\hline H08B.C186E & & 2.1 & & \\
\hline H08B.C186I & $<1$ & 2.4 & $<1$ & 1.4 as $\mathrm{N}$ \\
\hline
\end{tabular}


Table 82. Comparison of Data from the Culebra at H-9 (Footnotes follow Table 135)

\begin{tabular}{|c|c|c|c|c|c|}
\hline Well $^{1}$ & Agency ${ }^{2}$ & Collection Date & Pumping Rate & $\mathrm{Lab}^{3}$ & Sample ID \\
\hline H-9B & USGS & $02 / 05 / 80$ & bail or swab & USGS & H09B.C280G \\
\hline $\mathrm{H}-9 \mathrm{~B}$ & HGC & $10 / 07 / 83$ & 10 gpm & FLD & H09B.C1083F \\
\hline $\mathrm{H}-9 \mathrm{~B}$ & HGC & $10 / 07 / 83$ & $10 \mathrm{gpm}$ & H-B & H09B.C1083HB \\
\hline H-9B & HGC & $10 / 07 / 83$ & $10 \mathrm{gpm}$ & KCS & H09B.C1083KC \\
\hline H-9B & HGC & $10 / 07 / 83$ & $10 \mathrm{gpm}$ & KGS & H09B.C1083K \\
\hline$H-9 B$ & WQSP-R1 & $10 / 30 / 85-11 / 14 / 85$ & $38 \mathrm{gph}$ & FLD & H09B.C1185F \\
\hline H-9B & WQSP-R1 & $11 / 14 / 85$ & $38 \mathrm{gph}$ & BFEC & H09B.C1185B \\
\hline H-9B & WQSP-R1 & $11 / 14 / 85$ & $38 \mathrm{gph}$ & EEG & H09B.C1185E \\
\hline H-9B & WQSP-R1 & $11 / 14 / 85$ & $38 \mathrm{gph}$ & ITAS & H09B.C1185I \\
\hline
\end{tabular}

\begin{tabular}{|c|c|c|c|c|c|}
\hline Sample ID & $\begin{array}{c}\text { Density/ } \\
\text { Specific Gravity } 4 \\
\end{array}$ & $\mathrm{pH}$ & $\begin{array}{l}\text { TDS (calc) } \\
(\mathrm{mg} / \mathrm{L})^{5}\end{array}$ & $\begin{array}{c}\text { TDS (ROI) } \\
(\mathrm{mg} / \mathrm{L})\end{array}$ & $\begin{array}{c}\text { Charge-Balance } \\
\text { Error } 5 \\
\end{array}$ \\
\hline H09B.C280G & na & 7.3 & 4660 & $3590(105 \mathrm{C})$ & $26 \%$ \\
\hline H09B.C1083F & $1.000(\mathrm{sg})$ & 7.9 & & & \\
\hline H09B.C1083HB & & & 2290 & & $-5.4 \%$ \\
\hline $\begin{array}{l}\text { H09B.C1083KC } \\
\text { H09B.C1083K }\end{array}$ & & & & & \\
\hline H09B.C $1185 F$ & $1.002(\mathrm{sg})$ & 7.4 & & & \\
\hline H09B.C1185B & & & 3080 & & $0.5 \%$ \\
\hline H09B.C1185E & $1.019(\mathrm{~g} / \mathrm{mL})$ & 6.9 & 2960 & & $2.1 \%$ \\
\hline H09В.C1185I & & 7.7 & 2630 & $3300(180 \mathrm{C})$ & $10 \%$ \\
\hline
\end{tabular}

\begin{tabular}{|c|c|c|c|c|c|}
\hline Sample ID & $\begin{array}{c}\text { Alkalinity } \\
\left(\mathrm{mg} / \mathrm{L} \mathrm{CaCO}_{3}\right)^{6}\end{array}$ & $\begin{array}{c}\mathrm{HCO}_{\overline{3}} \\
(\mathrm{mg} / \mathrm{L})^{6}\end{array}$ & $\begin{array}{c}\mathrm{CO}_{\overline{3}}^{\overline{3}} \\
(\mathrm{mg} / \mathrm{L})^{6}\end{array}$ & $\begin{array}{c}\mathrm{Cl}^{-} \\
(\mathrm{mg} / \mathrm{L}) \\
\end{array}$ & $\begin{array}{c}\mathrm{SO} \overline{\overline{4}} \\
(\mathrm{mg} / \mathrm{L})\end{array}$ \\
\hline H09B.C280G & 90 & 110 & 0 & 320 & 2000 \\
\hline H09B.C1083F & & -240 & & & \\
\hline H09B.C1083HB & & & & 180 & 1500 \\
\hline H09B.C1083KC & & & & 255 & \\
\hline H09B.C1083K & & & & 206 & \\
\hline H09B.C1185F & 90 & 110 & 0 & 190 & \\
\hline H09B.C1185B & 87 & 110 & 0 & 194 & 1900 \\
\hline H09B.C1185E & & & & 195 & 1900 \\
\hline H09B.C1185I & 98 & 120 & 0 & 200 & 1450 \\
\hline
\end{tabular}


Table 82. Comparison of Data from the Culebra at H-9 (continued)

\begin{tabular}{|c|c|c|c|c|c|}
\hline Sample ID & $\begin{array}{c}\mathrm{Na} \\
(\mathrm{mg} / \mathrm{L})\end{array}$ & $\begin{array}{c}\mathrm{K} \\
(\mathrm{mg} / \mathrm{L})\end{array}$ & $\begin{array}{c}\mathrm{Ca} \\
(\mathrm{mg} / \mathrm{L})\end{array}$ & $\begin{array}{c}\mathrm{Mg} \\
(\mathrm{mg} / \mathrm{L})\end{array}$ & $\begin{array}{c}\mathrm{X}^{++} \\
(\mathrm{meq} / \mathrm{L})^{7}\end{array}$ \\
\hline $\begin{array}{l}\text { H09B.C280G } \\
\text { H09B.C1083F }\end{array}$ & 210 & 1400 & 580 & 150 & 41 \\
\hline $\begin{array}{l}\text { H09B.C1083HB } \\
\text { H09B.C1083KC } \\
\text { H09B.C1083K }\end{array}$ & 110 & 5.0 & 400 & 94 & 27.7 \\
\hline H09B.C1185F & & & & & 41 \\
\hline H09B.C1185B & 146 & 6.85 & 590 & 137 & 40.7 \\
\hline H09B.C1185E & 150 & 7.4 & 560 & 150 & 40.3 \\
\hline H09B.C1185I & 150 & 7.55 & 560 & 140 & 39.5 \\
\hline
\end{tabular}

\begin{tabular}{|c|c|c|c|c|c|c|c|}
\hline Sample ID & $\begin{array}{c}\text { B } \\
(\mathrm{mg} / \mathrm{L})\end{array}$ & $\begin{array}{c}\mathrm{Cs} \\
(\mathrm{mg} / \mathrm{L})\end{array}$ & $\begin{array}{c}\mathrm{Li} \\
(\mathrm{mg} / \mathrm{L})\end{array}$ & $\begin{array}{c}\mathrm{SiO}_{2} \\
(\mathrm{mg} / \mathrm{L})\end{array}$ & $\begin{array}{c}\mathrm{Sr} \\
(\mathrm{mg} / \mathrm{L})\end{array}$ & $\underset{(\mathrm{mg} / \mathrm{L})}{\mathrm{Fe}}$ & $\underset{(\mathrm{mg} / \mathrm{L})}{\mathrm{Mn}}$ \\
\hline $\begin{array}{l}\text { H09B.C280G } \\
\text { H09B.C1083F }\end{array}$ & 0.78 & & & 26 & & & \\
\hline $\begin{array}{l}\text { H09B.C1083HB } \\
\text { H09B.C1083KC } \\
\text { H09B.C1083K }\end{array}$ & & & 0.13 & $13 \mathrm{Si}$ & & 0.08 & $<0.02$ \\
\hline H09B.C1185F & & & & & & 0.1 & \\
\hline $\begin{array}{l}\text { H09B.C1185B } \\
\text { H09B.C1185E }\end{array}$ & 0.63 & $<0.01$ & $\begin{array}{l}0.18 \\
<0.5\end{array}$ & 27 & 7.5 & 0.032 & 0.015 \\
\hline H09B.C1185I & $<0.1$ & 0.2 & & 18 as $\mathrm{Si}$ & 7.0 & $<0.1$ & 0.060 \\
\hline
\end{tabular}

\begin{tabular}{|c|c|c|c|c|}
\hline Sample ID & $\begin{array}{c}\mathrm{Br}^{-} \\
(\mathrm{mg} / \mathrm{L})\end{array}$ & $\begin{array}{c}\mathrm{F}^{-} \\
(\mathrm{mg} / \mathrm{L})\end{array}$ & $\begin{array}{c}\mathrm{I}^{-} \\
(\mathrm{mg} / \mathrm{L})\end{array}$ & $\begin{array}{c}\mathrm{NO}_{3}^{-} \\
(\mathrm{mg} / \mathrm{L})\end{array}$ \\
\hline H09B.C280G & & 3.0 & & \\
\hline H09B.C1083F & & & & \\
\hline H09B.C1083HB & & & $<1$ & \\
\hline H09B.C1083KC & & & & \\
\hline H09B.C1083K & 0.43 & & 0.109 & \\
\hline H09B.C1185F & & & & \\
\hline H09B.C1185B & 0.24 & 3.3 & 0.11 & \\
\hline H09B.C1185E & & 2.8 & & \\
\hline H09B.C1185I & 1.0 & 2.6 & $<1$ & 0.20 as $\mathrm{N}$ \\
\hline
\end{tabular}


Table 83. Comparison of Data from the Culebra at H-10

(Footnotes follow Table 135)

$\frac{\text { Well }^{1}}{\text { H-10B }} \frac{\text { Agency }^{2}}{\text { USGS }} \frac{\text { Collection Date }}{03 / 21 / 80} \frac{\text { Pumping Rate }}{\text { bail or swab }} \frac{\text { Lab }^{3}}{\text { USGS }} \frac{\text { Sample ID }}{\text { H10B.C380G }}$

Sample ID
H10B.C380G $\frac{\begin{array}{c}\text { Density/ } \\ \text { Specific Gravity }\end{array}}{1.045(\mathrm{~g} / \mathrm{mL})} \frac{\mathrm{pH}}{8.3} \frac{\begin{array}{c}\text { TDS (calc) } \\ (\mathrm{mg} / \mathrm{L})^{5}\end{array}}{65700} \frac{\begin{array}{c}\text { TDS (ROI) } \\ (\mathrm{mg} / \mathrm{L})\end{array}}{69200(105 \mathrm{C})} \frac{\begin{array}{c}\text { Charge-Balance } \\ \text { Error }^{5}\end{array}}{-2.0 \%}$

$\frac{\text { Sample ID }}{\text { H10B.C380G }} \frac{\begin{array}{c}\text { Alkalinity } \\ (\mathrm{mg} / \mathrm{L} \mathrm{CaCO})^{6}\end{array}}{37} \frac{\begin{array}{c}\mathrm{HCO}_{3}^{-} \\ (\mathrm{mg} / \mathrm{L})^{6}\end{array}}{45} \frac{\begin{array}{c}\mathrm{CO}_{\overline{3}}^{\overline{3}} \\ (\mathrm{mg} / \mathrm{L})^{6}\end{array}}{0} \frac{\begin{array}{c}\mathrm{Cl}^{-} \\ (\mathrm{mg} / \mathrm{L})\end{array}}{36000} \frac{\begin{array}{c}\mathrm{SO}_{\overline{4}} \\ (\mathrm{mg} / \mathrm{L})\end{array}}{5600}$

$\frac{\text { Sample ID }}{\text { H10B.C380G }} \frac{\begin{array}{c}\mathrm{Na} \\ (\mathrm{mg} / \mathrm{L})\end{array}}{21000} \frac{\begin{array}{c}\mathrm{K} \\ (\mathrm{mg} / \mathrm{L})\end{array}}{520} \frac{\begin{array}{c}\mathrm{Ca} \\ (\mathrm{mg} / \mathrm{L})\end{array}}{1600} \frac{\begin{array}{c}\mathrm{Mg} \\ (\mathrm{mg} / \mathrm{L})\end{array}}{1000} \frac{\begin{array}{c}\mathrm{X}^{++} \\ (\mathrm{meq} / \mathrm{L})\end{array}}{162}$

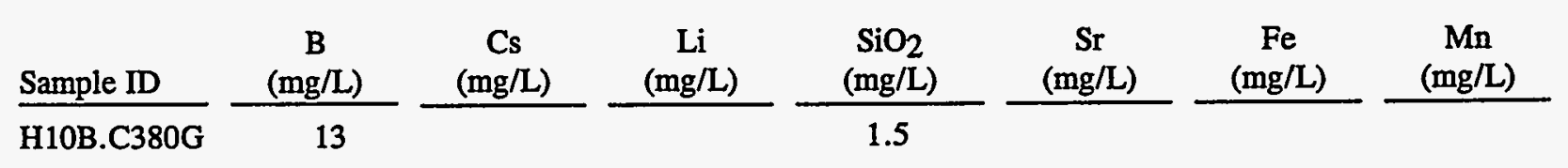

$\frac{\text { Sample ID }}{\text { H10B.C380G }} \frac{\begin{array}{c}\mathrm{Br}^{-} \\ (\mathrm{mg} / \mathrm{L})\end{array}}{\frac{\mathrm{F}^{-}}{(\mathrm{mg} / \mathrm{L})}}$


Table 84. Comparison of Data from the Culebra at H-11

(Footnotes follow Table 135)

\begin{tabular}{|c|c|c|c|c|c|}
\hline Well ${ }^{1}$ & Agency $^{2}$ & Collection Date & Pumping Rate & $\mathrm{Lab}^{3}$ & Sample ID \\
\hline H-11B3 & WQSP-R1 & $05 / 13 / 85-06 / 04 / 85$ & $6 \mathrm{gpm}$ & FLD & H11B3.C685F \\
\hline H-11B3 & WQSP-R1 & $06 / 03,04 / 85$ & $6 \mathrm{gpm}$ & BFEC & H11B3.C685B \\
\hline H-11B3 & WQSP-R1 & $06 / 03,04 / 85$ & $6 \mathrm{gpm}$ & EEG & H11B3.C685E \\
\hline H-11B3 & WQSP-R1 & $06 / 03 / 85$ & $6 \mathrm{gpm}$ & ITAS & H11B3.C685I \\
\hline
\end{tabular}

\begin{tabular}{|c|c|c|c|c|c|}
\hline Sample ID & $\begin{array}{c}\text { Density/ } \\
\text { Specific Gravity } 4 \\
\end{array}$ & $\mathrm{pH}$ & $\begin{array}{l}\text { TDS (calc) } \\
(\mathrm{mg} / \mathrm{L})^{5}\end{array}$ & $\begin{array}{c}\text { TDS (ROI) } \\
(\mathrm{mg} / \mathrm{L})\end{array}$ & $\begin{array}{c}\text { Charge-Balance } \\
\text { Error } 5\end{array}$ \\
\hline H11B3.C685F & $1.090(\mathrm{sg})$ & 7.2 & & & \\
\hline H11B3.C685B & & & 117400 & & $-0.9 \%$ \\
\hline H11B3.C685E & $1.10(\mathrm{~g} / \mathrm{mL})$ & 7.3 & 109500 & & $-0.7 \%$ \\
\hline H11B3.C685I & & 7.2 & & $122000(180 \mathrm{C}$ & \\
\hline
\end{tabular}

\begin{tabular}{|c|c|c|c|c|c|}
\hline Sample ID & $\begin{array}{c}\text { Alkalinity } \\
\left(\mathrm{mg} / \mathrm{L} \mathrm{CaCO}_{3}\right)^{6}\end{array}$ & $\begin{array}{l}\mathrm{HCO}_{3}^{-} \\
(\mathrm{mg} / \mathrm{L})^{6}\end{array}$ & $\begin{array}{c}\mathrm{CO}_{3}^{\overline{3}} \\
(\mathrm{mg} / \mathrm{L})^{6}\end{array}$ & $\begin{array}{c}\mathrm{Cl}^{-} \\
(\mathrm{mg} / \mathrm{L})\end{array}$ & $\begin{array}{c}\mathrm{SO} \overline{\overline{4}} \\
(\mathrm{mg} / \mathrm{L})\end{array}$ \\
\hline $\begin{array}{l}\text { H11B3.C685F } \\
\text { H11B3.C685B } \\
\text { H11B3.C685E }\end{array}$ & 44 & 54 & 0 & $\begin{array}{l}67000 \\
65900 \\
62000\end{array}$ & $\begin{array}{l}7180 \\
6040\end{array}$ \\
\hline
\end{tabular}

\begin{tabular}{|c|c|c|c|c|c|}
\hline Sample ID & $\begin{array}{c}\mathrm{Na} \\
(\mathrm{mg} / \mathrm{L})\end{array}$ & $\underset{(\mathrm{mg} / \mathrm{L})}{\mathrm{K}}$ & $\begin{array}{c}\mathrm{Ca} \\
(\mathrm{mg} / \mathrm{L})\end{array}$ & $\underset{(\mathrm{mg} / \mathrm{L})}{\mathrm{Mg}}$ & $\underset{(\mathrm{meq} / \mathrm{L})^{7}}{\mathrm{x}^{++}}$ \\
\hline H11B3.C685F & & & & & 190 \\
\hline H11B3.C685B & 40400 & 943 & 1700 & 1320 & 193 \\
\hline H11B3.C685E & 37800 & 680 & 1580 & 1360 & 190 \\
\hline
\end{tabular}

H11B3.C685I

\begin{tabular}{|c|c|c|c|c|c|c|c|}
\hline Sample ID & $\begin{array}{c}\text { B } \\
(\mathrm{mg} / \mathrm{L})\end{array}$ & $\underset{(\mathrm{mg} / \mathrm{L})}{\mathrm{Cs}}$ & $\underset{(\mathrm{mg} / \mathrm{L})}{\mathrm{Li}}$ & $\begin{array}{c}\mathrm{SiO}_{2} \\
(\mathrm{mg} / \mathrm{L})\end{array}$ & $\underset{(\mathrm{mg} / \mathrm{L})}{\mathrm{Sr}}$ & $\underset{(\mathrm{mg} / \mathrm{L})}{\mathrm{Fe}}$ & $\underset{(\mathrm{mg} / \mathrm{L})}{\mathrm{Mn}}$ \\
\hline H11B3.C685F & & & & & & 0.2 & \\
\hline H11B3.C685B & 32 & & 0.62 & & 25 & 0.14 & 0.22 \\
\hline H11B3.C685E & & & 0.38 & & & & \\
\hline H11B3.C685I & 13 & 0.29 & & 15 as $S$ & 18 & 0.66 & 0.39 \\
\hline
\end{tabular}

\begin{tabular}{|c|c|c|c|c|}
\hline Sample ID & $\begin{array}{c}\mathrm{Br}^{-} \\
(\mathrm{mg} / \mathrm{L})\end{array}$ & $\begin{array}{c}F^{-} \\
(\mathrm{mg} / \mathrm{L})\end{array}$ & $\begin{array}{c}\mathrm{I}^{-} \\
(\mathrm{mg} / \mathrm{L})\end{array}$ & $\begin{array}{c}\mathrm{NO}_{\overline{3}}^{-} \\
(\mathrm{mg} / \mathrm{L})\end{array}$ \\
\hline H11B3.C685F & & & & \\
\hline H11B3.C685B & 47 & & & \\
\hline H11B3.C685E & & 1.6 & & \\
\hline H11B3.C685I & 100 & 1.0 & 1.1 & $<0.1$ as $\mathrm{N}$ \\
\hline
\end{tabular}


Table 85. Comparison of Data from the Culebra at H-12

(Footnotes follow Table 135)

\begin{tabular}{|c|c|c|c|c|c|}
\hline Well 1 & Agency $^{2}$ & Collection Date & Pumping Rate & $\mathrm{Lab}^{3}$ & Sample ID \\
\hline $\mathrm{H}-12$ & HGC & $01 / 07 / 84-01 / 12 / 84$ & $8.4 \mathrm{gph}$ & FLD & H12.C184F \\
\hline $\mathrm{H}-12$ & HGC & $01 / 11 / 84$ & $8.4 \mathrm{gph}$ & H-B & $\mathrm{H} 12 . \mathrm{C} 184 \mathrm{HBa}$ \\
\hline $\mathrm{H}-12$ & HGC & $01 / 11 / 84$ & $8.4 \mathrm{gph}$ & KGS & $\mathrm{H} 12 . \mathrm{C} 184 \mathrm{Ka}$ \\
\hline $\mathrm{H}-12$ & HGC & $01 / 25 / 84$ & $13.5 \mathrm{gph}$ & H-B & $\mathrm{H} 12 . \mathrm{C} 184 \mathrm{HBb}$ \\
\hline $\mathrm{H}-12$ & HGC & $01 / 25 / 84$ & $13.5 \mathrm{gph}$ & KGS & $\mathrm{H} 12 . \mathrm{C} 184 \mathrm{~Kb}$ \\
\hline $\mathrm{H}-12$ & WQSP-R1 & 08/01/85 - 08/09/85 & $17 \mathrm{gph}$ & FLD & H12.C885F \\
\hline $\mathrm{H}-12$ & WQSP-R1 & $08 / 08 / 85$ & 17 gph & BFEC & H12.C885B \\
\hline $\mathrm{H}-12$ & WQSP-R1 & $08 / 09 / 85$ & $17 \mathrm{gph}$ & EEG & H12.C885E \\
\hline H-12 & WQSP-R1 & $08 / 09 / 85$ & $17 \mathrm{gph}$ & ITAS & H12.C885I \\
\hline
\end{tabular}

\begin{tabular}{|c|c|c|c|c|c|}
\hline Sample ID & $\begin{array}{c}\text { Density/ } \\
\text { Specific Gravity } 4\end{array}$ & $\mathrm{pH}$ & $\begin{array}{c}\text { TDS (calc) } \\
(\mathrm{mg} / \mathrm{L})^{5}\end{array}$ & $\begin{array}{l}\text { TDS (ROI) } \\
(\mathrm{mg} / \mathrm{L})\end{array}$ & $\begin{array}{c}\text { Charge-Balance } \\
\text { Error } 5\end{array}$ \\
\hline H12.C184F & $1.090(\mathrm{sg})$ & 7.9 & & & \\
\hline $\mathrm{H} 12 . \mathrm{C} 184 \mathrm{HBa}$ & & & 143700 & & $-1.3 \%$ \\
\hline H12.C184Ka & & & & & \\
\hline $\mathrm{H} 12 . \mathrm{C} 184 \mathrm{HBb}$ & & & 149100 & & $-0.8 \%$ \\
\hline $\mathrm{H} 12 . \mathrm{C} 184 \mathrm{~Kb}$ & & & & & \\
\hline H12.C885F & $1.096(\mathrm{sg})$ & 7.2 & & & \\
\hline H12.C885B & & & 140500 & & $0.9 \%$ \\
\hline H12.C885E & $1.12(\mathrm{~g} / \mathrm{mL})$ & 7.0 & 122400 & & $-4.2 \%$ \\
\hline H12.C885I & & 7.3 & 135200 & $142000(180 \mathrm{C})$ & $-4.4 \%$ \\
\hline
\end{tabular}

\begin{tabular}{|c|c|c|c|c|c|}
\hline Sample ID & $\begin{array}{c}\text { Alkalinity } \\
(\mathrm{mg} / \mathrm{L} \mathrm{CaCO})^{6} \\
\end{array}$ & $\begin{array}{l}\mathrm{HCO}_{3}^{-} \\
(\mathrm{mg} / \mathrm{L})^{6}\end{array}$ & $\begin{array}{c}\mathrm{CO} \overline{\overline{3}} \\
(\mathrm{mg} / \mathrm{L})^{6}\end{array}$ & $\begin{array}{c}\mathrm{Cl}^{-} \\
(\mathrm{mg} / \mathrm{L})\end{array}$ & $\begin{array}{c}\mathrm{SO} \overline{\overline{4}} \\
(\mathrm{mg} / \mathrm{L})\end{array}$ \\
\hline \multicolumn{6}{|l|}{ H12.C184F } \\
\hline $\mathrm{H} 12 . \mathrm{C} 184 \mathrm{HBa}$ & 85000 & 4000 & & & \\
\hline $\mathrm{H} 12 . \mathrm{C} 184 \mathrm{Ka}$ & na & 86500 & & & \\
\hline $\mathrm{H} 12 . \mathrm{C} 184 \mathrm{HBb}$ & 84000 & 8400 & & & \\
\hline $\mathrm{H} 12 . \mathrm{C} 184 \mathrm{~Kb}$ & na & 80100 & & & \\
\hline H12.C885F & 43 & 53 & 0 & 80000 & \\
\hline H12.C885B & 40 & 49 & 0 & 79000 & 7210 \\
\hline H12.C885E & 71700 & 6520 & & & \\
\hline H12.C885I & 46 & 56 & 0 & 80000 & 5900 \\
\hline
\end{tabular}


Table 85. Comparison of Data from the Culebra at H-12 (continued)

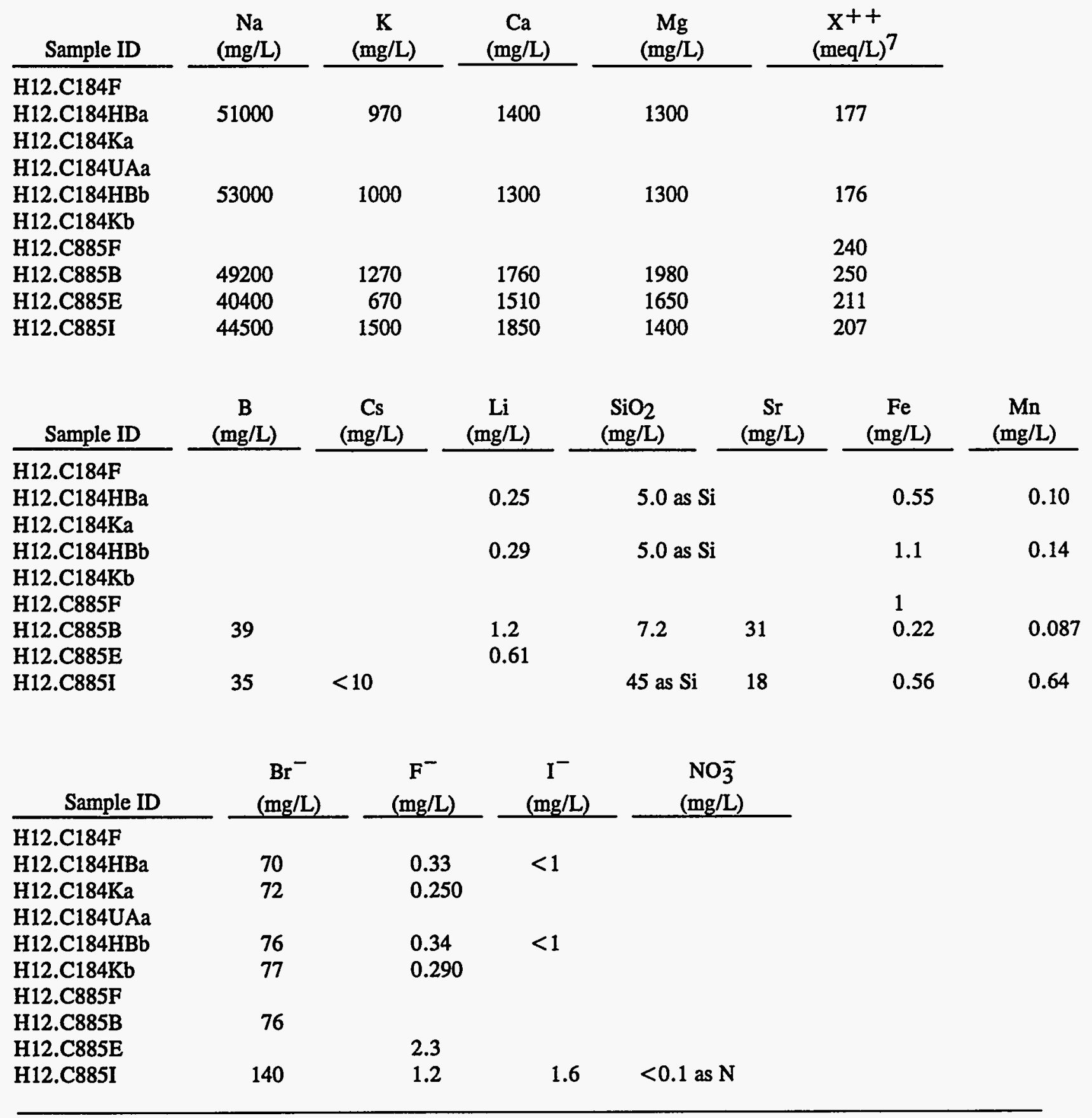


Table 86. Comparison of Data from the Culebra at P-14

(Footnotes follow Table 135)

\begin{tabular}{|c|c|c|c|c|c|}
\hline Well $^{1}$ & Agency 2 & Collection Date & Pumping Rate & $\mathrm{Lab}^{3}$ & Sample ID \\
\hline P-14 & USGS & $03 / 14 / 77$ & bail or swab & USGS & P14.C377G \\
\hline P-14 & WQSP-R1 & $02 / 18 / 86-02 / 27 / 86$ & $33 \mathrm{gph}$ & FLD & P14.C286F \\
\hline P-14 & WQSP-R1 & $02 / 26 / 86$ & $33 \mathrm{gph}$ & BFEC & P14.C286B \\
\hline P-14 & WQSP-R1 & $02 / 26 / 86$ & $33 \mathrm{gph}$ & EEG & P14.C286E \\
\hline P-14 & WQSP-R1 & $02 / 26,27 / 86$ & $33 \mathrm{gph}$ & ITAS & P14.C286I \\
\hline
\end{tabular}

\begin{tabular}{|c|c|c|c|c|c|}
\hline Sample ID & $\begin{array}{c}\text { Density/ } \\
\text { Specific Gravity }\end{array}$ & $\mathrm{pH}$ & $\begin{array}{c}\text { TDS (calc) } \\
(\mathrm{mg} / \mathrm{L})^{5}\end{array}$ & $\begin{array}{c}\text { TDS (ROI) } \\
(\mathrm{mg} / \mathrm{L})\end{array}$ & $\begin{array}{c}\text { Charge-Balanc } \\
\text { Error }\end{array}$ \\
\hline P14.C377G & & 6.0 & 33800 & $38000(105 \mathrm{C})$ & $-3.2 \%$ \\
\hline P14.C286F & $1.019(\mathrm{sg})$ & 6.8 & & & \\
\hline P14.C286B & & & 24900 & & $-0.9 \%$ \\
\hline P14.C286E & $1.04(\mathrm{~g} / \mathrm{mL})$ & 7.1 & 24800 & & $0.1 \%$ \\
\hline P14.C286I & & 7.0 & 24200 & $26000(180 \mathrm{C})$ & $-0.99 \%$ \\
\hline
\end{tabular}

\begin{tabular}{|c|c|c|c|c|c|}
\hline Sample ID & $\begin{array}{c}\text { Alkalinity } \\
(\mathrm{mg} / \mathrm{L} \mathrm{CaCO})^{6}\end{array}$ & $\begin{array}{c}\mathrm{HCO}_{3}^{-} \\
(\mathrm{mg} / \mathrm{L})^{6}\end{array}$ & $\begin{array}{c}\mathrm{CO}_{\overline{3}} \\
(\mathrm{mg} / \mathrm{L})^{6} \\
\end{array}$ & $\begin{array}{c}\mathrm{Cl}^{-} \\
(\mathrm{mg} / \mathrm{L})\end{array}$ & $\begin{array}{l}\mathrm{SO} \overline{\overline{4}} \\
(\mathrm{mg} / \mathrm{L})\end{array}$ \\
\hline P14.C377G & 290 & 360 & 0 & 20000 & 1400 \\
\hline P14.C286F & 90 & 110 & 0 & 15000 & \\
\hline P14.C286B & 80 & 98 & 0 & 14500 & 1590 \\
\hline P14.C286E & & & & 13900 & 1650 \\
\hline P14.C286I & 82 & 100 & 0 & 14000 & 1600 \\
\hline
\end{tabular}

\begin{tabular}{|c|c|c|c|c|c|}
\hline Sample ID & $\begin{array}{c}\mathrm{Na} \\
(\mathrm{mg} / \mathrm{L})\end{array}$ & $\underset{(\mathrm{mg} / \mathrm{L})}{\mathrm{K}}$ & $\underset{(m g / L)}{\mathrm{Ca}}$ & $\begin{array}{c}\mathrm{Mg} \\
(\mathrm{mg} / \mathrm{L})\end{array}$ & $\begin{array}{c}\mathrm{X}^{++} \\
(\mathrm{meq} / \mathrm{L})^{7}\end{array}$ \\
\hline P14.C377G & 7600 & 600 & 3100 & 760 & 217 \\
\hline P14.C286F & & & & & 260 \\
\hline P14.C286B & 4360 & 37.9 & 3520 & 840 & 244.8 \\
\hline P14.C286E & 4200 & 60.0 & 3640 & 740 & 297 \\
\hline P14.C286I & 3750 & 44.5 & 3900 & 760 & 257 \\
\hline
\end{tabular}

\begin{tabular}{|c|c|c|c|c|c|c|c|}
\hline Sample ID & $\begin{array}{c}\text { B } \\
(\mathrm{mg} / \mathrm{L})\end{array}$ & $\underset{(\mathrm{mg} / \mathrm{L})}{\mathrm{Cs}}$ & $\underset{(\mathrm{mg} / \mathrm{L})}{\mathrm{Li}}$ & $\begin{array}{c}\mathrm{SiO}_{2} \\
(\mathrm{mg} / \mathrm{L})\end{array}$ & $\begin{array}{c}\mathrm{Sr} \\
(\mathrm{mg} / \mathrm{L})\end{array}$ & $\begin{array}{c}\mathrm{Fe} \\
(\mathrm{mg} / \mathrm{L})\end{array}$ & $\begin{array}{c}\mathrm{Mn} \\
(\mathrm{mg} / \mathrm{L})\end{array}$ \\
\hline P14.C377G & 0.70 & & & 33 & & & \\
\hline P14.C286F & & & & & & 2 & \\
\hline P14.C286B & 0.72 & $<0.01$ & $\begin{array}{r}0.28 \\
<0.5\end{array}$ & 30 & 51 & 2.0 & 0.18 \\
\hline P14.C286I & 0.065 & $<0.01$ & & 32 as $\mathrm{Si}$ & 48 & 1.6 & 0.23 \\
\hline
\end{tabular}


Table 86. Comparison of Data from the Culebra at P-14 (continued)

\begin{tabular}{|c|c|c|c|c|}
\hline Sample ID & $\begin{array}{c}\mathrm{Br}^{-} \\
(\mathrm{mg} / \mathrm{L})\end{array}$ & $\begin{array}{c}\mathrm{F}^{-} \\
(\mathrm{mg} / \mathrm{L})\end{array}$ & $\begin{array}{c}\mathrm{I}^{-} \\
(\mathrm{mg} / \mathrm{L})\end{array}$ & $\begin{array}{c}\mathrm{NO}_{\overline{3}}^{-} \\
(\mathrm{mg} / \mathrm{L})\end{array}$ \\
\hline $\begin{array}{l}\text { P14.C377G } \\
\text { P14.C286F }\end{array}$ & & 0.9 & & \\
\hline P14.C286B & 72 & 1.7 & 0.42 & \\
\hline P14.C286E & & 1.5 & & \\
\hline P14.C286I & 24 & 1.2 & $<1$ & 0.20 as $\mathrm{N}$ \\
\hline
\end{tabular}


Table 87. Comparison of Data from the Culebra at P-15

(Footnotes follow Table 135)

\begin{tabular}{|c|c|c|c|c|c|}
\hline Well $^{1}$ & Agency $^{2}$ & Collection Date & Pumping Rate & $\mathrm{Lab}^{3}$ & Sample ID \\
\hline P-15 & USGS & $05 / 10 / 77$ & bail or swab & USGS & P15.C577G \\
\hline P-15 & USGS & $04 / 11 / 79$ & bail or swab & SNL & P15.C479S \\
\hline
\end{tabular}

\begin{tabular}{|c|c|c|c|c|c|}
\hline Sample ID & $\begin{array}{c}\text { Density/ } \\
\text { Specific Gravity }\end{array}$ & $\mathrm{pH}$ & $\begin{array}{l}\text { TDS (calc) } \\
(\mathrm{mg} / \mathrm{L})^{5}\end{array}$ & $\begin{array}{c}\text { TDS (ROI) } \\
(\mathrm{mg} / \mathrm{L})\end{array}$ & $\begin{array}{c}\text { Charge-Balance } \\
\text { Error } 5\end{array}$ \\
\hline P15.C577G & 1050 (1m) & & 23700 & $24000(105 \mathrm{C})$ & $1.2 \%$ \\
\hline
\end{tabular}

\begin{tabular}{|c|c|c|c|c|c|}
\hline Sample ID & $\begin{array}{c}\text { Alkalinity } \\
\left(\mathrm{mg} / \mathrm{L} \mathrm{CaCO}_{3}\right)^{6}\end{array}$ & $\begin{array}{c}\mathrm{HCO}_{3}^{-} \\
(\mathrm{mg} / \mathrm{L})^{6}\end{array}$ & $\begin{array}{c}\mathrm{CO}_{\overline{3}}^{\overline{3}} \\
(\mathrm{mg} / \mathrm{L})^{6}\end{array}$ & $\begin{array}{c}\mathrm{Cl}^{-} \\
(\mathrm{mg} / \mathrm{L})\end{array}$ & $\begin{array}{l}\mathrm{SO} \overline{\overline{4}} \\
(\mathrm{mg} / \mathrm{L})\end{array}$ \\
\hline $577 G$ & 92 & 63 & 24 & 11000 & 3200 \\
\hline
\end{tabular}

\begin{tabular}{|c|c|c|c|c|c|}
\hline Sample ID & $\begin{array}{c}\mathrm{Na} \\
(\mathrm{mg} / \mathrm{L})\end{array}$ & $\underset{(\mathrm{mg} / \mathrm{L})}{\mathrm{K}}$ & $\begin{array}{c}\mathrm{Ca} \\
(\mathrm{mg} / \mathrm{L})\end{array}$ & $\begin{array}{c}\mathrm{Mg} \\
(\mathrm{mg} / \mathrm{L})\end{array}$ & $\begin{array}{c}\mathrm{x}^{++} \\
(\mathrm{meq} / \mathrm{L})^{7}\end{array}$ \\
\hline P15.C577G & 6900 & 1700 & 770 & $\begin{array}{r}63 \\
\end{array}$ & $\begin{array}{r}44 \\
163\end{array}$ \\
\hline
\end{tabular}

\begin{tabular}{|c|c|c|c|c|c|c|c|}
\hline Sample ID & $\begin{array}{c}\text { B } \\
(\mathrm{mg} / \mathrm{L})\end{array}$ & $\begin{array}{c}\mathrm{Cs} \\
(\mathrm{mg} / \mathrm{L})\end{array}$ & $\begin{array}{c}\mathrm{Li} \\
(\mathrm{mg} / \mathrm{L})\end{array}$ & $\begin{array}{c}\mathrm{SiO}_{2} \\
(\mathrm{mg} / \mathrm{L})\end{array}$ & $\begin{array}{c}\mathrm{Sr} \\
(\mathrm{mg} / \mathrm{L})\end{array}$ & $\underset{(\mathrm{mg} / \mathrm{L})}{\mathrm{Fe}}$ & $\begin{array}{c}\mathrm{Mn} \\
(\mathrm{mg} / \mathrm{L})\end{array}$ \\
\hline $\begin{array}{l}\text { P15.C577G } \\
\text { P15.C479S }\end{array}$ & 4.7 & & & 1.6 & & & \\
\hline
\end{tabular}

$\frac{1}{\text { S15.C577G }} \frac{\begin{array}{c}\mathrm{Br}^{-} \\ (\mathrm{mg} / \mathrm{L})\end{array}}{\text { P15.C479S }} \frac{\begin{array}{c}\mathrm{F}^{-} \\ (\mathrm{mg} / \mathrm{L})\end{array}}{1.2}$


Table 88. Comparison of Data from the Culebra at P-17

(Footnotes follow Table 135)

\begin{tabular}{|c|c|c|c|c|c|}
\hline Well ${ }^{1}$ & Agency $^{2}$ & Collection Date & Pumping Rate & $\mathrm{Lab}^{3}$ & Sample ID \\
\hline P-17 & USGS & $05 / 10 / 77$ & bail or swab & USGS & P17.C577G \\
\hline P-17 & WQSP-R1 & $03 / 04 / 86-03 / 17 / 86$ & $.5 \mathrm{gpm}$ & FLD & P17.C386F \\
\hline P-17 & WQSP-R1 & $03 / 17 / 86$ & $.5 \mathrm{gpm}$ & BFEC & P17.C386B \\
\hline P-17 & WQSP-R1 & $03 / 17 / 86$ & $.5 \mathrm{gpm}$ & EEG & P17.C386E \\
\hline P-17 & WQSP-R1 & $03 / 17 / 86$ & $.5 \mathrm{gpm}$ & ITAS & P17.C386I \\
\hline
\end{tabular}

\begin{tabular}{|c|c|c|c|c|c|}
\hline Sample ID & $\begin{array}{c}\text { Density/ } \\
\text { Specific Gravity } \\
\end{array}$ & $\mathrm{pH}$ & $\begin{array}{l}\text { TDS (calc) } \\
(\mathrm{mg} / \mathrm{L})^{5}\end{array}$ & $\begin{array}{l}\text { TDS (ROI) } \\
(\mathrm{mg} / \mathrm{L})\end{array}$ & $\begin{array}{c}\text { Charge-Balance } \\
\text { Error } \\
\end{array}$ \\
\hline P17.C577G & & 7.4 & 92500 & $97000(105 \mathrm{C})$ & $-3.4 \%$ \\
\hline $\begin{array}{l}\text { P17.C386F } \\
\text { P17.C386B }\end{array}$ & $1.065(\mathrm{sg})$ & 7.5 & 86500 & & $-1.2 \%$ \\
\hline P17.C386E & $1.08(\mathrm{~g} / \mathrm{mL})$ & 6.9 & 81200 & & $-1.5 \%$ \\
\hline P17.C386I & & 7.0 & 90400 & $88000(180 \mathrm{C})$ & $-2.7 \%$ \\
\hline
\end{tabular}

\begin{tabular}{|c|c|c|c|c|c|}
\hline Sample ID & $\begin{array}{c}\text { Alkalinity } \\
(\mathrm{mg} / \mathrm{L} \mathrm{CaCO})^{6} \\
\end{array}$ & $\begin{array}{l}\mathrm{HCO}_{3}^{-} \\
(\mathrm{mg} / \mathrm{L})^{6}\end{array}$ & $\begin{array}{c}\mathrm{CO}_{\overline{3}}^{\overline{3}} \\
(\mathrm{mg} / \mathrm{L})^{6}\end{array}$ & $\begin{array}{c}\mathrm{Cl}^{-} \\
(\mathrm{mg} / \mathrm{L})\end{array}$ & $\begin{array}{c}\mathrm{SO} \overline{\overline{4}} \\
(\mathrm{mg} / \mathrm{L})\end{array}$ \\
\hline P17.C577G & 63 & 77 & 0 & 54000 & 5000 \\
\hline P17.C386F & 52 & 64 & 0 & 48000 & \\
\hline P17.C386B & 43 & 52 & 0 & 48200 & 6020 \\
\hline P17.C386E & & & & 45200 & 5960 \\
\hline P17.C386I & 44 & 54 & 0 & 51000 & 6400 \\
\hline
\end{tabular}

\begin{tabular}{|c|c|c|c|c|c|}
\hline Sample ID & $\begin{array}{c}\mathrm{Na} \\
(\mathrm{mg} / \mathrm{L})\end{array}$ & $\begin{array}{c}\mathrm{K} \\
(\mathrm{mg} / \mathrm{L})\end{array}$ & $\begin{array}{c}\mathrm{Ca} \\
(\mathrm{mg} / \mathrm{L})\end{array}$ & $\underset{(\mathrm{mg} / \mathrm{L})}{\mathrm{Mg}}$ & $\underset{(\mathrm{meq} / \mathrm{L})^{7}}{\mathrm{X}}$ \\
\hline $\begin{array}{l}\text { P17.C577G } \\
\text { P17.C386F }\end{array}$ & 30000 & 120 & 1700 & 1600 & $\begin{array}{l}216 \\
220\end{array}$ \\
\hline P17.C386B & 28300 & 782 & 1620 & 1460 & 201 \\
\hline P17.C386E & 26200 & 875 & 1560 & 1440 & 196 \\
\hline P17.C386I & 29000 & 795 & 1650 & 1550 & 210 \\
\hline
\end{tabular}

\begin{tabular}{|c|c|c|c|c|c|c|c|}
\hline Sample ID & $\begin{array}{c}\text { B } \\
(\mathrm{mg} / \mathrm{L})\end{array}$ & $\underset{(\mathrm{mg} / \mathrm{L})}{\mathrm{Cs}}$ & $\underset{(\mathrm{mg} / \mathrm{L})}{\mathrm{Li}}$ & $\begin{array}{c}\mathrm{SiO}_{2} \\
(\mathrm{mg} / \mathrm{L})\end{array}$ & $\begin{array}{c}\mathrm{Sr} \\
(\mathrm{mg} / \mathrm{L})\end{array}$ & $\underset{(\mathrm{mg} / \mathrm{L})}{\mathrm{Fe}}$ & $\underset{(\mathrm{mg} / \mathrm{L})}{\mathrm{Mn}}$ \\
\hline P17.C577G & 1.7 & & & 1.0 & & & \\
\hline P17.C386F & & & & & & 5 & \\
\hline P17.C386B & 38 & $<0.01$ & 0.87 & 8.5 & 29 & 4.0 & 0.87 \\
\hline P17.C386E & & & $<0.5$ & & & & \\
\hline P17.C386I & 36 & $<0.1$ & & $<0.2$ as $\mathrm{Si}$ & 28 & 3.8 & 0.80 \\
\hline
\end{tabular}


Table 88. Comparison of Data from the Culebra at P-17 (continued)

\begin{tabular}{|c|c|c|c|c|}
\hline Sample ID & $\begin{array}{c}\mathrm{Br}^{-} \\
(\mathrm{mg} / \mathrm{L})\end{array}$ & $\begin{array}{c}F^{-} \\
(\mathrm{mg} / \mathrm{L})\end{array}$ & $\begin{array}{c}\mathrm{I}^{-} \\
(\mathrm{mg} / \mathrm{L})\end{array}$ & $\begin{array}{c}\mathrm{NO}_{3}^{\overline{3}} \\
(\mathrm{mg} / \mathrm{L})\end{array}$ \\
\hline P17.C577G & & 1.5 & & \\
\hline P17.C386F & & & & \\
\hline P17.C386B & 72 & 1.9 & 0.18 & \\
\hline P17.C386E & & 1.9 & & \\
\hline P17.C386I & 98 & 1.2 & 7.3 & 0.30 as $\mathrm{N}$ \\
\hline
\end{tabular}


Table 89. Comparison of Data from the Culebra at P-18

(Footnotes follow Table 135)

$\frac{\text { Well }^{1}}{\text { P-18 }} \frac{\text { Agency }^{2}}{\text { USGS }} \frac{\text { Collection Date }}{05 / 10 / 77} \frac{\text { Pumping Rate }}{\text { bail or swab }} \frac{\text { Lab }^{3}}{\text { USGS }} \frac{\text { Sample ID }}{\text { P18.C577G }}$

\begin{tabular}{|c|c|c|c|c|c|}
\hline Sample ID & $\begin{array}{c}\text { Density/ } \\
\text { Specific Gravity } 4\end{array}$ & $\mathrm{pH}$ & $\begin{array}{c}\text { TDS (calc) } \\
(\mathrm{mg} / \mathrm{L})^{5}\end{array}$ & $\begin{array}{c}\text { TDS (ROI) } \\
(\mathrm{mg} / \mathrm{L})\end{array}$ & $\begin{array}{c}\text { Charge-Balance } \\
\text { Error } 5\end{array}$ \\
\hline P18.C577G & & 7.2 & 118300 & $420000(105 \mathrm{C})$ & $-3.0 \%$ \\
\hline
\end{tabular}

$\frac{\text { Sample ID }}{\text { P18.C577G }} \frac{\begin{array}{c}\text { Alkalinity } \\ \left(\mathrm{mg} / \mathrm{L} \mathrm{CaCO}_{3}\right)^{6}\end{array}}{250} \frac{\begin{array}{c}\mathrm{HCO}_{3}^{-} \\ (\mathrm{mg} / \mathrm{L})^{6}\end{array}}{310} \frac{\begin{array}{c}\mathrm{CO}_{\overline{3}}^{\overline{3}} \\ (\mathrm{mg} / \mathrm{L})^{6}\end{array}}{0} \frac{\begin{array}{c}\mathrm{Cl}^{-} \\ (\mathrm{mg} / \mathrm{L})\end{array}}{80000} \frac{\begin{array}{c}\mathrm{SO} \overline{\overline{4}} \\ (\mathrm{mg} / \mathrm{L})\end{array}}{980}$

$\frac{\text { Sample ID }}{\text { P18.C577G }} \frac{\begin{array}{c}\mathrm{Na} \\ (\mathrm{mg} / \mathrm{L})\end{array}}{9200} \frac{\begin{array}{c}\mathrm{K} \\ (\mathrm{mg} / \mathrm{L})\end{array}}{6200} \frac{\begin{array}{c}\mathrm{Ca} \\ (\mathrm{mg} / \mathrm{L})\end{array}}{5600} \frac{\begin{array}{c}\mathrm{Mg} \\ (\mathrm{mg} / \mathrm{L})\end{array}}{16000} \frac{\begin{array}{c}\mathrm{X}^{++} \\ (\mathrm{meq} / \mathrm{L})^{7}\end{array}}{1590}$

\begin{tabular}{|c|c|c|c|c|c|c|c|}
\hline Sample ID & $\begin{array}{c}\text { B } \\
(\mathrm{mg} / \mathrm{L})\end{array}$ & $\underset{(\mathrm{mg} / \mathrm{L})}{\mathrm{Cs}}$ & $\underset{(\mathrm{mg} / \mathrm{L})}{\mathrm{Li}}$ & $\underset{(\mathrm{mg} / \mathrm{L})}{\mathrm{SiO}_{2}}$ & $\begin{array}{c}\mathrm{Sr} \\
(\mathrm{mg} / \mathrm{L})\end{array}$ & $\begin{array}{c}\mathrm{Fe} \\
(\mathrm{mg} / \mathrm{L})\end{array}$ & $\underset{(\mathrm{mg} / \mathrm{L})}{\mathrm{Mn}}$ \\
\hline $18 . C 577 G$ & 100 & & & 1.0 & & & \\
\hline
\end{tabular}

$\frac{\text { Sample ID }}{\text { P18.C577G }} \frac{\begin{array}{c}\mathrm{Br}^{-} \\ (\mathrm{mg} / \mathrm{L})\end{array}}{\frac{\mathrm{F}^{-}}{(\mathrm{mg} / \mathrm{L})}}$


Table 90. Comparison of Data from the Culebra at WIPP-25

(Footnotes follow Table 135)

\begin{tabular}{|c|c|c|c|c|c|}
\hline Well $^{1}$ & Agency $^{2}$ & Collection Date & Pumping Rate & $\mathrm{Lab}^{3}$ & Sample ID \\
\hline W-25 & USGS & $08 / 14 / 80$ & bail or swab & USGS & W25.C880G \\
\hline W-25 & SNL & $08 / 19 / 80-08 / 20 / 80$ & 33 gpm & FLD & W25.C880F \\
\hline W-25 & SNL & $08 / 20 / 80$ & $33 \mathrm{gpm}$ & BFEC & W25.C880B \\
\hline W-25 & WQSP-R1 & $01 / 31 / 86-02 / 13 / 86$ & $7 \mathrm{gpm}$ & FLD & W25.C286F \\
\hline W-25 & WQSP-R1 & $02 / 12 / 86$ & $7 \mathrm{gpm}$ & BFEC & W25.C286B \\
\hline W-25 & WQSP-R1 & $02 / 12 / 86$ & $7 \mathrm{gpm}$ & ITAS & W25.C286I \\
\hline
\end{tabular}

\begin{tabular}{|c|c|c|c|c|c|}
\hline Sample ID & $\begin{array}{c}\text { Density/ } \\
\text { Specific Gravity } 4\end{array}$ & $\mathrm{pH}$ & $\begin{array}{l}\text { TDS (calc) } \\
(\mathrm{mg} / \mathrm{L})^{5}\end{array}$ & $\begin{array}{l}\text { TDS (ROI) } \\
(\mathrm{mg} / \mathrm{L})\end{array}$ & $\begin{array}{c}\text { Charge-Balance } \\
\text { Error }^{5} \\
\end{array}$ \\
\hline W25.C880G & $1.014(\mathrm{~g} / \mathrm{mL})$ & 7.3 & 17000 & $22100(105 \mathrm{C})$ & $0.8 \%$ \\
\hline W25.C880F & $1.01(\mathrm{sg})$ & 6.9 & & & \\
\hline W25.C880B & & & 12100 & & $1.4 \%$ \\
\hline W25.C286F & $1.010(\mathrm{sg})$ & 7.2 & & & \\
\hline W25.C286B & & & 13600 & & $-1.4 \%$ \\
\hline W25.C286I & & 7.7 & 13700 & $14000(180 \mathrm{C})$ & $1.5 \%$ \\
\hline
\end{tabular}

\begin{tabular}{|c|c|c|c|c|c|}
\hline Sample ID & $\begin{array}{c}\text { Alkalinity } \\
(\mathrm{mg} / \mathrm{L} \mathrm{CaCO})^{6}\end{array}$ & $\begin{array}{c}\mathrm{HCO}_{3}^{-} \\
(\mathrm{mg} / \mathrm{L})^{6}\end{array}$ & $\begin{array}{c}\mathrm{CO}_{\overline{3}} \\
(\mathrm{mg} / \mathrm{L})^{6}\end{array}$ & $\begin{array}{c}\mathrm{Cl}^{-} \\
(\mathrm{mg} / \mathrm{L})\end{array}$ & $\begin{array}{c}\mathrm{SO} \overline{\overline{4}} \\
(\mathrm{mg} / \mathrm{L})\end{array}$ \\
\hline W25.C880G & 370 & 450 & 0 & 8300 & 2400 \\
\hline W25.C880F & 170 & 210 & 0 & 5200 & -3000 \\
\hline W25.C880B & & & & 5250 & 2500 \\
\hline W25.C286F & 110 & 130 & 0 & 6200 & \\
\hline W25.C286B & 100 & 120 & 0 & 6320 & 2380 \\
\hline W25.C286I & 98 & 120 & 0 & 6200 & 2400 \\
\hline
\end{tabular}

\begin{tabular}{|c|c|c|c|c|c|}
\hline Sample ID & $\begin{array}{c}\mathrm{Na} \\
(\mathrm{mg} / \mathrm{L})\end{array}$ & $\underset{(\mathrm{mg} / \mathrm{L})}{\mathrm{K}}$ & $\begin{array}{c}\mathrm{Ca} \\
(\mathrm{mg} / \mathrm{L})\end{array}$ & $\begin{array}{c}\mathrm{Mg} \\
(\mathrm{mg} / \mathrm{L})\end{array}$ & $\underset{(m e q / L)^{7}}{\mathrm{X}^{++}}$ \\
\hline W25.C880G & 5100 & 0.9 & 920 & 250 & 66 \\
\hline $\mathrm{W} 25 . \mathrm{C} 880 \mathrm{~F}$ & & & 910 & & 66 \\
\hline W25.C880B & 3160 & 73.5 & 905 & 260 & 66.6 \\
\hline W25.C286F & & & & & 85 \\
\hline W25.C286B & 3180 & 102 & 1140 & 315 & 82.8 \\
\hline W25.C286I & 3350 & 105 & 1150 & 340 & 85.4 \\
\hline
\end{tabular}


Table 90. Comparison of Data from the Culebra at WIPP-25 (continued)

\begin{tabular}{|c|c|c|c|c|c|c|c|}
\hline Sample ID & $\begin{array}{c}\mathrm{B} \\
(\mathrm{mg} / \mathrm{L})\end{array}$ & $\begin{array}{c}\text { Cs } \\
(\mathrm{mg} / \mathrm{L})\end{array}$ & $\begin{array}{c}\mathrm{Li} \\
(\mathrm{mg} / \mathrm{L})\end{array}$ & $\begin{array}{c}\mathrm{SiO}_{2} \\
(\mathrm{mg} / \mathrm{L})\end{array}$ & $\begin{array}{c}\mathrm{Sr} \\
(\mathrm{mg} / \mathrm{L})\end{array}$ & $\begin{array}{c}\mathrm{Fe} \\
(\mathrm{mg} / \mathrm{L})\end{array}$ & $\begin{array}{c}\mathrm{Mn} \\
(\mathrm{mg} / \mathrm{L})\end{array}$ \\
\hline W25.C880G & 1.9 & & & 29 & & & \\
\hline W25.C880F & & & & & & -0.6 & \\
\hline W25.C880B & 1.5 & & 0.20 & 34 & 12 & & \\
\hline W25.C286F & & & & & & 0.5 & \\
\hline W25.C286B & 1.7 & $<0.01$ & 0.22 & 33 & 17 & 0.50 & 0.11 \\
\hline W25.C286I & 1.7 & $<0.1$ & & 31 as $\mathrm{Si}$ & 1.4 & 0.45 & 0.11 \\
\hline Sample ID & $\begin{array}{c}\mathrm{Br}^{-} \\
(\mathrm{mg} / \mathrm{L})\end{array}$ & $\begin{array}{c}F^{-} \\
(\mathrm{mg} / \mathrm{L})\end{array}$ & $\begin{array}{c}\mathrm{I}^{-} \\
(\mathrm{mg} / \mathrm{L}) \\
\end{array}$ & \multicolumn{2}{|c|}{$\begin{array}{c}\mathrm{NO}_{\overline{3}}^{-} \\
(\mathrm{mg} / \mathrm{L})\end{array}$} & & \\
\hline W25.C880G & & 1.4 & & & & & \\
\hline W25.C880F & & & & & & & \\
\hline W25.C880B & 2.6 & & & & & & \\
\hline W25.C286F & & & & & & & \\
\hline W25.C286B & 3.4 & 1.7 & 0.042 & & & & \\
\hline W25.C286I & 4.2 & 1.6 & $<1$ & \multicolumn{2}{|c|}{3.6 as $\mathrm{N}$} & & \\
\hline
\end{tabular}


Table 91. Comparison of Data from the Culebra at WIPP-26 (Footnotes follow Table 135)

\begin{tabular}{|c|c|c|c|c|c|}
\hline Well $^{1}$ & Agency $^{2}$ & Collection Date & Pumping Rate & $\mathrm{Lab}^{3}$ & Sample ID \\
\hline W-26 & USGS & $08 / 18 / 80$ & bail or swab & USGS & W26.C880G \\
\hline W-26 & SNL & $08 / 23 / 80-08 / 24 / 80$ & $34 \mathrm{gpm}$ & FLD & W26.C880F \\
\hline W-26 & SNL & $08 / 24 / 80$ & $34 \mathrm{gpm}$ & BFEC & W26.C880B \\
\hline W-26 & SNL & $08 / 24 / 80$ & 34 gpm & KCS & W26.C880KC \\
\hline W-26 & WQSP-R1 & $11 / 19 / 85-11 / 26 / 85$ & $52 \mathrm{gph}$ & FLD & W26.C1185F \\
\hline W-26 & WQSP-R1 & $11 / 25 / 85$ & $52 \mathrm{gph}$ & BFEC & W26.C1185B \\
\hline W-26 & WQSP-R1 & $11 / 25 / 85$ & $52 \mathrm{gph}$ & EEG & W26.C1185E \\
\hline W-26 & WQSP-R1 & $11 / 25 / 85$ & $52 \mathrm{gph}$ & ITAS & W26.C1185I \\
\hline
\end{tabular}

\begin{tabular}{|c|c|c|c|c|c|}
\hline Sample ID & $\begin{array}{c}\text { Density/ } \\
\text { Specific Gravity } 4\end{array}$ & $\mathrm{pH}$ & $\begin{array}{l}\text { TDS (calc) } \\
(\mathrm{mg} / \mathrm{L})^{5}\end{array}$ & $\begin{array}{c}\text { TDS (ROI) } \\
(\mathrm{mg} / \mathrm{L})\end{array}$ & $\begin{array}{c}\text { Charge-Balance } \\
\text { Error }^{5}\end{array}$ \\
\hline W26.C880G & $1.013(\mathrm{~g} / \mathrm{mL})$ & 6.9 & 15600 & $23800(105 \mathrm{C})$ & $-6.7 \%$ \\
\hline W26.C880F & $1.005(\mathrm{sg})$ & 6.9 & & & \\
\hline W26.C880B & & & 15100 & & $-0.4 \%$ \\
\hline \multicolumn{6}{|l|}{ W26.C880KC } \\
\hline W26.C1185F & $1.012(\mathrm{sg})$ & 7.1 & & & \\
\hline W26.C1185B & & & 17600 & & $-1.6 \%$ \\
\hline W26.C1185E & $1.033(\mathrm{~g} / \mathrm{mL})$ & 7.5 & 16800 & & $-2.6 \%$ \\
\hline W26.C1185I & & 7.4 & 18200 & $18000(180 \mathrm{C})$ & $0.13 \%$ \\
\hline
\end{tabular}

\begin{tabular}{|c|c|c|c|c|c|}
\hline Sample ID & $\begin{array}{c}\text { Alkalinity } \\
\left(\mathrm{mg} / \mathrm{L} \mathrm{CaCO}_{3}\right)^{6}\end{array}$ & $\begin{array}{c}\mathrm{HCO}_{3}^{-} \\
(\mathrm{mg} / \mathrm{L})^{6}\end{array}$ & $\begin{array}{c}\mathrm{CO}_{3} \overline{3} \\
(\mathrm{mg} / \mathrm{L})^{6}\end{array}$ & $\begin{array}{c}\mathrm{Cl}^{-} \\
(\mathrm{mg} / \mathrm{L})\end{array}$ & $\begin{array}{c}\mathrm{SO} \overline{\overline{4}} \\
(\mathrm{mg} / \mathrm{L})\end{array}$ \\
\hline W26.C880G & 130 & 160 & 0 & 8200 & 2300 \\
\hline W26.C880F & 120 & 140 & 0 & 6900 & -3000 \\
\hline W26.C880B & & & & 7200 & 2480 \\
\hline W26.C880KC & & & & 8240 & \\
\hline W26.C1185F & 98 & 120 & 0 & 8500 & \\
\hline W26.C1185B & 96 & 120 & 0 & 8770 & 2420 \\
\hline W26.C1185E & & & & 8490 & 2370 \\
\hline W26.C1185I & 110 & 130 & 0 & 9450 & 1950 \\
\hline
\end{tabular}

\begin{tabular}{|c|c|c|c|c|c|}
\hline Sample ID & $\begin{array}{c}\mathrm{Na} \\
(\mathrm{mg} / \mathrm{L})\end{array}$ & $\begin{array}{c}\mathrm{K} \\
(\mathrm{mg} / \mathrm{L})\end{array}$ & $\begin{array}{c}\mathrm{Ca} \\
(\mathrm{mg} / \mathrm{L})\end{array}$ & $\begin{array}{c}\mathrm{Mg} \\
(\mathrm{mg} / \mathrm{L})\end{array}$ & $\begin{array}{c}\mathrm{x}^{++} \\
(\mathrm{meq} / \mathrm{L})^{7}\end{array}$ \\
\hline W26.C880G & 3600 & 2.0 & 1200 & 340 & 88 \\
\hline W26.C880F & & & 1300 & & 91 \\
\hline W26.C880B & 3620 & 170 & 1240 & 355 & 91.1 \\
\hline \multicolumn{6}{|l|}{ W26.C880KC } \\
\hline W26.C1185F & & & & & 100 \\
\hline W26.C1185B & 4220 & 343 & 1340 & 380 & 98.2 \\
\hline W26.C1185E & 3820 & 360 & 1290 & 425 & 99.3 \\
\hline W26.C1185I & 4150 & 350 & 1800 & 375 & 121 \\
\hline
\end{tabular}


Table 91. Comparison of Data from the Culebra at WIPP-26 (continued)

\begin{tabular}{|c|c|c|c|c|c|c|c|}
\hline Sample ID & $\begin{array}{c}\text { B } \\
(\mathrm{mg} / \mathrm{L})\end{array}$ & $\begin{array}{c}\mathrm{Cs} \\
(\mathrm{mg} / \mathrm{L})\end{array}$ & $\begin{array}{c}\mathrm{Li} \\
(\mathrm{mg} / \mathrm{L})\end{array}$ & $\begin{array}{c}\mathrm{SiO}_{2} \\
(\mathrm{mg} / \mathrm{L})\end{array}$ & $\begin{array}{c}\mathrm{Sr} \\
(\mathrm{mg} / \mathrm{L})\end{array}$ & $\begin{array}{c}\mathrm{Fe} \\
(\mathrm{mg} / \mathrm{L})\end{array}$ & $\begin{array}{c}\mathrm{Mn} \\
(\mathrm{mg} / \mathrm{L})\end{array}$ \\
\hline W26.C880G & 1.8 & & & 20 & & & \\
\hline W26.C880F & & & & & & -0.3 & \\
\hline W26.C880B & 1.4 & & 0.24 & 33 & 17 & & \\
\hline W26.C880KC & & & & & & & \\
\hline W26.C1185F & & & & & & 0.1 & \\
\hline W26.C1185B & 1.6 & $<0.01$ & 0.23 & 35 & 20 & 0.026 & $<0.01$ \\
\hline W26.C1185E & & & $<0.5$ & & & & \\
\hline W26.C1185I & $<0.01$ & $<0.1$ & & 30 as $\mathbf{S i}$ & 17 & $<0.1$ & 0.090 \\
\hline Sample ID & $\begin{array}{c}\mathrm{Br}^{-} \\
(\mathrm{mg} / \mathrm{L}) \\
\end{array}$ & $\begin{array}{c}\mathrm{F}^{-} \\
(\mathrm{mg} / \mathrm{L}) \\
\end{array}$ & $\begin{array}{c}\mathrm{I}^{-} \\
(\mathrm{mg} / \mathrm{L}) \\
\end{array}$ & \multicolumn{2}{|c|}{$\begin{array}{c}\mathrm{NO}_{3}^{-} \\
(\mathrm{mg} / \mathrm{L})\end{array}$} & & \\
\hline $\begin{array}{l}\text { W26.C880G } \\
\text { W26.C880F }\end{array}$ & & 1.5 & & & & & \\
\hline $\begin{array}{l}\text { W26.C880B } \\
\text { W26.C880KC } \\
\text { W26.C1185F }\end{array}$ & 3.2 & & & & & & \\
\hline W26.C1185B & 3.9 & 1.7 & 0.070 & & & & \\
\hline W26.C1185E & & 1.5 & & & & & \\
\hline W26.C1185I & 12 & 1.3 & $<1$ & 5.7 & & & \\
\hline
\end{tabular}


Table 92. Comparison of Data from the Culebra at WIPP-27 (Footnotes follow Table 135)

\begin{tabular}{|c|c|c|c|c|c|}
\hline Well $^{1}$ & Agency $^{2}$ & Collection Date & Pumping Rate & $\mathrm{Lab}^{3}$ & Sample ID \\
\hline W-27 & USGS & $08 / 22 / 80$ & bail or swab & USGS & W27.C880G \\
\hline W-27 & SNL & $09 / 02 / 80-09 / 05 / 80$ & 25 gpm & FLD & W27.C980F \\
\hline W-27 & SNL & $09 / 03 / 80$ & $25 \mathrm{gpm}$ & BFEC & W27.C980B \\
\hline
\end{tabular}

\begin{tabular}{|c|c|c|c|c|c|}
\hline Sample ID & $\begin{array}{c}\text { Density/ } \\
\text { Specific Gravity }\end{array}$ & $\mathrm{pH}$ & $\begin{array}{l}\text { TDS (calc) } \\
(\mathrm{mg} / \mathrm{L})^{5}\end{array}$ & $\begin{array}{l}\text { TDS (ROI) } \\
(\mathrm{mg} / \mathrm{L})\end{array}$ & $\begin{array}{c}\text { Charge-Balance } \\
\text { Error } 5\end{array}$ \\
\hline W27.C880G & $1.094(\mathrm{~g} / \mathrm{mL})$ & 6.4 & 125700 & $186000(105 \mathrm{C})$ & $-5.2 \%$ \\
\hline W27.C980F & $1.09(\mathrm{sg})$ & 6.4 & & & \\
\hline W27.C980B & & & 134700 & & $-1.5 \%$ \\
\hline
\end{tabular}

\begin{tabular}{|c|c|c|c|c|c|}
\hline Sample ID & $\begin{array}{c}\text { Alkalinity } \\
(\mathrm{mg} / \mathrm{L} \mathrm{CaCO})^{6} \\
\end{array}$ & $\begin{array}{c}\mathrm{HCO}_{3}^{-} \\
(\mathrm{mg} / \mathrm{L})^{6}\end{array}$ & $\begin{array}{c}\mathrm{CO} \overline{\overline{3}} \\
(\mathrm{mg} / \mathrm{L})^{6} \\
\end{array}$ & $\begin{array}{c}\mathrm{Cl}^{-} \\
(\mathrm{mg} / \mathrm{L}) \\
\end{array}$ & $\begin{array}{c}\mathrm{SO} \overline{\overline{4}} \\
(\mathrm{mg} / \mathrm{L})\end{array}$ \\
\hline W27.C880G & 150 & 180 & 0 & 77000 & 3900 \\
\hline W27.C980F & 98 & 120 & 0 & 77000 & -4000 \\
\hline W27.C980B & & & & 78500 & 3830 \\
\hline
\end{tabular}

\begin{tabular}{|c|c|c|c|c|c|}
\hline Sample ID & $\underset{(\mathrm{mg} / \mathrm{L})}{\mathrm{Na}}$ & $\underset{(\mathrm{mg} / \mathrm{L})}{\mathrm{K}}$ & $\begin{array}{c}\mathrm{Ca} \\
(\mathrm{mg} / \mathrm{L})\end{array}$ & $\begin{array}{c}\mathrm{Mg} \\
(\mathrm{mg} / \mathrm{L})\end{array}$ & $\begin{array}{c}\mathrm{X}^{++} \\
(\mathrm{meq} / \mathrm{L})^{7}\end{array}$ \\
\hline W27.C880G & 39000 & 714 & 3100 & 2000 & 320 \\
\hline W27.C980F & & & 3300 & & 320 \\
\hline W27.C980B & 39200 & 8060 & 3210 & 1900 & 316 \\
\hline
\end{tabular}

\begin{tabular}{|c|c|c|c|c|c|c|c|}
\hline Sample ID & $\begin{array}{c}\text { B } \\
(\mathrm{mg} / \mathrm{L})\end{array}$ & $\begin{array}{c}\text { Cs } \\
(\mathrm{mg} / \mathrm{L})\end{array}$ & $\underset{(\mathrm{mg} / \mathrm{L})}{\mathrm{Li}}$ & $\begin{array}{c}\mathrm{SiO}_{2} \\
(\mathrm{mg} / \mathrm{L})\end{array}$ & $\begin{array}{c}\mathrm{Sr} \\
(\mathrm{mg} / \mathrm{L})\end{array}$ & $\begin{array}{c}\mathrm{Fe} \\
(\mathrm{mg} / \mathrm{L})\end{array}$ & $\underset{(\mathrm{mg} / \mathrm{L})}{\mathrm{Mn}}$ \\
\hline W27.C880G & 1.9 & & & 13 & & & \\
\hline W27.C980F & & & & & & -0.4 & \\
\hline W27.C980B & 2.3 & & 0.33 & 23 & 51 & & \\
\hline Sample ID & & $\begin{array}{c}\mathrm{Br}^{-} \\
(\mathrm{mg} / \mathrm{L})\end{array}$ & $\begin{array}{c}\mathrm{F}^{-} \\
(\mathrm{mg} / \mathrm{L})\end{array}$ & $\begin{array}{c}\mathrm{I}^{-} \\
(\mathrm{mg} / \mathrm{L})\end{array}$ & $\begin{array}{c}\mathrm{NO}_{3}^{-} \\
(\mathrm{mg} / \mathrm{L})\end{array}$ & & \\
\hline W27.C880G & & & 0.5 & & & & \\
\hline W27.C980F & & & & & & & \\
\hline W27.C980B & & 28 & & & & & \\
\hline
\end{tabular}


Table 93. Comparison of Data from the Culebra at WIPP-28

(Footnotes follow Table 135)

\begin{tabular}{|c|c|c|c|c|c|}
\hline Well ${ }^{1}$ & Agency ${ }^{2}$ & Collection Date & Pumping Rate & $\mathrm{Lab}^{3}$ & Sample ID \\
\hline W-28 & USGS & $08 / 21 / 80$ & bail or swab & USGS & W28.C880G \\
\hline W-28 & SNL & $09 / 09 / 80-09 / 12 / 80$ & 17 gpm & FLD & W28.C980F \\
\hline W-28 & SNL & $09 / 11 / 80$ & $17 \mathrm{gpm}$ & BFEC & W28.C980B \\
\hline W-28 & SNL & $09 / 11 / 80$ & $17 \mathrm{gpm}$ & KCS & W28.C980KC \\
\hline
\end{tabular}

\begin{tabular}{|c|c|c|c|c|c|}
\hline Sample ID & $\begin{array}{c}\text { Density/ } \\
\text { Specific Gravity } 4 \\
\end{array}$ & $\mathrm{pH}$ & $\begin{array}{l}\text { TDS (calc) } \\
(\mathrm{mg} / \mathrm{L})^{5}\end{array}$ & $\begin{array}{c}\text { TDS (ROI) } \\
(\mathrm{mg} / \mathrm{L})\end{array}$ & $\begin{array}{c}\text { Charge-Balance } \\
\text { Error } 5\end{array}$ \\
\hline W28.C880G & $1.044(\mathrm{~g} / \mathrm{mL})$ & 6.4 & 55900 & $74000(105 \mathrm{C})$ & $5.2 \%$ \\
\hline W28.C980F & $1.03(\mathrm{sg})$ & 6.5 & & & \\
\hline W28.C980B & & & 46600 & & $-0.9 \%$ \\
\hline
\end{tabular}

\begin{tabular}{|c|c|c|c|c|c|}
\hline Sample ID & $\begin{array}{c}\text { Alkalinity } \\
(\mathrm{mg} / \mathrm{L} \mathrm{CaCO} 3)^{6} \\
\end{array}$ & $\begin{array}{c}\mathrm{HCO}_{3}^{-} \\
(\mathrm{mg} / \mathrm{L})^{6}\end{array}$ & $\begin{array}{c}\mathrm{CO} \overline{\overline{3}} \\
(\mathrm{mg} / \mathrm{L})^{6}\end{array}$ & $\begin{array}{c}\mathrm{Cl}^{-} \\
(\mathrm{mg} / \mathrm{L})\end{array}$ & $\begin{array}{c}\mathrm{SO} \overline{\overline{4}} \\
(\mathrm{mg} / \mathrm{L})\end{array}$ \\
\hline W28.C880G & 670 & 820 & 0 & 30000 & 3200 \\
\hline W28.C980F & $(<290)$ & $(<350)$ & 0 & 24000 & -4000 \\
\hline W28.C980B & & & & 24800 & 4380 \\
\hline W28.C980KC & & & & 21600 & \\
\hline
\end{tabular}

\begin{tabular}{|c|c|c|c|c|c|c|c|}
\hline Sample ID & $\begin{array}{c}\text { B } \\
(\mathrm{mg} / \mathrm{L}) \\
\end{array}$ & $\begin{array}{c}\mathrm{Cs} \\
(\mathrm{mg} / \mathrm{L})\end{array}$ & $\begin{array}{c}\mathrm{Li} \\
(\mathrm{mg} / \mathrm{L})\end{array}$ & $\begin{array}{c}\mathrm{SiO}_{2} \\
(\mathrm{mg} / \mathrm{L})\end{array}$ & $\begin{array}{c}\mathrm{Sr} \\
(\mathrm{mg} / \mathrm{L})\end{array}$ & $\begin{array}{c}\mathrm{Fe} \\
(\mathrm{mg} / \mathrm{L})\end{array}$ & $\begin{array}{c}\mathrm{Mn} \\
(\mathrm{mg} / \mathrm{L})\end{array}$ \\
\hline W28.C880G & 5.4 & & & 28 & & & \\
\hline $\begin{array}{l}\text { W28.C980F } \\
W 28 . C 980 B \\
\text { W28.C } 980 \mathrm{KC}\end{array}$ & 5.8 & & 0.30 & 36 & 16 & -0.8 & \\
\hline
\end{tabular}

\begin{tabular}{|c|c|c|}
\hline Sample ID & $\begin{array}{c}\mathrm{Br}^{-} \\
(\mathrm{mg} / \mathrm{L})\end{array}$ & $\begin{array}{c}\mathrm{F}^{-} \\
(\mathrm{mg} / \mathrm{L})\end{array}$ \\
\hline $\begin{array}{l}\text { W28.C880G } \\
\text { W28.C980F }\end{array}$ & & 1.1 \\
\hline $\begin{array}{l}\text { W28.C980B } \\
\text { W28.C980KC }\end{array}$ & 7.2 & \\
\hline
\end{tabular}


Table 94. Comparison of Data from the Culebra at WIPP-29 (Footnotes follow Table 135)

\begin{tabular}{|c|c|c|c|c|c|}
\hline Well $^{1}$ & Agency $^{2}$ & Collection Date & Pumping Rate & $\mathrm{Lab}^{3}$ & Sample ID \\
\hline W-29 & USGS & $08 / 20 / 80$ & bail or swab & USGS & W29.C880G \\
\hline W-29 & SNL & $08 / 26 / 80-08 / 28 / 80$ & 37 gpm & FLD & W29.C880F \\
\hline W-29 & SNL & $08 / 28 / 80$ & $37 \mathrm{gpm}$ & BFEC & W29.C880B \\
\hline W-29 & SNL & $08 / 28 / 80$ & $37 \mathrm{gpm}$ & KCS & W29.C880KC \\
\hline W-29 & WQSP-R1 & $12 / 05 / 85-12 / 15 / 85$ & $60 \mathrm{gph}$ & FLD & W29.C1285F \\
\hline W-29 & WQSP-R1 & $12 / 14 / 85$ & $60 \mathrm{gph}$ & BFEC & W29.C1285B \\
\hline W-29 & WQSP-R1 & $12 / 14 / 85$ & $60 \mathrm{gph}$ & EEG & W29.C1285E \\
\hline W-29 & WQSP-RI & $12 / 14 / 85$ & $60 \mathrm{gph}$ & ITAS & W29.C1285I \\
\hline
\end{tabular}

\begin{tabular}{|c|c|c|c|c|c|}
\hline Sample ID & $\begin{array}{c}\text { Density/ } \\
\text { Specific Gravity }\end{array}$ & $\mathrm{pH}$ & $\begin{array}{l}\text { TDS (calc) } \\
(\mathrm{mg} / \mathrm{L})^{5}\end{array}$ & $\begin{array}{c}\text { TDS (ROI) } \\
(\mathrm{mg} / \mathrm{L})\end{array}$ & $\begin{array}{c}\text { Charge-Balance } \\
\text { Error } 5\end{array}$ \\
\hline W29.C880G & $1.178(\mathrm{~g} / \mathrm{mL})$ & 6.1 & 238700 & $239000(105 \mathrm{C})$ & $-3.4 \%$ \\
\hline W29.C880F & $1.16(\mathrm{sg})$ & 6.1 & & & \\
\hline W29.C880B & & & 245400 & & $-2.3 \%$ \\
\hline W29.C880KC & & & & & \\
\hline W29.C1285F & $1.216(\mathrm{sg})$ & 5.9 & & & \\
\hline W29.C1285B & & & 324100 & & $-1.8 \%$ \\
\hline W29.C1285E & $1.220(\mathrm{~g} / \mathrm{mL})$ & 6.9 & 265600 & & $-3.1 \%$ \\
\hline W29.C1285I & & 6.6 & 317200 & $330000(180 \mathrm{C})$ & $-3.7 \%$ \\
\hline
\end{tabular}

\begin{tabular}{|c|c|c|c|c|c|}
\hline Sample ID & $\begin{array}{c}\text { Alkalinity } \\
\left(\mathrm{mg} / \mathrm{L} \cdot \mathrm{CaCO}_{3}\right)^{6}\end{array}$ & $\begin{array}{c}\mathrm{HCO}_{3}^{-} \\
(\mathrm{mg} / \mathrm{L})^{6}\end{array}$ & $\begin{array}{c}\mathrm{CO}_{\overline{3}}^{\overline{3}} \\
(\mathrm{mg} / \mathrm{L})^{6}\end{array}$ & $\begin{array}{c}\mathrm{Cl}^{-} \\
(\mathrm{mg} / \mathrm{L})\end{array}$ & $\begin{array}{c}\text { SO } \overline{\overline{4}} \\
(\mathrm{mg} / \mathrm{L})\end{array}$ \\
\hline W29.C880G & 210 & 260 & 0 & 140000 & 13000 \\
\hline W29.C880F & 170 & 210 & 0 & 130000 & -10000 \\
\hline W29.C880B & & & & 138000 & 14000 \\
\hline W29.C880KC & & & & 201000 & \\
\hline W29.C1285F & 130 & 160 & 0 & 180000 & \\
\hline W29.C1285B & 120 & 150 & 0 & 179000 & 20000 \\
\hline W29.C1285E & & & & 147000 & 17000 \\
\hline W29.C1285I & 140 & 170 & 0 & 180000 & 17000 \\
\hline
\end{tabular}

\begin{tabular}{|c|c|c|c|c|c|}
\hline Sample ID & $\underset{(\mathrm{mg} / \mathrm{L})}{\mathrm{Na}}$ & $\begin{array}{c}\mathrm{K} \\
(\mathrm{mg} / \mathrm{L})\end{array}$ & $\begin{array}{c}\mathrm{Ca} \\
(\mathrm{mg} / \mathrm{L})\end{array}$ & $\begin{array}{c}\mathrm{Mg} \\
(\mathrm{mg} / \mathrm{L})\end{array}$ & $\underset{(\mathrm{meq} / \mathrm{L})^{7}}{\mathrm{X}^{++}}$ \\
\hline W29.C880G & 79000 & 150 & 810 & 5700 & 510 \\
\hline W29.C880F & & & 1100 & & 480 \\
\hline W29.C880B & 71400 & 15600 & 950 & 5480 & 497 \\
\hline \multicolumn{6}{|l|}{ W29.C880KC } \\
\hline W29.C1285F & & & & & 610 \\
\hline W29.C1285B & 94900 & 23300 & 413 & 6500 & 553 \\
\hline W29.C1285E & 75400 & 20800 & 675 & 4750 & 423 \\
\hline W29.C1285I & 90000 & 23000 & 630 & 6350 & 552 \\
\hline
\end{tabular}


Table 94. Comparison of Data from the Culebra at WIPP-29 (continued)

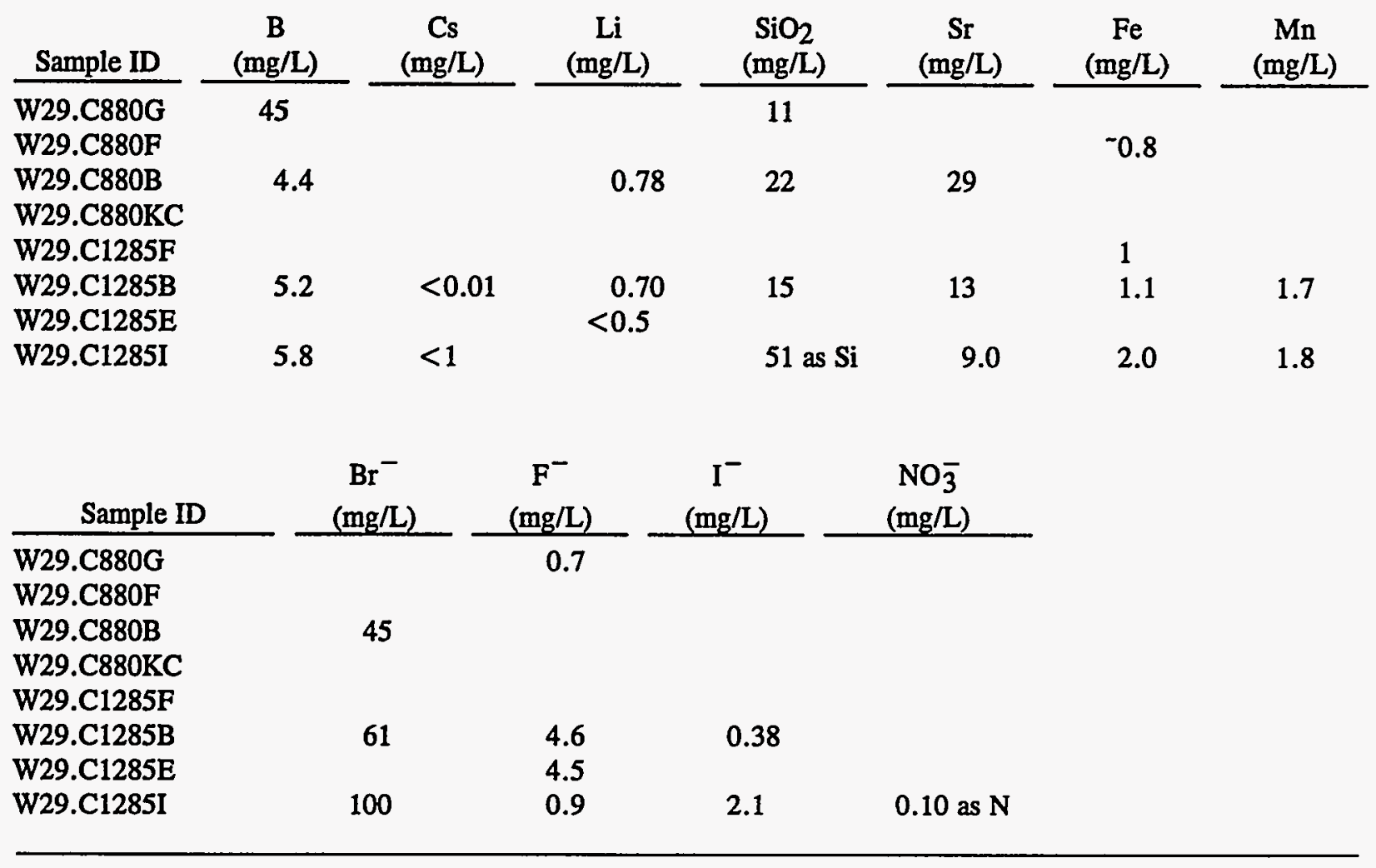


Table 95. Comparison of Data from the Culebra at WIPP-30

(Footnotes follow Table 135)

\begin{tabular}{|c|c|c|c|c|c|}
\hline Well ${ }^{1}$ & Agency $^{2}$ & Collection Date & Pumping Rate & $\mathrm{Lab}^{3}$ & Sample ID \\
\hline W-30 & USGS & $08 / 13 / 80$ & bail or swab & USGS & W30.C880G \\
\hline W-30 & SNL & $09 / 02 / 80-09 / 06 / 80$ & $.3->.1$, av.2gpm & FLD & W30.C980F \\
\hline W-30 & SNL & $09 / 06 / 80$ & $.3->.1$, av.2gpm & BFEC & W30.C980B \\
\hline W-30 & SNL & $09 / 06 / 80$ & $.3->.1$, av.2gpm & $\mathrm{KCS}$ & W30.C980KC \\
\hline
\end{tabular}

\begin{tabular}{|c|c|c|c|c|c|}
\hline Sample ID & $\begin{array}{c}\text { Density/ } \\
\text { Specific Gravity } 4 \\
\end{array}$ & $\mathrm{pH}$ & $\begin{array}{c}\text { TDS (calc) } \\
(\mathrm{mg} / \mathrm{L})^{5}\end{array}$ & $\begin{array}{c}\text { TDS (ROI) } \\
(\mathrm{mg} / \mathrm{L})\end{array}$ & $\begin{array}{c}\text { Charge-Balance } \\
\text { Error }^{5}\end{array}$ \\
\hline W30.C880G & $1.072(\mathrm{~g} / \mathrm{mL})$ & 6.8 & 108900 & $110000(105 \mathrm{C})$ & $-4.2 \%$ \\
\hline W30.C980F & $1.02(\mathrm{sg})$ & 8.8 & & & \\
\hline $\begin{array}{l}\text { W30.C980B } \\
\text { W30.C980KC }\end{array}$ & & & 29100 & & $-2.5 \%$ \\
\hline
\end{tabular}

\begin{tabular}{|c|c|c|c|c|c|}
\hline Sample ID & $\begin{array}{c}\text { Alkalinity } \\
\left(\mathrm{mg} / \mathrm{L} \mathrm{CaCO}_{3}\right)^{6}\end{array}$ & $\begin{array}{c}\mathrm{HCO}_{3}^{-} \\
(\mathrm{mg} / \mathrm{L})^{6}\end{array}$ & $\begin{array}{c}\mathrm{CO}_{3}^{\overline{3}} \\
(\mathrm{mg} / \mathrm{L})^{6}\end{array}$ & $\begin{array}{c}\mathrm{Cl}^{-} \\
(\mathrm{mg} / \mathrm{L})\end{array}$ & $\begin{array}{c}\mathrm{SO} \overline{\overline{4}} \\
(\mathrm{mg} / \mathrm{L})\end{array}$ \\
\hline W30.C880G & 74 & 90 & 0 & 64000 & 5050 \\
\hline W30.C980F & 61 & 40 & 17 & 15000 & -4000 \\
\hline W30.C980B & & & & 14600 & 4120 \\
\hline W30.C980KC & & & & 18700 & \\
\hline
\end{tabular}

\begin{tabular}{|c|c|c|c|c|c|}
\hline Sample ID & $\begin{array}{c}\mathrm{Na} \\
(\mathrm{mg} / \mathrm{L})\end{array}$ & $\underset{(\mathrm{mg} / \mathrm{L})}{\mathrm{K}}$ & $\underset{(\mathrm{mg} / \mathrm{L})}{\mathrm{Ca}}$ & $\underset{(\mathrm{mg} / \mathrm{L})}{\mathrm{Mg}}$ & $\begin{array}{c}\mathrm{X}^{++} \\
(\mathrm{meq} / \mathrm{L})^{7}\end{array}$ \\
\hline W30.C880G & 37000 & 888 & 1100 & 870 & 130 \\
\hline W30.C $980 F$ & & & 1200 & & 97 \\
\hline W30.C980B & 8570 & 255 & 1140 & 460 & 94.7 \\
\hline
\end{tabular}

\begin{tabular}{|c|c|c|c|c|c|c|c|}
\hline Sample ID & $\begin{array}{c}\mathrm{B} \\
(\mathrm{mg} / \mathrm{L})\end{array}$ & $\begin{array}{c}\mathrm{Cs} \\
(\mathrm{mg} / \mathrm{L})\end{array}$ & $\begin{array}{c}\mathrm{Li} \\
(\mathrm{mg} / \mathrm{L})\end{array}$ & $\begin{array}{c}\mathrm{SiO}_{2} \\
(\mathrm{mg} / \mathrm{L})\end{array}$ & $\begin{array}{c}\mathrm{Sr} \\
(\mathrm{mg} / \mathrm{L})\end{array}$ & $\begin{array}{c}\mathrm{Fe} \\
(\mathrm{mg} / \mathrm{L})\end{array}$ & $\begin{array}{c}\mathrm{Mn} \\
(\mathrm{mg} / \mathrm{L})\end{array}$ \\
\hline W30.C880G & 64 & & & 2.9 & & & \\
\hline W30.C980F & & & & & & -0.05 & \\
\hline $\begin{array}{l}\text { W30.C } 980 B \\
\text { W30.C } 980 \mathrm{KC}\end{array}$ & 6.1 & & 0.27 & 6.5 & 18 & & \\
\hline
\end{tabular}

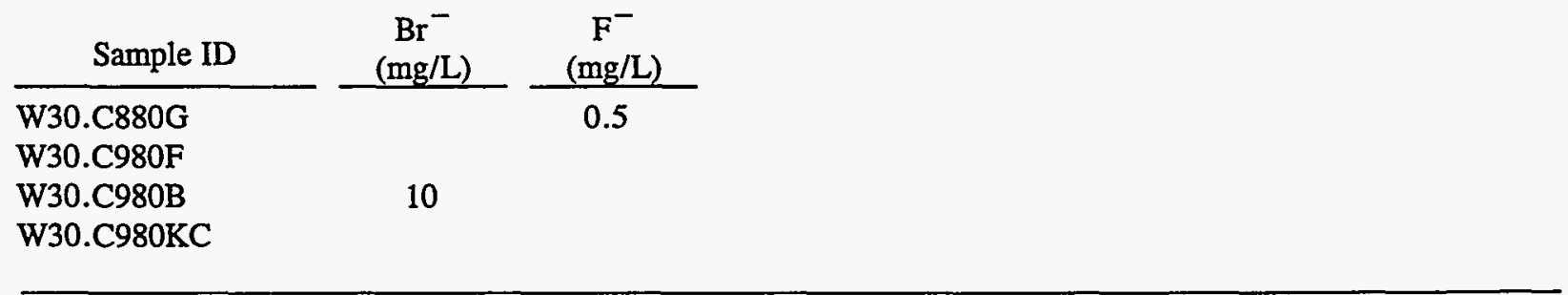


Table 96. Comparison of Data from the Culebra at Engle Well

(Footnotes follow Table 135)

\begin{tabular}{|c|c|c|c|c|c|}
\hline Well ${ }^{1}$ & Agency $^{2}$ & Collection Date & Pumping Rate & $\mathrm{Lab}^{3}$ & Sample ID \\
\hline ENGLE & HGC & $11 / 04 / 83-11 / 10 / 83$ & $9.8 \mathrm{gpm}$ & FLD & XENG.C11 \\
\hline ENGLE & HGC & $11 / 10 / 83$ & $9.8 \mathrm{gpm}$ & H-B & XENG.C11 \\
\hline ENGLE & $\mathrm{HGC}$ & $11 / 10 / 83$ & $9.8 \mathrm{gpm}$ & KGS & XENG.C11 \\
\hline ENGLE & HGC & $11 / 10 / 83$ & $9.8 \mathrm{gpm}$ & UA & XENG.C11 \\
\hline ENGLE & WQSP-R1 & $02 / 26 / 85-03 / 05 / 85$ & $.8 \mathrm{gpm}$ & FLD & XENG.C38 \\
\hline ENGLE & WQSP-R1 & $03 / 05 / 85$ & $.8 \mathrm{gpm}$ & BFEC & XENG.C38 \\
\hline ENGLE & WQSP-R1 & $03 / 04,05 / 85$ & $.8 \mathrm{gpm}$ & EEG & XENG.C38 \\
\hline ENGLE & WQSP-R1 & $03 / 04,05 / 85$ & $.8 \mathrm{gpm}$ & ITAS & XENG.C38 \\
\hline
\end{tabular}

\begin{tabular}{|c|c|c|c|c|c|}
\hline Sample ID & $\begin{array}{c}\text { Density/ } \\
\text { Specific Gravity } 4 \\
\end{array}$ & $\mathrm{pH}$ & $\begin{array}{l}\text { TDS (calc) } \\
(\mathrm{mg} / \mathrm{L})^{5}\end{array}$ & $\begin{array}{c}\text { TDS (ROI) } \\
\text { (mg/L) }\end{array}$ & $\begin{array}{c}\text { Charge-Balance } \\
\text { Error } 5\end{array}$ \\
\hline $\begin{array}{l}\text { XENG.C1183F } \\
\text { XENG.C1183HB }\end{array}$ & & 7.3 & & & \\
\hline $\begin{array}{l}\text { XENG.C1183K } \\
\text { XENG.C385F }\end{array}$ & & 7.4 & & & \\
\hline XENG.C385B & & & 3270 & & $1.0 \%$ \\
\hline $\begin{array}{l}\text { XENG.C385E } \\
\text { XENG.C385I }\end{array}$ & $1.015(\mathrm{~g} / \mathrm{mL})$ & $\begin{array}{l}7.8 \\
6.5\end{array}$ & 2940 & $3460(180 \mathrm{C})$ & $4.0 \%$ \\
\hline
\end{tabular}

\begin{tabular}{|c|c|c|c|c|c|}
\hline Sample ID & $\begin{array}{c}\text { Alkalinity } \\
\left(\mathrm{mg} / \mathrm{L} \mathrm{CaCO}_{3}\right)^{6} \\
\end{array}$ & $\begin{array}{l}\mathrm{HCO}_{3}^{-} \\
(\mathrm{mg} / \mathrm{L})^{6}\end{array}$ & $\begin{array}{c}\mathrm{CO}_{\overline{3}}^{\overline{3}} \\
(\mathrm{mg} / \mathrm{L})^{6}\end{array}$ & $\begin{array}{c}\mathrm{Cl}^{-} \\
(\mathrm{mg} / \mathrm{L})\end{array}$ & $\begin{array}{c}\mathrm{SO} \overline{\overline{4}} \\
(\mathrm{mg} / \mathrm{L})\end{array}$ \\
\hline XENG.C1183F & & -230 & & & \\
\hline XENG.C1183HB & & & & 230 & 1100 \\
\hline XENG.C1183K & & 98 & & 163 & \\
\hline XENG.C385F & 90 & 110 & 0 & 220 & \\
\hline XENG.C385B & 87 & 110 & 0 & 231 & 1990 \\
\hline XENG.C385E & & & & 170 & 1880 \\
\hline
\end{tabular}

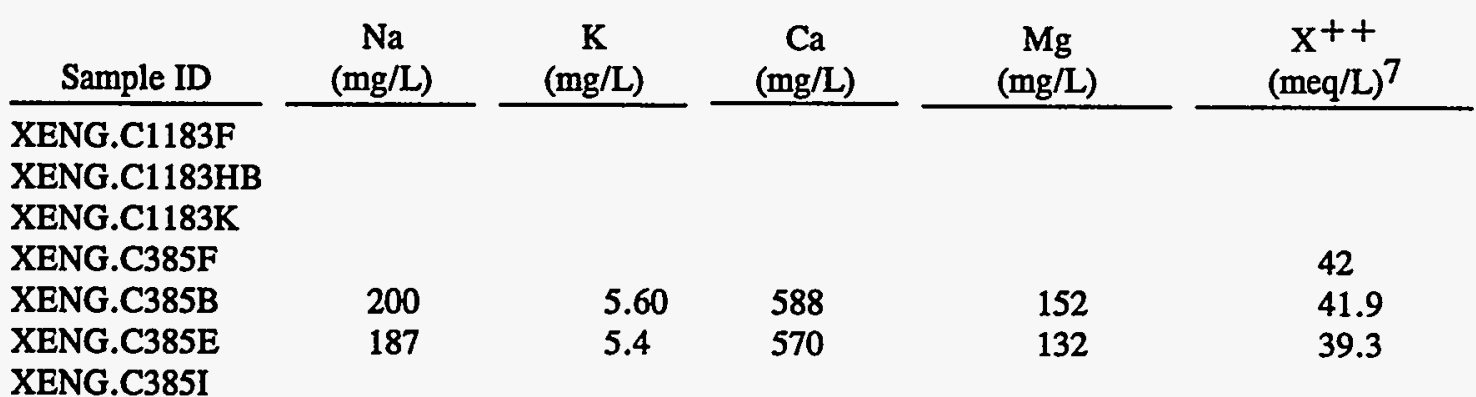


Table 96. Comparison of Data from the Culebra at Engle Well (continued)

\begin{tabular}{|c|c|c|c|c|c|c|c|}
\hline Sample ID & $\begin{array}{c}\mathrm{B} \\
(\mathrm{mg} / \mathrm{L})\end{array}$ & $\begin{array}{c}\mathrm{Cs} \\
(\mathrm{mg} / \mathrm{L})\end{array}$ & $\begin{array}{c}\mathrm{Li} \\
(\mathrm{mg} / \mathrm{L})\end{array}$ & $\begin{array}{c}\mathrm{SiO}_{2} \\
(\mathrm{mg} / \mathrm{L})\end{array}$ & $\begin{array}{c}\mathrm{Sr} \\
(\mathrm{mg} / \mathrm{L})\end{array}$ & $\begin{array}{c}\mathrm{Fe} \\
(\mathrm{mg} / \mathrm{L})\end{array}$ & $\begin{array}{c}\mathrm{Mn} \\
(\mathrm{mg} / \mathrm{L})\end{array}$ \\
\hline \multicolumn{8}{|l|}{ XENG.C1183F } \\
\hline \multicolumn{8}{|l|}{ XENG.C1183K } \\
\hline XENG.C385F & & & & & & 0.5 & \\
\hline XENG.C385B & 0.97 & $<0.001$ & 0.17 & 29 & 8.4 & 0.59 & 0.060 \\
\hline \multicolumn{8}{|l|}{ XENG.C385E } \\
\hline \multirow[t]{2}{*}{ XENG.C385I } & 0.77 & 0.07 & & 25 as $\mathrm{Si}$ & 7.0 & 0.32 & $\tau 0.01$ \\
\hline & $\begin{array}{c}\mathrm{Br}^{-} \\
(\mathrm{mg} / \mathrm{L})\end{array}$ & $\begin{array}{c}\mathrm{F}^{-} \\
(\mathrm{mg} / \mathrm{L}) \\
\end{array}$ & $\begin{array}{c}\mathrm{I}^{-} \\
(\mathrm{mg} / \mathrm{L})\end{array}$ & \multicolumn{2}{|c|}{$\begin{array}{c}\mathrm{NO}_{3}^{-} \\
(\mathrm{mg} / \mathrm{L})\end{array}$} & & \\
\hline \multicolumn{8}{|l|}{ XENG.C1183F } \\
\hline XENG.C1183HB & \multicolumn{7}{|c|}{2} \\
\hline XENG.C1183K & 0.47 & & 0.008 & & & & \\
\hline \multicolumn{8}{|l|}{ XENG.C385F } \\
\hline XENG.C385B & 0.27 & 2.8 & 0.12 & & & & \\
\hline XENG.C385E & & 2.9 & & & & & \\
\hline XENG.C385I & 1.2 & 2.8 & $<1$ & 0.5 & & & \\
\hline
\end{tabular}


Table 97. Comparison of Data from the Magenta at $\mathrm{H}-1$

(Footnotes follow Table 135)

\begin{tabular}{|c|c|c|c|c|c|}
\hline Well ${ }^{1}$ & Agency $^{2}$ & Collection Date & Pumping Rate & $\mathrm{Lab}^{3}$ & Sample ID \\
\hline $\mathrm{H}-1$ & USGS & $06 / 04 / 76$ & bail or swab & USGS & H01.M676G \\
\hline
\end{tabular}

\begin{tabular}{|c|c|c|c|c|c|}
\hline Sample ID & $\begin{array}{c}\text { Density/ } \\
\text { Specific Gravity } 4 \\
\end{array}$ & $\mathrm{pH}$ & $\begin{array}{l}\text { TDS (calc) } \\
(\mathrm{mg} / \mathrm{L})^{5}\end{array}$ & $\begin{array}{c}\text { TDS (ROI) } \\
(\mathrm{mg} / \mathrm{L})\end{array}$ & $\begin{array}{c}\text { Charge-Balance } \\
\text { Enror } \\
\end{array}$ \\
\hline H01.M676G & & 7.4 & 18900 & $18900(105 \mathrm{C})$ & $1.3 \%$ \\
\hline H01.M577G & & 7.2 & 22200 & & $2.8 \%$ \\
\hline
\end{tabular}

\begin{tabular}{|c|c|c|c|c|c|}
\hline Sample ID & $\begin{array}{c}\text { Alkalinity } \\
(\mathrm{mg} / \mathrm{L} \mathrm{CaCO})^{6}\end{array}$ & $\begin{array}{c}\mathrm{HCO}_{3}^{-} \\
(\mathrm{mg} / \mathrm{L})^{6}\end{array}$ & $\begin{array}{c}\mathrm{CO}_{\overline{3}}^{\overline{3}} \\
(\mathrm{mg} / \mathrm{L})^{6}\end{array}$ & $\begin{array}{c}\mathrm{Cl}^{-} \\
(\mathrm{mg} / \mathrm{L})\end{array}$ & $\begin{array}{c}\mathrm{SO} \overline{\overline{4}} \\
(\mathrm{mg} / \mathrm{L})\end{array}$ \\
\hline H01.M676G & 75 & 92 & 0 & 8000 & 3900 \\
\hline H01.M577G & 76 & 93 & 0 & 10000 & 3600 \\
\hline
\end{tabular}

\begin{tabular}{|c|c|c|c|c|c|}
\hline Sample ID & $\begin{array}{c}\mathrm{Na} \\
(\mathrm{mg} / \mathrm{L})\end{array}$ & $\underset{(m g / L)}{K}$ & $\begin{array}{c}\mathrm{Ca} \\
(\mathrm{mg} / \mathrm{L})\end{array}$ & $\begin{array}{c}\mathrm{Mg} \\
(\mathrm{mg} / \mathrm{L})\end{array}$ & $\underset{(\mathrm{meq} / \mathrm{L})^{7}}{\mathrm{X}^{++}}$ \\
\hline H01.M676G & 5700 & 70 & 890 & 270 & 67 \\
\hline
\end{tabular}

\begin{tabular}{|c|c|c|c|c|c|c|c|}
\hline Sample ID & $\begin{array}{c}\text { B } \\
(\mathrm{mg} / \mathrm{L})\end{array}$ & $\begin{array}{c}\mathrm{Cs} \\
(\mathrm{mg} / \mathrm{L})\end{array}$ & $\begin{array}{c}\mathrm{Li} \\
(\mathrm{mg} / \mathrm{L})\end{array}$ & $\begin{array}{c}\mathrm{SiO}_{2} \\
(\mathrm{mg} / \mathrm{L})\end{array}$ & $\begin{array}{c}\mathrm{Sr} \\
(\mathrm{mg} / \mathrm{L})\end{array}$ & $\begin{array}{c}\mathrm{Fe} \\
(\mathrm{mg} / \mathrm{L})\end{array}$ & $\underset{(\mathrm{mg} / \mathrm{L})}{\mathrm{Mn}}$ \\
\hline H01.M676G & 2.2 & & & 1.3 & & & \\
\hline H01.M577G & 3.3 & & & 1.7 & & & \\
\hline
\end{tabular}

$\frac{\text { Sample ID }}{\text { H01.M676G }}-\frac{\mathrm{Br}^{-}}{(\mathrm{mg} / \mathrm{L})}$
H01.M577G $\frac{\begin{array}{c}\mathrm{F}^{-} \\ (\mathrm{mg} / \mathrm{L})\end{array}}{2.8}$


Table 98. Comparison of Data from the Magenta at H-2

(Footnotes follow Table 135)

$\frac{\text { Well }^{1}}{\text { H-2A }} \frac{\text { Agency }^{2}}{\text { USGS }} \frac{\text { Collection Date }}{02 / 22 / 77} \frac{\text { Pumping Rate }}{\text { bail or swab }} \frac{\text { Lab }^{3}}{\text { USGS }} \frac{\text { Sample ID }}{\text { H02A.M277G }}$

$\frac{\text { Sample ID }}{\text { H02A.M277G }} \frac{\begin{array}{c}\text { Density/ } \\ \text { Specific Gravity }\end{array}}{2.6} \frac{\mathrm{pH}}{8.6} \frac{\begin{array}{c}\text { TDS (calc) } \\ (\mathrm{mg} / \mathrm{L})^{5}\end{array}}{10300} \frac{\begin{array}{c}\text { TDS (ROI) } \\ (\mathrm{mg} / \mathrm{L})\end{array}}{12000(105 \mathrm{C})} \frac{\begin{array}{c}\text { Charge-Balance } \\ \text { Error }^{5}\end{array}}{2.3 \%}$

$\frac{\text { Sample ID }}{\text { H02A.M277G }} \frac{\begin{array}{c}\text { Alkalinity } \\ \left(\mathrm{mg} / \mathrm{L} \mathrm{CaCO}_{3}\right)^{6}\end{array}}{61} \frac{\begin{array}{c}\mathrm{HCO}_{3}^{-} \\ (\mathrm{mg} / \mathrm{L})^{6}\end{array}}{74} \frac{\begin{array}{c}\mathrm{CO}_{\overline{3}} \\ (\mathrm{mg} / \mathrm{L})^{6}\end{array}}{0} \frac{\begin{array}{c}\mathrm{Cl}^{-} \\ (\mathrm{mg} / \mathrm{L})\end{array}}{4100} \frac{\begin{array}{c}\mathrm{SO} \overline{\overline{4}} \\ (\mathrm{mg} / \mathrm{L})\end{array}}{2400}$

$\frac{\text { Sample ID }}{\text { H02A.M277G }} \frac{\begin{array}{c}\mathrm{Na} \\ (\mathrm{mg} / \mathrm{L})\end{array}}{2700} \frac{\begin{array}{c}\mathrm{K} \\ (\mathrm{mg} / \mathrm{L})\end{array}}{81} \frac{\begin{array}{c}\mathrm{Ca} \\ (\mathrm{mg} / \mathrm{L})\end{array}}{820} \frac{\begin{array}{c}\mathrm{Mg} \\ (\mathrm{mg} / \mathrm{L})\end{array}}{170} \frac{\begin{array}{c}\mathrm{X}^{++} \\ (\mathrm{meq} / \mathrm{L})^{7}\end{array}}{55}$

$\frac{\text { Sample ID }}{\text { H02A.M277G }} \frac{\begin{array}{c}\mathrm{B} \\ (\mathrm{mg} / \mathrm{L})\end{array}}{0.22} \frac{\begin{array}{c}\mathrm{Cs} \\ (\mathrm{mg} / \mathrm{L})\end{array}}{\frac{(\mathrm{mg} / \mathrm{L})}{\mathrm{Li}}} \frac{\begin{array}{c}\mathrm{SiO}_{2} \\ (\mathrm{mg} / \mathrm{L})\end{array}}{6.0} \frac{\begin{array}{c}\mathrm{Sr} \\ (\mathrm{mg} / \mathrm{L})\end{array}}{\begin{array}{c}\mathrm{Fe} \\ (\mathrm{mg} / \mathrm{L})\end{array}} \underline{\begin{array}{c}\mathrm{Mn} \\ (\mathrm{mg} / \mathrm{L})\end{array}}$


Table 99. Comparison of Data from the Magenta at H-3

(Footnotes follow Table 135)

\begin{tabular}{|c|c|c|c|c|c|}
\hline Well $^{1}$ & Agency $^{2}$ & Collection Date & Pumping Rate & $\mathrm{Lab}^{3}$ & Sample ID \\
\hline H-3B1 & USGS & $05 / 10 / 77$ & bail or swab & USGS & H03B1.M577G \\
\hline H-3B1 & USGS & $05 / 10 / 79$ & bail or swab & SNL & H03B1.M579S \\
\hline H-3B1 & WQSP-R1 & $06 / 17 / 85-07 / 02 / 85$ & $14 \mathrm{gph}$ & FLD & H03B1.M785F \\
\hline H-3B1 & WQSP-R1 & $07 / 01 / 85$ & $14 \mathrm{gph}$ & BFEC & H03B1.M785B \\
\hline $\mathrm{H}-3 \mathrm{~B} 1$ & WQSP-R1 & $07 / 01 / 85$ & $14 \mathrm{gph}$ & EEG & H03B1.M785E \\
\hline H-3B1 & WQSP-R1 & $07 / 01 / 85$ & $14 \mathrm{gph}$ & ITAS & H03B1.M785I \\
\hline
\end{tabular}

\begin{tabular}{|c|c|c|c|c|c|}
\hline Sample ID & $\begin{array}{c}\text { Density/ } \\
\text { Specific Gravity } 4 \\
\end{array}$ & $\mathrm{pH}$ & $\begin{array}{c}\text { TDS (calc) } \\
(\mathrm{mg} / \mathrm{L})^{5}\end{array}$ & $\begin{array}{c}\text { TDS (ROI) } \\
(\mathrm{mg} / \mathrm{L})\end{array}$ & $\begin{array}{c}\text { Charge-Balance } \\
\text { Error } 5 \\
\end{array}$ \\
\hline H03B1.M577G & & 8.0 & 29700 & $32000(105 \mathrm{C})$ & $1.6 \%$ \\
\hline H03B1.M579S & $1.019(\mathrm{~g} / \mathrm{mL})$ & & 29000 & & $1.1 \%$ \\
\hline H03B1.M785F & $1.006(\mathrm{sg})$ & 8.0 & & & \\
\hline H03B1.M785B & & & 8560 & & $-1.0 \%$ \\
\hline H03B1.M785E & $1.02(\mathrm{~g} / \mathrm{mL})$ & 7.4 & 7820 & & $-2.0 \%$ \\
\hline H03B1.M785I & & 7.6 & & $9000(180 \mathrm{C})$ & \\
\hline
\end{tabular}

\begin{tabular}{|c|c|c|c|c|c|}
\hline Sample ID & $\begin{array}{c}\text { Alkalinity } \\
(\mathrm{mg} / \mathrm{L} \mathrm{CaCO})^{6} \\
\end{array}$ & $\begin{array}{c}\mathrm{HCO}_{3}^{-} \\
(\mathrm{mg} / \mathrm{L})^{6}\end{array}$ & $\begin{array}{c}\mathrm{CO}_{\overline{3}}^{\overline{3}} \\
(\mathrm{mg} / \mathrm{L})^{6} \\
\end{array}$ & $\begin{array}{c}\mathrm{Cl}^{-} \\
(\mathrm{mg} / \mathrm{L}) \\
\end{array}$ & $\begin{array}{c}\mathrm{SO} \overline{\overline{4}} \\
(\mathrm{mg} / \mathrm{L})\end{array}$ \\
\hline H03B1.M577G & 42 & 51 & 0 & 15000 & 3400 \\
\hline H03B1.M579S & 43 & 52 & 0 & 14300 & 3580 \\
\hline H03B1.M785F & 39 & 47 & 0 & 3400 & \\
\hline H03B1.M785B & 35 & 43 & 0 & 3360 & 2310 \\
\hline H03B1.M785E & & & & 3030 & 2240 \\
\hline
\end{tabular}

H03B1.M785I

\begin{tabular}{|c|c|c|c|c|c|}
\hline Sample ID & $\underset{(\mathrm{mg} / \mathrm{L})}{\mathrm{Na}}$ & $\underset{(\mathrm{mg} / \mathrm{L})}{\mathrm{K}}$ & $\underset{(\mathrm{mg} / \mathrm{L})}{\mathrm{Ca}}$ & $\begin{array}{c}\mathrm{Mg} \\
(\mathrm{mg} / \mathrm{L})\end{array}$ & $\underset{(\mathrm{meq} / \mathrm{L})^{7}}{\mathrm{X}^{++}}$ \\
\hline H03B1.M577G & 9300 & 250 & 1200 & 480 & 99 \\
\hline H03B1.M579S & 7810 & 1360 & 1120 & 730 & 116 \\
\hline H03B1.M785F & & & & & 74 \\
\hline H03B1.M785B & 1520 & 34.5 & 1000 & 292 & 73.9 \\
\hline H03В1.M785E & 1370 & 20.0 & 892 & 273 & 67.0 \\
\hline
\end{tabular}


Table 99. Comparison of Data from the Magenta at H-3 (continued)

\begin{tabular}{|c|c|c|c|c|c|c|c|}
\hline Sample ID & $\underset{(\mathrm{mg} / \mathrm{L})}{\mathrm{B}}$ & $\underset{(\mathrm{mg} / \mathrm{L})}{\mathrm{Cs}}$ & $\underset{(\mathrm{mg} / \mathrm{L})}{\mathbf{L i}}$ & $\underset{(\mathrm{mg} / \mathrm{L})}{\mathrm{SiO}_{2}}$ & $\underset{(\mathrm{mg} / \mathrm{L})}{\mathrm{Sr}}$ & $\begin{array}{c}\mathrm{Fe} \\
(\mathrm{mg} / \mathrm{L})\end{array}$ & $\underset{(\mathrm{mg} / \mathrm{L})}{\mathrm{Mn}}$ \\
\hline H03B1.M577G & 13 & & \multirow{6}{*}{$\begin{array}{l}0.32 \\
0.32\end{array}$} & \multirow[t]{2}{*}{6.4} & \multirow{5}{*}{17} & \multirow{5}{*}{$\begin{array}{l}0.7 \\
0.11\end{array}$} & \multirow{6}{*}{0.028} \\
\hline \multirow{5}{*}{$\begin{array}{l}\text { H03B1.M579S } \\
\text { H03B1.M785F } \\
\text { H03B1.M785B } \\
\text { H03B1.M785E } \\
\text { H03B1.M785I }\end{array}$} & & & & & & & \\
\hline & & & & \multirow{3}{*}{10} & & & \\
\hline & 2.0 & $<0.01$ & & & & & \\
\hline & & & & & & & \\
\hline & 4.5 & $<0.1$ & & 11 as $\mathrm{Si}$ & 17 & 0.14 & \\
\hline Sample ID & & $\begin{array}{c}\mathrm{Br}^{-} \\
(\mathrm{mg} / \mathrm{L})\end{array}$ & $\begin{array}{c}\mathrm{F}^{-} \\
(\mathrm{mg} / \mathrm{L})\end{array}$ & $\begin{array}{c}\mathrm{I}^{-} \\
(\mathrm{mg} / \mathrm{L})\end{array}$ & $\begin{array}{c}\mathrm{NO}_{3}^{-} \\
(\mathrm{mg} / \mathrm{L})\end{array}$ & & \\
\hline H03B1.M577G & & & 1.8 & & & & \\
\hline H03B1.M579S & & & & & & & \\
\hline H03B1.M785F & & & & & & & \\
\hline H03B1.M785B & & 5.8 & 2.4 & 1.2 & & & \\
\hline H03B1.M785E & & & 2.6 & & & & \\
\hline H03B1.M785I & & 23 & 1.8 & 1.6 & $<0.1$ as $\mathrm{N}$ & & \\
\hline
\end{tabular}


Table 100. Comparison of Data from the Magenta at $\mathrm{H}-4$ (Footnotes follow Table 135)

\begin{tabular}{|c|c|c|c|c|c|}
\hline Well ${ }^{1}$ & Agency $^{2}$ & Collection Date & Pumping Rate & $\mathrm{Lab}^{3}$ & Sample ID \\
\hline $\mathrm{H}-4 \mathrm{~A}$ & USGS & $12 / 14 / 78$ & bail or swab & USGS & H04A.M1278G \\
\hline $\mathrm{H}-4 \mathrm{C}$ & WQSP-R1 & $10 / 30 / 86-11 / 04 / 86$ & $4 \mathrm{gph}$ & FLD & H04C.M1186F \\
\hline $\mathrm{H}-4 \mathrm{C}$ & WQSP-R1 & $11 / 04 / 86$ & $4 \mathrm{gph}$ & BFEC & H04C.M1186B \\
\hline $\mathrm{H}-4 \mathrm{C}$ & WQSP-R1 & $11 / 04 / 86$ & $4 \mathrm{gph}$ & ITAS & H04C.M1186I \\
\hline
\end{tabular}

\begin{tabular}{|c|c|c|c|c|c|}
\hline Sample ID & $\begin{array}{c}\text { Density/ } \\
\text { Specific Gravity }{ }^{4} \\
\end{array}$ & $\mathrm{pH}$ & $\begin{array}{c}\text { TDS (calc) } \\
(\mathrm{mg} / \mathrm{L})^{5}\end{array}$ & $\begin{array}{c}\text { TDS (ROI) } \\
(\mathrm{mg} / \mathrm{L})\end{array}$ & $\begin{array}{c}\text { Charge-Balance } \\
\text { Error }^{5}\end{array}$ \\
\hline H04A.M1278G & & 8.0 & 22300 & $22300(105 \mathrm{C})$ & $-1.0 \%$ \\
\hline H04C.M1186F & $1.019(\mathrm{sg})$ & 8.4 & & & \\
\hline H04C.M1186B & & & 23900 & & $-1.4 \%$ \\
\hline H04C.M1186I & & 8.0 & 28200 & $22500(180 \mathrm{C})$ & $-5.8 \%$ \\
\hline
\end{tabular}

\begin{tabular}{|c|c|c|c|c|c|}
\hline Sample ID & $\begin{array}{c}\text { Alkalinity } \\
(\mathrm{mg} / \mathrm{L} \mathrm{CaCO} 3)^{6}\end{array}$ & $\begin{array}{c}\mathrm{HCO}_{3}^{-} \\
(\mathrm{mg} / \mathrm{L})^{6}\end{array}$ & $\begin{array}{c}\mathrm{CO}_{\overline{3}}^{\overline{-}} \\
(\mathrm{mg} / \mathrm{L})^{6}\end{array}$ & $\begin{array}{c}\mathrm{Cl}^{-} \\
(\mathrm{mg} / \mathrm{L})\end{array}$ & $\begin{array}{c}\mathrm{SO} \overline{\overline{4}} \\
(\mathrm{mg} / \mathrm{L})\end{array}$ \\
\hline H04A.M1278G & 52 & 63 & 0 & 7500 & 7000 \\
\hline H04C.M1186F & 69 & 70 & 7 & 8400 & \\
\hline H04C.M1186B & 61 & 74 & 0 & 8460 & 7100 \\
\hline H04C.M1186I & 82 & 100 & 0 & 11000 & 7850 \\
\hline
\end{tabular}

\begin{tabular}{|c|c|c|c|c|c|}
\hline Sample ID & $\begin{array}{c}\mathrm{Na} \\
(\mathrm{mg} / \mathrm{L})\end{array}$ & $\underset{(\mathrm{mg} / \mathrm{L})}{\mathrm{K}}$ & $\begin{array}{c}\mathrm{Ca} \\
(\mathrm{mg} / \mathrm{L})\end{array}$ & $\underset{(\mathrm{mg} / \mathrm{L})}{\mathrm{Mg}}$ & $\underset{(\mathrm{meq} / \mathrm{L})^{7}}{\mathrm{x}^{++}}$ \\
\hline H04A.M1278G & 7000 & 130 & 210 & 410 & 44 \\
\hline H04C.M1186F & & & & & 70 \\
\hline H04C.M1186B & 7110 & 85.1 & 651 & 411 & 66.2 \\
\hline H04C.M1186I & 7500 & 135 & 1100 & 470 & 93.5 \\
\hline
\end{tabular}

\begin{tabular}{|c|c|c|c|c|c|c|c|}
\hline Sample ID & $\begin{array}{c}\text { B } \\
(\mathrm{mg} / \mathrm{L})\end{array}$ & $\begin{array}{c}\mathrm{Cs} \\
(\mathrm{mg} / \mathrm{L})\end{array}$ & $\underset{(\mathrm{mg} / \mathrm{L})}{\mathrm{Li}}$ & $\begin{array}{c}\mathrm{SiO}_{2} \\
(\mathrm{mg} / \mathrm{L})\end{array}$ & $\begin{array}{c}\mathrm{Sr} \\
(\mathrm{mg} / \mathrm{L})\end{array}$ & $\underset{(\mathrm{mg} / \mathrm{L})}{\mathrm{Fe}}$ & $\underset{(m g / L)}{M n}$ \\
\hline H04A.M1278G & 13 & & & 6.4 & & & \\
\hline H04C.M1186F & & & & & & 0.7 & \\
\hline H04C.M1186B & 12 & $<0.01$ & 0.46 & 9.1 & 12 & 0.71 & 0.29 \\
\hline H04C.M1186I & 11 & 0.1 & 0.43 & 10 as $\mathrm{Si}$ & 13 & 0.90 & 0.46 \\
\hline
\end{tabular}

\begin{tabular}{|c|c|c|c|c|c|}
\hline Sample ID & $\begin{array}{c}\mathrm{Br}^{-} \\
(\mathrm{mg} / \mathrm{L})\end{array}$ & $\begin{array}{c}\mathrm{F}^{-} \\
(\mathrm{mg} / \mathrm{L})\end{array}$ & $\begin{array}{c}\mathrm{I}^{-} \\
(\mathrm{mg} / \mathrm{L})\end{array}$ & $\begin{array}{c}\mathrm{IO}_{3}^{-} \\
(\mathrm{mg} / \mathrm{L})\end{array}$ & $\begin{array}{c}\mathrm{NO}_{3}^{-} \\
(\mathrm{mg} / \mathrm{L})\end{array}$ \\
\hline $\begin{array}{l}\text { H04A.M1278G } \\
\text { H04C.M1186F }\end{array}$ & & 2.5 & & & \\
\hline H04C.M1186B & 5.9 & 2.4 & 0.31 & $<0.01$ & \\
\hline H04C.M1186I & 7.0 & 2.2 & 1.0 & & $<0.1$ as $\mathrm{N}$ \\
\hline
\end{tabular}


Table 101. Comparison of Data from the Magenta at H-5

(Footnotes follow Table 135)

\begin{tabular}{|c|c|c|c|c|c|}
\hline Well $^{1}$ & Agency $^{2}$ & Collection Date & Pumping Rate & $\mathrm{Lab}^{3}$ & Sample ID \\
\hline H-5A & USGS & $12 / 14 / 78$ & bail or swab & USGS & H05A.M1278G \\
\hline $\mathrm{H}-5 \mathrm{C}$ & WQSP-R1 & $10 / 07 / 86-10 / 24 / 86$ & $12 \mathrm{gph}$ & FLD & H05C.M1086F \\
\hline $\mathrm{H}-5 \mathrm{C}$ & WQSP-R1 & $10 / 24 / 86$ & $12 \mathrm{gph}$ & BFEC & H05C.M1086B \\
\hline $\mathrm{H}-5 \mathrm{C}$ & WQSP-R1 & $10 / 24 / 86$ & $12 \mathrm{gph}$ & ITAS & H05C.M1086I \\
\hline
\end{tabular}

\begin{tabular}{|c|c|c|c|c|c|}
\hline Sample ID & $\begin{array}{c}\text { Density/ } \\
\text { Specific Gravity } 4 \\
\end{array}$ & $\mathrm{pH}$ & $\begin{array}{l}\text { TDS (caic) } \\
(\mathrm{mg} / \mathrm{L})^{5}\end{array}$ & $\begin{array}{c}\text { TDS (ROI) } \\
(\mathrm{mg} / \mathrm{L})\end{array}$ & $\begin{array}{c}\text { Charge-Balance } \\
\text { Error } 5 \\
\end{array}$ \\
\hline H05A.M1278G & & 7.8 & 6090 & & $0.2 \%$ \\
\hline H05C.M1086F & $1.006(\mathrm{sg})$ & 8.0 & & & \\
\hline H05C.M1086B & & & 6980 & & $0.2 \%$ \\
\hline H05C.M1086I & & 7.4 & 8410 & $6800(180 \mathrm{C})$ & $-4.7 \%$ \\
\hline
\end{tabular}

\begin{tabular}{|c|c|c|c|c|c|}
\hline Sample ID & $\begin{array}{c}\text { Alkalinity } \\
(\mathrm{mg} / \mathrm{L} \mathrm{CaCO})^{6}\end{array}$ & $\begin{array}{c}\mathrm{HCO}_{\overline{3}} \\
(\mathrm{mg} / \mathrm{L})^{6}\end{array}$ & $\begin{array}{c}\mathrm{CO}_{\overline{3}}^{\overline{3}} \\
(\mathrm{mg} / \mathrm{L})^{6}\end{array}$ & $\begin{array}{c}\mathrm{Cl}^{-} \\
(\mathrm{mg} / \mathrm{L})\end{array}$ & $\begin{array}{c}\mathrm{SO} \overline{\overline{4}} \\
(\mathrm{mg} / \mathrm{L})\end{array}$ \\
\hline H05A.M1278G & 41 & 50 & 0 & 880 & 3200 \\
\hline H05C.M1086F & 46 & 56 & 0 & 1100 & \\
\hline H05C.M1086B & 41 & 50 & 0 & 1070 & 3620 \\
\hline H05C.M1086I & 57 & 69 & 0 & 1600 & 4200 \\
\hline
\end{tabular}

\begin{tabular}{|c|c|c|c|c|c|}
\hline Sample ID & $\begin{array}{c}\mathrm{Na} \\
(\mathrm{mg} / \mathrm{L})\end{array}$ & $\underset{(m g / L)}{K}$ & $\begin{array}{c}\mathrm{Ca} \\
(\mathrm{mg} / \mathrm{L})\end{array}$ & $\begin{array}{c}\mathrm{Mg} \\
(\mathrm{mg} / \mathrm{L})\end{array}$ & $\begin{array}{c}\mathrm{x}^{++} \\
(\mathrm{meq} / \mathrm{L})^{7}\end{array}$ \\
\hline H05A.M1278G & 1500 & 53 & 240 & 170 & 26 \\
\hline $\begin{array}{l}\text { H05C.M1086F } \\
\text { H05C.M1086B }\end{array}$ & 1480 & 33.6 & 550 & 173 & 41.7 \\
\hline H05C.M1086I & 1500 & 51.5 & 795 & 190 & 55.3 \\
\hline
\end{tabular}

\begin{tabular}{|c|c|c|c|c|c|c|c|}
\hline Sample ID & $\begin{array}{c}\text { B } \\
(\mathrm{mg} / \mathrm{L})\end{array}$ & $\underset{(\mathrm{mg} / \mathrm{L})}{\mathrm{Cs}}$ & $\underset{(\mathrm{mg} / \mathrm{L})}{\mathbf{L i}}$ & $\begin{array}{c}\mathrm{SiO}_{2} \\
(\mathrm{mg} / \mathrm{L})\end{array}$ & $\begin{array}{c}\mathrm{Sr} \\
(\mathrm{mg} / \mathrm{L})\end{array}$ & $\underset{(\mathrm{mg} / \mathrm{L})}{\mathrm{Fe}}$ & $\underset{(\mathrm{mg} / \mathrm{L})}{\mathrm{Mn}}$ \\
\hline H05A.M1278G & 11 & & & 9.0 & & & \\
\hline H05C.M1086F & & & & & & 1 & \\
\hline H05C.M1086B & 11 & $<0.01$ & 0.20 & 11 & 10 & 1.5 & 0.020 \\
\hline H05C.M1086I & 10 & 0.2 & 0.20 & 12 as $\mathrm{Si}$ & 8.4 & 1.3 & $<0.05$ \\
\hline
\end{tabular}

\begin{tabular}{|c|c|c|c|c|c|}
\hline Sample ID & $\begin{array}{c}\mathrm{Br}^{-} \\
(\mathrm{mg} / \mathrm{L})\end{array}$ & $\begin{array}{c}F^{-} \\
(\mathrm{mg} / \mathrm{L})\end{array}$ & $\begin{array}{c}\mathrm{I}^{-} \\
(\mathrm{mg} / \mathrm{L})\end{array}$ & $\begin{array}{c}\mathrm{IO}_{\overline{3}} \\
(\mathrm{mg} / \mathrm{L})\end{array}$ & $\begin{array}{c}\mathrm{NO}_{3}^{-} \\
(\mathrm{mg} / \mathrm{L})\end{array}$ \\
\hline H05A.M1278G & & 2.8 & & & \\
\hline H05C.M1086F & & & & & \\
\hline H05C.M1086B & 2.7 & 2.5 & 0.31 & $<0.01$ & \\
\hline H05C.M1086I & 4.0 & 2.5 & $<1$ & & $<0.1$ as $\mathrm{N}$ \\
\hline
\end{tabular}


Table 102. Comparison of Data from the Magenta at H-6

(Footnotes follow Table 135)

\begin{tabular}{|c|c|c|c|c|c|}
\hline Well $^{1}$ & Agency $^{2}$ & Collection Date & Pumping Rate & $\mathrm{Lab}^{3}$ & Sample ID \\
\hline $\mathrm{H}-6 \mathrm{~A}$ & USGS & $12 / 20 / 78$ & bail or swab & USGS & H06A.M1278G \\
\hline $\mathrm{H}-6 \mathrm{C}$ & WQSP-R1 & $09 / 22 / 86-10 / 01 / 86$ & $23 \mathrm{gph}$ & FLD & H06C.M1086F \\
\hline $\mathrm{H}-6 \mathrm{C}$ & WQSP-R1 & $10 / 01 / 86$ & $23 \mathrm{gph}$ & BFEC & H06C.M1086B \\
\hline $\mathrm{H}-6 \mathrm{C}$ & WQSP-R1 & $10 / 01 / 86$ & $23 \mathrm{gph}$ & ITAS & H06C.M1086I \\
\hline
\end{tabular}

\begin{tabular}{|c|c|c|c|c|c|}
\hline Sample ID & $\begin{array}{c}\text { Density/ } \\
\text { Specific Gravity } 4 \\
\end{array}$ & $\mathrm{pH}$ & $\begin{array}{c}\text { TDS (calc) } \\
(\mathrm{mg} / \mathrm{L})^{5}\end{array}$ & $\begin{array}{c}\text { TDS (ROI) } \\
(\mathrm{mg} / \mathrm{L})\end{array}$ & $\begin{array}{c}\text { Charge-Balance } \\
\text { Error }^{5}\end{array}$ \\
\hline H06A.M1278G & & 7.3 & 5780 & & $-1.6 \%$ \\
\hline H06C.M1086F & $1.003(\mathrm{sg})$ & 7.7 & & & \\
\hline H06C.M1086B & & & 4540 & & $-0.3 \%$ \\
\hline H06C.M1086I & & 7.2 & 4750 & $4600(180 \mathrm{C})$ & $19 \%$ \\
\hline
\end{tabular}

\begin{tabular}{|c|c|c|c|c|c|}
\hline Sample ID & $\begin{array}{c}\text { Alkalinity } \\
(\mathrm{mg} / \mathrm{L} \mathrm{CaCO} 3)^{6}\end{array}$ & $\begin{array}{c}\mathrm{HCO}_{3}^{-} \\
(\mathrm{mg} / \mathrm{L})^{6}\end{array}$ & $\begin{array}{c}\mathrm{CO}_{\overline{3}}= \\
(\mathrm{mg} / \mathrm{L})^{6}\end{array}$ & $\begin{array}{c}\mathrm{Cl}^{-} \\
(\mathrm{mg} / \mathrm{L})\end{array}$ & $\begin{array}{c}\mathrm{SO}_{\overline{4}} \\
(\mathrm{mg} / \mathrm{L})\end{array}$ \\
\hline H06A.M1278G & 42 & 51 & 0 & 1200 & 2700 \\
\hline H06C.M1086F & 42 & 51 & 0 & 420 & \\
\hline H06C.M1086B & 39 & 47 & 0 & 428 & 2700 \\
\hline H06C.M1086I & 43 & 52 & 0 & 430 & 2400 \\
\hline
\end{tabular}

\begin{tabular}{|c|c|c|c|c|c|}
\hline Sample ID & $\begin{array}{c}\mathrm{Na} \\
(\mathrm{mg} / \mathrm{L})\end{array}$ & $\underset{(\mathrm{mg} / \mathrm{L})}{\mathrm{K}}$ & $\begin{array}{c}\mathrm{Ca} \\
(\mathrm{mg} / \mathrm{L})\end{array}$ & $\begin{array}{c}\mathrm{Mg} \\
(\mathrm{mg} / \mathrm{L})\end{array}$ & $\begin{array}{c}\mathrm{X}^{++} \\
(\mathrm{meq} / \mathrm{L})^{7}\end{array}$ \\
\hline $\begin{array}{l}\text { H06A.M1278G } \\
\text { H06C.M1086F }\end{array}$ & 1100 & 46 & 520 & 160 & $\begin{array}{l}39 \\
41\end{array}$ \\
\hline H06C.M1086B & 642 & 16.6 & 546 & 160 & 40.4 \\
\hline H06C.M1086I & 1050 & 26.0 & 620 & 170 & 44.9 \\
\hline
\end{tabular}

\begin{tabular}{|c|c|c|c|c|c|c|c|}
\hline Sample ID & $\begin{array}{c}\text { B } \\
(\mathrm{mg} / \mathrm{L}) \\
\end{array}$ & $\begin{array}{c}\mathrm{Cs} \\
(\mathrm{mg} / \mathrm{L})\end{array}$ & $\begin{array}{c}\mathrm{Li} \\
(\mathrm{mg} / \mathrm{L})\end{array}$ & $\begin{array}{c}\mathrm{SiO}_{2} \\
(\mathrm{mg} / \mathrm{L})\end{array}$ & $\begin{array}{c}\mathrm{Sr} \\
(\mathrm{mg} / \mathrm{L})\end{array}$ & $\begin{array}{c}\mathrm{Fe} \\
(\mathrm{mg} / \mathrm{L})\end{array}$ & $\begin{array}{c}\mathrm{Mn} \\
(\mathrm{mg} / \mathrm{L})\end{array}$ \\
\hline H06A.M1278G & 2.5 & & & 7.7 & & & \\
\hline H06C.M1086F & & & & & & 0.4 & \\
\hline H06C.M1086B & 2.2 & $<0.01$ & 0.21 & 11 & 9.8 & 0.26 & 0.010 \\
\hline H06C.M1086I & 2.4 & 0.3 & 0.19 & 13 as $S$ & 7.1 & 0.30 & $<0.05$ \\
\hline
\end{tabular}

\begin{tabular}{|c|c|c|c|c|c|}
\hline Sample ID & $\begin{array}{c}\mathrm{Br}^{-} \\
(\mathrm{mg} / \mathrm{L})\end{array}$ & $\begin{array}{c}F^{-} \\
(\mathrm{mg} / \mathrm{L})\end{array}$ & $\begin{array}{c}\mathrm{I}^{-} \\
(\mathrm{mg} / \mathrm{L})\end{array}$ & $\begin{array}{c}\mathrm{IO}_{\overline{3}}^{-} \\
(\mathrm{mg} / \mathrm{L})\end{array}$ & $\begin{array}{c}\mathrm{NO}_{3}^{-} \\
(\mathrm{mg} / \mathrm{L})\end{array}$ \\
\hline $\begin{array}{l}\text { H06A.M1278G } \\
\text { H06C.M1086F }\end{array}$ & & 1.4 & & & \\
\hline H06C.M1086B & 1.1 & 1.5 & 0.086 & $<0.01$ & \\
\hline H06C.M1086I & 1.0 & 1.7 & $<1$ & & $<0.1$ as $\mathrm{N}$ \\
\hline
\end{tabular}


Table 103. Comparison of Data from the Magenta at H-8

(Footnotes follow Table 135)

\begin{tabular}{|c|c|c|c|c|c|}
\hline Well 1 & Agency 2 & Collection Date & Pumping Rate & $\mathrm{Lab}^{3}$ & Sample ID \\
\hline $\mathrm{H}-8 \mathrm{~A}$ & USGS & $02 / 12 / 80$ & bail or swab & USGS & H08A.M280G \\
\hline H-8A & WQSP-R1 & $10 / 21 / 85$ & 40 gph & ITAS & H08A.M1085I \\
\hline
\end{tabular}

\begin{tabular}{|c|c|c|c|c|c|}
\hline Sample ID & $\begin{array}{c}\text { Density/ } \\
\text { Specific Gravity }\end{array}$ & $\mathrm{pH}$ & $\begin{array}{c}\text { TDS (calc) } \\
(\mathrm{mg} / \mathrm{L})^{5}\end{array}$ & $\begin{array}{c}\text { TDS (ROI) } \\
(\mathrm{mg} / \mathrm{L})\end{array}$ & $\begin{array}{c}\text { Charge-Balance } \\
\text { Error } 5 \\
\end{array}$ \\
\hline H08A.M280G & $1.006(\mathrm{~g} / \mathrm{mL})$ & 9.3 & 8970 & $9410(105 \mathrm{C})$ & $3.1 \%$ \\
\hline H08A.M1085I & & -7.5 & 7150 & & $-5.3 \%$ \\
\hline
\end{tabular}

\begin{tabular}{|c|c|c|c|c|c|}
\hline Sample ID & $\begin{array}{c}\text { Alkalinity } \\
(\mathrm{mg} / \mathrm{L} \mathrm{CaCO})^{6}\end{array}$ & $\begin{array}{c}\mathrm{HCO}_{3}^{-} \\
(\mathrm{mg} / \mathrm{L})^{6}\end{array}$ & $\begin{array}{c}\mathrm{CO}_{\overline{3}} \\
(\mathrm{mg} / \mathrm{L})^{6}\end{array}$ & $\begin{array}{c}\mathrm{Cl}^{-} \\
(\mathrm{mg} / \mathrm{L})\end{array}$ & $\begin{array}{c}\mathrm{SO}_{\overline{4}} \\
(\mathrm{mg} / \mathrm{L})\end{array}$ \\
\hline H08A.M280G & $\begin{array}{l}26 \\
25\end{array}$ & 30 & 0 & 3500 & $\begin{array}{l}2100 \\
1700\end{array}$ \\
\hline
\end{tabular}

\begin{tabular}{|c|c|c|c|c|c|}
\hline Sample ID & $\begin{array}{c}\mathrm{Na} \\
(\mathrm{mg} / \mathrm{L})\end{array}$ & $\underset{(m g / L)}{K}$ & $\begin{array}{c}\mathrm{Ca} \\
(\mathrm{mg} / \mathrm{L})\end{array}$ & $\begin{array}{c}\mathrm{Mg} \\
(\mathrm{mg} / \mathrm{L})\end{array}$ & $\begin{array}{c}\mathrm{X}^{++} \\
(\mathrm{meq} / \mathrm{L})^{7}\end{array}$ \\
\hline H08A.M280G & 2400 & 84 & 870 & 17 & 45 \\
\hline H08A.M1085I & 1800 & 59.0 & 555 & 10.5 & 28.6 \\
\hline
\end{tabular}

\begin{tabular}{|c|c|c|c|c|c|c|c|}
\hline Sample ID & $\begin{array}{c}\mathrm{B} \\
(\mathrm{mg} / \mathrm{L})\end{array}$ & $\underset{(\mathrm{mg} / \mathrm{L})}{\mathrm{Cs}}$ & $\underset{(\mathrm{mg} / \mathrm{L})}{\mathrm{Li}}$ & $\begin{array}{c}\mathrm{SiO}_{2} \\
(\mathrm{mg} / \mathrm{L})\end{array}$ & $\begin{array}{c}\mathrm{Sr} \\
(\mathrm{mg} / \mathrm{L})\end{array}$ & $\underset{(\mathrm{mg} / \mathrm{L})}{\mathrm{Fe}}$ & $\underset{(\mathrm{mg} / \mathrm{L})}{\mathrm{Mn}}$ \\
\hline $\begin{array}{l}\text { H08A.M280G } \\
\text { H08A.M1085I }\end{array}$ & 3.1 & & & 0.9 & & & \\
\hline
\end{tabular}

$\frac{\text { Sample ID }}{\text { H08A.M280G }}-\frac{\begin{array}{c}\mathrm{Br}^{-} \\ (\mathrm{mg} / \mathrm{L})\end{array}}{\text { H08A.M1085I }} \frac{\begin{array}{c}\mathrm{F}^{-} \\ (\mathrm{mg} / \mathrm{L})\end{array}}{0.7}$


Table 104. Comparison of Data from the Magenta at H-9

(Footnotes follow Table 135)

$\frac{\text { Well }^{1}}{\text { H-9A }} \frac{\text { Agency }^{2}}{\text { USGS }} \frac{\text { Collection Date }}{02 / 05 / 80} \frac{\text { Pumping Rate }}{\text { bail or swab }} \frac{\text { Lab }^{3}}{\text { USGS }} \frac{\text { Sample ID }}{\text { H09A.M280G }}$

$\frac{\text { Sample ID }}{\text { H09A.M280G }} \frac{\begin{array}{c}\text { Density/ } \\ \text { Specific Gravity } 4\end{array}}{1.003(\mathrm{~g} / \mathrm{mL})} \frac{\mathrm{pH}}{8.5} \frac{\begin{array}{c}\text { TDS (calc) } \\ (\mathrm{mg} / \mathrm{L})^{5}\end{array}}{5000} \frac{\begin{array}{c}\text { TDS (ROI) } \\ (\mathrm{mg} / \mathrm{L})\end{array}}{5460(105 \mathrm{C})} \frac{\begin{array}{c}\text { Charge-Balance } \\ \text { Error }\end{array}}{-0.4 \%}$

$\frac{\text { Sample ID }}{\text { H09A.M280G }} \frac{\begin{array}{c}\text { Alkalinity } \\ \left(\mathrm{mg} / \mathrm{L} / \mathrm{CaCO}_{3}\right)^{6}\end{array}}{35} \frac{\begin{array}{c}\mathrm{HCO}_{3}^{-} \\ (\mathrm{mg} / \mathrm{L})^{6}\end{array}}{35} \frac{\begin{array}{c}\mathrm{CO}_{\overline{3}} \\ (\mathrm{mg} / \mathrm{L})^{6}\end{array}}{\frac{(\mathrm{mg} / \mathrm{L})}{750}} \frac{\begin{array}{c}\mathrm{Cl}^{-} \\ (\mathrm{mg} / \mathrm{L})\end{array}}{2700}$

$\frac{\text { Sample ID }}{\text { H09A.M280G }} \frac{\begin{array}{c}\mathrm{Na} \\ (\mathrm{mg} / \mathrm{L})\end{array}}{800} \frac{\begin{array}{c}\mathrm{K} \\ (\mathrm{mg} / \mathrm{L})\end{array}}{28} \frac{\begin{array}{c}\mathrm{Ca} \\ (\mathrm{mg} / \mathrm{L})\end{array}}{550} \frac{\begin{array}{c}\mathrm{Mg} \\ (\mathrm{mg} / \mathrm{L})\end{array}}{170} \frac{\begin{array}{c}\mathrm{X}^{++} \\ (\mathrm{meq} / \mathrm{L})^{7}\end{array}}{41}$

\begin{tabular}{|c|c|c|c|c|c|c|c|}
\hline Sample ID & $\begin{array}{c}\text { B } \\
(\mathrm{mg} / \mathrm{L})\end{array}$ & $\begin{array}{c}\mathrm{Cs} \\
(\mathrm{mg} / \mathrm{L})\end{array}$ & $\begin{array}{c}\mathrm{Li} \\
(\mathrm{mg} / \mathrm{L})\end{array}$ & $\begin{array}{c}\mathrm{SiO}_{2} \\
(\mathrm{mg} / \mathrm{L})\end{array}$ & $\begin{array}{c}\mathrm{Sr} \\
(\mathrm{mg} / \mathrm{L})\end{array}$ & $\begin{array}{c}\mathrm{Fe} \\
(\mathrm{mg} / \mathrm{L})\end{array}$ & $\underset{(\mathrm{mg} / \mathrm{L})}{\mathrm{Mn}}$ \\
\hline 09A.M280G & 2.6 & & & 3.3 & & & \\
\hline
\end{tabular}

$\frac{\text { Sample ID }}{\text { H09A.M280G }} \frac{\begin{array}{c}\mathrm{Br}^{-} \\ (\mathrm{mg} / \mathrm{L})\end{array}}{1.8} \frac{\begin{array}{c}\mathrm{F}^{-} \\ (\mathrm{mg} / \mathrm{L})\end{array}}{1.8}$


Table 105. Comparison of Data from the Magenta at $\mathrm{H}-10$

(Footnotes follow Table 135)

$\frac{\text { Well }^{1}}{\text { H-10A }} \frac{\text { Agency }^{2}}{\text { USGS }} \frac{\text { Collection Date }}{03 / 21 / 80} \frac{\text { Pumping Rate }}{\text { bail or swab }} \frac{\text { Lab }^{3}}{\text { USGS }} \frac{\text { Sample ID }}{\text { H10A.M380G }}$

$\frac{\text { Sample ID }}{\text { H10A.M380G }} \frac{\begin{array}{c}\text { Density/ } \\ \text { Specific Gravity }\end{array}}{1.175(\mathrm{~g} / \mathrm{mL})} \frac{\mathrm{pH}}{7.1} \frac{\begin{array}{c}\text { TDS (calc) } \\ (\mathrm{mg} / \mathrm{L})^{5}\end{array}}{261300} \frac{\begin{array}{c}\text { TDS (ROI) } \\ (\mathrm{mg} / \mathrm{L})\end{array}}{270000(105 \mathrm{C})} \frac{\begin{array}{c}\text { Charge-Balance } \\ \text { Error }\end{array}}{-2.0 \%}$

$\frac{\text { Sample ID }}{\text { H10A.M380G }} \frac{\begin{array}{c}\text { Alkalinity } \\ \left(\mathrm{mg} / \mathrm{L} \mathrm{CaCO}_{3}\right)^{6}\end{array}}{(\mathrm{mg} / \mathrm{L})^{6}} \frac{\begin{array}{c}\mathrm{CO}_{\overline{3}}^{-} \\ (\mathrm{mg} / \mathrm{L})^{6}\end{array}}{\frac{\mathrm{HCl}^{-}}{(\mathrm{mg} / \mathrm{L})}} \frac{\begin{array}{c}\mathrm{SO} \overline{\overline{4}} \\ (\mathrm{mg} / \mathrm{L})\end{array}}{2700000}$

$\frac{\text { Sample ID }}{\text { H10A.M380G }} \frac{\begin{array}{c}\mathrm{Na} \\ (\mathrm{mg} / \mathrm{L})\end{array}}{93000} \frac{\begin{array}{c}\mathrm{K} \\ (\mathrm{mg} / \mathrm{L})\end{array}}{510} \frac{\begin{array}{c}\mathrm{Ca} \\ (\mathrm{mg} / \mathrm{L})\end{array}}{2500} \frac{\begin{array}{c}\mathrm{Mg} \\ (\mathrm{mg} / \mathrm{L})\end{array}}{2600} \frac{\begin{array}{c}\mathrm{X}^{++} \\ (\mathrm{meq} / \mathrm{L})^{7}\end{array}}{340}$

$\frac{\text { Sample ID }}{\text { H10A.M380G }} \frac{\begin{array}{c}\mathrm{B} \\ (\mathrm{mg} / \mathrm{L})\end{array}}{3.9} \frac{\begin{array}{c}\mathrm{Cs} \\ (\mathrm{mg} / \mathrm{L})\end{array}}{\frac{(\mathrm{mg} / \mathrm{L})}{\mathrm{Li}}} \frac{\begin{array}{c}\mathrm{SiO}_{2} \\ (\mathrm{mg} / \mathrm{L})\end{array}}{1.9} \frac{\begin{array}{c}\mathrm{Sr} \\ (\mathrm{mg} / \mathrm{L})\end{array}}{(\mathrm{mg} / \mathrm{L})} \underbrace{(\mathrm{mg} / \mathrm{L})}$

$\frac{\text { Sample ID }}{\text { H10A.M380G }} \frac{\begin{array}{c}\mathrm{Br}^{-} \\ (\mathrm{mg} / \mathrm{L})\end{array}}{\frac{\mathrm{F}^{-}}{(\mathrm{mg} / \mathrm{L})}}$


Table 106. Comparison of Data from the Magenta at WIPP-25 (Footnotes follow Table 135)

\begin{tabular}{|c|c|c|c|c|c|}
\hline Well $^{1}$ & Agency $^{2}$ & Collection Date & Pumping Rate & $\mathrm{Lab}^{3}$ & Sample ID \\
\hline W-25 & USGS & $09 / 04 / 80$ & bail or swab & USGS & W25.M980G \\
\hline W-25 & SNL & $09 / 16 / 80-09 / 18 / 80$ & $34 \mathrm{gpm}$ & FLD & W25.M980F \\
\hline W-25 & SNL & $09 / 17 / 80$ & $34 \mathrm{gpm}$ & BFEC & W25.M980B \\
\hline
\end{tabular}

\begin{tabular}{|c|c|c|c|c|c|}
\hline Sample ID & $\begin{array}{c}\text { Density/ } \\
\text { Specific Gravity } 4\end{array}$ & $\mathrm{pH}$ & $\begin{array}{l}\text { TDS (calc) } \\
(\mathrm{mg} / \mathrm{L})^{5}\end{array}$ & $\begin{array}{c}\text { TDS (ROI) } \\
(\mathrm{mg} / \mathrm{L})\end{array}$ & $\begin{array}{c}\text { Charge-Balance } \\
\text { Error }^{5}\end{array}$ \\
\hline 25.1 & $1.010(\mathrm{~g} / \mathrm{mL})$ & 7.5 & 11800 & $18700(105 \mathrm{C})$ & $0.7 \%$ \\
\hline W25.M980F & 1.004 (sg) & 6.9 & & & \\
\hline
\end{tabular}

\begin{tabular}{|c|c|c|c|c|c|}
\hline Sample ID & $\begin{array}{c}\text { Alkalinity } \\
(\mathrm{mg} / \mathrm{L} \mathrm{CaCO})^{6}\end{array}$ & $\begin{array}{c}\mathrm{HCO}_{3}^{-} \\
(\mathrm{mg} / \mathrm{L})^{6}\end{array}$ & $\begin{array}{c}\mathrm{CO}_{3}^{\overline{3}} \\
(\mathrm{mg} / \mathrm{L})^{6}\end{array}$ & $\begin{array}{c}\mathrm{Cl}^{-} \\
(\mathrm{mg} / \mathrm{L})\end{array}$ & $\begin{array}{c}\mathrm{SO} \overline{\overline{4}} \\
(\mathrm{mg} / \mathrm{L})\end{array}$ \\
\hline W25.M980G & 150 & 180 & 0 & 5600 & 1900 \\
\hline W25.M980F & 150 & 180 & 0 & 4900 & -3000 \\
\hline W25.M980B & & & & 5250 & 2490 \\
\hline
\end{tabular}

\begin{tabular}{|c|c|c|c|c|c|}
\hline Sample ID & $\begin{array}{c}\mathrm{Na} \\
(\mathrm{mg} / \mathrm{L})\end{array}$ & $\begin{array}{c}\mathrm{K} \\
(\mathrm{mg} / \mathrm{L})\end{array}$ & $\begin{array}{c}\mathrm{Ca} \\
(\mathrm{mg} / \mathrm{L})\end{array}$ & $\begin{array}{c}\mathrm{Mg} \\
(\mathrm{mg} / \mathrm{L})\end{array}$ & $\begin{array}{c}\mathrm{x}^{++} \\
(\mathrm{meq} / \mathrm{L})^{7}\end{array}$ \\
\hline W25.M980G & 3100 & 0.8 & 910 & 240 & 65 \\
\hline W25.M980F & & & 920 & & 66 \\
\hline W25.M980B & 2910 & 71.5 & 905 & 260 & 66.6 \\
\hline
\end{tabular}

\begin{tabular}{|c|c|c|c|c|c|c|c|}
\hline Sample ID & $\begin{array}{c}\text { B } \\
(\mathrm{mg} / \mathrm{L})\end{array}$ & $\begin{array}{c}\mathrm{Cs} \\
(\mathrm{mg} / \mathrm{L})\end{array}$ & $\underset{(\mathrm{mg} / \mathrm{L})}{\mathrm{Li}}$ & $\begin{array}{c}\mathrm{SiO}_{2} \\
(\mathrm{mg} / \mathrm{L})\end{array}$ & $\underset{(\mathrm{mg} / \mathrm{L})}{\mathrm{Sr}}$ & $\begin{array}{c}\mathrm{Fe} \\
(\mathrm{mg} / \mathrm{L})\end{array}$ & $\underset{(\mathrm{mg} / \mathrm{L})}{\mathrm{Mn}}$ \\
\hline W25.M980G & 1.9 & & & 25 & & & \\
\hline W25.M980F & & & & & & -0.6 & \\
\hline W25.M980B & 1.5 & & 0.20 & 33 & 12 & & \\
\hline
\end{tabular}

\begin{tabular}{|c|c|c|}
\hline Sample ID & $\begin{array}{c}\mathrm{Br}^{-} \\
(\mathrm{mg} / \mathrm{L})\end{array}$ & $\begin{array}{c}\mathrm{F}^{-} \\
(\mathrm{mg} / \mathrm{L})\end{array}$ \\
\hline W25.M980G & & 1.5 \\
\hline $\begin{array}{l}\text { W25.M980F } \\
\text { W25.M980B }\end{array}$ & 25 & \\
\hline
\end{tabular}


Table 107. Comparison of Data from the Magenta at WIPP-27

(Footnotes follow Table 135)

\begin{tabular}{|c|c|c|c|c|c|}
\hline Well $^{1}$ & Agency $^{2}$ & Collection Date & Pumping Rate & $\mathrm{Lab}^{3}$ & Sample ID \\
\hline W-27 & USGS & $09 / 04 / 80$ & bail or swab & USGS & W27.M980G \\
\hline W-27 & SNL & $09 / 24 / 80-09 / 25 / 80$ & $9.4 \mathrm{gpm}$ & FLD & W27.M980F \\
\hline W-27 & SNL & $09 / 25 / 80$ & $9.4 \mathrm{gpm}$ & BFEC & W27.M980B \\
\hline
\end{tabular}

\begin{tabular}{|c|c|c|c|c|c|}
\hline Sample ID & $\begin{array}{c}\text { Density/ } \\
\text { Specific Gravity } 4\end{array}$ & $\mathrm{pH}$ & $\begin{array}{c}\text { TDS (calc) } \\
(\mathrm{mg} / \mathrm{L})^{5}\end{array}$ & $\begin{array}{l}\text { TDS (ROI) } \\
(\mathrm{mg} / \mathrm{L})\end{array}$ & $\begin{array}{c}\text { Charge-Balance } \\
\text { Error }^{5}\end{array}$ \\
\hline W27.M980G & & 6.5 & 146500 & $173000(105 \mathrm{C})$ & $0.3 \%$ \\
\hline W27.M980F & 1.09 (sg) & 6.4 & & & \\
\hline W27.M980B & & & 145700 & & $-0.7 \%$ \\
\hline
\end{tabular}

\begin{tabular}{|c|c|c|c|c|c|}
\hline Sample ID & $\begin{array}{c}\text { Alkalinity } \\
\left(\mathrm{mg} / \mathrm{L} \mathrm{CaCO}_{3}\right)^{6}\end{array}$ & $\begin{array}{c}\mathrm{HCO}_{3}^{-} \\
(\mathrm{mg} / \mathrm{L})^{6}\end{array}$ & $\begin{array}{c}\mathrm{CO}_{\overline{3}}^{\overline{3}} \\
(\mathrm{mg} / \mathrm{L})^{6}\end{array}$ & $\begin{array}{c}\mathrm{Cl}^{-} \\
(\mathrm{mg} / \mathrm{L})\end{array}$ & $\begin{array}{c}\mathrm{SO} \overline{\overline{4}} \\
(\mathrm{mg} / \mathrm{L})\end{array}$ \\
\hline W27.M980G & 180 & 220 & 0 & 85000 & 2900 \\
\hline W27.M980F & 170 & 210 & 0 & 84000 & -3000 \\
\hline W27.M980B & & & & 85200 & 3410 \\
\hline
\end{tabular}

\begin{tabular}{|c|c|c|c|c|c|}
\hline Sample ID & $\begin{array}{c}\mathrm{Na} \\
(\mathrm{mg} / \mathrm{L})\end{array}$ & $\underset{(\mathrm{mg} / \mathrm{L})}{\mathbf{K}}$ & $\begin{array}{c}\mathrm{Ca} \\
(\mathrm{mg} / \mathrm{L})\end{array}$ & $\begin{array}{c}\mathrm{Mg} \\
(\mathrm{mg} / \mathrm{L})\end{array}$ & $\begin{array}{c}\mathrm{X}^{++} \\
(\mathrm{meq} / \mathrm{L})^{7}\end{array}$ \\
\hline $\begin{array}{l}\text { W27.M980G } \\
\text { W27.M980F }\end{array}$ & 43000 & 10000 & $\begin{array}{l}3600 \\
3600\end{array}$ & 2000 & $\begin{array}{l}340 \\
330\end{array}$ \\
\hline $\begin{array}{l}\text { W27.M980F } \\
\text { W27.M980B }\end{array}$ & 43200 & 8090 & 3660 & 2100 & 355 \\
\hline
\end{tabular}

\begin{tabular}{|c|c|c|c|c|c|c|c|}
\hline Sample ID & $\begin{array}{c}\text { B } \\
(\mathrm{mg} / \mathrm{L})\end{array}$ & $\begin{array}{c}\mathrm{Cs} \\
(\mathrm{mg} / \mathrm{L})\end{array}$ & $\begin{array}{c}\mathrm{Li} \\
(\mathrm{mg} / \mathrm{L})\end{array}$ & $\begin{array}{c}\mathrm{SiO}_{2} \\
(\mathrm{mg} / \mathrm{L})\end{array}$ & $\underset{(\mathrm{mg} / \mathrm{L})}{\mathrm{Sr}}$ & $\begin{array}{c}\mathrm{Fe} \\
(\mathrm{mg} / \mathrm{L})\end{array}$ & $\underset{(\mathrm{mg} / \mathrm{L})}{\mathrm{Mn}}$ \\
\hline W27.M980G & 0.23 & & & 13 & & & \\
\hline W27.M980F & & & & & & -2 & \\
\hline W27.M980B & 2.3 & & 0.34 & 30 & 59 & & \\
\hline
\end{tabular}

$\begin{array}{ll}\frac{\text { Sample ID }}{\text { W27.M980G }} & \frac{\mathrm{Br}^{-}}{(\mathrm{mg} / \mathrm{L})} \\ \begin{array}{l}\text { W27.M980F } \\ \text { W27.M980B }\end{array} & 28\end{array}$


Table 108. Comparison of Data from the Magenta at WIPP-30

(Footnotes follow Table 135)

\begin{tabular}{|c|c|c|c|c|c|}
\hline Well $^{1}$ & Agency $^{2}$ & Collection Date & Pumping Rate & $\mathrm{Lab}^{3}$ & Sample ID \\
\hline W-30 & USGS & $09 / 20 / 80$ & bail or swab & USGS & \\
\hline $\mathrm{W}-30$ & SNL & $12 / 02 / 80-12 / 10 / 80$ & $100->50 \mathrm{~mL} / \mathrm{min}$ & FLD & W30.M1280F \\
\hline
\end{tabular}

\begin{tabular}{|c|c|c|c|c|c|}
\hline Sample ID & $\begin{array}{c}\text { Density/ } \\
\text { Specific Gravity } \\
\end{array}$ & $\mathrm{pH}$ & $\begin{array}{c}\text { TDS (calc) } \\
(\mathrm{mg} / \mathrm{L})^{5}\end{array}$ & $\begin{array}{c}\text { TDS (ROI) } \\
(\mathrm{mg} / \mathrm{L})\end{array}$ & $\begin{array}{c}\text { Charge-Balance } \\
\text { Error } 5 \\
\end{array}$ \\
\hline $\begin{array}{l}\text { W30.M980G } \\
\text { W30.M1280F }\end{array}$ & $\stackrel{\text { na }}{(<1.01)(s g)}$ & $\begin{array}{c}8.8 \\
(-8.6)\end{array}$ & 18400 & $19000(105 \mathrm{C})$ & $-3.3 \%$ \\
\hline
\end{tabular}

\begin{tabular}{|c|c|c|c|c|c|}
\hline Sample ID & $\begin{array}{c}\text { Alkalinity } \\
\left(\mathrm{mg} / \mathrm{L} \mathrm{CaCO}_{3}\right)^{6}\end{array}$ & $\begin{array}{l}\mathrm{HCO}_{3}^{-} \\
(\mathrm{mg} / \mathrm{L})^{6}\end{array}$ & $\begin{array}{c}\mathrm{CO}_{\overline{3}}^{\overline{3}} \\
(\mathrm{mg} / \mathrm{L})^{6}\end{array}$ & $\begin{array}{c}\mathrm{Cl}^{-} \\
(\mathrm{mg} / \mathrm{L})\end{array}$ & $\begin{array}{c}\mathrm{SO} \overline{\overline{4}} \\
(\mathrm{mg} / \mathrm{L})\end{array}$ \\
\hline $\begin{array}{l}\text { W30.M980G } \\
\text { W30.M1280F }\end{array}$ & $\begin{array}{r}62 \\
-60\end{array}$ & -50 & $\sim 10$ & $\begin{array}{r}8700 \\
<4000\end{array}$ & $\begin{array}{r}3200 \\
<4000\end{array}$ \\
\hline
\end{tabular}

\begin{tabular}{|c|c|c|c|c|c|}
\hline Sample ID & $\begin{array}{c}\mathrm{Na} \\
(\mathrm{mg} / \mathrm{L})\end{array}$ & $\underset{(\mathrm{mg} / \mathrm{L})}{\mathrm{K}}$ & $\begin{array}{c}\mathrm{Ca} \\
(\mathrm{mg} / \mathrm{L})\end{array}$ & $\begin{array}{c}\mathrm{Mg} \\
(\mathrm{mg} / \mathrm{L})\end{array}$ & $\begin{array}{c}\mathrm{x}^{++} \\
(\mathrm{meq} / \mathrm{L})^{7}\end{array}$ \\
\hline $\begin{array}{l}\text { W30.M980G } \\
\text { W30.M1280F }\end{array}$ & 5500 & 190 & $\begin{array}{r}690 \\
<620\end{array}$ & 170 & $\begin{array}{r}48 \\
<44\end{array}$ \\
\hline
\end{tabular}

\begin{tabular}{|c|c|c|c|c|c|c|c|}
\hline Sample ID & $\begin{array}{c}\text { B } \\
(\mathrm{mg} / \mathrm{L})\end{array}$ & $\underset{(\mathrm{mg} / \mathrm{L})}{\mathrm{Cs}}$ & $\underset{(\mathrm{mg} / \mathrm{L})}{\mathrm{Li}}$ & $\begin{array}{c}\mathrm{SiO}_{2} \\
(\mathrm{mg} / \mathrm{L})\end{array}$ & $\begin{array}{c}\mathrm{Sr} \\
(\mathrm{mg} / \mathrm{L})\end{array}$ & $\begin{array}{c}\mathrm{Fe} \\
(\mathrm{mg} / \mathrm{L})\end{array}$ & $\underset{(\mathrm{mg} / \mathrm{L})}{\mathrm{Mn}}$ \\
\hline $\begin{array}{l}\text { W30.M980G } \\
\text { W30.M1280F }\end{array}$ & 12 & & & 0.7 & & - 0.1 & \\
\hline
\end{tabular}

$\frac{\text { Sample ID }}{\begin{array}{l}\text { W30.M980G } \\ \text { W30.M1280F }\end{array}} \frac{\begin{array}{c}\mathrm{Br}^{-} \\ (\mathrm{mg} / \mathrm{L})\end{array}}{1.9} \frac{\begin{array}{c}\mathrm{F}^{-} \\ (\mathrm{mg} / \mathrm{L})\end{array}}{1.9}$


Table 109. Serial-Sampling Field Data from the Magenta at WIPP-30 (12/80) Compared with USGS Laboratory Data

Serial

Sample

No. Date

\begin{tabular}{cc}
1 & $12 / 03 / 80$ \\
2 & $12 / 04 / 80$ \\
3 & $12 / 04 / 80$ \\
$* *$ & \\
4 & $12 / 05 / 80$ \\
5 & $12 / 06 / 80$ \\
6 & $12 / 06 / 80$ \\
7 & $12 / 07 / 80$ \\
8 & $12 / 08 / 80$ \\
9 & $12 / 08 / 80$ \\
10 & $12 / 09 / 80$ \\
11 & $12 / 10 / 80$ \\
\hline
\end{tabular}

Temp

Time $\quad(\mathrm{C})$

$\begin{array}{lc}-- & \\ 13: 35 & 17.0 \\ 08: 55 & 15.0 \\ 12: 55 & 20.0 \\ & \\ 12: 45 & 19.0 \\ 08: 50 & 14.0 \\ 12: 45 & 20.0 \\ 08: 30 & 15.0 \\ 08: 15 & 4.0 \\ 14: 40 & 5.0 \\ 08: 30 & 7.0 \\ 08: 10 & 7.5\end{array}$

Alk. Alk. Alk.

total $\mathrm{HCO}_{3}^{-} \mathrm{CO}_{\overline{3}}^{\overline{3}} \mathrm{SO}_{\overline{4}}^{\overline{4}} \mathrm{Cl}^{-} \mathrm{X}^{++} \mathrm{Ca}^{++}$ $\underline{\mathrm{meq} / \mathrm{L}} \underline{\mathrm{mg} / \mathrm{L}} \underline{\mathrm{mg} / \mathrm{L}} \underline{\mathrm{mg} / \mathrm{L}} \underline{\mathrm{mg} / \mathrm{L}} \underline{\mathrm{meq} / \mathrm{L}} \underline{\mathrm{mg} / \mathrm{L}}$

$\begin{array}{lllll}8.8 & 3200 & 8700 & 48 & 690\end{array}$

$\begin{array}{llllllll}8.25 & 1.28 & 78 & 0 & 1500 & 4900 & 29 & 370\end{array}$

$8.6 \quad 1.25$

$\begin{array}{llllllll}8.45 & 1.28 & 75 & 4 & 1600 & 5000 & 30 & 370\end{array}$

$\begin{array}{llllllll}8.55 & 1.21 & 55 & 18 & 4400 & 8800 & 56 & 800\end{array}$

$8.55 \quad 1.21 \quad 63 \quad 11$

$\begin{array}{llll}8.6 & 1.19 & 58 & 14\end{array}$

$\begin{array}{llll}8.55 & 1.20 & 64 & 9\end{array}$

$\begin{array}{llll}8.55 & 1.05 & 48 & 15\end{array}$

$8.55 \quad 1.06$

$8.6 \quad 1.06$

$8.55 \quad 1.09$

50

49

59

* USGS laboratory data (from Mercer, 1983).

** Depth to water measured with steel tape during the afternoon of $12 / 04$ after serial sample 3 was collected (exact time unknown). 
Table 110. Comparison of Data from the Rustler/Salado Contact Zone at H-1 (Footnotes follow Table 135)

$\frac{\text { Well }^{1}}{\text { H-1 }} \frac{\text { Agency }^{2}}{\text { USGS }} \frac{\text { Collection Date }}{02 / 23 / 77} \frac{\text { Pumping Rate }}{\text { bail or swab }} \frac{\text { Lab }^{3}}{\text { USGS }} \frac{\text { Sample ID }}{\text { H01.R277G }}$

\begin{tabular}{|c|c|c|c|c|c|}
\hline Sample ID & $\begin{array}{c}\text { Density/ } \\
\text { Specific Gravity } 4 \\
\end{array}$ & $\mathrm{pH}$ & $\begin{array}{c}\text { TDS (calc) } \\
(\mathrm{mg} / \mathrm{L})^{5}\end{array}$ & $\begin{array}{c}\text { TDS (ROI) } \\
(\mathrm{mg} / \mathrm{L})\end{array}$ & $\begin{array}{c}\text { Charge-Balance } \\
\text { Error } 5 \\
\end{array}$ \\
\hline 01.R277G & & 7.9 & 327200 & $480000(105 \mathrm{C})$ & $0.3 \%$ \\
\hline
\end{tabular}

$\frac{\text { Sample ID }}{\text { H01.R277G }} \frac{\begin{array}{c}\text { Alkalinity } \\ \left(\mathrm{mg} / \mathrm{L} \mathrm{CaCO}_{3}\right)^{6}\end{array}}{550} \frac{\begin{array}{c}\mathrm{HCO}_{3}^{-} \\ (\mathrm{mg} / \mathrm{L})^{6}\end{array}}{680} \frac{\begin{array}{c}\mathrm{CO}_{\overline{3}} \\ (\mathrm{mg} / \mathrm{L})^{6}\end{array}}{0} \frac{\begin{array}{c}\mathrm{Cl}^{-} \\ (\mathrm{mg} / \mathrm{L})\end{array}}{210000} \frac{\begin{array}{c}\mathrm{SO} \overline{\overline{4}} \\ (\mathrm{mg} / \mathrm{L})\end{array}}{520}$

$\frac{\text { Sample ID }}{\text { H01.R277G }} \frac{\begin{array}{c}\mathrm{Na} \\ (\mathrm{mg} / \mathrm{L})\end{array}}{56000} \frac{\begin{array}{c}\mathrm{K} \\ (\mathrm{mg} / \mathrm{L})\end{array}}{17000} \frac{\begin{array}{c}\mathrm{Ca} \\ (\mathrm{mg} / \mathrm{L})\end{array}}{13000} \frac{\begin{array}{c}\mathrm{Mg} \\ (\mathrm{mg} / \mathrm{L})\end{array}}{30000} \frac{\begin{array}{c}\mathrm{X}^{++} \\ (\mathrm{meq} / \mathrm{L})^{7}\end{array}}{3100}$

\begin{tabular}{|c|c|c|c|c|c|c|c|}
\hline Sample ID & $\begin{array}{c}\mathrm{B} \\
(\mathrm{mg} / \mathrm{L})\end{array}$ & $\underset{(m g / L)}{C s}$ & $\underset{(\mathrm{mg} / \mathrm{L})}{\mathrm{Li}}$ & $\begin{array}{c}\mathrm{SiO}_{2} \\
(\mathrm{mg} / \mathrm{L})\end{array}$ & $\begin{array}{c}\mathrm{Sr} \\
(\mathrm{mg} / \mathrm{L})\end{array}$ & $\underset{(\mathrm{mg} / \mathrm{L})}{\mathrm{Fe}}$ & $\underset{(\mathrm{mg} / \mathrm{L})}{\mathrm{Mn}}$ \\
\hline H01.R277G & 110 & & & $<0.1$ & & & \\
\hline
\end{tabular}


Table 111. Comparison of Data from the Rustler/Salado Contact Zone at $\mathrm{H}-2$

(Footnotes follow Table 135)

$\frac{\text { Well }^{1}}{\text { H-2C }} \frac{\text { Agency }^{2}}{\text { USGS }} \frac{\text { Collection Date }}{02 / 23 / 77} \frac{\text { Pumping Rate }}{\text { bail or swab }} \frac{\text { Lab }^{3}}{\text { USGS }} \frac{\text { Sample ID }}{\text { H02C.R277G }}$

\begin{tabular}{|c|c|c|c|c|c|}
\hline Sample ID & $\begin{array}{c}\text { Density/ } \\
\text { Specific Gravity } 4\end{array}$ & $\mathrm{pH}$ & $\begin{array}{l}\text { TDS (calc) } \\
(\mathrm{mg} / \mathrm{L})^{5}\end{array}$ & $\begin{array}{c}\text { TDS (ROI) } \\
(\mathrm{mg} / \mathrm{L})\end{array}$ & $\begin{array}{c}\text { Charge-Balance } \\
\text { Error }\end{array}$ \\
\hline H02C.R277G & & 5.9 & 310800 & $450000(105 \mathrm{C})$ & $-0.6 \%$ \\
\hline
\end{tabular}

\begin{tabular}{|c|c|c|c|c|c|c|c|c|c|}
\hline \multirow{3}{*}{$\begin{array}{r}\text { H02C.R277G } \\
\text { Sample ID }\end{array}$} & \multicolumn{2}{|c|}{$\begin{array}{c}\text { Alkalinity } \\
(\mathrm{mg} / \mathrm{L} \mathrm{CaCO} 3)^{6}\end{array}$} & \multicolumn{2}{|c|}{$\begin{array}{l}\mathrm{HCO}_{3}^{-} \\
(\mathrm{mg} / \mathrm{L})^{6}\end{array}$} & \multicolumn{2}{|c|}{$\begin{array}{c}\mathrm{CO}_{\overline{3}} \\
(\mathrm{mg} / \mathrm{L})^{6} \\
\end{array}$} & \multicolumn{2}{|c|}{$\begin{array}{c}\mathrm{Cl}^{-} \\
(\mathrm{mg} / \mathrm{L})\end{array}$} & $\begin{array}{c}\mathrm{SO} \overline{\overline{4}} \\
(\mathrm{mg} / \mathrm{L})\end{array}$ \\
\hline & 160 & & 200 & & 0 & & & & 1300 \\
\hline & $\underset{(\mathrm{mg} / \mathrm{L})}{\mathrm{Na}}$ & $\underset{(\mathrm{mg} / \mathrm{L})}{\mathrm{K}}$ & & $\begin{array}{c}\mathrm{Ca} \\
\mathrm{mg} / \mathrm{L})\end{array}$ & & $\underset{(\mathrm{mg} / \mathrm{L})}{\mathrm{Mg}}$ & & $\underset{(\mathrm{meq} / \mathrm{L})^{7}}{\mathrm{X}^{++}}$ & \\
\hline H02C.R277G & 66000 & 9100 & & 9200 & & 25000 & & 2500 & \\
\hline Sample ID & $\begin{array}{c}\text { B } \\
(\mathrm{mg} / \mathrm{L})\end{array}$ & $\underset{(\mathrm{mg} / \mathrm{L})}{\mathrm{Cs}}$ & $\underset{(\mathrm{mg} / \mathrm{L})}{\mathrm{Li}}$ & & $\begin{array}{c}\mathrm{SiO}_{2} \\
(\mathrm{mg} / \mathrm{L}\end{array}$ & & $\begin{array}{c}\mathrm{Sr} \\
\mathrm{mg} / \mathrm{L})\end{array}$ & $\begin{array}{c}\mathrm{Fe} \\
(\mathrm{mg} / \mathrm{L})\end{array}$ & $\begin{array}{c}\mathrm{Mn} \\
(\mathrm{mg} / \mathrm{L})\end{array}$ \\
\hline H02C.R277G & 150 & & & & 2.0 & & & & \\
\hline
\end{tabular}


Table 112. Comparison of Data from the Rustler/Salado Contact Zone at H-3 (Footnotes follow Table 135)

$\frac{\text { Well }^{1}}{\text { H-3B1 }} \frac{\text { Agency }^{2}}{\text { USGS }} \frac{\text { Collection Date }}{02 / 23 / 77} \frac{\text { Pumping Rate }}{\text { bail or swab }} \frac{\text { Lab }^{3}}{\text { USGS }} \frac{\text { Sample ID }}{\text { H03B1.R277G }}$

\begin{tabular}{|c|c|c|c|c|c|}
\hline Sample ID & $\begin{array}{c}\text { Density/ } \\
\text { Specific Gravity } 4\end{array}$ & $\mathrm{pH}$ & $\begin{array}{l}\text { TDS (calc) } \\
(\mathrm{mg} / \mathrm{L})^{5}\end{array}$ & $\begin{array}{l}\text { TDS (ROI) } \\
\text { (mg/L) }\end{array}$ & $\begin{array}{c}\text { Charge-Balance } \\
\text { Error } 5\end{array}$ \\
\hline 103B1 & & 7.6 & 326800 & $327000(105 \mathrm{C})$ & $-0.6 \%$ \\
\hline
\end{tabular}

$\frac{\text { Sample ID }}{\text { H03B1.R277G }} \frac{\begin{array}{c}\text { Alkalinity } \\ \left(\mathrm{mg} / \mathrm{L} \mathrm{CaCO}_{3}\right)^{6}\end{array}}{380} \frac{\begin{array}{c}\mathrm{HCO}_{\overline{3}} \\ (\mathrm{mg} / \mathrm{L})^{6}\end{array}}{470} \frac{\begin{array}{c}\mathrm{CO}_{\overline{3}} \\ (\mathrm{mg} / \mathrm{L})^{6}\end{array}}{0} \frac{\begin{array}{c}\mathrm{Cl}^{-} \\ (\mathrm{mg} / \mathrm{L})\end{array}}{210000} \frac{\begin{array}{c}\mathrm{SO} \overline{4} \\ (\mathrm{mg} / \mathrm{L})\end{array}}{370}$

$\frac{\text { Sample ID }}{\text { H03B1.R277G }} \frac{\begin{array}{c}\mathrm{Na} \\ (\mathrm{mg} / \mathrm{L})\end{array}}{59000} \frac{\begin{array}{c}\mathrm{K} \\ (\mathrm{mg} / \mathrm{L})\end{array}}{14000} \frac{\begin{array}{c}\mathrm{Ca} \\ (\mathrm{mg} / \mathrm{L})\end{array}}{18000} \frac{\begin{array}{c}\mathrm{Mg} \\ (\mathrm{mg} / \mathrm{L})\end{array}}{25000} \frac{\begin{array}{c}\mathrm{X}^{++} \\ (\mathrm{meq} / \mathrm{L})^{7}\end{array}}{2900}$

$\frac{\text { Sample ID }}{\text { H03B1.R277G }} \frac{\begin{array}{c}\mathrm{B} \\ (\mathrm{mg} / \mathrm{L})\end{array}}{1.9} \frac{\begin{array}{c}\mathrm{Cs} \\ (\mathrm{mg} / \mathrm{L})\end{array}}{\frac{(\mathrm{mg} / \mathrm{L})}{\mathrm{Li}}} \frac{\begin{array}{c}\mathrm{SiO}_{2} \\ (\mathrm{mg} / \mathrm{L})\end{array}}{1.0} \frac{\begin{array}{c}\mathrm{Sr} \\ (\mathrm{mg} / \mathrm{L})\end{array}}{\frac{1 \mathrm{mg} / \mathrm{L})}{(\mathrm{mg} / \mathrm{L})}}$


Table 113. Comparison of Data from the Rustler/Salado Contact Zone at H-4

(Footnotes follow Table 135)

\begin{tabular}{|c|c|c|c|c|c|}
\hline Well ${ }^{1}$ & Agency 2 & Collection Date & Pumping Rate & $\mathrm{Lab}^{3}$ & Sample ID \\
\hline $\mathrm{H}-4 \mathrm{C}$ & USGS & $03 / 16 / 79$ & bail or swab & SNL & H04C.R379S \\
\hline $\mathrm{H}-4 \mathrm{C}$ & USGS & $03 / 16 / 79$ & bail or swab & USGS & H04C.R379G \\
\hline
\end{tabular}

\begin{tabular}{|c|c|c|c|c|c|}
\hline Sample ID & $\begin{array}{c}\text { Density/ } \\
\text { Specific Gravity } 4\end{array}$ & $\mathrm{pH}$ & $\begin{array}{c}\text { TDS (calc) } \\
(\mathrm{mg} / \mathrm{L})^{5}\end{array}$ & $\begin{array}{l}\text { TDS (ROI) } \\
(\mathrm{mg} / \mathrm{L})\end{array}$ & $\begin{array}{c}\text { Charge-Balance } \\
\text { Error } 5 \\
\end{array}$ \\
\hline $\begin{array}{l}\text { H04C.R379S } \\
\text { H04C.R379G }\end{array}$ & $1.208(\mathrm{~g} / \mathrm{mL})$ & & $\begin{array}{l}315200 \\
321300\end{array}$ & $322000(105 \mathrm{C}$ & $-0.2 \%$ \\
\hline
\end{tabular}

\begin{tabular}{|c|c|c|c|c|c|}
\hline Sample ID & $\begin{array}{c}\text { Alkalinity } \\
\left(\mathrm{mg} / \mathrm{L} \mathrm{CaCO}_{3}\right)^{6}\end{array}$ & $\begin{array}{l}\mathrm{HCO}_{3}^{-} \\
(\mathrm{mg} / \mathrm{L})^{6}\end{array}$ & $\begin{array}{c}\mathrm{CO}_{\overline{3}}^{\overline{3}} \\
(\mathrm{mg} / \mathrm{L})^{6}\end{array}$ & $\begin{array}{c}\mathrm{Cl}^{-} \\
(\mathrm{mg} / \mathrm{L})\end{array}$ & $\begin{array}{c}\text { SO } \overline{\overline{4}} \\
(\mathrm{mg} / \mathrm{L})\end{array}$ \\
\hline HU4C.Rs & $<10$ & $<10$ & 0 & 202000 & 730 \\
\hline
\end{tabular}

\begin{tabular}{|c|c|c|c|c|c|}
\hline Sample ID & $\begin{array}{c}\mathrm{Na} \\
(\mathrm{mg} / \mathrm{L})\end{array}$ & $\underset{(\mathrm{mg} / \mathrm{L})}{\mathrm{K}}$ & $\begin{array}{c}\mathrm{Ca} \\
(\mathrm{mg} / \mathrm{L})\end{array}$ & $\begin{array}{c}\mathrm{Mg} \\
(\mathrm{mg} / \mathrm{L})\end{array}$ & $\begin{array}{c}\mathrm{x}^{++} \\
(\mathrm{meq} / \mathrm{L})^{7}\end{array}$ \\
\hline H04C.R379S & 64400 & 14500 & 8560 & 25400 & 2510 \\
\hline H04C.R379G & 66000 & 8600 & 8300 & 27000 & 2600 \\
\hline
\end{tabular}

\begin{tabular}{|c|c|c|c|c|c|c|c|}
\hline Sample ID & $\begin{array}{c}\text { B } \\
(\mathrm{mg} / \mathrm{L})\end{array}$ & $\underset{(\mathrm{mg} / \mathrm{L})}{\mathrm{Cs}}$ & $\underset{(\mathrm{mg} / \mathrm{L})}{\mathrm{Li}}$ & $\begin{array}{c}\mathrm{SiO}_{2} \\
(\mathrm{mg} / \mathrm{L})\end{array}$ & $\underset{(\mathrm{mg} / \mathrm{L})}{\mathrm{Sr}}$ & $\begin{array}{c}\mathrm{Fe} \\
(\mathrm{mg} / \mathrm{L})\end{array}$ & $\underset{(\mathrm{mg} / \mathrm{L})}{\mathrm{Mn}}$ \\
\hline $\begin{array}{l}\text { H04C.R379S } \\
\text { H04C.R379G }\end{array}$ & 360 & & & 1.3 & & & \\
\hline
\end{tabular}

\begin{tabular}{|c|c|c|}
\hline Sample ID & $\begin{array}{c}\mathrm{Br}^{-} \\
(\mathrm{mg} / \mathrm{L})\end{array}$ & $\underset{(\mathrm{mg} / \mathrm{L})}{\mathrm{F}^{-}}$ \\
\hline H04C.R3 & & 17 \\
\hline
\end{tabular}


Table 114. Comparison of Data from the Rustler/Salado Contact Zone at H-5

(Footnotes follow Table 135)

\begin{tabular}{|c|c|c|c|c|c|}
\hline Well ${ }^{1}$ & Agency ${ }^{2}$ & Collection Date & Pumping Rate & $\mathrm{Lab}^{3}$ & Sample ID \\
\hline $\mathrm{H}-5 \mathrm{C}$ & USGS & $05 / 16 / 79$ & bail or swab & SNL & H05C.R579S \\
\hline $\mathrm{H}-5 \mathrm{C}$ & USGS & $05 / 16 / 79$ & bail or swab & USGS & H05C.R579G \\
\hline
\end{tabular}

\begin{tabular}{|c|c|c|c|c|c|}
\hline Sample ID & $\begin{array}{c}\text { Density/ } \\
\text { Specific Gravity } 4 \\
\end{array}$ & $\mathrm{pH}$ & $\begin{array}{c}\text { TDS (calc) } \\
(\mathrm{mg} / \mathrm{L})^{5}\end{array}$ & $\begin{array}{l}\text { TDS (ROI) } \\
(\mathrm{mg} / \mathrm{L})\end{array}$ & $\begin{array}{c}\text { Charge-Balance } \\
\text { Error } 5\end{array}$ \\
\hline $\begin{array}{l}\text { H05C.R579S } \\
\text { H05C.R579G }\end{array}$ & $1.258(\mathrm{~g} / \mathrm{mL})$ & & $\begin{array}{l}372300 \\
411400\end{array}$ & $412000(105 \mathrm{C})$ & $\begin{array}{l}-0.4 \% \\
-1.6 \%\end{array}$ \\
\hline
\end{tabular}

\begin{tabular}{|c|c|c|c|c|c|}
\hline Sample ID & $\begin{array}{c}\text { Alkalinity } \\
(\mathrm{mg} / \mathrm{L} \mathrm{CaCO})^{6} \\
\end{array}$ & $\begin{array}{l}\mathrm{HCO}_{3}^{-} \\
(\mathrm{mg} / \mathrm{L})^{6} \\
\end{array}$ & $\begin{array}{c}\mathrm{CO}_{\overline{3}}^{\overline{3}} \\
(\mathrm{mg} / \mathrm{L})^{6} \\
\end{array}$ & $\begin{array}{c}\mathrm{Cl}^{-} \\
(\mathrm{mg} / \mathrm{L})\end{array}$ & $\begin{array}{c}\mathrm{SO} \overline{\overline{4}} \\
(\mathrm{mg} / \mathrm{L})\end{array}$ \\
\hline H05C.R579S & 160 & 200 & 0 & 262000 & 1430 \\
\hline H05C.R579G & 180 & 300 & 0 & 290000 & 2000 \\
\hline
\end{tabular}

\begin{tabular}{|c|c|c|c|c|c|}
\hline Sample ID & $\begin{array}{c}\mathrm{Na} \\
(\mathrm{mg} / \mathrm{L})\end{array}$ & $\underset{(\mathrm{mg} / \mathrm{L})}{\mathrm{K}}$ & $\begin{array}{c}\mathrm{Ca} \\
(\mathrm{mg} / \mathrm{L})\end{array}$ & $\underset{(\mathrm{mg} / \mathrm{L})}{\mathrm{Mg}}$ & $\underset{(\mathrm{meq} / \mathrm{L})^{7}}{\mathrm{X}^{++}}$ \\
\hline HOS & 14200 & 16100 & 1780 & 76400 & 6350 \\
\hline
\end{tabular}

\begin{tabular}{|c|c|c|c|c|c|c|c|}
\hline Sample ID & $\begin{array}{c}\text { B } \\
(\mathrm{mg} / \mathrm{L})\end{array}$ & $\begin{array}{c}\mathrm{Cs} \\
(\mathrm{mg} / \mathrm{L})\end{array}$ & $\underset{(\mathrm{mg} / \mathrm{L})}{\mathrm{Li}}$ & $\begin{array}{c}\mathrm{SiO}_{2} \\
(\mathrm{mg} / \mathrm{L})\end{array}$ & $\begin{array}{c}\mathrm{Sr} \\
(\mathrm{mg} / \mathrm{L})\end{array}$ & $\begin{array}{c}\mathrm{Fe} \\
(\mathrm{mg} / \mathrm{L})\end{array}$ & $\underset{(\mathrm{mg} / \mathrm{L})}{\mathrm{Mn}}$ \\
\hline $\begin{array}{l}\text { H05C.R579S } \\
\text { H05C.R579G }\end{array}$ & 67 & & & 1.6 & & & \\
\hline
\end{tabular}

\begin{tabular}{|c|c|c|}
\hline Sample ID & $\begin{array}{c}\mathrm{Br}^{-} \\
(\mathrm{mg} / \mathrm{L})\end{array}$ & $\begin{array}{c}\mathrm{F}^{-} \\
(\mathrm{mg} / \mathrm{L})\end{array}$ \\
\hline $\begin{array}{l}\text { H05C.R579S } \\
\text { H05C.R579G }\end{array}$ & & $<0.1$ \\
\hline
\end{tabular}


Table 115. Comparison of Data from the Rustler/Salado Contact Zone at H-6 (Footnotes follow Table 135)

\begin{tabular}{|c|c|c|c|c|c|}
\hline Well ${ }^{1}$ & Agency $^{2}$ & Collection Date & Pumping Rate & $\mathrm{Lab}^{3}$ & Sample ID \\
\hline $\mathrm{H}-6 \mathrm{C}$ & USGS & $04 / 09 / 79$ & bail or swab & SNL & H06C.R479S \\
\hline $\mathrm{H}-6 \mathrm{C}$ & USGS & $04 / 09 / 79$ & bail or swab & USGS & H06C.R479G \\
\hline
\end{tabular}

\begin{tabular}{|c|c|c|c|c|c|}
\hline Sample ID & $\begin{array}{c}\text { Density/ } \\
\text { Specific Gravity } 4\end{array}$ & $\mathrm{pH}$ & $\begin{array}{c}\text { TDS (calc) } \\
(\mathrm{mg} / \mathrm{L})^{5}\end{array}$ & $\begin{array}{l}\text { TDS (ROI) } \\
(\mathrm{mg} / \mathrm{L})\end{array}$ & $\begin{array}{c}\text { Charge-Balance } \\
\text { Error }^{5} \\
\end{array}$ \\
\hline $\begin{array}{l}\text { H06C.R479S } \\
\text { H06C.R479G }\end{array}$ & $1.207(\mathrm{~g} / \mathrm{mL})$ & & $\begin{array}{l}312600 \\
315200\end{array}$ & $316000(105 \mathrm{C})$ & $\begin{array}{l}-1.9 \% \\
-0.7 \%\end{array}$ \\
\hline
\end{tabular}

\begin{tabular}{|c|c|c|c|c|c|}
\hline Sample ID & $\begin{array}{c}\text { Alkalinity } \\
(\mathrm{mg} / \mathrm{L} \mathrm{CaCO} 3)^{6}\end{array}$ & $\begin{array}{l}\mathrm{HCO}_{3}^{-} \\
(\mathrm{mg} / \mathrm{L})^{6}\end{array}$ & $\begin{array}{c}\mathrm{CO}_{\overline{3}}^{\overline{3}} \\
(\mathrm{mg} / \mathrm{L})^{6}\end{array}$ & $\begin{array}{c}\mathrm{Cl}^{-} \\
(\mathrm{mg} / \mathrm{L})\end{array}$ & $\begin{array}{c}\mathrm{SO} \overline{\overline{4}} \\
(\mathrm{mg} / \mathrm{L})\end{array}$ \\
\hline H06C.R479S & $<10$ & $<10$ & 0 & 201000 & 1450 \\
\hline H06C.R479G & 1 & 1 & 0 & 200000 & 2000 \\
\hline
\end{tabular}

\begin{tabular}{|c|c|c|c|c|c|}
\hline Sample ID & $\underset{(\mathrm{mg} / \mathrm{L})}{\mathrm{Na}}$ & $\underset{(\mathrm{mg} / \mathrm{L})}{\mathrm{K}}$ & $\begin{array}{c}\mathrm{Ca} \\
(\mathrm{mg} / \mathrm{L})\end{array}$ & $\underset{(\mathrm{mg} / \mathrm{L})}{\mathrm{Mg}}$ & $\begin{array}{c}\mathrm{X}^{++} \\
(\mathrm{meq} / \mathrm{L})^{7}\end{array}$ \\
\hline H06C.R479S & 79400 & 6670 & 4170 & 20200 & 1860 \\
\hline H06C.R479G & 80000 & 8000 & 4200 & 21000 & 1900 \\
\hline
\end{tabular}

\begin{tabular}{|c|c|c|c|c|c|c|c|}
\hline Sample ID & $\begin{array}{c}\mathrm{B} \\
(\mathrm{mg} / \mathrm{L})\end{array}$ & $\underset{(\mathrm{mg} / \mathrm{L})}{\mathrm{Cs}}$ & $\underset{(\mathrm{mg} / \mathrm{L})}{\mathrm{Li}}$ & $\begin{array}{c}\mathrm{SiO}_{2} \\
(\mathrm{mg} / \mathrm{L})\end{array}$ & $\begin{array}{c}\mathrm{Sr} \\
(\mathrm{mg} / \mathrm{L})\end{array}$ & $\begin{array}{c}\mathrm{Fe} \\
(\mathrm{mg} / \mathrm{L})\end{array}$ & $\underset{(\mathrm{mg} / \mathrm{L})}{\mathrm{Mn}}$ \\
\hline H06C.R479G & 200 & & & 1.4 & & & \\
\hline
\end{tabular}

$\frac{\text { Sample ID }}{\text { H06C.R479S }} \frac{\begin{array}{c}\mathrm{Br}^{-} \\ (\mathrm{mg} / \mathrm{L})\end{array}}{\text { H06C.R479G }} \frac{\begin{array}{c}\mathrm{F}^{-} \\ (\mathrm{mg} / \mathrm{L})\end{array}}{1.0}$


Table 116. Comparison of Data from the Rustler/Salado Contact Zone at H-7

(Footnotes follow Table 135)

$\frac{\text { Well }^{1}}{\text { H-7C }} \frac{\text { Agency }^{2}}{\text { USGS }} \frac{\text { Collection Date }}{03 / 20 / 80} \frac{\text { Pumping Rate }}{\text { bail or swab }} \frac{\text { Lab }^{3}}{\text { USGS }} \frac{\text { Sample ID }}{\text { H07C.R380G }}$

$\frac{\text { Sample ID }}{\text { H07C.R380G }} \frac{\begin{array}{c}\text { Density/ } \\ \text { Specific Gravity }\end{array}}{1.048(\mathrm{~g} / \mathrm{mL})} \frac{\mathrm{pH}}{6.8} \frac{\begin{array}{c}\text { TDS (calc) } \\ (\mathrm{mg} / \mathrm{L})^{5}\end{array}}{69600} \frac{\begin{array}{c}\text { TDS (RON) } \\ (\mathrm{mg} / \mathrm{L})\end{array}}{79800(105 \mathrm{C})} \frac{\begin{array}{c}\text { Charge-Balance } \\ \text { Error }\end{array}}{-2.2 \%}$

$\frac{\text { Sample ID }}{\text { H07C.R380G }} \frac{\begin{array}{c}\text { Alkalinity } \\ (\mathrm{mg} / \mathrm{L} \mathrm{CaCO})^{6}\end{array}}{35} \frac{\begin{array}{c}\mathrm{HCO}_{3}^{-} \\ (\mathrm{mg} / \mathrm{L})^{6}\end{array}}{43} \frac{\begin{array}{c}\mathrm{CO}_{\overline{3}} \\ (\mathrm{mg} / \mathrm{L})^{6}\end{array}}{0} \frac{\begin{array}{c}\mathrm{Cl}^{-} \\ (\mathrm{mg} / \mathrm{L})\end{array}}{41000} \frac{\begin{array}{c}\mathrm{SO} \overline{4} \\ (\mathrm{mg} / \mathrm{L})\end{array}}{2900}$

$\frac{\text { Sample ID }}{\text { H07C.R380G }} \frac{\begin{array}{c}\mathrm{Na} \\ (\mathrm{mg} / \mathrm{L})\end{array}}{22000} \frac{\begin{array}{c}\mathrm{K} \\ (\mathrm{mg} / \mathrm{L})\end{array}}{210} \frac{\begin{array}{c}\mathrm{Ca} \\ (\mathrm{mg} / \mathrm{L})\end{array}}{2600} \frac{\begin{array}{c}\mathrm{Mg} \\ (\mathrm{mg} / \mathrm{L})\end{array}}{910} \frac{\begin{array}{c}\mathrm{X}^{++} \\ (\mathrm{meq} / \mathrm{L})^{7}\end{array}}{200}$

\begin{tabular}{|c|c|c|c|c|c|c|c|}
\hline Sample ID & $\begin{array}{c}\mathbf{B} \\
(\mathrm{mg} / \mathrm{L})\end{array}$ & $\underset{(\mathrm{mg} / \mathrm{L})}{\mathrm{Cs}}$ & $\underset{(\mathrm{mg} / \mathrm{L})}{\mathrm{Li}}$ & $\underset{(\mathrm{mg} / \mathrm{L})}{\mathrm{SiO}_{2}}$ & $\begin{array}{c}\mathrm{Sr} \\
(\mathrm{mg} / \mathrm{L})\end{array}$ & $\underset{(\mathrm{mg} / \mathrm{L})}{\mathrm{Fe}}$ & $\underset{(\mathrm{mg} / \mathrm{L})}{\mathrm{Mn}}$ \\
\hline H07C.R380G & 3.1 & & & 7.2 & & & \\
\hline
\end{tabular}

$\frac{\text { Sample ID }}{\text { H07C.R380G }} \frac{\begin{array}{c}\mathrm{Br}^{-} \\ (\mathrm{mg} / \mathrm{L})\end{array}}{\frac{(\mathrm{mg} / \mathrm{L})}{}}$


Table 117. Comparison of Data from the Rustler/Salado Contact Zone at H-8 (Footnotes follow Table 135)

$\frac{\text { Well }^{1}}{\text { H-8C }} \frac{\text { Agency }^{2}}{\text { USGS }} \frac{\text { Collection Date }}{09 / 06 / 80} \frac{\text { Pumping Rate }}{\text { bail or swab }} \frac{\text { Lab }^{3}}{\text { USGS }} \frac{\text { Sample ID }}{\text { H08C.R980G }}$

$\frac{\text { Sample ID }}{\text { H08C.R980G }} \frac{\begin{array}{c}\text { Density/ } \\ \text { Specific Gravity }\end{array}}{\frac{\mathrm{pH}}{7.6}} \frac{\begin{array}{c}\text { TDS (calc) } \\ (\mathrm{mg} / \mathrm{L})^{5}\end{array}}{123600} \frac{\begin{array}{c}\text { TDS (ROI) } \\ (\mathrm{mg} / \mathrm{L})\end{array}}{130000(105 \mathrm{C})} \frac{\begin{array}{c}\text { Charge-Balance } \\ \text { Error }\end{array}}{0.7 \%}$

$\frac{\text { Sample ID }}{\text { H08C.R980G }} \frac{\begin{array}{c}\text { Alkalinity } \\ \left(\mathrm{mg} / \mathrm{L} \mathrm{CaCO}_{3}\right)^{6}\end{array}}{21} \frac{\begin{array}{c}\mathrm{HCO}^{-} \\ (\mathrm{mg} / \mathrm{L})^{6}\end{array}}{26} \frac{\begin{array}{c}\mathrm{CO}_{\overline{3}}^{\overline{3}} \\ (\mathrm{mg} / \mathrm{L})^{6}\end{array}}{0} \frac{\begin{array}{c}\mathrm{Cl}^{-} \\ (\mathrm{mg} / \mathrm{L})\end{array}}{70000} \frac{\begin{array}{c}\mathrm{SO} \overline{\overline{4}} \\ (\mathrm{mg} / \mathrm{L})\end{array}}{5300}$

$\frac{\text { Sample ID }}{\text { H08C.R980G }} \frac{\begin{array}{c}\mathrm{Na} \\ (\mathrm{mg} / \mathrm{L})\end{array}}{46000} \frac{\begin{array}{c}\mathrm{K} \\ (\mathrm{mg} / \mathrm{L})\end{array}}{660} \frac{\begin{array}{c}\mathrm{Ca} \\ (\mathrm{mg} / \mathrm{L})\end{array}}{1200} \frac{\begin{array}{c}\mathrm{Mg} \\ (\mathrm{mg} / \mathrm{L})\end{array}}{430} \frac{\begin{array}{c}\mathrm{X}^{++} \\ (\mathrm{meq} / \mathrm{L})^{7}\end{array}}{95}$

$\frac{\text { Sample ID }}{\text { H08C.R980G }} \frac{\begin{array}{c}\text { B } \\ (\mathrm{mg} / \mathrm{L})\end{array}}{1.3} \frac{\begin{array}{c}\mathrm{Cs} \\ (\mathrm{mg} / \mathrm{L})\end{array}}{\frac{(\mathrm{mg} / \mathrm{L})}{\mathrm{Li}}} \frac{\begin{array}{c}\mathrm{SiO}_{2} \\ (\mathrm{mg} / \mathrm{L})\end{array}}{0.8} \frac{\begin{array}{c}\mathrm{Sr} \\ (\mathrm{mg} / \mathrm{L})\end{array}}{(\mathrm{mg} / \mathrm{L})} \underbrace{(\mathrm{mg} / \mathrm{L})}$

$\frac{\text { Sample ID }}{\text { H08C.R980G }} \frac{\begin{array}{c}\mathrm{Br}^{-} \\ (\mathrm{mg} / \mathrm{L})\end{array}}{\frac{\mathrm{F}^{-}}{(\mathrm{mg} / \mathrm{L})}}$


Table 118. Comparison of Data from the Rustler/Salado Contact Zone at H-9

(Footnotes follow Table 135)

$\frac{\text { Well }^{1}}{\text { H-9C }} \frac{\text { Agency }^{2}}{\text { USGS }} \frac{\text { Collection Date }}{05 / 20 / 80} \frac{\text { Pumping Rate }}{\text { bail or swab }} \frac{\text { Lab }^{3}}{\text { USGS }} \frac{\text { Sample ID }}{\text { H09C.R580G }}$

$\frac{\text { Sample ID }}{\text { H09C.R580G }} \frac{\begin{array}{c}\text { Density/ } \\ \text { Specific Gravity }\end{array}}{1.202(\mathrm{~g} / \mathrm{mL})} \frac{\mathrm{pH}}{7.0} \frac{\begin{array}{c}\text { TDS (calc) } \\ (\mathrm{mg} / \mathrm{L})^{5}\end{array}}{326000} \frac{\begin{array}{c}\text { TDS (ROI) } \\ (\mathrm{mg} / \mathrm{L})\end{array}}{326000(105 \mathrm{C})} \frac{\begin{array}{c}\text { Charge-Balance } \\ \text { Error }^{5}\end{array}}{3.7 \%}$

$\frac{\text { Sample ID }}{\text { H09C.R580G }} \frac{\begin{array}{c}\text { Alkalinity } \\ (\mathrm{mg} / \mathrm{L} \mathrm{CaCO})^{6}\end{array}}{24} \frac{\begin{array}{c}\mathrm{HCO}_{3}^{-} \\ (\mathrm{mg} / \mathrm{L})^{6}\end{array}}{29} \frac{\begin{array}{c}\mathrm{CO}_{\overline{3}}^{\overline{3}} \\ (\mathrm{mg} / \mathrm{L})^{6}\end{array}}{0} \frac{\begin{array}{c}\mathrm{Cl}^{-} \\ (\mathrm{mg} / \mathrm{L})\end{array}}{190000} \frac{\begin{array}{c}\mathrm{SO} \overline{\overline{4}} \\ (\mathrm{mg} / \mathrm{L})\end{array}}{2600}$

$\frac{\text { Sample ID }}{\text { H09C.R580G }} \frac{\begin{array}{c}\mathrm{Na} \\ (\mathrm{mg} / \mathrm{L})\end{array}}{130000} \frac{\begin{array}{c}\mathrm{K} \\ (\mathrm{mg} / \mathrm{L})\end{array}}{1200} \frac{\begin{array}{c}\mathrm{Ca} \\ (\mathrm{mg} / \mathrm{L})\end{array}}{1300} \frac{\begin{array}{c}\mathrm{Mg} \\ (\mathrm{mg} / \mathrm{L})\end{array}}{870} \frac{\begin{array}{c}\mathrm{X}^{++} \\ (\mathrm{meq} / \mathrm{L})^{7}\end{array}}{140}$

\begin{tabular}{|c|c|c|c|c|c|c|c|}
\hline Sample ID & $\underset{(\mathrm{mg} / \mathrm{L})}{\mathrm{B}}$ & $\underset{(\mathrm{mg} / \mathrm{L})}{\mathrm{Cs}}$ & $\begin{array}{c}\mathrm{Li} \\
(\mathrm{mg} / \mathrm{L})\end{array}$ & $\begin{array}{c}\mathrm{SiO}_{2} \\
(\mathrm{mg} / \mathrm{L})\end{array}$ & $\begin{array}{c}\mathrm{Sr} \\
(\mathrm{mg} / \mathrm{L})\end{array}$ & $\begin{array}{c}\mathrm{Fe} \\
(\mathrm{mg} / \mathrm{L})\end{array}$ & $\underset{(\mathrm{mg} / \mathrm{L})}{\mathrm{Mn}}$ \\
\hline H09C.R580G & 19 & & & 3.8 & & & \\
\hline
\end{tabular}

$\frac{\text { Sample ID }}{\text { H09C.R580G }} \frac{\begin{array}{c}\mathrm{Br}^{-} \\ (\mathrm{mg} / \mathrm{L})\end{array}}{\frac{\mathrm{F}^{-}}{(\mathrm{mg} / \mathrm{L})}}$


Table 119. Comparison of Data from the Rustler/Salado Contact Zone at $\mathrm{H}-10$ (Footnotes follow Table 135)

$\frac{\text { Well }^{1}}{\text { H-10C }} \frac{\text { Agency }^{2}}{\text { USGS }} \frac{\text { Collection Date }}{05 / 19 / 80} \frac{\text { Pumping Rate }}{\text { bail or swab }} \frac{\text { Lab }^{3}}{\text { USGS }} \frac{\text { Sample ID }}{\text { H10C.R580G }}$

$\frac{\text { Sample ID }}{\text { H10C.R580G }} \frac{\begin{array}{c}\text { Density/ } \\ \text { Specific Gravity }\end{array}}{1.198(\mathrm{~g} / \mathrm{mL})} \frac{\mathrm{pH}}{6.3} \frac{\begin{array}{c}\text { TDS (calc) } \\ (\mathrm{mg} / \mathrm{L})^{5}\end{array}}{309800} \frac{\begin{array}{c}\text { TDS (ROI) } \\ (\mathrm{mg} / \mathrm{L})\end{array}}{323000(105 \mathrm{C})} \frac{\begin{array}{c}\text { Charge-Balance } \\ \text { Error }\end{array}}{-0.02 \%}$

$\frac{\text { Sample ID }}{\text { H10C.R580G }} \frac{\begin{array}{c}\text { Alkalinity } \\ (\mathrm{mg} / \mathrm{L} \mathrm{CaCO})^{6}\end{array}}{53} \frac{\begin{array}{c}\mathrm{HCO}_{3}^{-} \\ (\mathrm{mg} / \mathrm{L})^{6}\end{array}}{65} \frac{\begin{array}{c}\mathrm{CO}_{\overline{3}} \\ (\mathrm{mg} / \mathrm{L})^{6}\end{array}}{0} \frac{\begin{array}{c}\mathrm{Cl}^{-} \\ (\mathrm{mg} / \mathrm{L})\end{array}}{190000} \frac{\begin{array}{c}\mathrm{SO}_{\overline{4}} \\ (\mathrm{mg} / \mathrm{L})\end{array}}{3300}$

$\frac{\text { Sample ID }}{\text { H10C.R580G }} \frac{\begin{array}{c}\mathrm{Na} \\ (\mathrm{mg} / \mathrm{L})\end{array}}{100000} \frac{\begin{array}{c}\mathrm{K} \\ (\mathrm{mg} / \mathrm{L})\end{array}}{4000} \frac{\begin{array}{c}\mathrm{Ca} \\ (\mathrm{mg} / \mathrm{L})\end{array}}{1500} \frac{\begin{array}{c}\mathrm{Mg} \\ (\mathrm{mg} / \mathrm{L})\end{array}}{11000} \frac{\begin{array}{c}\mathrm{X}^{++} \\ (\mathrm{meq} / \mathrm{L})^{7}\end{array}}{980}$

$\frac{\text { Sample ID }}{\text { H10C.R580G }} \frac{\begin{array}{c}\mathrm{B} \\ (\mathrm{mg} / \mathrm{L})\end{array}}{120} \frac{\begin{array}{c}\mathrm{Cs} \\ (\mathrm{mg} / \mathrm{L})\end{array}}{\frac{\begin{array}{c}\mathrm{Li} \\ (\mathrm{mg} / \mathrm{L})\end{array}}{3.2}} \frac{\begin{array}{c}\mathrm{SiO}_{2} \\ (\mathrm{mg} / \mathrm{L})\end{array}}{3.2} \frac{\begin{array}{c}\mathrm{Sr} \\ (\mathrm{mg} / \mathrm{L})\end{array}}{(\mathrm{mg} / \mathrm{L})} \underbrace{(\mathrm{mg} / \mathrm{L})}$

$\frac{\text { Sample ID }}{\text { H10C.R580G }} \frac{\begin{array}{c}\mathrm{Br}^{-} \\ (\mathrm{mg} / \mathrm{L})\end{array}}{0.7} \frac{\begin{array}{c}\mathrm{F}^{-} \\ (\mathrm{mg} / \mathrm{L})\end{array}}{0.7}$


Table 120. Comparison of Data from the Rustler/Salado Contact Zone at P-14

(Footnotes follow Table 135)

$\frac{\text { Well }^{1}}{\text { P-14 }} \frac{\text { Agency }^{2}}{\text { USGS }} \frac{\text { Collection Date }}{02 / 24 / 77} \frac{\text { Pumping Rate }}{\text { bail or swab }} \frac{\text { Lab }^{3}}{\text { USGS }} \frac{\text { Sample ID }}{\text { P14.R277G }}$

$\frac{\text { Sample ID }}{\text { P14.R277G }} \frac{\begin{array}{c}\text { Density/ } \\ \text { Specific Gravity }\end{array}}{\frac{\mathrm{pH}}{7.2}} \frac{\begin{array}{c}\text { TDS (calc) } \\ (\mathrm{mg} / \mathrm{L})^{5}\end{array}}{313300} \frac{\begin{array}{c}\text { TDS (ROI) } \\ (\mathrm{mg} / \mathrm{L})\end{array}}{350000(105 \mathrm{C})} \frac{\begin{array}{c}\text { Charge-Balance } \\ \text { Error }^{5}\end{array}}{0.9 \%}$

$\frac{\text { Sample ID }}{\text { P14.R277G }} \frac{\begin{array}{c}\text { Alkalinity } \\ \left(\mathrm{mg} / \mathrm{L} \mathrm{CaCO}_{3}\right)^{6}\end{array}}{180} \frac{\begin{array}{c}\mathrm{HCO}_{\overline{3}} \\ (\mathrm{mg} / \mathrm{L})^{6}\end{array}}{220} \frac{\begin{array}{c}\mathrm{CO}_{\overline{3}} \\ (\mathrm{mg} / \mathrm{L})^{6}\end{array}}{0} \frac{\begin{array}{c}\mathrm{Cl}^{-} \\ (\mathrm{mg} / \mathrm{L})\end{array}}{180000} \frac{\begin{array}{c}\mathrm{SO} \overline{\overline{4}} \\ (\mathrm{mg} / \mathrm{L})\end{array}}{10000}$

$\frac{\text { Sample ID }}{\text { P14.R277G }} \frac{\begin{array}{c}\mathrm{Na} \\ (\mathrm{mg} / \mathrm{L})\end{array}}{120000} \frac{\begin{array}{c}\mathrm{K} \\ (\mathrm{mg} / \mathrm{L})\end{array}}{1300} \frac{\begin{array}{c}\mathrm{Ca} \\ (\mathrm{mg} / \mathrm{L})\end{array}}{570} \frac{\begin{array}{c}\mathrm{Mg} \\ (\mathrm{mg} / \mathrm{L})\end{array}}{1200} \frac{\begin{array}{c}\mathrm{X}^{++} \\ (\mathrm{meq} / \mathrm{L})^{7}\end{array}}{130}$

\begin{tabular}{|c|c|c|c|c|c|c|c|}
\hline Sample ID & $\begin{array}{c}\text { B } \\
(\mathrm{mg} / \mathrm{L})\end{array}$ & $\underset{(\mathrm{mg} / \mathrm{L})}{\mathrm{Cs}}$ & $\underset{(\mathrm{mg} / \mathrm{L})}{\mathrm{Li}}$ & $\underset{(\mathrm{mg} / \mathrm{L})}{\mathrm{SiO}_{2}}$ & $\underset{(\mathrm{mg} / \mathrm{L})}{\mathrm{Sr}}$ & $\begin{array}{c}\mathrm{Fe} \\
(\mathrm{mg} / \mathrm{L})\end{array}$ & $\underset{(\mathrm{Mg} / \mathrm{L})}{\mathrm{Mn}}$ \\
\hline P14.R277G & 1.7 & & & 2.0 & & & \\
\hline
\end{tabular}


Table 121. Comparison of Data from the Rustler/Salado Contact Zone at P-15

(Footnotes follow Table 135)

\begin{tabular}{|c|c|c|c|c|c|}
\hline Well $^{1}$ & Agency $^{2}$ & Collection Date & Pumping Rate & $\mathrm{Lab}^{3}$ & Sample ID \\
\hline P-15 & USGS & $04 / 03 / 79$ & bail or swab & SNL & P15.R479S \\
\hline
\end{tabular}

\begin{tabular}{|c|c|c|c|c|c|}
\hline Sample ID & $\begin{array}{c}\text { Density/ } \\
\text { Specific Gravity }\end{array}$ & $\mathrm{pH}$ & $\begin{array}{l}\text { TDS (calc) } \\
(\mathrm{mg} / \mathrm{L})^{5}\end{array}$ & $\begin{array}{l}\text { TDS (ROI) } \\
\text { (mg/L) }\end{array}$ & $\begin{array}{c}\text { Charge-Balance } \\
\text { Error } 5\end{array}$ \\
\hline $\begin{array}{l}\text { P15.R479S } \\
\text { P15.R479G }\end{array}$ & $1.045(\mathrm{~g} / \mathrm{mL})$ & & $\begin{array}{l}67600 \\
67300\end{array}$ & & $\begin{array}{r}-0.6 \% \\
0.8 \%\end{array}$ \\
\hline
\end{tabular}

\begin{tabular}{|c|c|c|c|c|c|}
\hline Sample ID & $\begin{array}{c}\text { Alkalinity } \\
(\mathrm{mg} / \mathrm{L} \mathrm{CaCO})^{6}\end{array}$ & $\begin{array}{l}\mathrm{HCO}_{3}^{-} \\
(\mathrm{mg} / \mathrm{L})^{6}\end{array}$ & $\begin{array}{c}\mathrm{CO}_{3}^{\overline{3}} \\
(\mathrm{mg} / \mathrm{L})^{6}\end{array}$ & $\begin{array}{c}\mathrm{Cl}^{-} \\
(\mathrm{mg} / \mathrm{L})\end{array}$ & $\begin{array}{c}\mathrm{SO} \overline{\overline{4}} \\
(\mathrm{mg} / \mathrm{L})\end{array}$ \\
\hline & 78 & 95 & 0 & 38000 & 3350 \\
\hline P15.R479G & 45 & 55 & 0 & 38000 & 2800 \\
\hline
\end{tabular}

\begin{tabular}{|c|c|c|c|c|c|}
\hline Sample ID & $\underset{(\mathrm{mg} / \mathrm{L})}{\mathrm{Na}}$ & $\underset{(\mathrm{mg} / \mathrm{L})}{\mathrm{K}}$ & $\underset{(\mathrm{mg} / \mathrm{L})}{\mathrm{Ca}}$ & $\begin{array}{c}\mathrm{Mg} \\
(\mathrm{mg} / \mathrm{L})\end{array}$ & $\begin{array}{c}\mathrm{X}^{++} \\
(\mathrm{meq} / \mathrm{L})^{7}\end{array}$ \\
\hline P15.R479S & 23700 & 1350 & 800 & 320 & 66.2 \\
\hline P15.R479G & 24000 & 1400 & 770 & 350 & 67 \\
\hline
\end{tabular}

\begin{tabular}{|c|c|c|c|c|c|c|c|}
\hline Sample ID & $\begin{array}{c}\text { B } \\
(\mathrm{mg} / \mathrm{L})\end{array}$ & $\begin{array}{c}\mathrm{Cs} \\
(\mathrm{mg} / \mathrm{L})\end{array}$ & $\begin{array}{c}\mathbf{L i} \\
(\mathrm{mg} / \mathrm{L})\end{array}$ & $\begin{array}{c}\mathrm{SiO}_{2} \\
(\mathrm{mg} / \mathrm{L})\end{array}$ & $\begin{array}{c}\mathrm{Sr} \\
(\mathrm{mg} / \mathrm{L})\end{array}$ & $\begin{array}{c}\mathrm{Fe} \\
(\mathrm{mg} / \mathrm{L})\end{array}$ & $\begin{array}{c}\mathrm{Mn} \\
(\mathrm{mg} / \mathrm{L})\end{array}$ \\
\hline $\begin{array}{l}\text { P15.R479S } \\
\text { P15.R479G }\end{array}$ & 3.7 & & & 1.3 & & & \\
\hline
\end{tabular}

\begin{tabular}{|c|c|c|}
\hline Sample ID & $\begin{array}{c}\mathrm{Br}^{-} \\
(\mathrm{mg} / \mathrm{L})\end{array}$ & $\begin{array}{c}F^{-} \\
(\mathrm{mg} / \mathrm{L})\end{array}$ \\
\hline $\begin{array}{l}15 . \mathrm{R} 479 \mathrm{~S} \\
15 . \mathrm{R} 479 \mathrm{G}\end{array}$ & & 1.3 \\
\hline
\end{tabular}


Table 122. Comparison of Data from the Rustler/Salado Contact Zone at P-17

(Footnotes follow Table 135)

\begin{tabular}{|c|c|c|c|c|c|}
\hline Well ${ }^{1}$ & Agency $^{2}$ & Collection Date & Pumping Rate & $\mathrm{Lab}^{3}$ & Sample ID \\
\hline P-17 & USGS & $05 / 11 / 79$ & bail or swab & SNL & P17.R579S \\
\hline P-17 & USGS & $05 / 11 / 79$ & bail or swab & USGS & P17.R579G \\
\hline
\end{tabular}

$\begin{aligned} & \frac{1}{\text { Sample ID }} \\ & \begin{array}{l}\text { P17.R579S } \\ \text { P17.R579G }\end{array}\end{aligned} \frac{\begin{array}{c}\text { Density/ } \\ \text { Specific Gravity }\end{array}}{1.194(\mathrm{~g} / \mathrm{mL})}-\frac{\mathrm{pH}}{268000} \frac{\begin{array}{c}\text { TDS (calc) } \\ (\mathrm{mg} / \mathrm{L})^{5}\end{array}}{2} \frac{\begin{array}{c}\text { TDS (ROI) } \\ (\mathrm{mg} / \mathrm{L})\end{array}}{\frac{\begin{array}{c}\text { Charge-Balance } \\ \text { Error }\end{array}}{5}}$

\begin{tabular}{|c|c|c|c|c|c|}
\hline Sample ID & $\begin{array}{c}\text { Alkalinity } \\
\left(\mathrm{mg} / \mathrm{L} \mathrm{CaCO}_{3}\right)^{6}\end{array}$ & $\begin{array}{l}\mathrm{HCO}_{3}^{-} \\
(\mathrm{mg} / \mathrm{L})^{6} \\
\end{array}$ & $\begin{array}{c}\mathrm{CO}_{\overline{3}}^{\overline{3}} \\
(\mathrm{mg} / \mathrm{L})^{6} \\
\end{array}$ & $\begin{array}{c}\mathrm{Cl}^{-} \\
(\mathrm{mg} / \mathrm{L}) \\
\end{array}$ & $\begin{array}{c}\mathrm{SO} \overline{\overline{4}} \\
(\mathrm{mg} / \mathrm{L})\end{array}$ \\
\hline $\begin{array}{l}\text { P17.R579S } \\
\text { P17.R579G }\end{array}$ & $\begin{array}{l}610 \\
650\end{array}$ & 740 & 0 & 186000 & 540 \\
\hline
\end{tabular}

\begin{tabular}{|c|c|c|c|c|c|}
\hline Sample ID & $\begin{array}{c}\mathrm{Na} \\
(\mathrm{mg} / \mathrm{L})\end{array}$ & $\underset{(\mathrm{mg} / \mathrm{L})}{\mathrm{K}}$ & $\underset{(\mathrm{mg} / \mathrm{L})}{\mathrm{Ca}}$ & $\underset{(\mathrm{mg} / \mathrm{L})}{\mathrm{Mg}}$ & $\underset{(\mathrm{meq} / \mathrm{L})^{7}}{\mathrm{X}^{++}}$ \\
\hline $\begin{array}{l}\text { P17.R579S } \\
\text { P17.R579G }\end{array}$ & $\begin{array}{r}\text { lost } \\
23000\end{array}$ & $\begin{array}{r}\text { lost } \\
8800\end{array}$ & $\begin{array}{r}\text { lost } \\
15000\end{array}$ & $\begin{array}{r}\text { lost } \\
40000\end{array}$ & 4000 \\
\hline
\end{tabular}

\begin{tabular}{|c|c|c|c|c|c|c|c|}
\hline Sample ID & $\begin{array}{c}\text { B } \\
(\mathrm{mg} / \mathrm{L})\end{array}$ & $\begin{array}{c}\mathrm{Cs} \\
(\mathrm{mg} / \mathrm{L})\end{array}$ & $\begin{array}{c}\mathrm{Li} \\
(\mathrm{mg} / \mathrm{L})\end{array}$ & $\begin{array}{c}\mathrm{SiO}_{2} \\
(\mathrm{mg} / \mathrm{L})\end{array}$ & $\begin{array}{c}\mathrm{Sr} \\
(\mathrm{mg} / \mathrm{L})\end{array}$ & $\begin{array}{c}\mathrm{Fe} \\
(\mathrm{mg} / \mathrm{L})\end{array}$ & $\begin{array}{c}\mathrm{Mn} \\
(\mathrm{mg} / \mathrm{L})\end{array}$ \\
\hline $\begin{array}{l}\text { P17.R579S } \\
\text { P17.R579G }\end{array}$ & 0.88 & & & 15 & & & \\
\hline
\end{tabular}

\begin{tabular}{|c|c|c|}
\hline Sample ID & $\begin{array}{c}\mathrm{Br}^{-} \\
(\mathrm{mg} / \mathrm{L})\end{array}$ & $\begin{array}{c}\mathrm{F}^{-} \\
(\mathrm{mg} / \mathrm{L})\end{array}$ \\
\hline $\begin{array}{l}\text { P17.R579S } \\
\text { P17.R579G }\end{array}$ & & 3.8 \\
\hline
\end{tabular}


Table 123. Comparison of Data from the Rustler/Salado Contact Zone at P-18

(Footnotes follow Table 135)

\begin{tabular}{|c|c|c|c|c|c|}
\hline Well ${ }^{1}$ & Agency ${ }^{2}$ & Collection Date & Pumping Rate & $\mathrm{Lab}^{3}$ & Sample ID \\
\hline P-18 & USGS & $05 / 11 / 79$ & bail or swab & SNL & P18.R579S \\
\hline P-18 & USGS & $05 / 11 / 79$ & bail or swab & USGS & P18.R579G \\
\hline
\end{tabular}

\begin{tabular}{|c|c|c|c|c|c|}
\hline Sample ID & $\begin{array}{c}\text { Density/ } \\
\text { Specific Gravity } 4 \\
\end{array}$ & $\mathrm{pH}$ & $\begin{array}{c}\text { TDS (calc) } \\
(\mathrm{mg} / \mathrm{L})^{5}\end{array}$ & $\begin{array}{c}\text { TDS (ROI) } \\
(\mathrm{mg} / \mathrm{L})\end{array}$ & $\begin{array}{c}\text { Charge-Balance } \\
\text { Error }^{5}\end{array}$ \\
\hline P18.R579S & $1.221(\mathrm{~g} / \mathrm{mL})$ & & 325200 & & $-0.7 \%$ \\
\hline P18.R579G & $1.266(\mathrm{~g} / \mathrm{mL})$ & 5.4 & 327500 & & $-2.4 \%$ \\
\hline
\end{tabular}

\begin{tabular}{|c|c|c|c|c|c|}
\hline Sample ID & $\begin{array}{c}\text { Alkalinity } \\
(\mathrm{mg} / \mathrm{L} \mathrm{CaCO})^{6} \\
\end{array}$ & $\begin{array}{c}\mathrm{HCO}_{3}^{-} \\
(\mathrm{mg} / \mathrm{L})^{6}\end{array}$ & $\begin{array}{c}\mathrm{CO}_{\overline{3}}^{\overline{3}} \\
(\mathrm{mg} / \mathrm{L})^{6}\end{array}$ & $\begin{array}{c}\mathrm{Cl}^{-} \\
(\mathrm{mg} / \mathrm{L})\end{array}$ & $\begin{array}{c}\mathrm{SO} \overline{\overline{4}} \\
(\mathrm{mg} / \mathrm{L})\end{array}$ \\
\hline P18.R579S & 330 & 400 & 0 & 217000 & 610 \\
\hline P18.R579G & 400 & 490 & 0 & 220000 & 480 \\
\hline
\end{tabular}

\begin{tabular}{|c|c|c|c|c|c|}
\hline Sample ID & $\begin{array}{c}\mathrm{Na} \\
(\mathrm{mg} / \mathrm{L})\end{array}$ & $\underset{(\mathrm{mg} / \mathrm{L})}{\mathbf{K}}$ & $\underset{(\mathrm{mg} / \mathrm{L})}{\mathrm{Ca}}$ & $\begin{array}{c}\mathrm{Mg} \\
(\mathrm{mg} / \mathrm{L})\end{array}$ & $\underset{(\mathrm{meq} / \mathrm{L})^{7}}{\mathrm{x}^{++}}$ \\
\hline P18.R579S & 45600 & 11700 & 10200 & 39800 & 3770 \\
\hline P18.R579G & 48000 & 12000 & 10000 & 37000 & 3500 \\
\hline
\end{tabular}

\begin{tabular}{|c|c|c|c|c|c|c|c|}
\hline Sample ID & $\begin{array}{c}\text { B } \\
(\mathrm{mg} / \mathrm{L})\end{array}$ & $\underset{(\mathrm{mg} / \mathrm{L})}{\mathrm{Cs}}$ & $\underset{(\mathrm{mg} / \mathrm{L})}{\mathrm{Li}}$ & $\begin{array}{c}\mathrm{SiO}_{2} \\
(\mathrm{mg} / \mathrm{L})\end{array}$ & $\begin{array}{c}\mathrm{Sr} \\
(\mathrm{mg} / \mathrm{L})\end{array}$ & $\begin{array}{c}\mathrm{Fe} \\
(\mathrm{mg} / \mathrm{L})\end{array}$ & $\underset{(\mathrm{mg} / \mathrm{L})}{\mathrm{Mn}}$ \\
\hline $\begin{array}{l}\text { P18.R579S } \\
\text { P18.R579G }\end{array}$ & 160 & & & 0.4 & & & \\
\hline
\end{tabular}

$\frac{\text { Sample ID }}{\text { P18.R579S }} \frac{\begin{array}{c}\mathrm{Br}^{-} \\ (\mathrm{mg} / \mathrm{L})\end{array}}{\text { P18.R579G }} \frac{\begin{array}{c}\mathrm{F}^{-} \\ (\mathrm{mg} / \mathrm{L})\end{array}}{2.3}$


Table 124. Comparison of Data from the Rustler/Salado Contact Zone at WIPP-25

(Footnotes follow Table 135)

\begin{tabular}{|c|c|c|c|c|c|}
\hline Well $^{1}$ & Agency $^{2}$ & Collection Date & Pumping Rate & $\mathrm{Lab}^{3}$ & Sample ID \\
\hline W-25 & USGS & $03 / 19 / 80$ & bail or swab & USGS & W25.R380G \\
\hline W-25 & SNL & $07 / 16 / 80-07 / 17 / 80$ & $1.1 \mathrm{gpm}$ & FLD & W25.R780F \\
\hline W-25 & SNL & $07 / 17 / 80$ & $1.1 \mathrm{gpm}$ & BFEC & W25.R780B \\
\hline
\end{tabular}

\begin{tabular}{|c|c|c|c|c|c|}
\hline Sample ID & $\begin{array}{c}\text { Density/ } \\
\text { Specific Gravity } 4\end{array}$ & $\mathrm{pH}$ & $\begin{array}{l}\text { TDS (calc) } \\
(\mathrm{mg} / \mathrm{L})^{5}\end{array}$ & $\begin{array}{l}\text { TDS (ROI) } \\
\text { (mg/L) }\end{array}$ & $\begin{array}{l}\text { Charge-Balance } \\
\text { Error } 5\end{array}$ \\
\hline W25.R380G & $1.173(\mathrm{~g} / \mathrm{mL})$ & 7.2 & 238200 & $252000(105 \mathrm{C})$ & $4.3 \%$ \\
\hline W25.R780F & & 7.4 & & & \\
\hline W25.R780B & & & 334400 & & $0.4 \%$ \\
\hline
\end{tabular}

\begin{tabular}{|c|c|c|c|c|c|}
\hline Sample ID & $\begin{array}{c}\text { Alkalinity } \\
(\mathrm{mg} / \mathrm{L} \mathrm{CaCO})^{6}\end{array}$ & $\begin{array}{l}\mathrm{HCO}_{3}^{-} \\
(\mathrm{mg} / \mathrm{L})^{6}\end{array}$ & $\begin{array}{c}\mathrm{CO}_{\overline{3}}^{\overline{3}} \\
(\mathrm{mg} / \mathrm{L})^{6}\end{array}$ & $\begin{array}{c}\mathrm{Cl}^{-} \\
(\mathrm{mg} / \mathrm{L})\end{array}$ & $\begin{array}{c}\mathrm{SO} \overline{\overline{4}} \\
(\mathrm{mg} / \mathrm{L})\end{array}$ \\
\hline W25.R380G & 80 & 98 & 0 & 130000 & 12000 \\
\hline W25.R780F & 110 & 130 & 0 & 190000 & \\
\hline W25.R780B & & & & 192000 & 12400 \\
\hline
\end{tabular}

\begin{tabular}{|c|c|c|c|c|c|}
\hline Sample ID & $\begin{array}{c}\mathrm{Na} \\
(\mathrm{mg} / \mathrm{L})\end{array}$ & $\underset{(\mathrm{mg} / \mathrm{L})}{\mathrm{K}}$ & $\begin{array}{c}\mathrm{Ca} \\
(\mathrm{mg} / \mathrm{L})\end{array}$ & $\underset{(\mathrm{mg} / \mathrm{L})}{\mathrm{Mg}}$ & $\underset{(\mathrm{meq} / \mathrm{L})^{7}}{\mathrm{X}^{++}}$ \\
\hline W25.R380G & 90000 & 2400 & 650 & 3200 & 290 \\
\hline W25.R780F & & & & & 290 \\
\hline W25.R780B & 122800 & 3330 & 560 & 3260 & 295 \\
\hline
\end{tabular}

\begin{tabular}{|c|c|c|c|c|c|c|c|}
\hline Sample ID & $\begin{array}{c}\mathrm{B} \\
(\mathrm{mg} / \mathrm{L})\end{array}$ & $\begin{array}{c}\mathrm{Cs} \\
(\mathrm{mg} / \mathrm{L})\end{array}$ & $\underset{(\mathrm{mg} / \mathrm{L})}{\mathrm{Li}}$ & $\begin{array}{c}\mathrm{SiO}_{2} \\
(\mathrm{mg} / \mathrm{L})\end{array}$ & $\begin{array}{c}\mathrm{Sr} \\
(\mathrm{mg} / \mathrm{L})\end{array}$ & $\underset{(\mathrm{mg} / \mathrm{L})}{\mathrm{Fe}}$ & $\begin{array}{c}\mathrm{Mn} \\
(\mathrm{mg} / \mathrm{L})\end{array}$ \\
\hline $\begin{array}{l}\text { W25.R380G } \\
\text { W25.R780F }\end{array}$ & 35 & & & 2.6 & & & \\
\hline W25.R780B & 41 & & 1.6 & 4.0 & 11 & & \\
\hline
\end{tabular}

\begin{tabular}{|c|c|}
\hline Sample ID & $\begin{array}{c}\mathrm{Br}^{-} \\
(\mathrm{mg} / \mathrm{L})\end{array}$ \\
\hline $\begin{array}{l}\text { W25.R380G } \\
\text { W25.R780F }\end{array}$ & \\
\hline W25.R780B & 51 \\
\hline
\end{tabular}


Table 125. Comparison of Data from the Rustler/Salado Contact Zone at WIPP-26

(Footnotes follow Table 135)

\begin{tabular}{|c|c|c|c|c|c|}
\hline Well $^{1}$ & Agency $^{2}$ & Collection Date & Pumping Rate & $\mathrm{Lab}^{3}$ & Sample ID \\
\hline W-26 & USGS & $03 / 18 / 80$ & bail or swab & USGS & W26.R380G \\
\hline W-26 & SNL & $07 / 22 / 80-07 / 23 / 80$ & $.42 \mathrm{gpm}$ & FLD & W26.R780F \\
\hline W-26 & SNL & $07 / 23 / 80$ & $.42 \mathrm{gpm}$ & BFEC & W26.R780B \\
\hline
\end{tabular}

\begin{tabular}{|c|c|c|c|c|c|}
\hline Sample ID & $\begin{array}{c}\text { Density/ } \\
\text { Specific Gravity }\end{array}$ & $\mathrm{pH}$ & $\begin{array}{c}\text { TDS (calc) } \\
(\mathrm{mg} / \mathrm{L})^{5}\end{array}$ & $\begin{array}{c}\text { TDS (ROI) } \\
(\mathrm{mg} / \mathrm{L})\end{array}$ & $\begin{array}{c}\text { Charge-Balance } \\
\text { Error } 5\end{array}$ \\
\hline W26.R380G & $1.078(\mathrm{~g} / \mathrm{mL})$ & 8.5 & 152600 & $153000(105 \mathrm{C})$ & $-2.2 \%$ \\
\hline $\begin{array}{l}\text { W26.R780F } \\
\text { W26 R780R }\end{array}$ & & 7.7 & 188400 & & $0.3 \%$ \\
\hline
\end{tabular}

\begin{tabular}{|c|c|c|c|c|c|}
\hline Sample ID & $\begin{array}{c}\text { Alkalinity } \\
\left(\mathrm{mg} / \mathrm{L} \mathrm{CaCO}_{3}\right)^{6}\end{array}$ & $\begin{array}{c}\mathrm{HCO}_{3}^{-} \\
(\mathrm{mg} / \mathrm{L})^{6}\end{array}$ & $\begin{array}{c}\mathrm{CO}_{\overline{3}}^{\overline{3}} \\
(\mathrm{mg} / \mathrm{L})^{6}\end{array}$ & $\begin{array}{c}\mathrm{Cl}^{-} \\
(\mathrm{mg} / \mathrm{L})\end{array}$ & $\begin{array}{c}\mathrm{SO} \overline{\overline{4}} \\
(\mathrm{mg} / \mathrm{L})\end{array}$ \\
\hline W26.R380G & 160 & & & 88000 & 7600 \\
\hline W26.R780F & 220 & 270 & 0 & 110000 & na \\
\hline W26.R780B & & & & 108000 & 7480 \\
\hline
\end{tabular}

\begin{tabular}{|c|c|c|c|c|c|}
\hline Sample ID & $\begin{array}{c}\mathrm{Na} \\
(\mathrm{mg} / \mathrm{L})\end{array}$ & $\underset{(\mathrm{mg} / \mathrm{L})}{\mathrm{K}}$ & $\begin{array}{c}\mathrm{Ca} \\
(\mathrm{mg} / \mathrm{L})\end{array}$ & $\begin{array}{c}\mathrm{Mg} \\
(\mathrm{mg} / \mathrm{L})\end{array}$ & $\begin{array}{c}\mathrm{X}^{++} \\
(\mathrm{meq} / \mathrm{L})^{7} \\
\end{array}$ \\
\hline W26.R380G & 52000 & 1000 & 2700 & 1300 & 240 \\
\hline W26.R780F & & & & & 190 \\
\hline W26.R780B & 68600 & 1200 & 1420 & 1660 & 207 \\
\hline
\end{tabular}

\begin{tabular}{|c|c|c|c|c|c|c|c|}
\hline Sample ID & $\begin{array}{c}\mathrm{B} \\
(\mathrm{mg} / \mathrm{L})\end{array}$ & $\begin{array}{c}\mathrm{Cs} \\
(\mathrm{mg} / \mathrm{L})\end{array}$ & $\begin{array}{c}\mathrm{Li} \\
(\mathrm{mg} / \mathrm{L})\end{array}$ & $\begin{array}{c}\mathrm{SiO}_{2} \\
(\mathrm{mg} / \mathrm{L})\end{array}$ & $\begin{array}{c}\mathrm{Sr} \\
(\mathrm{mg} / \mathrm{L})\end{array}$ & $\begin{array}{c}\mathrm{Fe} \\
(\mathrm{mg} / \mathrm{L})\end{array}$ & $\begin{array}{c}\mathrm{Mn} \\
(\mathrm{mg} / \mathrm{L})\end{array}$ \\
\hline W26.R380G & 30 & & & 2.5 & & & \\
\hline $\begin{array}{l}\text { W26.R780F } \\
\text { W26.R780B }\end{array}$ & 32 & & 12 & $6 ?$ & 27 & & \\
\hline
\end{tabular}

\begin{tabular}{|c|c|}
\hline Sample ID & $\begin{array}{c}\mathrm{Br}^{-} \\
(\mathrm{mg} / \mathrm{L})\end{array}$ \\
\hline $\begin{array}{l}\text { N26.R380G } \\
\text { N26.R780F }\end{array}$ & \\
\hline
\end{tabular}


Table 126. Comparison of Data from the Rustler/Salado Contact Zone at WIPP-27

(Footnotes follow Table 135)

\begin{tabular}{|c|c|c|c|c|c|}
\hline Well $^{1}$ & Agency 2 & Collection Date & Pumping Rate & $\mathrm{Lab}^{3}$ & Sample ID \\
\hline$n-2$ & USGS & $05 / 21 / 80$ & bail or swab & USGS & W27.R580G \\
\hline W-27 & SNL & $08 / 05 / 80-08 / 07 / 80$ & $.13->.02 \mathrm{gpm}$ & FLD & W27.R780F \\
\hline
\end{tabular}

\begin{tabular}{|c|c|c|c|c|c|}
\hline Sample ID & $\begin{array}{c}\text { Density/ } \\
\text { Specific Gravity } 4 \\
\end{array}$ & $\mathrm{pH}$ & $\begin{array}{c}\text { TDS (calc) } \\
(\mathrm{mg} / \mathrm{L})^{5}\end{array}$ & $\begin{array}{c}\text { TDS (ROI) } \\
(\mathrm{mg} / \mathrm{L})\end{array}$ & $\begin{array}{c}\text { Charge-Balance } \\
\text { Error } 5\end{array}$ \\
\hline $\begin{array}{l}\text { W27.R580G } \\
\text { W27.R780F }\end{array}$ & $\begin{array}{c}1.205(\mathrm{~g} / \mathrm{mL}) \\
(\sim 1.07)(\mathrm{sg})\end{array}$ & $\begin{array}{r}7.8 \\
(-7.1)\end{array}$ & 266000 & $363000(105 \mathrm{C})$ & $2.2 \%$ \\
\hline
\end{tabular}

\begin{tabular}{|c|c|c|c|c|c|}
\hline Sample ID & $\begin{array}{c}\text { Alkalinity } \\
\left(\mathrm{mg} / \mathrm{L} \mathrm{CaCO}_{3}\right)^{6}\end{array}$ & $\begin{array}{l}\mathrm{HCO}_{3}^{-} \\
(\mathrm{mg} / \mathrm{L})^{6} \\
\end{array}$ & $\begin{array}{c}\mathrm{CO}_{\overline{3}}^{\overline{3}} \\
(\mathrm{mg} / \mathrm{L})^{6}\end{array}$ & $\begin{array}{c}\mathrm{Cl}^{-} \\
(\mathrm{mg} / \mathrm{L})\end{array}$ & $\begin{array}{c}\mathrm{SO} \overline{\overline{4}} \\
(\mathrm{mg} / \mathrm{L})\end{array}$ \\
\hline $\begin{array}{l}\text { W27.R580G } \\
\text { W27.R780F }\end{array}$ & $(-60)$ & $(\sim 70)$ & 0 & $\begin{array}{c}154000 \\
(-58000)\end{array}$ & $\begin{array}{r}5190 \\
(\sim 10000)\end{array}$ \\
\hline
\end{tabular}

\begin{tabular}{|c|c|c|c|c|c|}
\hline Sample ID & $\begin{array}{c}\mathrm{Na} \\
(\mathrm{mg} / \mathrm{L})\end{array}$ & $\underset{(\mathrm{mg} / \mathrm{L})}{\mathrm{K}}$ & $\begin{array}{c}\mathrm{Ca} \\
(\mathrm{mg} / \mathrm{L})\end{array}$ & $\underset{(\mathrm{mg} / \mathrm{L})}{\mathrm{Mg}}$ & $\begin{array}{c}\mathrm{X}^{++} \\
(\mathrm{meq} / \mathrm{L})^{7}\end{array}$ \\
\hline $\begin{array}{l}\text { W27.R580G } \\
\text { W27.R780F }\end{array}$ & 102000 & 2570 & 1160 & 1040 & $\begin{array}{c}140 \\
(-220)\end{array}$ \\
\hline
\end{tabular}

\begin{tabular}{|c|c|c|c|c|c|c|c|}
\hline Sample ID & $\begin{array}{c}\mathrm{B} \\
(\mathrm{mg} / \mathrm{L})\end{array}$ & $\begin{array}{c}\mathrm{Cs} \\
(\mathrm{mg} / \mathrm{L})\end{array}$ & $\begin{array}{c}\mathrm{Li} \\
(\mathrm{mg} / \mathrm{L})\end{array}$ & $\begin{array}{c}\mathrm{SiO}_{2} \\
(\mathrm{mg} / \mathrm{L})\end{array}$ & $\begin{array}{c}\mathrm{Sr} \\
(\mathrm{mg} / \mathrm{L})\end{array}$ & $\begin{array}{c}\mathrm{Fe} \\
(\mathrm{mg} / \mathrm{L})\end{array}$ & $\begin{array}{c}\mathrm{Mn} \\
(\mathrm{mg} / \mathrm{L})\end{array}$ \\
\hline $\begin{array}{l}\text { W27.R580G } \\
\text { W27.R780F }\end{array}$ & 1.3 & & & 0.1 & & & \\
\hline
\end{tabular}

\begin{tabular}{|c|c|c|}
\hline Sample ID & $\begin{array}{c}\mathrm{Br}^{-} \\
(\mathrm{mg} / \mathrm{L})\end{array}$ & $\begin{array}{c}\mathrm{F}^{-} \\
(\mathrm{mg} / \mathrm{L})\end{array}$ \\
\hline $\begin{array}{l}\text { W27.R580G } \\
\text { W27.R780F }\end{array}$ & & 0.2 \\
\hline
\end{tabular}


Table 127. Comparison of Data from the Rustler/Salado Contact Zone at WIPP-28

(Footnotes follow Table 135)

\begin{tabular}{|c|c|c|c|c|c|}
\hline Well ${ }^{1}$ & Agency $^{2}$ & Collection Date & Pumping Rate & $\mathrm{Lab}^{3}$ & Sample ID \\
\hline W-28 & USGS & $03 / 20 / 80$ & bail or swab & USGS & W28.R380G \\
\hline W-28 & SNL & $07 / 30 / 80-07 / 31 / 80$ & $3.1 \mathrm{gpm}$ & FLD & W28.R780F \\
\hline W-28 & SNL & $07 / 31 / 80$ & $3.1 \mathrm{gpm}$ & BFEC & W28.R780B \\
\hline
\end{tabular}

\begin{tabular}{|c|c|c|c|c|c|}
\hline Sample ID & $\begin{array}{c}\text { Density/ } \\
\text { Specific Gravity }\end{array}$ & $\mathrm{pH}$ & $\begin{array}{l}\operatorname{TDS} \text { (calc) } \\
(\mathrm{mg} / \mathrm{L})^{5}\end{array}$ & $\begin{array}{c}\text { TDS (ROI) } \\
(\mathrm{mg} / \mathrm{L})\end{array}$ & $\begin{array}{c}\text { Charge-Balance } \\
\text { Error } 5 \\
\end{array}$ \\
\hline W28.R380G & $1.140(\mathrm{~g} / \mathrm{mL})$ & 7.0 & 182800 & & $-0.5 \%$ \\
\hline W28.R780F & $1.18(\mathrm{sg})$ & 7.0 & & & \\
\hline W28.R780B & & & 277100 & & $-0.9 \%$ \\
\hline
\end{tabular}

\begin{tabular}{|c|c|c|c|c|c|}
\hline Sample ID & $\begin{array}{c}\text { Alkalinity } \\
(\mathrm{mg} / \mathrm{L} \mathrm{CaCO})^{6}\end{array}$ & $\begin{array}{c}\mathrm{HCO}_{3}^{-} \\
(\mathrm{mg} / \mathrm{L})^{6}\end{array}$ & $\begin{array}{c}\mathrm{CO}_{3}^{\overline{3}} \\
(\mathrm{mg} / \mathrm{L})^{6}\end{array}$ & $\begin{array}{c}\mathrm{Cl}^{-} \\
(\mathrm{mg} / \mathrm{L})\end{array}$ & $\begin{array}{c}\mathrm{SO} \overline{\overline{4}} \\
(\mathrm{mg} / \mathrm{L})\end{array}$ \\
\hline W28.R380G & & & & 102000 & 11000 \\
\hline W28.R780F & 140 & 170 & 0 & 150000 & -20000 \\
\hline W28.R780B & & & & 155000 & 16700 \\
\hline
\end{tabular}

\begin{tabular}{|c|c|c|c|c|c|}
\hline Sample ID & $\begin{array}{c}\mathrm{Na} \\
(\mathrm{mg} / \mathrm{L})\end{array}$ & $\underset{(\mathrm{mg} / \mathrm{L})}{\mathrm{K}}$ & $\begin{array}{c}\mathrm{Ca} \\
(\mathrm{mg} / \mathrm{L})\end{array}$ & $\underset{(\mathrm{mg} / \mathrm{L})}{\mathrm{Mg}}$ & $\underset{(\mathrm{meq} / \mathrm{L})^{7}}{\mathrm{X}^{++}}$ \\
\hline W28.R380G & 65000 & 2070 & 615 & 2070 & 200 \\
\hline W28.R780F & & & & & 300 \\
\hline W28.R780B & 97100 & 4300 & 605 & 3400 & 309 \\
\hline
\end{tabular}

\begin{tabular}{|c|c|c|c|c|c|c|c|}
\hline Sample ID & $\begin{array}{c}\mathrm{B} \\
(\mathrm{mg} / \mathrm{L})\end{array}$ & $\begin{array}{c}\mathrm{Cs} \\
(\mathrm{mg} / \mathrm{L})\end{array}$ & $\underset{(\mathrm{mg} / \mathrm{L})}{\mathrm{Li}}$ & $\underset{(\mathrm{mg} / \mathrm{L})}{\mathrm{SiO}_{2}}$ & $\begin{array}{c}\mathrm{Sr} \\
(\mathrm{mg} / \mathrm{L})\end{array}$ & $\begin{array}{c}\mathrm{Fe} \\
(\mathrm{mg} / \mathrm{L})\end{array}$ & $\begin{array}{c}\mathrm{Mn} \\
(\mathrm{mg} / \mathrm{L})\end{array}$ \\
\hline W28.R380G & 54 & & & 6.0 & & & \\
\hline W28.R780F & & & & & & -0.1 & \\
\hline W28.R780B & 46 & & 1.8 & 7.8 & 12 & & \\
\hline
\end{tabular}

\begin{tabular}{|c|c|c|}
\hline Sample ID & $\begin{array}{c}\mathrm{Br}^{-} \\
(\mathrm{mg} / \mathrm{L})\end{array}$ & $\begin{array}{c}\mathrm{F}^{-} \\
(\mathrm{mg} / \mathrm{L})\end{array}$ \\
\hline $\begin{array}{l}\text { W28.R380G } \\
\text { W28.R780F }\end{array}$ & & 0.2 \\
\hline
\end{tabular}


Table 128. Comparison of Data from the Rustler/Salado Contact Zone at WIPP-29

(Footnotes follow Table 135)

\begin{tabular}{|c|c|c|c|c|c|}
\hline Well 1 & Agency $^{2}$ & Collection Date & Pumping Rate & $\mathrm{Lab}^{3}$ & Sample ID \\
\hline W-29 & USGS & $03 / 18 / 80$ & bail or swab & USGS & W29.R380G \\
\hline W-29 & SNL & $07 / 22 / 80-07 / 24 / 80$ & $1.5 \mathrm{gpm}$ & FLD & W29.R780F \\
\hline W-29 & SNL & $07 / 24 / 80$ & $1.5 \mathrm{gpm}$ & BFEC & W29.R780B \\
\hline
\end{tabular}

\begin{tabular}{|c|c|c|c|c|c|}
\hline Sample ID & $\begin{array}{c}\text { Density/ } \\
\text { Specific Gravity } 4 \\
\end{array}$ & $\mathrm{pH}$ & $\begin{array}{l}\text { TDS (calc) } \\
(\mathrm{mg} / \mathrm{L})^{5}\end{array}$ & $\begin{array}{c}\text { TDS (ROI) } \\
(\mathrm{mg} / \mathrm{L})\end{array}$ & $\begin{array}{c}\text { Charge-Balance } \\
\text { Error } 5\end{array}$ \\
\hline W29.R380G & $1.068(\mathrm{~g} / \mathrm{mL})$ & 7.3 & 96800 & $129000(105 \mathrm{C})$ & $-0.3 \%$ \\
\hline W29.R780F & & 7.2 & & & \\
\hline W29.R780B & & & 111000 & & $-1.0 \%$ \\
\hline
\end{tabular}

\begin{tabular}{|c|c|c|c|c|c|}
\hline Sample ID & $\begin{array}{c}\text { Alkalinity } \\
\left(\mathrm{mg} / \mathrm{L} \mathrm{CaCO}_{3}\right)^{6}\end{array}$ & $\begin{array}{c}\mathrm{HCO}_{3}^{-} \\
(\mathrm{mg} / \mathrm{L})^{6}\end{array}$ & $\begin{array}{c}\mathrm{CO}_{\overline{3}}^{\overline{3}} \\
(\mathrm{mg} / \mathrm{L})^{6}\end{array}$ & $\begin{array}{c}\mathrm{Cl}^{-} \\
(\mathrm{mg} / \mathrm{L})\end{array}$ & $\begin{array}{c}\mathrm{SO} \overline{\overline{4}} \\
(\mathrm{mg} / \mathrm{L})\end{array}$ \\
\hline W29.R380G & 130 & 160 & 0 & 49000 & 12000 \\
\hline W29.R780F & 160 & 200 & 0 & 57000 & -10000 \\
\hline W29.R780B & & & & 58000 & 12000 \\
\hline
\end{tabular}

\begin{tabular}{|c|c|c|c|c|c|}
\hline Sample ID & $\underset{(\mathrm{mg} / \mathrm{L})}{\mathrm{Na}}$ & $\underset{(m g / L)}{\mathbf{K}}$ & $\underset{(\mathrm{mg} / \mathrm{L})}{\mathrm{Ca}}$ & $\underset{(\mathrm{mg} / \mathrm{L})}{\mathrm{Mg}}$ & $\begin{array}{c}\mathrm{X}^{++} \\
(\mathrm{meq} / \mathrm{L})^{7}\end{array}$ \\
\hline W29.R380G & 32000 & 1000 & 850 & 2000 & 210 \\
\hline W29.R780F & & & & & 230 \\
\hline W29.R780B & 36100 & 1480 & 1080 & 2320 & 244 \\
\hline
\end{tabular}

\begin{tabular}{|c|c|c|c|c|c|c|c|}
\hline Sample ID & $\begin{array}{c}\text { B } \\
(\mathrm{mg} / \mathrm{L})\end{array}$ & $\begin{array}{c}\mathrm{Cs} \\
(\mathrm{mg} / \mathrm{L})\end{array}$ & $\underset{(\mathrm{mg} / \mathrm{L})}{\mathrm{Li}}$ & $\begin{array}{c}\mathrm{SiO}_{2} \\
(\mathrm{mg} / \mathrm{L})\end{array}$ & $\begin{array}{c}\mathrm{Sr} \\
(\mathrm{mg} / \mathrm{L})\end{array}$ & $\begin{array}{c}\mathrm{Fe} \\
(\mathrm{mg} / \mathrm{L})\end{array}$ & $\underset{(\mathrm{mg} / \mathrm{L})}{\mathrm{Mn}}$ \\
\hline $\begin{array}{l}\text { W29.R380G } \\
\text { W29.R780F }\end{array}$ & 21 & & & 3.5 & & & \\
\hline W29.R780B & 20 & & 1.3 & 15 & 21 & & \\
\hline
\end{tabular}

\begin{tabular}{|c|c|c|}
\hline Sample ID & $\begin{array}{c}\mathrm{Br}^{-} \\
(\mathrm{mg} / \mathrm{L})\end{array}$ & $\begin{array}{c}\mathrm{F}^{-} \\
(\mathrm{mg} / \mathrm{L})\end{array}$ \\
\hline $\begin{array}{l}\text { W29.R380G } \\
\text { W29.R780F }\end{array}$ & & 0.9 \\
\hline W29.R780B & 12 & \\
\hline
\end{tabular}


Table 129. Comparison of Data from the Rustler/Salado Contact Zone at WIPP-30 (Footnotes follow Table 135)

\begin{tabular}{|c|c|c|c|c|c|}
\hline Well $^{1}$ & Agency $^{2}$ & Collection Date & Pumping Rate & $\mathrm{Lab}^{3}$ & Sample ID \\
\hline W-30 & USGS & $03 / 19 / 80$ & bail or swab & USGS & W30.R380G \\
\hline W-30 & SNL & $07 / 16 / 80-07 / 17 / 80$ & $.22 \mathrm{gpm}$ & FLD & W30.R780F \\
\hline W-30 & SNL & $07 / 17 / 80$ & $.22 \mathrm{gpm}$ & BFEC & W30.R780B \\
\hline
\end{tabular}

\begin{tabular}{|c|c|c|c|c|c|}
\hline Sample ID & $\begin{array}{c}\text { Density/ } \\
\text { Specific Gravity } 4\end{array}$ & $\mathrm{pH}$ & $\begin{array}{c}\text { TDS (calc) } \\
(\mathrm{mg} / \mathrm{L})^{5}\end{array}$ & $\begin{array}{c}\text { TDS (ROI) } \\
(\mathrm{mg} / \mathrm{L})\end{array}$ & $\begin{array}{c}\text { Charge-Balance } \\
\text { Error } 5 \\
\end{array}$ \\
\hline W30.R380G & $1.201(\mathrm{~g} / \mathrm{mL})$ & 7.0 & 301600 & $302000(105 \mathrm{C})$ & $5.3 \%$ \\
\hline W30.R780F & & 7.5 & & & \\
\hline W30.R780B & & & 325900 & & $0.1 \%$ \\
\hline
\end{tabular}

\begin{tabular}{|c|c|c|c|c|c|}
\hline Sample ID & $\begin{array}{c}\text { Alkalinity } \\
(\mathrm{mg} / \mathrm{L} \mathrm{CaCO})^{6}\end{array}$ & $\begin{array}{l}\mathrm{HCO}_{3}^{-} \\
(\mathrm{mg} / \mathrm{L})^{6}\end{array}$ & $\begin{array}{c}\mathrm{CO}_{3}^{\overline{3}} \\
(\mathrm{mg} / \mathrm{L})^{6}\end{array}$ & $\underset{(\mathrm{mg} / \mathrm{L})}{\mathrm{Cl}^{-}}$ & $\begin{array}{c}\mathrm{SO}_{\overline{4}}^{\overline{4}} \\
(\mathrm{mg} / \mathrm{L})\end{array}$ \\
\hline W30.R380G & 320 & 390 & 0 & 170000 & 7000 \\
\hline W30.R780F & 510 & 620 & 0 & 180000 & \\
\hline W30.R780B & & & & 192000 & 7390 \\
\hline
\end{tabular}

\begin{tabular}{|c|c|c|c|c|c|}
\hline Sample ID & $\underset{(\mathrm{mg} / \mathrm{L})}{\mathrm{Na}}$ & $\underset{(\mathrm{mg} / \mathrm{L})}{\mathbf{K}}$ & $\begin{array}{c}\mathrm{Ca} \\
(\mathrm{mg} / \mathrm{L})\end{array}$ & $\begin{array}{c}\mathrm{Mg} \\
(\mathrm{mg} / \mathrm{L})\end{array}$ & $\begin{array}{c}\mathrm{X}^{++} \\
(\mathrm{meq} / \mathrm{L})^{7}\end{array}$ \\
\hline $\begin{array}{l}\text { W30.R380G } \\
\text { W30.R780F }\end{array}$ & 120000 & 1500 & $\begin{array}{c}850 \\
(-900)\end{array}$ & 2300 & $\begin{array}{l}230 \\
260\end{array}$ \\
\hline W30.R780B & 120600 & 2180 & 955 & 2770 & 275 \\
\hline
\end{tabular}

\begin{tabular}{|c|c|c|c|c|c|c|c|}
\hline Sample ID & $\begin{array}{c}\text { B } \\
(\mathrm{mg} / \mathrm{L})\end{array}$ & $\underset{(\mathrm{mg} / \mathrm{L})}{\mathrm{Cs}}$ & $\begin{array}{c}\mathrm{Li} \\
(\mathrm{mg} / \mathrm{L})\end{array}$ & $\begin{array}{c}\mathrm{SiO}_{2} \\
(\mathrm{mg} / \mathrm{L})\end{array}$ & $\begin{array}{c}\mathrm{Sr} \\
(\mathrm{mg} / \mathrm{L})\end{array}$ & $\begin{array}{c}\mathrm{Fe} \\
(\mathrm{mg} / \mathrm{L})\end{array}$ & $\begin{array}{c}\mathrm{Mn} \\
(\mathrm{mg} / \mathrm{L})\end{array}$ \\
\hline $\begin{array}{l}\text { W30.R380G } \\
\text { W30.R780F }\end{array}$ & 77 & & & 3.5 & & & \\
\hline W30.R780B & 82 & & 0.72 & 5.5 & 18 & & \\
\hline
\end{tabular}

\begin{tabular}{|c|c|}
\hline Sample ID & $\begin{array}{c}\mathrm{Br}^{-} \\
(\mathrm{mg} / \mathrm{L})\end{array}$ \\
\hline $\begin{array}{l}\text { W30.R380G } \\
\text { W30.R780F }\end{array}$ & \\
\hline W30.R780B & 78 \\
\hline
\end{tabular}


Table 130. Comparison of Data from the Dewey Lake Red Beds at Pocket Well (Footnotes follow Table 135)

\begin{tabular}{|c|c|c|c|c|c|}
\hline Well 1 & Agency $^{2}$ & Collection Date & Pumping Rate & $\mathrm{Lab}^{3}$ & Sample ID \\
\hline POCKET & HGC & $10 / 27 / 83-11 / 02 / 83$ & $8.6 \mathrm{gpm}$ & FLD & XPOC.D1183F \\
\hline POCKET & HGC & $11 / 02 / 83$ & $8.6 \mathrm{gpm}$ & H-B & XPOC.D1183HB \\
\hline POCKET & HGC & $11 / 02 / 83$ & $8.6 \mathrm{gpm}$ & KGS & XPOC.D1183Ka \\
\hline POCKET & HGC & $11 / 02 / 83$ & $8.6 \mathrm{gpm}$ & KGS & XPOC.D1183Kb \\
\hline
\end{tabular}

\begin{tabular}{|c|c|c|c|c|c|}
\hline Sample ID & $\begin{array}{c}\text { Density/ } \\
\text { Specific Gravity } 4\end{array}$ & $\mathrm{pH}$ & $\begin{array}{l}\text { TDS (calc) } \\
(\mathrm{mg} / \mathrm{L})^{5}\end{array}$ & $\begin{array}{c}\text { TDS (ROI) } \\
(\mathrm{mg} / \mathrm{L})\end{array}$ & $\begin{array}{c}\text { Charge-Balance } \\
\text { Error } 5 \\
\end{array}$ \\
\hline XPOC.D1183F & $1.000(\mathrm{sg})$ & 7.7 & & & \\
\hline
\end{tabular}

XPOC.D1183Ka

XPOC.D1183Kb

\begin{tabular}{|c|c|c|c|c|c|}
\hline Sample ID & $\begin{array}{c}\text { Alkalinity } \\
\left(\mathrm{mg} / \mathrm{L} \mathrm{CaCO}_{3}\right)^{6}\end{array}$ & $\begin{array}{r}\mathrm{HCO}_{3}^{-} \\
(\mathrm{mg} / \mathrm{L})^{6} \\
\end{array}$ & $\begin{array}{c}\mathrm{CO}_{\overline{3}}^{\overline{3}} \\
(\mathrm{mg} / \mathrm{L})^{6}\end{array}$ & $\begin{array}{c}\mathrm{Cl}^{-} \\
(\mathrm{mg} / \mathrm{L}) \\
\end{array}$ & $\begin{array}{l}\mathrm{SO} \overline{\overline{4}} \\
(\mathrm{mg} / \mathrm{L})\end{array}$ \\
\hline XPOC.D1183F & & $\sim 140$ & & & \\
\hline XPOC.D1183HB & & & & 210 & 1100 \\
\hline XPOC.D1183Ka & & 120 & & 340 & \\
\hline XPOC.D1183Kb & & 95 & & 214 & \\
\hline
\end{tabular}

\begin{tabular}{|c|c|c|c|c|c|}
\hline Sample ID & $\begin{array}{c}\mathrm{Na} \\
(\mathrm{mg} / \mathrm{L})\end{array}$ & $\underset{(\mathrm{mg} / \mathrm{L})}{\mathrm{K}}$ & $\begin{array}{c}\mathrm{Ca} \\
(\mathrm{mg} / \mathrm{L})\end{array}$ & $\underset{(\mathrm{mg} / \mathrm{L})}{\mathrm{Mg}}$ & $\underset{(\mathrm{meq} / \mathrm{L})^{7}}{\mathrm{x}^{++}}$ \\
\hline $\begin{array}{l}\text { XPOC.D1183F } \\
\text { XPOC.D1183HB } \\
\text { XPOC.D1183Ka } \\
\text { XPOC.D1183Kb }\end{array}$ & 95 & 2.4 & 380 & 96 & 26.9 \\
\hline
\end{tabular}

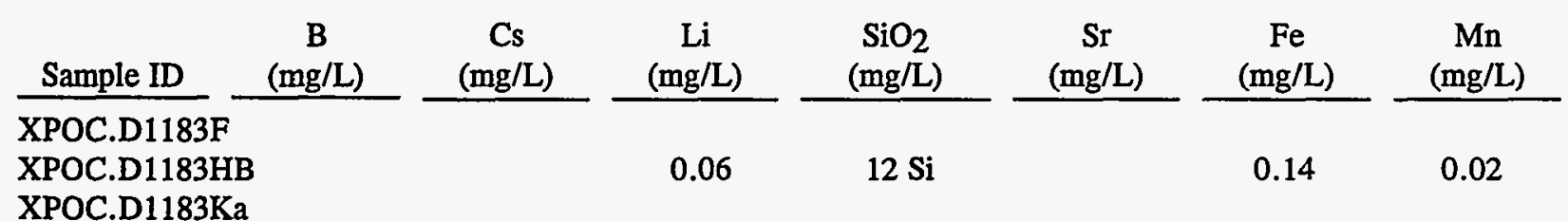

XPOC.D1183Kb

\begin{tabular}{|c|c|c|c|c|}
\hline Sample ID & $\begin{array}{c}\mathrm{Br}^{-} \\
(\mathrm{mg} / \mathrm{L})\end{array}$ & $\begin{array}{c}F^{-} \\
(\mathrm{mg} / \mathrm{L})\end{array}$ & $\begin{array}{c}\mathrm{I}^{-} \\
(\mathrm{mg} / \mathrm{L})\end{array}$ & $\begin{array}{c}\mathrm{NO}_{3}^{-} \\
(\mathrm{mg} / \mathrm{L})\end{array}$ \\
\hline $\begin{array}{l}\text { XPOC.D1183F } \\
\text { XPOC.D1183HB }\end{array}$ & & & & 8 \\
\hline XPOC.D1183Ka & .71 & & 0.019 & \\
\hline XPOC.D1183Kb & .46 & & 0.012 & \\
\hline
\end{tabular}


Table 131. Comparison of Data from the Dewey Lake Red Beds at Ranch Well (Footnotes follow Table 135)

\begin{tabular}{|c|c|c|c|c|c|}
\hline Well 1 & Agency 2 & Collection Date & Pumping Rate & $\mathrm{Lab}^{3}$ & Sample ID \\
\hline RANCH & WQSP-R1 & $06 / 13 / 86-06 / 18 / 86$ & $5.5 \mathrm{gpm}$ & FLD & XRAN.D \\
\hline RANCH & WQSP-R1 & $06 / 18 / 86$ & $5.5 \mathrm{gpm}$ & BFEC & XRAN.D \\
\hline RANCH & WQSP-R1 & $06 / 18 / 86$ & $5.5 \mathrm{gpm}$ & ITAS & XRAN.D \\
\hline
\end{tabular}

\begin{tabular}{|c|c|c|c|c|c|}
\hline Sample ID & $\begin{array}{c}\text { Density/ } \\
\text { Specific Gravity } \\
\end{array}$ & $\mathrm{pH}$ & $\begin{array}{c}\text { TDS (calc) } \\
(\mathrm{mg} / \mathrm{L})^{5}\end{array}$ & $\begin{array}{c}\text { TDS (ROI) } \\
(\mathrm{mg} / \mathrm{L})\end{array}$ & $\begin{array}{c}\text { Charge-Balance } \\
\text { Error } 5 \text {. } \\
\end{array}$ \\
\hline XRAN.D686F & $1.002(\mathrm{sg})$ & 7.0 & & & \\
\hline XRAN.D686B & & & 2520 & & $0.3 \%$ \\
\hline XRAN.D686I & & 7.7 & 2270 & $3300(180 \mathrm{C})$ & $-1.0 \%$ \\
\hline
\end{tabular}

\begin{tabular}{|c|c|c|c|c|c|}
\hline Sample ID & $\begin{array}{c}\text { Alkalinity } \\
(\mathrm{mg} / \mathrm{L} \mathrm{CaCO})^{6}\end{array}$ & $\begin{array}{c}\mathrm{HCO}_{3}^{-} \\
(\mathrm{mg} / \mathrm{L})^{6}\end{array}$ & $\begin{array}{c}\mathrm{CO}_{\overline{3}} \\
(\mathrm{mg} / \mathrm{L})^{6}\end{array}$ & $\begin{array}{c}\mathrm{Cl}^{-} \\
(\mathrm{mg} / \mathrm{L})\end{array}$ & $\begin{array}{c}\mathrm{SO} \overline{\overline{4}} \\
(\mathrm{mg} / \mathrm{L})\end{array}$ \\
\hline XRAN.D686F & 180 & 220 & 0 & 400 & \\
\hline XRAN.D686B & 140 & 170 & 0 & 418 & 1100 \\
\hline XRAN.D686I & 180 & 220 & 0 & 390 & 920 \\
\hline
\end{tabular}

\begin{tabular}{|c|c|c|c|c|c|}
\hline Sample ID & $\begin{array}{c}\mathrm{Na} \\
(\mathrm{mg} / \mathrm{L})\end{array}$ & $\underset{(\mathrm{mg} / \mathrm{L})}{\mathrm{K}}$ & $\begin{array}{c}\mathrm{Ca} \\
(\mathrm{mg} / \mathrm{L})\end{array}$ & $\begin{array}{c}\mathrm{Mg} \\
(\mathrm{mg} / \mathrm{L})\end{array}$ & $\begin{array}{c}\mathrm{X}^{++} \\
(\mathrm{meq} / \mathrm{L})^{7}\end{array}$ \\
\hline XRAN.D686F & & & & & 38 \\
\hline XRAN.D686B & 200 & 4.00 & 420 & 202 & 37.6 \\
\hline XRAN.D686I & 180 & 3.65 & 365 & 190 & 33.8 \\
\hline
\end{tabular}

\begin{tabular}{|c|c|c|c|c|c|c|c|}
\hline Sample ID & $\begin{array}{c}\text { B } \\
(\mathrm{mg} / \mathrm{L}) \\
\end{array}$ & $\underset{(\mathrm{mg} / \mathrm{L})}{\mathrm{Cs}}$ & $\begin{array}{c}\mathrm{Li} \\
(\mathrm{mg} / \mathrm{L})\end{array}$ & $\begin{array}{c}\mathrm{SiO}_{2} \\
(\mathrm{mg} / \mathrm{L})\end{array}$ & $\begin{array}{c}\mathrm{Sr} \\
(\mathrm{mg} / \mathrm{L})\end{array}$ & $\begin{array}{c}\mathrm{Fe} \\
(\mathrm{mg} / \mathrm{L})\end{array}$ & $\begin{array}{c}\mathrm{Mn} \\
(\mathrm{mg} / \mathrm{L})\end{array}$ \\
\hline XRAN.D686F & & & & & & 0.1 & \\
\hline XRAN.D686B & 0.10 & $<0.01$ & 0.12 & 52 & 5.9 & 0.024 & $<0.01$ \\
\hline XRAN.D686I & 0.19 & 0.1 & & 40 as $\mathrm{Si}$ & 3.2 & 0.020 & $<0.005$ \\
\hline
\end{tabular}

\begin{tabular}{|c|c|c|c|c|c|}
\hline Sample ID & $\begin{array}{c}\mathrm{Br}^{-} \\
(\mathrm{mg} / \mathrm{L})\end{array}$ & $\begin{array}{c}\mathrm{F}^{-} \\
(\mathrm{mg} / \mathrm{L})\end{array}$ & $\begin{array}{c}\mathrm{I}^{-} \\
(\mathrm{mg} / \mathrm{L})\end{array}$ & $\begin{array}{c}\mathrm{IO}_{\overline{3}} \\
(\mathrm{mg} / \mathrm{L}) \\
\end{array}$ & $\begin{array}{c}\mathrm{NO}_{\mathbf{3}} \\
(\mathrm{mg} / \mathrm{L}) \\
\end{array}$ \\
\hline XRAN.D686F & & & & & \\
\hline XRAN.D686B & 2.3 & 0.82 & 0.13 & 0.15 & 520 \\
\hline XRAN.D686I & 2.3 & 1.0 & .96 & & 120 as $\mathrm{N}\left(=530\right.$ as $\left.\mathrm{NO}_{\overline{3}}\right)$ \\
\hline
\end{tabular}


Table 132. Comparison of Data from the Dewey Lake Red Beds at Twin Wells (Footnotes follow Table 135)

\begin{tabular}{|c|c|c|c|c|c|}
\hline Well ${ }^{1}$ & Agency 2 & Collection Date & Pumping Rate & $\mathrm{Lab}^{3}$ & Sample ID \\
\hline TWIN-P & WQSP-R1 & $01 / 24 / 86-02 / 02 / 86$ & $33 \mathrm{gph}$ & FLD & XTWP.D186F \\
\hline TWIN-P & WQSP-R1 & $01 / 30 / 86$ & $33 \mathrm{gph}$ & BFEC & XTWP.D186B \\
\hline TWIN-P & WQSP-R1 & $01 / 31 / 86$ & $33 \mathrm{gph}$ & EEG & XTWP.D186E \\
\hline TWIN-P & WQSP-R1 & $01 / 30,31 / 86$ & $33 \mathrm{gph}$ & ITAS & XTWP.D186I \\
\hline
\end{tabular}

\begin{tabular}{|c|c|c|c|c|c|}
\hline Sample ID & $\begin{array}{c}\text { Density/ } \\
\text { Specific Gravity }\end{array}$ & $\mathrm{pH}$ & $\begin{array}{l}\text { TDS (calc) } \\
(\mathrm{mg} / \mathrm{L})^{5}\end{array}$ & $\begin{array}{c}\text { TDS (ROI) } \\
(\mathrm{mg} / \mathrm{L})\end{array}$ & $\begin{array}{c}\text { Charge-Balance } \\
\text { Error } 5\end{array}$ \\
\hline XTWP.D186F & $0.998(\mathrm{sg})$ & 7.8 & & & \\
\hline XTWP.D186B & & & 401 & & $9.2 \%^{*}$ \\
\hline XTWP.D186E & $1.0(\mathrm{~g} / \mathrm{mL})$ & 7.9 & 227 & & $-6.3 \%$ \\
\hline XTWP.D186I & & 8.0 & 671 & $400(180 \mathrm{C})$ & $-19 \%$ \\
\hline
\end{tabular}

\begin{tabular}{|c|c|c|c|c|c|}
\hline Sample ID & $\begin{array}{c}\text { Alkalinity } \\
(\mathrm{mg} / \mathrm{L} \mathrm{CaCO})^{6}\end{array}$ & $\begin{array}{c}\mathrm{HCO}_{3}^{-} \\
(\mathrm{mg} / \mathrm{L})^{6}\end{array}$ & $\begin{array}{c}\mathrm{CO} \overline{\overline{3}} \\
(\mathrm{mg} / \mathrm{L})^{6}\end{array}$ & $\begin{array}{c}\mathrm{Cl}^{-} \\
(\mathrm{mg} / \mathrm{L})\end{array}$ & $\begin{array}{c}\mathrm{SO}_{\overline{4}} \\
(\mathrm{mg} / \mathrm{L})\end{array}$ \\
\hline XTWP.D186F & 190 & 230 & 0 & 45 & \\
\hline XTWP.D186B & 120 & 150 & 0 & 44.1 & 75.1 \\
\hline XTWP.D186E & & & & 44 & 70 \\
\hline XTWP.D186I & 180 & 220 & 0 & 47.0 & 270 \\
\hline
\end{tabular}

\begin{tabular}{|c|c|c|c|c|c|}
\hline Sample ID & $\underset{(\mathrm{mg} / \mathrm{L})}{\mathrm{Na}}$ & $\underset{(\mathrm{mg} / \mathrm{L})}{\mathrm{K}}$ & $\begin{array}{c}\mathrm{Ca} \\
(\mathrm{mg} / \mathrm{L})\end{array}$ & $\underset{(\mathrm{mg} / \mathrm{L})}{\mathrm{Mg}}$ & $\underset{(\mathrm{meq} / \mathrm{L})^{7}}{\mathrm{X}^{++}}$ \\
\hline XTWP.D186F & & & & & 5.9 \\
\hline XTWP.D186B & 25.4 & 3.85 & 80.4 & 22.5 & 5.86 \\
\hline XTWP.D186E & 24 & 4.3 & 60 & 25 & 5.05 \\
\hline XTWP.D186I & 26.0 & 3.70 & 81.0 & 23.5 & 5.98 \\
\hline
\end{tabular}

\begin{tabular}{|c|c|c|c|c|c|c|c|}
\hline Sample ID & $\begin{array}{c}\text { B } \\
(\mathrm{mg} / \mathrm{L})\end{array}$ & $\begin{array}{c}\mathrm{Cs} \\
(\mathrm{mg} / \mathrm{L})\end{array}$ & $\begin{array}{c}\mathrm{Li} \\
(\mathrm{mg} / \mathrm{L})\end{array}$ & $\begin{array}{c}\mathrm{SiO}_{2} \\
(\mathrm{mg} / \mathrm{L})\end{array}$ & $\begin{array}{c}\mathrm{Sr} \\
(\mathrm{mg} / \mathrm{L})\end{array}$ & $\begin{array}{c}\mathrm{Fe} \\
(\mathrm{mg} / \mathrm{L})\end{array}$ & $\begin{array}{c}\mathrm{Mn} \\
(\mathrm{mg} / \mathrm{L})\end{array}$ \\
\hline $\begin{array}{l}\text { XTWP.D186F } \\
\text { XTWP.D186B } \\
\text { XTWP.D186E }\end{array}$ & 0.13 & $<0.01$ & $\begin{array}{l}<.05 \\
<0.5\end{array}$ & 47 & 1.1 & $\begin{array}{r}0.05 \\
<0.01\end{array}$ & $<0.01$ \\
\hline XTWP.D186I & 0.16 & $<0.1$ & & 42 as $S$ & 0.6 & 0.34 & $<0.05$ \\
\hline
\end{tabular}

\begin{tabular}{|c|c|c|c|c|}
\hline Sample ID & $\begin{array}{c}\mathrm{Br}^{-} \\
(\mathrm{mg} / \mathrm{L})\end{array}$ & $\begin{array}{c}\mathrm{F}^{-} \\
(\mathrm{mg} / \mathrm{L})\end{array}$ & $\begin{array}{c}\mathrm{I}^{-} \\
(\mathrm{mg} / \mathrm{L})\end{array}$ & $\begin{array}{c}\mathrm{NO}_{3}^{-} \\
(\mathrm{mg} / \mathrm{L})\end{array}$ \\
\hline $\begin{array}{l}\text { XTWP.D186F } \\
\text { XTWP D186B }\end{array}$ & 0.17 & $0 \leq 0$ & - & \\
\hline XTWP.D186E & & 1.4 & & \\
\hline XTWP.D186I & $<1$ & 0.7 & $<1$ & 7.8 as $\mathrm{N}$ \\
\hline
\end{tabular}

* CBE is $-1.0 \%$ if field alkalinity value used instead of lab value. 
Table 133. Comparison of Data from the Dewey Lake Red Beds at Unger Well (Footnotes follow Table 135)

\begin{tabular}{|c|c|c|c|c|c|}
\hline Well $^{1}$ & Agency $^{2}$ & Collection Date & Pumping Rate & $\mathrm{Lab}^{3}$ & Sample ID \\
\hline UNGER & HGC & $01 / 26 / 84$ & $9.6 \mathrm{gpm}$ & H-B & XUNG.D1 \\
\hline UNGER & HGC & $01 / 26 / 84$ & $9.6 \mathrm{gpm}$ & KGS & XUNG.D1 \\
\hline
\end{tabular}

\begin{tabular}{|c|c|c|c|c|c|}
\hline Sample ID & $\begin{array}{c}\text { Density/ } \\
\text { Specific Gravity } 4\end{array}$ & $\mathrm{pH}$ & $\begin{array}{l}\text { TDS (calc) } \\
(\mathrm{mg} / \mathrm{L})^{5}\end{array}$ & $\begin{array}{c}\text { TDS (ROI) } \\
(\mathrm{mg} / \mathrm{L})\end{array}$ & $\begin{array}{c}\text { Charge-Balance } \\
\text { Error } 5\end{array}$ \\
\hline $\begin{array}{l}\text { XUNG.D184HB } \\
\text { XUNG.D184K }\end{array}$ & & & 2840 & & $-2.9 \%$ \\
\hline
\end{tabular}

\begin{tabular}{|c|c|c|c|c|c|}
\hline Sample ID & $\begin{array}{c}\text { Alkalinity } \\
\left(\mathrm{mg} / \mathrm{L} \mathrm{CaCO}_{3}\right)^{6}\end{array}$ & $\begin{array}{c}\mathrm{HCO}_{3}^{-} \\
(\mathrm{mg} / \mathrm{L})^{6}\end{array}$ & $\begin{array}{c}\mathrm{CO}_{\overline{3}} \\
(\mathrm{mg} / \mathrm{L})^{6}\end{array}$ & $\begin{array}{c}\mathrm{Cl}^{-} \\
(\mathrm{mg} / \mathrm{L})\end{array}$ & $\begin{array}{c}\mathrm{SO} \overline{\overline{4}} \\
(\mathrm{mg} / \mathrm{L})\end{array}$ \\
\hline $\begin{array}{l}\text { XUNG.D184HB } \\
\text { XUNG.D184K }\end{array}$ & & & & 260 & 1800 \\
\hline
\end{tabular}

\begin{tabular}{|c|c|c|c|c|c|}
\hline Sample ID & $\begin{array}{c}\mathrm{Na} \\
(\mathrm{mg} / \mathrm{L})\end{array}$ & $\underset{(m g / L)}{K}$ & $\begin{array}{c}\mathrm{Ca} \\
(\mathrm{mg} / \mathrm{L})\end{array}$ & $\begin{array}{c}\mathrm{Mg} \\
(\mathrm{mg} / \mathrm{L})\end{array}$ & $\begin{array}{c}\mathrm{x}^{++} \\
(\mathrm{meq} / \mathrm{L})^{7}\end{array}$ \\
\hline $\begin{array}{l}\text { XUNG.D184HB } \\
\text { XUNG.D184K }\end{array}$ & 120 & 3.2 & 530 & 130 & 36.9 \\
\hline
\end{tabular}

$\frac{\text { Sample ID }}{\begin{array}{l}\text { XUNG.D184HB } \\ \text { XUNG.D184K }\end{array}} \frac{\begin{array}{c}\mathrm{B} \\ (\mathrm{mg} / \mathrm{L})\end{array}}{\frac{\begin{array}{c}\mathrm{Cs} \\ (\mathrm{mg} / \mathrm{L})\end{array}}{2}} \frac{\begin{array}{c}\mathrm{Li} \\ (\mathrm{mg} / \mathrm{L})\end{array}}{0.05} \frac{\begin{array}{c}\mathrm{SiO}_{2} \\ (\mathrm{mg} / \mathrm{L})\end{array}}{1 \text { as Si}} \frac{\begin{array}{c}\mathrm{Sr} \\ (\mathrm{mg} / \mathrm{L})\end{array}}{\frac{1 \mathrm{mg} / \mathrm{L})}{<0.05}} \frac{\begin{array}{c}\mathrm{Fe} \\ (\mathrm{mg} / \mathrm{L})\end{array}}{<0.03}$

\begin{tabular}{|c|c|c|c|c|}
\hline Sample ID & $\begin{array}{c}\mathrm{Br}^{-} \\
(\mathrm{mg} / \mathrm{L})\end{array}$ & $\begin{array}{c}\mathrm{F}^{-} \\
(\mathrm{mg} / \mathrm{L})\end{array}$ & $\begin{array}{c}\mathrm{I}^{-} \\
(\mathrm{mg} / \mathrm{L})\end{array}$ & $\begin{array}{c}\mathrm{NO}_{3}^{-} \\
(\mathrm{mg} / \mathrm{L})\end{array}$ \\
\hline XUNG.D184HB & & & 0.06 & 11 \\
\hline
\end{tabular}


Table 134. Comparison of Data from the Bell Canyon Formation at DOE-2

(Footnotes follow Table 135)

\begin{tabular}{|c|c|c|c|c|c|}
\hline Well ${ }^{1}$ & Agency $^{2}$ & Collection Date & Pumping Rate & $\mathrm{Lab}^{3}$ & Sample ID \\
\hline DOE-2 & WQSP-R1 & $07 / 20 / 85-07 / 23 / 85$ & swab & FLD & D2.B785F \\
\hline DOE-2 & WOSP-R1 & $07 / 23 / 85$ & swab & BFEC & D2.B785B \\
\hline DOE-2 & WQSP-R1 & $07 / 23 / 85$ & swab & EEG & D2.B785E \\
\hline DOE-2 & WQSP-R1 & $07 / 23 / 85$ & swab & ITAS & D2.B785I \\
\hline
\end{tabular}

\begin{tabular}{|c|c|c|c|c|c|}
\hline Sample ID & $\begin{array}{c}\text { Density/ } \\
\text { Specific Gravity } 4\end{array}$ & $\mathrm{pH}$ & $\begin{array}{c}\text { TDS (calc) } \\
(\mathrm{mg} / \mathrm{L})^{5}\end{array}$ & $\begin{array}{c}\text { TDS (ROI) } \\
(\mathrm{mg} / \mathrm{L})\end{array}$ & $\begin{array}{c}\text { Charge-Balance } \\
\text { Error } 5 \\
\end{array}$ \\
\hline D2.B785F & & 6.8 & & & \\
\hline D2.B785B & & & 149500 & & $0.2 \%$ \\
\hline D2.B785E & $1.122(\mathrm{~g} / \mathrm{mL})$ & 6.8 & 130800 & & $-2.2 \%$ \\
\hline D2.B785I & & 6.7 & & $160000(180$ & \\
\hline
\end{tabular}

\begin{tabular}{|c|c|c|c|c|c|}
\hline Sample ID & $\begin{array}{c}\text { Alkalinity } \\
\left(\mathrm{mg} / \mathrm{L} \mathrm{CaCO}_{3}\right)^{6} \\
\end{array}$ & $\begin{array}{c}\mathrm{HCO}_{3}^{-} \\
(\mathrm{mg} / \mathrm{L})^{6}\end{array}$ & $\begin{array}{c}\mathrm{CO}_{3}^{\overline{3}} \\
(\mathrm{mg} / \mathrm{L})^{6} \\
\end{array}$ & $\begin{array}{c}\mathrm{Cl}^{-} \\
(\mathrm{mg} / \mathrm{L}) \\
\end{array}$ & $\begin{array}{c}\mathrm{SO} \overline{\overline{4}} \\
(\mathrm{mg} / \mathrm{L})\end{array}$ \\
\hline D2.B785F & & & & 90000 & \\
\hline D2.B785B & 39 & 48 & 0 & 89700 & 2020 \\
\hline D2.B785E & & & & 80000 & 1880 \\
\hline
\end{tabular}

\begin{tabular}{|c|c|c|c|c|c|}
\hline Sample ID & $\begin{array}{c}\mathrm{Na} \\
(\mathrm{mg} / \mathrm{L})\end{array}$ & $\underset{(\mathrm{mg} / \mathrm{L})}{\mathrm{K}}$ & $\begin{array}{c}\mathrm{Ca} \\
(\mathrm{mg} / \mathrm{L})\end{array}$ & $\begin{array}{c}\mathrm{Mg} \\
(\mathrm{mg} / \mathrm{L})\end{array}$ & $\underset{(\mathrm{meq} / \mathrm{L})^{7}}{\mathrm{x}^{++}}$ \\
\hline D2.B785F & & & & & 400 \\
\hline D2.B785B & 49600 & 885 & 5910 & 1330 & 405 \\
\hline D2.B785E & 41800 & 600 & 5320 & 1200 & 364 \\
\hline
\end{tabular}

\begin{tabular}{|c|c|c|c|c|c|c|c|}
\hline Sample ID & $\begin{array}{c}\text { B } \\
(\mathrm{mg} / \mathrm{L})\end{array}$ & $\underset{(\mathrm{mg} / \mathrm{L})}{\mathrm{Cs}}$ & $\underset{(\mathrm{mg} / \mathrm{L})}{\mathrm{Li}}$ & $\begin{array}{c}\mathrm{SiO}_{2} \\
(\mathrm{mg} / \mathrm{L})\end{array}$ & $\underset{(\mathrm{mg} / \mathrm{L})}{\mathrm{Sr}}$ & $\begin{array}{c}\mathrm{Fe} \\
(\mathrm{mg} / \mathrm{L})\end{array}$ & $\underset{(\mathrm{mg} / \mathrm{L})}{\mathrm{Mn}}$ \\
\hline 2.B785F & & & & & & & \\
\hline $\begin{array}{l}\text { D2.B785B } \\
\text { D2.B785E }\end{array}$ & 54 & $<0.01$ & $\begin{array}{l}5.8 \\
2.8\end{array}$ & $14, \mathrm{Ci}$ & 150 & 11 & 2.8 \\
\hline
\end{tabular}

\begin{tabular}{|c|c|c|c|c|}
\hline Sample ID & $\begin{array}{c}\mathrm{Br}^{-} \\
(\mathrm{mg} / \mathrm{L})\end{array}$ & $\begin{array}{c}F^{-} \\
(\mathrm{mg} / \mathrm{L})\end{array}$ & $\begin{array}{c}\mathrm{I}^{-} \\
(\mathrm{mg} / \mathrm{L})\end{array}$ & $\begin{array}{c}\mathrm{NO}_{\overline{3}}^{\overline{3}} \\
(\mathrm{mg} / \mathrm{L})\end{array}$ \\
\hline D2.B785F & & & & \\
\hline D2.B785B & 250 & 1.1 & 6.4 & \\
\hline D2.B785E & & 1.4 & & \\
\hline D2.B785I & 94 & 0.4 & 7.9 & 0.75 as $\mathrm{N}$ \\
\hline
\end{tabular}


Table 135. Comparison of Data from the Alluvium at WIPP-15

(Footnotes follow Table 135)

$\frac{\text { Well }^{1}}{\text { W-15 }} \frac{\text { Agency }^{2}}{\text { USGS }} \frac{\text { Collection Date }}{03 / 12 / 79} \frac{\text { Pumping Rate }}{\text { bail or swab }} \frac{\text { Lab }^{3}}{\text { SNL }} \frac{\text { Sample ID }}{\text { W15.Q379S }}$

\begin{tabular}{|c|c|c|c|c|c|}
\hline Sample ID & $\begin{array}{c}\text { Density/ } \\
\text { Specific Gravity } 4 \\
\end{array}$ & $\mathrm{pH}$ & $\begin{array}{c}\text { TDS (calc) } \\
(\mathrm{mg} / \mathrm{L})^{5}\end{array}$ & $\begin{array}{l}\text { TDS (ROI) } \\
(\mathrm{mg} / \mathrm{L})\end{array}$ & $\begin{array}{c}\text { Charge-Balance } \\
\text { Error }^{5}\end{array}$ \\
\hline W15.Q379S & $0.999(\mathrm{~g} / \mathrm{mL})$ & & 1920 & & $1.0 \%$ \\
\hline
\end{tabular}

$\frac{\text { Sample ID }}{\text { W15.Q379S }} \frac{\begin{array}{c}\text { Alkalinity } \\ (\mathrm{mg} / \mathrm{L} \mathrm{CaCO})^{6}\end{array}}{1100} \frac{\begin{array}{c}\mathrm{HCO}_{3}^{-} \\ (\mathrm{mg} / \mathrm{L})^{6}\end{array}}{1130} \frac{\begin{array}{c}\mathrm{CO}_{\overline{3}} \\ (\mathrm{mg} / \mathrm{L})^{6}\end{array}}{92} \frac{\begin{array}{c}\mathrm{Cl}^{-} \\ (\mathrm{mg} / \mathrm{L})\end{array}}{109} \frac{\begin{array}{c}\mathrm{SO} \overline{\overline{4}} \\ (\mathrm{mg} / \mathrm{L})\end{array}}{32}$

$\frac{\text { Sample ID }}{\text { W15.Q379S }} \frac{\begin{array}{c}\mathrm{Na} \\ (\mathrm{mg} / \mathrm{L})\end{array}}{480} \frac{\begin{array}{c}\mathrm{K} \\ (\mathrm{mg} / \mathrm{L})\end{array}}{20} \frac{\begin{array}{c}\mathrm{Ca} \\ (\mathrm{mg} / \mathrm{L})\end{array}}{20} \frac{\begin{array}{c}\mathrm{Mg} \\ (\mathrm{mg} / \mathrm{L})\end{array}}{42} \frac{\begin{array}{c}\mathrm{X}^{++} \\ (\mathrm{meq} / \mathrm{L})^{7}\end{array}}{4.44}$


Footnotes for Tables to 71 to 135 :

1. Abbreviations of well names are explained in Table 1.

2. Key to agencies that collected samples:

HGC: Hydro Geo Chem, Inc. Tucson, AZ

SNL: Sandia National Laboratories, Albuquerque, NM

USGS: United States Geological Survey

WQSP-R1: Water Quality Sampling Program, Round One

3. Key to labs that did analyses:

BFEC: Bendix Field Engineering Corp., Grand Junction, CO (now UNC Technical Services; called UNC/Bendix in the text)

EEG: $\quad$ New Mexico Bureau of Mines \& Mineral Resources, Socorro, NM

FLD: Field measurements, either steady-state values or best available values

H-B: $\quad$ Bendix Field Engineering Corp., Grand Junction, CO

ITAS: IT Analytical Services, Murraysville, PA

KCS: KC Services

KGS: Kansas Geological Survey

UA: University of Arizona, Laboratory of Isotope Geochemistry

USGS: United States Geological Survey, Central Laboratories

4. Density/specific gravity: designation "sg" after a value means that value is a specific gravity. The units " $\mathrm{mg} / \mathrm{L}$ " indicate that the value is a density.

5. Total-dissolved-solids (TDS-calc) concentrations and charge-balance errors (CBEs) were calculated as described in the text. Except for the Twin Well/Pasture Well sample, alkalinity values were not included in the CBE calculations for the EEG samples. Lab alkalinity values were used to calculate CBEs for the UNC/Bendix, ITAS, and USGS samples.

6. Alkalinities originally reported as $\mathrm{mg} / \mathrm{L} \mathrm{CaCO}$ were converted to $\mathrm{HCO}_{3} / \mathrm{CO}_{3}$ when the sample $\mathrm{pH}$ was less than 8.0 , as described in the text. Alkalinities originally reported as $\mathrm{mg} / \mathrm{L} \mathrm{HCO}_{3} / \mathrm{CO}_{3}$ were converted to $\mathrm{CaCO}_{3}$ as described in the text.

7. Laboratory values of divalent cations, $\mathrm{X}^{++}$, were calculated as described in the text. 


\section{WIPP \\ UC721 - DISTRIBUTION LIST \\ SAND86-0917}

\section{Federal Agencies}

US Department of Energy (4)

Office of Civilian Radioactive Waste Mgmt.

Attn: Deputy Director, RW-2

Acting Director, RW-10

Office of Human Resources \& Admin.

Director, RW-30

Office of Program Mgmt. \& Integ.

Director, RW-40

Office of Waste Accept., Stor., \& Tran.

Forrestal Building

Washington, DC 20585

Attn: Project Director

Yucca Mountain Site Characterization Office Director, RW-3

Office of Quality Assurance

P.O. Box 30307

Las Vegas, NV 89036-0307

US Department of Energy

Albuquerque Operations Office

Attn: National Atomic Museum Library

P.O. Box 5400

Albuquerque, NM 87185-5400

US Department of Energy

Research \& Waste Management Division

Attn: Director

P.O. Box E

Oak Ridge, TN 37831

US Department of Energy (5)

Carlsbad Area Office

Attn: G. Dials

D. Galbraith

M. McFadden

R. Lark

J. A. Mewhinney

P.O. Box 3090

Carlsbad, NM 88221-3090

US Department of Energy

Office of Environmental Restoration and

Waste Management

Attn: M Frei, EM-30

Forrestal Building

Washington, DC 20585-0002
US Department of Energy (3)

Office of Environmental Restoration and

Waste Management

Attn: J. Juri, EM-34, Trevion II

Washington, DC 20585-0002

US Department of Energy

Office of Environmental Restoration and

Waste Management

Attn: S. Schneider, EM-342, Trevion II

Washington, DC 20585-0002

US Department of Energy (2)

Office of Environment, Safety \& Health

Attn: C. Borgstrom, EH-25

R. Pelletier, EH-231

Washington, DC 20585

US Department of Energy (2)

Idaho Operations Office

Fuel Processing \& Waste Mgmt. Division

785 DOE Place

Idaho Falls, ID 83402

US Environmental Protection Agency (2)

Radiation Protection Programs

Attn: M. Oge

ANR-460

Washington, DC 20460

\section{Boards}

Defense Nuclear Facilities Safety Board

Attn: D. Winters

625 Indiana Ave. NW, Suite 700

Washington, DC 20004

Nuclear Waste Technical Review Board (2)

Attn: Chairman

J. L. Cohon

1100 Wilson Blvd., Suite 910

Arlington, VA 22209-2297 


\section{State Agencies}

Attorney General of New Mexico

P.O. Drawer 1508

Santa Fe, NM 87504-1508

Environmental Evaluation Group (3)

Attn: Library

7007 Wyoming NE

Suite F-2

Albuquerque, NM 87109

NM Environment Department (3)

Secretary of the Environment

Attn: Mark Weidler

1190 St. Francis Drive

Santa Fe, NM 87503-0968

NM Bureau of Mines \& Mineral Resources

Socorro, NM 87801

\section{Laboratories/Corporations}

Battelle Pacific Northwest Laboratories Battelle Blvd.

Richland, WA 99352

Los Alamos National Laboratory

Attn: B. Erdal, INC-12

P.O. Box 1663

Los Alamos, NM 87544

Tech Reps, Inc. (3)

Attn: J. Chapman (1)

Loretta Robledo (2)

5000 Marble NE, Suite 222

Albuquerque, NM 87110

Westinghouse Electric Corporation (5)

Attn: Library

J. Epstein

J. Lee

B. A. Howard

R. Kehrman

P.O. Box 2078

Carlsbad, NM 88221

S. Cohen \& Associates

Attn: Bill Thurber

1355 Beverly Road

McLean, VA 22101
National Academy of Sciences, WIPP Panel

Howard Adler

Oxyrase, Incorporated

7327 Oak Ridge Highway

Knoxville, TN 37931

Tom Kiess

Board of Radioactive Waste Management

GF456

2101 Constitution Ave.

Washington, DC 20418

Rodney C. Ewing

Department of Geology

University of New Mexico

Albuquerque, NM 87131

Charles Fairhurst

Department of Civil and Mineral Engineering

University of Minnesota

500 Pillsbury Dr. SE

Minneapolis, MN 55455-0220

B. John Garrick

PLG Incorporated

4590 MacArthur Blvd., Suite 400

Newport Beach, CA 92660-2027

Leonard F. Konikow

US Geological Survey

431 National Center

Reston, VA 22092

Carl A. Anderson, Director

Board of Radioactive Waste Management

National Research Council

HA 456

2101 Constitution Ave. NW

Washington, DC 20418

Christopher G. Whipple

ICF Kaiser Engineers

1800 Harrison St., 7th Floor

Oakland, CA 94612-3430

John O. Blomeke

720 Clubhouse Way

Knoxville, TN 37909 
Sue B. Clark

University of Georgia

Savannah River Ecology Lab

P.O. Drawer $E$

Aiken, SC 29802

Konrad B. Krauskopf

Department of Geology

Stanford University

Stanford, CA 94305-2115

Della Roy

Pennsylvania State University

217 Materials Research Lab

Hastings Road

University Park, PA 16802

David A. Waite

$\mathrm{CH}_{2} \mathrm{M}$ Hill

P.O. Box 91500

Bellevue, WA 98009-2050

Thomas A. Zordon

Zordan Associates, Inc.

3807 Edinburg Drive

Murrysville, PA 15668

Universities

University of New Mexico

Geology Department

Attn: Library

141 Northrop Hall

Albuquerque, NM 87131

University of Washington

College of Ocean \& Fishery Sciences

Attn: G. R. Heath

583 Henderson Hall, HN-15

Seattle, WA 98195

\section{Libraries}

Thomas Brannigan Library

Attn: D. Dresp

$106 \mathrm{~W}$. Hadley St.

Las Cruces, NM 88001

Government Publications Department

Zimmerman Library

University of New Mexico

Albuquerque, NM 87131
New Mexico Junior College

Pannell Library

Attn: R. Hill

Lovington Highway

Hobbs, NM 88240

New Mexico State Library

Attn: N. McCallan

325 Don Gaspar

Santa Fe, NM 87503

New Mexico Tech

Martin Speere Memorial Library

Campus Street

Socorro, NM 87810

WIPP Public Reading Room

Carlsbad Public Library

101 S. Halagueno St.

Carlsbad, NM 88220

\section{Foreign Addresses}

Atomic Energy of Canada, Ltd.

Whiteshell Laboratories

Attn: B. Goodwin

Pinawa, Manitoba, CANADA R0E ILO

Francois Chenevier (2)

ANDRA

Route de Panorama Robert Schumann

B. P. 38

92266 Fontenay-aux-Roses, Cedex

FRANCE

Claude Sombret

Centre d'Etudes Nucleaires de la Vallee Rhone

CEN/VALRHO

S.D.H.A. B.P. 171

30205 Bagnols-Sur-Ceze

FRANCE

Commissariat a L'Energie Atomique

Attn: D. Alexandre

Centre d'Etudes de Cadarache

13108 Saint Paul Lez Durance Cedex

FRANCE

Bundesanstalt fur Geowissenschaften und

Rohstoffe

Attn: M. Langer

Postfach 510153

D-30631 Hannover

GERMANY 
Bundesministerium fur Forschung und

Technologie

Postfach 200706

5300 Bonn 2

GERMANY

Institut fur Tieflagerung

Attn: K. Kuhn

Theodor-Heuss-Strasse 4

D-3300 Braunschweig

GERMANY

Gesellschaft fur Anlagen und Reaktorsicherheit (GRS)

Attn: B. Baltes

Schwertnergasse 1

D-50667 Cologne

GERMANY

Shingo Tashiro

Japan Atomic Energy Research Institute

Tokai-Mura, Ibaraki-Ken, 319-11

JAPAN

Netherlands Energy Research Foundation ECN

Attn: J. Prij

3 Westerduinweg

P.O. Box 1

1755 ZG Petten

THE NETHERLANDS

Svensk Karnbransleforsorjning $A B$

Attn: F. Karlsson

Project KBS (Karnbranslesakerhet)

Box 5864

S-102 48 Stockholm

SWEDEN

Nationale Genossenschaft fur die Lagerung

Radioaktiver Abfalle (2)

Attn: S. Vomvoris

P. Zuidema

Hardstrasse 73

CH-5430 Wettingen

SWITZERLAND

AEA Technology

Attn: J. H. Rees

D5W/29 Culham Laboratory

Abington, Oxfordshire OX14 3DB

UNITED KINGDOM
AEA Technology

Attn: W. R. Rodwell

044/A31 Winfrith Technical Centre

Dorchester, Dorset DT2 8DH

UNTTED KINGDOM

AEA Technology

Attn: J. E. Tinson

B4244 Harwell Laboratory

Didcot, Oxfordshire OX11 ORA

UNITED KINGDOM

Internal

$\underline{\text { MS }} \quad$ Org.

$1324 \quad 6115 \quad$ P. B. Davies

$13206831 \quad$ E. J. Nowak

$13226121 \quad$ J. R. Tillerson

$13286849 \quad$ D. R. Anderson

$13286848 \quad$ H. N. Jow

$13356801 \quad$ M. Chu

$13416832 \quad$ J. T. Holmes

$13956800 \quad$ L. Shephard

13956821 M. Marietta

$11476682 \quad$ K. L. Robinson

$13306811 \quad$ K. Hart (2)

$13304415 \quad$ NWM Library (20)

9018 8940-2 Central Technical Files

08994916 Technical Library (5)

061912690 Review and Approval Desk (2), For DOE/OSTI 